Argonne

ANL-ART-86

FASTER Test Reactor Preconceptual Design Report

Nuclear Engineering Division 


\section{About Argonne National Laboratory}

Argonne is a U.S. Department of Energy laboratory managed by UChicago Argonne, LLC under contract DE-AC02-06CH11357. The Laboratory's main facility is outside Chicago, at 9700 South Cass Avenue, Argonne, Illinois 60439. For information about Argonne and its pioneering science and technology programs, see www.anl.gov.

\section{DOCUMENT AVAILABILITY}

Online Access: U.S. Department of Energy (DOE) reports produced after 1991 and a growing number of pre-1991 documents are available free via DOE's SciTech Connect (http://www.osti.gov/scitech/

Reports not in digital format may be purchased by the public from the National Technical Information Service (NTIS):

U.S. Department of Commerce National Technical Information Service 5301 Shawnee Rd

Alexandria, VA 22312

www.ntis.gov

Phone: (800) 553-NTIS (6847) or (703) 605-6000 Fax: (703) 605-6900

Email: orders@ntis.gov

Reports not in digital format are available to DOE and DOE contractors from the Office of Scientific and Technical Information (OSTI):

U.S. Department of Energy Office of Scientific and Technical Information

P.O. Box 62

Oak Ridge, TN 37831-0062

www.osti.gov

Phone: (865) 576-8401

Fax: (865) 576-5728

Email:reports@osti.gov

\section{Disclaimer}

This report was prepared as an account of work sponsored by an agency of the United States Government. Neither the United States Government nor any agency thereof, nor UChicago Argonne, LLC, nor any of their employees or officers, makes any warranty, express or implied, or assumes any legal liability or responsibility for the accuracy, completeness, or usefulness of any information, apparatus, product, or process disclosed, or represents that its use would not infringe privately owned rights. Reference herein to any specific commercial product, process, or service by trade name, trademark, manufacturer, or otherwise, does not necessarily constitute or imply its endorsement, recommendation, or favoring by the United States Government or any agency thereof. The views and opinions of document authors expressed herein do not necessarily state or reflect those of the United States Government or any agency thereof, Argonne National Laboratory, or UChicago Argonne, LLC. 
ANL-ART-86

\title{
FASTER Test Reactor Preconceptual Design Report
}

\author{
Prepared by \\ C. Grandy, H. Belch, A. J. Brunett, F. Heidet, R. Hill, E. Hoffman, E. Jin, W. Mohamed, A. \\ Moisseytsev, S. Passerini, J. Sienicki, T. Sumner, R. Vilim, S. Hayes* \\ Nuclear Engineering Division, Argonne National Laboratory \\ *Nuclear Fuels and Materials Division, Idaho National Laboratory
}

March 31, 2016 



\section{EXECUTIVE SUMMARY}

The FASTER test reactor plant is a sodium-cooled fast spectrum test reactor that provides high levels of fast and thermal neutron flux for scientific research and development. The 120MWe FASTER reactor plant has a superheated steam power conversion system which provides electrical power to a local grid allowing for recovery of operating costs for the reactor plant. In addition, the FASTER reactor plant could be used for isotope production or as a heat source, if desired. The FASTER reactor plant has the following main attributes (Table 1):

Table 1 - FASTER Reactor Plant Summary Characteristics

\begin{tabular}{|l|l|}
\hline Reactor Power & $300 \mathrm{MWt} / 120 \mathrm{MWe} / 40 \%$ efficiency \\
\hline Coolant & Sodium \\
\hline Coolant Temperature, inlet/outlet & $355^{\circ} \mathrm{C} / 510^{\circ} \mathrm{C}$ \\
\hline Coolant Pressure (cover gas pressure) & Cover Gas pressure - few inches of water \\
\hline Fuel, Cladding, Duct & $\mathrm{U}-\mathrm{Pu}-\mathrm{Zr}$ metal fueled core, HT-9, HT-9 \\
\hline Cycle Length & 100 days \\
\hline Average/peak burnup & $34.3 \mathrm{GWd} / \mathrm{t}$ \\
\hline Power density (average, peak) & $558.8 \mathrm{~W} / \mathrm{cc}, 917 \mathrm{~W} / \mathrm{cc}$ \\
\hline Plant Life & 30 years with expectation of life extension \\
\hline PHTS Configuration & Pool plant geometry \\
\hline Reactor vessel structural materials & Austenitic stainless steel \\
\hline Primary and Secondary Pumps & Mechanical centrifugal pumps (2) \\
\hline Intermediate Heat Exchanger & Tube-and-Shell heat exchanger (4) \\
\hline Reactor Vessel Support & Conical Ring - Top Support \\
\hline Emergency Decay Heat Removal & Direct Reactor Auxiliary Heat Exchanger in cold pool (3) \\
\hline Primary Purification System & Conventional cold and nuclide trap technology \\
\hline Power Conversion System & Superheated steam cycle \\
\hline Containment & Steel reinforced concrete containment \\
\hline In-vessel Fuel Handling Mechanism & Single Rotatable Plug with pantograph FHM (3) \\
\hline
\end{tabular}

The reactor power level is the minimum that assures achievement of the neutron flux goals. In its current configuration (Figure 1), the FASTER reactor provides 33 fast flux test locations, three (3) thermal flux test locations, two (2) fast flux closed loops and one (1) thermal flux closed loop (Table 2 and Table 3). Among the fast spectrum test locations, four of them are located near the core center and cannot be repositioned without affecting the core neutronics performance. It is anticipated that the FASTER reactor plant will be utilized by domestic and international researchers with its broad appeal to many different reactor types: sodium-cooled fast reactors, lead-cooled fast reactors, gas-cooled fast reactors, and thermal spectrum reactors. 


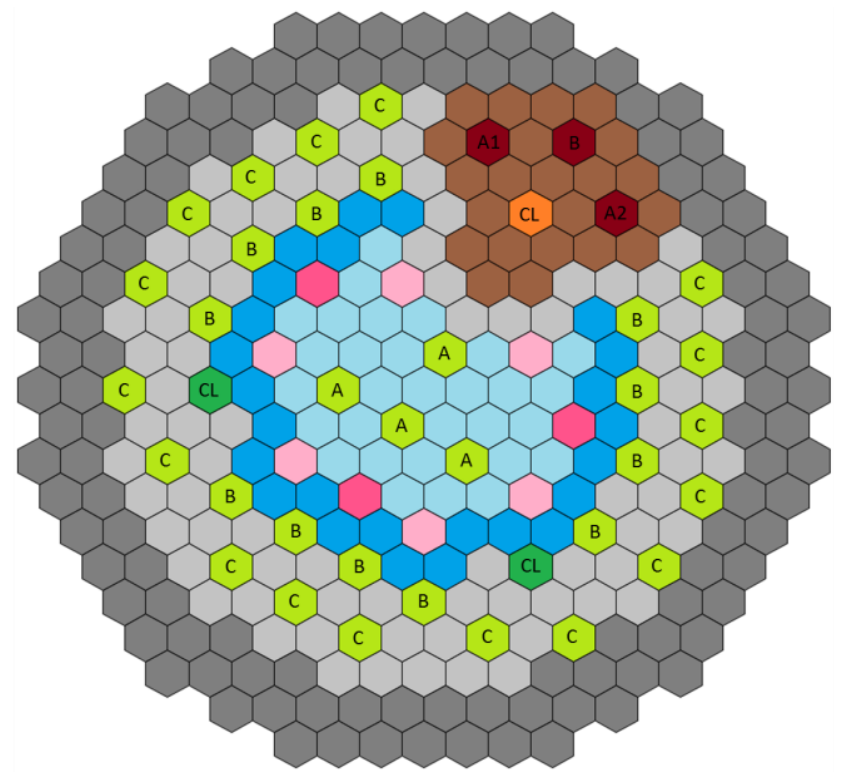

Inner core (30)

Outer core (25)

Prim. control (6)

Sec. control (3)

Reflector (77)

Shield (111)

Fast test location (33)

Fast closed loop (2)

Moderator (22)

Thermal test location (3)

Thermal closed loop (1)

Figure 1 - FASTER Reactor Core Layout

Table 2 - Summary of Fast Flux Conditions in the Test Assemblies

\begin{tabular}{|l|l|l|l|l|}
\hline Group & $\begin{array}{l}\text { Number of } \\
\text { assemblies }\end{array}$ & $\begin{array}{c}\text { Peak fast flux range } \\
\left(10^{15} \mathrm{n} / \mathrm{cm}^{2}-\mathrm{s}\right)\end{array}$ & $\begin{array}{c}\text { Fast flux*Volume range } \\
\left(10^{19} \mathrm{n}-\mathrm{cm} / \mathrm{s}\right)\end{array}$ & $\begin{array}{c}\text { Total fast flux*Volume } \\
\left(10^{19} \mathrm{n}-\mathrm{cm} / \mathrm{s}\right)\end{array}$ \\
\hline A & 4 & $4.7-5.2$ & $4.0-4.9$ & 17.9 \\
\hline Closed loops & 2 & 2.3 & 1.7 & 3.4 \\
\hline B & 10 & $1.9-2.7$ & $1.4-2.1$ & 15.8 \\
\hline C & 19 & $0.3-1.3$ & $0.2-0.9$ & 10.3 \\
\hline
\end{tabular}

Table 3 - Summary of Thermal Flux Conditions in the Test Assemblies

\begin{tabular}{|l|l|l|}
\hline Location & Peak thermal flux $\left(10^{14} \mathrm{n} / \mathrm{cm}^{2}-\mathrm{s}\right)$ & Thermal flux*Volume $\left(10^{18} \mathrm{n}-\mathrm{cm} / \mathrm{s}\right)$ \\
\hline Closed loop & 5.8 & 3.7 \\
\hline A1 & 1.9 & 1.2 \\
\hline A2 & 1.9 & 1.2 \\
\hline B & 1.7 & 1.1 \\
\hline
\end{tabular}


Test Reactor Objectives and Motivation for Concept Selection - The FASTER plant has been designed with extended testing capabilities in mind, while trying to keep it as simple as possible in order to make it attractive and cost efficient. The main function of the reactor is to provide neutrons for irradiation testing and thus no significant technology innovations were adopted for the FASTER reactor plant to maintain a high technology readiness level. The FASTER reactor plant will rely upon the liquid metal base technology developed in the U.S. for EBR-II, FFTF, CRBR, and the ALMR program with a special emphasis on the irradiation testing capabilities developed for EBR-II and FFTF. The reactor core design discussed here is not based on any previously existing fast reactor, but uses materials and dimensions consistent with the U.S. base technology program. The main objective of the FASTER reactor design efforts was to achieve a very high fast flux as well as a significant thermal flux while offering a large number of test locations.

Ternary metallic fuel, U-Pu-Zr, is used with HT-9 stainless steel for cladding and structural material. Although there is no mandated limit on the weight fraction of Pu that can be used in the fuel, it was decided to limit it to $20 \mathrm{wt} \%$ based on the availability of irradiation data. Another incentive for not resorting to higher Pu wt $\%$ is the degradation of the fuel thermal conductivity as $\mathrm{Pu}$ content is increased. This is of particular importance for the FASTER reactor due to the high power density during operations.

In order to optimize the reactor performance and obtain a relatively compact core, the $\mathrm{Zr}$ wt $\%$ in the fuel is assumed to be $6 \mathrm{wt} \%$ and the fuel smear density is assumed to be $85 \%$. Using $6 \mathrm{wt} \%$ instead of the more traditional $10 \mathrm{wt} \%$ does not affect the characteristics of the ternary fuel and irradiation tests have previously been performed for such a fuel type. The decision to use an $85 \%$ smear density, instead of the $75 \%$ typically used for metallic fuel, is based on the relatively low peak burnup that will be achieved. Because of the lower fuel burnup, the internal stress applied by the fuel on the cladding, as a result of irradiation swelling, will be less important than typically observed in metallic fuel that reaches a high burnup. Furthermore, the fission gas plenum length relative to the active fuel length does not need to be as long as what is typically used in SFR core designs, because of the lower fuel burnup achieved. For the FASTER core design the fission gas plenum length is set to be $65 \%$ of the active fuel length.

Core Layout and Assemblies Description - The $300 \mathrm{MW}_{\text {th }}$ FASTER core, shown in Figure 1, is composed of 55 fuel assemblies, each with the same Pu wt fraction. The fuel, coolant and structural material volume fractions are $30.93 \%, 37.36 \%$, and $23.65 \%$, respectively. The active fuel height is $80 \mathrm{~cm}$. Six primary control rod assemblies and three secondary control rod assemblies composed of $\mathrm{B}_{4} \mathrm{C}$ rods ensure the safe shutdown of the core. There are 33 fast neutron flux test locations, in addition to the two closed loops also being exposed to a fast neutron flux. The fuel assembly positions have been chosen to enhance neutron leakage probability toward the moderated zone (brown in Figure 1). The purpose of the moderator is to take advantage of the neutrons leaking out of the active core region and thermalize them in order to provide thermal spectrum testing capabilities. With the current design, fast neutrons are thermalized by the moderator and do not return into the active core region because of the reflector layer between the two regions. This design approach prevents a number of potential issues. There are three thermal test locations and one closed loop having a thermal neutron flux. Canned beryllium is used as the moderator and zircaloy is used as the structural material in that region to avoid parasitic absorption of thermal neutrons in iron. The moderated region does not 
contain any fuel and is cooled with sodium. The assembly descriptions and dimensions are provided in Table 4.

Table 4 - Assembly Descriptions and Dimensions

\begin{tabular}{|l|l|l|l|l|l|}
\hline Assembly type & Fuel & Reflector & Test & Control & Shield \\
\hline Assembly pitch (hot) & 11.870 & 11.870 & 11.870 & 11.870 & 11.870 \\
\hline Smear density & 85 & 100 & 100 & 85 & 81 \\
\hline Pins/assembly & 271 & 91 & 91 & 91 & 61 \\
\hline Pin Outside Diameter (mm) & 5.405 & 11.072 & 11.072 & 9.512 & 13.462 \\
\hline Cladding Thickness (mm) & 0.35 & 1.0 & 1.0 & 0.3 & 0.4 \\
\hline Pin Pitch/Diameter Ratio & 1.210 & 1.023 & 1.023 & 1.024 & 1.012 \\
\hline Clad inner diameter (mm) & 4.701 & 9.059 & 9.059 & 8.941 & 12.833 \\
\hline Outer Flat-to-Flat Distance (cm) & 11.568 & 11.568 & 11.568 & 11.568 & 11.568 \\
\hline Duct Wall Thickness (mm) & 3.0 & 3.0 & 3.0 & 3.0 & 3.0 \\
\hline Duct inside flat-to-flat distance (cm) & 10.964 & 10.964 & 10.964 & 10.964 & 10.964 \\
\hline Duct Bundle Clearance (mm) & 0.05 & 0.05 & 0.05 & 0.05 & 0.05 \\
\hline Inter-assembly Gap (mm) & 3.0 & 3.0 & 3.0 & 3.0 & 3.0 \\
\hline Inlet coolant height (cm) & 35.0 & 35.0 & N/A & N/A & 35.0 \\
\hline Lower reflector height (cm) & 95.0 & 277.0 & N/A & N/A & 277.0 \\
\hline Fuel length (cm) & 80.0 & 277.0 & N/A & N/A & 277.0 \\
\hline Fission gas plenum (flooded) height $(\mathrm{cm})$ & 12.0 & 277.0 & N/A & N/A & 277.0 \\
\hline Fission gas plenum (empty) height $(\mathrm{cm})$ & 40.0 & 277.0 & N/A & N/A & 277.0 \\
\hline Upper shield height (cm) & 50.0 & 277.0 & N/A & N/A & 277.0 \\
\hline Outlet coolant height (cm) & 30.0 & 30.0 & N/A & N/A & 30.0 \\
\hline
\end{tabular}

For the purpose of the point design activity, the test locations have been modeled as entirely filled with sodium when determining the core neutronics performance characteristics, in order to maximize the neutron leakage probability and therefore the $\mathrm{Pu} w \mathrm{t} \%$ required in the fuel. For the safety analysis, including calculation of reactivity coefficients, the test locations have been filled will reflector assemblies in order to minimize the neutron leakage probability and not to overestimate the favorable effect resulting from sodium voiding.

The reactor is to be operated in a three fuel batch management scheme with a cycle length of 100 effective full power days (EFPD). At the end of a cycle, one third of the fuel assemblies, having the highest burnup, are discharged and replaced with fresh fuel assemblies. The fuel assemblies remaining in the core are not shuffled.

FASTER Reactor Performance Characteristics - The core performance characteristics at equilibrium are provided in Table 3-2. It should be noted that most of those characteristics will vary slightly based on the type and amount of materials loaded in the test locations, in particular those located in the active core region. In practice, a new core analysis will be required for every new core configuration, including each time a new test assembly is inserted. However, the results presented here are expected to be conservative and not to vary significantly. The reactor power level of $300 \mathrm{MW}_{\text {th }}$ is the minimum that assures that the neutron flux goals can be met. 
The required $\mathrm{Pu} w \mathrm{wt} \%$ is $19.4 \%$, which is slightly lower than the $20 \%$ limit used. The average fuel discharge burnup is about $34 \mathrm{GWd} / \mathrm{t}$ while the peak discharge burnup is less than $50 \mathrm{GWd} / \mathrm{t}$. This is consistent with the assumptions made for the fuel smear density and plenum length, which were based on a low fuel burnup. It is important to note that the average core power density is about $560 \mathrm{~W} / \mathrm{cm}^{3}$ over the active fuel region. When normalized only over the fuel volume, this corresponds to an average power density of $1580 \mathrm{~W} / \mathrm{cm}^{3}$ and a peak value of almost 3000 $\mathrm{W} / \mathrm{cm}^{3}$. This is larger than what is typically observed in SFRs, and proper cooling of the core will need to be ensured. The thermal flux provided in this table is calculated for the moderated region.

Table 5 - Core Performance Characteristics

\begin{tabular}{|c|c|}
\hline Characteristic & FASTER \\
\hline Nominal power, $\mathrm{MW}_{\text {th }}$ & 300 \\
\hline Required enrichment & $19.41 \%$ \\
\hline $\mathrm{BOC} / \mathrm{EOC} \mathrm{k}_{\text {eff }}$ & $1.02672 / 1.00080$ \\
\hline Average discharge burnup, GWd/t & 34.3 \\
\hline Total HM mass, kg & 2621 \\
\hline HM charge per cycle, $\mathrm{kg}$ & 874 \\
\hline Average power density, $\mathrm{W} / \mathrm{cm}^{3}$ & 558.8 \\
\hline Peak power density, $\mathrm{W} / \mathrm{cm}^{3}$ & 917.0 \\
\hline Specific power, W/g & 114.5 \\
\hline Average linear power, $\mathrm{kW} / \mathrm{m}$ & 25.2 \\
\hline Axial/radial leakage & $11.36 \% / 30.17 \%$ \\
\hline Total flux, $10^{15} \mathrm{n} / \mathrm{cm}^{2}-\mathrm{s}$ & 3.74 \\
\hline Peak total flux, $10^{15} \mathrm{n} / \mathrm{cm}^{2}-\mathrm{s}$ & 6.78 \\
\hline Fast flux $(>0.1 \mathrm{MeV}), 10^{15} \mathrm{n} / \mathrm{cm}^{2}-\mathrm{s}$ & 2.70 \\
\hline Peak fast flux $(>0.1 \mathrm{MeV}), 10^{15} \mathrm{n} / \mathrm{cm}^{2}-\mathrm{s}$ & 5.19 \\
\hline Peak thermal flux $(<0.1 \mathrm{eV}), 10^{14} \mathrm{n} / \mathrm{cm}^{2}-\mathrm{s}$ & 6.19 \\
\hline Peak thermal flux $(<0.625 \mathrm{eV}), 10^{14} \mathrm{n} / \mathrm{cm}^{2}-\mathrm{s}$ & $>12.0$ \\
\hline
\end{tabular}

The core power density distribution is shown in Figure 3-2, and since almost no energy is deposited in the moderated region it does not show up in this figure. It is also observed that the peak value is reached at the core center and not at the interface between the fast and moderated region, indicating that no thermal neutrons are returning from the moderated region.

The fast flux and thermal flux distributions are shown together in Figure 3-3. Different scales are used in the two regions. The thermal flux is only significant on the right-end side of the figure, corresponding to the moderated region of the core, while the fast flux is only largest in the active core region where neutrons are produced. Although not shown in Figure 3 because of the threshold value used, the fast flux remains significant in the entire reflector region. It is reduced by a factor of $\sim 50$ between its peak value at the core center and the values observed in the test assemblies located the farthest away from the core center (i.e., in the reflector).

The only region in which a significant thermal flux is observed is the moderated region. All the neutrons present in this region are neutrons leaking from the active core region and being moderated. Although this region is not fully optimized, a peak thermal flux of at least $6.0 \times 10^{14}$ $\mathrm{n} / \mathrm{cm}^{2}$-s is achievable solely by using leaking neutrons. In this study, the energy threshold used for thermal neutrons is taken to be $0.1 \mathrm{eV}$. However, the metrics used to evaluate the test reactor performance later stated that the threshold energy for thermal neutrons should be taken as 0.625 $\mathrm{eV}$. This means that the thermal fluxes claimed in this document are conservative and would be two to three times larger when using the energy threshold $(0.625 \mathrm{eV})$ stated in the ATDR study. 
FASTER Plant Design - Within the primary pool plant geometry, the primary heat transport system (PHTS) includes the primary pumps (2), the reactor core, the intermediate heat exchangers (4), and various structures and connections between these components (Figure 2). The primary pumps are mechanical centrifugal pumps with the characteristics shown in Table 6.

Table 6 - Primary Pump Design Characteristics

\begin{tabular}{|l|l|}
\hline Flow rate, $\mathrm{m}^{3} / \mathrm{s}$ & 758.3 \\
\hline Pump head, $\mathrm{kPa}$ & 704 \\
\hline Power, $\mathrm{kW}$ & 950 \\
\hline Efficiency, $\%$ & 90 \\
\hline Pump length, $\mathrm{m}$ & 9.18 \\
\hline Pump diameter (case), $\mathrm{m}$ & 0.889 \\
\hline
\end{tabular}

The IHXs are conventional sodium tube-and-shell heat exchangers that allow the primary (hot) sodium to flow through the shell side of the IHX and provide sensible heat to the secondary sodium that flows through the tube side of the IHX. The design characteristics of the IHX are provided in Table 7.

Table 7 - IHX Design Parameters

\begin{tabular}{|c|c|}
\hline Heat transfer capacity, MW & 75 \\
\hline Thermal Design Margin, (for average case) & $\pm \% 25$ \\
\hline Heat transfer area, $\mathrm{m}^{2}$ & 231 \\
\hline Primary sodium temperature, inlet, ${ }^{\circ} \mathrm{C} /$ outlet, ${ }^{\circ} \mathrm{C}$ & $355 / 510$ \\
\hline Primary sodium mass flowrate, $\mathrm{kg} / \mathrm{s}$ & 379.15 \\
\hline Secondary sodium temperature, inlet, ${ }^{\circ} \mathrm{C} /$ outlet, ${ }^{\circ} \mathrm{C}$ & $279 / 499$ \\
\hline Secondary side sodium mass flowrate, $\mathrm{kg} / \mathrm{s}$ & 265 \\
\hline Tube outer diameter, $\mathrm{cm}$ & 1.59 \\
\hline Tube wall thickness, $\mathrm{mm}$ & 0.889 \\
\hline Tube pitch, $\mathrm{cm}$ & 2.5 \\
\hline Effective tube length, $\mathrm{m}$ & 3.85 \\
\hline Number of tubes & 1,200 \\
\hline Tube sheet thickness, mm & 100 \\
\hline Downcomer piping-OD, $\mathrm{cm}$ & 32.385 \\
\hline Downcomer piping-thickness, $\mathrm{mm}$ & 9.525 \\
\hline Downcomer piping-length, $\mathrm{m}$ & TBD \\
\hline Outlet piping $-\mathrm{OD}, \mathrm{cm}$ & 45.72 \\
\hline Outlet piping -thickness, $\mathrm{mm}$ & 9.525 \\
\hline Outlet piping -length, $\mathrm{m}$ & TBD \\
\hline Shell (primary) side pressure drop, $\mathrm{kPa}$ & 15.96 \\
\hline Tube (secondary) side pressure drop, $\mathrm{kPa}$ & 30.76 \\
\hline Shell height, $\mathrm{m}$ & 4.96 \\
\hline Shell outside diameter, $\mathrm{m}$, main body/maximum & $1.038 / 1.145$ \\
\hline Shell thickness, mm & 19 \\
\hline Tube material & $9 \mathrm{Cr}-1 \mathrm{Mo}$ \\
\hline
\end{tabular}

The intermediate heat transport system (IHTS) (Figure 3) consists of centrifugal (2) mechanical pumps, two helical coil steam generators (HCSGs), the tube side of the IHX, and interconnected piping. The IHTS is protected from overpressure by a sodium-water reaction protection system in case of a steam generator tube leak. The components are connected via the IHTS piping. The normal shutdown heat removal path is through the PHTS, through the IHTS, and through the steam plant bypassing the turbine and dumping the steam to the main condenser. This heat removal path can provide for all heat removal capabilities needed when electrical power exists. 
Primary and secondary sodium coolant is purified in separate cold traps located in the primary and intermediate coolant systems. These cold traps will remove oxygen, hydrogen, and other impurities via conventional crystallization techniques. In addition, the primary sodium system has a nuclide trap for the specific removal of cesium and other radionuclides that may result from cladding breach testing. The cover gas purity is maintained by an argon cover gas supply and purification system, for both the PHTS and IHTS.

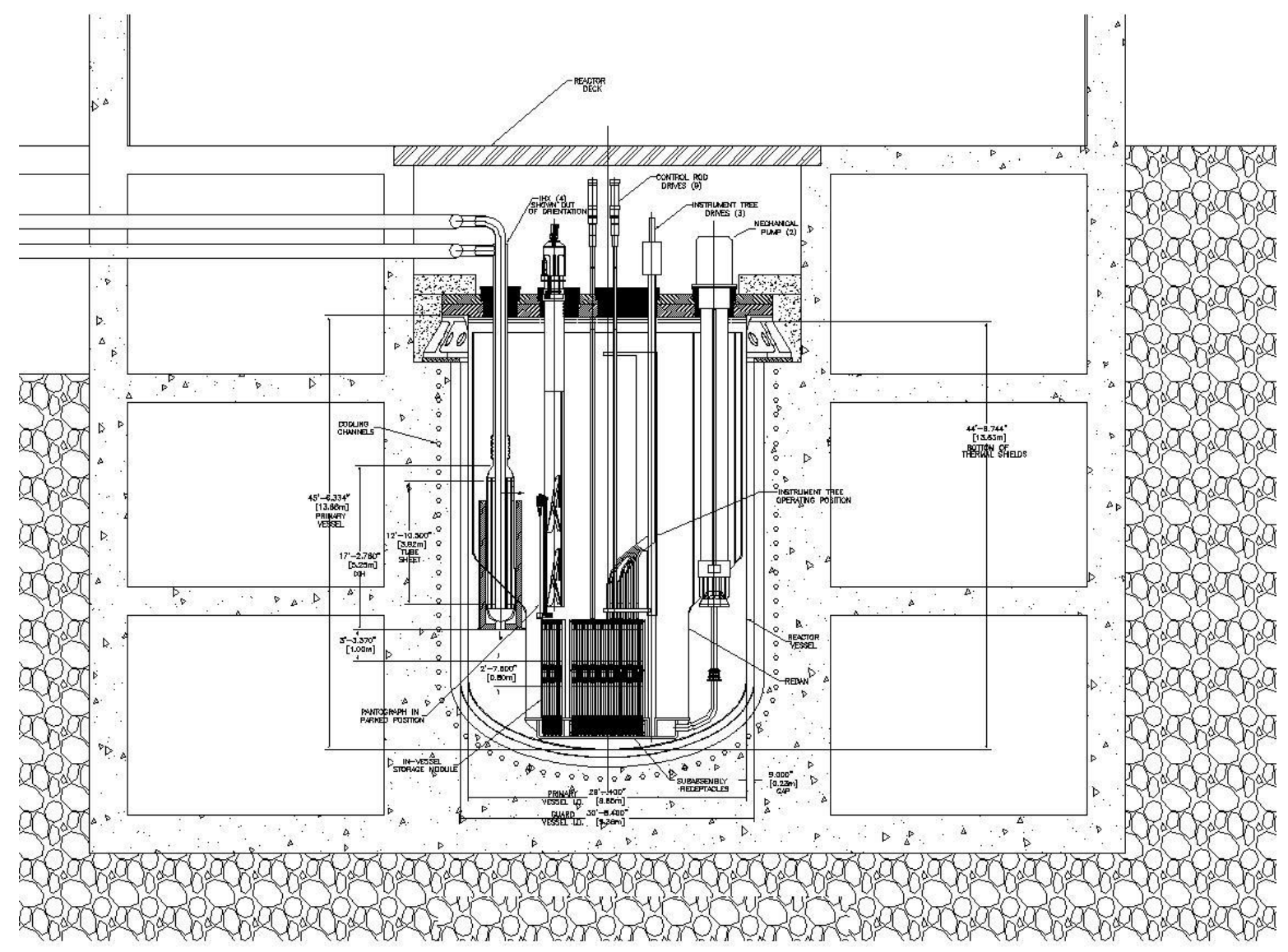

Figure 2 - Elevation View of PHTS 
The containment design is a low leakage steel reinforced concrete containment that is designed for all internal and external threats while minimizing the release of radionuclides to the environment during design basis and beyond design basis accidents. The containment and those parts of the nuclear island (NI) containing sodium piping and components incorporate design features to mitigate the effects of postulated sodium leakages and sodium fires such that temperature and pressure loadings following sodium leakage remain small or negligible. These features include sodium leak detectors, detecting a sodium leak when it is small before it can grow, shutting down the pump and draining the sodium from a failed sodium loop into the loop sodium dump tank to limit the amount of sodium released upon detection of a sodium leak or sodium burning, automatic isolation of ventilation lines serving a compartment upon detection of aerosols in the outlet duct, compartmentalization to reduce the volume of an air-filled partiallysealed compartment housing sodium piping or components thereby reducing the amount of available oxygen such that a sodium fire will rapidly consume the available oxygen and burn itself out, use of sodium catch pan fire suppression decks to significantly reduce the sodium burning rate from a sodium pool and protect the underlying concrete, confining sodium released from a failed pipe inside the gap between the pipe and surrounding thermal insulation and draining it through drain pipes to eliminate or significantly reduce the potential for formation of sodium jets or sprays, and the use of steel liners on compartment inner surfaces to further protect concrete. These mitigation approaches were previously developed and tested as part of the CRBR, PRISM, and SAFR design activities. 


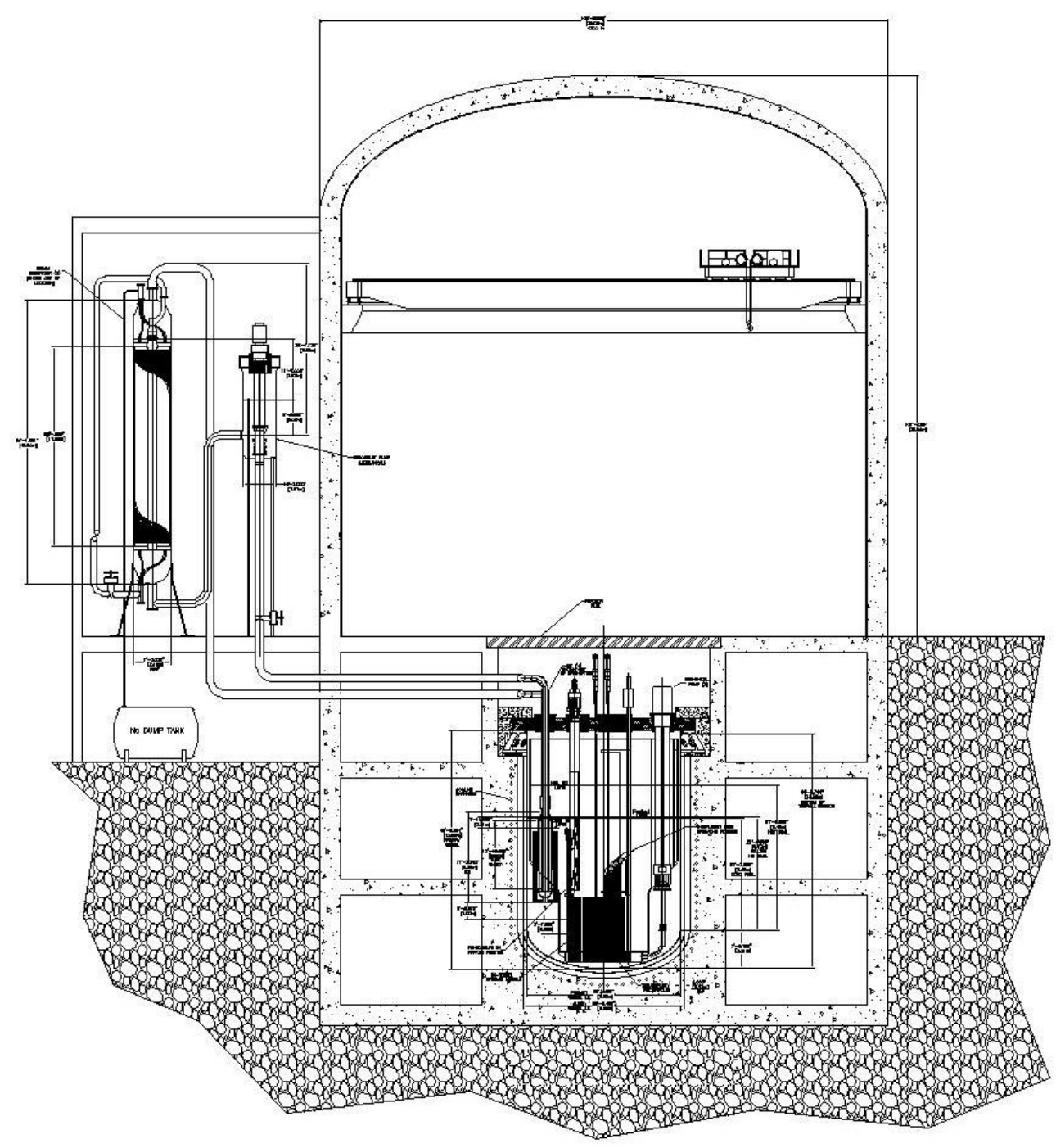

Figure 3 - FASTER NSSS - Elevation View 
Emergency decay heat removal is provided through three independent direct reactor auxiliary cooling system (DRACS) loops that allow for the passive removal of emergency decay heat from the primary heat transport system. The DRACS heat exchanger (3) (a tube-and-shell HX) is submerged in the FASTER reactor vessel cold pool. It is connected via piping to an air dump heat exchanger (ADHX) located outside of containment. Dampers on the ADHX minimize the parasitic losses from the emergency decay heat removal system during normal operation and will open fully upon a protective signal or loss of power.

Table 8 - DRACS HX - each

\begin{tabular}{|c|c|}
\hline Heat transfer capacity, KW & 750 \\
\hline Heat transfer area, $\mathrm{m}^{2}$ & 7.64 \\
\hline Primary sodium temperature, inlet, $\mathrm{C}^{\circ} /$ outlet, $\mathrm{C}^{\circ}$ & $510 / 355$ \\
\hline Primary sodium mass flowrate, $\mathrm{kg} / \mathrm{s}$ & 3.793 \\
\hline Secondary NaK temperature, inlet, $\mathrm{C}^{\circ}$ outlet, $\mathrm{C}^{\circ}$ & $328 / 484$ \\
\hline Secondary $\mathrm{NaK}$ mass flowrate, $\mathrm{kg} / \mathrm{s}$ & 5.47 \\
\hline Tube outer diameter, $\mathrm{cm}$ & 2.22 \\
\hline Tube wall thickness, $\mathrm{mm}$ & 0.9 \\
\hline Tube pitch, $\mathrm{cm}$ & 3.79 \\
\hline Effective tube length, $\mathrm{m}$ & 2.489 \\
\hline Number of tubes & 44 \\
\hline Shell OD, cm & 32.26 \\
\hline Shell wall thickness, mm & 9.525 \\
\hline Material & $9 \mathrm{Cr}-1 \mathrm{Mo}$ \\
\hline
\end{tabular}

The balance of plant consists of a conventional superheated steam cycle attached to the (2) oncethrough sodium heated steam generators. Conditions are calculated with the GateCycle software

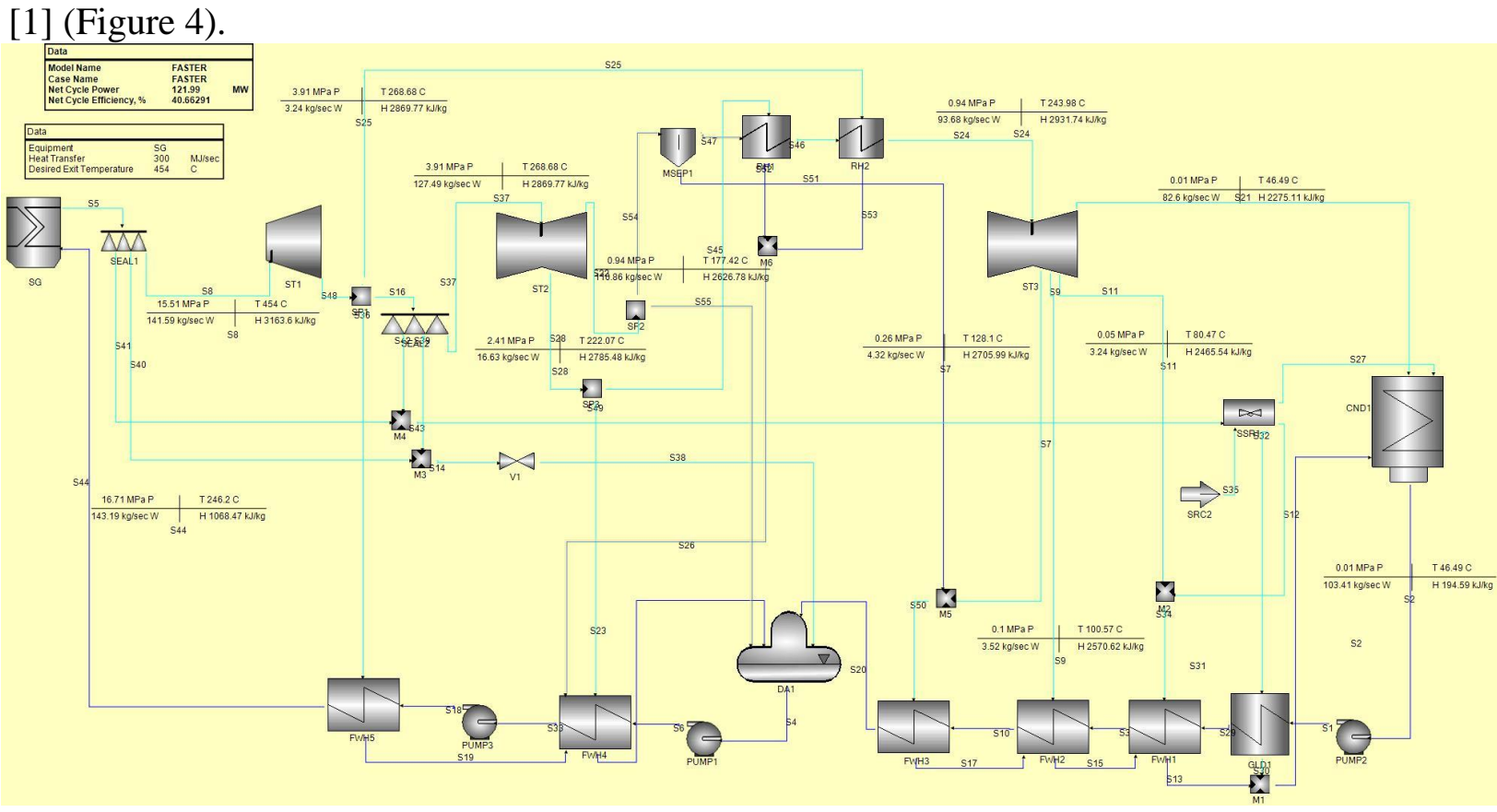

Figure 4 - FASTER Thermodynamic Cycle and Balance of Plant 
Test Assembly Flux Levels and Volumes - as mentioned above, in its current configuration (Figure 1), the FASTER core provides 33 fast flux test locations, three (3) thermal flux test locations, two (2) fast flux closed loops and one thermal flux closed loop. Among the fast spectrum test locations, four of them are located near the core center and cannot be repositioned without affecting the core neutronics performance. The other 29 fast flux test locations are located in the radial reflector region and their position can be changed without significantly affecting the core performance. In fact, any of the reflector assembly locations could be used as a test location without having any significant impact on the core performance. In a similar way, the number of thermal flux test locations could be increased by replacing reflector assemblies with moderator and thermal test assemblies. This would result in a reduction of the number of fast flux test locations. It is important to note that the closed loop and instrumented irradiation positions are fixed because the fuel handling machines and instrumentation trees have been designed around these fixed core positions.

The core assembly length is estimated to be $\sim 2.77 \mathrm{~m}$. The actual test length will depend on the test assembly design; in particular, the length of the lower adaptor and core handling socket. The likely resulting effective test length will be around two meters, corresponding to an available test volume of $\sim 24$ liters in each test location. The total test volume in the current core configuration is about $0.95 \mathrm{~m}^{3}$. The flux level achieved in a test assembly depends on its distance from the core center, as well as on its composition. Given that the materials to be tested are currently undetermined, the flux levels provided here were obtained when test locations are filled with a reflector assembly ( $80 \%$ steel, $20 \%$ coolant).

The normalized axial fast flux profile is shown in Figure 5 for a test assembly located in the active core region and for a test assembly located in the reflector region. The characteristics of the fast flux test assemblies based on their flux values and their characteristics are summarized in Table 9. In order to provide a measure of the total irradiation capacity available, the total fast fluxes are multiplied by the test volumes. This captures the fact that the fast flux near the extremities of the test location is significantly smaller than near the center and that increasing the test length without increasing the active core length will not significantly increase the irradiation capacity.

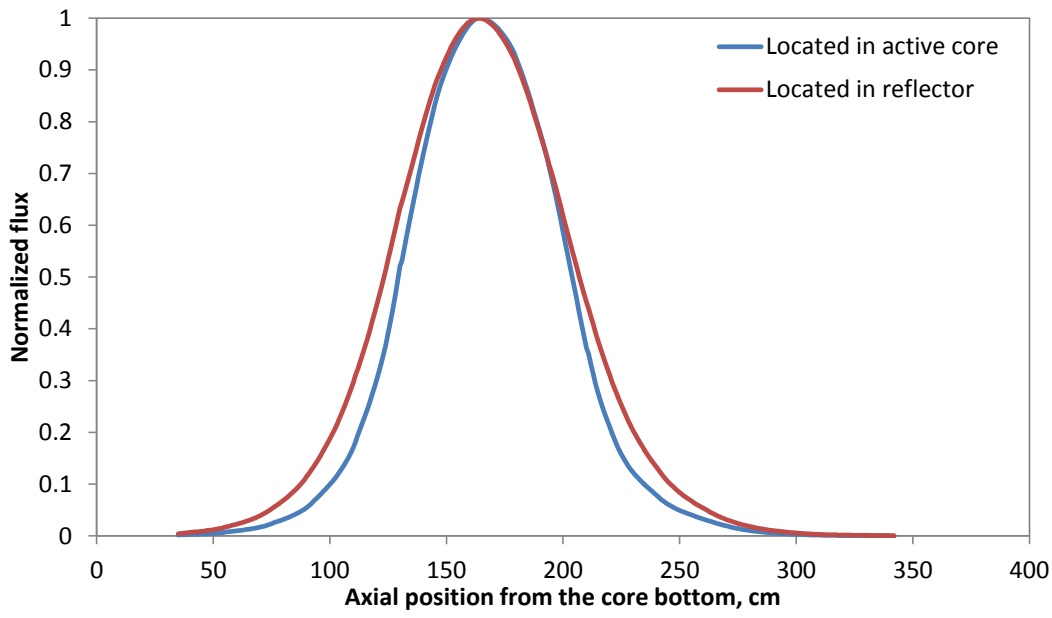

Figure 5 - Normalized axial fast flux distribution in test locations 
Table 9 - Summary of Fast Flux Conditions in the Test Assemblies

\begin{tabular}{|l|l|l|l|l|}
\hline Group & $\begin{array}{l}\text { Number of } \\
\text { assemblies }\end{array}$ & $\begin{array}{l}\text { Peak fast flux range } \\
\left(10^{15} \mathrm{n} / \mathrm{cm}^{2} \cdot \mathrm{s}\right)\end{array}$ & $\begin{array}{l}\text { Fast flux*Volume } \\
\text { range }\left(10^{19} \mathrm{n} \cdot \mathrm{cm} / \mathrm{s}\right)\end{array}$ & $\begin{array}{l}\text { Total fast flux*Volume }\left(10^{19}\right. \\
\mathrm{n} \cdot \mathrm{cm} / \mathrm{s})\end{array}$ \\
\hline A & 4 & $4.7-5.2$ & $4.0-4.9$ & 17.9 \\
\hline Closed loops & 2 & 2.3 & 1.7 & 3.4 \\
\hline B & 10 & $1.9-2.7$ & $1.4-2.1$ & 15.8 \\
\hline C & 19 & $0.3-1.3$ & $0.2-0.9$ & 10.3 \\
\hline
\end{tabular}

In the thermal flux test assemblies and thermal closed loop, the fast flux level is not relevant and the thermal flux level is provided instead. It is important to note that the thermal neutrons were defined as all neutrons having an energy lower than $0.1 \mathrm{eV}$. By using the energy threshold later established as part of the ATDR study framework $(0.625 \mathrm{eV})$, these thermal flux values would be two to three times larger.

The peak thermal flux values calculated in the closed loop and three test assemblies located in the moderated region are provided in Table 3-9 for each location individually. The peak value is typically achieved near the side of the assembly that is facing the active core region (i.e., where the neutrons are coming from). The thermal flux is radially reduced by a factor of $\sim 2$ across an assembly, for a given axial position. The normalized axial thermal flux distribution is shown in Figure 3-7. The rough aspect of the curve is due to the uncertainties of the calculations performed with MCNP.

Table 10 - Summary of Thermal Flux Conditions in the Test Assemblies

\begin{tabular}{|l|c|c|}
\hline Location & Peak thermal flux $\left(10^{14} \mathrm{n} / \mathrm{cm}^{2} \cdot \mathrm{s}\right)$ & Thermal flux*Volume $\left(10^{18} \mathrm{n} / \mathrm{cm}^{2} \cdot \mathrm{s}\right)$ \\
\hline Closed loop & 5.8 & 3.7 \\
\hline A1 & 1.9 & 1.2 \\
\hline A2 & 1.9 & 1.2 \\
\hline B & 1.7 & 1.1 \\
\hline
\end{tabular}

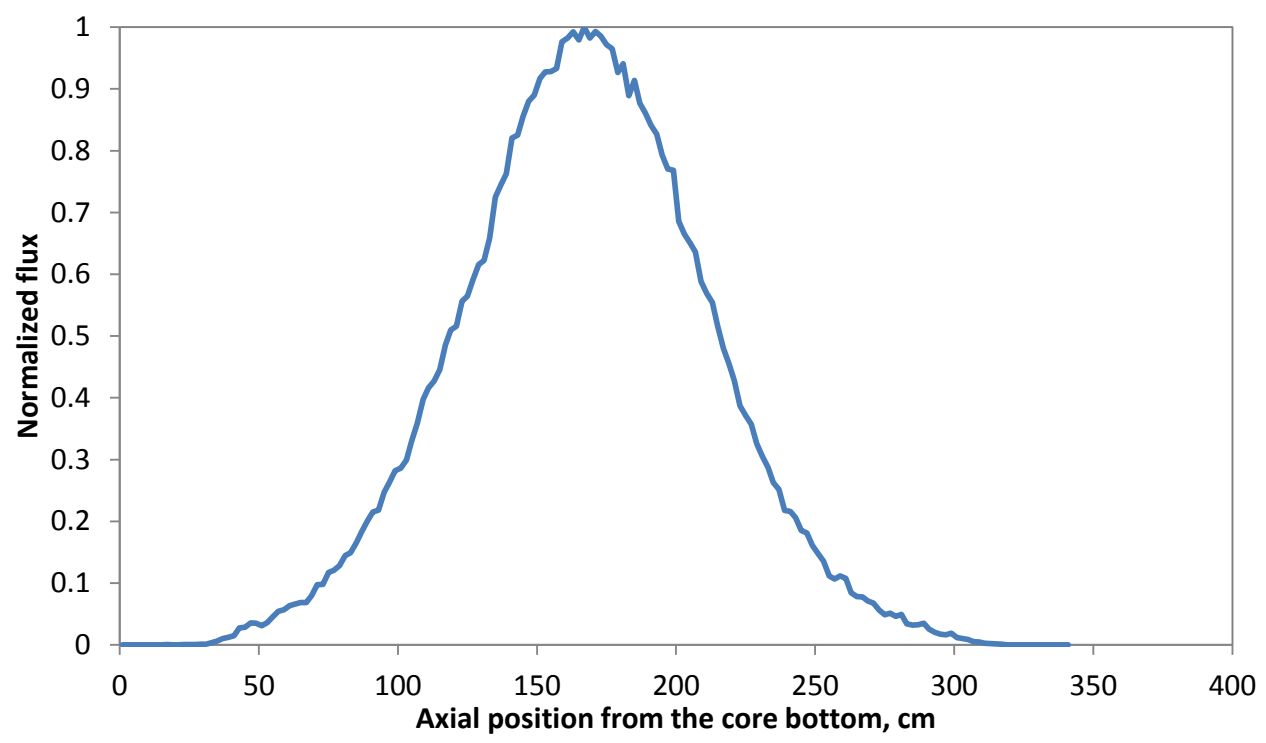

Figure 6 - Normalized axial thermal flux distribution in the test locations 
Closed Loop Systems - The three closed loop systems (CLS) are an important capability of FASTER and part of the study metrics. They enable FASTER to be utilized to irradiate and test fuels and materials in a prototypical flowing coolant environment with different coolants for different reactor types. The closed loop (CL) testing capability goes beyond just fuels and materials testing. Each CLS with a different coolant is a demonstration of that coolant and its technology inside of an operating nuclear reactor. Thus, one has an integrated demonstration of fuel, core materials, coolant, coolant chemistry control, and optionally coolant cleanup technologies under prototypical conditions in either a fast or thermalized neutron spectrum, as appropriate. For a different reactor coolant than sodium, this can be a test and demonstration as well as an approach to increasing the TRL level for the fuel, materials, and coolant technologies for far less cost than designing, building, and operating a separate nuclear reactor with those fuel, materials, and coolant technologies. The closed loop approach might reveal unanticipated problems with a different reactor technology for a far less expense than designing, building, and operating a separate reactor.

CLSs incorporating sodium were an integral part of the FFTF design [2], [3] that could have simultaneously incorporated four such CLs. Two compact integrated closed loop primary modules were actually built and one was installed in a cell inerted with nitrogen inside of the FFTF containment. None of the CLs at FFTF were actually used, however, during its 10 year operating life. For irradiation and testing with flowing coolants at different conditions other than the main primary coolant flow, the closed loop approach is essential. Pressurized water CLs are also an integral part of the Advanced Test Reactor (ATR) design and are utilized for irradiation and testing [4].

For FASTER, heat removal requirements for different coolants and reactor configurations were first investigated assuming that each CLS can accommodate a test section inside of a flow tube having an inner diameter of $6.985 \mathrm{~cm}(2.75 \mathrm{inch})$ and a closed loop heat rejection rate capability of $2.3 \mathrm{MW}_{\mathrm{t}}$ per loop, similar to the CLS designs for FFTF [2], [3]. Heat removal rate and coolant flowrate requirements for different coolants for different example reactor designs are shown in Table 11 for test sections simulating a small portion of each reactor core inside of the flow tube. For nominal steady state temperature and velocity conditions, the heat removal rate capability of $2.3 \mathrm{MW}_{\mathrm{t}}$ is sufficient. A single possible exception is the Pebble Bed Fluoride-SaltCooled High-Temperature Reactor (PB-FHR) for which it might be necessary to slightly reduce the size of the core mockup to reduce the power deposition below the indicated $2.2 \mathrm{MW}_{\mathrm{t}}$. The $2.3 \mathrm{MW}_{\mathrm{t}}$ heat rejection rate generally provides some margin for transient testing that can include greater power deposition rates than at nominal steady state.

Table 11 - Heat Rejection Rate and Flowrate Requirements for Closed Loops for Different Reactor Coolants and Example Reactor Designs

\begin{tabular}{|l|l|l|l|l|l|l|l|l|}
\hline Coolant & Sodium & Sodium & Lead, Pb & $\begin{array}{l}\text { Liquid Salt, } \\
\text { FLiBe, } \\
2 \mathrm{LiF}_{-B e F}\end{array}$ & $\begin{array}{l}\text { Liquid Salt, } \\
\text { FLiBe, } \\
2{\mathrm{LiF}-B e F_{2}}\end{array}$ & $\begin{array}{l}\text { Pressurized } \\
\text { Helium }\end{array}$ & $\begin{array}{l}\text { Pressurized } \\
\text { Water }\end{array}$ & $\begin{array}{l}\text { Pressurized } \\
\text { Water }\end{array}$ \\
\hline Reactor & $\begin{array}{l}\text { PGSFR for } \\
\text { Nominal } \\
\text { Conditions }\end{array}$ & $\begin{array}{l}\text { PGSFR for } \\
\text { Unprotected } \\
\text { Transient } \\
\text { Overpower } \\
\text { Conditions }\end{array}$ & $\begin{array}{l}\text { LFR with } \\
\text { High Core } \\
\text { Outlet } \\
\text { Temperature }\end{array}$ & $\begin{array}{l}\text { ORNL } \\
\text { AHTR }\end{array}$ & $\begin{array}{l}\text { UCB Pebble } \\
\text { Bed FHR }\end{array}$ & $\begin{array}{l}\text { GA } \\
\text { Prismatic } \\
\text { HTGR }\end{array}$ & $\begin{array}{l}\text { WEC } \\
\text { AP1000 }\end{array}$ & $\begin{array}{l}\text { High Flux } \\
\text { Isotope } \\
\text { Reactor } \\
\text { (HFIR) }\end{array}$ \\
\hline $\begin{array}{l}\text { Flow } \\
\text { Direction }\end{array}$ & Up & Up & Up & Up & Up & Down & Up & Down \\
\hline Flow Area & 0.38 & 0.38 & 0.599 & 0.15 & 0.60 & 0.187 & 0.531 & 0.50 \\
\hline
\end{tabular}


FASTER Test Reactor Preconceptual Design Report

March 31, 2016

\begin{tabular}{|c|c|c|c|c|c|c|c|c|}
\hline $\begin{array}{l}\text { Fraction } \\
\text { Inside } \\
\text { Reactor Core }\end{array}$ & & & & & & & & \\
\hline $\begin{array}{l}\text { Coolant Inlet } \\
\text { Pressure, } \\
\text { MPa }\end{array}$ & $\begin{array}{l}\text { Near } \\
\text { Atmospheric }\end{array}$ & $\begin{array}{l}\text { Near } \\
\text { Atmospheric }\end{array}$ & $\begin{array}{l}\text { Near } \\
\text { Atmospheric }\end{array}$ & $\begin{array}{l}\text { Near } \\
\text { Atmospheric }\end{array}$ & $\begin{array}{l}\text { Near } \\
\text { Atmospheric }\end{array}$ & 6.39 & 15.5 & 2.24 \\
\hline $\begin{array}{l}\text { Coolant } \\
\text { Outlet/Inlet } \\
\text { Temperatures, } \\
{ }^{\circ} \mathrm{C}\end{array}$ & $547 / 395$ & $738 / 395$ & $650 / 400$ & $700 / 650$ & $700 / 600$ & $750 / 322$ & $321 / 281$ & $67.8 / 57.2$ \\
\hline $\begin{array}{l}\text { Coolant Inlet } \\
\text { Velocity, } \mathrm{m} / \mathrm{s}\end{array}$ & 5.52 & 5.52 & 2.0 & 1.94 & 2.0 & 20.2 & 4.85 & 15.5 \\
\hline $\begin{array}{l}\text { Coolant Mass } \\
\text { Flowrate, } \mathrm{kg} / \mathrm{s}\end{array}$ & 6.91 & 6.91 & 48.5 & 2.18 & 9.14 & 0.0737 & 7.53 & 29.4 \\
\hline $\begin{array}{l}\text { Coolant } \\
\text { Volume } \\
\text { Flowrate, } \\
\text { m3/s (gpm) }\end{array}$ & $\begin{array}{l}0.00804 \\
(127)\end{array}$ & $\begin{array}{l}0.00804 \\
(127)\end{array}$ & $\begin{array}{l}0.00459 \\
(72.8)\end{array}$ & $\begin{array}{l}0.00111 \\
(17.6)\end{array}$ & $\begin{array}{l}0.00460 \\
(72.9)\end{array}$ & $\begin{array}{l}0.0145 \\
(229)\end{array}$ & $\begin{array}{l}0.00986 \\
(156)\end{array}$ & $\begin{array}{l}0.0298 \\
(472)\end{array}$ \\
\hline $\begin{array}{l}\text { Power } \\
\text { Removed by } \\
\text { Coolant, } \\
\text { MWt }\end{array}$ & 1.33 & 2.98 & 1.75 & 0.263 & 2.21 & 0.164 & 1.66 & 1.30 \\
\hline
\end{tabular}

Next, the feasibility of designing closed loop in-reactor assemblies for different coolants and reactor configurations was examined. It is assumed that the pressure boundary of the in-reactor assembly is a double-walled pressure tube. The incorporation of a double-walled pressure tube is viewed as a necessary and sufficient approach to incorporate coolants other than sodium inside of a SFR. Required wall thicknesses for each of the two pressure tubes were calculated using the formulae and tables in the ASME Boiler and Pressure Vessel Code Section III, "Rules for Construction of Nuclear Facility Components," Division 1-Subsection NH, "Class 1 Components in Elevated Temperature Service," 2001 Edition. The lifetime of each in-reactor assembly is assumed to be 10,000 hours which is a $4 \%$ margin over the duration of four FASTER operating cycles. The outer tube outer diameter of $11.26 \mathrm{~cm}$ (4.44 inches) is assumed identical to that of the hexcan duct-to-duct inner distance for a FASTER fuel assembly. The outer tube outer diameter is the largest value that can fit inside of an assembly location in the FASTER core with clearances filled with sodium between the outer tube and the hexcans of the six neighboring core assembles. For the low pressure coolants (sodium, lead, and pressurized water under HFIR conditions), the design pressure is taken equal to the same value for the inreactor assemblies in FFTF $(2.5 \mathrm{MPa}=363 \mathrm{psig})$. The case of liquid salt coolant is not analyzed because a suitable structural material has not yet been codified in the ASME code. For helium and pressurized water under PWR conditions, the design pressure is assumed to be $10 \%$ greater than the values assumed in Table 11. The required pressure tube dimensions for a design temperature of $649^{\circ} \mathrm{C}(1200 \mathrm{~F})$ are shown in Table 12. For the low pressure coolants, the required wall thicknesses of the outer pressure and inner pressure tubes are $2.51 \mathrm{~mm}(0.0986 \mathrm{in})$ and $2.25 \mathrm{~mm}$ (0.0887 in), respectively. To insure against concerns about potential buckling of the pressure tubes under external pressure, effects of irradiation, and other uncertainties, the wall thicknesses are increased to a minimum of $6.35 \mathrm{~mm}(0.25 \mathrm{in})$. The inner tube inner diameter of $8.09 \mathrm{~cm}$ (3.18 in) provides plenty of space for a flow tube to separate downward and upward flows and a test section inside of the flow tube. For pressurized helium coolant, the inner tube inner diameter of $8.16 \mathrm{~cm}$ (3.21 in) also provides ample space. For pressurized water under PWR conditions, there is space for a flow tube and test section but the number of fuel pins would need to be reduced below that implied by the assumptions in Table 11 . 
Table 12 - Required Pressure Tube Dimensions for $649^{\circ} \mathrm{C}\left(1200^{\circ} \mathrm{F}\right)$ Design Temperature

\begin{tabular}{|l|l|l|l|l|}
\hline Coolant & $\begin{array}{l}\text { Sodium, Lead, or } \\
\text { Low Pressurized } \\
\text { Water }\end{array}$ & $\begin{array}{l}\text { Sodium, Lead, or } \\
\text { Low Pressurized } \\
\text { Water with 0.25 in } \\
\text { Wall Thicknesses }\end{array}$ & $\begin{array}{l}\text { Pressurized } \\
\text { Helium }\end{array}$ & $\begin{array}{l}\text { Highly } \\
\text { Pressurized } \\
\text { Water }\end{array}$ \\
\hline Pressure Tube Material & 316 & 316 & $800 \mathrm{H}$ & 316 \\
\hline Design Gauge Pressure, MPa (psig) & $2.50(363)$ & $2.50(363)$ & $7.82(1019)$ & $17.05(2473)$ \\
\hline Design Temperature, ${ }^{\circ} \mathrm{C}$ (F) & $649(1200)$ & $649(1200)$ & $649(1200)$ & $649(1200)$ \\
\hline Design Lifetime, hours & 10,000 & 10,000 & 10,000 & 10,000 \\
\hline Outer Pressure Outer Diameter, cm (in) & $11.26(4.443)$ & $11.26(4.443)$ & $11.26(4.443)$ & $11.26(4.443)$ \\
\hline Outer Pressure Tube Wall Thickness, cm (in) & $0.251(0.0986)$ & $0.635(0.25)$ & $0.677(0.266)$ & $1.850(0.728)$ \\
\hline Outer Pressure Tube Inner Diameter, cm (in) & $10.76(4.236)$ & $9.990(3.933)$ & $9.907(3.900)$ & $7.560(2.976)$ \\
\hline Gap Between Pressure Tubes, cm (in) & $0.318(0.125)$ & $0.318(0.125)$ & $0.318(0.125)$ & $0.318(0.125)$ \\
\hline Inner Pressure Tube Outer Diameter, cm (in) & $10.12(3.986)$ & $9.355(3.683)$ & $9.272(3.650)$ & $6.925(2.726)$ \\
\hline Inner Pressure Tube Wall Thickness, cm (in) & $0.225(0.0887)$ & $0.635(0.25)$ & $0.557(0.219)$ & $1.14(0.448)$ \\
\hline Inner Pressure Tube Inner Diameter, cm (in) & $9.673(3.808)$ & $8.085(3.183)$ & $8.157(3.212)$ & $4.649(1.830)$ \\
\hline
\end{tabular}

For liquid salt and pressurized helium coolant, it is desirable to achieve higher temperatures. For a design temperature of $704{ }^{\circ} \mathrm{C}(1300 \mathrm{~F})$, ample space is still available with the low pressure and pressurized helium coolants (Table 13). There still remains space when the design temperature is further increased to $760{ }^{\circ} \mathrm{C}(1400 \mathrm{~F})$ as shown in Table 14. The test sections in the FFTF closed loop in-reactor assemblies were designed for a sodium outlet temperature of $760{ }^{\circ} \mathrm{C}(1400$ F) while the double-walled pressure tube and other closed loop hardware was designed for 649 ${ }^{\circ} \mathrm{C}(1200 \mathrm{~F})$. This was achieved by bypassing part of the upward sodium flow around the test section in the annular space between a cylindrical thermal baffle surrounding the test section and the flow tube separating the downward and upward sodium flows inside of the pressure tube. An alternate approach that permits more space for a test section is to design the entire in-reactor assembly for a greater temperature and mix the outlet coolant with a cooler coolant bypass stream inside of a mixing component outside of the reactor.

Table 13 - Required Pressure Tube Dimensions for $704^{\circ} \mathrm{C}$ (1300 F) Design Temperature

\begin{tabular}{|c|c|c|c|c|}
\hline Coolant & $\begin{array}{l}\text { Sodium, Lead, or } \\
\text { Low Pressurized } \\
\text { Water }\end{array}$ & $\begin{array}{l}\text { Sodium, Lead, or } \\
\text { Low Pressurized } \\
\text { Water with } 0.25 \text { in } \\
\text { Wall Thicknesses }\end{array}$ & $\begin{array}{l}\text { Pressurized } \\
\text { Helium }\end{array}$ & $\begin{array}{l}\text { Highly } \\
\text { Pressurized } \\
\text { Water }\end{array}$ \\
\hline Pressure Tube Material & 316 & 316 & $800 \mathrm{H}$ & 316 \\
\hline Design Gauge Pressure, MPa (psig) & $2.50(363)$ & $2.50(363)$ & $7.82(1019)$ & $17.05(2473)$ \\
\hline Design Temperature, ${ }^{\circ} \mathrm{C}(\mathrm{F})$ & $704(1300)$ & $704(1300)$ & $704(1300)$ & $704(1300)$ \\
\hline Design Lifetime, hours & 10,000 & 10,000 & 10,000 & 10,000 \\
\hline Outer Pressure Outer Diameter, cm (in) & $11.26(4.443)$ & $11.26(4.443)$ & $11.26(4.443)$ & $11.26(4.443)$ \\
\hline Outer Pressure Tube Wall Thickness, cm (in) & $0.456(0.179)$ & $0.635(0.25)$ & $1.08(0.427)$ & $3.61(1.42)$ \\
\hline Outer Pressure Tube Inner Diameter, cm (in) & $10.35(4.074)$ & $9.990(3.933)$ & $9.091(3.579)$ & $4.033(1.588)$ \\
\hline Gap Between Pressure Tubes, cm (in) & $0.318(0.125)$ & $0.318(0.125)$ & $0.318(0.125)$ & $0.318(0.125)$ \\
\hline Inner Pressure Tube Outer Diameter, cm (in) & $9.714(3.824)$ & $9.355(3.683)$ & $8.456(3.329)$ & $3.398(1.338)$ \\
\hline Inner Pressure Tube Wall Thickness, cm (in) & $0.393(0.155)$ & $0.635(0.25)$ & $0.814(0.321)$ & $1.09(0.429)$ \\
\hline Inner Pressure Tube Inner Diameter, cm (in) & $8.928(3.515)$ & $8.085(3.183)$ & $6.827(2.688)$ & $1.217(0.4793)$ \\
\hline
\end{tabular}

Table 14 - Required Pressure Tube Dimensions for $760^{\circ} \mathrm{C}(1400$ F) Design Temperature

\begin{tabular}{|l|l|l|}
\hline Coolant & $\begin{array}{l}\text { Sodium, Lead, or } \\
\text { Low Pressurized } \\
\text { Water }\end{array}$ & $\begin{array}{l}\text { Pressurized } \\
\text { Helium }\end{array}$ \\
\hline Pressure Tube Material & 316 & $800 \mathrm{H}$ \\
\hline Design Gauge Pressure, $\mathrm{MPa}(\mathrm{psig})$ & $2.50(363)$ & $7.82(1019)$ \\
\hline Design Temperature, ${ }^{\circ} \mathrm{C}(\mathrm{F})$ & $760(1400)$ & $760(1400)$ \\
\hline
\end{tabular}




\begin{tabular}{|l|l|l|}
\hline Design Lifetime, hours & 10,000 & 10,000 \\
\hline Outer Pressure Outer Diameter, cm (in) & $11.26(4.443)$ & $11.26(4.443)$ \\
\hline Outer Pressure Tube Wall Thickness, cm (in) & $0.905(0.356)$ & $1.85(0.726)$ \\
\hline Outer Pressure Tube Inner Diameter, cm (in) & $9.450(3.720)$ & $7.569(2.980)$ \\
\hline Gap Between Pressure Tubes, cm (in) & $0.318(0.125)$ & $0.318(0.125)$ \\
\hline Inner Pressure Tube Outer Diameter, cm (in) & $8.815(3.470)$ & $6.934(2.730)$ \\
\hline Inner Pressure Tube Wall Thickness, cm (in) & $0.709(0.279)$ & $1.14(0.447)$ \\
\hline Inner Pressure Tube Inner Diameter, cm (in) & $7.398(2.913)$ & $4.662(1.835)$ \\
\hline
\end{tabular}

The CLS for each alternative (non-sodium) coolant incorporates an in-reactor assembly with a test section, a primary loop with the particular coolant for irradiation and testing, a secondary loop with an appropriate secondary coolant for heat transport, a primary coolant-to-secondary coolant IHX, a secondary coolant-to-air DHX for heat rejection to the atmospheric heat sink, and interconnecting piping. Six different CL primary coolants have been included thus far in the FASTER design; others can be added in the future. The six primary coolants and the major features of the CLS for each are shown in Table 15. For sodium, lead or lead-bismuth eutectic (LBE), liquid salt, and helium, each primary CL in-reactor assembly is designed for a maximum temperature of $760{ }^{\circ} \mathrm{C}\left(1400{ }^{\circ} \mathrm{F}\right)$. For sodium, lead or LBE, liquid salt, and helium primary coolants, sodium is used as the secondary coolant to reject heat to air. A single secondary coolant, sodium, is utilized because it is a low pressure coolant and because of its low freezing temperature, excellent heat transfer properties, excellent compatibility with stainless steel and other alloys, and to avoid the cost of designing and installing a secondary loop and secondary DHX for a different fluid. Sodium is not used for the pressurized water primary coolants to provide separation between sodium and water components and piping, and because heat rejection for primary water coolant can occur at temperatures below or above but near the sodium freezing temperature.

Table 15 - Closed Loop System Primary Coolants and Major Features

\begin{tabular}{|c|c|c|c|c|c|c|}
\hline $\begin{array}{l}\text { Primary } \\
\text { Coolant for } \\
\text { In-Reactor } \\
\text { Irradiation } \\
\text { and Testing }\end{array}$ & Sodium & $\begin{array}{l}\text { Lead, } \mathrm{Pb} \text {, or } \\
\text { Lead-Bismuth } \\
\text { Eutectic, } 45 \mathrm{wt} \\
\% \mathrm{~Pb}-55 \text { wt \% } \\
\mathrm{Bi}\end{array}$ & $\begin{array}{l}\text { Liquid Salt, } \\
\text { FLiBe, } \\
\text { 2LiF-BeF } 2\end{array}$ & $\begin{array}{l}\text { Pressurized } \\
\text { Helium }\end{array}$ & $\begin{array}{l}\text { Pressurized } \\
\text { Water for NPP } \\
\text { Conditions }\end{array}$ & $\begin{array}{l}\text { Pressurized } \\
\text { Water for } \\
\text { Research and } \\
\text { Test Reactor } \\
\text { Conditions }\end{array}$ \\
\hline $\begin{array}{l}\text { Secondary } \\
\text { Coolant }\end{array}$ & Sodium & Sodium & Sodium & Sodium & $\begin{array}{l}\text { Pressurized } \\
\text { Water }\end{array}$ & $\begin{array}{l}\text { Pressurized } \\
\text { Water }\end{array}$ \\
\hline $\begin{array}{l}\text { Primary } \\
\text { Materials }\end{array}$ & $316 \mathrm{H}, 316$ & $\begin{array}{l}\text { ALD-Coated } \\
316 \mathrm{H} \text { and } 316\end{array}$ & Hastelloy N & $800 \mathrm{H}$ & $\begin{array}{l}\text { Low Alloy and } \\
\text { Carbon Steel } \\
\text { with Stainless } \\
\text { Steel Cladding }\end{array}$ & $\begin{array}{l}\text { Low Alloy and } \\
\text { Carbon Steel } \\
\text { with Stainless } \\
\text { Steel Cladding }\end{array}$ \\
\hline $\begin{array}{l}\text { Secondary } \\
\text { Materials }\end{array}$ & $316 \mathrm{H}, 316$ & $316 \mathrm{H}, 316$ & $316 \mathrm{H}, 316$ & $316 \mathrm{H}, 316$ & $\begin{array}{l}\text { Low Alloy and } \\
\text { Carbon Steel } \\
\text { with Stainless } \\
\text { Steel Cladding }\end{array}$ & $\begin{array}{l}\text { Low Alloy and } \\
\text { Carbon Steel } \\
\text { with Stainless } \\
\text { Steel Cladding }\end{array}$ \\
\hline $\begin{array}{l}\text { Intermediat } \\
\text { e Heat } \\
\text { Exchanger }\end{array}$ & $\begin{array}{l}\text { Single-Walled } \\
\text { Tube Helical } \\
\text { Coil Similar to } \\
\text { FFTF Closed } \\
\text { Loop System } \\
\text { Design }\end{array}$ & $\begin{array}{l}\text { Double-Walled } \\
\text { Straight Tube to } \\
\text { Preclude } \\
\text { Leakage }\end{array}$ & $\begin{array}{l}\text { Double-Walled } \\
\text { Straight Tube } \\
\text { with Hastelloy } \\
\text { N Tubes to } \\
\text { Preclude } \\
\text { Leakage }\end{array}$ & $\begin{array}{l}\text { Double-Walled } \\
\text { Straight Tube to } \\
\text { Preclude Leakage }\end{array}$ & $\begin{array}{l}\text { Single-Walled } \\
\text { Tube Helical } \\
\text { Coil }\end{array}$ & $\begin{array}{l}\text { Single-Walled } \\
\text { Tube Helical } \\
\text { Coil }\end{array}$ \\
\hline $\begin{array}{l}\text { In-Reactor } \\
\text { Assembly }\end{array}$ & $\begin{array}{l}\text { Single-Wall } \\
\text { Flow Tube }\end{array}$ & $\begin{array}{l}\text { Double-Wall } \\
\text { Flow Tube with } \\
\text { Monitored Gap } \\
\text { to Preclude } \\
\text { Leakage }\end{array}$ & $\begin{array}{l}\text { Double-Wall } \\
\text { Flow Tube with } \\
\text { Monitored Gap } \\
\text { to Preclude } \\
\text { Leakage }\end{array}$ & $\begin{array}{l}\text { Double-Wall } \\
\text { Flow Tube with } \\
\text { Monitored Gap to } \\
\text { Preclude Leakage }\end{array}$ & $\begin{array}{l}\text { Double-Wall } \\
\text { Flow Tube } \\
\text { with Monitored } \\
\text { Gap to } \\
\text { Preclude } \\
\text { Leakage and }\end{array}$ & $\begin{array}{l}\text { Double-Wall } \\
\text { Flow Tube } \\
\text { with Monitored } \\
\text { Gap to } \\
\text { Preclude } \\
\text { Leakage and }\end{array}$ \\
\hline
\end{tabular}


FASTER Test Reactor Preconceptual Design Report

March 31, 2016

\begin{tabular}{|c|c|c|c|c|c|c|}
\hline & & & & & $\begin{array}{l}\text { for Thermal } \\
\text { Insulation }\end{array}$ & $\begin{array}{l}\text { for Thermal } \\
\text { Insulation }\end{array}$ \\
\hline $\begin{array}{l}\text { Primary } \\
\text { Coolant } \\
\text { Pumps } \\
\end{array}$ & $\begin{array}{l}\text { Electromagneti } \\
\mathrm{c}\end{array}$ & $\begin{array}{l}\text { Electromagneti } \\
\mathrm{c}\end{array}$ & $\begin{array}{l}\text { Electromagneti } \\
\mathrm{c}\end{array}$ & $\begin{array}{l}\text { Centrifugal/Radia } \\
\text { l Pump }\end{array}$ & Canned Rotor & Canned Rotor \\
\hline $\begin{array}{l}\text { Primary } \\
\text { Coolant } \\
\text { Chemistry } \\
\text { Control and } \\
\text { Cleanup }\end{array}$ & $\begin{array}{l}\text { Cold Trap, } \\
\text { Plugging Meter } \\
\text { Measurements }\end{array}$ & $\begin{array}{l}\text { Intermixing } \\
\text { with Hydrogen } \\
\text { to Reduce } \\
\text { Oxygen } \\
\text { Content, } \\
\text { Oxygen Sensor } \\
\text { Measurements }\end{array}$ & $\begin{array}{l}\text { Redox Potential } \\
\text { Control, } \\
\text { Tritium } \\
\text { Stripping and } \\
\text { Capture }\end{array}$ & $\begin{array}{l}\text { Makeup for } \\
\text { Coolant } \\
\text { Leakages, } \\
\text { Minimal } \\
\text { Chemistry } \\
\text { Control }\end{array}$ & $\begin{array}{l}\mathrm{pH} \text { Control, } \\
\text { Mixed Bed } \\
\text { Demineralizers } \\
\text {, Cation Bed } \\
\text { Demineralizer, } \\
\text { Control of } \\
\text { Radiolysis } \\
\text { Reactions }\end{array}$ & $\begin{array}{l}\mathrm{pH} \text { Control, } \\
\text { Mixed Bed } \\
\text { Demineralizers } \\
\text {, Cation Bed } \\
\text { Demineralizer, } \\
\text { Control of } \\
\text { Radiolysis } \\
\text { Reactions }\end{array}$ \\
\hline $\begin{array}{l}\text { Primary } \\
\text { Coolant } \\
\text { Loop Cell } \\
\text { Volume } \\
\text { Normalized } \\
\text { by FFTF } \\
\text { Closed } \\
\text { Loop } \\
\text { Primary } \\
\text { Cell } \\
\text { Volume }\end{array}$ & 1 & 1 & 3 & 1 & 3 & 3 \\
\hline
\end{tabular}

It is necessary to prevent leakages of other primary coolants into sodium. Lead, LBE, or liquid salt leaking into sodium could attack structural materials such as 316SS. To preclude leakages, the pressure tube of the in-reactor assembly is made double-walled with a gap between the two walls that is monitored for leakage. The primary coolant-to-sodium IHX is a double-walled straight tube (DWST) HX to preclude leakage. For helium primary coolant, a double-walled pressure tube with a gap is provided to preclude leakage of helium into sodium that might result in the formation of bubbles that could enter the core with reactivity effects and to preclude a blowdown of high pressure helium into the reactor vessel sodium. A DWST IHX is utilized to preclude a blowdown of high pressure helium into secondary sodium. For pressurized water primary coolant, a double-walled pressure tube is needed to preclude water/steam leakage into reactor vessel sodium or a blowdown of high pressure water/steam into surrounding sodium and sodium-water reactions. The gap between the two walls will also incorporate a vacuum to reduce heat transfer from the hotter surrounding sodium to water. In particular water at research and test reactor conditions will be significantly cooler than the surrounding reactor vessel sodium. The gap between the two walls will be monitored for leaks.

Details of the closed loop modules are provided in the Table 15 and in the main report. The CLS design for each coolant type and the fast reactor containment design must accommodate the effects of postulated CLS accidents resulting in the inability to remove heat from the in-reactor assembly. For the FFTF CLS design, the in-reactor assembly was designed to accommodate a Test Section Meltdown Accident (TSMDA) [3]. A meltdown cup was provided below the bottom cup end of the pressure tube. The meltdown cup was designed to contain 0.75 liter $\left(46 \mathrm{inch}^{3}\right)$ of molten $\mathrm{UO}_{2}$ fuel. It incorporated a tungsten funnel to collect fuel, a TZM molybdenum alloy cup with six inwardly projecting fins to contain molten fuel, and a tungsten washer followed by a borated graphite shield block beneath the TZM cup. For each individual CLS primary coolant type and reactor type core simulation, an assessment will to be carried out of the accident phenomena and an approach to contain the test section materials as 
well as mitigate the release of radionuclides from the in-reactor assembly will be engineered. This type of analysis could not be carried out during the time frame of this study.

Testing Under Prototypical Conditions - Specific core locations and their associated instrumented assemblies provide an online monitoring and measurement capability for irradiation experiments. This meets the basic requirement of an irradiation testing facility, that it provide for irradiation and testing of fuels, materials and specimens under prototypical reactor conditions with continuous monitoring of quantities of interest (e.g., temperature and flow rate). The monitoring capability is enabled by dedicated instrument lines which reach each assembly through dedicated experimenters' leads from the center island of the reactor head. Seven locations for independently instrumented assemblies are envisioned for the FASTER design. Instrumented assemblies use a standard fuel duct with an attached stalk to guide the instrumented lines. Flow is controlled with an inlet orifice. Instrumented assemblies were also part of the FFTF design (there they were referred to as open test assemblies) which represents a good starting point as the base technology for the FASTER instrumented assemblies. In FASTER, the instrumented subassemblies will support three types of experiments:

1. Encapsulated Fuel Element Experiments

2. Un-encapsulated Fuel Element Experiments

3. Encapsulated Structural Material Experiments

Rabbit tubes to provide for the insertion and retrieval of specimen can be located at the instrumented test assembly locations and in the closed loop locations. The rabbit tubes will be inserted through the head of the reactor vessel down to the core and grid plate structure. The rabbit tubes will be filled with inert gas (argon) to facilitate rapid insert and retrieval of irradiation specimens.

FASTER Test Reactor Safety Performance - The normal process of performing safety assessments considers a spectrum of DBAs as tests of the various safety systems. These DBAs generally assume single failures. Accidents within the design basis must be accommodated by the design and shown to present risks to the public that are within regulatory standards. Beyond the design basis, there exists a class of accidents of such low probability that they have been termed "hypothetical." These events involve multiple failures of safety grade systems, and usually are considered to have a frequency of less than $10^{-6}$ per reactor-year. Because of the potentially severe consequences of accidents in this class, they have received significant regulatory scrutiny in prior sodium-cooled fast reactor licensing reviews for the purpose of characterizing thermal and structural safety margins beyond the design basis. These accidents are currently referred to as design extension conditions (DECs, between $10^{-6}$ and $10^{-8}$ per reactoryear) or severe accidents (SAs, less than $10^{-8}$ per reactor-year) depending upon the specific frequency.

Three DECs calculated here, each involving failure of both reactor scram systems, have received attention in past licensing safety assessments. In the unprotected loss-of-flow (ULOF) sequence, it is assumed that power is lost to all primary and secondary coolant pumps and the reactor scram systems fail to activate. In the unprotected transient overpower (UTOP) sequence, it is assumed that one or more inserted control rods are withdrawn, and the reactor scram systems fail to operate. In the unprotected loss-of-heat-sink (LOHS) accident, it is assumed that heat removal 
through the power conversion system is lost, and the reactor scram systems do not activate. Taken collectively, these three accident initiators encompass all the ways that an operating reactor can be perturbed, i.e. by a change in coolant flow, by a change in reactivity, or by a change in coolant inlet temperature. A preliminary safety analysis was performed for FASTER using the systems analysis code SAS4A/SASSYS-1 to assess the reactor's safety performance during the transients. [5] A series of ULOF, ULOHS, and UTOP transients were simulated at both beginning of cycle (BOC) and end of cycle (EOC) conditions, except for the UTOP, which was only simulated at BOC because the control rods are already withdrawn at end of cycle. Maintaining coolable geometry within the core is the primary consideration when evaluating events with such low frequencies. For example, fuel melting can be tolerated at the center of the fuel pin as long as molten fuel is not breaching the cladding and entering the coolant channel. However, the favorable features of FASTER, and SFRs in general (i.e., strong inherent reactivity feedbacks, the excellent heat transfer capabilities of sodium, and the large heat sink of multiple sodium regions inside of the pool-type reactor vessel), lead to such large safety margins that the transient scenarios can be evaluated under higher scrutiny. For this analysis, the results of a transient are considered acceptable when reasonably large margins to sodium boiling and fuel melting are maintained.

Best estimate simulations of ULOF, UTOP, and ULOHS transients were performed to determine the margins to sodium boiling and fuel melting, with an assumed fuel melting temperature of $1071^{\circ} \mathrm{C}$. Additionally, low enough temperatures in the primary system must be maintained to ensure prolonged structural stability of the major components. Of all the structures, maintaining the integrity of the reactor vessel is the most important as it provides the boundary for the primary sodium circuit. The maximum allowable temperature for the reactor vessel and sodium pool is assumed to be $732^{\circ} \mathrm{C}$, which is the Service Level D limit used in the SAFR PSID. [6] Results from the ULOF, ULOHS, and UTOP transient simulations are summarized in the tables below. Adequate safety margins are maintained during each of the analyzed transients. In the UTOP scenario, a single control rod is assumed to be unintentionally withdrawn until it reaches its rod stop, $6 \mathrm{~cm}$ above the critical insertion depth, limiting the reactivity insertion to $0.5 \$$. The UTOP scenario attains the highest fuel temperatures of all of the transients, with a peak fuel temperature of $889^{\circ} \mathrm{C}$; a fuel melting margin of $182^{\circ} \mathrm{C}$ is maintained.

Technology Readiness of Test Reactor Concept - The FASTER reactor plant, with its sodium coolant, pool plant geometry, and metallic fuel can trace its heritage to the beginning of fast reactor technology with the Experimental Breeder Reactor-II. Base sodium-cooled fast reactor technology has been utilized in the FASTER reactor concept to increase the technology readiness of the system and components.

Table 16 - TRL Evaluation of FASTER Reactor Plant Systems and Components

\begin{tabular}{|c|c|l|}
\hline Component & TRL & \multicolumn{1}{c|}{ Risk Description } \\
\hline Driver Fuel & TRL8 & $\begin{array}{l}\text { U-19Pu-6Zr - Reestablishment of domestic fabrication capability or } \\
\text { foreign supply required. The preferred option would be to reestablish the } \\
\text { capability of fabricating this fuel at a collocated facility with the FASTER } \\
\text { reactor plant. Assumes that prior irradiation testing data is suitable for } \\
\text { licensing. }\end{array}$ \\
\hline
\end{tabular}


FASTER Test Reactor Preconceptual Design Report

March 31, 2016

\begin{tabular}{|c|c|c|}
\hline Component & TRL & Risk Description \\
\hline Reflector Assemblies & TRL8 & $\begin{array}{l}\text { Reflector assemblies made from metal pins or blocks are conventional } \\
\text { sodium fast reactor technology and thus achieve a high TRL level. }\end{array}$ \\
\hline Shield Assemblies & TRL8 & $\begin{array}{l}\text { Shield assemblies made from clad boron carbide pins are conventional } \\
\text { sodium fast reactor technology and thus achieve a high TRL level. }\end{array}$ \\
\hline Control Rod Assemblies & TRL8 & $\begin{array}{l}\text { The FASTER control rod assemblies are constructed of boron carbide rods } \\
\text { clad in HT-9. This technology is conventional sodium fast reactor } \\
\text { technology and thus achieves a high TRL level. }\end{array}$ \\
\hline $\begin{array}{l}\text { Core Structural Materials - } \\
\text { Fast Zone }\end{array}$ & TRL8 & $\begin{array}{l}\text { Demonstrated at full scale. Burnup is very low so there will be zero issue } \\
\text { using HT-9 as the core structural materials in the fast neutron spectrum } \\
\text { zone. }\end{array}$ \\
\hline $\begin{array}{l}\text { Core Structural Materials - } \\
\text { Thermal Zone }\end{array}$ & TRL5 & $\begin{array}{l}\text { Literature review will need to be performed for structural materials in } \\
\text { thermal zone. Zircaloy is compatible with sodium but is typically not used } \\
\text { as core structural materials for fast reactor cores (cladding and ducting). } \\
\text { Zircaloy is also an oxygen getter - so time in service will need to be } \\
\text { understood and evaluated, but is not expected to be an issue. The zircaloy } \\
\text { will also clad beryllium with the beryllium being a moderator. }\end{array}$ \\
\hline $\begin{array}{l}\text { Coolant Control } \\
\text { Technology }\end{array}$ & TRL9 & $\begin{array}{l}\text { Coolant control technology using cold traps and nuclide traps is } \\
\text { conventional proven sodium coolant control technology and has been } \\
\text { demonstrated and operated at full scale. Coolant control technology used } \\
\text { in EBR-II, FFTF, and developed for CRBRP can be adopted for use in the } \\
\text { FASTER reactor plant. }\end{array}$ \\
\hline Cover Gas Technology & TRL9 & $\begin{array}{l}\text { Argon cover gas is conventional proven technology and this will be used } \\
\text { in the FASTER reactor plant systems. Nitrogen may also be used in some } \\
\text { locations where needed for space inerting. }\end{array}$ \\
\hline $\begin{array}{l}\text { Cover Gas Cleanup } \\
\text { Technology }\end{array}$ & TRL8-9 & $\begin{array}{l}\text { The cover gas cleanup technology will be initially based upon that used at } \\
\text { EBR-II and FFTF and proposed for CRBRP with updates to technologies } \\
\text { that may be used today for cleaning radioactively contaminated argon } \\
\text { cover gas. }\end{array}$ \\
\hline Gas Seal Technology & TRL7 & $\begin{array}{l}\text { Gas seal technology is known, but will need to be updated/evaluated from } \\
\text { the 1970-1980's technology used in FFTF and EBR-II to determine } \\
\text { whether advancements in elastomers and other gas seal technologies are } \\
\text { suitable and perform better than the technologies used in the past. }\end{array}$ \\
\hline $\begin{array}{l}\text { Primary System } \\
\text { Configuration }\end{array}$ & TRL7 & $\begin{array}{l}\text { Several components must be adapted from previous fast reactor designs, } \\
\text { however, a pool plant geometry has proven to be most cost effective. } \\
\text { However, no pool plant geometry has included } 3 \text { closed loops and multiple } \\
\text { instrumented test assembly locations that stay in the reactor greater than } \\
\text { one cycle. }\end{array}$ \\
\hline $\begin{array}{l}\text { Reactor Vessel and } \\
\text { Structures }\end{array}$ & TRL8 & $\begin{array}{l}\text { For pool configuration, certain features such as the redan and reactor } \\
\text { enclosure must be adapted for the particular geometry }\end{array}$ \\
\hline $\begin{array}{l}\text { Primary and Secondary } \\
\text { Pumps }\end{array}$ & TRL8 & $\begin{array}{l}\text { The primary and secondary pumps are based upon mechanical centrifugal } \\
\text { pump technology which has been deployed successfully in EBR-II, FFTF, } \\
\text { and developed and tested for CRBRP. The exact pump will have } \\
\text { characteristics that are specific for the FASTER reactor plant, but is } \\
\text { expected to be smaller in capacity to the FFTF reactor plant. }\end{array}$ \\
\hline $\begin{array}{l}\text { Intermediate Heat } \\
\text { exchangers }\end{array}$ & TRL8 & $\begin{array}{l}\text { The (4) IHX are tube-and-shell heat exchangers and are conventional } \\
\text { sodium-to-sodium heat exchangers with a high TRL level. } 9 \mathrm{Cr}-1 \mathrm{Mo} \text { heat } \\
\text { exchangers have been developed and installed in the Indian reactor. } 9 \mathrm{Cr}- \\
\text { 1Mo is a code qualified materials. }\end{array}$ \\
\hline $\begin{array}{l}\text { Direct Reactor Auxiliary } \\
\text { Cooling System }\end{array}$ & TRL8 & $\begin{array}{l}\text { DRACS emergency decay heat removal systems have been used in EBR-II } \\
\text { and other sodium cooled fast reactors. }\end{array}$ \\
\hline
\end{tabular}




\begin{tabular}{|c|c|c|}
\hline Component & TRL & Risk Description \\
\hline $\begin{array}{l}\text { Direct Reactor Heat } \\
\text { Exchangers }\end{array}$ & TRL8 & $\begin{array}{l}\text { The (3) DRACS heat exchangers are tube-and-shell heat exchangers and } \\
\text { are based on conventional sodium-to-sodium heat exchangers with a high } \\
\text { TRL level. These heat exchangers will have to be scaled appropriately for } \\
\text { the size requirements for the FASTER reactor plant, but besides this, that } \\
\text { is the only issue. }\end{array}$ \\
\hline Air dump heat exchangers & TRL8 & $\begin{array}{l}\text { The (3) DRACS system each have one sodium-to-air heat exchanger } \\
\text { which will be based upon the technology developed for FFTF, EBR-II, } \\
\text { and CRBRP. }\end{array}$ \\
\hline Steam Generator & TRL7 & $\begin{array}{l}\text { The steam generator adopted for the FASTER reactor plant is the helical } \\
\text { coil steam generator (HSCG). There are two HCSGs that each provide } \\
\text { 150MWth of superheated steam for the steam turbine. The HCSG is } \\
\text { approximately twice the size of the HSCG that was developed by Babcock } \\
\text { and Wilcox and tested at ETEC. That HCSG used 2.25Cr-1Mo steel for } \\
\text { the tubes. The FASTER HCSG uses 9Cr-1Mo steel which is an acceptable } \\
\text { alternative for heat exchanger materials. Superphenix installed a HCSG } \\
\text { that was larger than needed for the FASTER reactor plant, but was made } \\
\text { from Alloy600. }\end{array}$ \\
\hline $\begin{array}{l}\text { Sodium Water Reaction } \\
\text { Protection System }\end{array}$ & TRL7 & $\begin{array}{l}\text { The technology for accommodating the sodium-water reaction resulting } \\
\text { from a tube leak in a sodium-heated steam generator was developed in the } \\
\text { past liquid metal technology development programs and tested at the } \\
\text { Energy Technology Engineering Center. }\end{array}$ \\
\hline $\begin{array}{l}\text { Sodium Fire Mitigation } \\
\text { System }\end{array}$ & TRL8 & $\begin{array}{l}\text { The technology for mitigation of sodium fires has been developed in past } \\
\text { liquid metal technology programs. }\end{array}$ \\
\hline Balance of Plant & TRL8 & $\begin{array}{l}\text { Superheated steam BOP is a conventional technology used with sodium- } \\
\text { cooled fast reactor technologies around the world. }\end{array}$ \\
\hline Containment & TRL8 & $\begin{array}{l}\text { Steel-reinforced concrete containment technology has been demonstrated } \\
\text { at full scale both domestically and internationally. }\end{array}$ \\
\hline Seismic Restraints & TRL8 & $\begin{array}{l}\text { Seismic restraints for piping and other components are expected to be } \\
\text { conventional reactor technology. }\end{array}$ \\
\hline $\begin{array}{l}\text { Reactor Instrumentation } \\
\text { and Control }\end{array}$ & TRL7 & $\begin{array}{l}\text { Demonstrated at full scale. The reactor project expects to adopt digital } \\
\text { controls as appropriate. }\end{array}$ \\
\hline $\begin{array}{l}\text { Primary Control Rod Drive } \\
\text { System }\end{array}$ & $\begin{array}{l}\text { TRL7 } \\
\text { TRL4 - Rod } \\
\text { Stops for } \\
\text { UTOP }\end{array}$ & $\begin{array}{l}\text { The primary control rod drive system will be similar to the system for the } \\
\text { AFR-100 plant which is an adaptation of the PCRDS from FFTF and } \\
\text { CRBR. Interface between the PCRDS and the three instrumentation trees } \\
\text { will need to be determined, but will be similar to technology developed for } \\
\text { FFTF. Control rod stops will need to be implemented into the PCRDS } \\
\text { system. }\end{array}$ \\
\hline $\begin{array}{l}\text { Secondary Control Rod } \\
\text { Drive System }\end{array}$ & TRL6 & $\begin{array}{l}\text { The secondary control rod drive system is similar to the system for AFR- } \\
100 \text { plant and the SCRDS for CRBR and ALMR. Engineering will have to } \\
\text { be performed to ensure that the SCRDS will interface successfully with } \\
\text { the three instrumentation trees in the FASTER reactor vessel. }\end{array}$ \\
\hline Fuel Handling & TRL5 & $\begin{array}{l}\text { The starting point for the FASTER in-vessel refueling machines will be } \\
\text { the machine developed for the AFR-100 plant. Mechanisms related to the } \\
\text { in-vessel refueling machine will need to be evaluated to ensure that the } \\
\text { machine will function as designed. If FFTF IVHM system was adopted a } \\
\text { higher TRL would be assigned. }\end{array}$ \\
\hline $\begin{array}{l}\text { Maintenance and } \\
\text { Inspection }\end{array}$ & TRL5 & $\begin{array}{l}\text { New techniques for in-service inspection, especially under sodium } \\
\text { inspection, needs to be demonstrated. Technologies developed for FFTF } \\
\text { and EBR-II need to be redeveloped. }\end{array}$ \\
\hline
\end{tabular}


FASTER Test Reactor Preconceptual Design Report

March 31, 2016

\begin{tabular}{|c|c|c|}
\hline Component & TRL & Risk Description \\
\hline Closed Loop Technology & $\begin{array}{l}\text { TRL8 for } \\
\text { sodium } \\
\text { TRL3-6 for } \\
\text { other fast } \\
\text { reactor } \\
\text { coolants } \\
\text { TRL3-6 for } \\
\text { the thermal } \\
\text { reactor } \\
\text { coolants. }\end{array}$ & $\begin{array}{l}\text { The starting point for the closed loop technology will be the designs that } \\
\text { were created by Westinghouse for the FFTF reactor. There are three } \\
\text { closed loops in the FASTER reactor plant - two fast closed loops and one } \\
\text { thermal closed loop. The power/heat removal rate capability of the sodium } \\
\text { closed loop will be identical to the FFTF reactor closed loop in-reactor } \\
\text { assembly and primary module. It is expected that the two fast closed loops } \\
\text { will be very similar in technology design to FFTF and thus will have a } \\
\text { very high TRL. } \\
\text { The thermal spectrum close loop will have a lower TRL mainly to reflect } \\
\text { the design of the module that supplies the primary (in-loop) coolant for the } \\
\text { thermal closed loop. }\end{array}$ \\
\hline $\begin{array}{l}\text { Instrumented test assembly } \\
\text { technology }\end{array}$ & TRL7 & $\begin{array}{l}\text { The starting point for the instrumented test assembly technology will be } \\
\text { the technology used in EBR-II and FFTF. The technology will be updated } \\
\text { with modern sensors for temperature, flow, and other parameters as } \\
\text { appropriate, but the technological foundation will be EBR-II, FFTF, and } \\
\text { CRBR technologies and will evolve from there. Test }\end{array}$ \\
\hline $\begin{array}{l}\text { Non-instrumented test } \\
\text { assembly technology }\end{array}$ & TRL8 & $\begin{array}{l}\text { Non-instrumented test assembly technology are configured identical to a } \\
\text { fuel, reflector, and shield test assemblies. The technology to include test } \\
\text { pins in fueled core assemblies is known and thus they are evaluated with a } \\
\text { high TRL level. }\end{array}$ \\
\hline Licensing & & $\begin{array}{l}\text { Technical criteria for advanced reactor licensing needs to be clarified and } \\
\text { the regulatory structure re-established. It is expected that the selected } \\
\text { ATDR reactor will be licensed by the U.S. NRC. }\end{array}$ \\
\hline $\begin{array}{l}\text { Fast Reactor } \\
\text { Manufacturing } \\
\text { Infrastructure }\end{array}$ & & $\begin{array}{l}\text { Infrastructure for manufacturing fast reactor components will need to be } \\
\text { reestablished domestically if this is important to DOE, otherwise, there are } \\
\text { international sources of liquid metal technology components such as } \\
\text { pumps, valves, heat exchangers, etc. }\end{array}$ \\
\hline
\end{tabular}

Test Reactor Licensing, Development and Deployment Plans - FASTER will be licensed under 10 CFR Part 50 as a testing facility that also produces electricity onto an electrical grid. The Preliminary Safety Analysis Report (PSAR) must include the principal design criteria for the facility. 10 CFR Part 50 Appendix A, "General Design Criteria for Nuclear Power Plants," establishes minimum requirements for the principal design criteria for water-cooled nuclear power plants similar in design and location to plants for which construction permits have previously been issued by the NRC and provides guidance to applicants for construction permits in establishing principal design criteria for other types of nuclear power units. Historically, specific SFR principal design criteria were developed for CRBR, PRISM, and SAFR, instead of directly utilizing the General Design Criteria (GDC) from 10 CFR Part 50 Appendix A. A set of draft SFR design criteria has been developed under a joint initiative between DOE and the NRC. The criteria include five new criteria specific to SFRs. A report containing the SFR criteria was prepared by DOE and transmitted to the NRC. The NRC internally reviewed the criteria and is expected to soon issue a report for public comment. It is expected that this will be followed by NRC guidance including SFR principal design criteria. The FASTER design satisfies the current draft SFR principal design criteria and will satisfy the final criteria included in the NRC guidance. 
Under the DOE-funded Regulatory Technology Development Plan, work has been launched to develop the SFR safety analysis codes and methods required for use in a licensing framework, and to identify the Quality Assurance (QA) requirements for licensing applications. A report, ANL-ART-37, was recently prepared that identifies the types of safety analysis computer codes that may be required for licensing of metallic-fueled SFRs and assesses the current status of existing relevant safety analysis codes including existing QA practices.

Pre-conceptual, conceptual, and final design will be carried out consistent with the DOE CD-0, CD-1, etc. process. A licensing strategy and schedule will be developed for FASTER. Preapplication meetings will be held with the NRC. As required, a PSID will be prepared. Interactions will be conducted with the NRC to pursue applications for a construction permit and operating license. A Preliminary Safety Analysis Report (PSAR) will be prepared as part of an application for a construction permit. A Final Safety Analysis Report (FSAR) will be prepared as part of an application for an operating license. Testing of the particular metallic fuel type used in FASTER shall be carried out to obtain the data needed to enable the use of this fuel. The FASTER design utilizes structural materials that are currently qualified for use by the appropriate ASME codes, with the exception of the Hastelloy-N alloy envisioned for use in closed loop systems for liquid salt. If a need for closed loop testing with liquid salt continues, then effort will be devoted to developing and submitting a code case for Hastelloy-N.

Development of required safety analysis computer codes meeting QA requirements for licensing use shall be completed, and the codes will be used in preparation of the PSAR and FSAR. The FASTER design shall incorporate instrumentation to detect postulated sodium leakages from sodium piping and components consistent with ASME Boiler and Pressure Vessel Code requirements for Nuclear Power Plant components.

The licensing strategy will include a strategy for testing of components for FASTER including fuel assemblies, control rods and control rod drive systems, fuel handling systems, steam generators, intermediate heat exchangers, sodium pumps, as well as instrumentation for use in FASTER. Testing will be carried out, where feasible, in existing testing facilities, as well as new testing facilities that will be identified and assembled. Appropriate QA requirements for test data will be identified and followed.

Following the granting of an operating license, fabrication of the first core and loading of the first core, then criticality, low power testing and ascent to full power shall be carried out. During the ascent to full power, transient testing shall be carried out to determine the actual FASTER reactivity feedback behavior and to verify that it meets the requirements for inherent passive safety and inherent passive shutdown.

Economics and Schedule - It is expected that the following notional schedule will be used for the design and construction of FASTER.

- 1 year for conceptual design

- 2 years for preliminary design

- 3-5 years for detailed design, licensing, and long-lead item fabrication

- $<5$ years for construction and final licensing 
Total of 11 to 13 years for the FASTER reactor project from CD-0 with the assumption that there are no constraints on cash flow for the project and that licensing will not be the limiting factor. The schedule that includes the remaining research and development to get the FASTER power plant up and running will extend the schedule to 15 years or less with a concurrent R\&D program. This schedule is consistent with a small modular advanced demo plant such as PRISM Mod A which has a power level slightly greater than FASTER. The sodium closed loop technology development will run in parallel with the schedule to construct and startup FASTER and use as its starting base, the sodium closed loop technology developed for FFTF. The nonsodium closed loop technology development will be independent of the main FASTER power plant construction, licensing, and operations and will not impact the schedule to startup FASTER.

It is estimated that the FASTER test reactor with the steam plant will cost approximately $\$ 2.8 \mathrm{~B}$ (with a 30\% contingency) to design ( $\$ 1.1 \mathrm{~B}$ ) and construct (with each closed loop contributing $\sim \$ 100 \mathrm{M}$ (includes contingency) to overall estimated TPC). If it was decided to remove the steam plant and just dump the 300MWth of heat to the atmosphere, then the TPC cost (design and construction) would be significantly less than $\$ 2.5 \mathrm{~B}$ because the project would save both the cost for design, equipment, and construction for the steam plant (everything from the steam generators through the steam plant and electrical yard). In addition, the FASTER design team did not take any explicit credit during the cost estimate for prior design work and technology development work that may have been performed that would relate to the FASTER reactor plant. So, as the FASTER test reactor moves forward, more detailed cost estimates will better refine these cost figures.

The annual FASTER reactor plant operating costs in power generation mode are estimated to be less than $\$ 100 \mathrm{M}$. The FASTER reactor plant annual operating costs including irradiation operations are expected to be less than $\$ 150 \mathrm{M}$ (using FFTF as the high end basis) [7]. All estimates are in 2016 dollars. The replacement fuel is estimated to cost about $\$ 20 \mathrm{M} /$ year. The FASTER reactor will provide $120 \mathrm{MW}_{\mathrm{e}}$ to the electrical grid at the location of installation. The FASTER reactor is expected to achieve a capacity factor of $80 \%$ or greater while putting power on the grid. The sales from this power are expected to be around $\$ 89 \mathrm{M}$ to $\$ 100 \mathrm{M}$ per year depending upon overall electrical generation capacity and power purchasing agreements, offsetting the operational and fuels costs.

The cost and schedule estimates are based upon the best available information from the ALMR program, the FFTF project, and current consumer price index and construction cost index escalation factors averaged to 2016.

Operating and Maintenance Costs - The cost estimate to operate and maintain the FASTER reactor is divided into two estimated costs. One to operate the reactor and provide power and maintain the reactor and one that includes those costs and the costs to run experiments in FASTER. The costs to run experiments in FASTER include the costs related to operating and maintaining any experiments, secondary loops or other aspects of the facility such as hot cell facilities that are not related to the functions of the FASTER reactor which provide the experiment conditions (i.e., flux, temperature, etc.) and produce electrical power. Given the purpose of the FASTER reactor as a test reactor, it will be capable of supporting multiple large experiment programs simultaneously which may have significant costs associated with them. 
These costs are not included as part of the FASTER reactor operation and maintenance (O\&M) costs. Those costs are assumed to be part of the larger annual operating costs.

Estimating the O\&M costs is difficult because there are no directly comparable sources of data. The estimates must be extrapolated from a variety of sources, each of which has obvious issues with extrapolation to the FASTER reactor. There are three categories of cost. The smaller of the two are consumables (i.e., materials, supplies, etc.) and mandated fees (i.e., NRC fees, insurance, etc.). The largest cost is personnel.

The cost of consumables and fees is expected to be no more than $\$ 15 \mathrm{M}$ to $\$ 20 \mathrm{M}$ per year. These estimates are based on the costs associated with power reactors. The fees are not assumed to scale. The consumables are expected to scale, but far from linearly resulting in only modest reductions relative to a larger commercial-scale reactor.

The cost of personnel is based on the number of personnel required and the average cost of those personnel. These estimates are generally broken down to onsite and offsite staff. The onsite staff consisting of the technicians, maintenance, training, and other personnel involved primarily in the direct operation and maintenance of the plant. The offsite staff, which is not necessarily physically offsite, mostly provides the technical support and is a much smaller contributor to cost than the onsite staff.

The nature of the work done by these two manpower groups results in the average cost of onsite staff generally being significantly lower than the average cost of offsite staff. The specific mix for a given power plant will also impact this. The average salaries are expected to average around $\$ 100 \mathrm{k}$ per year for onsite staff and around $\$ 200 \mathrm{k}$ per year for offsite staff. For each, there will be a multiplier on these costs for benefits and other related staffing costs of no more than two times and more likely around 1.6 to 1.8 .

The AP1000, a large commercial LWR is estimated to require an onsite staff of between 386 and 502 , depending on whether it is located on an existing operational nuclear site or on its own. The commercial-scale S-PRISM is expected to have a total staff of roughly 650 for a twin-unit power plant. There are a lot of data on the variation in O\&M costs for LWR stations as a function of size and units at the commercial scale. This information is used to identify where there will be cost savings for a smaller unit (e.g., annualized maintenance) and where there will not (e.g., one plant manager regardless). By combining this information and extrapolating it to a much reduced size, it suggests that a reactor of this size could be operated and maintained by a staff of significantly less than 200 . To be conservative, since this is an extrapolation, the upper bound was assumed to be a total staff of 250 split into 210 onsite and 40 offsite personnel. This assumes a standalone site that receives no cost benefit from being on an existing nuclear site which will share a lot of resources, particularly related to security. This results in personnel costs in the $\$ 40 \mathrm{M}$ (staff of 200 ) to $\$ 60 \mathrm{M}$ (staff of 250 ) per year range.

The decommissioning and decontamination (D\&D) costs are typically covered by a sinking fund payment. The annual cost of payments to such a fund will be a small fraction of the annual O\&M cost assuming that the facility operates for decades. As a result, the D\&D funds are within the overall uncertainty and do not impact the estimate at the current level of design detail. 
The total O\&M costs are expected to be in the range of $\$ 55 \mathrm{M}$ to $\$ 80 \mathrm{M}$ per year and certainly could be significantly lower. There may be significant additional costs associated with experiments conducted at this facility that are not included.

Fuel Cost Estimate - The cost associated with fueling the reactor is even more challenging to estimate than the O\&M costs. The fuel cost estimate assumes that a fixed unit cost (\$ per kg of heavy metal) is charged to the FASTER reactor that is equivalent to the cost of producing the fuel. This unit or levelized cost as it is typical referred to includes the capital investment, O\&M, and cost of materials (e.g., plutonium, cladding, etc.). Like most nuclear facilities, the capital investment will be the largest contributor if a new facility must be built to supply the fuel. The other major contributors to cost are the cost of the fissile material and the O\&M of the facility. It is assumed that the plutonium will be provided at no cost. The other materials (e.g., cladding and other assembly hardware) tend to be a relatively small cost contributor, although this needs to ultimately be confirmed since producing unique materials in small quantities can result in far higher unit costs.

The cost of manufacturing plutonium fuels on a commercial scale is estimated to be in the range of $\$ 2,500$ to $\$ 7,000$ per $\mathrm{kg}$ of heavy metal. This includes all costs except the cost of the heavy metal itself (i.e., cladding, assembly hardware, etc.), which is assumed to be negligible ( $\mathrm{Pu}$ is free and DU will be at very small fraction at most). The assumption is that the manufacture of the FASTER reactor fuel will not require the construction of a standalone fabrication facility like the MOX plant at Savannah River Site, but will be done by upgrading an existing national laboratory facility to produce the relatively small quantities ( $\sim 60$ assemblies per year). There will be significant investment into this facility, but it was assumed that this would be bounded by the upper cost estimate of $\$ 7,000$ per $\mathrm{kg}$, which results in a cost estimate of approximately $\$ 300 \mathrm{k}$ per assembly. This would result in the fuel costs being no more than $\$ 20 \mathrm{M}$ per year. This equivalent annual cost implies an upfront investment in fuel fabrication capabilities in the $\$ 100 \mathrm{M}$ to $\$ 200 \mathrm{M}$ range.

Annual Operational Cost Estimate - When the O\&M and fuel costs are added together, this results in an annual cost of no more than $\$ 100 \mathrm{M}$ per year and likely significantly less than that. The annual costs of FFTF escalated for inflation would be on the order of $\$ 150 \mathrm{M}$ per year, but this seems to include all costs associated with the experimental programs that were utilizing FFTF and not just the operational cost of the reactor. Given the labor intense nature of the FFTF experience and the high costs of irradiation experiments, this value seems consistent with the expectation that the annual operational costs of the FASTER reactor will be between less than $\$ 150 \mathrm{M}$ per year. 


\section{TABLE OF CONTENTS}

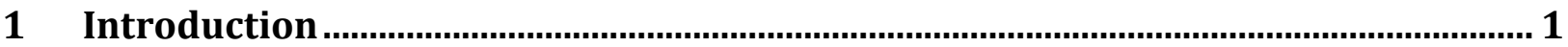

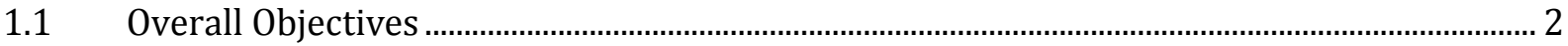

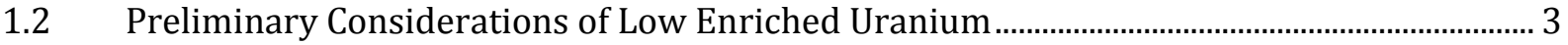

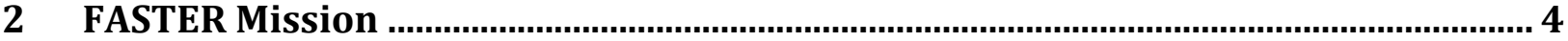

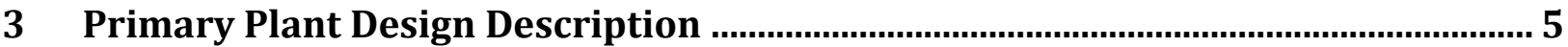

3.1 Reactor Assembly System............................................................................................................... 5

3.1.1 Core Design Approach ………………………………………………………………………..... 5

3.1.2 Core Layout and Assemblies ....................................................................................................... 5

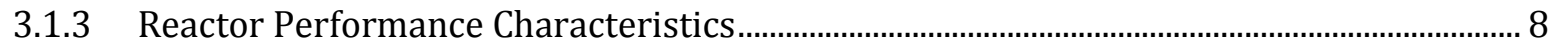

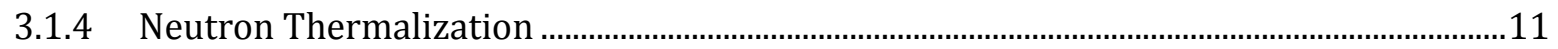

3.1.5 Reactivity Coefficients and Quasi-Static Balance..................................................................11

3.1.6 Test Locations ..........................................................................................................................15

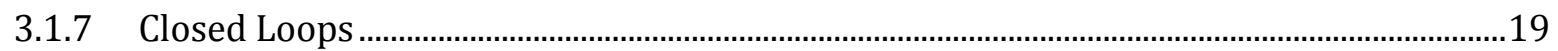

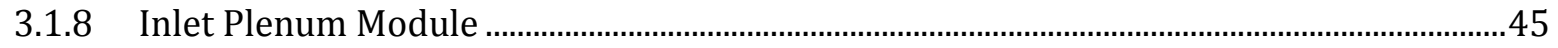

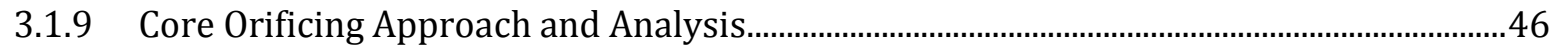

3.1.10 Lower Internals Structure Assembly..................................................................................4

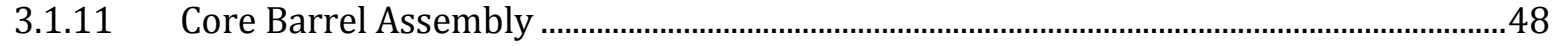

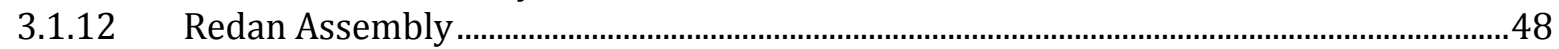

3.1.13 Upper Internal Structure (UIS) and Instrumentation Trees...............................................50

3.1.14 Core Restraint System Design …………………………………………………………….....69

3.2 Reactivity Control and Shutdown Systems................................................................................71

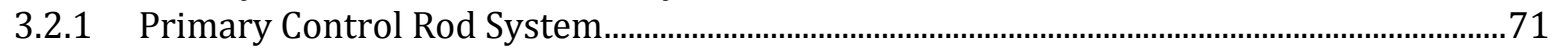

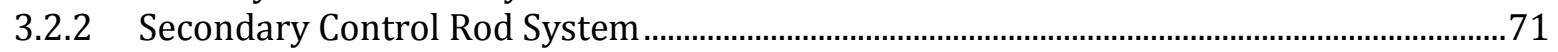

3.3 Reactor Vessel and Enclosure System ...............................................................................................72

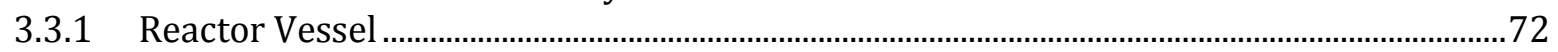

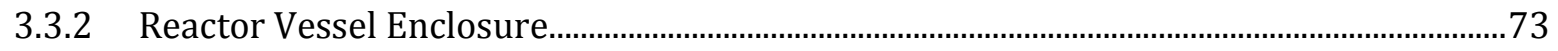

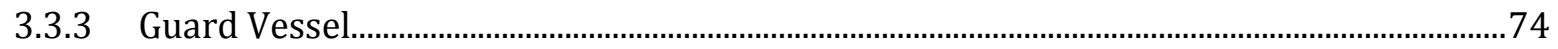

3.3.4 Reactor Containment Boundary and Structure.....................................................................74

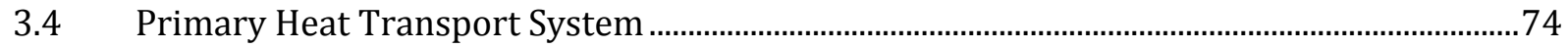

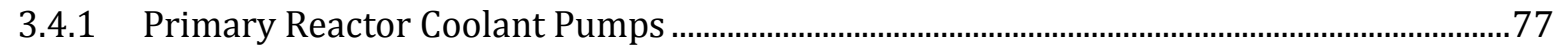

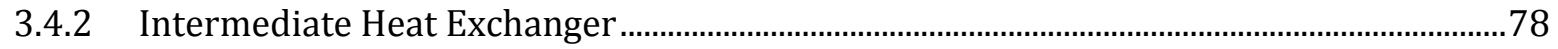

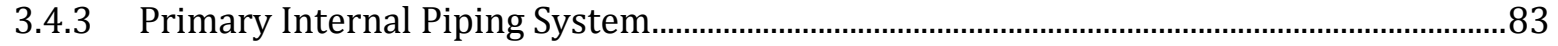

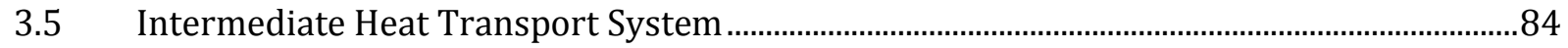

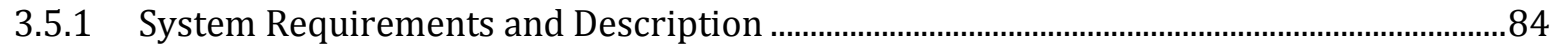

3.5.2 Intermediate Sodium Pump ………………………………………………………………………...

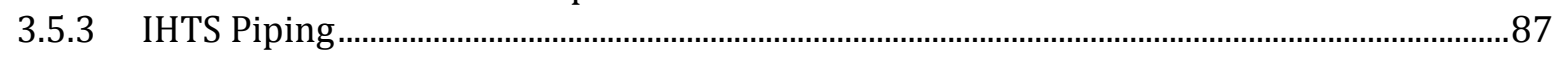

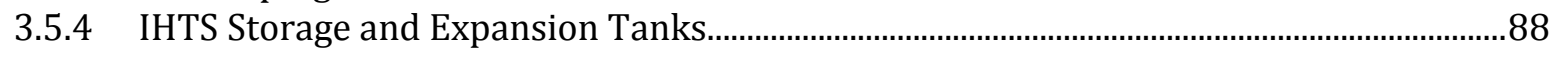

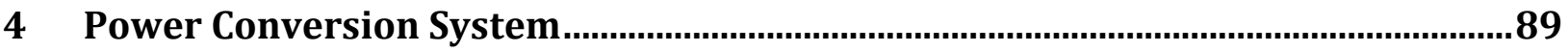

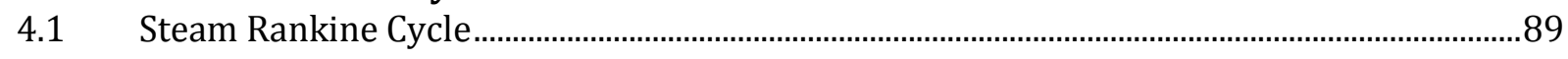

5 Shutdown Heat Removal System ………...............................................................

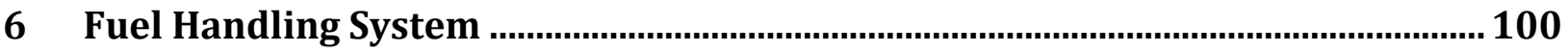

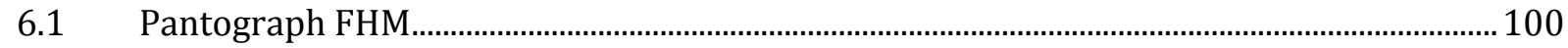

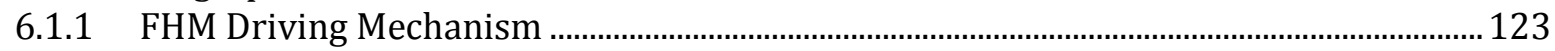

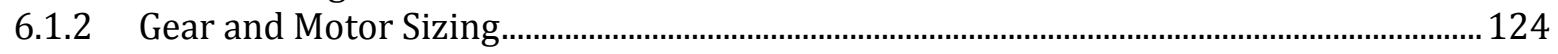


6.2 Time required for fuel handling operations ….......................................................................... 131

6.3 Typical FHM Cycle Operations inside the Reactor Vessel ......................................................... 132

6.4 Control System Design Recommendations....................................................................................... 135

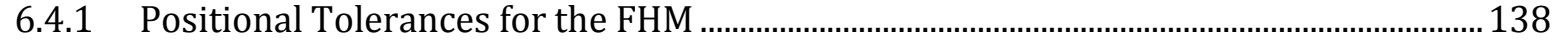

6.4.2 Core Hold-Down Control System using Force Control ......................................................... 141

6.4.3 Uncertainty and Error in Position......................................................................................... 145

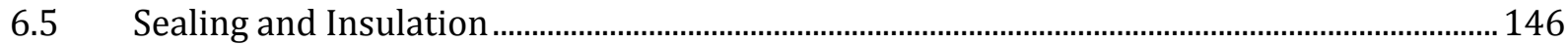

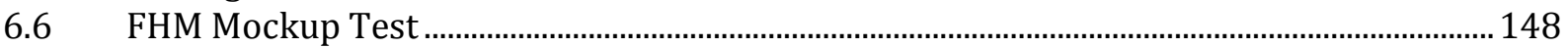

$7 \quad$ Ex-Vessel Refueling Operations ……........................................................................ 150

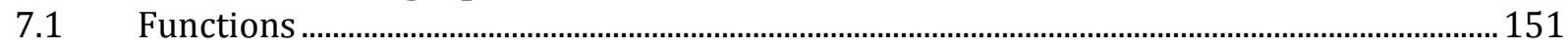

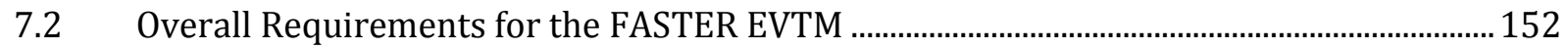

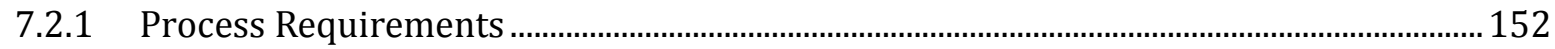

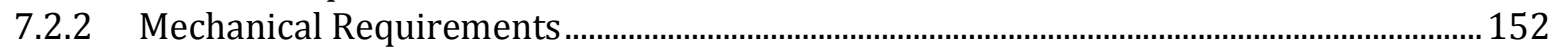

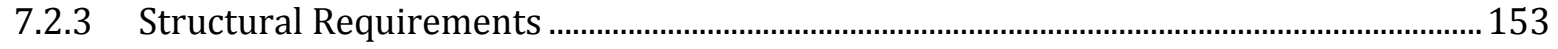

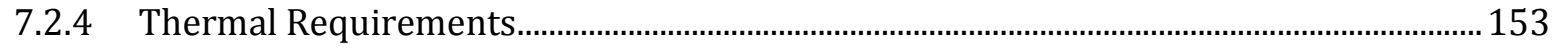

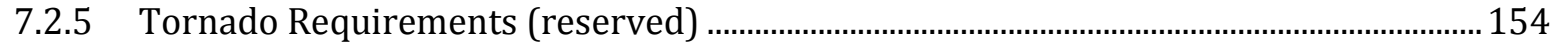

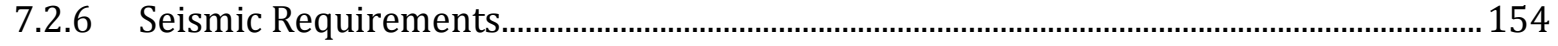

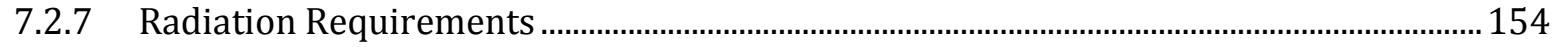

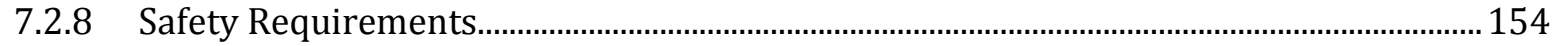

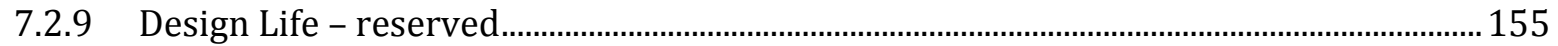

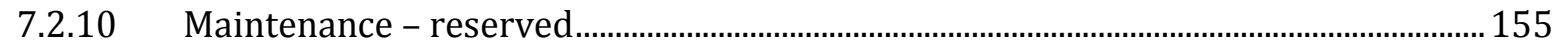

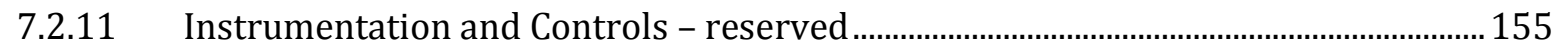

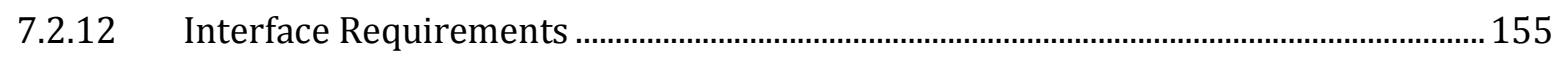

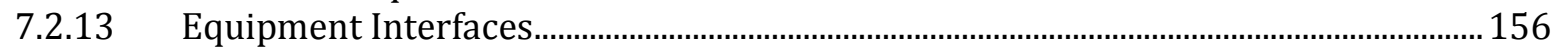

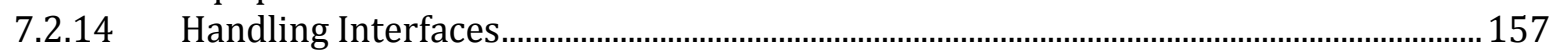

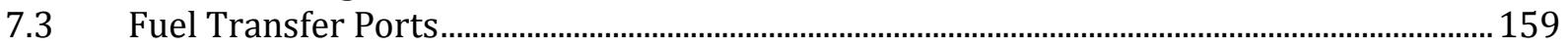

7.4 Inter-Building Transfer Cask Design Requirements.............................................................. 160

8 Sodium Purification Systems ................................................................................. 161

$8.1 \quad$ Primary Sodium Purification System .................................................................................. 161

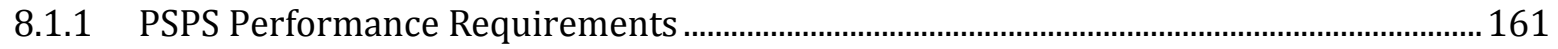

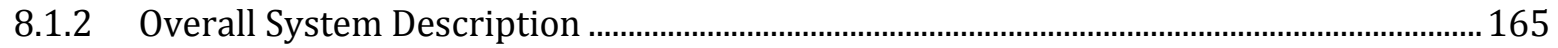

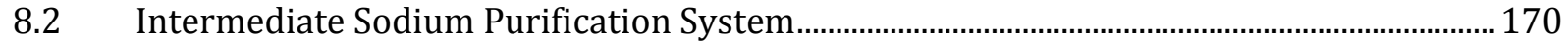

8.2.1 ISPS Performance Requirements and Design Considerations ............................................. 170

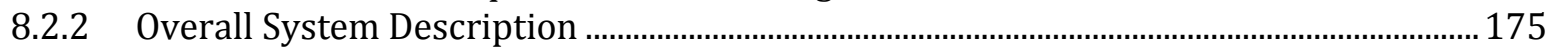

8.2.3 Functions and Specifications of Major Components ............................................................. 178

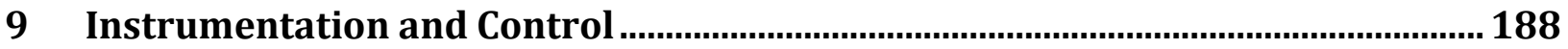

$9.1 \quad$ Plant Monitoring System................................................................................................... 188

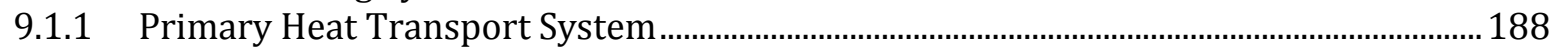

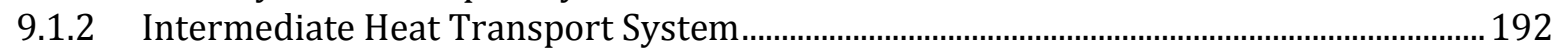

9.1.3 Decay Heat Removal System ..................................................................................................... 194

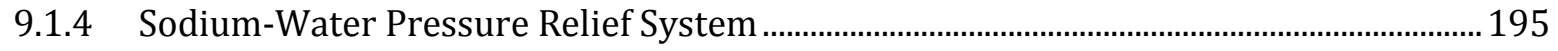

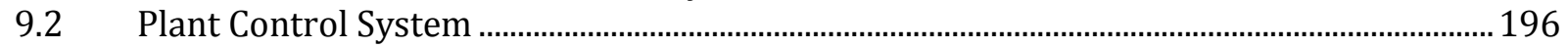

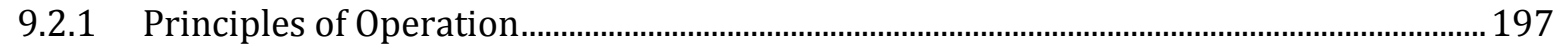

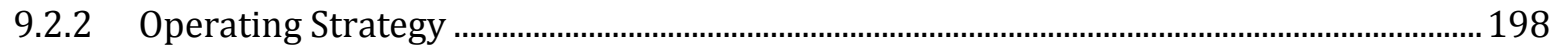

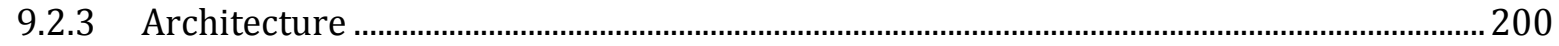

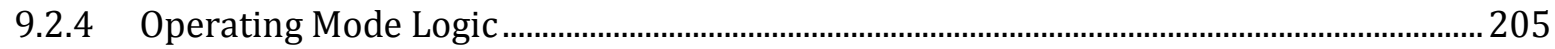

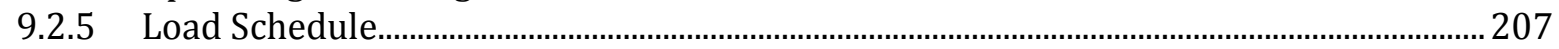

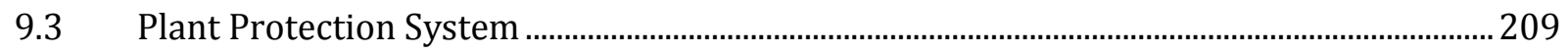




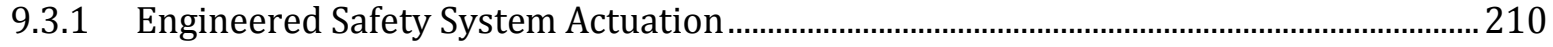

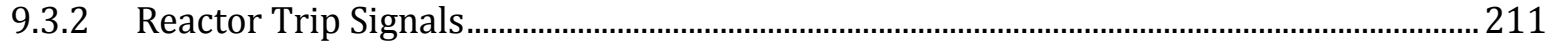

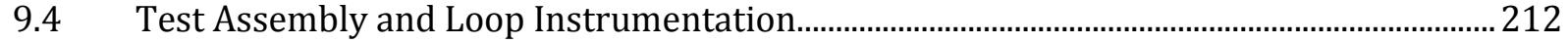

9.5 Advanced Instrumentation Test Capability …………………………………………………...22 214

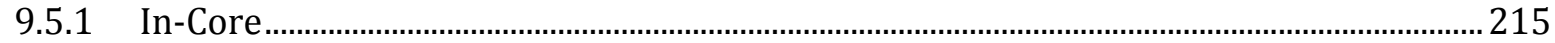

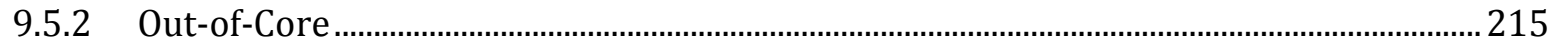

9.6 Data Handling and Signal Transmission System...........................................................................22

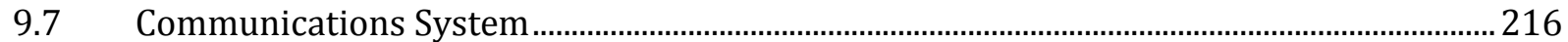

9.8 On-Line Fault Detection and Diagnosis......................................................................................2216

9.9 Industrial Security and Safeguards System.............................................................................. 217

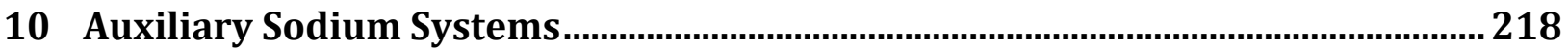

11 Reactor Containment Building and Site .............................................................. 219

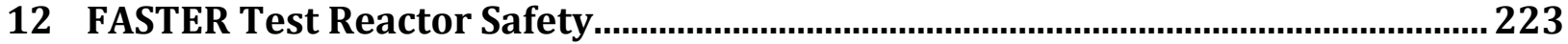

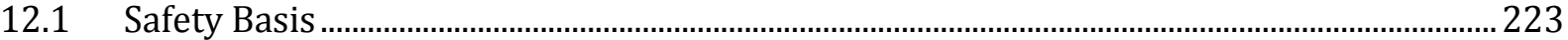

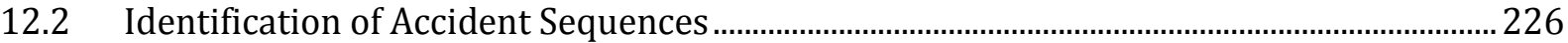

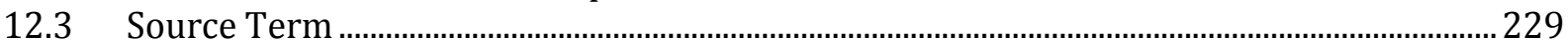

12.3.1 In-Core Transport and Retention Phenomena ................................................................. 230

12.3.2 Ex-Core Transport and Release Phenomena........................................................................2. 233

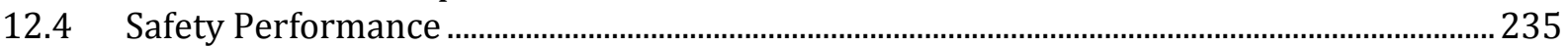

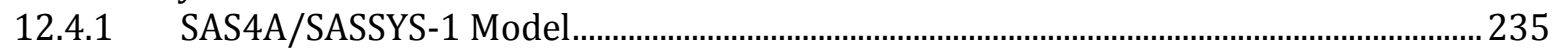

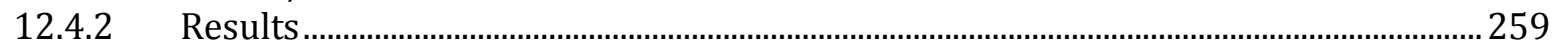

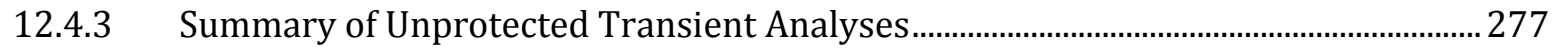

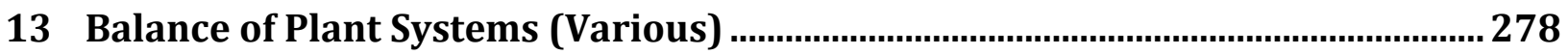

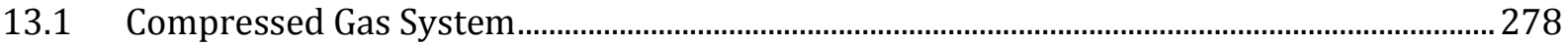

13.2 Chilled Water System ................................................................................................................ 279

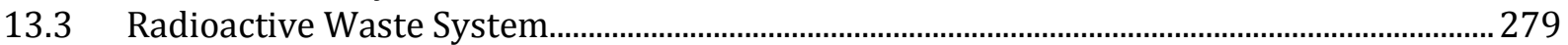

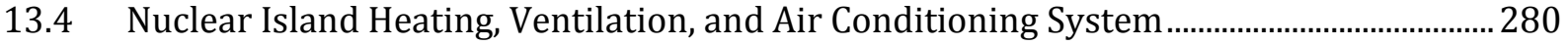

13.5 Balance of Plant Heating, Ventilation, and Air Conditioning System.....................................2 281

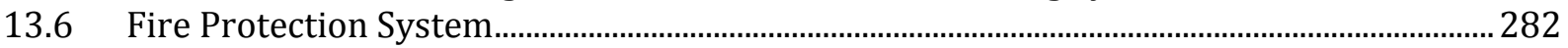

13.7 Re-circulating Gas Cooling System.......................................................................................... 283

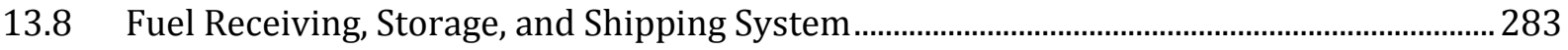

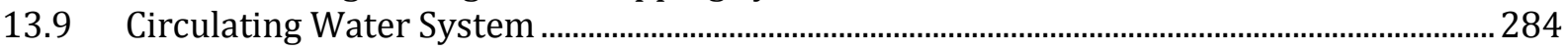

13.10 Service Water System....................................................................................................... 284

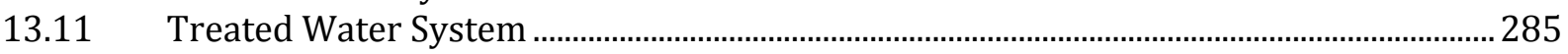

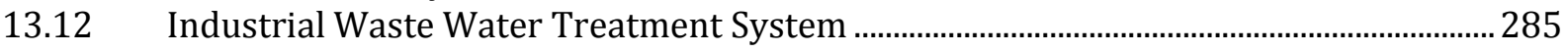

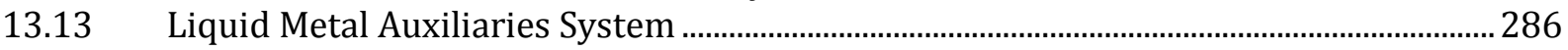

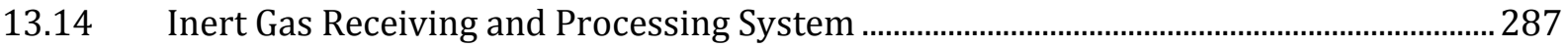

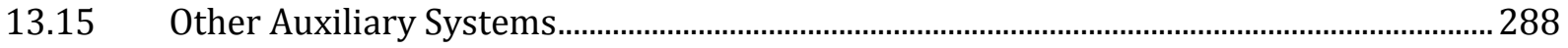

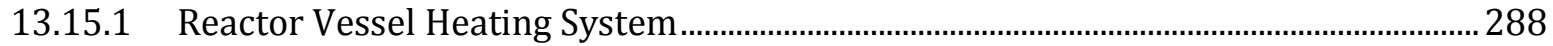

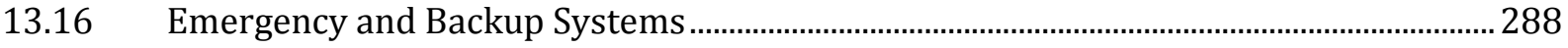

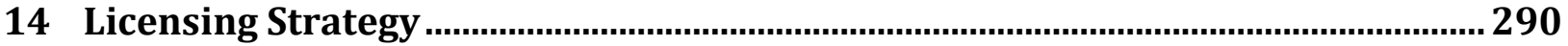

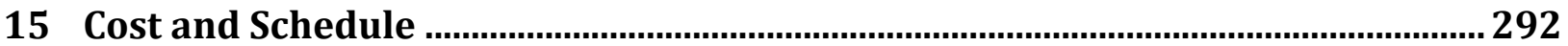

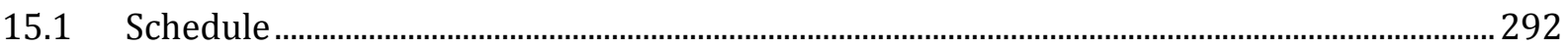

15.2 Design, Licensing, and Construction Costs ............................................................................... 292

15.2.1 Initial Core Load..................................................................................................................293

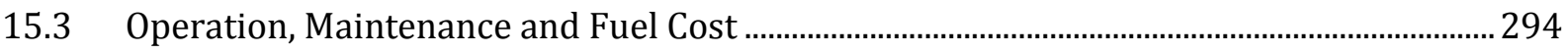


FASTER Test Reactor Preconceptual Design Report

March 31, 2016

15.3.1 Operation and Maintenance Cost.

15.3.2 Fuel Cost

295

15.3.3 Decommissioning and Decontamination Cost

295

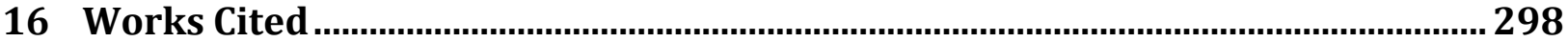




\section{LIST OF FIGURES}

Figure 1 - FASTER Reactor Core Layout ............................................................................ii

Figure 2 - Elevation View of PHTS ....................................................................................

Figure 3 - FASTER NSSS - Elevation View ....................................................................ix

Figure 4 - FASTER Thermodynamic Cycle and Balance of Plant ……………………………....

Figure 5 - Normalized axial fast flux distribution in test locations ...............................................

Figure 6 - Normalized axial thermal flux distribution in the test locations...................................

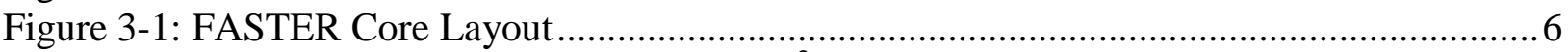

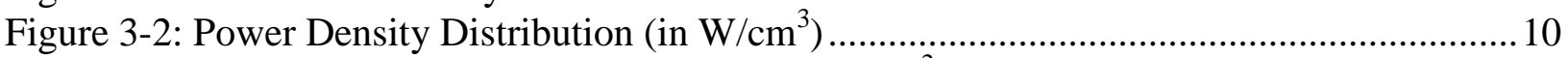

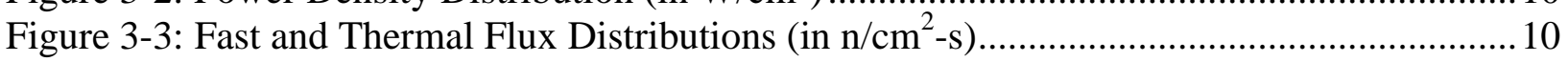

Figure 3-4: Single Rod Worth and Core Reactivity for the Primary Control System ...................13

Figure 3-5: Single Rod Worth and Core Reactivity for the Secondary Control System ...............13

Figure 3-6: Normalized Axial Fast Flux Distribution in Test Locations ....................................... 16

Figure 3-7: Normalized Axial Thermal Flux Distribution in the Test Locations ..........................18

Figure 3-8: Spectra Comparison in Fast and Thermal Test Assemblies ......................................19

Figure 3-9: $\mathrm{N}_{\mathrm{s}}-\mathrm{D}_{\mathrm{s}}$ Diagram for Pumps with Selected Helium Pump Operating Point Highlighted

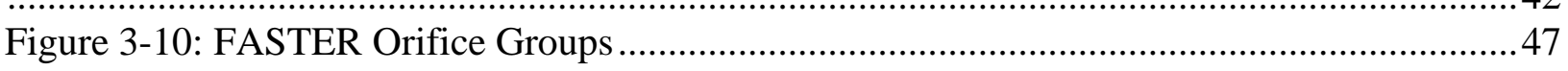

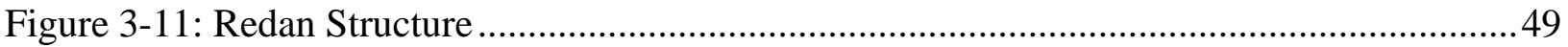

Figure 3-12: Detailed Section View through the FASTER Vessel Cover ...................................50

Figure 3-13: Plan View of FASTER Reactor Vessel Arrangement (Translucent Vessel Cover). 51

Figure 3-14: Perspective View of Vessel Cover, Fixed UIS, Instrument Trees, and FHMs ........53

Figure 3-15: Instrument Tree with Control Rod Drive Segment .................................................5

Figure 3-16: Instrument Tree Rotation Drive Motor and Housing ...............................................55

Figure 3-17: Section Below Fixed UIS Showing Location of Instrument Trees During Reactor

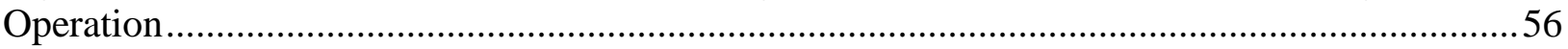

Figure 3-18: Section Below Fixed UIS Showing Location of Instrument Trees During Refueling

Figure 3-20: Displacement Results for Instrument Tree under Gravity Loading ..........................59

Figure 3-21: Section through Instrument Trees Showing Instrumentation Conduit Routing

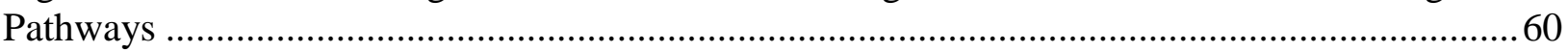

Figure 3-22: Section through Sensor Assembly, Seals, and Instrument Tree................................61

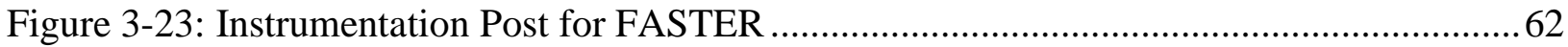

Figure 3-24: View Looking Upward from the Top of Core Showing Instrument Trees and Fixed UIS

Figure 3-25: Perspective View Above Core Centerline During Reactor Operation .......................64

Figure 3-26: Program for Calculation of Successive Roots of an Infinite Series ...........................66

Figure 3-27: Transient Temperature Distribution in Heat Shield ...............................................67

Figure 3-28: Maximum Transient Stress in the Bottom Inconel 718 Heat Shield.........................68

Figure 3-29: Transient Stress Distribution in the Bottom Inconel 718 Heat Shield Plate .............69

Figure 3-30: Vertical View of Primary System .................................................................... 75

Figure 3-31: Plan View of the Primary System ......................................................................76

Figure 3-32: Schematic Comparison of FASTER and EBR-II Pumps .........................................78

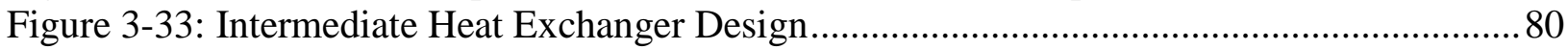




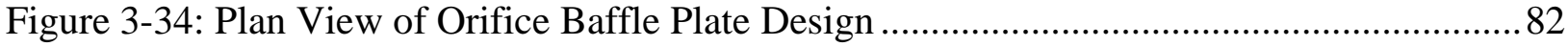

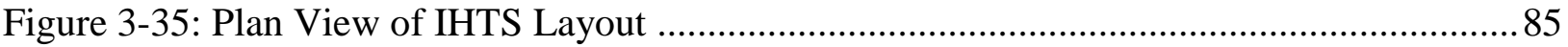

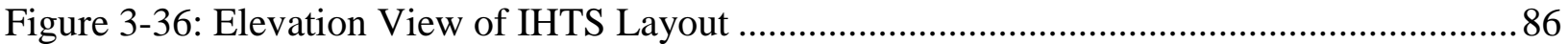

Figure 4-1: FASTER Steam Cycle Power Conversion …………………………………........ 90

Figure 4-2: Temperature-Entropy Diagram of FASTER Steam Cycle........................................99

Figure 5-1: Schematic Diagram of Shutdown Heat Removal System ..........................................95

Figure 5-2: Details of DRACS Design ...............................................................................

Figure 6-1: FHM Located Above the Core Assembly (1 - Instrument Tree and 1 - FHM

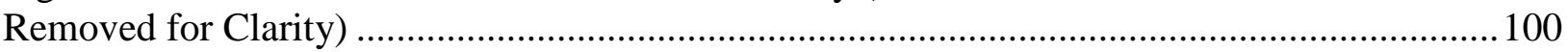

Figure 6-2: FHM in Fully Extended and Retracted Positions....................................................101

Figure 6-3: Overall Exploded Assembly View of Pantograph FHM..........................................102

Figure 6-4: Pantograph FHM Drive System Component Arrangement ......................................105

Figure 6-5: Assembly view of the pantograph FHM showing its major components. ...............107

Figure 6-6: Upper Universal Joints for FHM Drive System...................................................... 108

Figure 6-7: The Velocity Ratio Variation through a Universal Joint with Angle of Bend.........109

Figure 6-8: Details of Extension Shaft Arrangement..............................................................110

Figure 6-9: Lower Universal Joint Connections to Pantograph Arm Gearbox............................111

Figure 6-10: Core Assembly Spreader and Hold Down Interface at the Surrounding Core

Assemblies ............................................................................................................... 112

Figure 6-11: Matching Tapered Features on Top of Core Handling Socket Required for Spreader

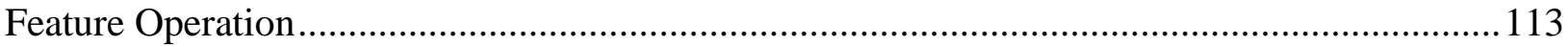

Figure 6-12: AFBMA Load Ratings for Tapered Roller Bearings .............................................114

Figure 6-13: Typical Analysis for Hydrodynamic Bearing Design Based on Sommerfield

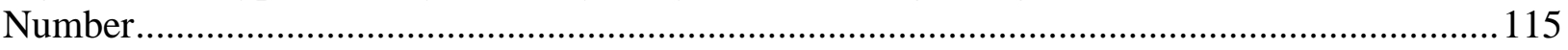

Figure 6-14: Gripper Drive Mechanism at Top of Pantograph Arm .......................................116

Figure 6-15: Section View through Gripper Head Assembly ....................................................117

Figure 6-16: Gripper Jaws in the Extended and Retracted Positions using Jaw Actuator ..........118

Figure 6-17: Exploded Assembly View of FASTER Gripper Assembly ...................................118

Figure 6-18: Static Deflection and Stress Results for $6000 \mathrm{lb}$ Force on Hold Down Surface.... 120

Figure 6-19: Modal Analysis Results for the FASTER FHM (First Modal Frequency 3.39 Hertz)

Figure 6-20: Finite Element Analysis Results of Linear Buckling Analysis for FASTER FHM

Figure 6-21: Stress Analysis Results for the Gripper Assembly using Different Jaw Designs .. 123

Figure 6-22: Dynamic Analysis basis of the Spline Shaft Based on Acceleration of the Mass .124

Figure 6-23: Finite Element Analysis Severely Underestimates Gear Contact and Bending

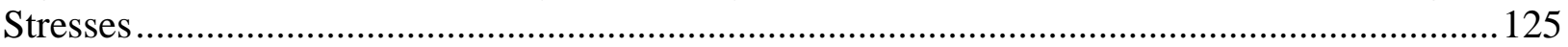

Figure 6-24: Hertz Contact Stress Distribution Indicates Peak Stress below Contact Surface ..126

Figure 6-25: AGMA Defined Safety Factors for Contact and Bending Fatigue .........................127

Figure 6-26: Typical Motor Sizing Calculation Based on Required Torque ..............................129

Figure 6-27: Conceptual Design of the Manual Drive Back-up and Visual Position Indicator .130

Figure 6-28: Elevation Views of the Manual Drive Back-up and Rotary Position Indicator .....131

Figure 6-29: Preliminary Time Estimate for Initial Shift Fuel Handling Operations ..................134

Figure 6-30: Preliminary Time Estimate for Subsequent Shift Fuel Handling Operations ........134

Figure 6-31: Conceptual FASTER - FHM Operators Display Pane ...........................................137

Figure 6-32: FHM Control System Programming Flowchart .....................................................140 
Figure 6-33: Conceptual Design of a Load Limiting Device used in the Core Hold Down System

Figure 6-34: Analysis of Conceptual Load Limiting Device for Core Hold Down.....................143

Figure 6-35: General Positioning System with Feedback......................................................... 143

Figure 6-36: General Block Diagram for a Positioning System with Feedback ..........................144

Figure 6-37: Transfer Functions for the General Positioning System with Feedback ................145

Figure 6-38: Sealing Arrangement for Shaft Penetrations in Reactor Vessel Head ...................147

Figure 6-39: Typical Belleville Washer Design Parameters ..................................................... 148

Figure 7-1: Instrumented, Closed Loop Assemblies, and Fuel Transfer Positions in Reactor Head

Figure 7-2: Preliminary layout of the EVTM in position over a Fuel Transfer Port ....

Figure 8-1: Estimate Oxide-Hydride Deposition in the Primary Sodium to be Removed by the

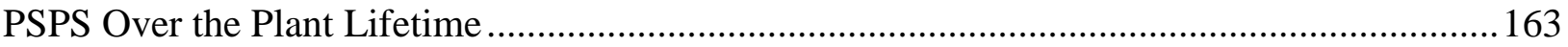

Figure 8-2: Preliminary Piping Diagram of FASTER Primary Sodium Purification System ....167

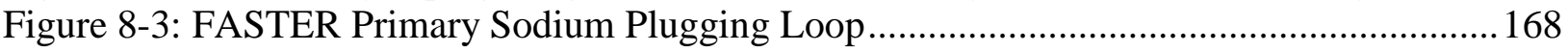

Figure 8-4: Primary Sodium Sampling Station ..................................................................... 169

Figure 8-5: Preliminary Piping Diagram of PGSFR ISPS- Normal Operation with CT1 on Line

Figure 8-6: Preliminary Piping Diagram of PGSFR ISPS- Normal Operation with CT 2 on Line

Figure 8-7: IHTS Cold Trap Dimensions

Figure 8-8: IHTS Plugging Meter Dimensions

Figure 8-9: FASTER Secondary Sodium Plugging Loop ........................................

Figure 9-1: Schematic of Plant Showing Control and Controlled Variables .............................. 199

Figure 9-2: Schematic of Supervisory Control System............................................................220

Figure 9-3: Supervisory Control System. SP = Setpoint, PV = Process variable, CV = Controlled

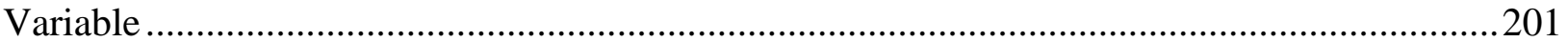

Figure 9-4: Core Power Subsystem Controller ..................................................................2202

Figure 9-5: Core Outlet Temperature Controller ………………………............................202

Figure 9-6: Steam Temperature Controller .........................................................................203

Figure 9-7: Core Outlet Temperature Controller with Actuator-Local Controller ......................204

Figure 9-8: Steam Temperature Controller with Actuator-Local Controller ..............................2.205

Figure 9-9: Representative Control Logic for the Supervisory Control System........................207

Figure 9-10: Temperature Profiles During Plant Startup ......................................................2. 208

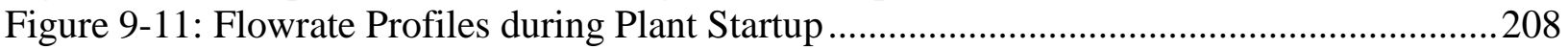

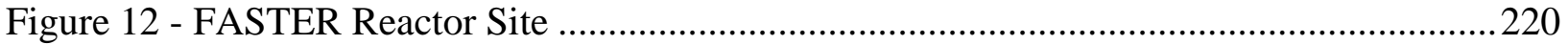

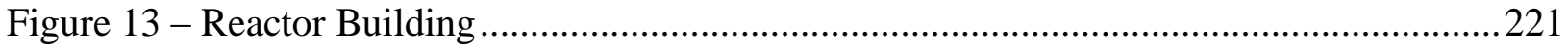

Figure 12-1: Transport and Retention Phenomena for In-Core Releases .................................223

Figure 12-2: PRIMAR-4 Model of the Primary Sodium Heat Transport System .......................237

Figure 12-3: SAS4A/SASSYS-1 Core Channels and Heat Transfer Areas.................................2239

Figure 12-4: SAS4A/SASSYS-1 Core Channels Axial Geometry ............................................24

Figure 12-5: SAS4A/SASSYS-1 Simple Radial Expansion Model ...........................................246

Figure 12-6: Obtaining Coefficients for CRDL Feedback, All Transients Except UTOP .........248

Figure 12-7: SAS4A/SASSYS-1 PRIMAR-4 Modeling ........................................................2.

Figure 12-8: PRIMAR-4 Model of the Primary Sodium Heat Transport System ......................251

Figure 12-9: PRIMAR-4 Model of the Intermediate Sodium Heat Transport System ................252 
Figure 12-10: PRIMAR-4 Model of the Direct Reactor Auxiliary Cooling System 253

Figure 12-11: Components in Control Rod Driveline and Reactor Vessel Expansion Model ...258 Figure 12-12: BOEC UTOP with 2 DRACS Units: Total, Fission, and Decay Heat Power Production 262

Figure 12-13: BOEC UTOP with 2 DRACS Units: Reactivity Feedbacks ................................263

Figure 12-14: BOEC UTOP with 2 DRACS Units: Peak In-Core Temperatures .......................264

Figure 12-15: BOEC ULOHS: Total, Fission, and Decay Heat Power Production ...................266

Figure 12-16: BOEC ULOHS: Reactivity Feedbacks ..................................................266

Figure 12-17: BOEC ULOHS: Peak In-Core Temperatures.................................................267

Figure 12-18: BOEC ULOHS: Primary System Temperatures ............................................268

Figure 12-19: EOEC ULOHS: Total, Fission, and Decay Heat Power Production...................269

Figure 12-20: EOEC ULOHS: Primary System Temperatures ..........................................270

Figure 12-21: EOEC ULOHS: Peak In-Core Temperatures...........................................2270

Figure 12-22: BOEC USBO: Total, Fission, and Decay Heat Power Production .....................2272

Figure 12-23: BOEC USBO: Reactivity Feedbacks, Short-Term ......................................2272

Figure 12-24: BOEC USBO: Reactivity Feedbacks, Long-Term......................................2273

Figure 12-25: BOEC USBO: Peak In-Core Temperatures ...............................................2273

Figure 12-26: EOEC USBO: Total, Fission, and Decay Heat Power Production .....................2275

Figure 12-27: EOEC USBO: Reactivity Feedbacks, Short-Term......................................2275

Figure 12-28: EOEC USBO: Reactivity Feedbacks, Long-Term .......................................2276

Figure 12-29: EOEC USBO: Peak In-Core Temperatures ................................................276 


\section{LIST OF TABLES}

Table 1 - FASTER Reactor Plant Summary Characteristics ........................................................ i

Table 2 - Summary of Fast Flux Conditions in the Test Assemblies ............................................ii

Table 3 - Summary of Thermal Flux Conditions in the Test Assemblies ....................................ii

Table 4 - Assembly Descriptions and Dimensions......................................................................iv

Table 5 - Core Performance Characteristics............................................................................

Table 6 - Primary Pump Design Characteristics .......................................................................vi

Table 7 - IHX Design Parameters ……………………………................................................vi

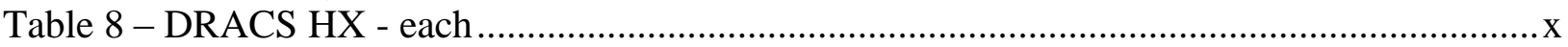

Table 9 - Summary of Fast Flux Conditions in the Test Assemblies .............................................

Table 10 - Summary of Thermal Flux Conditions in the Test Assemblies ...................................

Table 11 - Heat Rejection Rate and Flowrate Requirements for Closed Loops for Different

Reactor Coolants and Example Reactor Designs.....................................................................ii

Table 12 - Required Pressure Tube Dimensions for $649^{\circ} \mathrm{C}\left(1200^{\circ} \mathrm{F}\right)$ Design Temperature.........

Table 13 - Required Pressure Tube Dimensions for $704^{\circ} \mathrm{C}(1300 \mathrm{~F})$ Design Temperature .........xv

Table 14 - Required Pressure Tube Dimensions for $760^{\circ} \mathrm{C}(1400 \mathrm{~F})$ Design Temperature ...........xv

Table 15 - Closed Loop System Primary Coolants and Major Features..........................................xvi

Table 16 - TRL Evaluation of FASTER Reactor Plant Systems and Components......................xix

Table 1-1: FASTER Reactor Plant Summary Characteristics ....................................................... 1

Table 1-2: LEU Core Performance Characteristics ..................................................................

Table 3-1: Assembly Dimensions by Type ……………………............................................

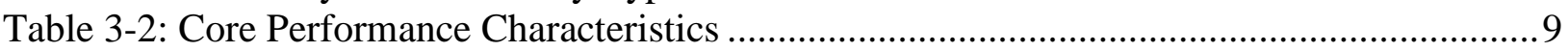

Table 3-3: Reactivity Worth of the Primary and Secondary Control Systems ..............................12

Table 3-4: Reactivity Worths and Shutdown Margins of the Primary Control System.................14

Table 3-5: Reactivity Worths and Shutdown Margins of the Secondary Control System............. 14

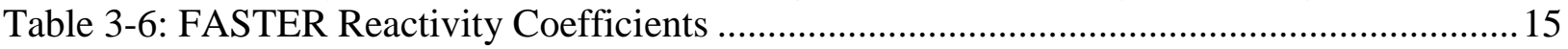

Table 3-7: Quasi-static Reactivity Balance Coefficients and Conditions ........................................15

Table 3-8: Summary of Fast Flux Conditions in the Test Assemblies .......................................... 17

Table 3-9: Summary of Thermal Flux Conditions in the Test Assemblies................................... 17

Table 3-10: Heat Rejection Rates and Flowrate Requirements for Closed Loops for Different

Reactor Coolants and Example Reactor Designs ....................................................................2.

Table 3-11: Required Pressure Tube Dimensions for $649^{\circ} \mathrm{C}\left(1200^{\circ} \mathrm{F}\right)$ Design Temperature …...25

Table 3-12: Required Pressure Tube Dimensions for $704^{\circ} \mathrm{C}\left(1300^{\circ} \mathrm{F}\right)$ Design Temperature .......25

Table 3-13: Required Pressure Tube Dimensions for $760^{\circ} \mathrm{C}\left(1400^{\circ} \mathrm{F}\right)$ Design Temperature .......26

Table 3-14: Closed Loop System Primary Coolants and Major Features......................................2 28

Table 3-15: IHX Design Calculations for Required Tube Length for Seventeen-Tube Helical

Coil IHX or Number of Tubes and Shell Inner Diameter for DWST IHX or Larger Helical Coil

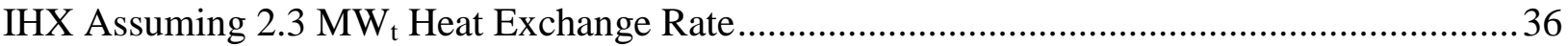

Table 3-16: Coolant Flow Characteristics for Each Orifice Group (4 Fuel Groups) ......................47

Table 3-17: Maximum Temperatures $\left({ }^{\circ} \mathrm{C}\right)$ for Various Numbers of Fuel Orifice Groups ............48

Table 3-18: Comparison of Room Temperature Properties of 316 Stainless \& Inconel 718 ........64

Table 3-19: Mechanical Pump Design Parameters …………………………………………..... 77

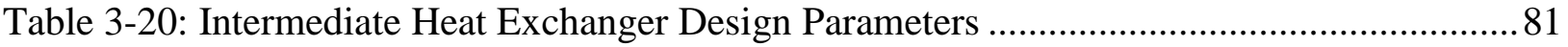

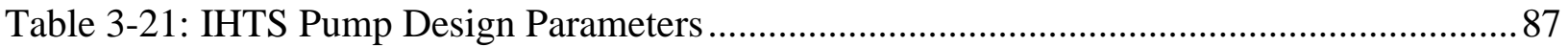

Table 4-1: Assumptions for GateCycle Model of Steam Cycle …………………………............ 91 
Table 4-2: Stream Conditions from GateCycle Model ...............................................................99

Table 4-3: Steam Cycle Power Balance ................................................................................99

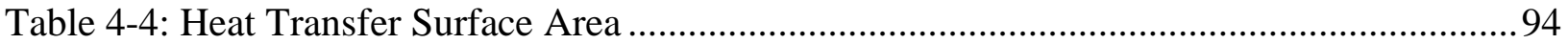

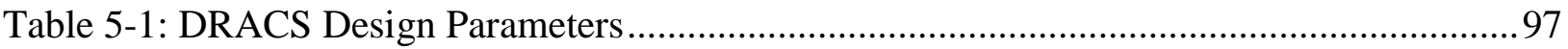

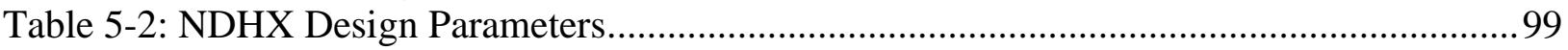

Table 6-1: Estimated Times for General Fuel Handling Operations .........................................132

Table 6-2: Estimated Time Required for Individual FHM Motions ...........................................133

Table 8-1: Cold Trap Oxygen-Oxide Removal Requirements from Primary Sodium Integrated

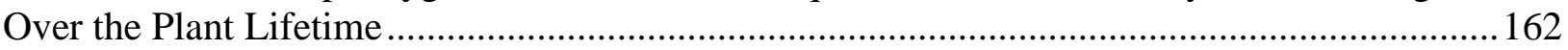

Table 8-2: EBR-II Primary Sodium Steady-State Impurity Levels at Full Power (62.5 $\mathrm{MW}_{\text {th }}$ )

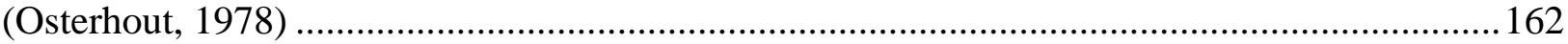

Table 8-3: Cesium-134 and -137 Deposition in Primary Sodium per Fuel Pin Failure (Farmer, Jin., \& Momozaki, 2016) (Jin, Feb. 24, 2016) ........................................................................163

Table 8-4: Summary of High Level FASTER PSPS Performance Requirements........................165

Table 8-5: Steam Generator Tube Designs from Different Reactor Designs ..............................171

Table 8-6: Initial Impurity Levels in EBR-II Reactor Grade Sodium ......................................173

Table 8-7: Estimated FASTER IHTS Loop Oxygen, Hydrogen, and Tritium Source Rates .....174

Table 8-8: Total Accumulated Impurity Mass for IHTS Sodium Loop*.....................................174

Table 8-9: FASTER IHTS Cold Trap Design Dimensions.......................................................180

Table 8-10: FASTER IHTS Economizer Design Dimensions....................................................182

Table 8-11: FASTER IHTS Plugging Meter Design Dimensions ..............................................184

Table 9-1: Comparison for Metal and Oxide Cores of Tendency of Core Power to Inherently

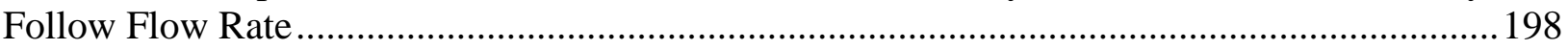

Table 9-2: Controllers and Process Variables Controlled as a Function of Operating Mode.....206

Table 9-3: Plant Transition Phases....................................................................................2. 208

Table 9-4: Trip Parameters for Representative Design Basis Events ........................................22

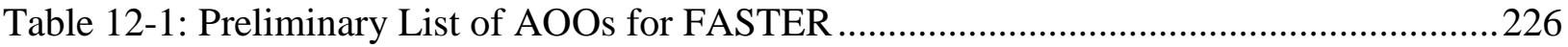

Table 12-2: Preliminary List of DBAs for FASTER …………………….............................22

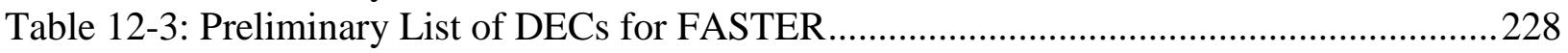

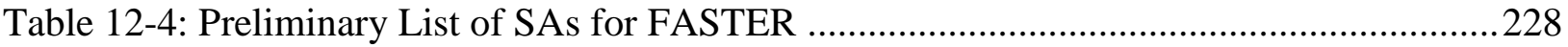

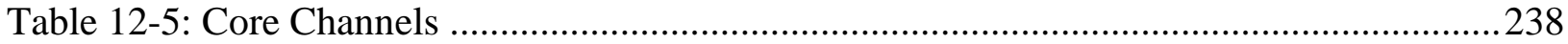

Table 12-6: Number of Assembly Sides Participating in the Channel-to-Channel Heat Transfer

Table 12-7: Reactivity Coefficients by Channel

Table 12-8: Core Radial Expansion Reactivity Feedback Coefficient ......................................2.246

Table 12-9: CRDL Reactivity Feedback Coefficients .............................................................248

Table 12-10: Primary System Element and Compressible Volume Input Parameters ................254

Table 12-11: Intermediate Heat Transport System Element and Compressible Volume Input

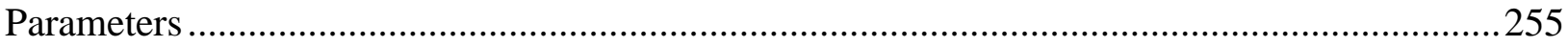

Table 12-12: Decay Heat Removal System Element and Compressible Volume Input Parameters

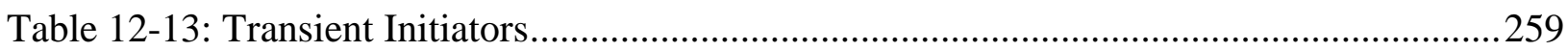

Table 12-14: Peak Temperatures for BOEC and EOEC Transients ..........................................227

Table 12-15: Safety Margins for BOEC and EOEC Transients ................................................2.

Table 15-1: Estimate of FASTER Reactor Plant Annual Operation and Maintenance Cost.Error! Bookmark not defined. 
FASTER Test Reactor Preconceptual Design Report

March 31, 2016 
FASTER Test Reactor Preconceptual Design Report

March 31, 2016 


\section{Introduction}

The FASTER reactor plant is a sodium-cooled fast spectrum test reactor that provides high levels of fast and thermal neutron flux for scientific research and development. The $120 \mathrm{MW}_{\mathrm{e}}$ FASTER reactor plant has a superheated steam power conversion system which provides electrical power to a local grid allowing for recovery of operating costs for the reactor plant. In addition, the FASTER reactor plant could be used for isotope production or as a heat source, if desired. The FASTER reactor plant has the main attributes listed in Table 1-1.

Table 1-1: FASTER Reactor Plant Summary Characteristics

\begin{tabular}{ll}
\hline Characteristic & \\
\hline Reactor Power & $300 \mathrm{MWt} / 120 \mathrm{MWe} / 40 \%$ efficiency \\
Coolant & Sodium \\
Coolant Temperature, Inlet/Outlet & $355^{\circ} \mathrm{C} / 510^{\circ} \mathrm{C}$ \\
Coolant Pressure (cover gas pressure) & Cover Gas pressure - few inches of water \\
Fuel, Cladding, Duct & $\mathrm{U}-\mathrm{Pu}-\mathrm{Zr}$ metal fueled core, HT-9, HT-9 \\
Cycle Length & 100 days \\
Average/Peak Burnup & $34.3 \mathrm{GWd} / \mathrm{t}$ \\
Power Density (Average, Peak) & $558.8 \mathrm{~W} / \mathrm{cc}, 917 \mathrm{~W} / \mathrm{cc}$ \\
Plant Life & 30 years with expectation of life extension \\
PHTS Configuration & Pool plant geometry \\
Reactor Vessel Structural Materials & Austenitic stainless steel \\
Primary and Secondary Pumps & Mechanical centrifugal pumps (2) \\
Intermediate Heat Exchanger & Tube-and-Shell heat exchanger (4) \\
Reactor Vessel Support & Conical Ring - Top Support \\
Emergency Decay Heat Removal & Direct Reactor Auxiliary Heat Exchanger in cold pool (3) \\
Primary Purification System & Conventional cold and nuclide trap technology \\
Power Conversion System & Superheated steam cycle \\
Containment & Steel reinforced concrete containment \\
In-vessel Fuel Handling Mechanism & Single Rotatable Plug with pantograph FHM (3) \\
\hline
\end{tabular}

The reactor power level is the minimum that assures achievement of the neutron flux goals. In its current configuration, the FASTER reactor provides 33 fast flux test locations, three (3) thermal flux test locations, two (2) fast flux closed loops and one (1) thermal flux closed loop. Among the fast spectrum test locations, four of them are located near the core center and cannot be repositioned without affecting the core neutronics performance.

It is anticipated that the FASTER reactor plant will be utilized by domestic and international researchers with its broad appeal to many different reactor types: sodium-cooled fast reactors, lead-cooled fast reactors, gas-cooled fast reactors, and thermal spectrum reactors.

It is estimated that the FASTER test reactor will require approximately 11 to 13 years from the issuance of CD-0 to the core startup, assuming funding and licensing are not limiting factors. In 
addition, the FASTER test reactor with the steam plant will cost approximately $\$ 2.8 \mathrm{~B}$ (with a $30 \%$ contingency) to design ( $\sim \$ 1.1 \mathrm{~B}$ ) and construct (with each closed loop contributing $\sim \$ 100 \mathrm{M}$ (includes contingency) to overall estimated TPC). If it was decided to remove the steam plant and just reject the $300 \mathrm{MW}_{\mathrm{t}}$ of heat to the atmosphere, then the cost will be significantly less than $\$ 2.5 \mathrm{~B}$. The annual FASTER reactor plant operating costs are estimated to be less than $\$ 100 \mathrm{M}$. The FASTER reactor plant annual operating costs including irradiation operations are expected to be less than $\$ 150 \mathrm{M}$ (using FFTF as the high end basis). All estimates are in 2016 dollars. The replacement fuel is estimated to cost about $\$ 20 \mathrm{M} /$ year. The FASTER reactor is expected to achieve a capacity factor of $80 \%$ or greater while putting power on the grid. The sales from this power are expected to be around $\$ 89 \mathrm{M}$ to $\$ 100 \mathrm{M}$ per year depending upon overall electrical generation capacity and power purchasing agreements, offsetting the operational and fuels costs.

\subsection{Overall Objectives}

While the FASTER plant has been designed with extended testing capabilities in mind, a simple design with proven components and technology has been utilized as a framework in order to promote the attractiveness and cost efficiency of the facility. The main function of the reactor is to provide neutrons for irradiation testing and thus no significant technology innovations were adopted for the FASTER plant to maintain a high technology readiness level. The FASTER plant will rely upon the liquid metal base technology developed in the U.S. for EBR-II, FFTF, CRBR, and the ALMR program with a special emphasis on the irradiation testing capabilities developed for EBR-II and FFTF. The reactor core design discussed here is not based on any previously existing fast reactor, but uses materials and dimensions consistent with the U.S. base technology program. The main objective of the FASTER reactor design efforts was to achieve a very high fast flux as well as a significant thermal flux while offering a large number of test locations.

Ternary metallic fuel, U-Pu-Zr, is used with HT-9 stainless steel for cladding and structural material. Although there is no mandated limit on the weight fraction of Pu that can be used in the fuel, it was decided to limit it to $20 \mathrm{wt} \%$ based on the availability of irradiation data. Another incentive for not resorting to higher $\mathrm{Pu} w \mathrm{w} \%$ is the degradation of the fuel thermal conductivity as $\mathrm{Pu}$ content is increased. This is of particular importance for the FASTER reactor due to the high power density during operations.

In order to optimize the reactor performance and obtain a relatively compact core, the $\mathrm{Zr}$ wt $\%$ in the fuel is assumed to be $6 \mathrm{wt} \%$ and the fuel smear density is assumed to be $85 \%$. Using $6 \mathrm{wt} \%$ instead of the more traditional $10 \mathrm{wt} \%$ does not affect the characteristics of the ternary fuel; additionally, irradiation tests have previously been performed for such a fuel type. The decision to use an $85 \%$ smear density, instead of the $75 \%$ typically used for metallic fuel, is based on the relatively low peak burnup that will be achieved. Because of the lower fuel burnup, the internal stress applied by the fuel on the cladding as a result of irradiation swelling will be less important than typically observed in metallic fuel that reaches a high burnup. Furthermore, the fission gas plenum length relative to the active fuel length does not need to be as long as what is typically used in SFR core designs, because of the lower fuel burnup achieved. For the FASTER core design the fission gas plenum length is set to be $65 \%$ of the active fuel length. 


\subsection{Preliminary Considerations of Low Enriched Uranium}

At the very beginning of the study, the performance which could be achieved by using LEU fuel in a sodium-cooled test reactor was examined at a high level. The first core layout used to initiate the design of the test reactor was used with LEU fuel having an enrichment of less than $20 \%$

${ }^{235} \mathrm{U}$. The same core layout and dimensions were used to examine two different scenarios using LEU fuel. The size of the core model used corresponds approximately to the minimum critical core size. In the first scenario, the power level was arbitrarily limited to $500 \mathrm{MW}_{\mathrm{t}}$, and the maximum achievable peak fast flux was determined. In the second scenario, the power level was increased until the targeted peak fast flux $\left(5.0 \times 10^{15} \mathrm{n} / \mathrm{cm}^{2}\right.$-s) was achieved, and the cycle length reduced to maintain roughly the same discharge burnup. Results obtained for this very preliminary analysis are compared in Table 1-2. Preliminary calculations were also performed for a plutonium-based core and are included in Table 1-2 for comparison. It is important to note that the results shown in this table for the plutonium-based core are not related to the characteristics of the FASTER core discussed in this report. These results clearly show that when using plutonium instead of LEU it is possible to reduce the core power rating by at least a factor 2 , to achieve the same peak fast flux level. Subsequent efforts have therefore been focused on the plutonium-based core for FASTER.

Table 1-2: LEU Core Performance Characteristics

\begin{tabular}{lccc}
\hline Characteristic & LEU-case 1 & LEU-case 2 & UPu \\
\hline Nominal power, MWth & 500 & 715 & 300 \\
Required enrichment & $18.90 \%$ & $19.77 \%$ & $19.25 \%$ \\
BOC/EOC keff & $1.0108 / 1.0000$ & $1.01622 / 1.00017$ & $1.0262 / 1.0000$ \\
Average discharge burnup, GWd/t & 22.8 & 21.7 & 35.0 \\
Heavy metal inventory, $\mathrm{kg}$ & 6575 & 6575 & 2570 \\
Heavy metal charge per cycle, $\mathrm{kg}$ & 2192 & 3288 & 857 \\
Average power density, W/cm3 & 321.3 & 459.5 & 570.0 \\
Peak power density, W/cm3 & 574.9 & 787.9 & 914.6 \\
Specific power, W/g & 76.0 & 108.7 & 116.7 \\
Average linear power, $\mathrm{kW} / \mathrm{m}$ & 16.3 & 23.3 & 36.1 \\
Axial/radial leakage & $9.42 \% / 19.46 \%$ & $13.86 \% / 16.02 \%$ & $16.01 \% / 26.04 \%$ \\
Total flux, $1 \mathrm{E}+15 \mathrm{n} / \mathrm{cm} 2-\mathrm{s}$ & 2.89 & 3.91 & 4.05 \\
Peak total flux, $1 \mathrm{E}+15 \mathrm{n} / \mathrm{cm} 2-\mathrm{s}$ & 5.42 & 7.07 & 6.83 \\
Fast flux, $1 \mathrm{E}+15 \mathrm{n} / \mathrm{cm} 2-\mathrm{s}$ & 2.04 & 2.78 & 2.95 \\
Peak fast flux, $1 \mathrm{E}+15 \mathrm{n} / \mathrm{cm} 2-\mathrm{s}$ & 3.87 & 5.12 & 5.06 \\
\hline
\end{tabular}




\section{FASTER Mission}

Research and development of advanced nuclear fuels and materials within the various DOE Nuclear Energy programs requires an adequate fast-neutron irradiation capability to test candidate fuels and materials samples in a prototypic environment and to provide irradiated fuels and materials for transient testing. Testing is necessary to ensure the adequate performance of the fuels and materials prior to their implementation in an advanced reactor system. The irradiation facility must meet certain requirements for test volume, instrumentation, neutron spectrum, and physical conditions characteristic of the anticipated operating environment. It is recognized that a user facility of this type will also benefit other DOE programs such as the space reactor and fusion energy programs. Therefore, to address the performance gap in irradiation test facilities, FASTER will meet the following mission needs and have the following benefits:

- Provide a domestic capability to irradiate advanced fuels and materials in a fast-neutron spectrum and a prototypic environment to meet the technology needs of the DOE Nuclear Energy programs and thereby allow them to perform the necessary fuels and materials development work and proof-of-performance and safety demonstrations.

- Provide a facility for the testing of reactor systems and components of various types in a prototypic environment at or near commercial scale. (Such systems and components may include advanced power conversion systems, compact self-cooled electromagnetic pumps, compact fuel handling systems, advanced heat exchanges, large steam generators, for example.)

- Provide a user facility for the DOE to perform fast-neutron spectrum irradiations for university, industrial, and international researchers, including those of other U.S. programs. In addition, the "user" facility could be used for the testing of advanced systems and components depending upon the functionality and design of the FASTER.

- Provide a wide range of practical opportunities for next generation U.S. scientists and engineers to become involved in the development of an advanced reactor from system conception to operation, including the development and evaluation of component and system design options, performance of operational and safety analyses, etc., leading to a greater participation of those personnel within the international advanced-reactor development community. FASTER will also allow for engagement of the regulatory authority to support future fast reactor licensing decisions.

- Provide a project that will engage the U.S. industrial base for building systems and components for fast reactor applications.

- Provide a "full"-scale prototypic system for the verification of advanced computer modeling and simulation codes for fast reactors.

- Provide impetus for stronger U.S.-international collaborations in fast reactor development and commercialization. 


\section{Primary Plant Design Description}

This section provides details on the primary plant design. This includes descriptions of the reactor assembly system (Section 3.1), control and shutdown systems (Section 3.2), reactor vessel (Section 3.3), and the primary (Section 3.4) and intermediate (Section 3.5) heat transport systems.

\subsection{Reactor Assembly System}

The reactor assembly system consists of the core assemblies, test loop locations, inlet plenum, lower internals, core barrel, redan, instrumentation trees, and core restraint system. These are described in the following sections.

\subsubsection{Core Design Approach}

The proposed FASTER core layout and design characteristics are the result of a multi-step design process. Initially the smallest core volume resulting in a critical core was determined, using $20 \mathrm{wt} \%$ plutonium or less. Then the power of the core was increased until the desired peak fast flux level was achieved. Thermal hydraulic and safety analyses were performed for that core configuration, and the core layout and dimensions were progressively modified in order to achieve inherent passive safety and meet thermal hydraulics constraints. This required slightly flattening the core and therefore the volume of the proposed core is larger than the minimum volume needed for criticality.

The Argonne code suite for fast reactor analysis (DIF3D/REBUS) and MCNP6 are used to perform the neutronics and depletion calculations. A different set of cross sections is used in the different regions of the core in order to properly capture all the spectra changes, and have been generated using MC2-3 associated with TWODANT, based on the ENDF/B.VII library. All assemblies are modeled as having a homogenous composition, which might introduce some slight bias in the region where neutrons are moderated, and might require more detailed assessment.

\subsubsection{Core Layout and Assemblies}

The $300 \mathrm{MW}_{\mathrm{t}}$ FASTER core, shown in Figure 3-1, is composed of 55 fuel assemblies, each with the same Pu wt fraction. The fuel, coolant and structural material volume fractions are $30.93 \%$, $37.36 \%$, and $23.65 \%$, respectively. The active fuel height is $80 \mathrm{~cm}$. Six primary control rod assemblies and three secondary control rod assemblies composed of $\mathrm{B}_{4} \mathrm{C}$ rods ensure the safe shutdown of the core. There are 33 fast neutron flux test locations, in addition to the two closed loops also being exposed to a fast neutron flux. 

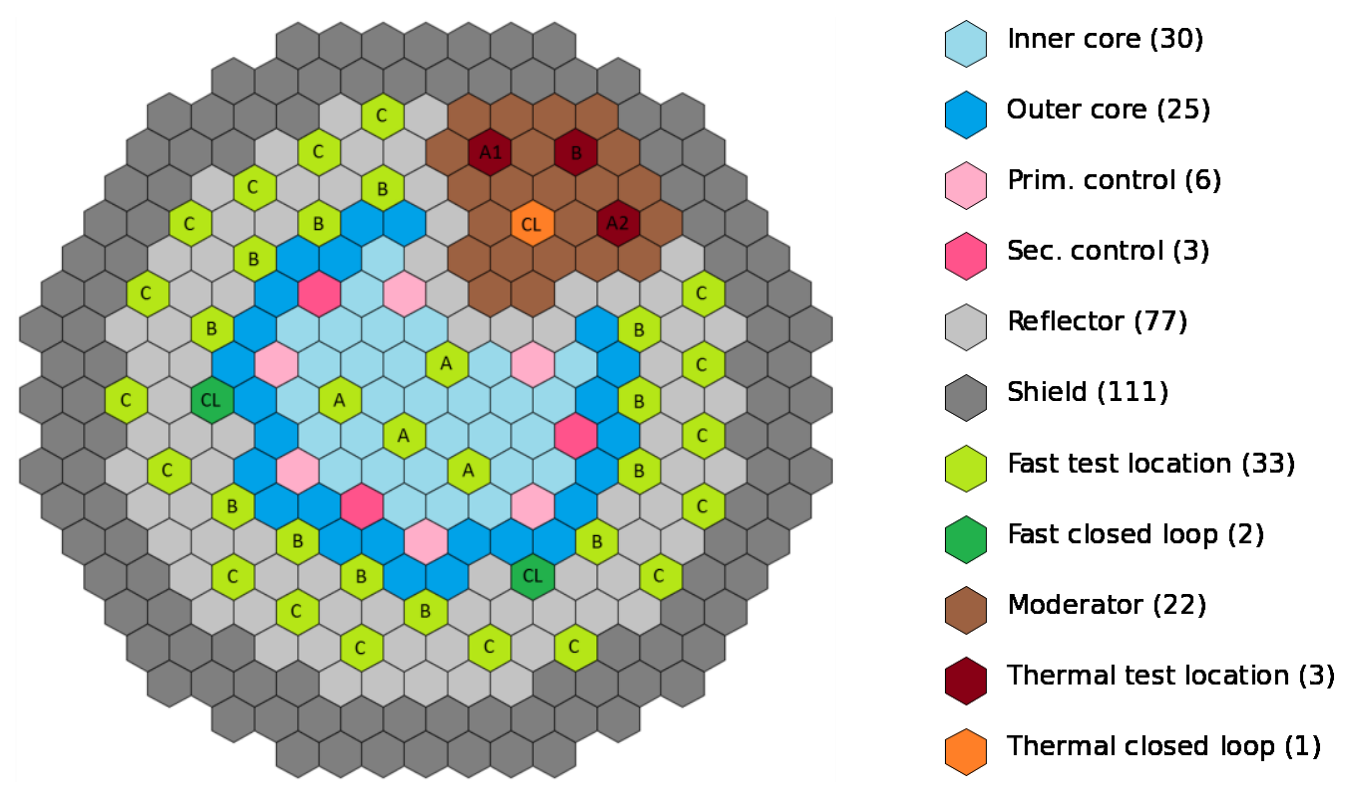

Figure 3-1: FASTER Core Layout

The fuel assembly positions have been chosen to enhance neutron leakage probability toward the moderated zone (brown in Figure 3-1). The purpose of the moderator is to take advantage of the neutrons leaking out of the active core region and thermalize them in order to provide thermal spectrum testing capabilities. With the current design, fast neutrons are thermalized by the moderator and do not return into the active core region because of the reflector layer between the two regions. This design approach prevents a number of potential issues. There are three thermal test locations and one closed loop having a thermal neutron flux. Canned beryllium is used as the moderator and zircaloy is used as the structural material in that region to avoid parasitic absorption of thermal neutrons in iron. The moderated region does not contain any fuel and is cooled with sodium. The assembly descriptions and dimensions are provided in Table 3-1. 
Table 3-1: Assembly Dimensions by Type

\begin{tabular}{|c|c|c|c|c|c|}
\hline Assembly Type & Fuel & Reflector & Test & Control & Shield \\
\hline Assembly pitch (hot) & 11.870 & 11.870 & 11.870 & 11.870 & 11.870 \\
\hline Smear density & 85 & 100 & 100 & 85 & 81 \\
\hline Pins/assembly & 271 & 91 & 91 & 91 & 61 \\
\hline Pin Outside Diameter ( $\mathrm{mm}$ ) & 5.405 & 11.072 & 11.072 & 9.512 & 13.462 \\
\hline Cladding Thickness (mm) & 0.35 & 1.0 & 1.0 & 0.3 & 0.4 \\
\hline Pin Pitch/Diameter Ratio & 1.210 & 1.023 & 1.023 & 1.024 & 1.012 \\
\hline Clad inner diameter ( $\mathrm{mm}$ ) & 4.701 & 9.059 & 9.059 & 8.941 & 12.833 \\
\hline Outer Flat-to-Flat Distance (cm) & 11.568 & 11.568 & 11.568 & 11.568 & 11.568 \\
\hline Duct Wall Thickness (mm) & 3.0 & 3.0 & 3.0 & 3.0 & 3.0 \\
\hline Duct inside flat-to-flat distance $(\mathrm{cm})$ & 10.964 & 10.964 & 10.964 & 10.964 & 10.964 \\
\hline Duct Bundle Clearance ( $\mathrm{mm}$ ) & 0.05 & 0.05 & 0.05 & 0.05 & 0.05 \\
\hline Inter-assembly Gap (mm) & 3.0 & 3.0 & 3.0 & 3.0 & 3.0 \\
\hline Inlet coolant height $(\mathrm{cm})$ & 35.0 & 35.0 & N/A & N/A & 35.0 \\
\hline Lower reflector height $(\mathrm{cm})$ & 95.0 & 277.0 & N/A & N/A & 277.0 \\
\hline Fuel length $(\mathrm{cm})$ & 80.0 & 277.0 & N/A & N/A & 277.0 \\
\hline Fission gas plenum (flooded) height (cm) & 12.0 & 277.0 & N/A & N/A & 277.0 \\
\hline Fission gas plenum (empty) height (cm) & 40.0 & 277.0 & N/A & N/A & 277.0 \\
\hline Upper shield height (cm) & 50.0 & 277.0 & N/A & N/A & 277.0 \\
\hline Outlet coolant height $(\mathrm{cm})$ & 30.0 & 30.0 & N/A & N/A & 30.0 \\
\hline
\end{tabular}

For the purpose of the preconceptual design activity, the test locations have been modeled as entirely filled with sodium when determining the core neutronics performance characteristics, in order to maximize the neutron leakage probability and therefore the $\mathrm{Pu} w \mathrm{t} \%$ required in the fuel. For the safety analyses, including calculation of reactivity coefficients, the test locations have been filled will reflector assemblies in order to minimize the neutron leakage probability and not to overestimate the favorable effect resulting from sodium voiding.

The reactor is to be operated in a three-fuel batch management scheme with a cycle length of 100 effective full power days (EFPD). At the end of a cycle, one third of the fuel assemblies, having the highest burnup, are discharged and replaced with fresh fuel assemblies. The fuel assemblies remaining in the core are not shuffled. In order to keep the simulation relatively simple and limit computation time, the fuel management scheme is not represented discretely. Instead, any given fuel assembly has a composition corresponding to the average of that of a fresh fuel assembly, of an assembly having resided in the core one cycle, and of an assembly having resided in the core two cycles. This approach, although not realistic, is commonly used to model fast reactors as it is practical and core performance characteristics obtained have been shown to be very close to those obtained with a discrete fuel management model.

Although the proposed cycle length for FASTER is 100 days, by using a plutonium weight fraction of $20 \%$ instead of the $19.4 \%$ currently used, it would be possible to increase the cycle length to about 135 days. In fact the cycle length will be dependent on the type of materials 
present in the test locations. If strongly absorbing materials are present, especially in the locations near the core center, the core reactivity will likely become lower than unity before the intended 100 days, assuming the plutonium weight fraction used in the fuel is unchanged. There are a number of approaches to overcome this effect which, for instance, includes replacing more than $1 / 3$ rd of the fuel assemblies every cycle. However, a new analysis will need to be performed for every new experiment being loaded in the FASTER core to determine the core performance and ensure its safe behavior.

The height of the fission gas plenum is not directly proportional to the active fuel height. Since the bond sodium, initially located between the fuel and the cladding, is squeezed out of the active core region, it ends up in the lower region of the fission gas plenum. Fission gas will accumulate in the upper region of the plenum, and this available space is typically proportional to the fuel active length and peak burnup expected. Typically, for fuel reaching $100 \mathrm{GWd} / \mathrm{t}$ and having an active length of $100 \mathrm{~cm}$, the fission gas plenum is assumed to be approximately $125 \mathrm{~cm}$, and the bond sodium occupies up to $25 \mathrm{~cm}$ of that plenum, leaving about $100 \mathrm{~cm}$ for the fission gases equal to the active fuel length. In case of FASTER, the active fuel length is $80 \mathrm{~cm}$ and the peak burnup is only $\sim 45 \mathrm{GWd} / \mathrm{t}$, which mean that the plenum length needed for the fission products is about $36 \mathrm{~cm}$. Due to the $85 \%$ smear density used, the displaced bond sodium will occupy about $12 \mathrm{~cm}$ of the plenum length (shown in Table 1-1). In order to account for the axial fuel swelling and larger fuel density (compared to U-10Zr) the total plenum length is taken to be $52 \mathrm{~cm}$.

\subsubsection{Reactor Performance Characteristics}

The core performance characteristics at equilibrium are provided in Table 3-2. It should be noted that most of those characteristics will vary slightly based on the type and amount of materials loaded in the test locations, in particular those located in the active core region. In practice, a new core analysis will be required for every new core configuration, including each time a new test assembly is inserted. The results presented in this section have been obtained by modeling an empty assembly duct in all the test locations such as to maximize the neutron leakage probability and therefore determine the higher bound for the required plutonium weight fraction. This is a conservative assumption with the exception that when highly absorbing test assemblies are inserted, the required plutonium weight fraction will be larger, or the achievable cycle length reduced. Except in the case where highly absorbing materials are tested, the core performance characteristics reported here are not expected to vary significantly. The reactor power level of $300 \mathrm{MW}_{\mathrm{t}}$ is the minimum that assures that the neutron flux goals can be met.

The required Pu wt $\%$ is $19.4 \%$, which is slightly lower than the $20 \%$ limit used. The average fuel discharge burnup is about $34 \mathrm{GWd} / \mathrm{t}$ while the peak discharge burnup is less than $50 \mathrm{GWd} / \mathrm{t}$. This is consistent with the assumptions made for the fuel smear density and plenum length, which were based on a low fuel burnup. Fuel burnup could be increased by up to $35 \%$ by increasing the plutonium weight fraction and the cycle length or number of fuel batches used. However, the fuel considered has a high smear density and short fission gas plenum which are both related to the peak burnup the fuel is expected to experience. Although increasing fuel burnup could reduce fuel cost, it might make it necessary to use a longer fission gas plenum (increasing the total reactor height) and lower smear density. 
It is important to note that the average core power density is approximately $560 \mathrm{~W} / \mathrm{cm}^{3}$ over the active fuel region. When normalized only over the fuel volume, this corresponds to an average power density of $1580 \mathrm{~W} / \mathrm{cm}^{3}$ and a peak value of almost $3000 \mathrm{~W} / \mathrm{cm}^{3}$. This is larger than what is typically observed in SFRs, and proper cooling of the core will need to be ensured. The thermal flux provided in Table 3-2 is calculated for the moderated region.

The core power density distribution is shown in Figure 3-2, and since almost no energy is deposited in the moderated region it is not visible in this figure. It is also observed that the peak value is reached at the core center and not at the interface between the fast and moderated region, indicating that no thermal neutrons are returning from the moderated region. The empty locations shown in this figure correspond to the test assemblies and reactivity control assembly locations since only little power is deposited in those assemblies. It is worth noting that the peak power density value shown in Figure 3-2 is lower than the value reported in Table 3-2 which is due to the coarse mesh used in the figure. The figure shows the average power density each mesh volume and does not account for the peaking within that volume.

Table 3-2: Core Performance Characteristics

\begin{tabular}{lc}
\hline Characteristic & FASTER \\
\hline Nominal power, $M W_{t}$ & 300 \\
Required enrichment & $19.41 \%$ \\
BOC/EOC $k_{\text {eff }}$ & $1.02672 / 1.00080$ \\
Average discharge burnup, $\mathrm{GWd} / \mathrm{t}$ & 34.3 \\
Total HM mass, $\mathrm{kg}$ & 2621 \\
HM charge per cycle, $\mathrm{kg}$ & 874 \\
Average power density, $\mathrm{W} / \mathrm{cm}^{3}$ & 558.8 \\
Peak power density, $\mathrm{W} / \mathrm{cm}^{3}$ & 917.0 \\
Specific power, $\mathrm{W} / \mathrm{g}$ & 114.5 \\
Average linear power, $\mathrm{kW} / \mathrm{m}$ & 25.2 \\
Axial/radial leakage & $11.36 \% / 30.17 \%$ \\
Total flux, $10^{15} \mathrm{n} / \mathrm{cm}^{2}-\mathrm{s}$ & 3.74 \\
Peak total flux, $10^{15} \mathrm{n} / \mathrm{cm}^{2}-\mathrm{s}$ & 6.78 \\
Fast flux $(>0.1 \mathrm{MeV}), 10^{15} \mathrm{n} / \mathrm{cm}^{2}-\mathrm{s}$ & 2.70 \\
Peak fast flux $(>0.1 \mathrm{MeV}), 10^{15} \mathrm{n} / \mathrm{cm}^{2}-\mathrm{s}$ & 5.19 \\
Peak thermal flux $(<0.1 \mathrm{eV}), 10^{14} \mathrm{n}_{\mathrm{cm}}{ }^{-s}$ & 6.19 \\
Peak thermal flux $(<0.625 \mathrm{eV}), 10^{14} \mathrm{n}_{\mathrm{cm}}^{2}-\mathrm{s}$ & $>12.0$ \\
\hline
\end{tabular}

The fast flux and thermal flux distributions are shown together in Figure 3-3. Note that different scales are used in the two regions. The thermal flux is only significant on the right-end side of the figure, corresponding to the moderated region of the core, while the fast flux is only largest in the active core region where neutrons are produced. Although not shown in Figure 3-3 because of the threshold value used, the fast flux remains significant in the entire reflector region. It is reduced by a factor of $\sim 50$ between its peak value at the core center and the values observed in the test assemblies located the farthest away from the core center (i.e., in the 
reflector). One can observe flux depressions near the core center which are caused by the test and reactivity control assemblies. At the interface between the fast flux and thermal flux regions, it is observed that the fast flux is being reduced very abruptly (compared to the opposite side) due to the moderating material used in the thermal region.

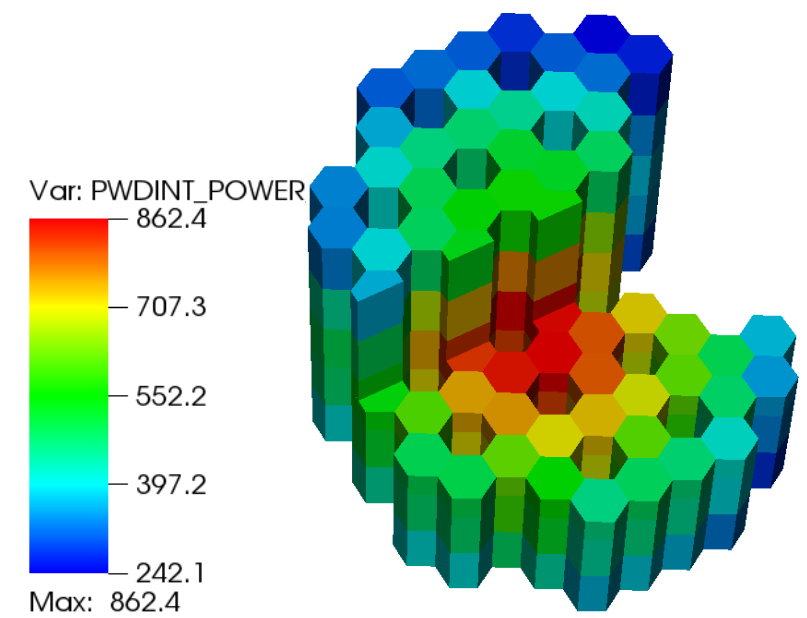

Figure 3-2: Power Density Distribution (in $\mathrm{W} / \mathrm{cm}^{3}$ )

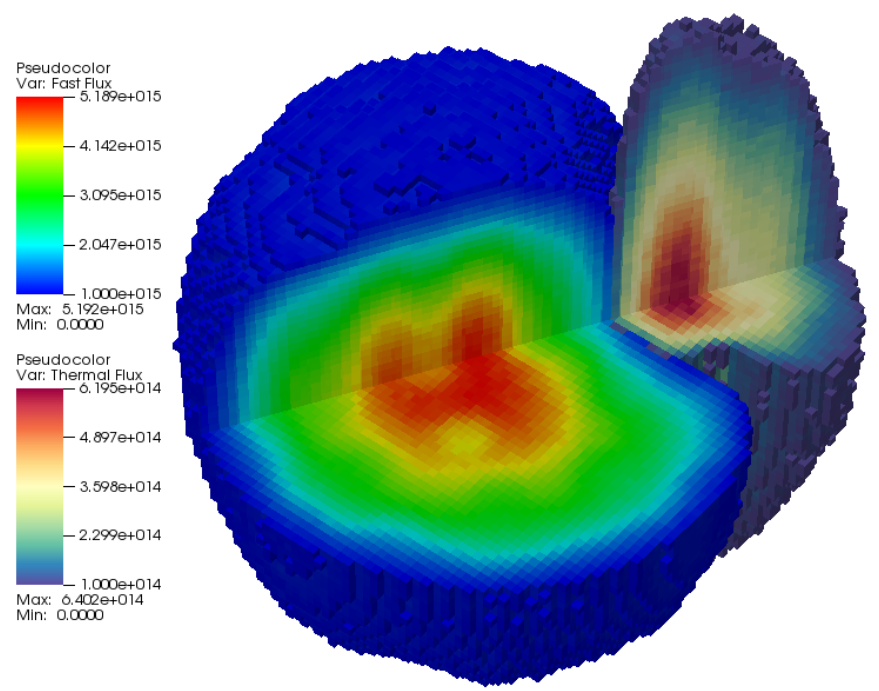

Figure 3-3: Fast and Thermal Flux Distributions (in n/cm²-s)

The only region in which a significant thermal flux is observed is the moderated region. All neutrons present in this region are neutrons leaking from the active core region and being moderated. Although this region is not fully optimized, a peak thermal flux of at least $6.0 \times 10^{14}$ $\mathrm{n} / \mathrm{cm}^{2}$-s is achievable solely by using leaking neutrons. In this study, the energy threshold used for thermal neutrons is assumed to be $0.1 \mathrm{eV}$. However, the metrics used to evaluate the test reactor performance later stated that the threshold energy for thermal neutrons should be taken as $0.625 \mathrm{eV}$. This means that the thermal fluxes claimed in this document are conservative and would be two to three times larger when using the energy threshold stated in the main Advanced Test Demo Reactor (ATDR) study (to be published). 


\subsubsection{Neutron Thermalization}

One of the unique features of FASTER is its ability to offer both a very high fast flux and very high thermal flux for irradiation purposes. Although high fast fluxes are common features of fast reactors, the thermal flux in these systems is usually negligible. FASTER is taking advantage of its very compact core configuration, resulting in a very large neutron leakage probability, to thermalize some of the leaking neutrons and enable thermal flux irradiation capabilities.

The first key consideration to achieve this objective is to identify materials that enable achievement of the desired neutron moderation. The second key consideration is to ensure that no thermalized neutrons are returning into the fuel region in order to prevent very large power peaking which would result in fuel melting.

Numerous parametric studies have been performed with a simple core model in order to assess the performance expected when using graphite, beryllium, or yttrium-hydride as moderators. The impact of the buffer thickness and moderator thickness of the flux levels has also been assessed as part of the parametric studies. The buffer region is located in a layer of material between the fuel region and the moderated region. Its function is to allow fast neutrons to leak through but act as a sink for thermal neutrons. It was found that using one layer of reflector assemblies (mostly containing HT-9) makes for a sufficient buffer. Iron isotopes have a low capture cross-section in the fast energy range but have a significant capture cross-section in the thermal energy range. This is the reason HT-9 is used as cladding in fast reactors and that light water reactors are using iron-free alloys.

Regarding the material used for neutron thermalization, it was found that when graphite is used, a very large amount is needed, resulting in very large volume. As beryllium has a significantly larger moderating power than graphite, a smaller volume of it is required to achieve the desired neutron thermalization. Having one or two rows of assemblies made mostly of beryllium ( $\sim 60 \%$ vol. fraction) between the buffer and the thermal test locations was found to create thermal fluxes on the order of $10^{15} \mathrm{n} / \mathrm{cm}^{2}$-s and higher. The last material considered is yttrium-hydride. It has a very strong moderating power and it was found that when a single row of assemblies containing large amounts of yttrium-hydride is located between the buffer and the thermal test location too much moderation is achieved and thermalized neutrons having very low energies are immediately absorbed, making for poor irradiation conditions. By significantly reducing the amount of yttrium-hydride contained in the assemblies (to $<10 \%$ vol. fraction) thermal flux levels comparable to those obtained with beryllium were generated. These results regarding yttrium-hydride are not surprising as this material was considered for use in FFTF as a means to thermalize neutrons at the pin level and enable medical isotope production in the pin.

\subsubsection{Reactivity Coefficients and Quasi-Static Balance}

The reactivity worth of the primary and secondary control rod assemblies (PCRA and SCRA) has been determined for the FASTER core in order to ensure that the core can be safely shut down from any operating condition. All nine control rods present in the core are composed of a $90 \mathrm{~cm}$ tall region containing a $47.58 \%$ by volume of $\mathrm{B}_{4} \mathrm{C}$, as well as $29.4 \%$ sodium and $23.1 \%$ HT-9. The $\mathrm{B}_{4} \mathrm{C}$ is assumed to have an $85 \%$ smear density (i.e., the effective $\mathrm{B}_{4} \mathrm{C}$ vol\% is $39.8 \%$ ). Natural boron is used in both the primary and secondary control systems. The length of absorbing material in the control elements is purposely $10 \mathrm{~cm}$ longer than the height of the active 
fuel region. This is done in part to make up for the irradiation fuel swelling as well as due to the fact that fast neutrons do not get absorbed as soon as they leak out of the fuel region. This results in slightly more reactivity worth than if the absorbing material was equal to the active fuel height. During nominal operations, the secondary control rods are fully withdrawn and only the primary control rods are used to compensate for the burnup reactivity swing. In fact, when control rods are located exactly at the top of the active core region (i.e. such should be the case at the end of a cycle), withdrawing them further would result in a small increase of the core reactivity which could be useful if the core was to run out of reactivity sooner than anticipated as a result of uncertainties. This is assuming that control rod mechanism has been design to allow withdrawing control rods past the top of the active core region.

At the beginning of the equilibrium cycle (BOEC), the PCRAs need to be inserted by approximately $34 \mathrm{~cm}$ to make up for the initial excess reactivity, and by the end of the equilibrium cycle (EOEC) PCRAs are fully withdrawn from the core. Although the requirement is that any of the control systems must be able to safely shut down the core with the highest worth control rod being stuck in the operating condition, the total worth of each system has also been evaluated when no rod is stuck. The results are shown in Table 3-3. For the rod having the highest worth, the single rod worth for the primary system is about $3.9 \$$ and it is about $4.9 \$$ for the secondary system. The single rod worth and the total core reactivity as a function of the control rods position are shown at BOEC in Figure 3-4 for the primary reactivity control system and in Figure 3-5 for the secondary reactivity control system. The secondary system having one of its control rod nearer to the core center than the primary system, its maximum single rod worth for the secondary system is larger.

Table 3-3: Reactivity Worth of the Primary and Secondary Control Systems

\begin{tabular}{lcc}
\hline Control Rod System & $\begin{array}{c}\text { Worth at } \\
\text { BOEC } \mathbf{( \$ )}\end{array}$ & $\begin{array}{c}\text { Worth at } \\
\text { EOEC } \mathbf{( \$ )}\end{array}$ \\
\hline Primary & 21.1 & 22.0 \\
Primary -rod stuck & 17.3 & 17.9 \\
Secondary & 10.6 & 11.2 \\
Secondary -rod stuck & 5.7 & 6.1 \\
\hline
\end{tabular}




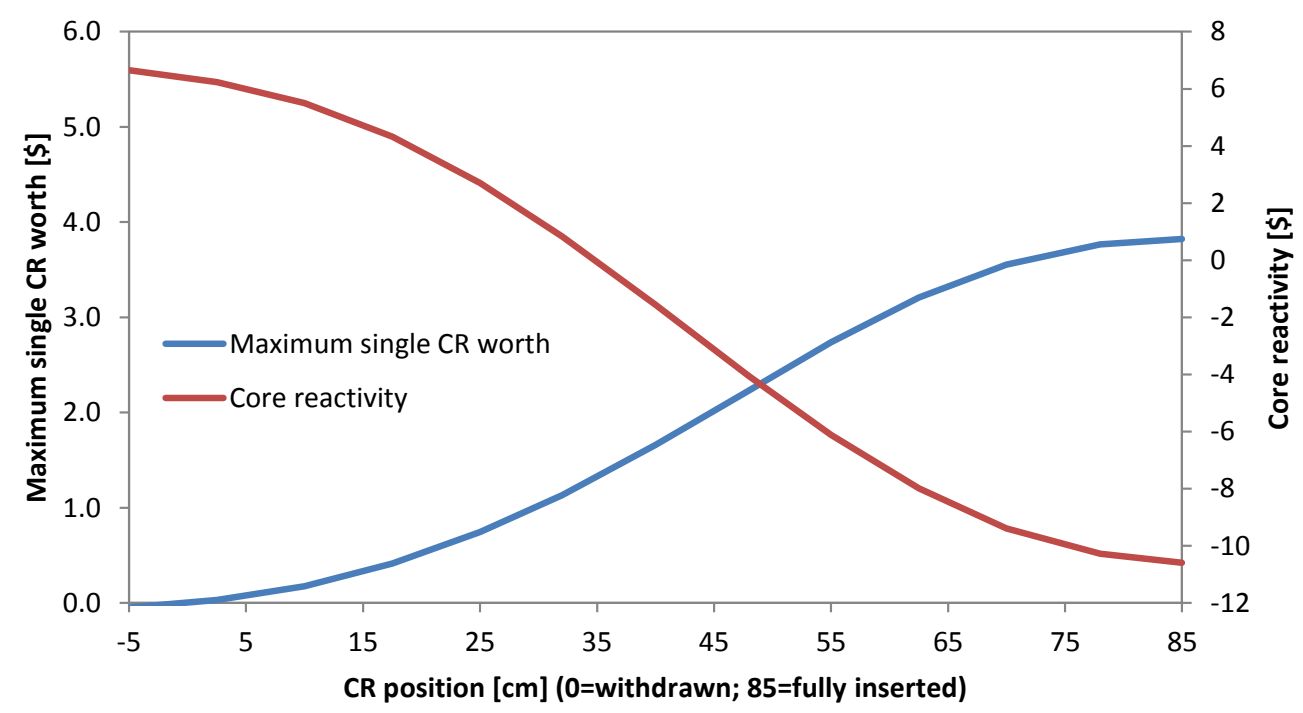

Figure 3-4: Single Rod Worth and Core Reactivity for the Primary Control System

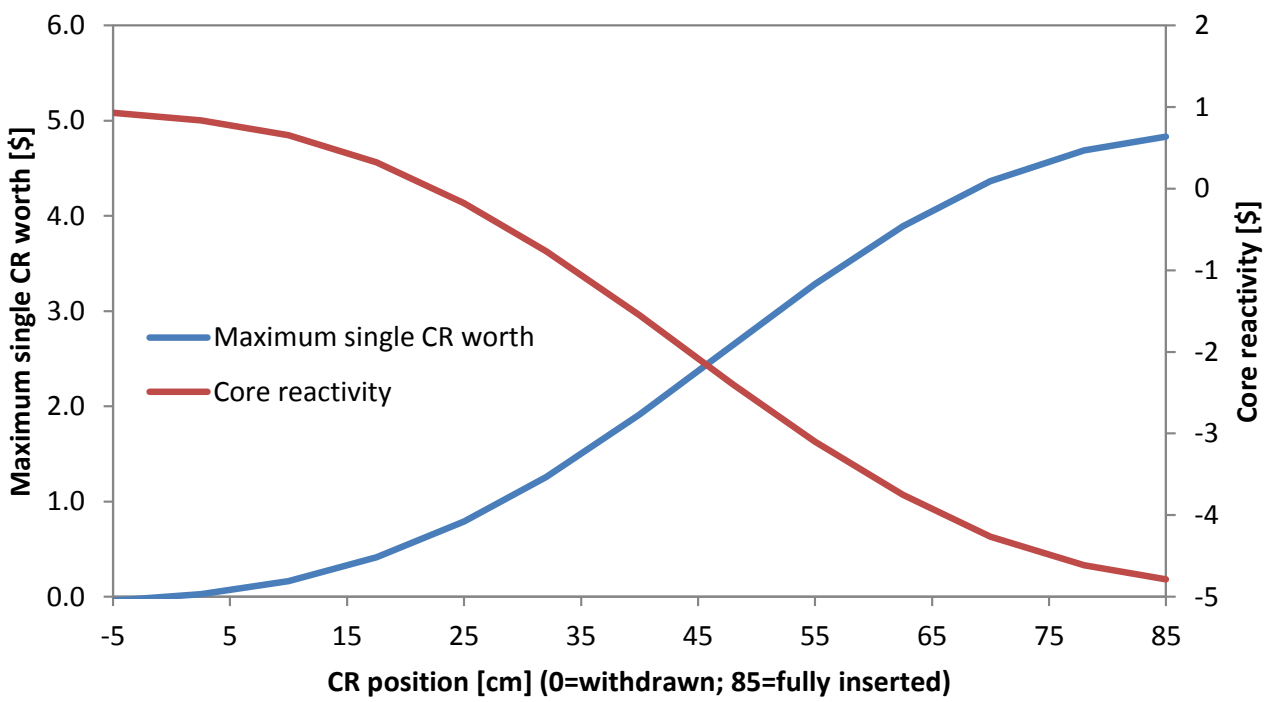

Figure 3-5: Single Rod Worth and Core Reactivity for the Secondary Control System

The methodology used to determine the shutdown margins for each reactivity control system is not detailed here, but it is the methodology typically used for fast reactor analysis. In particular, it accounts for the reactivity change between the "resting state of the core" and its operating condition, for a single rod reactivity fault (ejection), considering uncertainties and a number of other factors. The detailed worths, total worth requirement, and shutdown margins, with the highest worth control rod being stuck, are provided in Table 3-4 for the primary control system and in Figure 3-5 for the secondary control system. As the function of the secondary system is not to compensate for the initial excess reactivity of the fuel ("burnup reactivity swing"), the total worth requirements are significantly smaller than for the primary control system. Given that the core has the most excess reactivity at BOEC, this is when the shutdown margins are the smallest. The margins obtained are large and could allow for reducing the $\mathrm{B}_{4} \mathrm{C}$ volume fraction used, if needed. 
Table 3-4: Reactivity Worths and Shutdown Margins of the Primary Control System

\begin{tabular}{lcc}
\hline Primary system (\$) & BOEC & EOEC \\
\hline Worth All in & 21.13 & 21.97 \\
Worth All in except one (stuck) & 18.38 & 17.98 \\
HFP to CZP - temperature defect & 1.91 & 1.93 \\
Overpower (+15\%) - 15\% of HFP to HZP & 0.11 & 0.11 \\
\hline Excess reactivity & 9.05 & 0.29 \\
Burnup & 7.83 & 0.29 \\
Axial growth (<4\%) & 1.22 & 0 \\
\hline Uncertainties & 2.98 & 0.47 \\
Temperature defect (20\%) & 0.38 & 0.39 \\
Burnup reactivity (30\%) & 2.35 & 0.09 \\
Fuel axial growth (20\%) & 0.24 & 0.00 \\
\hline Reactivity fault (CR withdrawn) & 1.13 & 0.03 \\
\hline Maximum worth requirement & 15.18 & 2.84 \\
\hline Shutdown margin & $\mathbf{3 . 2 1}$ & $\mathbf{1 5 . 1 4}$ \\
\hline
\end{tabular}

Table 3-5: Reactivity Worths and Shutdown Margins of the Secondary Control System

\begin{tabular}{lcc}
\hline Secondary system (\$) & BOEC & EOEC \\
\hline Worth All in & 10.59 & 11.25 \\
Worth All in except one (stuck) & 5.72 & 6.08 \\
HFP to HZP - temperature defect & 0.74 & 0.75 \\
Overpower (+15\%) - 15\% of temperature defect & 0.11 & 0.11 \\
\hline Uncertainties & 0.15 & 0.15 \\
$\quad$ Temperature defect (20\%) & 0.15 & 0.15 \\
\hline Reactivity fault (CR withdrawn) & 1.13 & 0 \\
\hline Maximum worth requirement & 2.13 & 1.04 \\
\hline Shutdown margin & $\mathbf{3 . 5 9}$ & $\mathbf{5 . 0 4}$ \\
\hline
\end{tabular}

The reactivity coefficients required for the safety analysis have been determined at BOEC and EOEC using the PERSENT [8] code coupled with DIF3D [9]. Although not detailed here, the assumptions used for determining these coefficients are commonly used for fast reactor analysis. The various reactivity coefficients calculated are summarized in Table 3-6. It is important to note that the sodium void worth is negative during the entire cycle despite using Pu-based fuel. This is due to the very large neutron leakage probability and high quality Pu being used. Another noteworthy reactivity coefficient is the radial expansion which is observed to be very negative due the active fuel region having a relatively small height-to-diameter ratio and very large neutron leakage probability. Other reactivity coefficients are typical of a SFR fueled with metal fuel. 
Table 3-6: FASTER Reactivity Coefficients

\begin{tabular}{lcc}
\hline & BOEC & EOEC \\
\hline$\beta_{\text {eff }}$ & 0.00332 & 0.00333 \\
Prompt Lifetime, $\mu$ s & 0.349 & 0.373 \\
Generation Time, $\mu$ s & 0.348 & 0.373 \\
Radial Expansion, cent $/{ }^{\circ}$ C & -0.445 & -0.451 \\
Axial Expansion, cent $/{ }^{\circ}$ C & -0.126 & -0.118 \\
Sodium Void Worth, $\$$ & -2.242 & -2.420 \\
Sodium Density, cent $/{ }^{\circ} \mathrm{C}$ & -0.063 & -0.067 \\
Doppler, cent $/{ }^{\circ} \mathrm{C}$ & -0.109 & -0.119 \\
Sodium Voided Doppler, cent $/{ }^{\circ} \mathrm{C}$ & -0.089 & -0.097 \\
Fuel Density, cent $/{ }^{\circ} \mathrm{C}$ & -0.820 & -0.800 \\
Structure Density, cent $/{ }^{\circ} \mathrm{C}$ & 0.009 & 0.010 \\
\hline
\end{tabular}

The quasi-static reactivity balance [10] has been performed for the FASTER core, using the reactivity coefficients previously discussed. The results are provided in Table 3-7. The single rod reactivity fault, $\Delta \rho$, is approximately $1.13 \$$ at BOEC and nearly $0.0 \$$ at EOEC. Although the results indicate that all three required conditions are met and that the core is expected to be inherently safe, it may still be necessary to use control rod stops in order to reduce the single rod reactivity fault and limit the maximum temperatures reached during unprotected transients.

Table 3-7: Quasi-static Reactivity Balance Coefficients and Conditions

\begin{tabular}{lcc}
\hline Coefficients & & \\
\hline$A$ - Power/flow reactivity decrement (cents) & -33.9 & -34.2 \\
$B$ - Power/flow coefficient (cents) & -141.4 & -106.4 \\
$C$ - Inlet temperature coefficient $\left(\right.$ cents $\left./{ }^{\circ} C\right)$ & -1.4 & -0.9 \\
\hline Quasi-static reactivity conditions & & \\
\hline$A / B<=1$ & 0.24 & 0.32 \\
$l<=C D T_{C} / B<=2$ & 1.51 & 1.34 \\
$\Delta \rho /|B|<=1$ & 0.80 & 0.03 \\
\hline
\end{tabular}

\subsubsection{Test Locations}

In its current configuration (Figure 3-1), the FASTER core provides 33 fast flux test locations, three (3) thermal flux test locations, two (2) fast flux closed loops and one thermal flux closed loop. Among the fast spectrum test locations, four of them are located near the core center and cannot be repositioned without affecting the core neutronics performance. The other 29 fast flux test locations are located in the radial reflector region and their position can be changed without significantly affecting the core performance. In fact, any of the reflector assembly locations could be used as a test location without having any significant impact on the core performance. In a similar way, the number of thermal flux test locations could be increased by replacing reflector assemblies with moderator and thermal test assemblies. This would result in a reduction of the number of fast flux test locations. It is important to note that the closed loop and 
instrumented irradiation positions are fixed because the fuel handling machines and instrumentation trees have been designed around these fixed core positions.

The core assembly length is estimated to be $\sim 2.77 \mathrm{~m}$. The actual test length will depend on the test assembly design; in particular, the length of the lower adaptor and core handling socket. The likely resulting effective test length will be around two meters, corresponding to an available test volume of $\sim 24$ liters in each test location. The total test volume in the current core configuration is about $0.95 \mathrm{~m}^{3}$. The flux level achieved in a test assembly depends on its distance from the core center, as well as on its composition. Given that the materials to be tested are currently undetermined, the flux levels provided here were obtained when test locations are filled with a reflector assembly ( $80 \%$ steel, 20\% coolant). For the test assemblies located in the thermalized region, the steel was replaced with a zirconium-based alloy to prevent excess parasitic neutron capture in iron.

The normalized axial fast flux profile is shown in Figure 3-6 for a test assembly located in the active core region and for a test assembly located in the reflector region. This figure clearly illustrates the fact that the neutron flux does not suddenly decrease as neutrons are exiting the active fuel region. When taking an arbitrarily low flux level of 5\% the peak flux value, the usable irradiation length is approximately $170 \mathrm{~cm}$ for a test assembly located at the core center and approximately $200 \mathrm{~cm}$ for those located in the reflector region. The flux distribution expands axially with increasing distance from the fuel assemblies due to neutron leakage; while neutrons leak radially from the core, they also spread axially.

The characteristics of the fast flux test assemblies based on their flux values and their characteristics are summarized in Table 3-8. In order to provide a measure of the total irradiation capacity available, the total fast fluxes are multiplied by the test volumes. This captures the fact that the fast flux near the extremities of the test location is significantly smaller than near the center and that increasing the test length without increasing the active core length will not significantly increase the irradiation capacity.

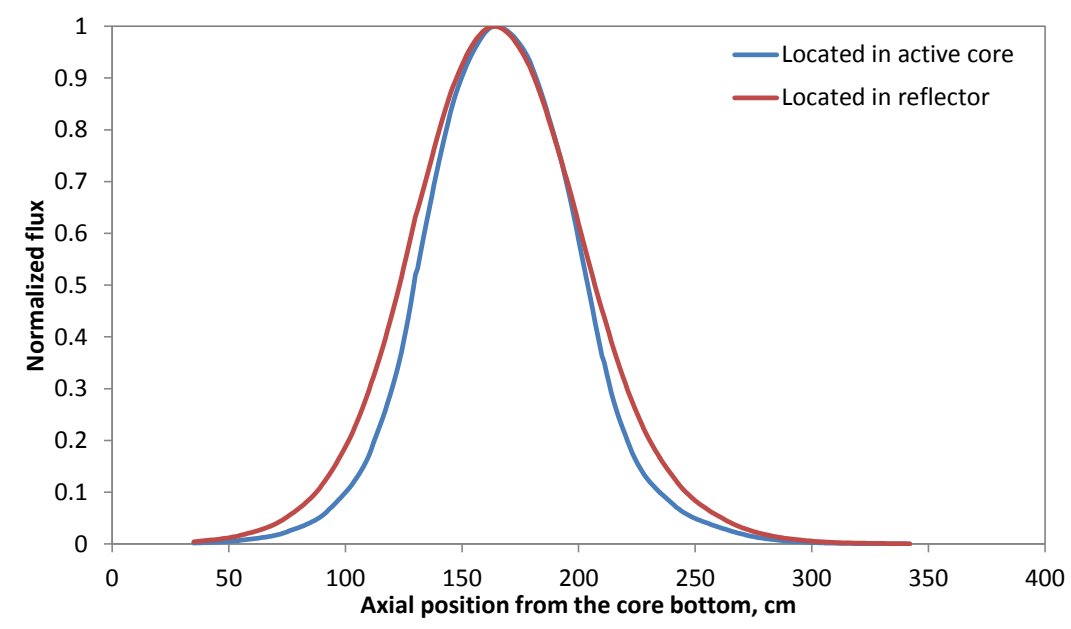

Figure 3-6: Normalized Axial Fast Flux Distribution in Test Locations 
Table 3-8: Summary of Fast Flux Conditions in the Test Assemblies

\begin{tabular}{lcccc}
\hline Group & $\begin{array}{c}\text { Number of } \\
\text { Assemblies }\end{array}$ & $\begin{array}{c}\text { Peak Fast Flux } \\
\text { Range } \\
\left(\mathbf{1 0}^{\mathbf{1 5}} \mathbf{n} / \mathbf{c m}^{\mathbf{2}} \cdot \mathbf{s}\right)\end{array}$ & $\begin{array}{c}\text { Fast Flux*Volume } \\
\text { Range } \\
\left(\mathbf{1 0}^{\mathbf{1 9}} \mathbf{n} \cdot \mathbf{c m} / \mathbf{s}\right)\end{array}$ & $\begin{array}{c}\text { Total Fast } \\
\text { Flux*Volume } \\
\left(\mathbf{1 0}^{\mathbf{1 9}} \mathbf{n} \cdot \mathbf{c m} / \mathbf{s}\right)\end{array}$ \\
\hline$A$ & 4 & $4.7-5.2$ & $4.0-4.9$ & 17.9 \\
Closed Loops & 2 & 2.3 & 1.7 & 3.4 \\
$B$ & 10 & $1.9-2.7$ & $1.4-2.1$ & 15.8 \\
$C$ & 19 & $0.3-1.3$ & $0.2-0.9$ & 10.3 \\
\hline
\end{tabular}

In the thermal flux test assemblies and thermal closed loop, the fast flux level is not relevant and the thermal flux level is provided instead. It is important to note that the thermal neutrons were defined as all neutrons having an energy lower than $0.1 \mathrm{eV}$. By using the energy threshold later established as part of the ATDR study framework $(0.625 \mathrm{eV})$, these thermal flux values would be two to three times larger.

The peak thermal flux values calculated in the closed loop and three test assemblies located in the moderated region are provided in Table 3-9 for each location individually. The peak value is typically achieved near the side of the assembly that is facing the active core region (i.e., where the neutrons originate from). The thermal flux is radially reduced by a factor of $\sim 2$ across an assembly, for a given axial position. The normalized axial thermal flux distribution is shown in Figure 3-7. The rough aspect of the curve is due to the uncertainties of the calculations performed with MCNP.

Table 3-9: Summary of Thermal Flux Conditions in the Test Assemblies

\begin{tabular}{lcc}
\hline Location & $\begin{array}{c}\text { Peak Thermal Flux } \\
\left(\mathbf{1 0}^{\mathbf{1 4}} \mathbf{~} / \mathbf{c m}^{\mathbf{2}} \cdot \mathbf{s}\right)\end{array}$ & $\begin{array}{c}\text { Thermal Flux*Volume } \\
\left(\mathbf{1 0}^{\mathbf{1 8}} \mathbf{n} / \mathbf{c m}^{\mathbf{2}} \cdot \mathbf{s}\right)\end{array}$ \\
\hline Closed loop & 5.8 & 3.7 \\
A1 & 1.9 & 1.2 \\
A2 & 1.9 & 1.2 \\
$B$ & 1.7 & 1.1 \\
\hline
\end{tabular}




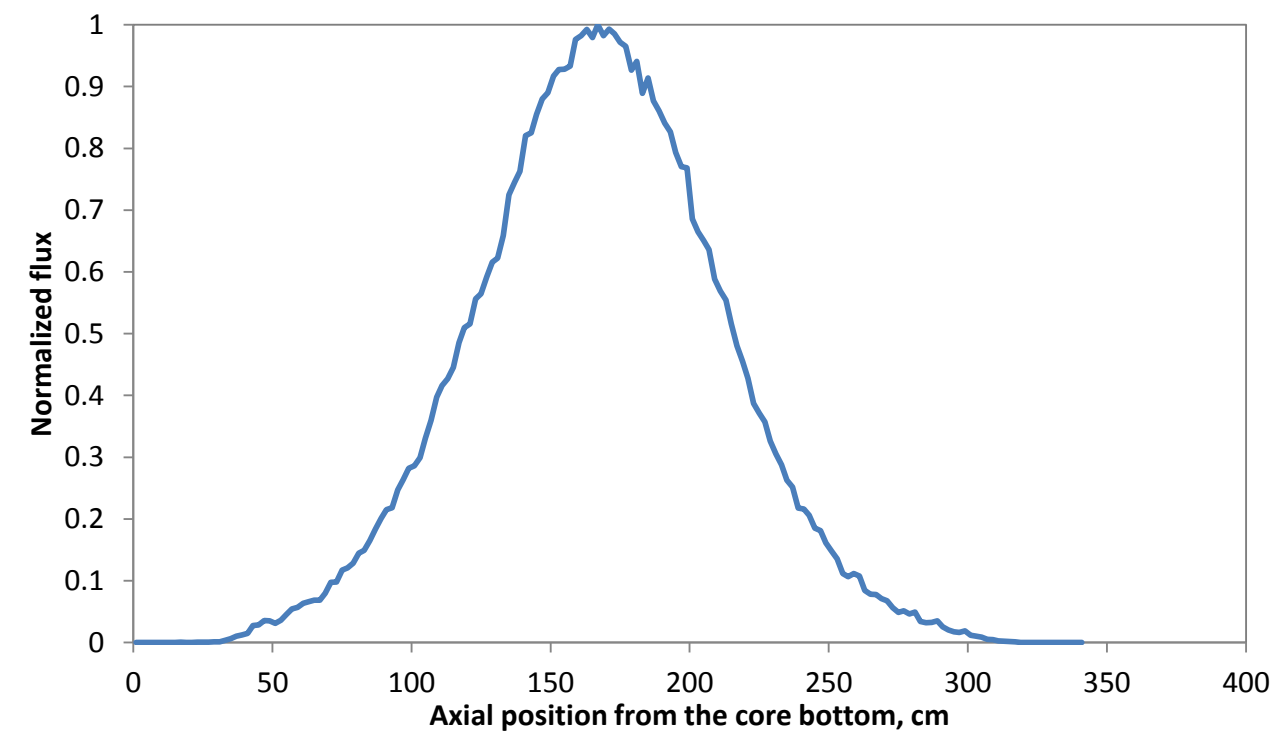

Figure 3-7: Normalized Axial Thermal Flux Distribution in the Test Locations

The neutron spectrum obtained in the test assembly nearest the core center is compared to the spectrum obtained for a test assembly located in the thermalized region in Figure 3-8. In this figure the vertical lines indicate the various energy thresholds used, that is $0.1 \mathrm{eV}$ and $0.625 \mathrm{eV}$ for the thermal energy upper threshold, and $0.1 \mathrm{MeV}$ for the fast energy lower threshold. In the test assembly located in the fast flux region, the spectrum is typical of an SFR with more than $70 \%$ of the neutrons in the fast energy range and virtually no neutrons in the thermal energy range. For the test assembly located in the thermalized region, only about $6 \%$ of the neutrons are fast, and most of the neutrons are in the epithermal region. Using the $0.1 \mathrm{eV}$ threshold, about $13 \%$ of neutrons are thermal. By using the $0.625 \mathrm{eV}$ threshold, this fraction goes up to about $35 \%$. The fact that almost no neutrons are in the fast energy range is due to the fact that no neutrons are produced in the thermalized region, and they have been thermalized before reaching the test assembly. 


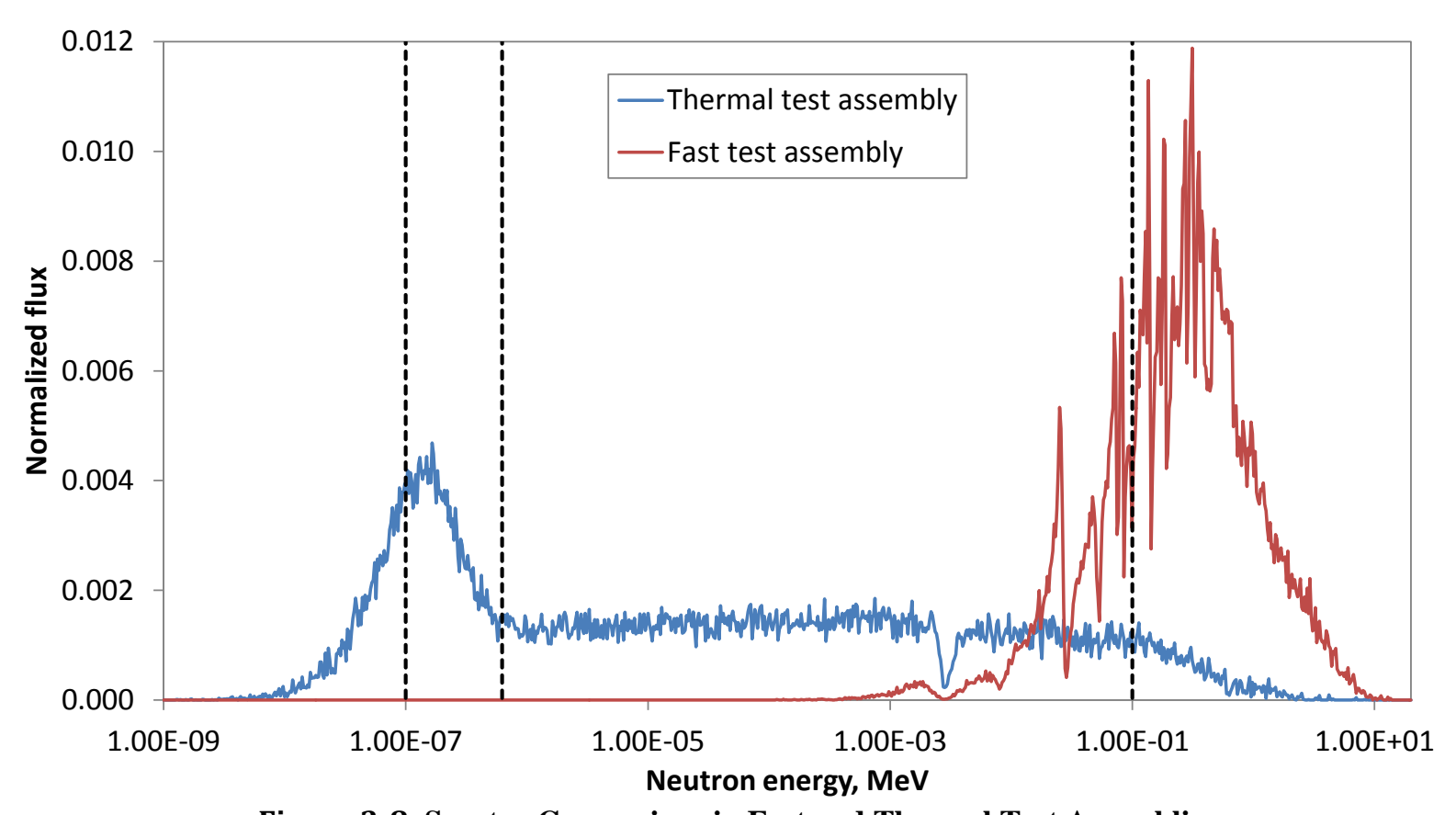

Figure 3-8: Spectra Comparison in Fast and Thermal Test Assemblies

\subsubsection{Closed Loops}

The three closed loop systems are an important capability of FASTER. They enable FASTER to be utilized to irradiate and test fuels and materials in a prototypical flowing coolant environment with different coolants of different reactor types. The closed loop testing capability goes beyond just fuels and materials testing. Each closed loop system, with a different coolant, is a demonstration of that coolant and its technology inside of an operating nuclear reactor. Thus, one has an integrated demonstration of fuel, core materials, coolant, coolant chemistry control, and optionally coolant cleanup technologies under prototypical conditions and either a fast or thermalized neutron spectrum, as appropriate. For a different reactor coolant than sodium, this can be a test and demonstration as well as an approach to raise the Technology Readiness Levels (TRLs) for the fuel, materials, and coolant technologies for far less cost than designing, building, and operating a separate nuclear reactor with those fuel, materials, and coolant technologies. The closed loop approach might reveal unanticipated problems with a different reactor technology for far less expense than designing, building, and operating a separate reactor.

While the principal purpose of the closed loops is testing under normal steady state operating conditions, the closed loops system approach also enables transient testing by changing the closed loop primary coolant flowrate, the heat removal from the closed loop primary coolant, or the reactor core power in the vicinity of the closed loop test section. Transient testing including melting of fuel was a capability of the Fast Flux Test Facility (FFTF) closed loop system design.

Closed loops incorporating sodium were an integral part of the FFTF design [11,3] that could have simultaneously incorporated four such closed loops. Two integrated closed loop primary modules were built and one was installed in a cell inerted with nitrogen inside of the FFTF containment. None of the closed loops at FFTF were actually used, however. The FFTF closed loops incorporated sodium coolant and that may have been a factor in their lack of use as 
irradiation of fuels and materials in a fast neutron spectrum could still be performed in sodium without a closed loop. However, for irradiation and testing with flowing coolants other than sodium, the closed loop approach is essential. Pressurized water closed loops are also an integral part of the Advanced Test Reactor (ATR) design and are utilized for irradiation and testing [12].

For each of the FFTF closed loops, a Closed Loop In-Reactor Assembly (CLIRA) would be installed inside of the reactor. Inside of the CLIRA, a test section (e.g., a hexcan with wirewrapped fuel pins arranged on a triangular pitch) was envisioned to fit inside of a surrounding innermost flow tube having a $6.985 \mathrm{~cm}(2.75 \mathrm{inch})$ inner diameter [11]. The heat rejection rate capability per closed loop was $2.3 \mathrm{MW}_{\mathrm{t}}$ of which $2.0 \mathrm{MW}_{\mathrm{t}}$ could be removed from the test section [11]. The FFTF closed loop systems were designed and incorporated features that could later enable the heat rejection per loop to be increased to $4.3 \mathrm{MW}_{\mathrm{t}}$. Specifically, many of the components could still be utilized while the interconnecting 3 inch sodium piping could be cut off at the nozzles and replaced by 4 inch piping to facilitate transport of a greater power. Each FFTF closed loop system could provide a primary sodium flowrate of 1.44 to $16.5 \mathrm{~kg} / \mathrm{s}$ equivalent to 0.00167 to $0.0192 \mathrm{~m}^{3} / \mathrm{s}$ (26.5 to $305 \mathrm{gpm}$ ). The FFTF maximum closed loop system, primary sodium coolant test section outlet temperature was $760^{\circ} \mathrm{C}\left(1400^{\circ} \mathrm{F}\right)$, although the maximum mean mixed outlet temperature from a CLIRA housing the test section was $649^{\circ} \mathrm{C}$ $\left(1200^{\circ} \mathrm{F}\right.$ ). Higher temperatures inside of the test section (up to $760^{\circ} \mathrm{C}$ ) that exceed the design temperature of the primary sodium module $\left(649^{\circ} \mathrm{C}\right)$ would be achieved by bypassing part of the upward cooler inlet sodium flow through an annulus outside of the innermost flow tube surrounding the test section, and intermixing hotter sodium exiting the test section with the cooler bypass sodium to reduce the intermixed sodium temperature. The maximum sodium coolant temperature rise through a test section was $222^{\circ} \mathrm{C}\left(400^{\circ} \mathrm{F}\right)$. The closed loop system secondary sodium-to-air heat exchanger was designed for a secondary sodium inlet temperature of $327^{\circ} \mathrm{C}\left(620^{\circ} \mathrm{F}\right)$ and a secondary sodium outlet temperature of $216^{\circ} \mathrm{C}\left(420^{\circ} \mathrm{F}\right)$ at the maximum sodium flowrate $(16.5 \mathrm{~kg} / \mathrm{s})$.

The FASTER closed loop system for each alternative coolant incorporates an in-reactor assembly with a test section, a primary loop with the particular coolant for irradiation and testing, a secondary loop with an appropriate secondary coolant for heat transport, a primary coolant-to-secondary coolant Intermediate Heat Exchanger (IHX), a secondary coolant-to-air Dump Heat Exchanger (DHX) for heat rejection to the atmosphere heat sink, and interconnecting piping.

\subsubsection{Closed Loop Heat Rejection Rate Requirements for Different Coolants and Different Reactor Types}

For FASTER, heat removal requirements for different coolants and reactor configurations were investigated assuming that each closed loop can accommodate a test section inside of a flow tube having an inner diameter of $6.985 \mathrm{~cm}(2.75 \mathrm{inch})$ and a closed loop heat rejection rate capability of $2.3 \mathrm{MW}_{\mathrm{t}}$ per loop, the same as the closed loop system design for FFTF [11].

Results of the investigation of heat rejection rate requirements for alternate primary coolants and different reactor types are shown in Table 3-10. It is assumed that for each coolant and reactor type that a small portion of a core is simulated across the available cross-sectional area inside of the flow tube. It is found that a key factor is the flow area fraction through the core. For a fixed 
coolant velocity in the core, those designs having a greater flow area fraction can remove a greater power due to the greater coolant flowrate. For sodium coolant, the core design and conditions for the KAERI-ANL Prototype Generation IV Sodium-Cooled Fast Reactor (PGSFR) are assumed as typical of advanced SFR core designs. The flow area fraction of 0.38 is typical of SFR core designs that typically have a high power density. For nominal steady state temperature and velocity conditions, the required heat removal rate capability from the core mockup is 1.3 $\mathrm{MW}_{\mathrm{t}}$. This fits well within the assumed $2.0 \mathrm{MW}_{\mathrm{t}}$ envelope. The required volumetric flowrate is also well within the assumed loop capability.

For the sodium PGSFR design, simulation of postulated accident conditions inside of a closed loop is also of interest. As an example, for an assumed unprotected transient overpower accident involving the insertion of 30 cents of reactivity over 15 seconds, the reactor eventually transitions to a new quasi-steady state at a higher power. The core outlet temperature rises to a transient peak value of $738^{\circ} \mathrm{C}$ and then falls to a quasi-steady value of $670^{\circ} \mathrm{C}$ after fifteen minutes versus the nominal core outlet temperature of $547^{\circ} \mathrm{C}$. The greater power deposition requires a greater heat removal rate capability of $3.0 \mathrm{MW}_{\mathrm{t}}$. This exceeds the $2.0 \mathrm{MW}_{\mathrm{t}}$ capability of the FFTF closed loop design. For simulation of unprotected transient overpower accident conditions, either the amount of the simulated total reactivity insertion would need to be reduced or the number of fuel pins in the core mockup would need to be reduced, if the heat rejection capability is maintained at $2.0 \mathrm{MW}_{\mathrm{t}}$.

Lead-Cooled Fast Reactor (LFR) designs have been developed for lead $(\mathrm{Pb})$ and lead-bismuth eutectic (LBE, $44.5 \mathrm{wt} \% \mathrm{~Pb}-55.5 \mathrm{wt} \% \mathrm{Bi}$ ) coolants. They are collectively referred to as Heavy Liquid Metal Coolants (HLMCs). For LFRs, the neutronic properties of $\mathrm{Pb}$ or LBE relative to sodium allow the core flow area fraction to be increased. A value of 0.60 is assumed, typical of ANL LFR designs. A high core outlet temperature of $650^{\circ} \mathrm{C}$ is assumed which would require demonstration of an effective new coating for cladding or a new cladding material resistant to attack by molten $\mathrm{Pb}$ or LBE up to higher temperatures. There is interest in material approaches that would enable LFR core outlet temperatures this high or even higher in order to take advantage of the greater efficiency that can be achieved with advanced power conversion approaches such as the supercritical carbon dioxide Brayton cycle. For the traditional ferriticmartensitic steel materials considered for LFR designs, it has been found that the lead coolant velocity must be limited. A value of $2.0 \mathrm{~m} / \mathrm{s}$ is therefore assumed. The required heat removal rate is $1.8 \mathrm{MW}_{\mathrm{t}}$ which fits inside of the $2.0 \mathrm{MW}_{\mathrm{t}}$ envelope.

For liquid salt coolant, two reactor designs are investigated. The first incorporates coolant flow channels inside of prismatic graphite blocks while the second incorporates coolant flow through a pebble bed of large spherical fuel particles. The first case is based upon the ORNL Advanced High Temperature Reactor (AHTR) concept using FLiBe (a mixture of $2 \mathrm{Lif}$ and $\mathrm{BeF}_{2}$ salts also denoted as $\mathrm{Li}_{2} \mathrm{BeF}_{4}$ ) coolant. The flow area fraction is only 0.15 mainly due to the need to accommodate a significant amount of graphite moderator across the core. The heat removal rate requirement is only $0.26 \mathrm{MW}_{\mathrm{t}}$. The second case is based upon the University of California, Berkeley Pebble Bed Fluoride-Salt-Cooled High-Temperature Reactor (PB-FHR) that also uses FLiBe coolant and has a high flow fraction of 0.6 through the pebble bed. The velocity is deliberately limited to $2.0 \mathrm{~m} / \mathrm{s}$ in the PB-FHR design. The required closed loop heat removal rate capability is $2.2 \mathrm{MW}_{\mathrm{t}}$ which somewhat exceeds the assumed $2.0 \mathrm{MW}_{\mathrm{t}}$ capability. Thus, it might 
be necessary to slightly reduce the size of the core mockup to reduce the power deposition below the indicated $2.2 \mathrm{MW}_{\mathrm{t}}$.

For helium coolant, conditions for the General Atomics Prismatic High Temperature Gas Cooled Reactor (HTGR) with prismatic graphite blocks and downward coolant flow through the core are assumed. The flow area fraction is 0.19 which results in a heat removal rate requirement of only $0.16 \mathrm{MW}_{\mathrm{t}}$.

For testing of advanced fuel and cladding under Light Water Reactor (LWR) conditions, core conditions for the Westinghouse Electric Company, LLC AP1000 Pressurized Water Reactor (PWR) are assumed. The flow area fraction is 0.53 and the required heat rate removal capability is $1.7 \mathrm{MW}_{\mathrm{t}}$ which is within the $2.0 \mathrm{MW}_{\mathrm{t}}$ envelope.

Another case of pressurized water coolant investigated is water-cooled, water-moderated research and test reactor conditions. Irradiation and testing leading to qualification of Low Enriched Uranium (LEU) aluminum alloy-clad U-10Mo fuel for such reactors is expected to be an ongoing requirement. Conditions for the High Flux Isotope Reactor (HFIR) at ORNL which is a low pressure PWR with downward coolant flow through the core are assumed. The HFIR has a coolant flow fraction of 0.50 and a high coolant velocity. Thus, although the coolant temperature rise is small, HFIR has a high power density core and the heat removal rate requirement for a closed loop is $1.3 \mathrm{MW}_{\mathrm{t}}$.

Thus, it is found that the assumed test assembly heat removal rate capability of $2.0 \mathrm{MW}_{\mathrm{t}}$ is sufficient for irradiation and testing at nominal steady state conditions for the different coolants and different reactor designs with the possible exception of a pebble bed liquid salt-cooled reactor. In that case, a slightly greater heat removal rate capability of $2.2 \mathrm{MW}_{\mathrm{t}}$ is indicated. For testing under transient and accident conditions, only the case of a SFR was examined. For an assumed unprotected transient overpower accident, the reactor power increases resulting in a significantly higher core outlet temperature, raising the heat removal rate requirement to 3.0 $\mathrm{MW}_{\mathrm{t}}$ which is significantly greater than the assumed $2.0 \mathrm{MW}_{\mathrm{t}}$ capability. If the $2.0 \mathrm{MW}_{\mathrm{t}}$ heat removal rate capability is retained, then either the simulated total reactivity insertion would need to be reduced or the size of the test assembly (i.e., the number of fuel pins) would need to be reduced. Other than those exceptions, the $2.3 \mathrm{MW}_{\mathrm{t}}$ heat rejection rate generally provides some margin for transient testing that can include greater power deposition rates than at nominal steady state. 
FASTER Test Reactor Preconceptual Design Report

March 31, 2016

Table 3-10: Heat Rejection Rates and Flowrate Requirements for Closed Loops for Different Reactor Coolants and Example Reactor Designs

\begin{tabular}{|c|c|c|c|c|c|c|c|c|}
\hline Coolant & Sodium & Sodium & Lead, $\mathrm{Pb}$ & $\begin{array}{l}\text { Liquid Salt, } \\
\text { FLiBe, } \\
2{\mathrm{LiF}-B e F_{2}}^{2}\end{array}$ & $\begin{array}{l}\text { Liquid Salt, } \\
\text { FLiBe, } \\
2{\mathrm{LiF}-B e F_{2}}^{\text {FiF }}\end{array}$ & $\begin{array}{l}\text { Pressurized } \\
\text { Helium }\end{array}$ & $\begin{array}{c}\text { Pressurized } \\
\text { Water }\end{array}$ & $\begin{array}{c}\text { Pressurized } \\
\text { Water }\end{array}$ \\
\hline Reactor & $\begin{array}{l}\text { PGSFR for } \\
\text { Nominal } \\
\text { Conditions }\end{array}$ & $\begin{array}{l}\text { PGSFR for } \\
\text { Unprotected } \\
\text { Transient } \\
\text { Overpower } \\
\text { Conditions }\end{array}$ & $\begin{array}{c}\text { LFR with } \\
\text { High Core } \\
\text { Outlet } \\
\text { Temperature }\end{array}$ & $\begin{array}{l}\text { ORNL } \\
\text { AHTR }\end{array}$ & $\begin{array}{l}\text { UCB Pebble } \\
\text { Bed FHR }\end{array}$ & $\begin{array}{c}\text { GA } \\
\text { Prismatic } \\
\text { HTGR }\end{array}$ & $\begin{array}{c}\text { WEC } \\
\text { AP1000 }\end{array}$ & $\begin{array}{c}\text { High Flux } \\
\text { Isotope } \\
\text { Reactor } \\
\text { (HFIR) }\end{array}$ \\
\hline $\begin{array}{l}\text { Flow } \\
\text { Direction }\end{array}$ & Up & Up & Up & Up & Up & Down & Up & Down \\
\hline $\begin{array}{l}\text { Cross- } \\
\text { Sectional } \\
\text { Area Inside } \\
\text { Closed Loop } \\
\text { Flow Tube, } \\
m^{2}\end{array}$ & 0.00383 & 0.00383 & 0.00383 & 0.00383 & 0.00383 & 0.00383 & 0.00383 & 0.00383 \\
\hline $\begin{array}{l}\text { Flow Area } \\
\text { Inside Closed } \\
\text { Loop Flow } \\
\text { Tube, } \mathrm{m}^{2}\end{array}$ & 0.00146 & 0.00146 & 0.00230 & 0.000573 & 0.0023 & 0.000715 & 0.00203 & 0.00192 \\
\hline $\begin{array}{l}\text { Coolant Inlet } \\
\text { Pressure, } \\
\text { МРa }\end{array}$ & $\begin{array}{c}\text { Near } \\
\text { Atmospheric }\end{array}$ & $\begin{array}{c}\text { Near } \\
\text { Atmospheric }\end{array}$ & $\begin{array}{c}\text { Near } \\
\text { Atmospheric }\end{array}$ & $\begin{array}{c}\text { Near } \\
\text { Atmospheric }\end{array}$ & $\begin{array}{c}\text { Near } \\
\text { Atmospheric }\end{array}$ & 6.39 & 15.5 & 2.24 \\
\hline $\begin{array}{l}\text { Coolant } \\
\text { Outlet/Inlet } \\
\text { Temperatures, } \\
{ }^{\circ} \mathrm{C}\end{array}$ & $547 / 395$ & $738 / 395$ & $650 / 400$ & $700 / 650$ & $700 / 600$ & $750 / 322$ & $321 / 281$ & $67.8 / 57.2$ \\
\hline $\begin{array}{l}\text { Coolant Inlet } \\
\text { Density, } \\
\mathrm{kg} / \mathrm{m}^{3}\end{array}$ & 859 & 859 & 10,563 & 1,963 & 1,987 & 5.10 & 763 & 986 \\
\hline $\begin{array}{l}\text { Coolant Inlet } \\
\text { Viscosity, } \\
\text { Pa } \cdot \text { s }\end{array}$ & 0000280 & 0.000280 & 0.00223 & 0.0056 & 0.0056 & 0.0000321 & 0.0000961 & 0.000487 \\
\hline $\begin{array}{l}\text { Coolant Inlet } \\
\text { Thermal } \\
\text { Conductivity, } \\
W /(m \cdot K)\end{array}$ & 69.7 & 69.7 & 16.6 & 1.0 & 1.0 & 0.254 & 0.595 & 0.653 \\
\hline $\begin{array}{l}\text { Coolant } \\
\text { Specific Heat, } \\
\mathrm{kJ} /(\mathrm{kg} \cdot \mathrm{K})\end{array}$ & 1.268 & 1.256 & 1.26 & 2.41 & 2.41 & 5.189 & 5.46 & 4.18 \\
\hline $\begin{array}{l}\text { Coolant } \\
\text { Prandtl } \\
\text { Number }\end{array}$ & 0.00509 & 0.00509 & 0.0194 & 13.5 & 13.5 & 0.655 & 0.881 & 3.12 \\
\hline $\begin{array}{l}\text { Coolant Inlet } \\
\text { Velocity, } \mathrm{m} / \mathrm{s}\end{array}$ & 5.52 & 5.52 & 2.0 & 1.94 & 2.0 & 20.2 & 4.85 & 15.5 \\
\hline $\begin{array}{l}\text { Coolant } \\
\text { Specific } \\
\text { Enthalpy } \\
\text { Rise, MJ/kg }\end{array}$ & 0.193 & 0.431 & 0.0362 & 0.121 & 0.241 & 2.22 & 0.221 & 0.0441 \\
\hline $\begin{array}{l}\text { Coolant Mass } \\
\text { Flowrate, } \mathrm{kg} / \mathrm{s}\end{array}$ & 6.91 & 6.91 & 48.5 & 2.18 & 9.14 & 0.0737 & 7.53 & 29.4 \\
\hline $\begin{array}{l}\text { Coolant } \\
\text { Volume } \\
\text { Flowrate, } \\
\text { m3/s }(\mathrm{gpm})\end{array}$ & $\begin{array}{l}0.00804 \\
(127)\end{array}$ & $\begin{array}{l}0.00804 \\
(127)\end{array}$ & $\begin{array}{c}0.00459 \\
(72.8)\end{array}$ & $\begin{array}{c}0.00111 \\
(17.6)\end{array}$ & $\begin{array}{c}0.00460 \\
(72.9)\end{array}$ & $\begin{array}{c}0.0145 \\
(229)\end{array}$ & $\begin{array}{c}0.00986 \\
(156)\end{array}$ & $\begin{array}{c}0.0298 \\
(472)\end{array}$ \\
\hline $\begin{array}{l}\text { Power } \\
\text { Removed by } \\
\text { Coolant, } M W t\end{array}$ & 1.33 & 2.98 & 1.75 & 0.263 & 2.21 & 0.164 & 1.66 & 1.30 \\
\hline
\end{tabular}




\subsubsection{Feasibility of Closed Loop In-Reactor Assemblies for Different Coolants and Reactor} Types

Next, the feasibility of designing closed loop in-reactor assemblies for different coolants and reactor configurations was examined. It is assumed that the pressure boundary of the in-reactor assembly is a double-walled pressure tube. The incorporation of a double-walled pressure tube is viewed as a necessary and sufficient approach to incorporate coolants other than sodium inside of an SFR. Required wall thicknesses for each of the two pressure tubes were calculated using the formulae and tables in the ASME Boiler and Pressure Vessel Code Section III, "Rules for Construction of Nuclear Facility Components," Division 1-Subsection NH, "Class 1 Components in Elevated Temperature Service," 2001 Edition. The lifetime of each in-reactor assembly is assumed to be 10,000 hours ( 417 days) which is a margin of $4 \%$ greater than the duration of four FASTER 100-day operating cycles. The outer tube outer diameter of $11.26 \mathrm{~cm}$ (4.44 inches) is assumed identical to that of the hexcan duct-to-duct inner distance for a FASTER fuel assembly. The outer tube outer diameter is the largest value that can fit inside of an assembly location in the FASTER core with clearances filled with sodium between the outer tube and the hexcans of the six neighboring core assembles. For the low pressure coolants (sodium, lead or LBE, and pressurized water under HFIR conditions), the design pressure is taken equal to the same value for the CLIRAs in FFTF ( $2.5 \mathrm{MPa}=363 \mathrm{psig}$ ). The case of liquid salt coolant is not analyzed here because a suitable structural material for use with liquid salt has not yet been codified in the ASME code. For helium and pressurized water under PWR conditions, the design pressure is assumed to be $10 \%$ greater than the values assumed in Table 3-10. The required pressure tube dimensions for a design temperature of $649^{\circ} \mathrm{C}\left(1200^{\circ} \mathrm{F}\right)$ are shown in Table 3-11. For the low pressure coolants, the required wall thicknesses of the outer pressure and inner pressure tubes are $2.51 \mathrm{~mm}$ (0.0986 in) and $2.25 \mathrm{~mm}$ (0.0887 in), respectively. To ensure against concerns about potential buckling of the pressure tubes under external pressure, effects of irradiation, and other uncertainties, the wall thicknesses are increased to a minimum of $6.35 \mathrm{~mm}(0.25 \mathrm{in})$. The inner tube inner diameter of $8.09 \mathrm{~cm}$ (3.18 in) provides plenty of space for a flow tube to separate downward and upward flows and a test section inside of the flow tube. For pressurized helium coolant, the inner tube inner diameter of $8.16 \mathrm{~cm}$ (3.21 in) also provides ample space. For pressurized water under PWR conditions, there is space for a flow tube and test section but the number of fuel pins would need to be reduced below that implied by the assumptions in Table $3-10$. 
FASTER Test Reactor Preconceptual Design Report

March 31, 2016

Table 3-11: Required Pressure Tube Dimensions for $649^{\circ} \mathrm{C}\left(1200^{\circ} \mathrm{F}\right)$ Design Temperature

\begin{tabular}{|c|c|c|c|c|}
\hline Coolant & $\begin{array}{c}\text { Sodium, Lead, or } \\
\text { Low Pressurized } \\
\text { Water }\end{array}$ & $\begin{array}{c}\text { Sodium, Lead, or } \\
\text { Low Pressurized } \\
\text { Water with } 0.25 \\
\text { in Wall } \\
\text { Thicknesses }\end{array}$ & $\begin{array}{c}\text { Pressurized } \\
\text { Helium }\end{array}$ & $\begin{array}{c}\text { Highly } \\
\text { Pressurized } \\
\text { Water }\end{array}$ \\
\hline Pressure Tube Material & 316 & 316 & $800 \mathrm{H}$ & 316 \\
\hline Design Gauge Pressure, MPa (psig) & $2.50(363)$ & $2.50(363)$ & $7.82(1019)$ & $17.05(2473)$ \\
\hline Design Temperature, ${ }^{\circ} \mathrm{C}(F)$ & $649(1200)$ & $649(1200)$ & $649(1200)$ & $649(1200)$ \\
\hline Design Lifetime, hours & 10,000 & 10,000 & 10,000 & 10,000 \\
\hline Outer Pressure Outer Diameter, cm (in) & $11.26(4.443)$ & $11.26(4.443)$ & $11.26(4.443)$ & $11.26(4.443)$ \\
\hline Outer Pressure Tube Wall Thickness, cm (in) & $0.251(0.0986)$ & $0.635(0.25)$ & $0.677(0.266)$ & $1.850(0.728)$ \\
\hline Outer Pressure Tube Inner Diameter, cm (in) & $10.76(4.236)$ & $9.990(3.933)$ & $9.907(3.900)$ & $7.560(2.976)$ \\
\hline Gap Between Pressure Tubes, cm (in) & $0.318(0.125)$ & $0.318(0.125)$ & $0.318(0.125)$ & $0.318(0.125)$ \\
\hline Inner Pressure Tube Outer Diameter, cm (in) & $10.12(3.986)$ & $9.355(3.683)$ & $9.272(3.650)$ & $6.925(2.726)$ \\
\hline Inner Pressure Tube Wall Thickness, cm (in) & $0.225(0.0887)$ & $0.635(0.25)$ & $0.557(0.219)$ & $1.14(0.448)$ \\
\hline Inner Pressure Tube Inner Diameter, cm (in) & $9.673(3.808)$ & $8.085(3.183)$ & $8.157(3.212)$ & $4.649(1.830)$ \\
\hline
\end{tabular}

For liquid salt and pressurized helium coolant, it is desirable to achieve higher temperatures. For a design temperature of $704^{\circ} \mathrm{C}\left(1300^{\circ} \mathrm{F}\right)$, space is still available with the low pressure and pressurized helium coolants (Table 3-12). There still remains space when the design temperature is further increased to $760^{\circ} \mathrm{C}\left(1400^{\circ} \mathrm{F}\right)$ as shown in Table 3-13.

Table 3-12: Required Pressure Tube Dimensions for $704^{\circ} \mathrm{C}\left(1300^{\circ} \mathrm{F}\right)$ Design Temperature

\begin{tabular}{|c|c|c|c|c|}
\hline Coolant & $\begin{array}{c}\text { Sodium, Lead, or } \\
\text { Low Pressurized } \\
\text { Water }\end{array}$ & $\begin{array}{c}\text { Sodium, Lead, or } \\
\text { Low Pressurized } \\
\text { Water with } 0.25 \\
\text { in Wall } \\
\text { Thicknesses } \\
\end{array}$ & $\begin{array}{c}\text { Pressurized } \\
\text { Helium }\end{array}$ & $\begin{array}{c}\text { Highly } \\
\text { Pressurized } \\
\text { Water } \\
\end{array}$ \\
\hline Pressure Tube Material & 316 & 316 & $800 \mathrm{H}$ & 316 \\
\hline Design Gauge Pressure, $M P a$ (psig) & $2.50(363)$ & $2.50(363)$ & $7.82(1019)$ & $17.05(2473)$ \\
\hline Design Temperature, ${ }^{\circ} \mathrm{C}(F)$ & $704(1300)$ & $704(1300)$ & $704(1300)$ & $704(1300)$ \\
\hline Design Lifetime, hours & 10,000 & 10,000 & 10,000 & 10,000 \\
\hline Outer Pressure Outer Diameter, cm (in) & $11.26(4.443)$ & $11.26(4.443)$ & $11.26(4.443)$ & $11.26(4.443)$ \\
\hline Outer Pressure Tube Wall Thickness, cm (in) & $0.456(0.179)$ & $0.635(0.25)$ & $1.08(0.427)$ & $3.61(1.42)$ \\
\hline Outer Pressure Tube Inner Diameter, cm (in) & $10.35(4.074)$ & $9.990(3.933)$ & $9.091(3.579)$ & $4.033(1.588)$ \\
\hline Gap Between Pressure Tubes, cm (in) & $0.318(0.125)$ & $0.318(0.125)$ & $0.318(0.125)$ & $0.318(0.125)$ \\
\hline Inner Pressure Tube Outer Diameter, cm (in) & $9.714(3.824)$ & $9.355(3.683)$ & $8.456(3.329)$ & $3.398(1.338)$ \\
\hline Inner Pressure Tube Wall Thickness, cm (in) & $0.393(0.155)$ & $0.635(0.25)$ & $0.814(0.321)$ & $1.09(0.429)$ \\
\hline Inner Pressure Tube Inner Diameter, cm (in) & $8.928(3.515)$ & $8.085(3.183)$ & $6.827(2.688)$ & $1.217(0.4793)$ \\
\hline
\end{tabular}


Table 3-13: Required Pressure Tube Dimensions for $760^{\circ} \mathrm{C}\left(1400^{\circ} \mathrm{F}\right)$ Design Temperature

\begin{tabular}{lcc}
\hline Coolant & $\begin{array}{c}\text { Sodium, Lead, or Low } \\
\text { Pressurized Water }\end{array}$ & $\begin{array}{c}\text { Pressurized } \\
\text { Helium }\end{array}$ \\
\hline Pressure Tube Material & 316 & $800 \mathrm{H}$ \\
Design Gauge Pressure, MPa $($ psig) & $2.50(363)$ & $7.82(1019)$ \\
Design Temperature, ${ }^{\circ} \mathrm{C}(\mathrm{F})$ & $760(1400)$ & $760(1400)$ \\
Design Lifetime, hours & 10,000 & 10,000 \\
Outer Pressure Outer Diameter, cm (in) & $11.26(4.443)$ & $11.26(4.443)$ \\
Outer Pressure Tube Wall Thickness, cm (in) & $0.905(0.356)$ & $1.85(0.726)$ \\
Outer Pressure Tube Inner Diameter, cm (in) & $9.450(3.720)$ & $7.569(2.980)$ \\
Gap Between Pressure Tubes, cm (in) & $0.318(0.125)$ & $0.318(0.125)$ \\
Inner Pressure Tube Outer Diameter, cm (in) & $8.815(3.470)$ & $6.934(2.730)$ \\
Inner Pressure Tube Wall Thickness, cm (in) & $0.709(0.279)$ & $1.14(0.447)$ \\
Inner Pressure Tube Inner Diameter, cm (in) & $7.398(2.913)$ & $4.662(1.835)$ \\
\hline
\end{tabular}

The test sections in the FFTF CLIRAs were designed for a sodium outlet temperature of $760^{\circ} \mathrm{C}$ $\left(1400^{\circ} \mathrm{F}\right)$ while the double-walled pressure tube and other closed loop hardware was designed for $649^{\circ} \mathrm{C}\left(1200^{\circ} \mathrm{F}\right)[11,13]$. This was achieved by bypassing part of the upward sodium flow around the test section in the annular space between a cylindrical thermal baffle surrounding the test section and the flow tube separating the downward and upward sodium flows inside of the pressure tube. An alternate approach that permits more space for a test section is to design the entire in-reactor assembly for a greater temperature and mix the outlet coolant with a cooler coolant bypass stream inside of a mixing component outside of the reactor.

\subsubsection{Overview of FASTER Closed Loop System Designs}

The closed loop system for each alternative coolant incorporates an in-reactor assembly with a test section, a primary loop with the particular coolant for irradiation and testing, a secondary loop with an appropriate secondary coolant for heat transport, a primary coolant-to-secondary coolant IHX, a secondary coolant-to-air DHX for heat rejection to the atmosphere heat sink, and interconnecting piping. The primary sodium loops for the FFTF closed loop systems were cleverly designed as remarkably compact integrated modules that fit through the containment equipment airlock and were inserted into the compact cell for that particular loop located beneath the containment operating floor through a removable concrete access plug in the operating floor using the containment polar crane. The access plug was sealed during operation. FASTER incorporates provisions for three closed loops operating simultaneously; two in the fast neutron region and one in the thermalized neutron region. A goal is to just as cleverly design a compact transportable and replaceable primary coolant loop module for each of the different closed loop primary coolants in FASTER.

Six different closed loop primary coolants have been included thus far in FASTER; others may be added in the future. The six primary coolants and the major features of the closed loop system for each are shown in Table 3-14. For sodium, lead or lead-bismuth eutectic, liquid salt, and helium primary coolants, sodium is used as the secondary coolant to reject heat to air. A single secondary coolant, sodium, is utilized because it is a low pressure coolant and because of its low freezing temperature, excellent heat transfer properties, excellent compatibility with stainless steel and other alloys, and to avoid the cost of designing and installing a secondary loop and 
secondary coolant-to-air heat exchanger for a different fluid. Sodium is not used for the pressurized water primary coolants to provide separation between sodium and water components and piping, and because heat rejection for primary water coolant can occur at temperatures below or above but near the sodium freezing temperature.

It is necessary to prevent leakages of other primary coolants into sodium. Lead, lead-bismuth eutectic, or liquid salt leaking into sodium could attack structural materials such as 316 . To preclude leakages, the pressure tube of the in-reactor assembly is made double-walled with a gap between the two walls that is monitored for leakage. The primary coolant-to-sodium IHX is a double-walled straight tube (DWST) heat exchanger to preclude leakage. For helium primary coolant, a double-walled pressure tube with a gap is provided to preclude leakage of helium into sodium that might result in the formation of bubbles that could enter the core with reactivity effects and to preclude a blowdown of high pressure helium into the reactor vessel sodium. A DWST IHX is utilized to preclude a blowdown of high pressure helium into secondary sodium. For pressurized water primary coolant, a double-walled pressure tube is needed to preclude water/steam leakage into reactor vessel sodium or a blowdown of high pressure water/steam into surrounding sodium and sodium-water reactions. The gap between the two walls shall also incorporate a vacuum to reduce heat transfer from hotter surrounding sodium to water. In particular, water at research and test reactor conditions will be significantly cooler than the surrounding reactor vessel sodium. The gap between the two walls will be monitored for leaks.

Pressurized water primary coolant conditions for water-cooled and water-moderated research and test reactor conditions lie in a significantly different regime than the conditions for Water-Cooled Nuclear Power Plants (NPPs). Instead of attempting to design a single pressurized water closed loop system that can encompass both regimes, it is better to design and install a separate closed loop system for research and test reactor conditions because of the requirements for a significantly greater heat exchange area in the IHX, a significantly greater heat exchange area in the DHX, and the need for larger diameter piping. 
FASTER Test Reactor Preconceptual Design Report

March 31, 2016

Table 3-14: Closed Loop System Primary Coolants and Major Features

\begin{tabular}{|c|c|c|c|c|c|c|}
\hline $\begin{array}{l}\text { Primary } \\
\text { Coolant for } \\
\text { In-Reactor } \\
\text { Irradiation } \\
\text { and Testing }\end{array}$ & Sodium & $\begin{array}{c}\text { Lead, } \mathrm{Pb} \text {, or } \\
\text { Lead-Bismuth } \\
\text { Eutectic, } 45 \text { wt } \\
\% \text { Pb-55 wt \% Bi }\end{array}$ & $\begin{array}{l}\text { Liquid Salt, } \\
\text { FLiBe, } \\
2{\mathrm{LiF}-\mathrm{BeF}_{2}}^{2}\end{array}$ & $\begin{array}{l}\text { Pressurized } \\
\text { Helium }\end{array}$ & $\begin{array}{c}\text { Pressurized Water } \\
\text { for NPP } \\
\text { Conditions }\end{array}$ & $\begin{array}{l}\text { Pressurized Water } \\
\text { for Research and } \\
\text { Test Reactor } \\
\text { Conditions }\end{array}$ \\
\hline $\begin{array}{l}\text { Secondary } \\
\text { Coolant }\end{array}$ & Sodium & Sodium & Sodium & Sodium & Pressurized Water & Pressurized Water \\
\hline $\begin{array}{l}\text { Primary } \\
\text { Materials }\end{array}$ & $316 \mathrm{H}, 316$ & $\begin{array}{l}\text { ALD-Coated } \\
316 \mathrm{H} \text { and } 316\end{array}$ & Hastelloy N & $800 \mathrm{H}$ & $\begin{array}{l}\text { Low Alloy and } \\
\text { Carbon Steel with } \\
\text { Stainless Steel } \\
\text { Cladding }\end{array}$ & $\begin{array}{l}\text { Low Alloy and } \\
\text { Carbon Steel with } \\
\text { Stainless Steel } \\
\text { Cladding }\end{array}$ \\
\hline $\begin{array}{l}\text { Secondary } \\
\text { Materials }\end{array}$ & $316 \mathrm{H}, 316$ & $316 \mathrm{H}, 316$ & $316 \mathrm{H}, 316$ & $316 \mathrm{H}, 316$ & $\begin{array}{l}\text { Low Alloy and } \\
\text { Carbon Steel with } \\
\text { Stainless Steel } \\
\text { Cladding }\end{array}$ & $\begin{array}{l}\text { Low Alloy and } \\
\text { Carbon Steel with } \\
\text { Stainless Steel } \\
\text { Cladding }\end{array}$ \\
\hline $\begin{array}{l}\text { Intermediate } \\
\text { Heat } \\
\text { Exchanger }\end{array}$ & $\begin{array}{l}\text { Single-Walled } \\
\text { Tube Helical } \\
\text { Coil Similar to } \\
\text { FFTF Closed } \\
\text { Loop System } \\
\text { Design }\end{array}$ & $\begin{array}{l}\text { Double-Walled } \\
\text { Straight Tube to } \\
\text { Preclude } \\
\text { Leakage }\end{array}$ & $\begin{array}{l}\text { Double-Walled } \\
\text { Straight Tube } \\
\text { with Hastelloy } \\
\text { N Tubes to } \\
\text { Preclude } \\
\text { Leakage }\end{array}$ & $\begin{array}{l}\text { Double-Walled } \\
\text { Straight Tube to } \\
\text { Preclude Leakage }\end{array}$ & $\begin{array}{l}\text { Single-Walled } \\
\text { Tube Helical Coil }\end{array}$ & $\begin{array}{l}\text { Single-Walled } \\
\text { Tube Helical Coil }\end{array}$ \\
\hline $\begin{array}{l}\text { In-Reactor } \\
\text { Assembly }\end{array}$ & $\begin{array}{l}\text { Single-Wall } \\
\text { Flow Tube }\end{array}$ & $\begin{array}{l}\text { Double-Wall } \\
\text { Flow Tube with } \\
\text { Monitored Gap } \\
\text { to Preclude } \\
\text { Leakage }\end{array}$ & $\begin{array}{l}\text { Double-Wall } \\
\text { Flow Tube with } \\
\text { Monitored Gap } \\
\text { to Preclude } \\
\text { Leakage }\end{array}$ & $\begin{array}{c}\text { Double-Wall } \\
\text { Flow Tube with } \\
\text { Monitored Gap to } \\
\text { Preclude Leakage }\end{array}$ & $\begin{array}{l}\text { Double-Wall Flow } \\
\text { Tube with } \\
\text { Monitored Gap to } \\
\text { Preclude Leakage } \\
\text { and for Thermal } \\
\text { Insulation }\end{array}$ & $\begin{array}{c}\text { Double-Wall Flow } \\
\text { Tube with } \\
\text { Monitored Gap to } \\
\text { Preclude Leakage } \\
\text { and for Thermal } \\
\text { Insulation }\end{array}$ \\
\hline $\begin{array}{l}\text { Primary } \\
\text { Coolant } \\
\text { Pumps }\end{array}$ & Electromagnetic & Electromagnetic & Electromagnetic & $\begin{array}{c}\text { Centrifugal/Radial } \\
\text { Pump }\end{array}$ & Canned Rotor & Canned Rotor \\
\hline $\begin{array}{l}\text { Primary } \\
\text { Coolant } \\
\text { Chemistry } \\
\text { Control and } \\
\text { Cleanup }\end{array}$ & $\begin{array}{l}\text { Cold Trap, } \\
\text { Plugging Meter } \\
\text { Measurements }\end{array}$ & $\begin{array}{l}\text { Intermixing with } \\
\text { Hydrogen to } \\
\text { Reduce Oxygen } \\
\text { Content, Oxygen } \\
\text { Sensor } \\
\text { Measurements }\end{array}$ & $\begin{array}{l}\text { Redox Potential } \\
\text { Control, } \\
\text { Tritium } \\
\text { Stripping and } \\
\text { Capture }\end{array}$ & $\begin{array}{c}\text { Makeup for } \\
\text { Coolant Leakages, } \\
\text { Minimal } \\
\text { Chemistry } \\
\text { Control }\end{array}$ & $\begin{array}{c}\text { pH Control, } \\
\text { Mixed Bed } \\
\text { Demineralizers, } \\
\text { Cation Bed } \\
\text { Demineralizer, } \\
\text { Control of } \\
\text { Radiolysis } \\
\text { Reactions }\end{array}$ & $\begin{array}{l}\text { pH Control, } \\
\text { Mixed Bed } \\
\text { Demineralizers, } \\
\text { Cation Bed } \\
\text { Demineralizer, } \\
\text { Control of } \\
\text { Radiolysis } \\
\text { Reactions }\end{array}$ \\
\hline $\begin{array}{l}\text { Primary } \\
\text { Coolant Loop } \\
\text { Cell Volume } \\
\text { Normalized by } \\
\text { FFTF Closed } \\
\text { Loop Primary } \\
\text { Cell Volume }\end{array}$ & 1 & 1 & 3 & 1 & 3 & 3 \\
\hline
\end{tabular}

Electromagnetic pumps are used for sodium, lead or lead-bismuth eutectic, and liquid salt to preclude pump leakages. Canned rotor pumps are used with the water loops to preclude leakages. Helium at high pressure is circulated with a small centrifugal pump having a high rotational speed.

The primary loop materials selected are currently codified under the ASME Boiler and Pressure Vessel Code Section III with the exception of Hastelloy $\mathrm{N}$ that is required to resist corrosion by liquid salt. Until a code case for Hastelloy $\mathrm{N}$ has been prepared and accepted, a closed loop incorporating this material as the pressure boundary cannot be used in FASTER.

The liquid salt primary loop needs to incorporate a system to strip and capture tritium formed by neutron reactions with lithium and beryllium as well as systems to control the salt redox potential 
and to clean up the salt of contaminants and other radionuclides. The pressurized water system primary loops need to incorporate bed demineralizers to remove ionic corrosion products and certain ionic fission products, a cation bed demineralizer to remove mainly lithium and cesium isotopes in the event of fuel failure as well as control the coolant $\mathrm{pH}$, and a system to inject hydrogen to control water decomposition from radiolysis. The pressurized water system primary loop for research and test reactor conditions also needs to provide chemistry control for aluminum alloy clad research and test reactor fuels and aluminum alloy structures. In addition, the primary water loop incorporates a heater to preheat water before it is introduced into the inreactor assembly and a regenerative let down heat exchanger.

Because of their unique chemistry control and cleanup requirements, the liquid salt and pressurized water primary loops have more components and require a larger volume for the cell in which they are housed inside of the fast test reactor containment. The primary sodium loops for FFTF were cleverly designed as remarkably compact transportable modules that fit through the containment equipment airlock and were inserted into the compact cell for that particular loop located beneath the containment operating floor through a removable concrete access plug in the operating floor using the containment polar crane. The access plug was sealed during operation. It is expected that for FASTER, for the lead or lead bismuth eutectic, as well as the helium primary loops, that similarly clever equipment layouts can be achieved such that the cell volume required for each of the modules shall be similar to that of FFTF. However, for the liquid salt and each of the pressurized water loops, it is roughly estimated that for clever equipment layouts that three times the volume of an FFTF cell shall be needed. For flexibility in interchanging primary coolant modules, the primary loop volume requirement for each cell is thus three times that of FFTF. Since those are thermal reactor coolants, space to accommodate the larger required primary coolant module is provided in the thermalized neutron region. To accommodate pressurized water loops, the cell also has a sump and water leakage collection system.

The cell and containment designs must also accommodate the effects of a postulated pressurized helium or pressurized water pipe rupture and primary coolant release resulting in pressure and temperature loadings in the cell atmosphere. For sodium, lead or lead-bismuth eutectic, and liquid salt primary coolants, the cell and containment designs must accommodate the effects of a postulated pipe leak and primary coolant release. Release of lead-bismuth eutectic, and to a significantly lesser extent lead, will be accompanied by the release of ${ }^{210} \mathrm{Po}$ that has accumulated in the primary coolant. Release of liquid salt will be accompanied by the release of tritium present in the primary coolant.

The closed loop system design for each coolant type and the FASTER containment design must accommodate the effects of postulated closed loop system accidents resulting in the inability to remove heat from the in-reactor assembly. For the FFTF closed loop system design, the CLIRA was designed to accommodate a Test Section Meltdown Accident (TSMDA). A meltdown cup was provided below the bottom end of the pressure tube. The meltdown cup was designed to contain 0.75 liter $\left(46 \mathrm{inch}^{3}\right)$ of molten $\mathrm{UO}_{2}$ fuel. It incorporated a tungsten funnel to collect fuel, a TZM molybdenum alloy cup with six inwardly projecting fins to contain molten fuel, and a tungsten washer followed by a borated graphite shield block beneath the TZM cup. For each individual closed loop system primary coolant type and reactor type core simulation, an 
assessment needs to be carried out of the accident phenomena and an approach to contain the test section materials as well as mitigate the release of radionuclides from the in-reactor assembly needs to be engineered.

The following discusses in greater detail main considerations for each of the closed loop systems. The first consideration is the physical size requirement of the primary coolant module for each primary coolant type. This includes the physical space requirements for the coolant chemistry control system as well as any optional coolant cleanup system. A second consideration is the materials for piping and components for use with each of the different coolants. A third is what coolant to use in the secondary heat transport circuit between the primary coolant delivered to the test section inside of the in-reactor assembly installed in the reactor and the atmospheric heat sink. It is of interest to limit the number of different types of secondary coolants, if practical.

\subsubsection{Detailed Investigations of FASTER Closed Loop System Designs}

To design the FASTER reactor containment and building structures, it is necessary to determine the physical space requirements for the closed loop systems for the different primary coolants. To allow for interchangeability of closed loop primary coolant modules, the space provided must be able to accommodate the closed loop hardware for the coolant type having the largest space requirements.

\section{$\underline{\text { Sodium }}$}

The sodium closed loop system primary and secondary sodium loops for FASTER are assumed to essentially be replicas of the ones developed for FFTF. Those designs were clearly optimized to save space and were successfully designed to the appropriate ASME codes including the ASME Boiler and Pressure Vessel Code Section III for the primary coolant module components. The maximum temperature of $649^{\circ} \mathrm{C}$ is retained for FASTER. The loops were designed for a heat removal rate capacity of $2.3 \mathrm{MW}_{\mathrm{t}}$. However, the designs also incorporated features that would enable the heat removal capacity to later be increased to $4.3 \mathrm{MW}_{\mathrm{t}}$ using many of the same components such as the primary-to-secondary sodium IHX and the secondary sodium-to-air DHX but increasing the size of piping from 3 inch to 4 inch piping. This was accomplished by welding 4 inch nozzles with reducers onto the components. If needed, the reducers and 3 inch piping could later be cut off and 4 inch piping welded to the nozzles. Piping and components were generally fabricated from $316 \mathrm{H}$ for the hot leg and 316 for the cold leg.

The primary sodium system for each of the closed loops was designed as a compact module that fit inside of a compact cell inerted with nitrogen inside of the containment beneath the FFTF containment operating floor. Access to the cell was through a removable concrete access plug in the operating floor; the access plug was sealed during operation. The primary module was installed and could be removed using the polar crane inside of the containment dome.

Each primary module was assembled in a frame $8.69 \mathrm{~m}$ (28.5 feet) high by $2.90 \mathrm{~m}$ ( 9.50 feet) by $3.00 \mathrm{~m}$ ( $9.83 \mathrm{feet})$. It fit tightly into a cell $8.84 \mathrm{~m}$ (29.0 feet) high by $3.05 \mathrm{~m}$ (10.0 feet) by $3.66 \mathrm{~m}$ (12.0 feet). The module laid on one of its sides could fit through the FFTF containment $7.62 \mathrm{~m}$ ( 25.0 feet) diameter equipment airlock. Branch arm piping for hot and cold sodium connected to the CLIRA above the reactor vessel head. The module included the primary-to-secondary sodium IHX. 
Secondary sodium loop components would have been housed inside of a compact service building outside of the containment and both partially above and partially below grade with secondary sodium hot and cold leg piping passing through the containment boundary to the IHX as well as hot and cold leg piping routed largely below grade to the secondary sodium-to air DHX.

The design of the sodium-to-sodium IHX is crucial to the closed loop approach. Detailed multinodal heat exchange calculations were carried out to examine and confirm the thermal hydraulic performance of the IHX design developed for the FFTF closed loops applied to SFR conditions of current interest. The FFTF IHX design was a helical coil shell-and-tube heat exchanger with seventeen tubes. Although for nominal PGSFR conditions, the required heat removal rate is $1.3 \mathrm{MW}_{\mathrm{t}}$ (Table 3-10), the calculations assume the maximum heat duty of 2.3 $\mathrm{MW}_{\mathrm{t}}$. The exact tube size, pitch-to-diameter ratio, and length are not known, although the total heat exchange area and the IHX primary and secondary sodium volumes are known. Consistent with those values, it is assumed that each tube has an outer diameter of $2.54 \mathrm{~cm}(1 \mathrm{inch})$ and a wall thickness of $1.0 \mathrm{~mm}$, and that the tubes are arranged with a pitch-to-diameter ratio of 1.9. The heat transfer coefficient on each sodium side is assumed to be given by the liquid metal (LM) Nusselt number correlation of Seban and Shimazaki:

$$
\mathrm{Nu}=\frac{\mathrm{h} \mathrm{D}_{\mathrm{h}}}{\mathrm{k}}=5.0+0.025 \quad(\operatorname{Re} \operatorname{Pr})^{0.8}
$$

For the stated FFTF design conditions that specify a temperature change on each of the primary and secondary sodium sides of $222^{\circ} \mathrm{C}\left(400^{\circ} \mathrm{F}\right)$ for primary and secondary flowrates of 8.176 and $8.159 \mathrm{~kg} / \mathrm{s}$, respectively, at $2.3 \mathrm{MW}_{\mathrm{t}}$ heat duty, a tube length of $8.04 \mathrm{~m}$ is calculated as that which provides the required heat duty as shown in the first entry in Table 3-15. This is a reasonable number when compared with available information.

The design flowrates are one-half of the maximum value for the FFTF closed loop system design. For one-half of the design temperature change at the maximum flowrates together with the different resulting secondary sodium inlet and outlet temperatures, a tube length of $8.34 \mathrm{~m}$ is calculated (Table 3-15).

For the tube length of $8.04 \mathrm{~m}$ calculated for the stated FFTF IHX design conditions, the performance of the assumed IHX design was examined for PGSFR nominal inlet and outlet temperature conditions but with $2.3 \mathrm{MW}_{\mathrm{t}}$ heat removal. The secondary sodium flowrate was assumed equal to the primary sodium flowrate. The secondary sodium inlet temperature to the IHX was adjusted to enable the required heat duty. As shown in the third entry in Table 3-15, the secondary inlet temperature of $352^{\circ} \mathrm{C}$ is reasonable. For a similar calculation assuming PGSFR inlet and outlet temperatures for the transient overpower event (Table 3-10) with $2.3 \mathrm{MW}_{\mathrm{t}}$ heat removal, a secondary sodium inlet temperature of $340^{\circ} \mathrm{C}$ is calculated. Thus, the sodium-tosodium IHX design is robust over a range of conditions at the maximum heat duty. 
The primary and secondary sodium loops for the FFTF design each incorporated cold traps to purify the sodium and sodium plugging meters to measure the plugging temperature from which the sodium purity is determined. The primary cold trap was part of the primary coolant module. Cold trapping will also be used for the primary and secondary sodium loops of the FASTER closed loop systems.

The primary cell and containment designs must accommodate a postulated leak from a sodium pipe and the release of sodium into the cell. In the FFTF design, the primary cell was inerted with nitrogen to prevent sodium burning, heat release from sodium combustion, and aerosol formation from sodium burning.

\section{Lead or Lead-Bismuth Eutectic}

For a lead $(\mathrm{Pb})$ or LBE closed loop system primary module, the maximum test section temperature requirement is retained as the FFTF value of $760^{\circ} \mathrm{C}$. This is consistent with advanced LFR designs that seek to achieve higher core outlet temperatures for improved plant efficiency and optional process heat applications. For lead or alternate LBE HLMCs, a key challenge is identification of a suitable structural material to use for piping and components exposed to the primary coolant. Austenitic stainless steel is resistant to attack by HLMC up to about $400^{\circ} \mathrm{C}$. The traditional approach to go to higher temperatures of about $550^{\circ} \mathrm{C}$ involves the use of ferritic-martensitic steel together with dissolution of oxygen inside of the coolant to provide a sufficient amount of oxygen to form an oxide layer on the steel surface to reduce the erosion/corrosion rate but not so high as to precipitate solid lead oxide $(\mathrm{PbO})$. The oxygen concentration is typically measured with an oxygen sensor that measures the potential drop across an electrolyte that depends upon the diffusion rate of oxygen ions through the electrolyte. The oxygen concentration in HLMC test loops is typically reduced by intermixing flowing coolant with hydrogen gas and increased by flowing coolant through a bed of lead oxide particles that are dissolved into the coolant. The use of ferritic-martensitic steel would not be expected to enable primary coolant temperatures as high as $760^{\circ} \mathrm{C}$.

There are approaches that could potentially allow the realization of such high temperatures for the lead or LBE test section as well as for LFR designs. One is to coat steel with silicon carbide or another suitable coating material by means of Atomic Layer Deposition (ALD). Coating by means of ALD is currently under development at Argonne but not specifically for use with HLMCs. The main virtue of the ALD approach is that it is carried out inside of a vessel at low temperature. As a result, existing codified materials such as $316 \mathrm{H}$ and 316 could presumably be coated without undergoing heating during the process that might otherwise alter their properties. Another virtue is that the coating is effectively realized over the entire exposed metal alloy surface enabling the coating of complex alloy shapes. A new development program shall be needed to produce coated stainless steel having different shapes and to demonstrate its corrosion resistance to HLMCs. If successful in preventing corrosion, the coating approach would be expected not to require the presence of dissolved oxygen inside of the coolant such that the oxygen concentration could be maintained at a low value.

Another approach is to line $316 \mathrm{H}$ and 316 with a suitable liner material that is resistant to attack by HLMC. Such a material is expected to be $\mathrm{Ti}_{3} \mathrm{SiC}_{2}$ (3-ONE-2, LLC). It is stated that it can be pressed, slip cast, and injection molded. It is machinable or can be thermally sprayed onto metals 
to form coatings. It is described as stiff, thermal shock resistant, damage tolerant, tough, and fatigue resistant. Its corrosion resistance has been tested at Argonne by exposure to $\mathrm{Pb}$ with low oxygen potential at 800 and $650^{\circ} \mathrm{C}$ for 1000 hours in a quartz Harp loop. No evidence of $\mathrm{Ti}_{3} \mathrm{SiC}_{2}$ attack by $\mathrm{Pb}$ was observed.

While the goal is to achieve a test section temperature as high as $760^{\circ} \mathrm{C}$, the primary loop module outside of the in-reactor assembly is designed for a temperature of $649^{\circ} \mathrm{C}$. Part of the primary coolant inlet flow from the IHX can be bypassed instead of flowing through the in-reactor assembly and then intermixed with the exit flow from the in-reactor assembly inside of a mixing component.

The oxygen content of the lead or LBE coolant can be decreased, if necessary, through intermixing of flowing lead with hydrogen gas in a mixer. The required mixer and hydrogen system should not require significant physical space. The hydrogen would likely be mixed with helium or another inert gas such that the hydrogen concentration remains below the flammability limit eliminating the risk of hydrogen burning. The lead primary loop does not need a cold trap as does a sodium loop which actually saves space.

Lead is a low pressure coolant but has a freezing temperature of $327^{\circ} \mathrm{C}$. This is too high for effective heat rejection to air without the risk of freezing. Therefore, sodium with a freezing temperature of $97.85^{\circ} \mathrm{C}$ is retained as the secondary coolant. Lead-bismuth eutectic is also a low pressure coolant with a freezing temperature of $125^{\circ} \mathrm{C}$ and could also be utilized as a secondary coolant. However, sodium is preferred for its low freezing temperature, excellent heat transfer properties, excellent compatibility with stainless steel and other alloys, and it eliminates the need for the design and installation of a separate dedicated LBE secondary loop and a separate dedicated LBE-to-air heat exchanger.

The IHX model was applied for lead primary coolant at the assumed nominal LFR inlet and outlet temperature conditions shown in Table 3-10 at a heat removal rate of $2.3 \mathrm{MW}_{\mathrm{t}}$. It was found that a lead primary-to-sodium secondary helical coil IHX requires about twice the heat exchange area of a sodium primary-to-sodium secondary IHX (Table 3-15). The need for greater heat exchange area could be accommodated by increasing the number of IHX helical coil tubes from seventeen by somewhat increasing the diameter of the IHX shell. This would not significantly increase the physical size of the IHX. Thus, a lead or LBE primary loop with a helical coil IHX would still fit into the space for a sodium primary loop.

However, a helical coil IHX would incorporate single-walled tubes with the risk of leakage between the lead or LBE primary and sodium secondary coolants. Detection of small leaks of one coolant into the other might be difficult. If lead or LBE were to leak into sodium, then it could corrode the $316 \mathrm{H}$ or 316 of the secondary loop. This could increase the risk of sodium leakage from piping and a sodium fire. If the dissolved oxygen were controlled to support oxide formation upon exposed steel, the leakage of sodium into lead or LBE could result in reduction of the oxygen concentration. The sodium intermixed with lead or LBE would act as a getter for oxygen. However, if the intent is to maintain a low oxygen concentration, then the presence of sodium might not adversely affect the oxygen level. 
The risk of a leak in the IHX can be significantly reduced through the use of double-walled tubes. EBR-II successfully incorporated double-walled tubes in its steam generators. Both mechanically bonded and metallurgically bonded tubes were utilized in the EBR-II steam generators. Double-walled tubes need to be straight. This will increase the height of the IHX relative to an IHX with helical coiled tubes.

The IHX model was extended to also include a DWST IHX. A fixed tube length of $2.0 \mathrm{~m}$ is assumed which matches the FFTF IHX height. A tube length of $2.0 \mathrm{~m}$ is also expected to permit the practical fabrication of double-walled tubes. The IHX model calculates the required number of tubes. The tube size of $2.54 \mathrm{~cm}$ outer diameter and a tube pitch-to-diameter ratio of 1.9 are retained. However, because the tubes are double-walled, the total wall thickness is increased to 2 $\mathrm{mm}$. The FFTF secondary side sodium conditions with respect to inlet and outlet temperatures and flowrate are also retained to enable effective heat rejection to air. It is found that 257 doublewalled straight tubes are required (Table 3-15). However, this only increases the IHX shell inner diameter from $0.74 \mathrm{~m}$ for the helical coil design to $0.80 \mathrm{~m}$ for the DWST design. Thus, the leadto-sodium IHX will fit into essentially the same space.

Similar considerations about leakage of HLMC into sodium apply to the portion of the closed loop inside of the reactor vessel. One would not want to risk the investment in FASTER because of the potential of a lead or LBE leak into the reactor vessel sodium. The portion of the primary loop residing inside of the reactor vessel thus needs to incorporate a double wall. There will be a gap between the two walls to monitor for the effects of leakage.

Electromagnetic (EM) pumps will be utilized to circulate the HLMC. The efficiency of an EM pump is significantly less with HLMC than with sodium. However, it is still sufficient to make the use of EM pumps practical, avoids the need for mechanical pumps that would need an impeller material resistant to attack by HLMC at high rotational speeds, and eliminates the possibility of leakage from a mechanical pump.

For $316 \mathrm{H}$ and 316 that are ALD coated, the coolant chemistry control system would incorporate components to mix hydrogen and an inert carrier gas with the HLMC coolant. This could be accomplished by passing primary coolant flow through a Venturi-type mixer into which the gas mixture is injected. This hardware would not take up significant space in the primary module. The HLMC dissolved oxygen level would be determined from oxygen sensor measurements. The oxygen sensors may be installed on piping and take up little space.

The primary cell and containment designs must accommodate a postulated leak from a primary coolant pipe and the release of lead or LBE. Neither HLMC is combustible in air. Neutron capture in ${ }^{209} \mathrm{Bi}$ leads directly to production of the isotope ${ }^{210} \mathrm{Po}\left({ }^{209} \mathrm{Bi}+\mathrm{n} \rightarrow{ }^{210} \mathrm{Po}+\mathrm{e}^{-}\right)$. The ${ }^{210} \mathrm{Po}$ is an alpha emitter with a half-life of 138 days. Elemental Po is a solid at room temperature and has a melting temperature of $254^{\circ} \mathrm{C}$ and an atmospheric boiling temperature of $962^{\circ} \mathrm{C}$. Despite the high boiling temperature, polonium has a high volatility. In HLMC, the ${ }^{210} \mathrm{Po}$ is retained in the form of the compound lead polonide, $\mathrm{PbPo}$. However, contact with moisture can result in the formation of polonium hydride, $\mathrm{PoH}_{2}$, with a melting temperature of $-36.1^{\circ} \mathrm{C}$ and atmospheric boiling temperature of $35.3^{\circ} \mathrm{C}$, which is volatile. Thus, the release of LBE and reaction with moisture in the cell atmosphere results in gaseous compounds and aerosols 
containing ${ }^{210} \mathrm{Po}$ including polonium hydride which represent a health hazard in terms of transport and inhalation. The generation of ${ }^{210} \mathrm{Po}$ with LBE is the main reason for selecting $\mathrm{Pb}$ coolant for some LFR design concepts for which the amount of ${ }^{210} \mathrm{Po}$ is calculated to be reduced by two to four orders of magnitude relative to LBE. However, ${ }^{210} \mathrm{Po}$ is not completely eliminated due to $\mathrm{Bi}$ impurities as well as creation of ${ }^{209} \mathrm{Bi}$ from transmutation reactions $\left({ }^{208} \mathrm{~Pb}+\mathrm{n} \rightarrow{ }^{209} \mathrm{~Pb}\right.$ $\left.\rightarrow{ }^{209} \mathrm{Bi}+\mathrm{e}^{-}\right)$. Thus, the fast test reactor design needs to accommodate potential ${ }^{210} \mathrm{Po}$ releases accompanying postulated LBE releases.

One approach to mitigating ${ }^{210} \mathrm{Po}$ releases is to incorporate an online system to continuously remove it from the HLMC coolant. This would require the development and demonstration of a suitable process. 
FASTER Test Reactor Preconceptual Design Report

March 31, 2016

Table 3-15: IHX Design Calculations for Required Tube Length for Seventeen-Tube Helical Coil IHX or Number of Tubes and Shell Inner Diameter for DWST IHX or Larger Helical Coil IHX Assuming 2.3 MW Heat Exchange Rate

\begin{tabular}{|c|c|c|c|c|c|c|c|c|c|c|c|}
\hline Side & Fluid & Case Description & $\begin{array}{c}\text { Inlet } \\
\text { Temp., } \\
{ }^{\circ} \mathbf{C}\end{array}$ & $\begin{array}{c}\text { Outlet } \\
\text { Temp., } \\
{ }^{\circ} \mathbf{C}\end{array}$ & $\begin{array}{l}\text { Flow } \\
\text { Rate, } \\
\mathrm{kg} / \mathrm{s}\end{array}$ & $\begin{array}{l}\text { Pres., } \\
\text { MPa }\end{array}$ & $\begin{array}{c}\text { HT } \\
\text { Corel } \\
\cdot\end{array}$ & $\begin{array}{l}\text { Tube } \\
\text { Mat. }\end{array}$ & $\begin{array}{c}\text { Tube } \\
\text { OD } \\
\text { and } \\
\text { Wall, } \\
\text { mm }\end{array}$ & $\begin{array}{c}\text { No. of } \\
\text { Tubes } \\
\text { and } \\
\text { Length, } \\
\text { m }\end{array}$ & $\begin{array}{c}\text { IHX } \\
\text { Shel } \\
\text { ID, } \\
\text { m }\end{array}$ \\
\hline Pri & $\mathrm{Na}$ & \multirow{2}{*}{$\begin{array}{c}\text { FFTF IHX Design } \\
\text { Conditions }\left(400^{\circ} \mathrm{F}\right)\end{array}$} & 650 & 427.8 & 8.176 & 0.1 & $\mathrm{LM}$ & 316 & 25 & 17 & \multirow{2}{*}{0.74} \\
\hline $\mathrm{Sec}$ & $\mathrm{Na}$ & & 379.4 & 602 & $\begin{array}{l}8.1 \\
59 \\
\end{array}$ & 0.1 & LM & & 1 & 8.04 & \\
\hline Pri & $\mathrm{Na}$ & \multirow{2}{*}{$\begin{array}{l}\text { FFTF IHX Full } \\
\text { Flow }\left(200^{\circ} \mathrm{F}\right)\end{array}$} & 650 & 537.8 & 16.384 & 0.1 & $\mathrm{LM}$ & 316 & 25 & 17 & \multirow{2}{*}{0.74} \\
\hline $\mathrm{Sec}$ & $\mathrm{Na}$ & & 498.9 & 610 & 16.367 & 0.1 & $\mathrm{LM}$ & & 1 & 8.34 & \\
\hline Pri & $\mathrm{Na}$ & \multirow{2}{*}{$\begin{array}{l}\text { PGSFR Nominal } \\
\text { Conditions with } \\
\text { FFTF IHX. Adjust } \\
\text { Sec. Inlet T } \\
\end{array}$} & 547 & 395 & 11.92 & 0.1 & LM & 316 & 25 & 17 & \multirow{2}{*}{0.74} \\
\hline $\mathrm{Sec}$ & $\mathrm{Na}$ & & 352 & 503 & 11.92 & 0.1 & LM & & 1 & 8.04 & \\
\hline Pri & $\mathrm{Na}$ & \multirow{2}{*}{$\begin{array}{l}\text { PGSFR TOP with } \\
\text { FFTF IHX. Adjust } \\
\text { Sec. Inlet T }\end{array}$} & 738 & 395 & 5.297 & 0.1 & LM & 316 & 25 & 17 & \multirow{2}{*}{0.74} \\
\hline $\mathrm{Sec}$ & $\mathrm{Na}$ & & 340 & 683 & 5.297 & 0.1 & $\mathrm{LM}$ & & 1 & 8.04 & \\
\hline Pri & $\mathrm{Na}$ & \multirow{2}{*}{$\begin{array}{l}\text { PGSFR Nominal } \\
\text { Conditions on Pri, } \\
\text { Side. FFTF IHX } \\
\text { Design Conditions } \\
\text { on Sec. Side }\end{array}$} & 547 & 395 & 11.92 & 0.1 & LM & 316 & 25 & 17 & \multirow[b]{2}{*}{0.74} \\
\hline $\mathrm{Sec}$ & $\mathrm{Na}$ & & 379.4 & & 8.159 & 0.1 & LM & & 1 & $\begin{array}{l}\text { Doesn't } \\
\text { Work } \\
\text { Due to } \\
\text { Pinch } \\
\text { Point }\end{array}$ & \\
\hline Pri & $\mathrm{Pb}$ & \multirow{2}{*}{$\begin{array}{c}\text { LFR Nominal } \\
\text { Conditions on Pri. } \\
\text { Side. FFTF IHX } \\
\text { Design Conditions } \\
\text { on Sec. Side }\end{array}$} & 650 & 400 & 63.63 & 0.1 & $\mathrm{LM}$ & 316 & 25 & 17 & \multirow[b]{2}{*}{0.74} \\
\hline $\mathrm{Sec}$ & $\mathrm{Na}$ & & 379.4 & 602 & 8.159 & 0.1 & $\mathrm{LM}$ & & 1 & 15.26 & \\
\hline Pri & $\mathrm{Pb}$ & \multirow{2}{*}{$\begin{array}{c}\text { DWST IHX } \\
\text { LFR Nominal } \\
\text { Conditions on Pri. } \\
\text { Side. FFTF IHX } \\
\text { Design Conditions } \\
\text { on Sec. Side } \\
\end{array}$} & 650 & 400 & 63.63 & 0.1 & $\mathrm{LM}$ & 316 & 25 & 257 & \multirow[b]{2}{*}{0.8} \\
\hline $\mathrm{Sec}$ & $\mathrm{Na}$ & & 379.4 & 602 & 8.159 & 0.1 & $\mathrm{LM}$ & & 2 & 2.0 & \\
\hline Pri & FLiBe & \multirow{2}{*}{$\begin{array}{c}\text { AHTR Nominal } \\
\text { Conditions on Pri. } \\
\text { Side. FFTF IHX } \\
\text { Design Conditions } \\
\text { on Sec. Side } \\
\end{array}$} & 700 & 650 & 19.28 & 0.1 & $\begin{array}{l}\text { Gnie- } \\
\text { linski }\end{array}$ & Hast.N & 25 & 17 & \multirow{2}{*}{0.74} \\
\hline $\mathrm{Sec}$ & $\mathrm{Na}$ & & 379.4 & 602 & 8.159 & 0.1 & $\mathrm{LM}$ & & 1 & 4.07 & \\
\hline Pri & FLiBe & \multirow{2}{*}{$\begin{array}{c}\text { DWST IHX } \\
\text { AHTR Nominal } \\
\text { Conditions on Pri. } \\
\text { Side. FFTF IHX } \\
\text { Design Conditions } \\
\text { on Sec. Side }\end{array}$} & 700 & 650 & 19.28 & 0.1 & $\begin{array}{l}\text { Gnie- } \\
\text { linski }\end{array}$ & $\begin{array}{l}\text { Hast. } \\
\mathrm{N}\end{array}$ & 25 & 475 & \multirow{2}{*}{1.09} \\
\hline $\mathrm{Sec}$ & $\mathrm{Na}$ & & 379.4 & 602 & 8.159 & 0.1 & $\mathrm{LM}$ & & 2 & 2.0 & \\
\hline Pri & FLiBe & $\begin{array}{l}\text { PB FHR Nominal } \\
\text { Conditions on Pri. }\end{array}$ & 700 & 600 & 9.64 & 0.1 & $\begin{array}{l}\text { Gnie- } \\
\text { linski }\end{array}$ & $\begin{array}{c}\text { Hast. } \\
\mathrm{N}\end{array}$ & 25 & 17 & 0.74 \\
\hline
\end{tabular}




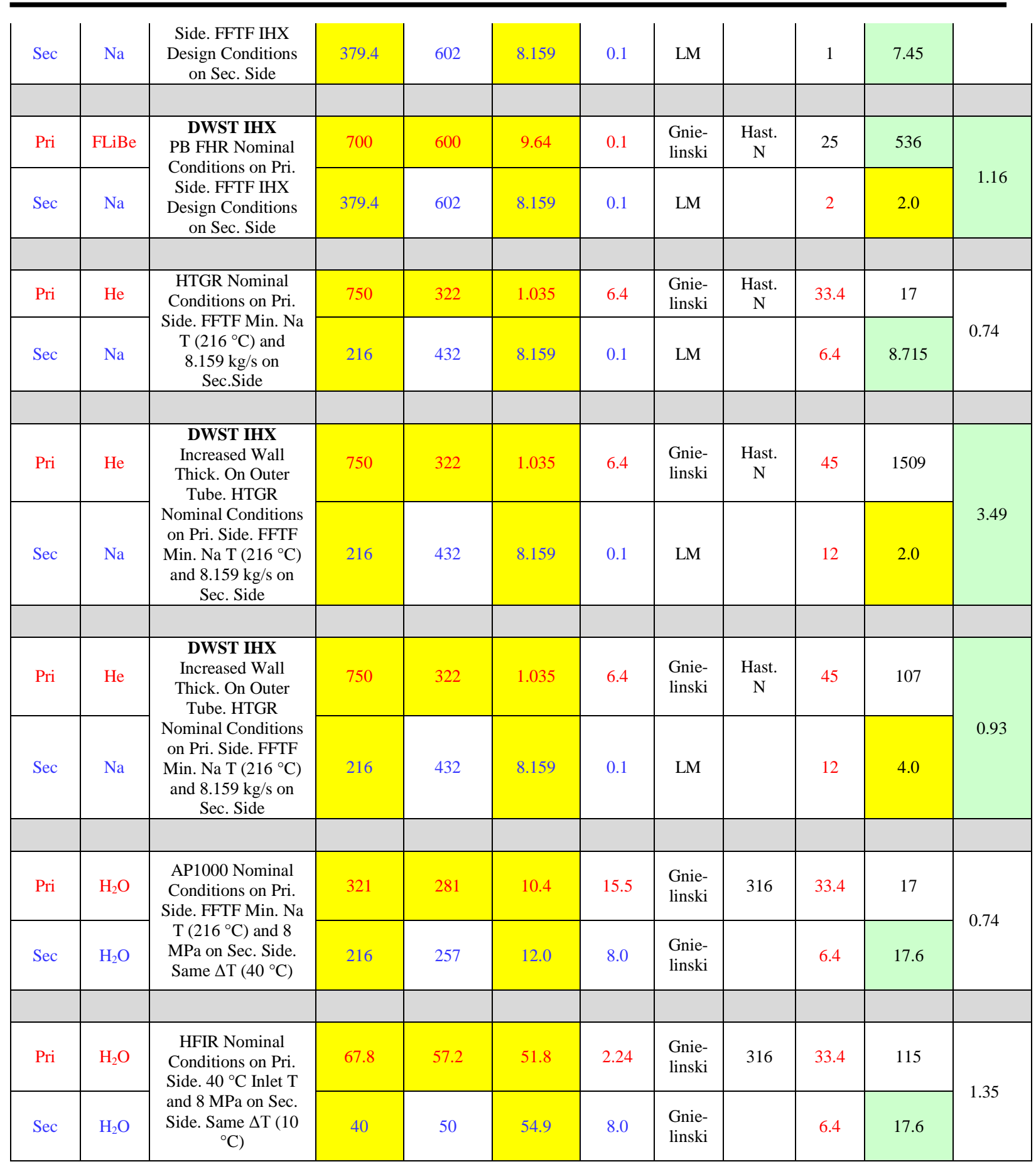

\section{Liquid Salt}

The liquid salt is assumed to be $\mathrm{FLiBe}$ which is a mixture of $\mathrm{LiF}$ and $\mathrm{BeF}_{2}$ in the proportions $2 \mathrm{LiF}-\mathrm{BeF}_{2}$, which is sometimes written as $\mathrm{Li}_{2} \mathrm{BeF}_{4}$. FLiBe is a low pressure coolant but has a freezing temperature of $460^{\circ} \mathrm{C}$. In view of the high liquid salt freezing temperature, sodium is retained as the secondary coolant for heat rejection to air. Liquid salt containing fluorine, including FLiBe, is corrosive to stainless steel as well as many other structural materials. The nickel alloy, Hastelloy N, was developed as part of the Molten Salt Reactor Experiment (MSRE) 
Program and is resistant to attack up to $700^{\circ} \mathrm{C}$. Thus, it is selected as the structural material for the primary portion of the closed loop.

Hastelloy $\mathrm{N}$ is not currently a codified material under the ASME Boiler and Pressure Vessel Code Section III. A code case would need to be prepared and accepted before a primary closed loop fabricated from Hastelloy N could be operated inside of FASTER.

Due to the corrosive nature of liquid salt, the liquid salt-to-sodium IHX must incorporate doublewalled straight Hastelloy $\mathrm{N}$ tubes and in-reactor assembly must also be double-walled Hastelloy N. Data on the compatibility of Hastelloy $\mathrm{N}$ with sodium is currently unknown. It would be straightforward to generate such data in the high temperature sodium loop for material compatibility testing with sodium at Argonne. If Hastelloy $\mathrm{N}$ turns out to undergo corrosion in sodium at high temperatures, then an option might be to use stainless steel for the IHX tube on the sodium side together with a Hastelloy $\mathrm{N}$ tube on the liquid salt side.

The IHX model was applied to the temperature conditions for both the AHTR and the Pebble Bed FHR. Liquid salt does not behave like a liquid metal such as sodium with a Prandtl number of 0.005 or lead with a Prandtl number of 0.02. Liquid salt has a large Prandtl number of 14 (Table 3-10) and behaves more like an ordinary fluid. The heat transfer coefficient on the liquid salt side is thus modeled with a correlation for an ordinary fluid. The local Nusselt number is assumed to be given by the Gnielinski correlation for the mean heat transfer coefficient along a channel:

$$
\mathrm{Nu}=\frac{\mathrm{h} \mathrm{D} h}{\mathrm{k}}=\frac{\frac{\mathrm{f}}{2}(\operatorname{Re}-1000) \operatorname{Pr}}{1+12.7\left(\frac{\mathrm{f}}{2}\right)^{\frac{1}{2}}\left(\operatorname{Pr}^{\frac{2}{3}}-1\right)}\left[1+\left(\frac{\mathrm{D}_{\mathrm{h}}}{\mathrm{L}}\right)^{\frac{2}{3}}\right] !\left(\frac{\operatorname{Pr}}{\operatorname{Pr}_{\text {wall }}}\right)^{0.11}
$$

where the friction factor is given by the Blasius friction factor, and

$$
f=\frac{0.0791}{\operatorname{Re}^{\frac{1}{4}}}
$$

and $L$ is the length of the heat exchange channel.

For the AHTR liquid salt inlet and outlet temperatures, a heat removal rate of $2.3 \mathrm{MW}_{\mathrm{t}}$, and FFTF secondary sodium design conditions, it is found that 475 double-walled straight tubes are required (Table 3-15). The resulting IHX shell inner diameter is $1.09 \mathrm{~m}$. For Pebble Bed FHR inlet and outlet liquid salt temperatures, 536 tubes are required increasing the shell inner diameter to $1.16 \mathrm{~m}$.

To mitigate corrosion and assure compatibility of the liquid salt with Hastelloy N, it is necessary to control the redox potential of the salt. This may be accomplished through the addition of metallic constituents such as zirconium or through the introduction of hydrogen or hydrogen fluoride gas. 
When irradiated with neutrons, the lithium and beryllium in FLiBe are both transmuted by reactions that form tritium. The amount of tritium generated is significant. While some may be retained in graphite moderator or graphite in TRISO fuel particles, tritium could diffuse through the Hastelloy N primary coolant piping, the IHX tubes, or the double-walled pressure tube inside of the reactor. It is therefore necessary to actively remove tritium from the liquid salt. This could be done by circulating a fraction of the liquid salt flow through a bypass loop containing a shelland-tube tritium stripper. It is also necessary to capture and trap the stripped tritium; this might be done in a second shell-and-tube reactor. This approach for removing and capturing tritium is similar to that considered for the ORNL AHTR.

In SFRs, tritium is normally cold trapped from the secondary sodium. Cold trapping is effective because for a SFR with a steam cycle power converter, there is a significant diffusion rate of hydrogen from the steam side of the steam generator through the steam generator tube walls into the secondary sodium. The diffusion of hydrogen through the steam generator tube walls results in a significant concentration of hydrogen which is cold trapped together with tritium when the sodium temperature is reduced inside of the cold trap. However, the secondary sodium of a closed loop rejects heat to air. Thus, the amount of dissolved hydrogen in the secondary sodium is too low for the concentration of hydrogen and tritium to exceed the solubility limit at the low cold trap temperature. Deliberately adding hydrogen to the secondary sodium and cold trapping might be an approach to reducing potential tritium releases from the secondary sodium loop boundary especially the sodium-to-air heat exchanger tubes. By itself, it is not a desirable overall approach at tritium trapping for the primary circuit as it would not be effective at stopping tritium diffusion through the liquid salt primary structural boundary.

In addition, there is a need for a cleanup system for the liquid salt to remove contaminants such as small graphite particles, radionuclides potentially released from failed TRISO fuel particles, as well as corrosion products such as nickel, chromium, and iron dissolved in the liquid salt.

Similar to HLMC, it is planned to use two EM pumps with liquid salt in the primary loop. The circuit for stripping and trapping tritium as well as cleaning the liquid salt will also need one or more EM pumps. Although the efficiency of an EM pump used with liquid salt might be low, it is expected to be sufficient to be practical.

It is roughly estimated that the larger IHX, redox potential control, tritium stripping and capture, and cleanup systems would require at least as much volume space as the original sodium primary cell in FFTF. Thus, the space requirement is assumed to be three times that of a sodium primary closed loop. In FASTER, this requirement is accommodated by increasing the width of the closed loop primary cell in one dimension while maintaining the height and the width in the other dimension.

The primary coolant loop cell and the containment designs must accommodate a postulated rupture of liquid salt primary pipe and release of liquid salt. FLiBe is not combustible in air. However, as noted above, a significant amount of tritium is produced in the liquid salt. Although tritium will be stripped from the liquid salt during operation of the closed loop system, there will still be some level of tritium in the salt entering the stripper that is not zero. Without knowing 
what the tritium stripping process is, it is not possible to currently estimate what that tritium level is. Thus, the release of liquid salt would be accompanied by the release of tritium into the cell atmosphere. The FASTER design needs to accommodate the release of tritium from released liquid salt that represents a health hazard in terms of transport and inhalation. Released liquid salt contains beryllium which is also a health hazard and would complicate any salt cleanup efforts.

\section{Pressurized Helium}

For pressurized helium coolant, it is necessary to provide double walls for the pressure tube of the in-reactor assembly inside of the reactor vessel to preclude small leaks of helium or a high pressure blowdown of pressurized helium into surrounding sodium. The former might potentially result in the transportation of small bubbles through the core with reactivity effects while the latter could result in the formation of void as well as pressurization of the reactor vessel. Similarly, a double-walled straight tube IHX is employed to preclude a blowdown of high pressure helium into the sodium secondary coolant.

The pressurized helium primary loop is fabricated from $800 \mathrm{H}$. Incoloy $800 \mathrm{H}$ is the only high temperature and high strength alloy that is currently codified for use under the ASME Boiler and Pressure Vessel Code Section III and is selected for that reason.

Helium is the only closed loop primary coolant considered that is in a gaseous state. Because of the low gas density even at a pressure of $6.39 \mathrm{MPa}$, it has the highest volumetric flowrate and velocity. Removing $2.3 \mathrm{MW}_{\mathrm{t}}$ at the GA HTGR inlet and outlet temperature conditions would require high helium velocities through 3 inch piping. It is desired to limit the helium velocities. Assuming a limit of $20 \mathrm{~m} / \mathrm{s}$, it is calculated that the primary loop hot leg piping inner diameter would need to be enlarged to $0.15 \mathrm{~m}$ ( $5.8 \mathrm{inch}$ ). For a 6 inch Schedule 160 pipe, the inner diameter is $0.13 \mathrm{~m}(5.2 \mathrm{inch})$. Using such a pipe size could increase the maximum helium velocity by $26 \%$ from the $20 \mathrm{~m} / \mathrm{s}$ value to $25 \mathrm{~m} / \mathrm{s}$. This is regarded as acceptable. Thus, for helium coolant, the primary coolant pipe size would need to be increased to 6 inches.

The DWST IHX model was applied for the removal of $2.3 \mathrm{MW}_{\mathrm{t}}$ assuming the FFTF sodium secondary design inlet temperature and flowrate but lowering the outlet temperature to $432^{\circ} \mathrm{C}$. For each double-walled tube, it is assumed that the inner tube is a 1 inch Schedule 160 tube and that the outer tube has the same wall thickness. Thus, the double-walled tube outer diameter is $4.5 \mathrm{~cm}$ and the total wall thickness is $12 \mathrm{~mm}$. It is found that 1509 double-walled tubes of $2.0 \mathrm{~m}$ length are required resulting in an IHX shell inner diameter of $3.49 \mathrm{~m}$. This is a large diameter. The calculation assumes that the tube surface on the helium side is bare. By incorporating fins on the helium surface, the effective heat transfer area from helium could be enhanced, reducing the required number of tubes. However, this was not done. Instead, the DWST length was increased to $4.0 \mathrm{~m}$. This allows the number of tubes to be dramatically reduced to 107 and the shell inner diameter to be reduced to $0.93 \mathrm{~m}$.

Assuming the calculated required piping dimensions for the $20 \mathrm{~m} / \mathrm{s}$ velocity limit, pressure drops were estimated for the piping lengths, IHX, and test section for the flow conditions at $2.3 \mathrm{MW}_{\mathrm{t}}$ heat removal rate. Most of the pressure drop occurs inside of the test section inside of the inreactor assembly due to the relatively small hydraulic diameter of the coolant flow channels 
through the graphite. A test section pressure drop of $0.21 \mathrm{MPa}$ is estimated. The total pressure drop is estimated to be $0.28 \mathrm{MPa}$.

A helium circulator is required to circulate the pressurized helium through the primary loop. It is possible to size the circulator by selecting a desired circulator design (e.g., a high efficiency centrifugal/radial circulator) and non-dimensional specific diameter $\left(\mathrm{D}_{\mathrm{s}}\right)$ plus non-dimensional specific speed $\left(\mathrm{N}_{\mathrm{s}}\right)$ from a $\mathrm{N}_{\mathrm{s}}-\mathrm{D}_{\mathrm{s}}$ diagram appropriate for that design. $A \mathrm{~N}_{\mathrm{s}}-\mathrm{D}_{\mathrm{s}}$ diagram is shown in Figure 3-9 together with the selected operating point for a radial circulator. For the selected values of $\mathrm{N}_{\mathrm{s}}=60$ and $\mathrm{D}_{\mathrm{s}}=2$, it is calculated that the required rotor diameter is $0.14 \mathrm{~m}(5.5$ inches) and the required shaft speed is 25,000 revolutions per minute (rpm). The circulator casing outer diameter would be about twice the rotor diameter or about $0.28 \mathrm{~m}$ (11 inches). Thus, the circulator size is physically small. The shaft speed is high but small compressors have been designed, built, and installed in supercritical carbon dioxide test loops for shaft speeds up to $75,000 \mathrm{rpm}$. Thus, the required helium circulator is judged to be within existing technology. The circulator impeller and other internal parts can be fabricated from materials other than $800 \mathrm{H}$, since they are not part of the pressure boundary.

A system is needed to charge the helium primary loop with helium and to make up for leakages. That system will include a helium storage vessel/tank, a charging helium compressor, valves, and interconnecting piping. The storage vessel and charging compressor can be located outside of the containment with piping passing through the containment boundary into the primary loop cell. A high pressure helium system may be inherently leaky. Helium leakage was significant at the Fort St. Vrain Nuclear Power Plant. Thus, there might be a need to regularly make up for helium losses from the primary helium loop.

Because helium does not react significantly with structural materials, the chemistry control and cleanup system requirements for the helium primary loop are expected to be relatively minimal.

It is expected that a helium primary coolant loop can be designed to fit inside of the same cell volume as one of the FFTF primary closed loops.

The primary cell and containment designs must accommodate a postulated rupture of a primary helium pipe. Helium is an inert gas but the release could pressurize the cell as well as raise the temperature of the cell atmosphere. 


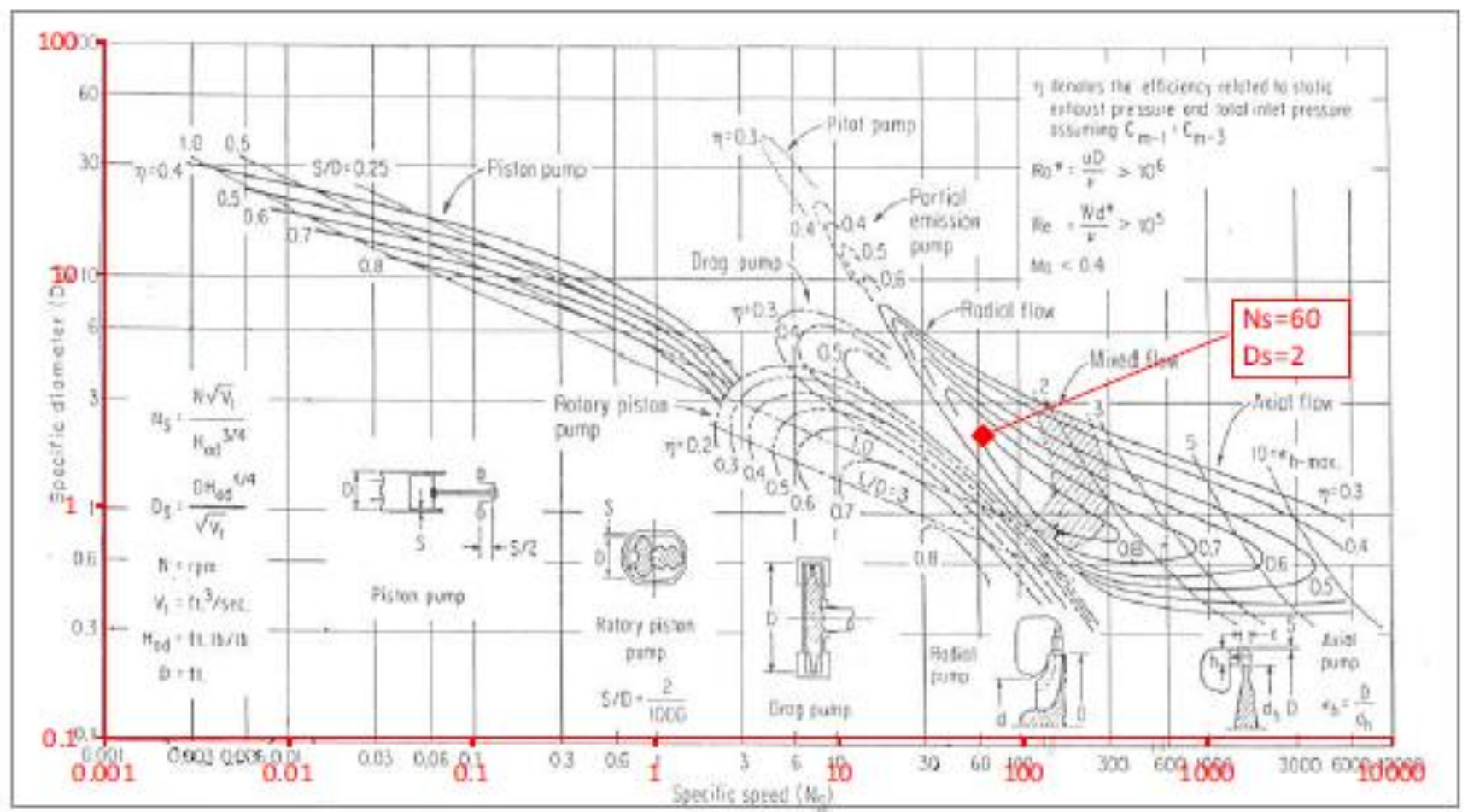

Figure 3-9: $\mathrm{N}_{\mathrm{s}}-\mathrm{D}_{\mathrm{s}}$ Diagram for Pumps with Selected Helium Pump Operating Point Highlighted

\section{Pressurized Water for LWR NPP Conditions}

For pressurized water closed loop systems, it is necessary to provide a double wall between the water and the reactor vessel sodium to preclude the leakage of water/steam into the reactor vessel sodium or a blowdown of high pressure water/steam into the surrounding sodium together with sodium-water reactions. It is also prudent to create a vacuum between the two walls to reduce heat transfer from the hotter surrounding sodium to the flowing water. The gap between the two walls will be monitored for leaks. The primary water loop transfers heat to a secondary pressurized water loop that rejects heat to the atmosphere heat sink. A secondary sodium loop is not used to further eliminate the possibility of sodium-water reactions. In addition to eliminating the risk of sodium-water reactions inside of a heat exchanger, this choice also eliminates the presence of both water and sodium piping inside of the primary closed loop cell. Only water piping and components are present inside of the primary closed loop cell. Another reason to use water as the secondary coolant is that for some applications heat may be rejected to the atmosphere at temperatures below the sodium freezing temperature or above but near to the sodium freezing temperature.

PWRs typically utilize ferrtic low alloy and carbon steels clad with stainless steel for corrosion resistance. It is expected that the same materials would be used for the primary and secondary water closed loops.

The primary water coolant loop is similar to the primary coolant circuit of a PWR. It incorporates a pressurizer to pressurize the loop and maintain the pressure together with two or more mechanical pumps to circulate the water at pressure. At least two pumps are provided such that flow can be maintained, in the event that one of the pumps fails. Canned rotor pumps will be 
used as they eliminate water leakages. It is desired to minimize the likelihood of water releases inside of the cell.

The IHX model was applied with pressurized water on both the primary and secondary sides. It is not necessary to use a double-walled straight tube IHX. A helical coil IHX similar to the FFTF IHX design is assumed with seventeen thick-walled 316 tubes to withstand the high primary loop pressure. Each tube is assumed to be a 1 inch Schedule 160 pipe having an outer diameter of 3.34 $\mathrm{cm}$ and a wall thickness of $6.4 \mathrm{~mm}$. The AP1000 primary coolant inlet and outlet temperatures are assumed together with the flowrate for $2.3 \mathrm{MW}_{\mathrm{t}}$ heat removal rate. A pressure of $8 \mathrm{MPa}$ is assumed on the secondary water side as well as the FFTF secondary inlet temperature to the IHX of $216^{\circ} \mathrm{C}$. It is found that with a tube length of $17.6 \mathrm{~m}$ that a secondary outlet temperature of $257^{\circ} \mathrm{C}$ is calculated (Table 3-15). This is a reasonable temperature. The tube length is a little more than twice the tube length calculated for the FFTF IHX such that a compact helical coil water-to-water IHX design is practical.

The primary pressurized water loop also incorporates a heater and a bypass line that can be used to preheat the water before it is introduced to the test section inside of the reactor vessel. This is necessary to avoid thermal shocking of the in-reactor assembly and the test section when flowing water at a prototypical inlet temperature is introduced to the in-reactor assembly after it has resided inside of the reactor vessel and has been heated to the higher temperature of the surroundings.

Similar to a PWR, the primary pressurized water loop needs a system to compensate for leakages, control the coolant chemistry, and clean up unwanted radionuclides from the coolant. The Chemical and Volume Control System (CVCS) for the primary coolant loops is similar in principle to that of the AP1000 PWR where it is denoted as the CVS. The CVCS is needed to control the $\mathrm{pH}$ of the coolant, scavenge oxygen from the coolant during heatup, and control radiolysis reactions involving hydrogen, oxygen, and nitrogen. The CVCS incorporates a regenerative heat exchanger to cool water let down from the primary loop cold leg and preheat treated water prior to returning it to the suction side of the primary loop pumps. The CVCS also incorporates mixed bed demineralizers, a cation bed demineralizer, and filters. Similar to the AP1000, the CVCS does not incorporate a pump. Instead the head provided by the primary loop pumps is utilized to circulate the coolant through the CVCS. In the AP1000 design, this was done to eliminate the possibility of pump failure; otherwise the pump would have had to be safety grade.

The mixed bed demineralizers have the external shape of cylindrical vessels. One is normally always in service. They remove ionic corrosion products as well as certain ionic fission products and also act as filters. The cation bed demineralizer also has the external shape of a cylindrical vessel. In the event of fuel failure, it is used to remove mainly lithium and cesium isotopes. It is also used to control the primary coolant $\mathrm{pH}$. The AP1000 CVS controls $\mathrm{pH}$ through the addition of lithium hydroxide enriched to $99.9 \%$ in ${ }^{7} \mathrm{Li}$. The AP1000 uses hydrazine to scavenge oxygen from the coolant. High pressure hydrogen is injected into the coolant to control water decomposition from radiolysis; hydrogen reacts with oxygen formed by radiolysis. Ideally, the coolant will also contain boron to be prototypical of PWR coolant. This needs to be examined in terms of its effects on the thermalized neutron flux. 
The CVCS is connected to a liquid radwaste system and a coolant makeup system providing demineralized water with suitable chemicals added located outside of the containment. Some components of those systems can be housed together with the water secondary loop components outside of the containment.

The primary water loop cell and the secondary water loop compartment or building will incorporate floor sumps and drains to collect any water leakages for processing by a water leakage collection system.

The primary coolant loop and the CVCS incorporate a number of components with space requirements including the pressurizer, IHX, heater, pumps, and the demineralizers. It is roughly estimated that the primary loop needs three times the volume of a primary coolant system cell in the FFTF. In FASTER, this volume requirement is accommodated by increasing the width of the closed loop primary cell in one dimension while maintaining the height and the width in the other dimension.

The primary loop cell and containment designs must accommodate a postulated pressurized water pipe rupture and the release of pressurized water and steam. Flashing of pressurized water will result in pressure and temperature loadings inside of the cell atmosphere.

\section{Pressurized Water for Water-Cooled and Water Moderated Research and Test Reactor}

\section{Conditions}

For the HFIR research and test reactor conditions in Table 3-10, it is observed that the temperatures are significantly lower and the water coolant flowrate significantly higher than for a PWR Nuclear Power Plant. Ideally, one would want to design a primary pressurized water closed loop, IHX, secondary pressurized water closed loop, and DHX that could encompass testing for both reactor types and both sets of pressurized water conditions.

The IHX model was applied to determine if the IHX design in Table 3-15 developed for AP1000 temperature conditions could also work for HFIR temperature conditions for a heat duty of 2.3 $\mathrm{MW}_{\mathrm{t}}$. A negative answer was obtained. In particular, if the secondary water flowrate is assumed equal to the primary water flowrate and the secondary coolant temperature rise is assumed to be $10^{\circ} \mathrm{C}$, then the secondary water inlet temperature to the IHX would need to be $0^{\circ} \mathrm{C}$. This result indicates that a significantly greater heat exchange area is required in the IHX.

Holding the IHX tube length fixed at $17.6 \mathrm{~m}$ and the tube outer diameter and wall thickness fixed at $3.34 \mathrm{~cm}$ and $6.4 \mathrm{~mm}$, the number of rows of tubes inside of the IHX was increased. It is thought that the seventeen-tube FFTF IHX design incorporated two rows of helical coil tubes with eight tubes in the first row and nine tubes in the second row. Thus, the number of tubes in each row increases by one as a row is added. It is assumed that the secondary pressurized water inlet temperature to the $\mathrm{IHX}$ is $40^{\circ} \mathrm{C}$ and that the temperature rise is $10^{\circ} \mathrm{C}$. It is found that an IHX design with 115 helical coil tubes in ten rows is needed. The shell inner diameter is $1.35 \mathrm{~m}$. A significantly larger DHX would also be required due to the low secondary coolant temperatures. The high water flowrates for HFIR conditions would also require larger piping 
diameters. Thus, the need for a separate closed loop system design is indicated for research and test reactor conditions.

For the low primary pressurized water temperatures, it is necessary to create a vacuum between the double walls of the pressure tubes inside of the reactor vessel or otherwise thermally insulate the test section from the hotter temperatures of the surroundings.

The requirements for a CVCS are expected to be similar to those described above. In addition, the pressurized water system primary loop for research and test reactor conditions also needs to provide chemistry control for aluminum alloy clad research and test reactor fuels and aluminum alloy structures. The cell volume requirement for the primary coolant loop is estimated to be three times that of the primary coolant cell in FFTF.

The primary loop cell and containment designs must accommodate a postulated pressurized water pipe rupture and the release of pressurized water and steam. Flashing of pressurized water will result in pressure and temperature loadings inside of the cell atmosphere.

\subsubsection{Inlet Plenum Module}

The primary coolant flow into the FASTER core assemblies is via the inlet plenum modules. These modules are designed with multiple inlets to prevent plugging in case of loose parts in the reactor vessel and provide for the necessary flow to each of the core assemblies. The individual core assemblies do not have (in general) their own individual orificing to balance the sodium coolant flow across the core - this is accomplished by the inlet plenum modules. Similar to the PRISM inlet module concept, the inlet plenum modules have a location for orifice plates to be inserted into the inlet module to provide for the necessary flow balancing. A discrimination post is located in the module to ensure that only core assemblies that are a match for the particular inlet plenum module are actually inserted into the module. The core assemblies that are inserted in the wrong inlet module will not be fully inserted into the inlet modules - this condition will be noticed by the in-vessel fuel handling machine(s) during the insertion of the new or used core assembly. The in-vessel fuel handling machine(s) has instrumentation and features to monitor the azimuthal and vertical location of the core assemblies in relation to other permanent structures within the reactor vessel.

The inlet plenum modules have an outer receptacle body which forms the overall module and spans the distance between the two grid plate structures. Inner chamfers in the outer receptacle body provide for alignment and guides during insertion of the core assemblies into the receptacles when using the pantograph in-vessel fuel handling machine. Piston rings located at the lower end of the outer receptacle body seal the receptacle body to the lower grid plate structures. The receptacle body has multiple inlet flow holes that provide for high pressure sodium flow into the receptacle body even if one or more of the flow holes are blocked. When the sodium coolant enters the inlet module through the flow holes, it makes a $90^{\circ}$ turn from a radial (horizontal) direction to the axial (vertical) direction and flows up into the receptacle body. Depending upon the zone of the core assembly, the sodium will flow through a series of (zero to 9) stacked orifice plates which provide for flow balancing across the core. Each orifice plate has multiple holes to ensure the core assembly receives flow in the event that one or more of the 
orifice plate holes are plugged. After exiting the stacked orifice plate (depending upon the flow zone), the sodium flows into the bottom of the core assembly lower adaptor. The lower adaptor contains multiple inlet flow holes to ensure that if one or two of the inlet flow holes are plugged that the core assembly is not starved for coolant flow. The core assembly is sealed to the inlet plenum module with piston rings located in the core assembly lower adaptor. A flow balancing hole is drilled axially through the center of the inlet module body (inner receptacle body) to allow for hydraulic hold-down of the individual core assemblies. The core assemblies are held in place vertically by a combination of their own weight and hydraulic hold-down.

\subsubsection{Core Orificing Approach and Analysis}

In order to achieve the desired flux levels, the FASTER core has been designed with a very high power density and therefore adequate coolability of the core needs to be ensured. The multiassembly steady state thermal hydraulic code SE2-ANL [14] is used to determine orifice groups and calculate the required coolant flow rates and temperature distributions. The inlet coolant temperature is $355^{\circ} \mathrm{C}$ and the bulk outlet coolant temperature is $510^{\circ} \mathrm{C}$, corresponding to an average coolant temperature rise of $155^{\circ} \mathrm{C}$. These temperatures are typical for SFRs with metallic fuel.

In order to limit the peak coolant and peak mid-wall cladding temperatures to acceptable values it was found that using four orifice groups for the fuel assemblies is sufficient. The temperature distribution has also been determined when using a larger number of groups, but this resulted in a reduction of the peak temperatures of only a few degrees. The proposed orifice groups are represented in Figure 3-10.

Seven orifice groups are used for the non-fuel assemblies, but the flow rates in those assemblies are significantly smaller than in the fuel assemblies, meaning it is possible to use more or fewer groups without significantly affecting the bulk outlet coolant temperature. Additionally, test assemblies and closed loop locations are currently modeled with reflector assemblies and will likely require specific orifice sizes depending on the desired test conditions.

The coolant flow rate, velocity, number of assemblies, and other characteristics are provided in Table 3-16 for each orifice group shown in Figure 3-10. The temperatures are provided in ${ }^{\circ} \mathrm{C}$. The coolant velocity required in the orifice group containing the highest power assemblies is $\sim 10$ $\mathrm{m} / \mathrm{s}$. This is only the coolant velocity required inside the active fuel region, and is different from the velocity of the coolant exiting the core and going to the heat exchanger. The peak $2 \sigma$ midwall temperature for the non-fuel assemblies is larger than for the fuel assemblies, but this is not a concern since no fuel-cladding interaction will occur in those assemblies. By increasing the coolant flow rate in those non-fuel assemblies, the mid-wall temperature could be easily reduced, but this would also result in a lower coolant outlet temperature. This would in turn slightly reduce the average core outlet temperature, but only by a few tenths of a degree given the significantly lower flow rate in the non-fuel assemblies compared to the fuel assemblies.

The large required coolant velocity in the fuel assemblies is a direct result of the large power density of the FASTER core. Although this velocity is larger than typically reported in more conventional fast reactor designs, there is no counter-indication to this value. Velocities reported 
in Table 3-16 should not be confused with the coolant velocity on the piping of the primary system, as it typically requires lower velocities to prevent adverse mechanical issues. The only potential issue of a large core coolant velocity is the resulting large pressure drop, which might make it difficult to establish natural circulation in some accident scenarios when it gets too large. Initial safety analyses of the FASTER core indicated that no such issue was encountered.

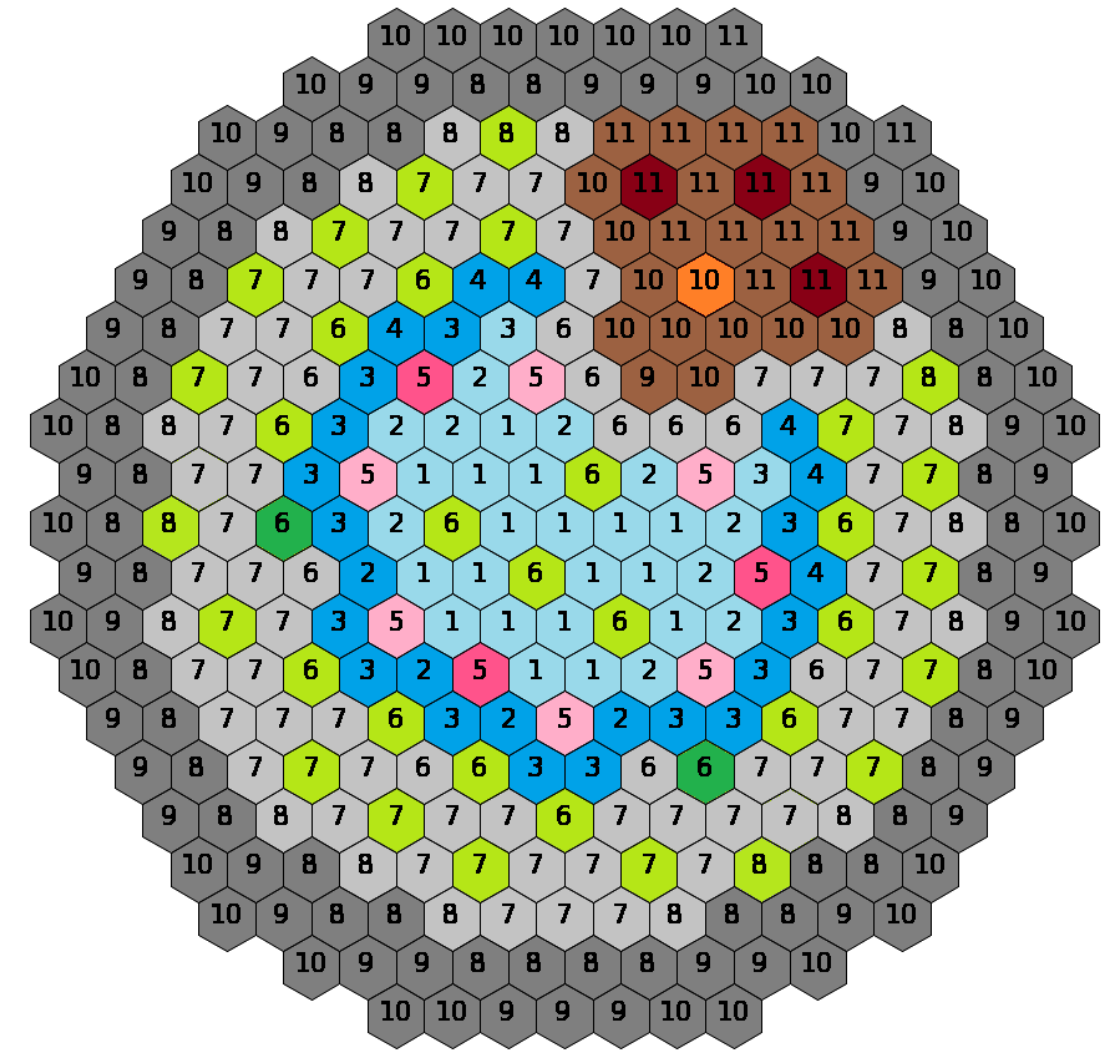

Figure 3-10: FASTER Orifice Groups

Table 3-16: Coolant Flow Characteristics for Each Orifice Group (4 Fuel Groups)

\begin{tabular}{|c|c|c|c|c|c|c|c|c|}
\hline & Group & $\begin{array}{c}\text { Assembly } \\
\#\end{array}$ & $\begin{array}{l}\text { Flow Rate } \\
\text { /Assy, kg/s }\end{array}$ & $\begin{array}{l}\text { Total Flow } \\
\text { Rate, kg/s }\end{array}$ & $\begin{array}{c}\text { Velocity, } \\
\mathbf{m} / \mathbf{s}\end{array}$ & $\begin{array}{c}\text { Avg. Outlet } \\
\text { Coolant } \\
\text { Temp., }{ }^{\circ} \mathrm{C}\end{array}$ & $\begin{array}{c}\text { Peak Outlet } \\
\text { Coolant } \\
\text { Temp., }{ }^{\circ} \mathrm{C}\end{array}$ & 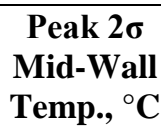 \\
\hline \multirow{4}{*}{ త্ } & 1 & 18 & 34.53 & 621.5 & 10.3 & 510 & 549 & 587 \\
\hline & 2 & 14 & 28.07 & 392.9 & 8.4 & 510 & 548 & 587 \\
\hline & 3 & 17 & 21.43 & 364.3 & 6.4 & 510 & 549 & 587 \\
\hline & 4 & 6 & 16.77 & 100.6 & 5.0 & 513 & 550 & 587 \\
\hline \multirow{7}{*}{ 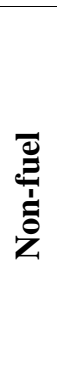 } & 5 & 9 & 0.55 & 4.95 & $<1$ & 506 & 744 & n.a \\
\hline & 6 & 26 & 0.55 & 14.3 & $<1$ & 514 & 779 & 1039 \\
\hline & 7 & 67 & 0.22 & 14.9 & $<1$ & 499 & 667 & 909 \\
\hline & 8 & 56 & 0.068 & 3.82 & $<1$ & 495 & 589 & 786 \\
\hline & 9 & 37 & 0.018 & 0.68 & $<1$ & 480 & 553 & 739 \\
\hline & 10 & 46 & 0.006 & 0.28 & $<1$ & 473 & 525 & 620 \\
\hline & 11 & 17 & 0.001 & 0.02 & $<1$ & 489 & 533 & 636 \\
\hline
\end{tabular}


The various peak temperatures obtained by using a different number of orifice zones for the fuel assemblies are summarized in Table 3-17. The values provided for the " 4 groups" case correspond to the proposed orifice layout and are consistent with the results shown in Table 3-16. By using 6 groups instead of 5, the coolant and mid-wall cladding temperatures are reduced by only a few degrees, while when using fewer groups these temperatures are increased by about $+8^{\circ} \mathrm{C}$. Although the temperatures obtained for the steady-state using 3 orifice groups (for fuel assemblies) seem acceptable, temperatures reached during transients will be higher and might be limiting. Additional transient calculations would be required to verify whether or not 3 orifice groups could be used.

Table 3-17: Maximum Temperatures $\left({ }^{\circ} \mathrm{C}\right)$ for Various Numbers of Fuel Orifice Groups

\begin{tabular}{|c|c|c|c|c|c|c|c|}
\hline \multirow[b]{2}{*}{ Fuel orifices } & \multicolumn{2}{|c|}{ Nominal coolant out } & \multicolumn{2}{|c|}{ Peak coolant out } & \multicolumn{3}{|c|}{$2 \sigma$ mid-wall clad } \\
\hline & BOC & EOC & BOC & EOC & BOC & EOC & Peak \\
\hline 3 groups & 535 & 532 & 556 & 556 & 595 & 595 & 595 \\
\hline $4 \mathrm{grol}$ & (2) & 52 & 5 & 55 & 7 & 587 & 587 \\
\hline 5 groups & 522 & 521 & 542 & 54 & 579 & 579 & 579 \\
\hline 6 groups & 521 & 518 & 540 & 540 & 577 & 577 & 577 \\
\hline
\end{tabular}

\subsubsection{Lower Internals Structure Assembly}

The lower internals structure supports the reactor inlet plenum, the core assemblies, the fixed radial shielding, the 4 sodium inlet pipes, and various shields, brackets and baffles. It is designed to withstand seismic events with acceptable stresses and deflections. The lower internal structure contains the inlet coolant flow distribution system that controls the rate of flow to the core assemblies. This distribution system consists of an annular-shaped manifold and associated piping that encircles the inlet coolant plenum. The plenum or grid assembly does not have a high and low pressure plenum. The core assemblies are individually orificed as discussed above to provide sufficient flow through the fuel assemblies, reflector assemblies, and shield assemblies. Four large pipes carry coolant from the primary pumps into the inlet manifold.

\subsubsection{Core Barrel Assembly}

The core barrel assembly is a single integrated unit that provides the internal structure for the reactor core assemblies and provides a barrier between the hot and cold sodium pools. The core barrel is a right circular cylinder fabricated from stainless steel. It is attached to the inlet plenum and lower support structure. It also provides support for the core restraint system.

\subsubsection{Redan Assembly}

The core barrel and redan assembly, illustrated in Figure 3-11 is a single integrated unit that provides the internal structure for the reactor core assemblies and provides a barrier between the hot and cold sodium pools. The core barrel is a right circular cylinder fabricated from stainless steel. It is attached to the inlet plenum and lower support structure. The upper portion of the redan consists of a conical shell and cylindrical shell with lobes that encircle the IHXs. The IHXs penetrate through the conical portion of the redan from the inside (sodium hot pool) to the outside (sodium cold pool). The penetrations are sealed to prevent mixing of hot and cold 
sodium. All other major components, primary pumps, and the Direct Reactor Auxiliary Cooling System (DRACS) are located outside of the redan and in the cold pool of the reactor. This arrangement enables the maximum amount of cold sodium to exist within the reactor vessel for absorption of heat during transients.

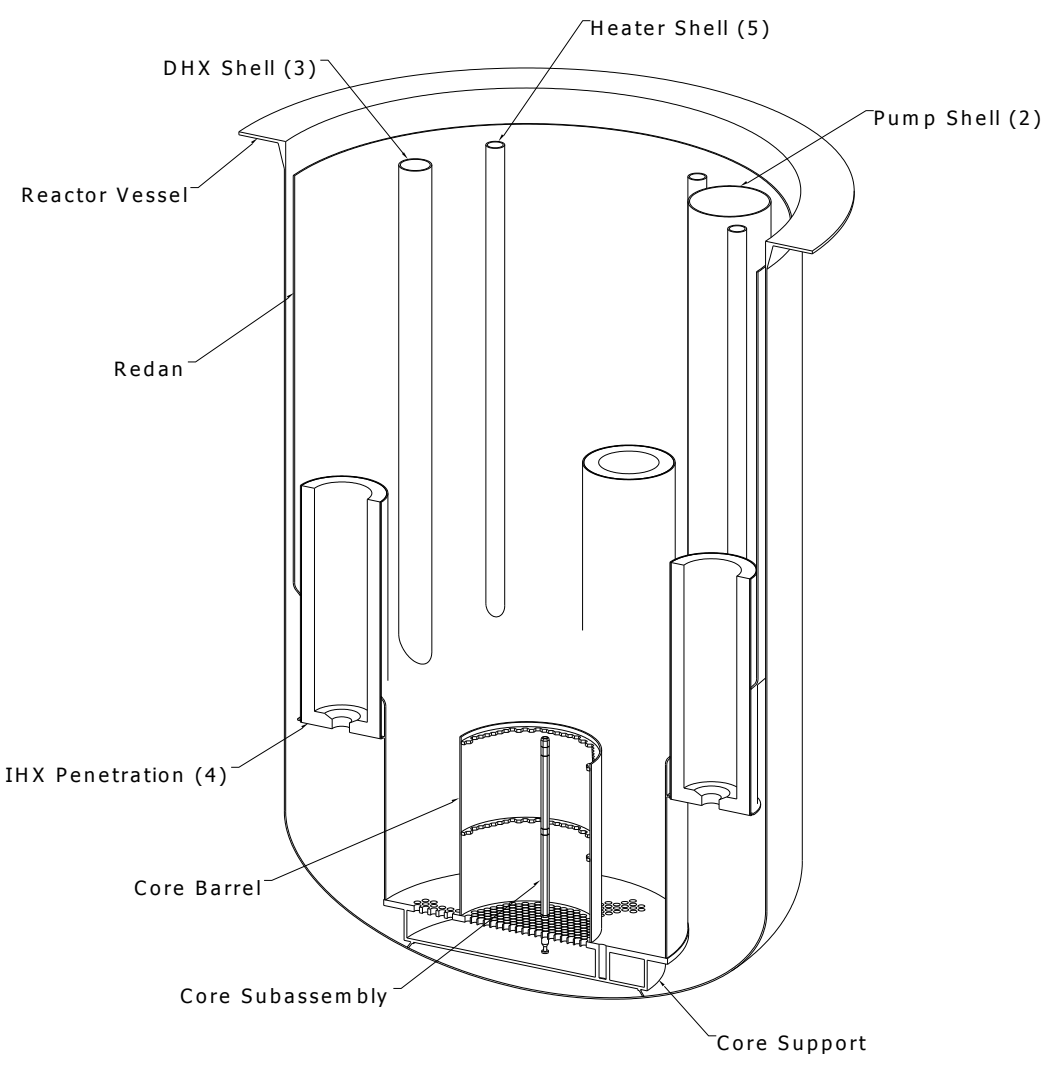

Figure 3-11: Redan Structure

The use of an open-sodium outlet-plenum concept, such as use of the redan to direct the hot outlet coolant to the IHXs results in several key design features:

- An instrument tree(s), is (are) required for flow, temperature, and monitoring of the core outlet coolant.

- Space used for closed outlet sodium piping (such as that used on EBR-II and Phenix) is not required, thus leading to a less complicated reactor primary system.

- The vertical lift distance required for handling fuel subassemblies is reduced when using the open-outlet-plenum.

- The reactor vessel top closure (deck) is exposed to hot primary sodium $\left(950^{\circ} \mathrm{F} / 510^{\circ} \mathrm{C}\right)$, which presents certain major structural design challenges for the reactor vessel and deck.

- Insulation and cooling of the deck is required.

- Insulation and cooling of the reactor vessel wall is a special concern. 
- Flow baffles are required above the core outlet sodium in order to obtain a quiescent hot sodium pool free surface.

- Low differential liquid levels between the hot and cold sodium requires a low pressure drop through the IHX.

\subsubsection{Upper Internal Structure (UIS) and Instrumentation Trees}

The Upper Internal Structure for FASTER consists of several components, a short fixed structural assembly which is located in the hot pool above the reactor core, and three rotatable structural assemblies called "Instrument Trees" (located below the fixed UIS) which contain segments of the control rod drivelines and the instrumentation for monitoring the core outlet temperatures. The fixed portion of the upper internal structure is a cylindrical stainless steel assembly welded to the vessel cover (Figure 3-12). Sensor assemblies are mounted to the underside of the instrument trees and locate sensors within three inches of the core assembly coolant outlets during operational mode to monitor the coolant temperature and flow parameters. Instrumentation conduits are routed from the top of the vessel cover (for maintenance or replacement access) through the instrument tree support columns and attach to the top of the sensor assemblies which extend below the bottom of the instrument tree.

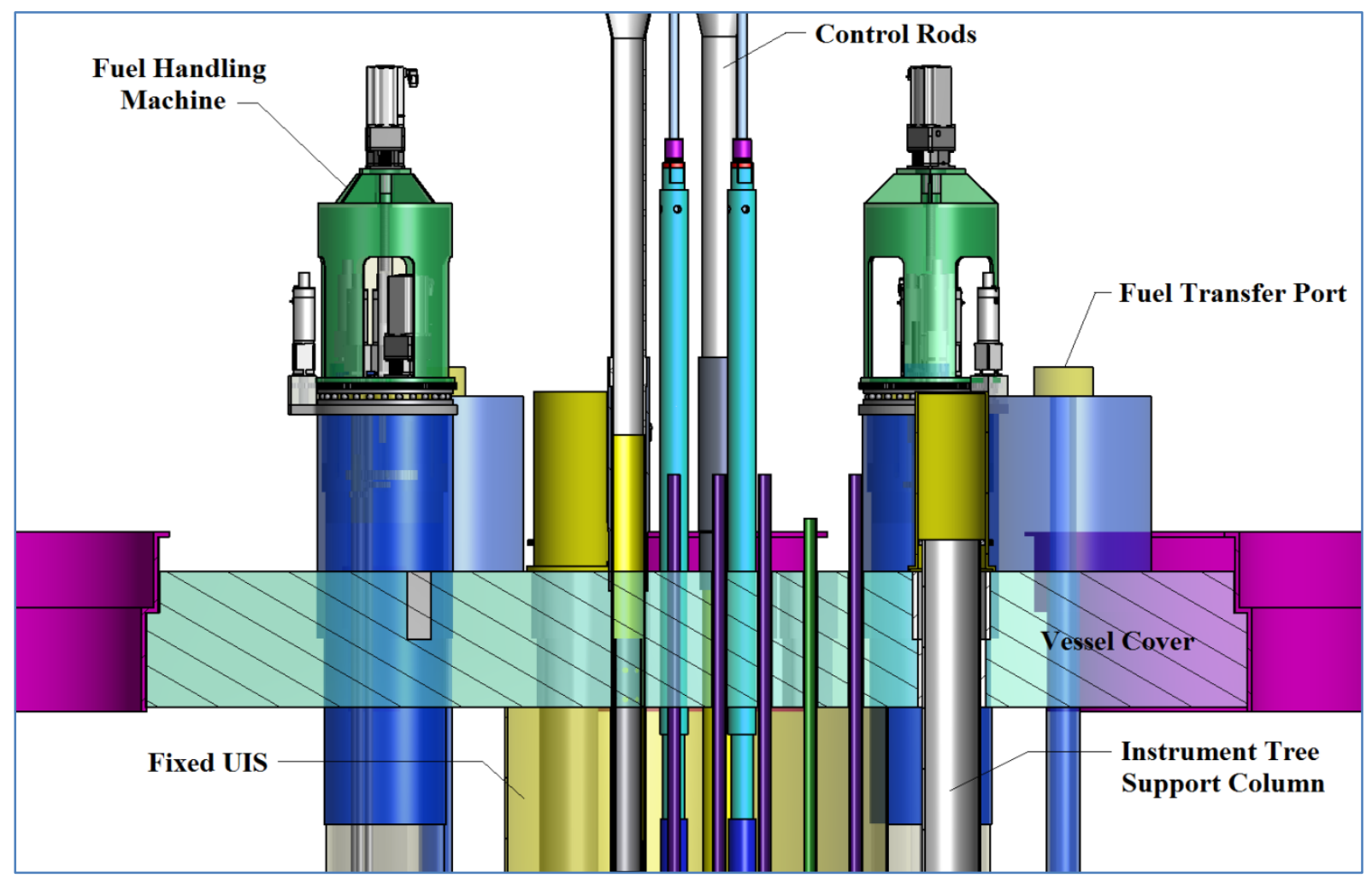

Figure 3-12: Detailed Section View through the FASTER Vessel Cover

Several penetrations are located in the vessel cover (Figure 3-13) for mechanical and electrical connections which support fuel handling systems for FASTER. The penetrations which pass through the FASTER vessel cover consist of: 
- Nine - 7.5" $(19.1 \mathrm{~cm})$ diameter penetrations for the control rods,

- Three - Large penetrations for removal or replacement of the instrument trees,

- Ten $-8 "(20.3 \mathrm{~cm})$ diameter penetrations for the closed loop and instrumented test assemblies,

- Three - 8" $(20.3 \mathrm{~cm})$ diameter penetrations for fuel transfer positions, and

- Three - 28.0" $(71.1 \mathrm{~cm})$ diameter penetration for the Fuel Handling Machines.

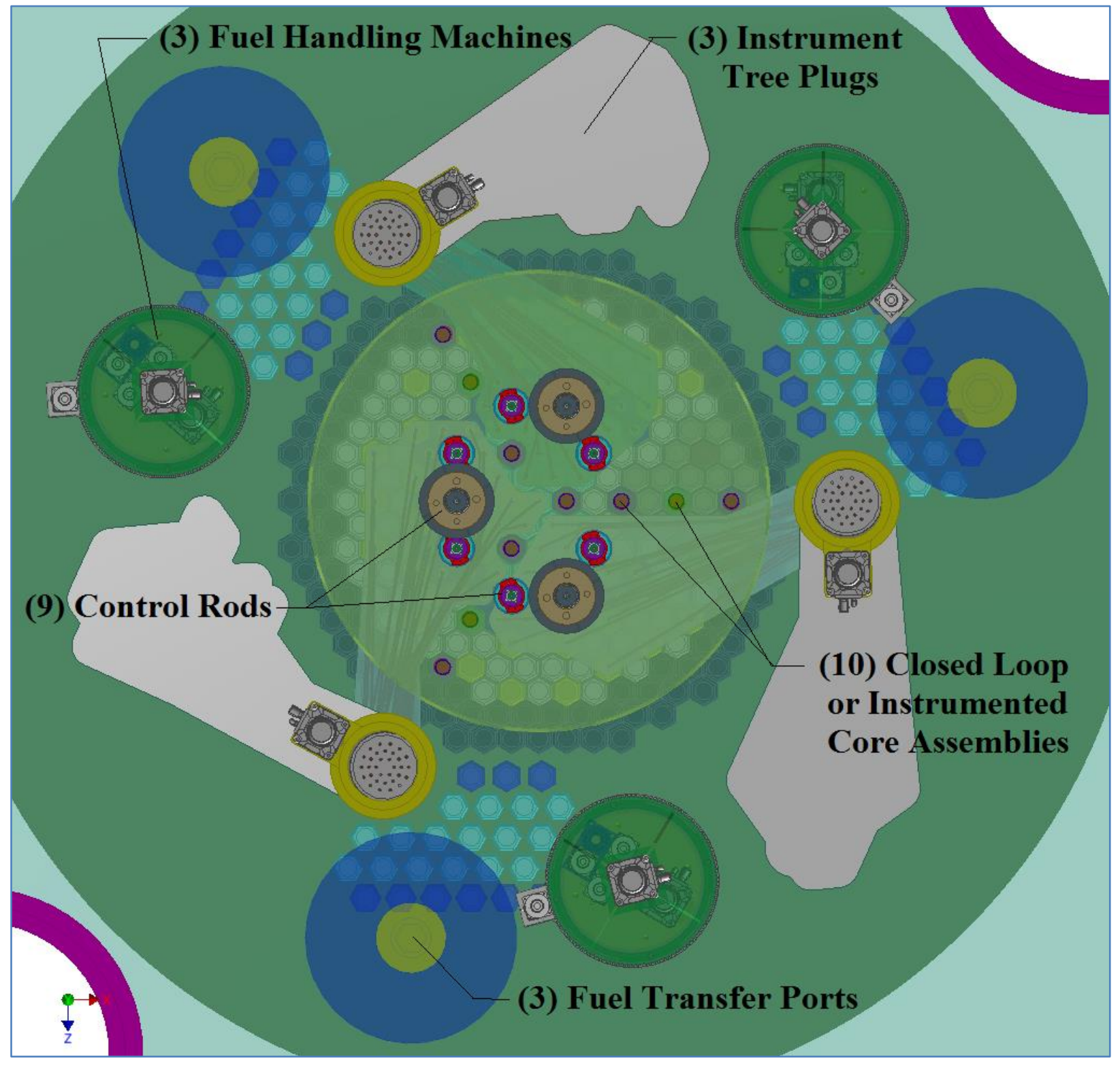

Figure 3-13: Plan View of FASTER Reactor Vessel Arrangement (Translucent Vessel Cover) 
The functional requirements of the upper internal structure and instrument trees are:

1. Provide secondary core hold down for the fuel, blanket (if any), reflector, shield and control assemblies.

2. Maintain vertical alignment between the core assemblies, the UIS, instrument trees and the reactor closure head assembly.

3. Align the Control Rod Drivelines (CRDL) horizontally to the control rod positions in the core to within $1 / 8 "(0.32 \mathrm{~cm})$.

4. Provide some flow into the control rod drivelines to ensure negative reactivity feedback during overheating transients.

5. Limit flow induced vibration and mechanical loading on the control rod drivelines due to cross flow in the outlet plenum.

6. Provide for mixing of the coolant thermal environment to the IHX less than $550^{\circ} \mathrm{C}$.

7. Provide for a quiescent pool of sodium within the reactor vessel.

8. Support the control system dashpots and react to the scram arrest dashpot loads.

9. Limit leakage of cover gas through all UIS to head penetrations to as low as reasonably achievable.

10. Provide radiation shielding for all UIS to head penetrations.

11. Provide support for routing "in-vessel instrumentation" to selected core assemblies.

12. Operate for 60 years without replacement of components exclusive of instrumentation and design the routes to allow replacement of thermocouples, etc.

13. Capability of UIS removal after installation and/or operation of the reactor.

14. Provide access to reactor assemblies for the Fuel Handling Machine (FHM) and provide passage for removable reactor assemblies and components.

15. Provide a plug with shielding and sealing capabilities to occupy the FHM access passage.

16. Provide a source of material (sample coupons) for surveillance of the UIS. 


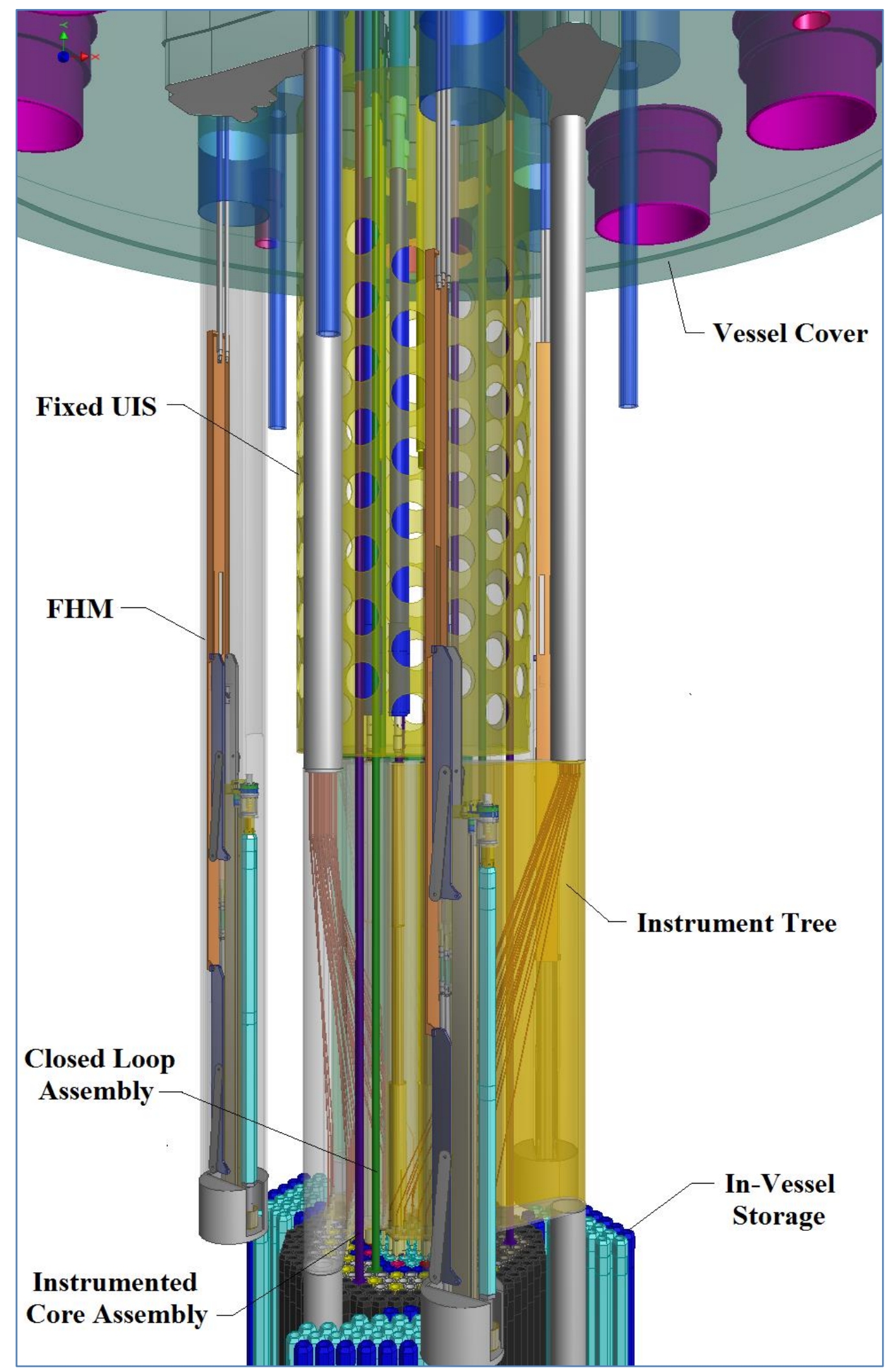

Figure 3-14: Perspective View of Vessel Cover, Fixed UIS, Instrument Trees, and FHMs 
Each of the three instrument trees contains (3) segments of the control rod drivelines which separate from the main control rod drivelines during reactor refueling operations. Each segment of the control rod driveline is mechanically supported inside the instrument tree control rod guide tubes (chimneys) and move with the instrument tree when it rotates for fuel handling operations. When the main control rod disconnects from the control rod segment inside the instrument tree, either mechanical support features may be extended or the control segment may be rotated to engage support features which hold the control rod segment securely inside the instrument tree. The main control rod drive lines may then be withdrawn fully from the segments inside the instrument tree to provide the necessary clearance before the instrument trees are rotated.

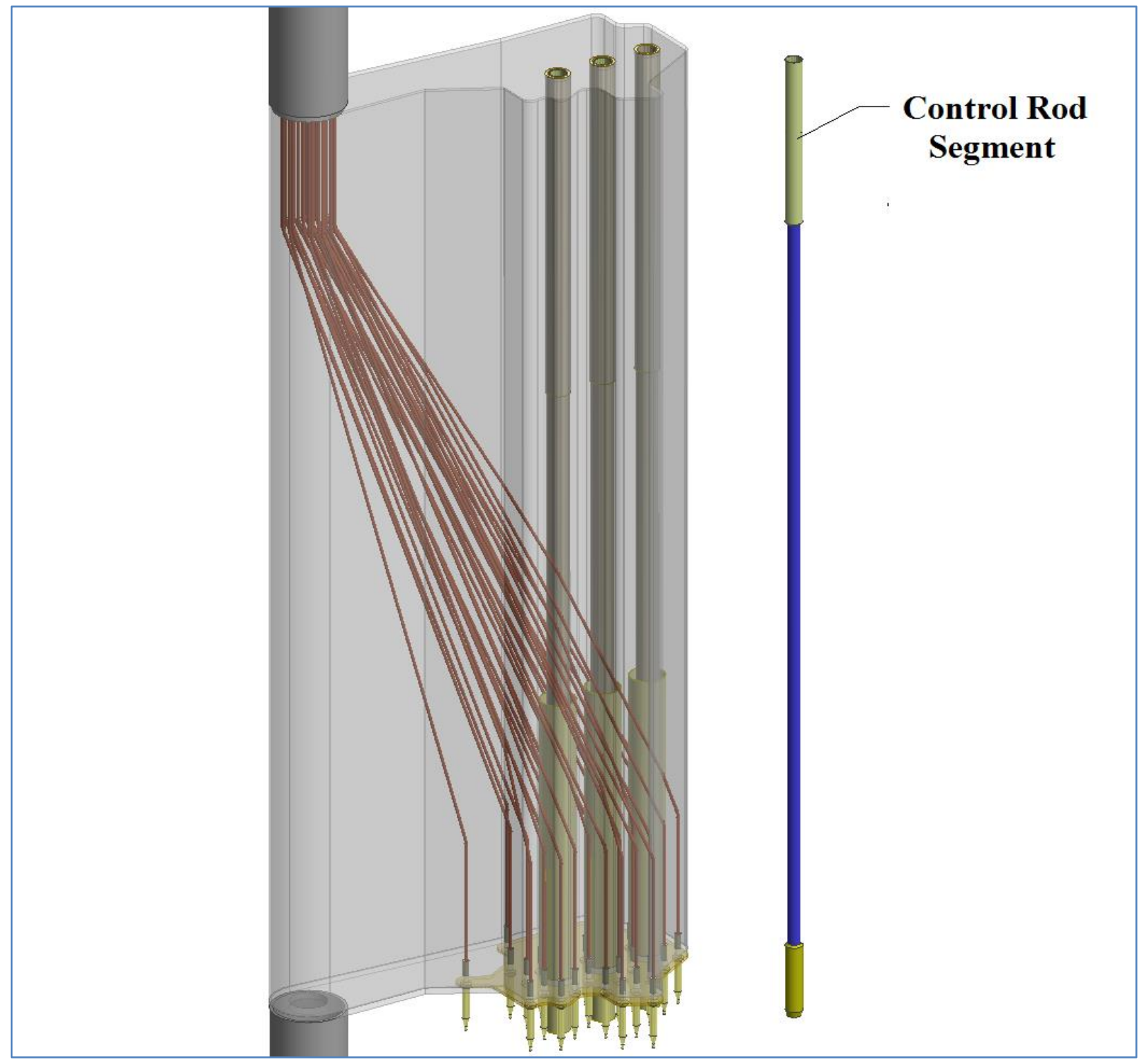

Figure 3-15: Instrument Tree with Control Rod Drive Segment

Each of the instrument trees is rotated using a DC servo motor with a planetary reduction gear which is mounted to a sealed housing on top of the reactor cover. The instrument tree is supported inside the vessel cover plug using sets of tapered roller bearings. A flange on the 
support column transfers the entire weight of the instrument tree onto the lower tapered roller bearing while the upper bearing is used to maintain its angular alignment inside the vessel. The lower support column fits into a socket located on top of the grid plenum for radial support and alignment. A set of inflatable seals is used to isolate the cover gas inside the reactor vessel from maintenance areas above the reactor head; inert gas is used to pressurize the volume between the inflatable seals to prevent escape of the cover gas. A labyrinth seal is used below the inflatable seals between the support column and the vessel cover plug to further prevent the escape of cover gas. Inert gas is used to slowly purge the volume below the inflatable seals to assure that the labyrinth seals remain free of sodium frost.

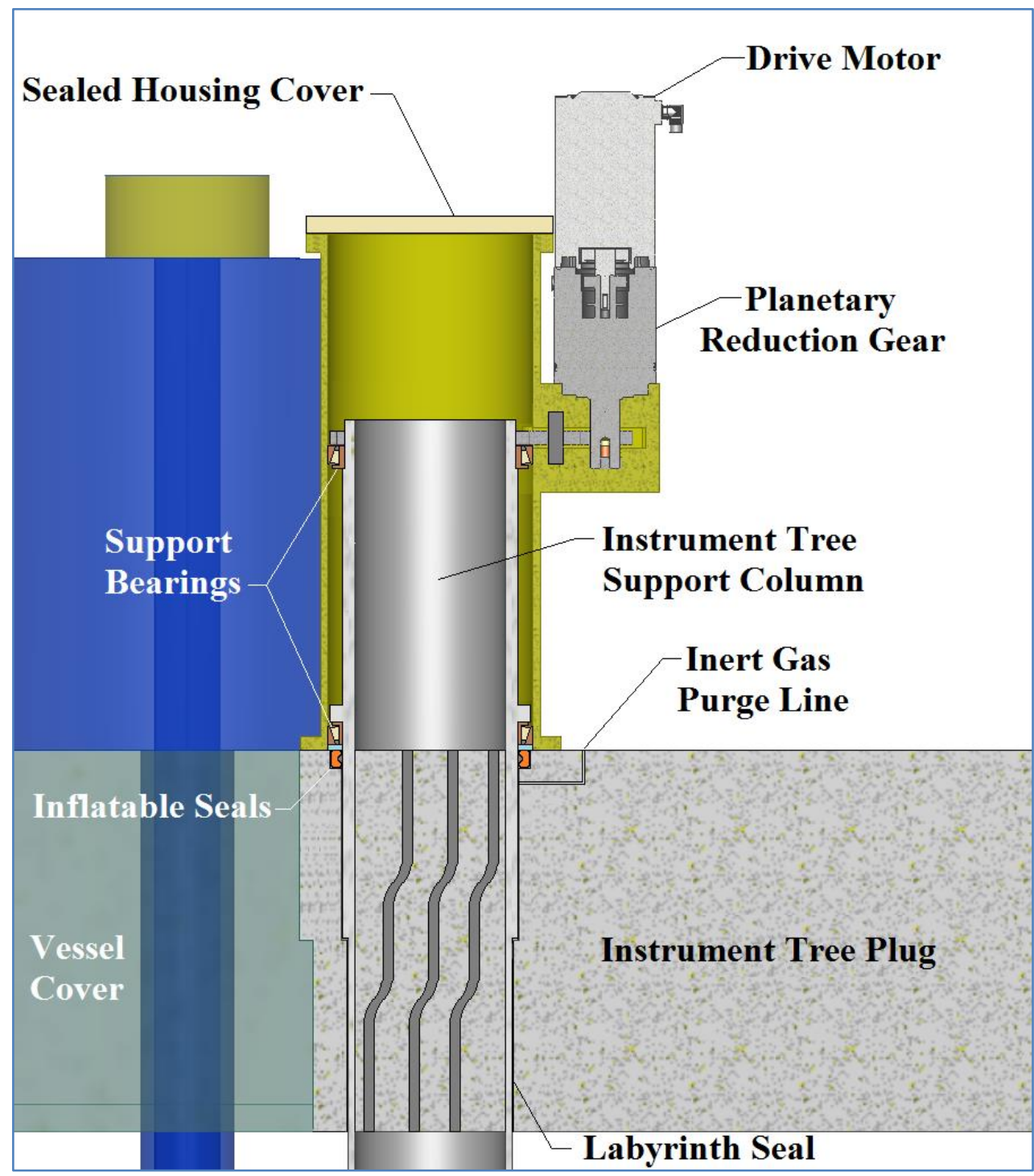

Figure 3-16: Instrument Tree Rotation Drive Motor and Housing

The following images show the instrument trees in the reactor operation (Figure 3-17) and refueling (Figure 3-18) positions. The views are taken just below the bottom of the fixed portion of the UIS and show the locations of the three fuel handling machines as well as the in-vessel storage positions. 


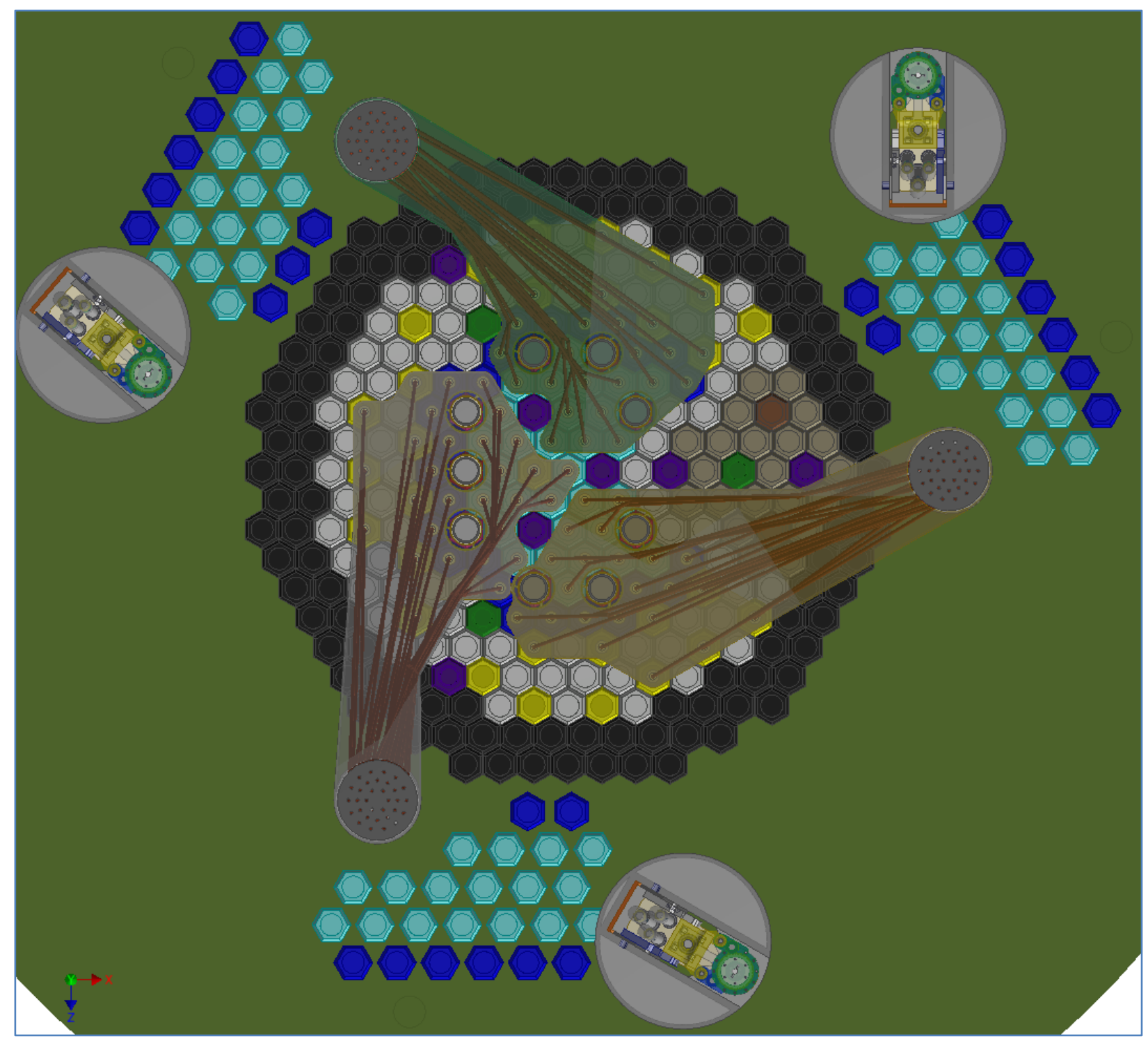

Figure 3-17: Section Below Fixed UIS Showing Location of Instrument Trees During Reactor Operation 


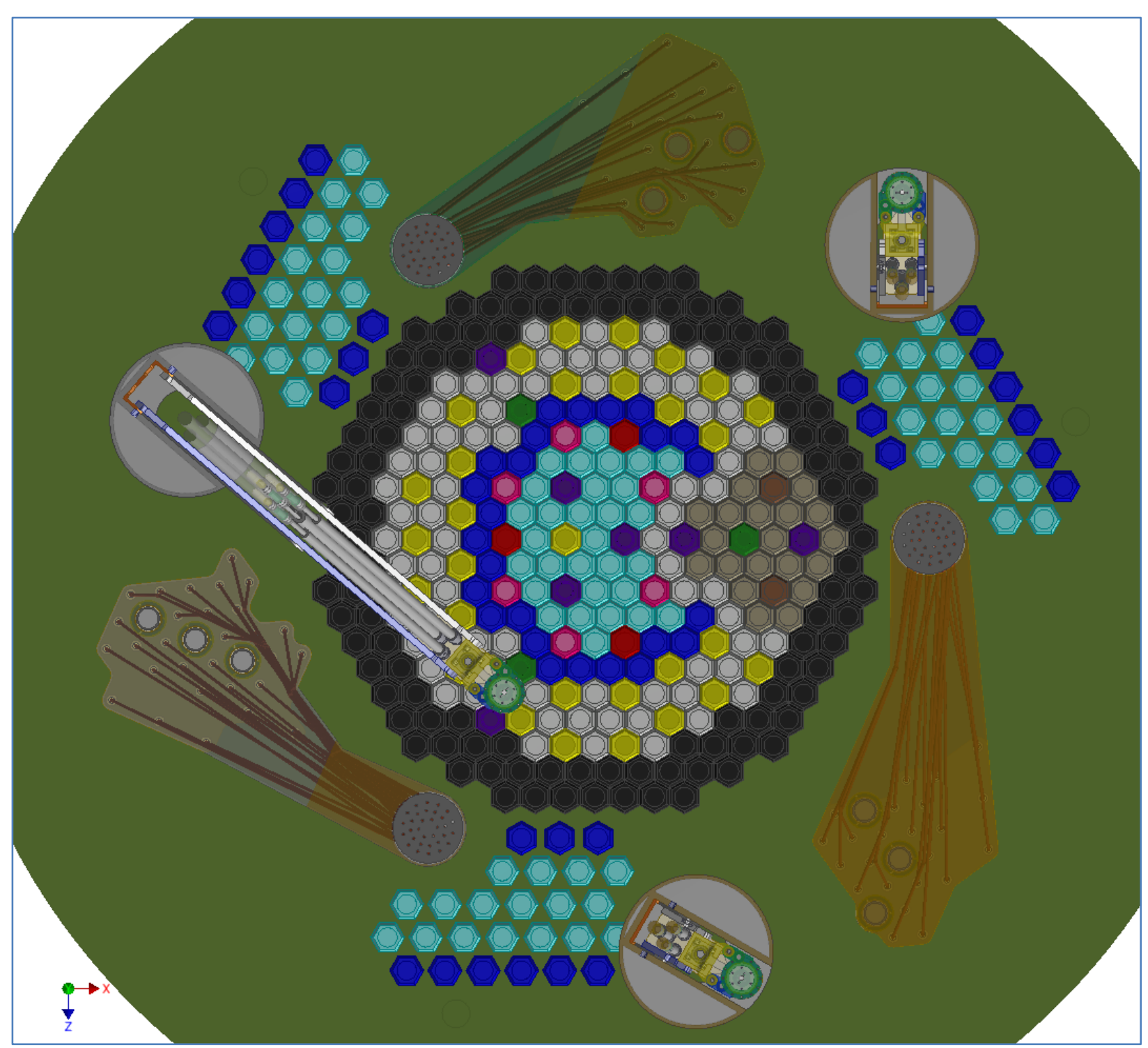

Figure 3-18: Section Below Fixed UIS Showing Location of Instrument Trees During Refueling

Several rounds of preliminary stress analyses were performed on the largest instrument tree (neglecting structural support from other reactor internal components) assuming twice gravity loading on the preliminary structural model. Fixed supports were located at the top and bottom of the instrument tree support column (preliminarily located at the vessel cover and the top of the grid plenum). The results of the simulations performed indicate that peak stresses (Figure 3-19) are below the allowable values given in Table 1 of the ASME Boiler and Pressure Vessel Code for the selected material. Additional analyses will need to be performed in the future as updated maximum core outlet flow rates are obtained to optimize the design.

The results of the analyses performed thus far indicate less than 0.05 " maximum deflection (Figure 3-20) in the instrument tree based upon the preliminary load used in the analyses. The support column diameter will be increased to reduce the overall deflection of the instrument tree assemblies. Additional stiffeners and structural supports are also being considered to reduce deflections in the preliminary design. 
FASTER Test Reactor Preconceptual Design Report

March 31, 2016

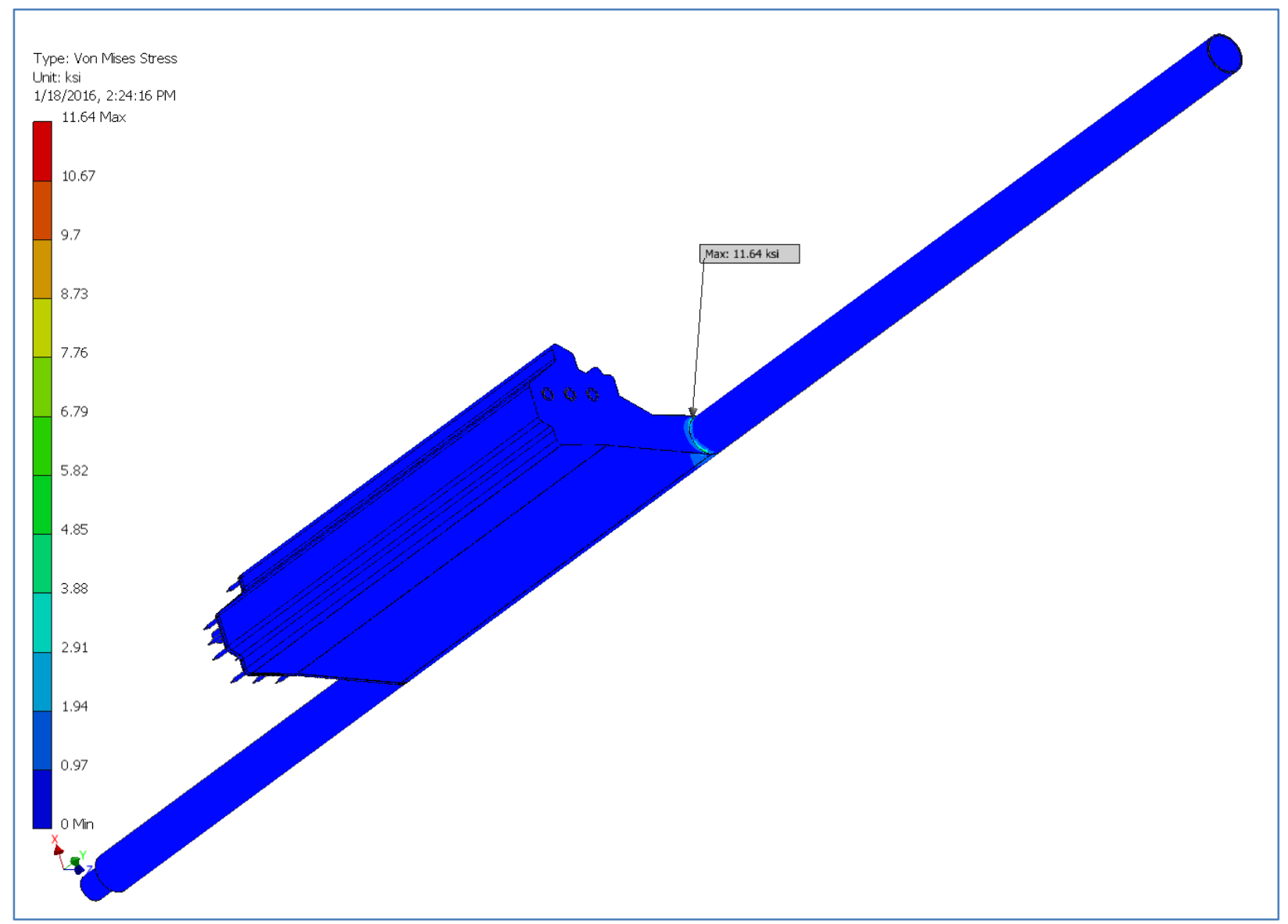

Figure 3-19: Stress Results for Instrument Tree under Gravity Loading 


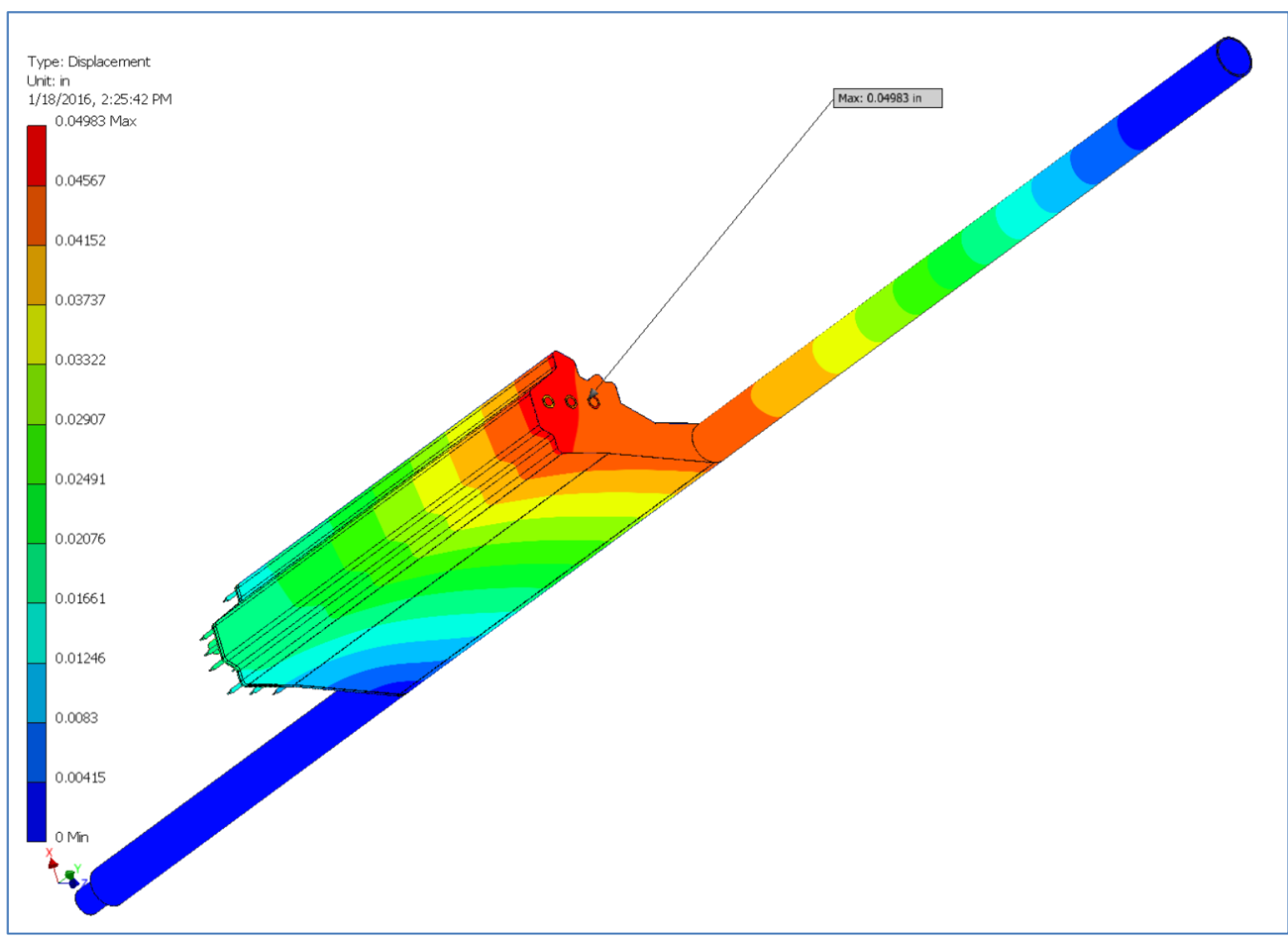

Figure 3-20: Displacement Results for Instrument Tree under Gravity Loading

The instrumentation conduits (Figure 3-21) route the sensor guide tubes from the sensor assemblies into the instrumentation support columns (through openings), up through stepped shielding (inside the columns) to above the fixed vessel cover. The conduits follow a "nonstraight" path through the shielding inside the upper portion of the support columns to eliminate radiation streaming paths to the head access area. Each of the support conduits contains a single (or several) sealed and helium filled instrumentation guide tubes through which the sensor assembly is inserted (from above the vessel cover) at room temperature. Conduit supports (pipe hangers) will be incorporated in the final design to limit stresses and prevent damage due to mechanical and flow induced vibrations experienced during reactor operation.

The instrumentation conduits and guide tubes have large radius bends at locations of directional changes to assure easy replacement of sensors through the instrument trees. The instrumentation guide tubes mechanically attach to the top of the instrumentation posts and are seal welded to provide a "snag free" installation path for sensor assemblies.

The conduits in each instrumentation tree are routed to instrumentation support columns at the top baffle plate of the instrument tree to minimize the number of bends in the conduits (otherwise required to avoid interference with the control rod drive lines). 


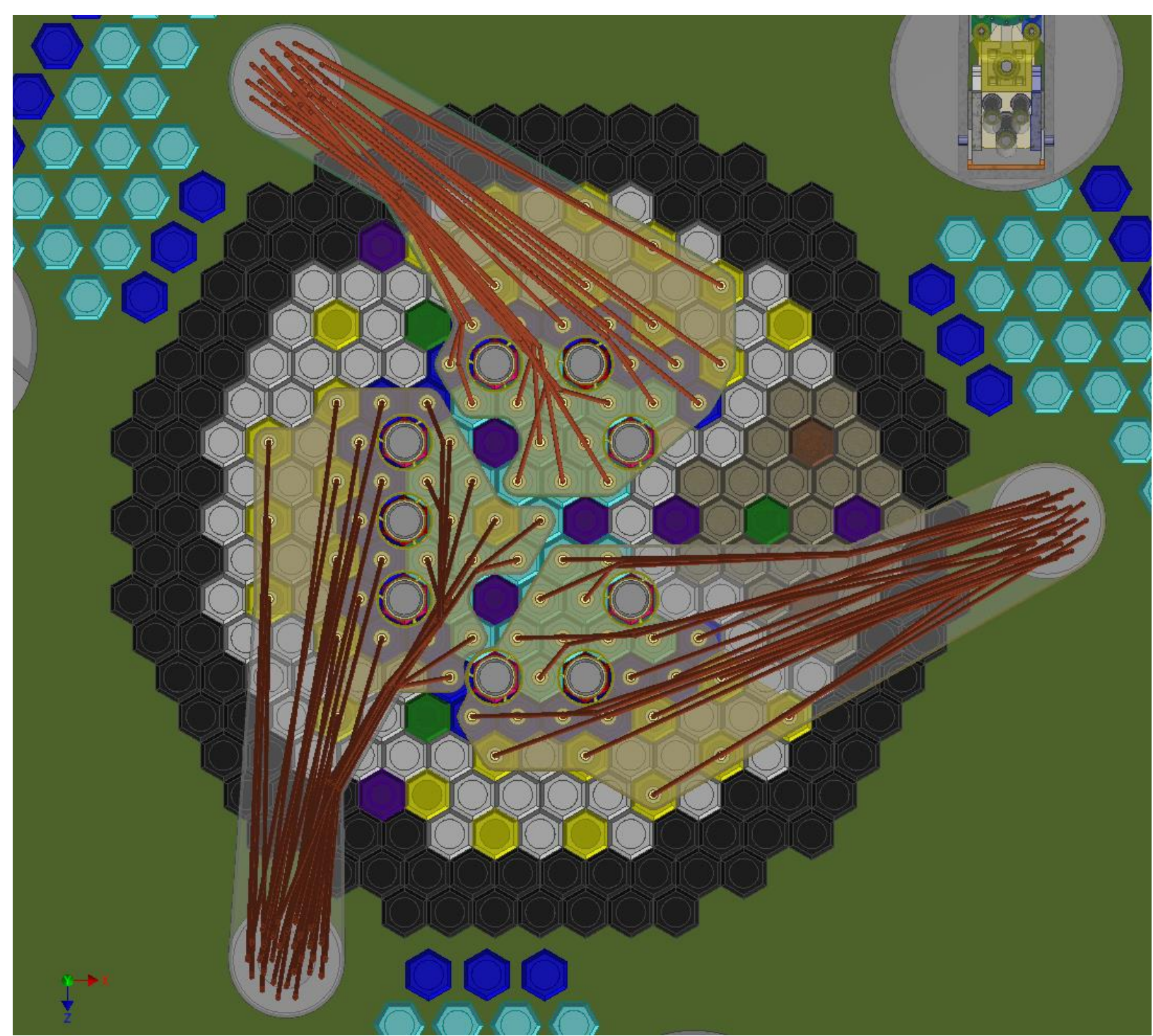

Figure 3-21: Section through Instrument Trees Showing Instrumentation Conduit Routing Pathways

The instrumentation posts attach mechanically to the instrumentation tree and are designed to support the Inconel 718 heat shield plates. Clearances between the posts and shield plates are incorporated into the design to allow for free horizontal thermal expansion or contraction of the Inconel heat shield plates when exposed to variations in the coolant temperature (due to changes in the operational state of the reactor). By allowing the plates to freely expand or contract horizontally, the thermal-mechanical stresses experienced by the plates are minimized. The shield plates are supported in the vertical direction to reduce mechanical vibrations.

The mechanical connections between the instrument posts and the cover plate on the UIS (and conduit connectors) are represented in Figure 3-22 as threaded connections for ease and brevity although, in the actual assembly, an alternative method of mechanical fastening may be used which will provide the required location and load support based upon various analyses. Preloaded metallic seal rings will be used in all joints to prevent leakage of sodium coolant into 
the conduits or helium filled tubes and seal welds will be used as a secondary boundary to provide assurance against leakage.

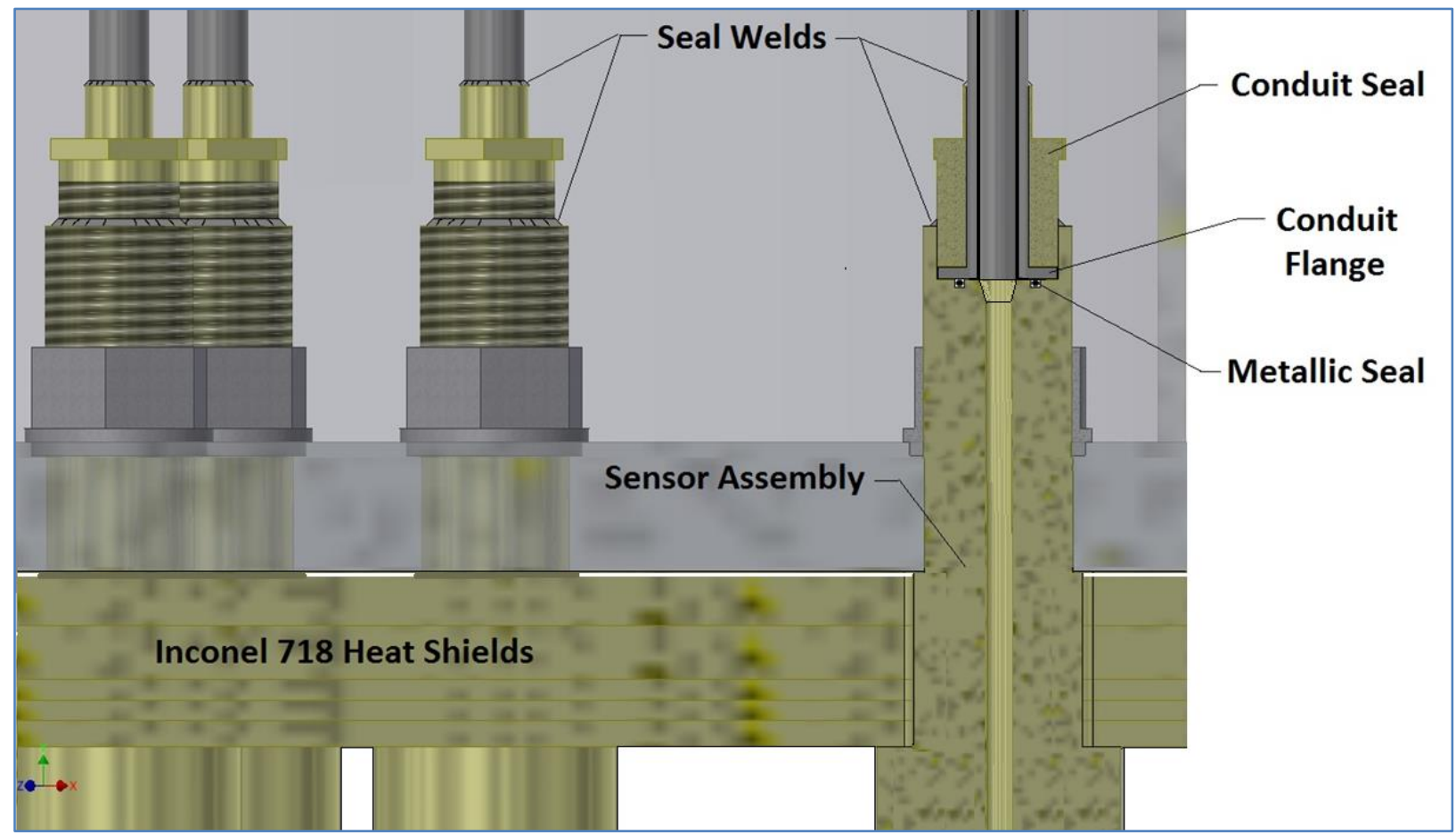

Figure 3-22: Section through Sensor Assembly, Seals, and Instrument Tree

The instrumentation post is a welded Inconel 718 assembly (Figure 3-23). The instrumentation post contains guide tube(s) for the sensor (thermocouple) assemblies which are incorporated into the weldment. The guide tubes terminate at thin walled spherically shaped receptacles which are positioned above the centerlines of the core assembly coolant outlet ports. During reactor operation, the instrumentation post is located within four inches above the core assembly handling socket to provide monitoring data to reactor monitoring computers and personnel.

Thermocouple sensors inside the instrumentation post tubes are surrounded by helium gas because of its high thermal conductivity to provide an acceptable response time to changes in temperature of the flowing liquid sodium coolant. The sensor assemblies are wrapped in a flexible metal jacket which allows them to be inserted efficiently and assure effective contact between the receptacle and the thermocouple. 


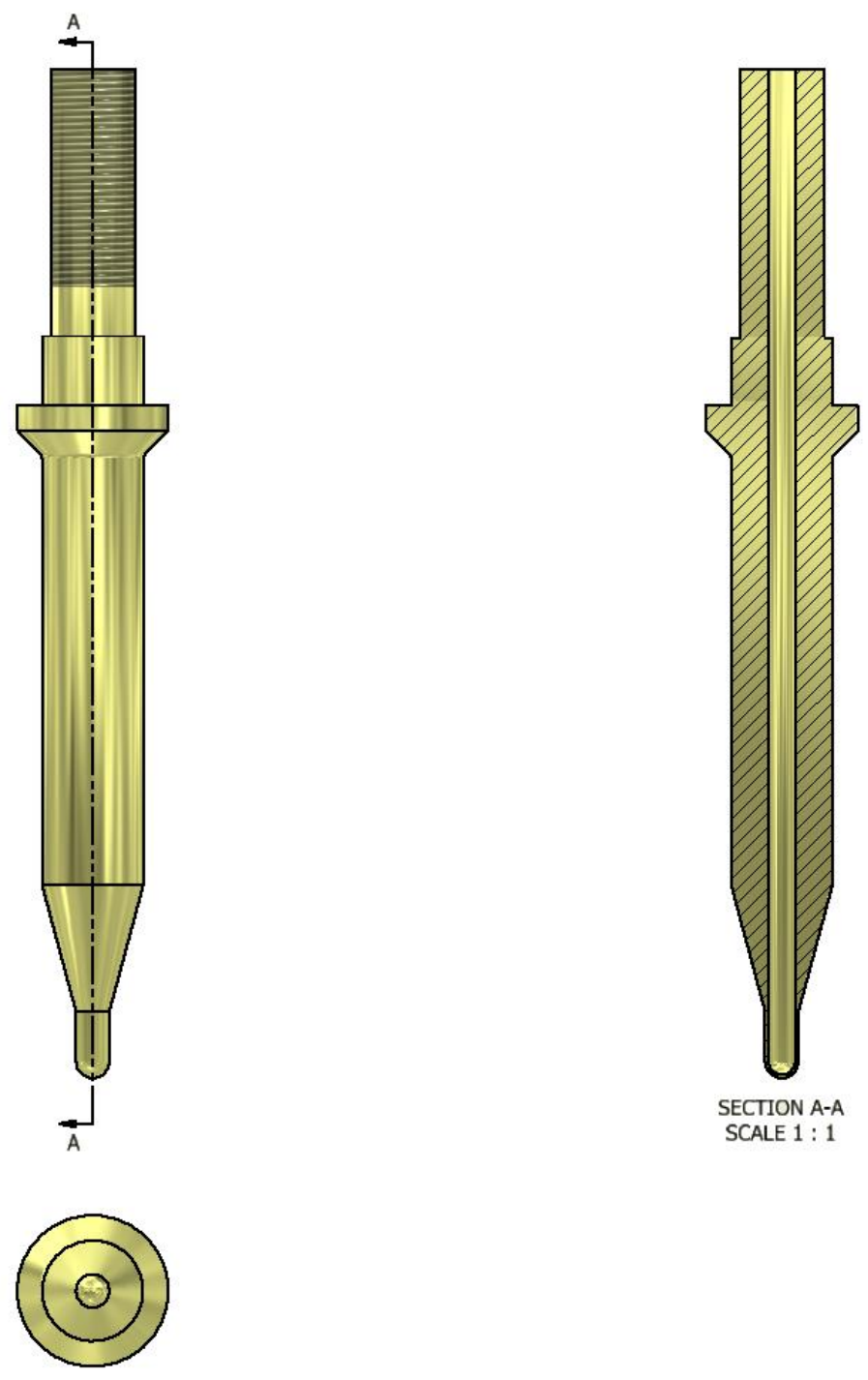

Figure 3-23: Instrumentation Post for FASTER

The instrumentation trees are located directly in the path of the hot liquid sodium coolant that exits the reactor core assemblies. The main structure is manufactured and assembled at room temperature and when installed into the reactor is then exposed to the hot flowing liquid sodium coolant at temperatures up to $550^{\circ} \mathrm{C}\left(1022^{\circ} \mathrm{F}\right)$. Figure $3-24$ shows a view of the instrumentation trees viewed looking upward from just above the core assembly coolant outlet openings. Sudden changes in the temperature of the liquid sodium coolant will affect the instrument post assemblies and then continue to the underside of the instrument tree structural plate. 


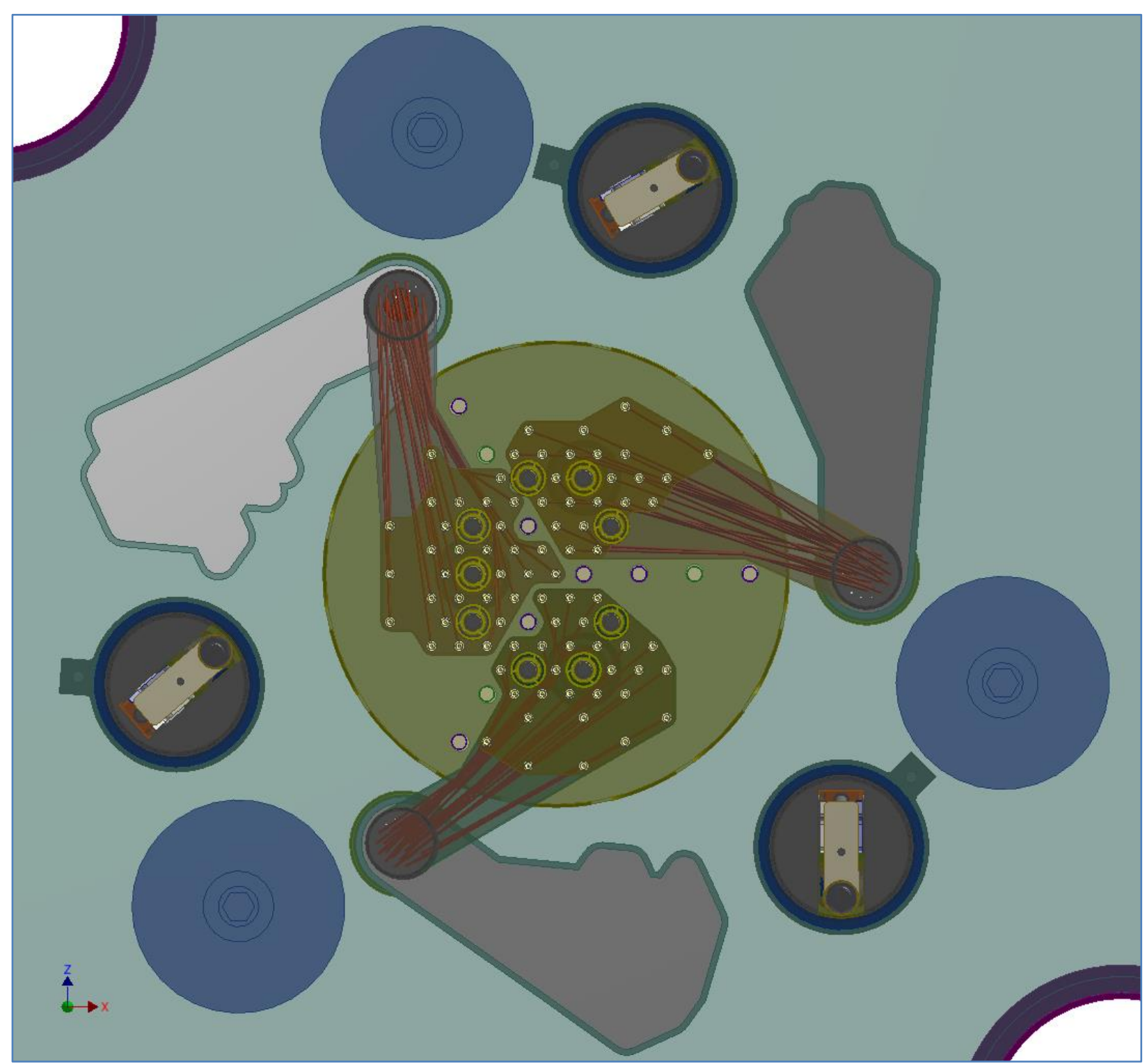

Figure 3-24: View Looking Upward from the Top of Core Showing Instrument Trees and Fixed UIS

The upper internal structure assembly (Figure 3-25) is protected from transient temperature changes caused by sudden changes in the sodium coolant during changes in reactor operation (insertion of the control rods or "scram the reactor" for example). Components which are manufactured from Inconel 718 are used to shield the 316 stainless steel structure from rapid temperature changes due to its higher strength properties. Table 3-18 lists the room temperature properties of 316 stainless steel and Inconel 718. 


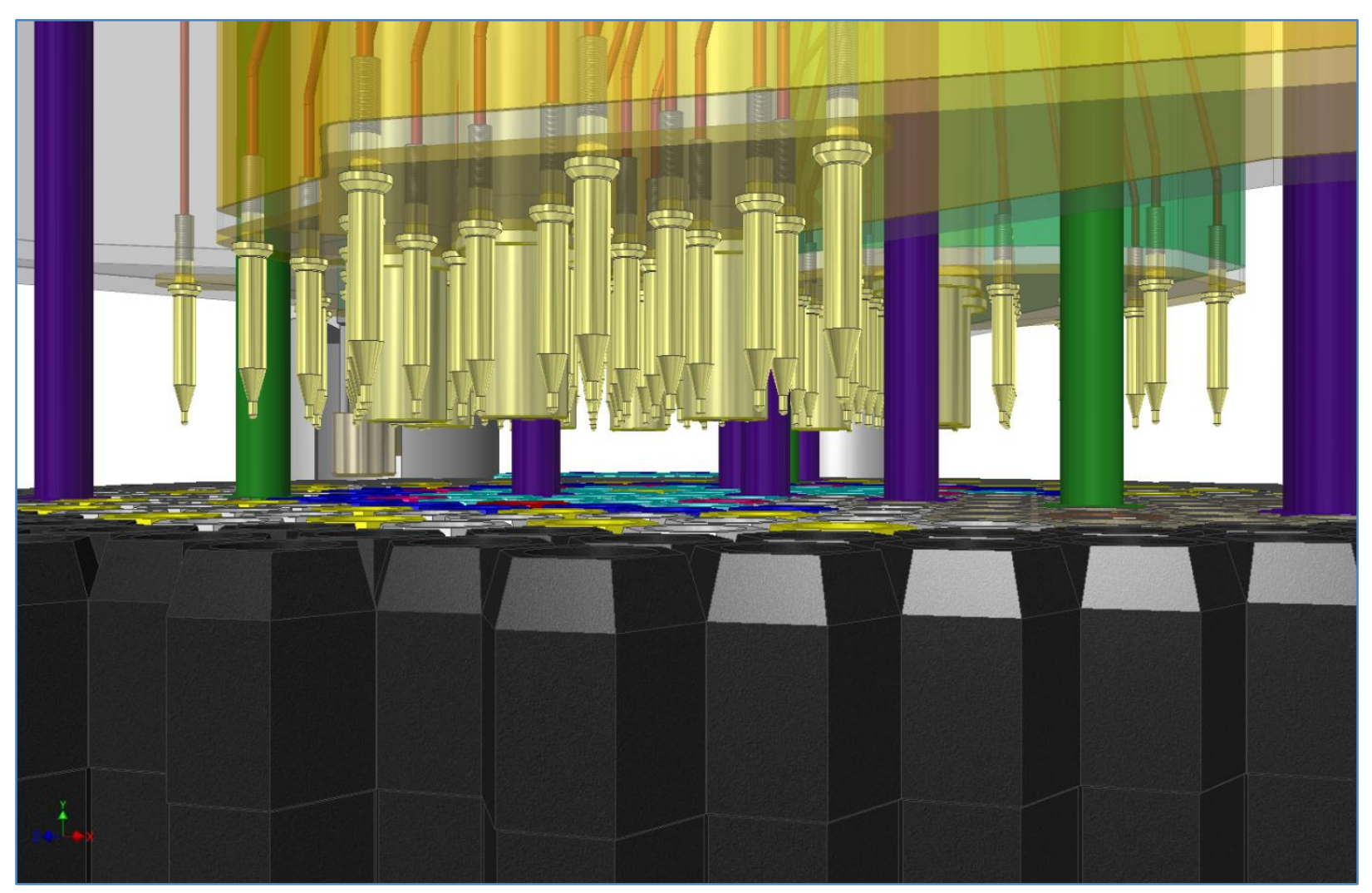

Figure 3-25: Perspective View Above Core Centerline During Reactor Operation

Using data generated by SAS4A/SASSYS-1 for the core configuration, the temperature of the flowing sodium at the core assembly outlet (during reactor scram) can change by approximately $100^{\circ} \mathrm{C}$ in approximately 6 seconds with a maximum drop in temperature of $160^{\circ} \mathrm{C}$ in approximately 20 seconds. The temperature of the liquid sodium can oscillate rapidly due to mixing and turbulence during the initiation of a scram and can cause cyclic stresses (thermal striping) in the structural material.

Table 3-18: Comparison of Room Temperature Properties of 316 Stainless \& Inconel 718

\begin{tabular}{cccc}
\hline Material & $\begin{array}{c}\text { Yield Strength } \\
(\text { RT })\end{array}$ & $\begin{array}{c}\text { Fracture Toughness } \\
\text { KIC (RT) }\end{array}$ & $\begin{array}{c}\text { Endurance Limit } \\
(\text { RT })\end{array}$ \\
\hline $\begin{array}{c}\text { 316L Stainless } \\
\text { (Annealed) }\end{array}$ & $170 \mathrm{MPa}$ & $100 \mathrm{MPa} * \sqrt{m}$ & $169 \mathrm{MPa}$ \\
Inconel 718 & $1100 \mathrm{MPa}$ & $120 \mathrm{MPa}^{*} \sqrt{m}$ & $458 \mathrm{MPa}$ \\
\hline
\end{tabular}

Transient thermal analyses were performed to evaluate the transient temperature distribution in the Inconel 718 components attached to the bottom of the instrumentation trees. The flow of the liquid sodium (at $2.46 \mathrm{~m} / \mathrm{s}$ ) from the simulated core assembly exit was assumed to "step" change in temperature by approximately $200^{\circ} \mathrm{C}$ at the flow inlet.

The convection coefficient used was calculated based upon the geometry for the liquid sodium flow conditions using a $200^{\circ} \mathrm{C}$ temperature difference. Fluid properties of the liquid sodium coolant were calculated at the film temperature and used to determine the Prandtl number. The Reynolds and Peclet numbers were calculated based upon the case of external liquid metal 
coolant flowing over a flat plate. The flow conditions were estimated using a converged computational fluid dynamics solution for the flow configuration under investigation.

A general transient solution (for a constant convection coefficient) was developed using the method of separation of variables. The second order partial differential equation (which conservatively simulates the transient thermal conditions experienced in the Inconel plate) was solved. The hand calculation was used to determine the one dimensional temperature profile and stress distribution in the plate based upon convection boundary conditions at the surface of the plate.

Several one dimensional transient thermal cases were solved by hand for comparison to the computational fluid dynamic results. The one dimensional heat equation (second order partial differential equations) was solved for various cases which included: insulated boundary conditions on one end of the Inconel component and convection on the other end; or fixed temperature on one end and convection condition on the other end. Reviews of the results confirm that the largest temperature difference is provided by the fixed end temperature case.

A simple program (Figure 3-26) was written to calculate the roots of the infinite series solution. Roots were calculated out to 10,000 terms to increase the accuracy of the result. The difference in temperature between the initial temperature condition and the calculated temperature at time equal to zero at the convection boundary was negligible. 
FASTER Test Reactor Preconceptual Design Report

March 31, 2016

$$
\begin{aligned}
& \mathrm{h}:=66680 \cdot \frac{\mathrm{W}}{\mathrm{m}^{2} \cdot \mathrm{K}} \quad \mathrm{k}:=11.1 \cdot \frac{\mathrm{W}}{\mathrm{m} \cdot \mathrm{K}} \quad \mathrm{L}:=0.0127 \cdot \mathrm{m} \\
& f(\lambda):=\tan (\lambda \cdot L)+\lambda \cdot \frac{k}{h} \\
& \lambda:=\mid \begin{array}{l}
\operatorname{lam} \leftarrow 0 \\
\lambda_{0} \leftarrow \operatorname{root}(\mathrm{f}(\mathrm{lam}), \mathrm{lam}) \\
\text { for } \mathrm{n} \in 1 . .10000 \\
\mid \begin{array}{l}
\operatorname{lam} \leftarrow \lambda_{\mathrm{n}-1}+\frac{\pi}{\mathrm{L}} \\
\lambda_{\mathrm{n}} \leftarrow \operatorname{root}(\mathrm{f}(\mathrm{lam}), \text { lam })
\end{array}
\end{array}
\end{aligned}
$$

$\lambda=$\begin{tabular}{|r|r|}
\hline & \multicolumn{1}{|c|}{0} \\
\hline 0 & 0 \\
\hline 1 & 244.1707648 \\
\hline 2 & 488.3519173 \\
\hline 3 & 732.5536462 \\
\hline 4 & 976.7857509 \\
\hline 5 & 1221.0574698 \\
\hline 6 & 1465.3773336 \\
\hline 7 & 1709.7530488 \\
\hline 8 & 1954.1914136 \\
\hline 9 & 2198.6982679 \\
\hline 10 & 2443.2784751 \\
\hline 11 & 2687.9359317 \\
\hline 12 & 2932.6736032 \\
\hline 13 & 3177.4935778 \\
\hline 14 & 3422.3971357 \\
\hline 15 & \\
\hline
\end{tabular}

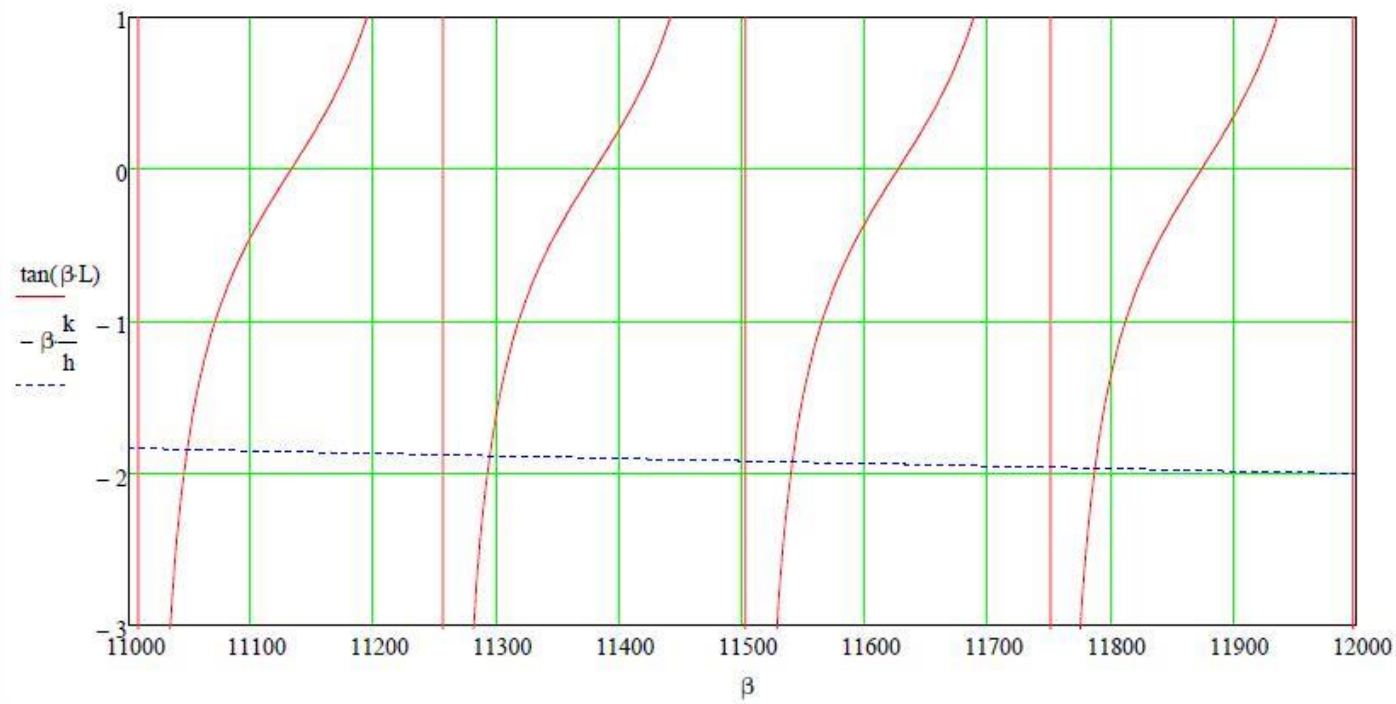

Figure 3-26: Program for Calculation of Successive Roots of an Infinite Series

The transient temperature profile was plotted using the first five hundred terms of the infinite series solution (Figure 3-27). 


$$
\begin{aligned}
& u_{1}(x)=810.23 \cdot K \quad a_{n}:=\frac{\left[\frac{T_{i}}{L}-\frac{\frac{T_{i}}{L}+\frac{h}{k} \cdot T_{f}}{\left(\frac{h}{k}+\frac{1}{L}\right) \cdot L}\right] \cdot\left[\frac{\sin \left(\lambda_{n} \cdot L\right)}{\left(\lambda_{n}\right)^{2}}-\frac{L \cdot \cos \left(\lambda_{n} \cdot L\right)}{\lambda_{n}}\right]}{\left(\frac{\lambda_{n} \cdot L-\sin \left(\lambda_{n} \cdot L\right) \cdot \cos \left(\lambda_{n} \cdot L\right)}{2 \cdot \lambda_{n}}\right)} \\
& u_{f}(x, t):=T_{i} \cdot\left(1-\frac{x}{L}\right)+\left[\frac{\left(\frac{T_{i}}{L}\right)+\left(\frac{h}{k}\right) \cdot T_{f}}{\left(\frac{h}{k}+\frac{1}{L}\right)}\right] \cdot\left(\frac{x}{L}\right)+\sum_{n=1}^{S 00}\left[\left(a_{n}\right) \cdot e^{-\left[\left(x_{n}\right)^{2} \cdot k\right] \cdot t} \cdot \sin \left(\lambda_{n} \cdot x\right)\right] \\
& u_{f}(0,0)=810.23 \mathrm{~K} \quad u_{f}(L, 0)=803.7350383741 \mathrm{~K}
\end{aligned}
$$

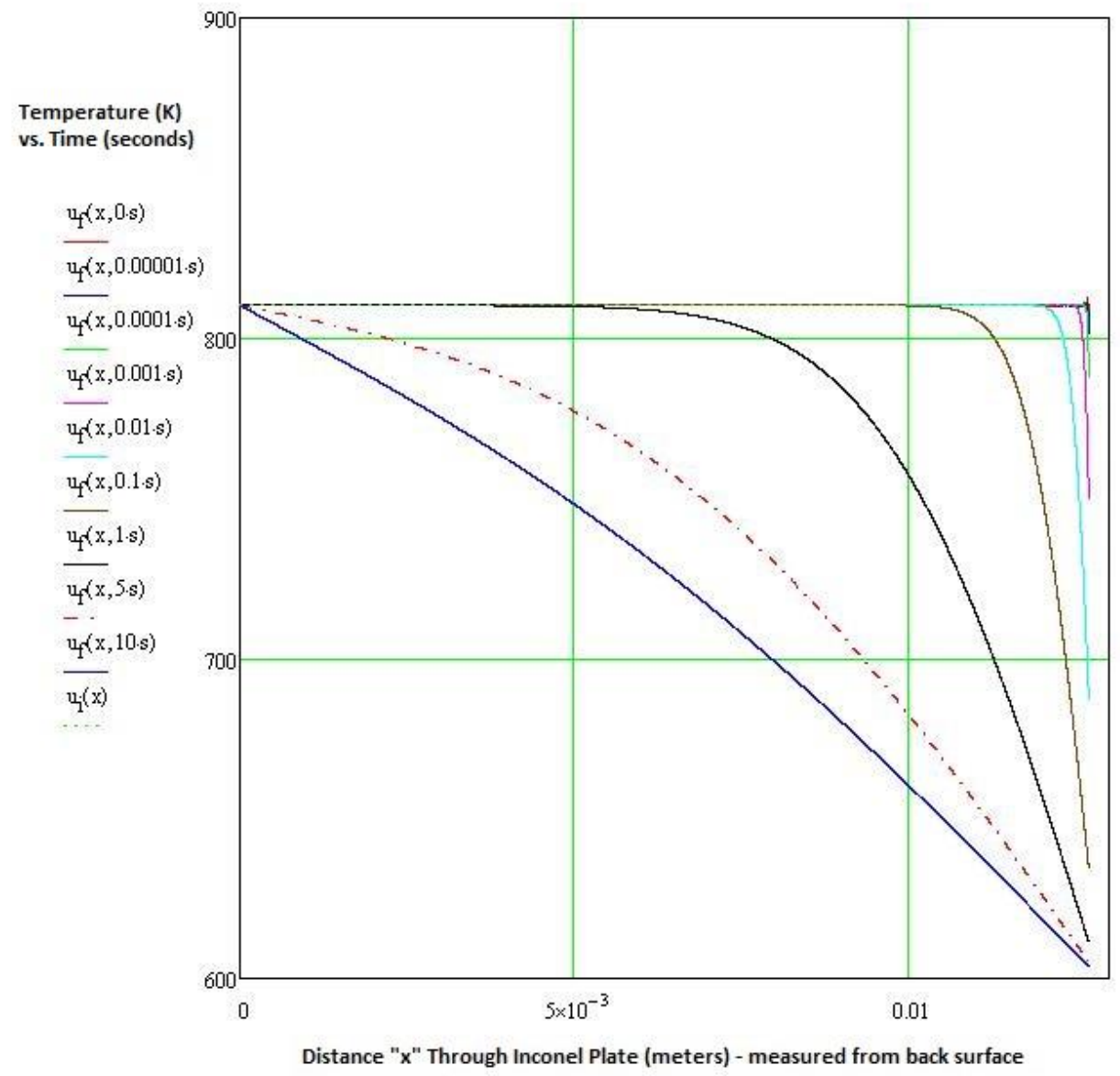

Figure 3-27: Transient Temperature Distribution in Heat Shield

Polynomial curve fits of temperature dependent material properties of liquid sodium (density, specific heat, thermal conductivity, dynamic viscosity, volumetric expansion, and enthalpy) were developed from data obtained from ANL/RE-95/2 "Thermodynamic and Transport Properties of Liquid Sodium and Vapor" [15] for use in future analyses to provide more accurate results. 
Standard unrestrained plate theory was used to calculate the one dimensional stress distribution in the plate (Figure 3-28 \& Figure 3-29). The first Inconel 718 heat shield plate is set at one-half inch $(12.7 \mathrm{~mm})$ thick. The " $\mathrm{x}$ " axis is parallel to the direction of the plate thickness and the " $y$ " and " $\mathrm{z}$ " axes are tangent to the plate surface. An assumption of the unrestrained plate stress theory is that the temperature varies only through the thickness of the plate. The transient "surface" stresses (in the " $y$ " and "z" directions) are determined in the plate using the equations shown in the Figure 3-28. The maximum stress in the half inch thick Inconel plate occurred at approximately 0.17 seconds.

$$
\begin{aligned}
& \text { Inconel Properties: } \quad \mathrm{E}:=205 \cdot 10^{9} \cdot \mathrm{Pa} \quad \quad \quad \quad=0.284 \quad \alpha:=14.4 \cdot 10^{-6} \cdot \frac{\mathrm{m}}{\mathrm{m} \cdot \mathrm{K}} \\
& \mathrm{x}:=0 \cdot \mathrm{m}, 0.00001 \cdot \mathrm{m} . . \mathrm{L} \\
& \mathrm{N}_{\mathrm{T}}(\mathrm{x}, \mathrm{t}):=\alpha \cdot \mathrm{E} \cdot \int_{0}^{\mathrm{L}}\left(\mathrm{u}_{\mathrm{f}}(\mathrm{x}, \mathrm{t})-810.23 \cdot \mathrm{K}\right) \mathrm{dx} \\
& M_{T}(x, t):=\alpha \cdot E \cdot \int_{0}^{L}\left[\left(u_{f}(x, t)-810.23 \cdot K\right) \cdot x\right] d x \\
& \sigma_{\mathrm{Yz} z}(x, t):=\frac{1}{1-\nu} \cdot\left[-\alpha \cdot E \cdot\left(u_{\mathrm{f}}(x, t)-810.23 \cdot \mathrm{K}\right)+\frac{1}{2 \cdot \mathrm{L}} \cdot \mathrm{N}_{\mathrm{T}}(\mathrm{x}, \mathrm{t})+\frac{3 \cdot \mathrm{x}}{2 \cdot \mathrm{L}^{3}} \cdot \mathrm{M}_{\mathrm{T}}(\mathrm{x}, \mathrm{t})\right] \\
& \sigma_{\mathrm{yz}}(0,0)=35.2892717693 \mathrm{~Pa} \\
& \sigma_{\mathrm{y} Z \mathrm{~L}}(\mathrm{~L}, 0)=2.6823977581 \times 10^{7} \mathrm{~Pa} \\
& \sigma_{\mathrm{yz}}(L, 0.16 \cdot s)=6.6860573801 \times 10^{8} \mathrm{~Pa} \\
& \sigma_{\mathrm{yz}}(\mathrm{L}, 0.17 \cdot \mathrm{s})=6.6875749235 \times 10^{8} \mathrm{~Pa} \\
& \sigma_{\mathrm{Yz}}(\mathrm{L}, 0.18 \cdot \mathrm{s})=6.6874184677 \times 10^{8} \mathrm{~Pa} \\
& \sigma_{\mathrm{Yz}}(\mathrm{L}, 1 \cdot \mathrm{s})=5.9314899147 \times 10^{8} \mathrm{~Pa} \quad \text { (Compare with Ansys) }
\end{aligned}
$$

Figure 3-28: Maximum Transient Stress in the Bottom Inconel 718 Heat Shield

The transient stress analysis results generated for this "worst case" scenario being considered for this series of calculations (Figure 3-29) indicate that the one dimensional stresses are below the room temperature yield point in the Inconel 718 plate material.

Preliminary fatigue life calculations performed using Inconel 718 endurance limit data for completely reversed bending and assuming 100 scrams per year have determined an approximate 60 year lifetime of the bottom heat shield. 


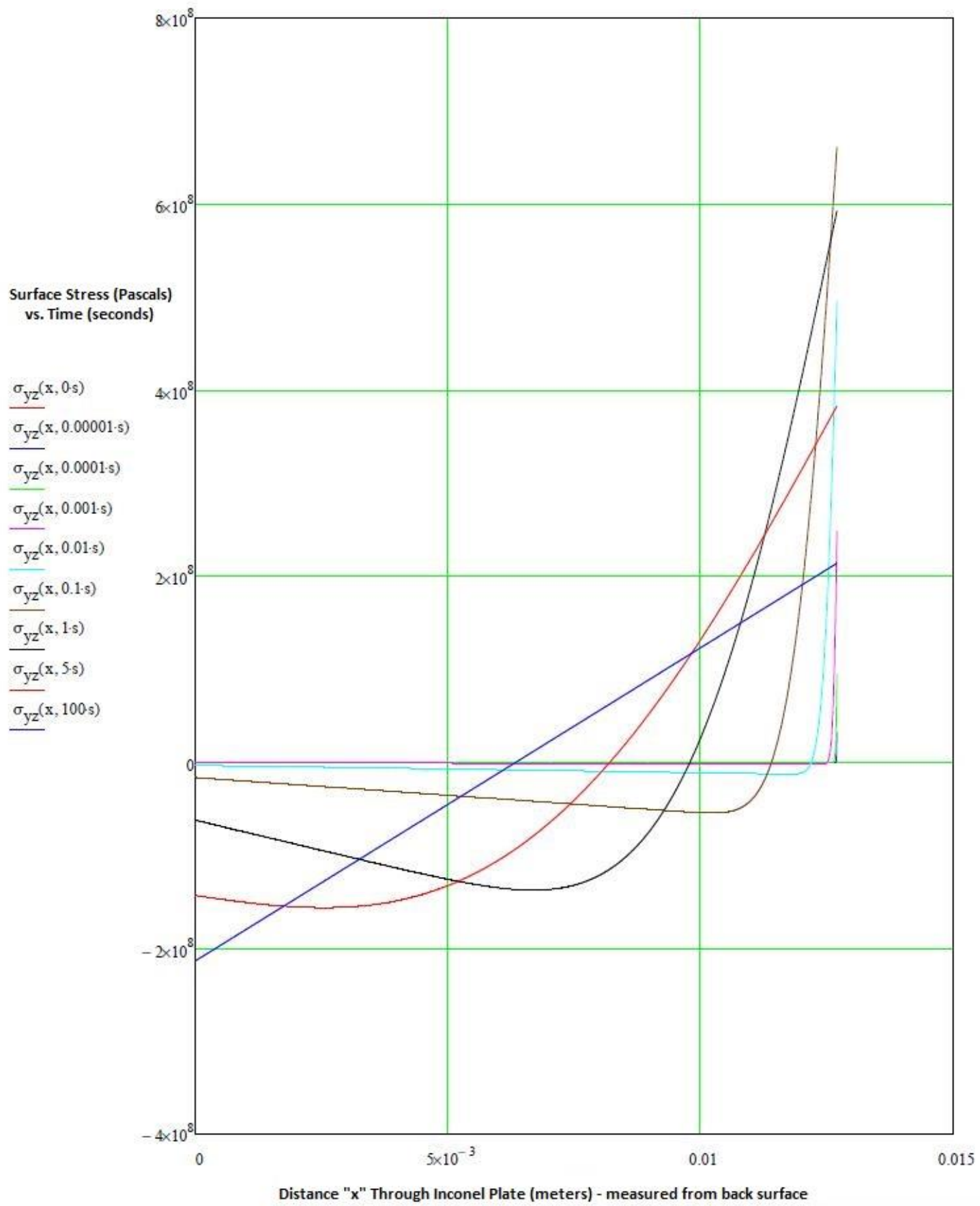

Figure 3-29: Transient Stress Distribution in the Bottom Inconel 718 Heat Shield Plate

\subsubsection{Core Restraint System Design}

The core restraint system consists of distributed passive hardware features which, acting together, must meet the following functional requirements: 
- Establish the positions of the individual core assemblies in the horizontal plane;

- Control horizontal movements of core assemblies arising from thermal expansion effects, irradiation-induced swelling, and irradiation-enhanced creep, in such a way that reactivity effects are acceptable and control rod driveline alignments are maintained within specified tolerances;

- Accommodate horizontal seismic motions within alignment and stress specifications; and

- Maintain sufficient clearances in the horizontal plane to allow for fuel handling within specified vertical withdrawal and insertion force limits.

The design choices representing the major decisions in the design of a passive core restraint system are:

- Length and stiffness of the core assembly lower adapters;

- Lower Internals Structure interface with the core assembly lower adapters -- clearances, seals, and number of support points ( 1 or 2 );

- Number, location, configuration and height of the core assembly load pads;

- Rigidity of the peripheral boundary -- stiff radial shield assemblies or a rigid, shaped, core former ring attached to the core barrel;

- Allowable vertical core assembly insertion and withdrawal loads.

The major challenge in core restraint design is to find the "design window" which contains sufficient clearance for fuel handling (even when core assemblies are bowed due to swelling and creep effects) and sufficient tightness or stiffness for adequate radial- position control. The thermal contraction produced by the cooldown to refueling conditions is very important in creating this window of design feasibility. The tool used in core restraint design is the NUBOW3D computer code. It calculates the elastic and inelastic effects on the shape of individual core assemblies in a three-dimensional representation of the whole core or typical sector thereof, the reactivity effects associated with short- or long-term movements from one set of equilibrium positions to another, and the side loads at all contact points. Under refueling conditions, the sum of these side loads, times the coefficient of friction yields the required initial withdrawal force over and above the dead weight.

The two core restraint system design strategies are referred to as the "limited free bow" approach and the "free-flowering core." The first, used in FFTF and CRBR, employs a short lower adapter horizontally restrained in the lower internals structure (LIS) at one point (the lower end), and rigid core formers at the two elevations of core assembly load pads -- one near the top end and one about 4 in. above the fueled zone. The second, used in EBR-II, Phenix and SuperPhenix, employs a long lower adapter horizontally restrained in the LIS at two points, and the "fence" of stiff and essentially isothermal radial shield assemblies constitutes the peripheral restraint. The FASTER reactor adopts the limited free bow approach. 
A rigid core former ring at the elevation of the top load pads provides positive peripheral restraint. The ring has enough clearance, relative to a tight array of assemblies, to permit removal and replacement of individual assemblies by the in-vessel transfer machine (IVTM), yet is tight enough so that the freedom of assemblies to move does not have adverse reactivity or alignment implications. The inner diameter of the ring is shaped so as to achieve flush contact with the outermost assemblies. The core former ring is welded to the inner diameter of the core barrel. Each core assembly is equipped with a second load pad centered $4 \mathrm{in}$. above the fueled zone of the reactor and a peripheral core former ring is present at this elevation. Normally the core assemblies contact one another only at the two load pads, which completely circumscribe the hexagonal ducts. The clearance between ducts is provided to prevent general contact at end of life due to swelling, creep (rounding of the flats), and differential bowing, but the exact clearance will need to be confirmed by analysis.

\subsection{Reactivity Control and Shutdown Systems}

As mentioned above, two independent safety-grade reactivity control systems were employed: a primary and a secondary reactivity control system. The primary system is required to have sufficient reactivity worth to bring the reactor from any operating condition to cold sub-critical at the refueling temperature with the most reactive control assembly stuck at the full power operating position. Any operating condition means an overpower condition together with a reactivity fault. The maximum worth of a control assembly is used as the base of this reactivity fault. The primary system also serves to compensate for the reactivity effects of the fuel burnup and axial growth of metal fuel. The reactivity associated with uncertainties in criticality and fissile loading is accommodated by the primary control system.

The secondary system is required to shut down the reactor from any operating condition to the hot standby condition, also with the most reactive assembly inoperative. It does not have to duplicate the primary system capability to hold down the excess reactivity for the fuel cycle since this excess reactivity is not additional reactivity to be overridden at an accident. Although the secondary system must shut down the reactor without insertion of the primary control assemblies, it is not necessary to assume that the primary assemblies are removed from the core during an accident situation. Since reactivity uncertainties are accommodated by the primary system, they are not a part of the secondary system requirements. However, the reactivity fault is included in the secondary system requirements since the secondary system should override the uncontrollable withdrawal of one primary control assembly that is being used for burnup control.

\subsubsection{Primary Control Rod System}

\section{Reserved}

\subsubsection{Secondary Control Rod System}

Reserved 


\subsection{Reactor Vessel and Enclosure System}

\subsubsection{Reactor Vessel}

The reactor vessel assembly is comprised of the reactor vessel, top closure head (or deck), the rotatable plugs. the guard vessel, the vessel/deck support structure, the core support structure, core barrel, thermal barriers, shielding, the redan, and other permanent internal structures. The design is based on the experience of the reactor vessels used for the EBR-II, Phenix, PFR, and SuperPhenix LMR reactor plants. A major difference, however, is that the design concept shown here separates the reactor and guard vessels, and also employs a conical ring support structure that avoids the need for welding dissimilar metals. There are no penetrations in the reactor vessel; all equipment - IHXs, pumps, piping, instrumentation, cold traps, fuel handling equipment, and other components---penetrate the top closure head, or deck. The entire reactor vessel assembly is located in a steel-lined concrete cavity in the reactor containment building. The top of the reactor vessel deck is approximately at grade level. The reactor vessel assembly constitutes the primary sodium coolant system boundary that envelopes and supports the reactor core, reactor vessel internals, and all of the primary system components. There is an inert gas (argon) blanket between the reactor vessel deck and the bulk sodium free surface.

The design of the reactor vessel assembly incorporates appropriate measures and details that will facilitate fabrication, construction, and operational maintenance. The design incorporates recommendations made by an experienced reactor vessel fabricator on a similar concept developed at ANL. In addition, removal of any component for repair or replacement follows a common scheme, i.e., use of a heavy-shielded cask placed over the piece of equipment, sealed to the component support flange in the deck, and lifting the equipment up into the cask.

The reactor vessel assembly is designed to:

- Provide a very high level of reliability of primary sodium containment.

- Provide support for the reactor core, reactor vessel internals, primary system components, and certain components of the fuel handling system

- Accommodate high static loads at design temperatures.

- Accommodate loads from design basis natural hazards.

- Accommodate loads from design basis accidents, including dynamic loads and thermal transients.

- Minimize the dead load deflections and thermal distortions (e.g., bowing of the deck structure) to assure positive equipment alignment.

- Provide a structure that can be field-erected to stringent tolerances,

- Ensure symmetrical radial thermal expansion of the reactor vessel assembly about its vertical center axis.

- $\quad$ Provide reliable positioning of supported components (e.g., pumps, IHXs, etc.). 


\subsubsection{Reactor Vessel Enclosure}

The reactor vessel enclosure forms the top closure for the reactor vessel. It supports the primary pumps, intermediate heat exchangers (IHXs), cold trap nozzles, rotatable plugs, the direct reactor auxiliary system heat exchangers, and other equipment. The individual rotatable plugs, in turn, supports the three instrument trees and the three in-vessel fuel handling machines, the control rod drivelines, as well as various instruments needed to monitor conditions inside the reactor vessel.

The reactor vessel enclosure is constructed of austenitic stainless steel. The enclosure, along with the reactor vessel, is supported by the conical support skirt that transfers the entire weight of the enclosure and the reactor vessel to the concrete support structure. The enclosure is bolted to the reactor vessel and there are seals welded around the interface between the enclosure and the reactor vessel to eliminate the release of cover gases through the reactor vessel/enclosure interface.

The reactor vessel enclosure is a solid piece of stainless steel about $\langle\mathrm{TBD}\rangle$ inches in thickness. It is $\langle\mathrm{TBD}\rangle$ feet in outer diameter. Openings are machined in the cover for those primary systems components that penetrate through to the primary vessel, such as the components mentioned above. Nozzles are welded to these openings that provide support for the primary system components and a location for sealing the components to the vessel enclosure. Reflective thermal insulation is attached to the bottom of the reactor vessel enclosure to reduce the amount of heat being conducted through the enclosure itself. Fiberglass insulation is added above the cover to reduce the amount of heat lost to the surrounding concrete.

The reactor vessel enclosure fulfills several important functions. These are:

- The reactor vessel and some portion of the enclosure form the primary coolant boundary, and contain all of the radioactive materials produced by the reactor during operation. These materials include the sodium coolant and any gaseous or solid radioactive materials released from the fuel elements due to cladding failure.

- Provides support for four IHXs, two primary pumps, three DRACS heat exchangers, two cold trap nozzles, the rotatable plugs, and various other equipment and instrumentation. A gas tight seal is provided between the enclosure and all penetrations.

- Provides sufficient stiffness to limit the vertical deformation during the safe shutdown earthquake (SSE) to a very small number (TBD).

- Minimize heat loss to the inside of the reactor building.

- Provide adequate rigidity to meet alignment needs for the primary sodium pumps, intermediate heat exchangers, rotatable plug, and the upper internal structure. 


\subsubsection{Guard Vessel}

The guard vessel provides the secondary containment for the primary sodium in the very unlikely event that the reactor vessel develops a leak. The guard vessel is sized such that the gap (8.5 inches) between it and the reactor vessel is:

- Wide enough to accommodate in-service inspection devices

- Narrow enough to prevent the primary sodium from dropping to an unacceptable level within the reactor vessel if the reactor vessel should develop a leak. The sodium level must remain high enough to keep the IHX and DRACS HX inlets covered to provide a path for natural convection cooling of the core during a leak in the reactor vessel.

The guard vessel is constructed of austenitic stainless steel. If carbon steel were acceptable, it would facilitate the use of magnetically-operated remote devices needed to carry out the periodic in-service inspection (ISI) required for the reactor vessel and associated structures and components. With austenitic stainless steel, the equipment used for ISI would require use of friction or scissors-like devices to scan the entire outer surface of the reactor vessel.

Insulation is provided on the exterior of the guard vessel to reduce the heat lost to the guard vessel cooling system. A guard cooling shroud is provided on the outside of the insulation that forces air to flow around the supporting concrete structure and up over the guard vessel insulation to prevent overheating of the concrete support structure during normal and off-normal conditions.

\subsubsection{Reactor Containment Boundary and Structure}

Reserved

\subsection{Primary Heat Transport System}

The basic function of the primary heat transport system (PHTS) is to transport heat from the reactor to the intermediate heat transport system (IHTS) under normal and off- normal operating conditions. The arrangement of the PHTS is shown in Figure 3-30 and Figure 3-31. 


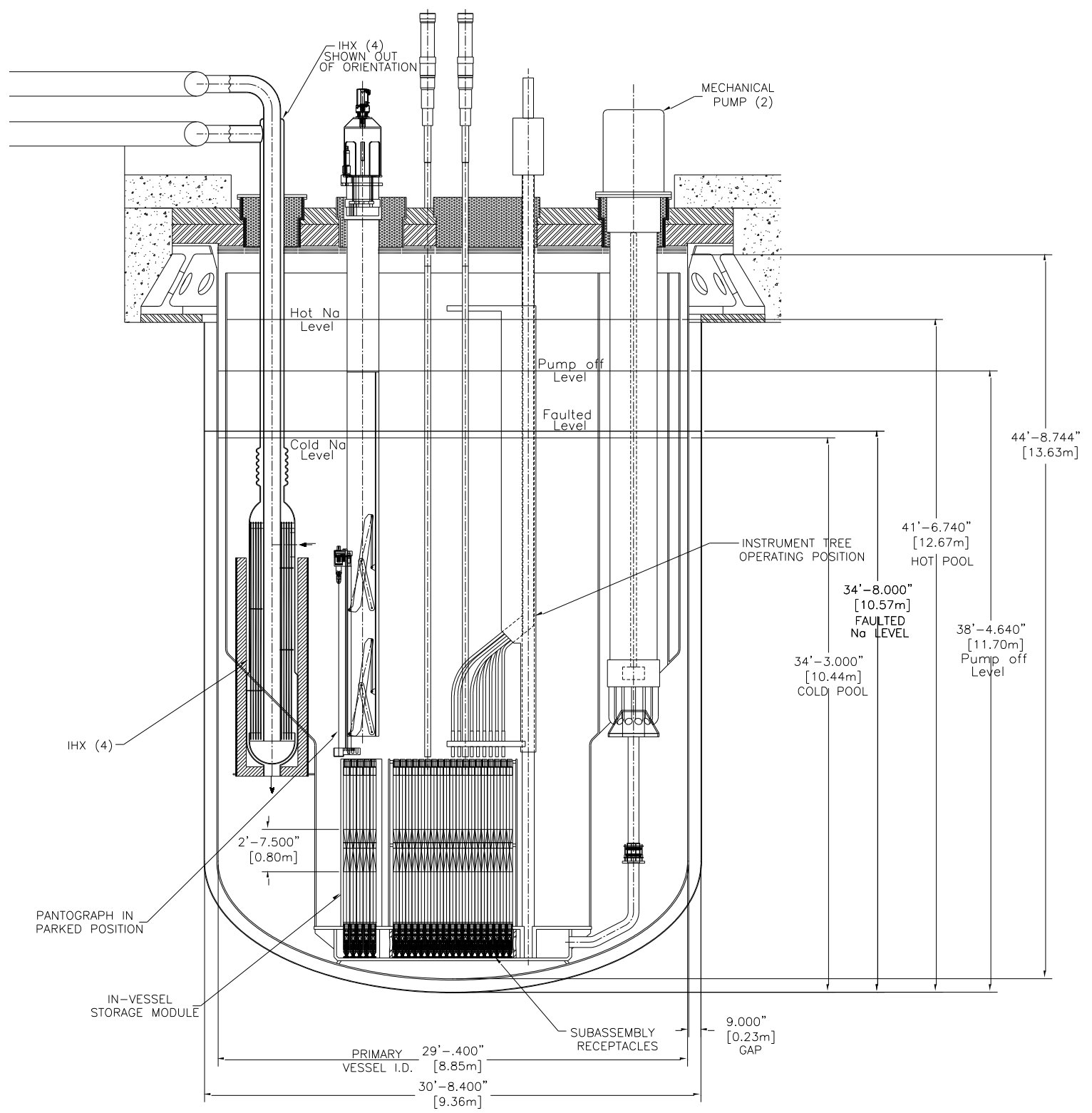

Figure 3-30: Vertical View of Primary System 


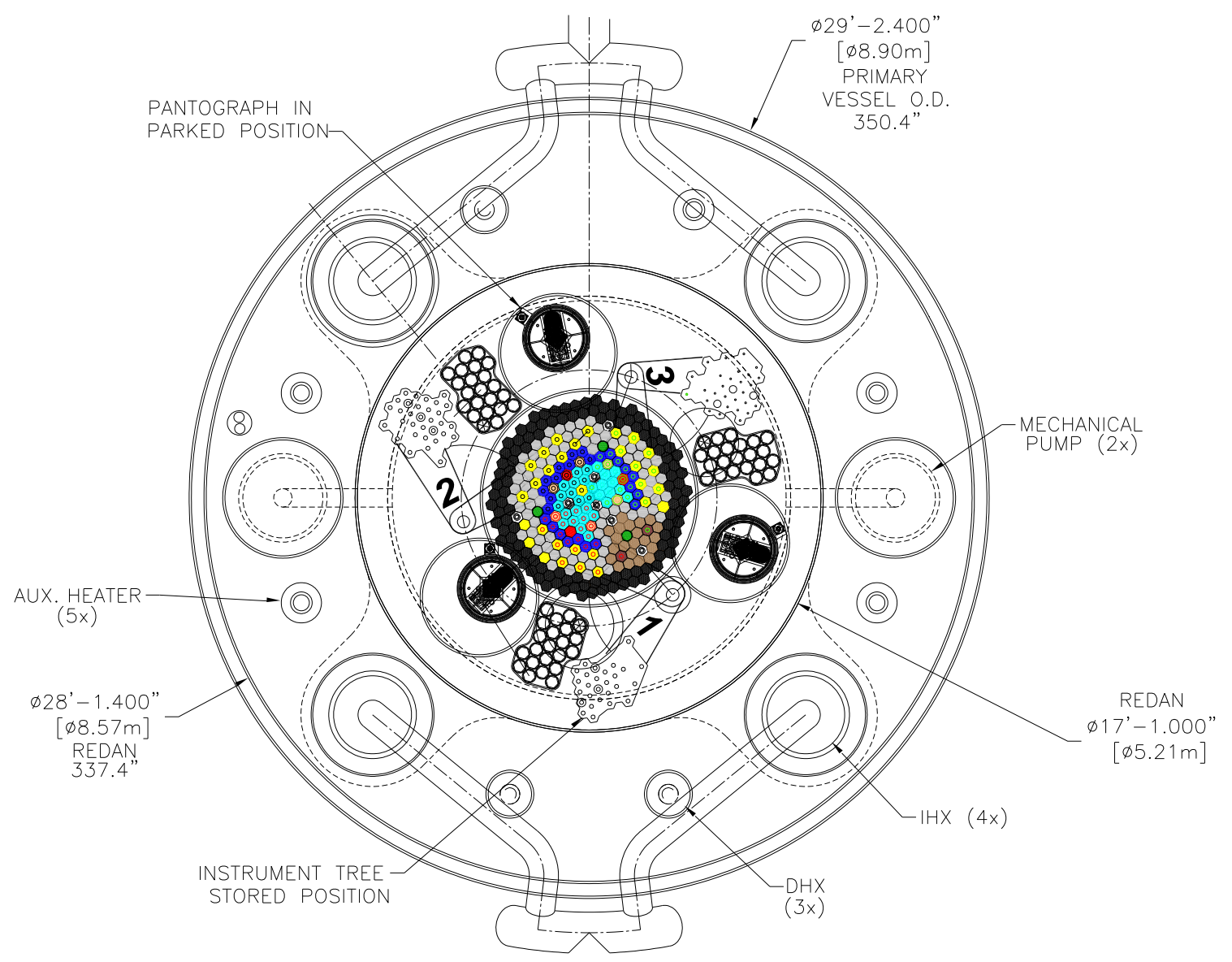

Figure 3-31: Plan View of the Primary System

The PHTS is located inside of the primary vessel. The coolant used for heat transport in the PHTS is sodium. The sodium in the primary vessel is divided into a hot pool and cold pool by a cylindrical and lobed structure, called the redan. The PHTS consists of two primary pumps, four intermediate heat exchangers (IHXs), and expansion joints between the pumps and the reactor inlet plenum. The two pumps and four IHXs are located symmetrically around the reactor. The two pumps are located in the cold pool, and each of the four IHXs is located within the redan and penetrates through the redan from the hot pool to the cold pool. The IHXs have no primary piping associated with them; the hot primary sodium enters the IHX inlet through openings in the IHX shell side at the top of the IHX and is discharged to the cold region at the bottom of the IHX. The hydraulic difference between the hot pool and cold pool is the driving force of flow through the IHXs.

In this pool configuration the pumps as well as the IHXs are supported from the reactor vessel deck, which is maintained near ambient temperature. The flexible seal between each IHX and the redan accommodates thermal and seismic motions. The flexible coupling between the discharge of each pump and the reactor inlet plenum, which is fixed to the lower core support structure, also accommodates thermal and seismic motions. The flexible coupling is designed to accommodate the small amount of differential thermal expansion between the pump and the 
lower support structure, including the differential thermal expansion of these items from shutdown to full power conditions.

A total sodium flow of $3,344 \mathrm{lbs} / \mathrm{s}$ removes the heat from the core and passes into the upper plenum at an average temperature of $510^{\circ} \mathrm{C}$. The core effluent mixes with the hot sodium in the plenum and flows up into the redan to four IHXs. Approximately $75 \mathrm{MW}_{\mathrm{t}}$ of heat is transferred from the primary to the secondary coolant in each IHX. The primary sodium leaves the IHX at $355^{\circ} \mathrm{C}$ and enters the cold pool region of the reactor vessel. Two pumps take the sodium from the cold pool and discharge it through inlet piping to the inlet plenum below the reactor core.

The PHTS must satisfy all normal and off-normal conditions specified in the duty cycle for the plant. In addition to full power 2-loop operation, the PHTS must provide heat removal for 50\% power operation when only one IHTS loop is available or $50 \%$ when one primary pump is outof-service. The system, along with the core and the IHX, is arranged to remove decay heat under natural circulation conditions. Maintainability and inspectability are important considerations in the design of the PHTS.

\subsubsection{Primary Reactor Coolant Pumps}

This subsection provides details on the primary reactor coolant pumps. Characteristics of the mechanical pumps are described below, and a description of the design analysis follows the pump characteristics.

\subsubsection{Mechanical Pump Characteristics}

The FASTER primary and secondary pumps are mechanical centrifugal pumps located in the cold pool of the primary system and the cold leg of the intermediate heat transport system.

The resulting design parameters are summarized in Table 3-19 and the FASTER mechanical pump is schematically compared with that of EBR-II in Figure 3-32.

Table 3-19: Mechanical Pump Design Parameters

\begin{tabular}{lc}
\hline Characteristic & \\
\hline Mass flow rate, $\mathrm{kg} / \mathrm{s}$ & 758.3 \\
Vol. flow rate, $\mathrm{m}^{3} / \mathrm{s}\left(868 \mathrm{~kg} / \mathrm{m}^{3} \mathrm{Na}\right.$ density) & 0.88 \\
Pump head, $\mathrm{kPa}$ & 704 \\
Power, $\mathrm{kW}$ & 950 \\
Efficiency, $\%$ & 85 \\
Pump length, $\mathrm{m}$ & 9.18 \\
Pump diameter, m & 0.889 \\
Suction nozzle diameter, $\mathrm{cm}$ & 60.96 \\
Discharge nozzle diameter, $\mathrm{cm}$ & 50.8 \\
\hline
\end{tabular}




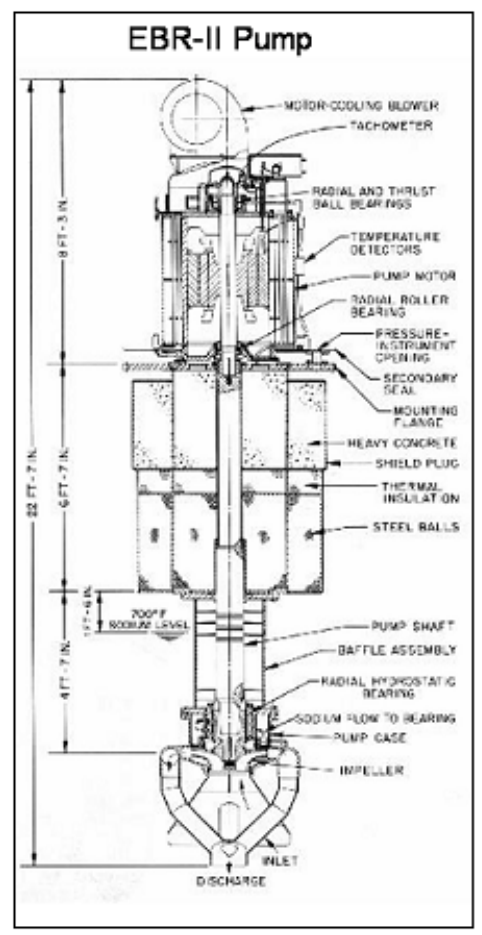

FASTER PRIMARY MECHANICAL PUMP

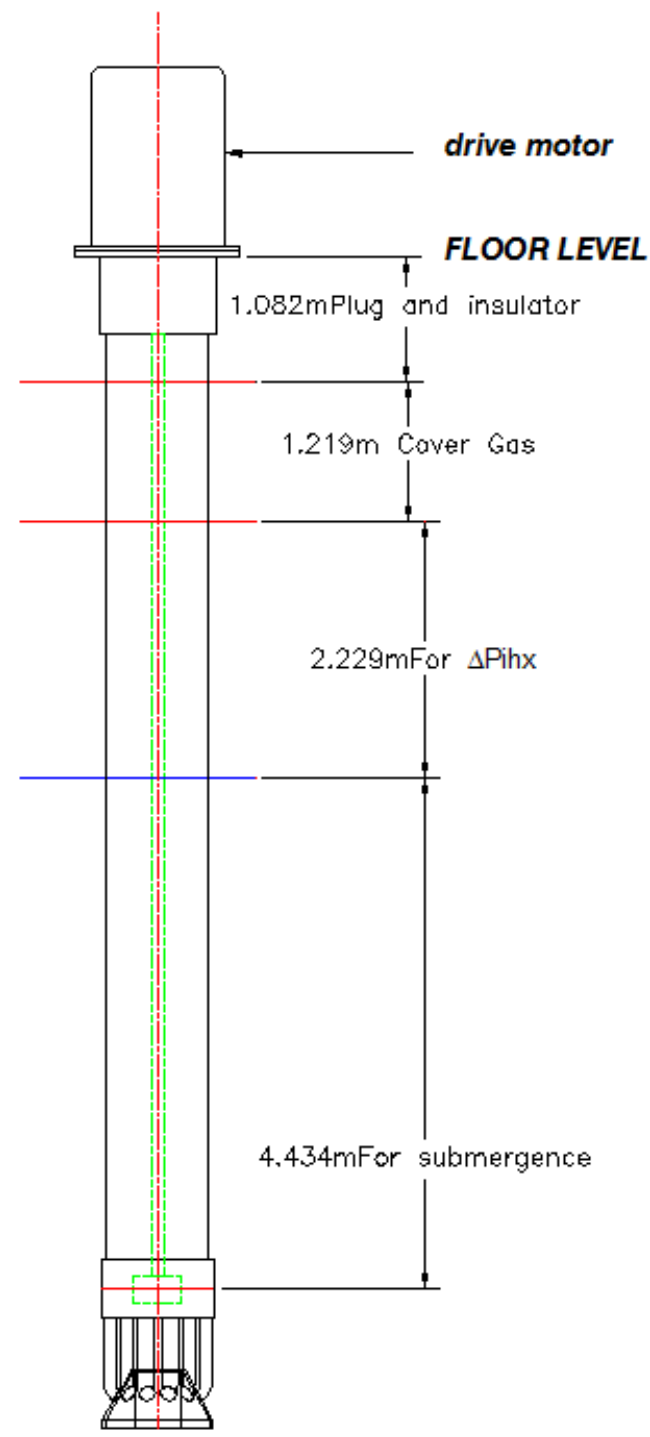

Figure 3-32: Schematic Comparison of FASTER and EBR-II Pumps

\subsubsection{Intermediate Heat Exchanger}

The IHXs transfer heat from the radioactive sodium coolant in the primary heat transport system to the nonradioactive sodium coolant in the intermediate heat transport system. Four sodium-tosodium heat exchangers rated at $75 \mathrm{MW}_{\mathrm{t}}$ each are used to transfer the $300 \mathrm{MW}_{\mathrm{t}}$ core power at full-power conditions corresponding to core inlet and outlet temperatures of $355^{\circ} \mathrm{C}$ and $510^{\circ} \mathrm{C}$, respectively. 
There are several factors that are important in the evaluation of the overall IHX design. These factors include materials of construction, tube configuration (straight vs. bent), shell vs. tube-side primary flow, elevation of the IHX within the primary system, shape of the IHX (in plan view), and primary flow-side pressure drop (i.e., low pressure loss is needed to ensure adequate natural convection primary sodium flow during loss-of-flow events). The various design choices that have been made, along with the underlying rationale for these choices, are described below.

The heat exchanger arrangement selected is a shell-and-tube counter-current flow arrangement with the primary flow on the shell-side, and secondary sodium flow on the tube side. Major features of these heat exchangers are graphically depicted in Figure 3-33, while key design information is provided in Table 3-20. The tube-side secondary flow was selected to simplify cleaning of the heat exchanger tubes in the event of a leak in the water Rankine superheated steam cycle system. Moreover, this configuration maximizes the ability of the IHX to accommodate any pressure transients that may arise if a secondary heat exchanger tube were to rupture, since for a given tube wall thickness the tubing is much stronger in tension (internal pressure source) versus compression (external pressure source). 


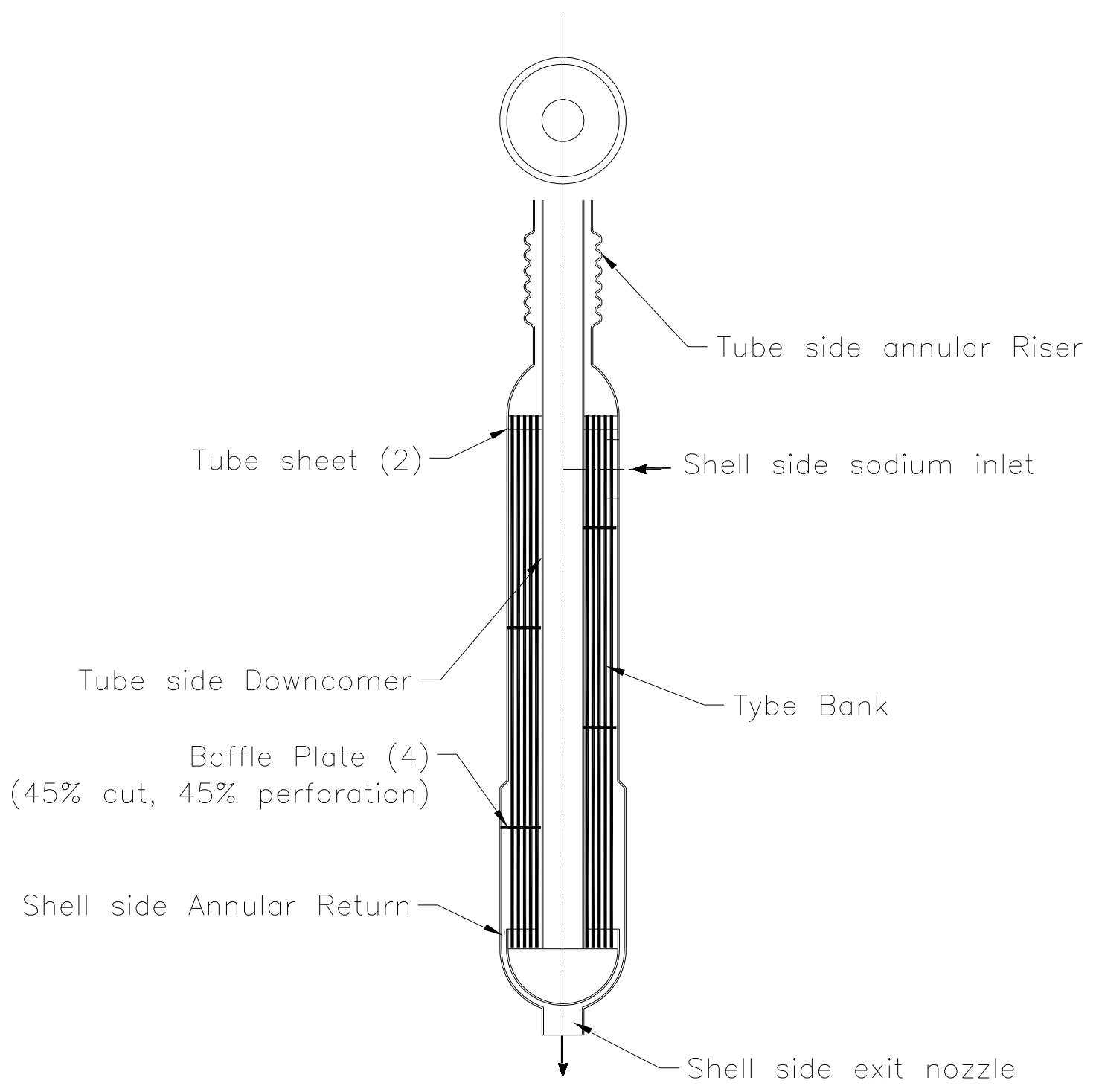

Figure 3-33: Intermediate Heat Exchanger Design

The installation of the IHXs inside the reactor vessel is illustrated in Figure 3-30. Each unit is vertically suspended from two rigid pipes that are welded to the IHX shroud. These pipes extend upward from the hot pool and are welded to the underside of a removable integral plug in the reactor vessel head. The IHXs pass through horizontal plate sections of the redan, which is contoured (in plan view) to accommodate the kidney-shaped IHX design that has been selected to minimize the reactor vessel diameter. 
Table 3-20: Intermediate Heat Exchanger Design Parameters

\begin{tabular}{lc}
\hline Characteristic & \\
\hline Heat transfer capacity, MW & 75 \\
Thermal design margin & $+25 \%$ \\
Heat transfer area, ${ }^{2}$ & 231 \\
Primary sodium temperature, inlet ${ }^{\circ} \mathrm{C} /$ outlet $^{\circ} \mathrm{C}$ & $510 / 355$ \\
Primary sodium mass flowrate, $\mathrm{kg} / \mathrm{s}$ & 379.15 \\
Secondary sodium temperature, inlet ${ }^{\circ} \mathrm{C} / \mathrm{outlet}^{\circ} \mathrm{C}$ & $279 / 499$ \\
Secondary side sodium mass flowrate, $\mathrm{kg} / \mathrm{s}$ & 265 \\
Tube outer diameter, cm & 1.59 \\
Tube wall thickness, mm & 0.889 \\
Tube pitch, cm & 2.5 \\
Active Tube Length, m & 3.85 \\
Number of tubes & 1,200 \\
Tube sheet - thickness, mm & 100 \\
Downc omer piping - OD, cm & 32.39 \\
Downcomer piping- thickness, mm & 9.525 \\
Downcomer piping - length, m & 11.89 \\
Riser piping - OD, cm & 45.72 \\
Riser piping - thickness, mm & 9.525 \\
Riser piping - length, m & 7.14 \\
Shell (primary) side pressure drop, KPa & 15.96 \\
Tube (secondary) side pressure drop, KPa & 30.76 \\
Shell height, m & 4.96 \\
Shell outside diameter, main body, $\mathrm{m} / \mathrm{maximum,} \mathrm{m}$ & $1.038 / 1.145$ \\
Shell thickness, mm & 19 \\
Tube material & $9 \mathrm{Cr}-1 \mathrm{Mo}$ \\
\hline
\end{tabular}

Primary sodium enters the shell side of each IHX through a series of $20 \mathrm{~cm}$ diameter circular openings in the shell approximately $30 \mathrm{~cm}$ below the upper tube sheet. These openings allow sodium from the hot plenum to enter the IHX with minimal head loss. Also, introduction of the sodium below the upper tube sheet minimizes the thermal shock to this relatively thick component during transients. The sodium then flows downward through the shell and vents through a $10 \mathrm{~cm}$ wide gap around the lower tube sheet that leads to a $32 \mathrm{~cm}$ diameter exit nozzle that discharge directly into the cold pool.

A seal mechanism between the IHX vertical outer wall and the vertical inner wall of the neutron shielding well is provided to prevent sodium bypass from the hot pool to the cold pool. Minor leakage of these seals is permissible. As shown in Figure 3-33, the shell side includes a series of horizontally mounted, disk and donut-type baffle plates uniformly spaced at $77 \mathrm{~cm}$ intervals along the length of the tube bank. Aside from providing lateral support for the tubes, these plates promote cross-flow and mixing that enhances thermal performance on the shell (primary) side. The plates are made from $6.4 \mathrm{~mm}$ steel plate and occlude $55 \%$ of the vertical flow path at each 
plate location. As shown Table 3-20, the plates are orificed (45\% equivalent porosity) to reduce flow pressure drop; a schematic showing the orifice design is provided in Figure 3-34. This approach is similar to that used in the GE PRISM Mod B IHX design.

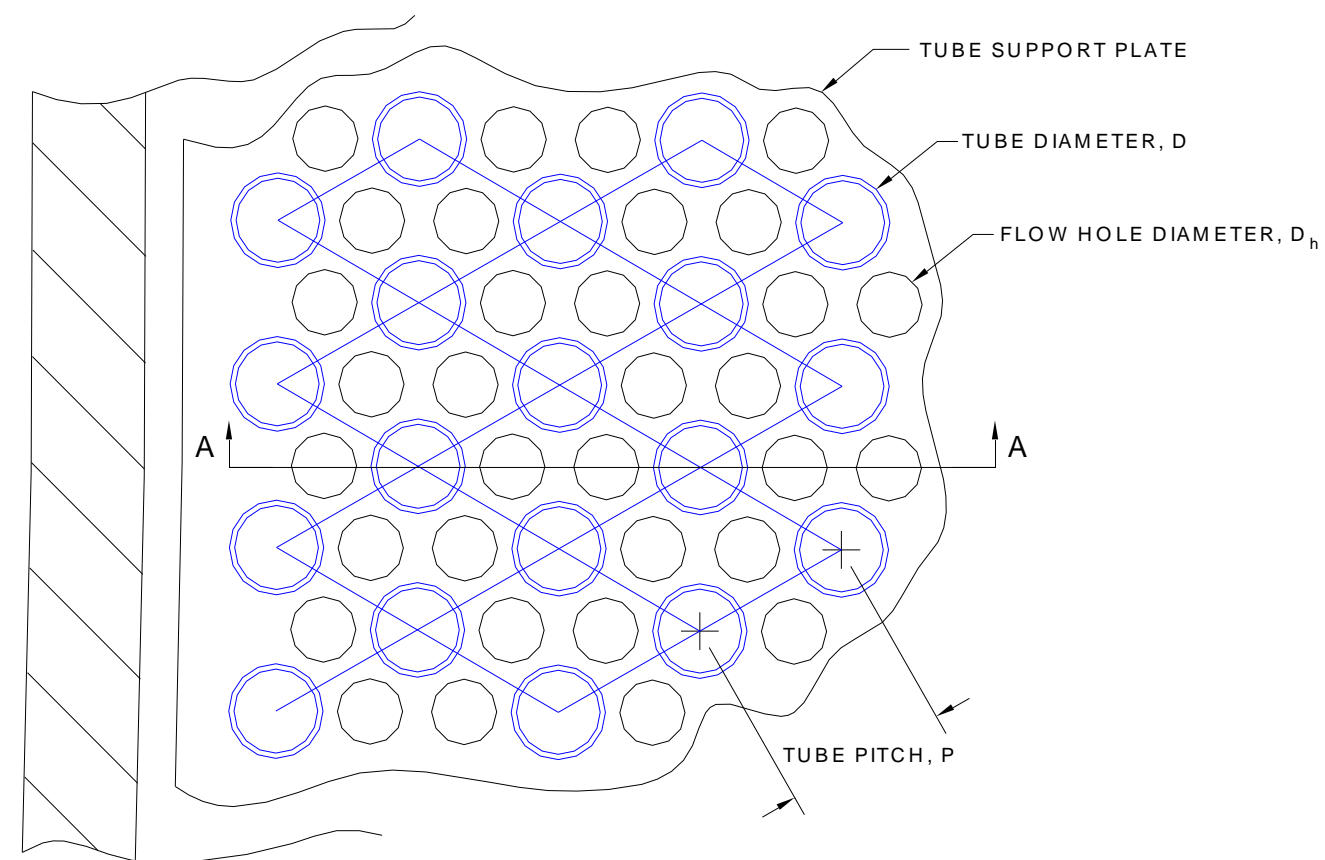

Figure 3-34: Plan View of Orifice Baffle Plate Design

As shown in Figure 3-33, cold intermediate sodium enters the IHX through a central $32.4 \mathrm{~cm}$ downcomer. The downcomer delivers the cold sodium through the lower tube sheet into a header manifold, where it then turns $180^{\circ}$ and rises through the tube bank in counter current flow to the shell side primary sodium. The hot intermediate sodium exits the tubes into an upper header manifold, and then flows through an annular riser which is concentric to the downcomer. The downcomer is double walled with an annular gap for thermal insulation between the hot and cold streams. As shown in Figure 3-33, both the downcomer and the $45.7 \mathrm{~cm}$ OD annular riser pipes are equipped with bellows just above the shroud to accommodate any differences in thermal expansion between the piping and the body of the IHX itself (each unit is rigidly attached to the removable plug in the reactor vessel head). The upper tube sheet is welded to the shroud, while the lower tube sheet floats. Thus, the design accommodates differential thermal expansion within the tube bank also.

The inner wall of the shell operates near the bulk temperature of the sodium in the hot plenum. Since primary sodium flow is on the shell side of the IHX, there is no need for an insulating annulus to eliminate heat losses to the bulk sodium or to alleviate high thermal stresses in the shell.

Modified 9Cr-1Mo steel was chosen as the material of construction primarily because the thermal conductivity is higher than that of the austenitic steels such as Type 304 stainless steel. Since the heat transfer in sodium-to-sodium heat exchangers can be dominated by the tube wall thermal resistance, using modified $9 \mathrm{Cr}-1 \mathrm{Mo}$ steel results in considerable reduction in the 
required heat transfer area. The use of Type 304 stainless steel tubes would result in the need for as much as $20 \%$ more heat transfer area as compared to modified $9 \mathrm{Cr}$-1Mo tubes with the same design characteristics. In addition, modified 9Cr-1Mo has a lower thermal expansion coefficient compared to Type 304 stainless steel. The higher thermal conductivity material results in lower temperature differences in component sections and, coupled with the reduced thermal expansion, results in lower thermal stresses in structural members. This is advantageous during thermal transients. Straight tubes are selected to simplify fabrication and reduce flow induced vibration problems.

The design of the IHX has been selected such that the primary flow of sodium on the shell side provides a low pressure drop. Low pressure drop on the primary side is important from two viewpoints: 1) minimizing the pressure-related structural requirements for the IHX shell, and 2) promoting the ability to establish natural circulation of the primary sodium in the case of a lossof-flow event. Adequate natural convection flow for shutdown heat removal is essential. One key element of the direct reactor auxiliary cooling system (DRACS) shutdown heat removal system relies on natural circulation of the primary sodium through the core and IHX to the sodium pool surrounding the core barrel. Thus, the IHX has been sized and positioned to locate the primary sodium inlet below the faulted sodium level (primary sodium leak from the primary vessel to the annulus between it and the guard vessel).

Aside from the overall thermal-hydraulic design of the IHXs, additional analysis is needed to verify that the thermal stresses in various regions of these units will remain below acceptable levels to ensure that the plant design lifetime requirement can be met without undue risk of stress-related failure(s). Furthermore, shielding may need to be incorporated into the design if calculations indicate excessive activation of the secondary sodium by virtue of the close proximity of the IHXs to the core.

Note that as part of the design process, thermal-hydraulic calculations were performed that formed the technical basis for sizing of these units such that they would fit within the available space between the redan and reactor vessel inner surface, while achieving the desired $75 \mathrm{MW}_{\mathrm{t}}$ rating. In addition, a specialized model was developed in order to accurately evaluate flow pressure drop on the shell side of the IHX, including the effect of the orificed baffle plates.

\subsubsection{Primary Internal Piping System}

There is very little primary piping within the reactor vessel assembly for the mechanical pump connections with the inlet plenum. The discharge of the mechanical centrifugal pump flows into an articulated coupling that connects the primary pump to the inlet plenum structure. This primary piping would consist of a main header for each pump with multiple pipes leading from each pump header into the inlet plenum structure. The main header is connected to a flexible coupling. The other end of the internal piping is welded to the core inlet plenum.

Each primary piping assembly is supported to take the appropriate mechanical, thermal and hydraulic loads. The pump hangs from the reactor vessel enclosure and is connected to the inlet plenum or inlet pipe header (depending upon pump application) by a special, nonrigid, easily disconnected, low leakage articulated coupling. The flexible coupling allows lateral and vertical 
movement without losing metal-to-metal contact and accommodates relative displacements between the pump and the inlet plenum. The coupling has a slip joint to extend or retract the coupling length with a ball joint at the bottom end. The ball joint at the bottom end is unattached and connects with the mating seat on the reactor core vessel inlet plenum. During installation, the pump is lowered vertically into the reactor vessel. When the bottom ball joint contacts with the mating seat on the inlet plenum, the coupling is compressed, creating spring pressure in the coupling. The spring pressure maintains the coupling in position and seals the ball joint against the mating joint of the inlet plenum.

The coupling allows the pump to be removed or installed without cutting the inlet interface. The coupling can permit some leakage but must provide flexibility to accommodate thermal movements, be sufficiently stable to avoid flow induced vibrations, and accommodate seismic loads. No valves or movable flow control devices are part of the inlet piping or flexible coupling. Pipe insulation is not required.

\subsection{Intermediate Heat Transport System}

This section provides details on the Intermediate Heat Transport System (IHTS). Requirements of the IHTS and a general description are provided in Section 3.5.1. The intermediate sodium pump is described in Section 3.5.2. Associated piping is described in Section 3.5.3, and a description of the IHTS storage and expansion tanks is provided in Section 3.5.4.

\subsubsection{System Requirements and Description}

The intermediate heat transport system (IHTS) circulates secondary sodium coolant, transporting heat from the radioactive sodium in the primary heat transport system (PHTS) to the power generation system. Currently, Rankine steam cycle power generation system is adopted for FASTER.

The IHTS is composed of two completely independent loops, as shown in Figure 3-35. This figure shows the plan view of the piping runs to the secondary steam generator. The flowrate through both loops is controlled to maintain the primary sodium coolant temperature at design operation conditions. With the exception of the short pipe runs of the hot and cold sodium piping connected to the IHX and running from the IHX to the steam generator, the entire IHTS is contained within the steam generator facility that is part of the reactor building. 


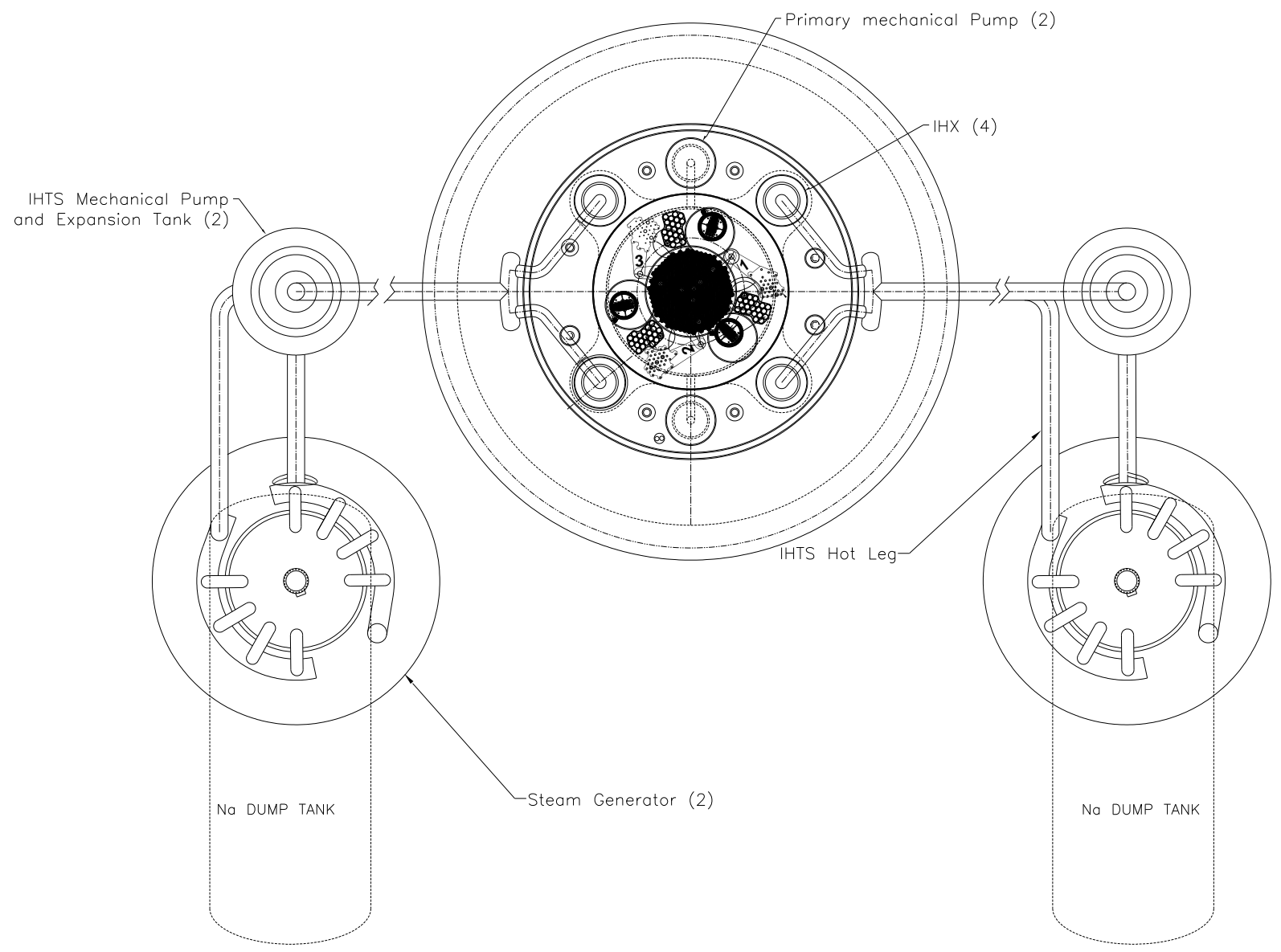

Figure 3-35: Plan View of IHTS Layout 


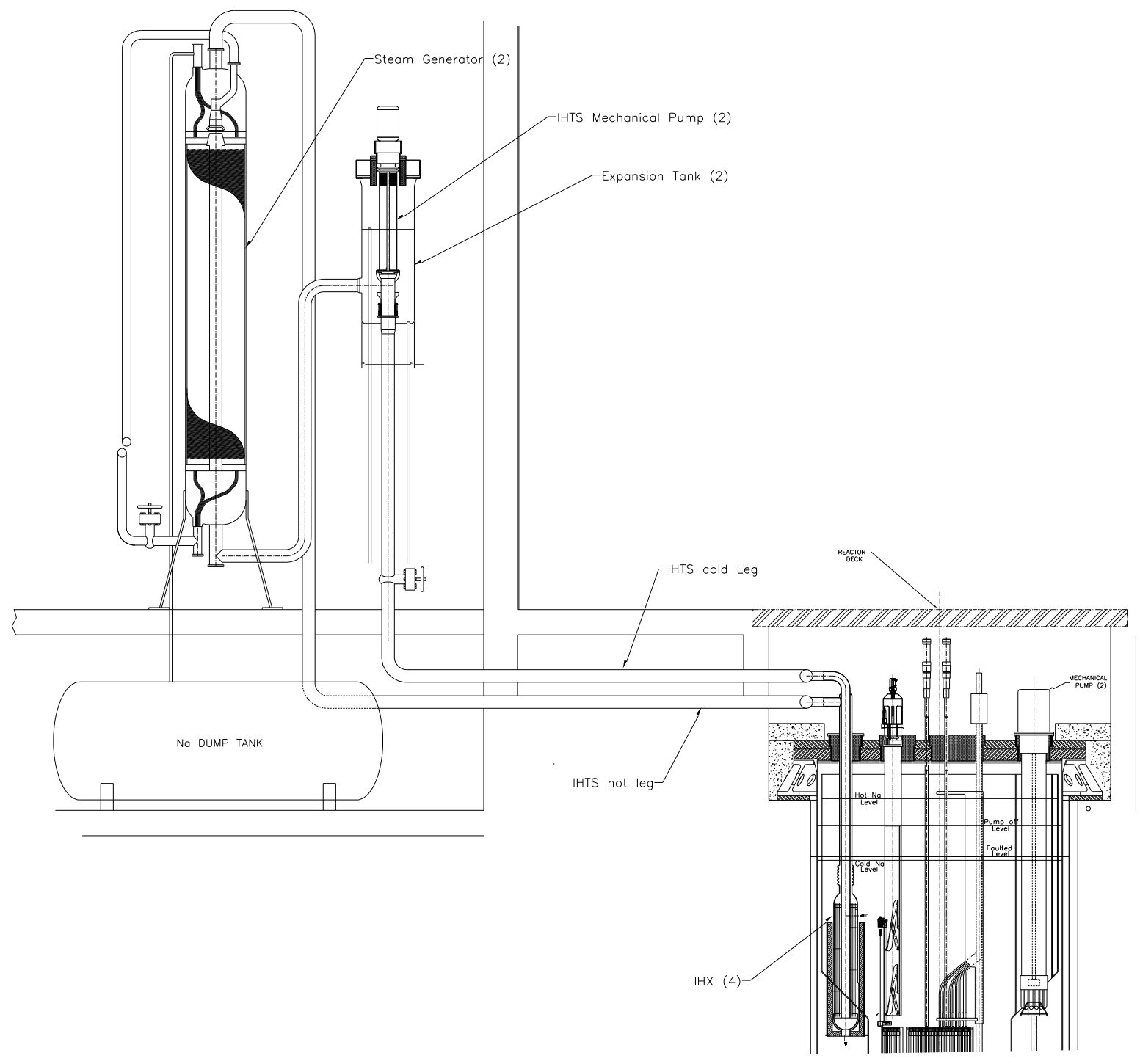

Figure 3-36: Elevation View of IHTS Layout

The secondary sodium exits the upper portion of the IHX after being heated to $499^{\circ} \mathrm{C}$. The sodium then exits the reactor containment and traverses the short distance to the adjacent steam generator production facility inside the reactor building. Here, the hot sodium enters the top of the steam generators and transfers heat to the water before exiting at the bottom of these units. After exiting at the bottom of the steam generator, the secondary sodium circulates to the IHTS mechanical pump where it is pumped back to the reactor containment and cold side of the IHX. The tube walls of the IHX constitute the principal barrier for isolation of the activated primary sodium from the sodium in the secondary system. In the unlikely event of an IHX tube leak, sodium leakage will occur from the IHTS to the PHTS due to the fact that the secondary system is maintained at a pressure of at least $1.72 \mathrm{bar}(24.9 \mathrm{psig})$ in excess of the primary system. The excess pressure is due to sodium hydrostatic head $(\sim 20.6 \mathrm{~m})$ that is provided by the higher elevation of the secondary loop relative to the primary loop (see Figure 3-36). Radiation detectors on the outlet (hot leg) piping from the IHX monitor for indications of contamination of the secondary loop sodium. 
Major components in each of the two loops include a mechanical pump, a steam generator, a sodium storage tank, two IHXs (tube side) and the piping connecting these components to each as well as the IHX and steam generator. Details regarding the balance of key system components are provided below.

Auxiliary systems that connect to the IHTS main loop that are necessary to achieve operational requirements include a circulating sodium purification system, trace heating, thermal insulation, and instrumentation that monitors key system parameters including flowrate (with permanently installed magnetic flowmeter in each cold leg), and temperature differential across the IHTS (with thermocouples installed at the steam generator inlet and outlet legs).

\subsubsection{Intermediate Sodium Pump}

One sodium pump is used in each IHTS loop. Each vertically mounted mechanical pump is submerged in an expansion tank. The pump operates in the cold leg at nominally $279^{\circ} \mathrm{C}$. The pump installation location is shown in the plant elevation view provided in Figure 3-36, where design details are summarized in Table 3-21. The pump design is very similar to primary mechanical pump (Section 3.4.1), which minimizes the developmental requirements for FASTER.

Table 3-21: IHTS Pump Design Parameters

\begin{tabular}{lc}
\hline Characteristic & \\
\hline Flow rate, $\mathrm{m}^{3} / \mathrm{s}$ & 758.3 \\
Pump head, $\mathrm{KPa}$ & 266 \\
Power, $\mathrm{kW}$ & 260 \\
Efficiency, \% & 85 \\
Pump length, $m$ (without motor) & 4.5 \\
Pump diameter (case), $m$ & 0.635 \\
Suction nozzle diameter, $\mathrm{cm}$ & 53.3 \\
Discharge nozzle diameter, $\mathrm{cm}$ & 53.3 \\
Drive motor length, $m$ & 1.4 \\
Drive motor diameter, $m$ & 0.75 \\
\hline
\end{tabular}

Each pump is installed in the expansion tank with controlled cover gas pressure in the gas space of the tank. The discharge nozzle of the pump is connected to the outlet pipe of the expansion tank which in turn is connected to the down comer manifold of the two IHXs. The suction nozzle of the pump is located $2.03 \mathrm{~m}$ below the sodium surface in the expansion tank to keep from forming of vortex in the sodium during the normal pump operation. This sodium level is maintained through proper cover gas control in the expansion tank and the steam generator.

\subsubsection{IHTS Piping}

The IHTS piping consists primarily of the main system hot and cold legs which make the necessary connections between the IHX and the steam generator. The hot leg piping connects to the secondary sodium outlet of the IHX directly to the steam generator sodium inlet. The IHTS 
cold leg piping connects the sodium outlet from the steam generator to the EM pump tank inlet and then from the pump tank discharge to the secondary cold sodium inlet to the IHX.

The IHTS piping is constructed from $45.7 \mathrm{~cm}$ OD, $0.952 \mathrm{~cm}$ thick-walled (18 inch Schedule 40S) 304 stainless steel piping, primarily because of the lack of corrosion issues for sodium and the ease of fabrication with this material. The use of this piping diameter and schedule maintains the sodium flow velocity through the secondary piping system below $\sim 7 \mathrm{~m} / \mathrm{sec}$ (actual value is $6.5 \mathrm{~m} / \mathrm{sec}$ at full power conditions), which is a rule-of- thumb design criterion for these types of systems. The use of 304 stainless steel requires dissimilar metal welds connecting the austenitic Type 304 stainless steel to the ferritic steels used in the IHX. The welding technology for joining these dissimilar metals is well established.

\subsubsection{IHTS Storage and Expansion Tanks}

A small secondary loop is included in the IHTS to maintain sodium volume and to provide a purification pathway for the secondary sodium. The loop supplies sodium from a cold trap to the IHTS pump tank to maintain a constant level of sodium in the IHTS loop. The recirculation system uses a fill and overflow approach to maintain the sodium level constant. Spillover into the pump tank overflow line flows through the secondary piping to the storage tank. Sodium is then pumped from the storage tank by a small recirculation pump through interconnecting piping to the cold trap. After circulating through the trap, the sodium circulates back to the pump tank.

The circulating sodium to the storage tank keeps the tank at system temperature during normal operations. When flow is not available, trace heating is used to keep system components above the sodium freezing point.

Pressurized argon cover gas is maintained in the pump tank upper plenum. Subsystems must also be provided to control the argon cover gas pressure and supply. 


\section{Power Conversion System}

The FASTER reactor incorporates a Rankine superheated steam cycle power converter to provide electrical power to the grid. Revenue earned through the sale of electricity will be substantial and may more than offset the annual operating and maintenance costs as well as defraying part of the construction cost.

\subsection{Steam Rankine Cycle}

The FASTER power conversion superheated steam cycle is based on the steam cycle previously developed for the ABR-1000 concept [16,17]. The same cycle layout, developed for ABR-1000, is currently adopted for FASTER. The steam cycle (Figure 4-1) is assumed to have three stages of a high pressure turbine, intermediate pressure turbine, and low pressure turbine with moisture separation and reheat before the last stage, five stages of feedwater heating with steam extraction lines from the intermediate and low pressure turbines, and three stages of condensate/feedwater pumping.

The FASTER steam cycle performance was analyzed using the GateCycle software [18]. The main assumptions for the model are presented in Table 4-1. Because the FASTER and ABR1000 concepts have the same reactor coolant temperature, the same water-side conditions at the steam generator, $246^{\circ} \mathrm{C}$ and $16.7 \mathrm{MPa}$ at the inlet and $454^{\circ} \mathrm{C}$ and $15.5 \mathrm{MPa}$ at the outlet, are preserved for the FASTER steam cycle from the ABR-1000 design. Similarly, the condenser back pressure of $0.01 \mathrm{MPa}$ (with a saturation temperature of $46.5^{\circ} \mathrm{C}$ ) and cooling water temperature of $15.5^{\circ} \mathrm{C}\left(60^{\circ} \mathrm{F}\right)$ are retained for the FASTER steam plant from the ABR-1000 design.

Selected GateCycle results are shown in Figure 4-1. The detailed calculated conditions for each stream are presented in Table 4-2. Figure 4-2 shows the conditions around the cycle on a temperature-entropy diagram. Table 4-3 presents the calculated power levels for the turbines, compressors, and generator. The net power available from the cycle is $122 \mathrm{MW}_{\mathrm{e}}$, which, for the $300 \mathrm{MW}_{\text {th }}$ heat input, corresponds to $40.7 \%$ of net cycle efficiency. The gross cycle efficiency equal to the power delivered by the electric generator divided by the heat rate input to the cycle is equal to $41.8 \%$. The net power and net efficiency values account only for the components modeled in the cycle in Figure 4-1, such as feedwater pumps. They do not include other plant loads, such as primary and intermediate sodium pumps, cooling water pumps, closed loop pumps and air fans, and other electrical plant loads. Therefore, the net plant output and the net plant efficiency will be less than $122 \mathrm{MWe}$ and $40.7 \%$, respectively. The net plant values may be calculated later when information on those additional loads becomes available. 
FASTER Test Reactor Preconceptual Design Report

March 31, 2016

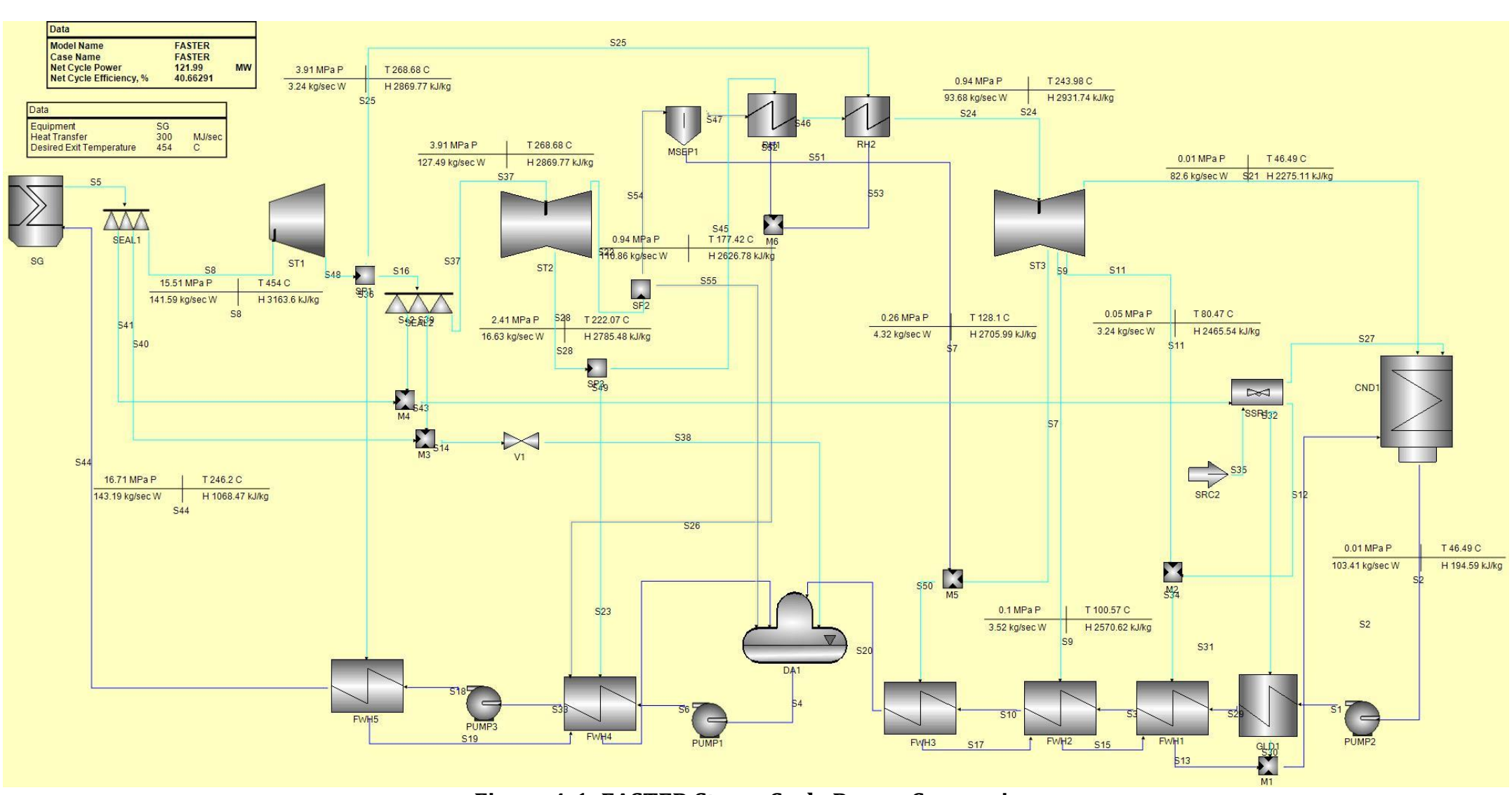

Figure 4-1: FASTER Steam Cycle Power Conversion 
Table 4-1: Assumptions for GateCycle Model of Steam Cycle

\begin{tabular}{|c|c|c|}
\hline Component & Parameter/Assumption & Value \\
\hline \multirow{2}{*}{ System } & Generator efficiency & $98 \%$ \\
\hline & BOP power loss & 0 \\
\hline \multirow{4}{*}{ Turbines } & Three turbines are used in the cycle & HP, IP, LP \\
\hline & Turbine isentropic efficiency & $90 \%$ (all turbines) \\
\hline & Number of extraction lines & HP-0, IP-1, LP-3 \\
\hline & Shaft/gearbox losses & 0 \\
\hline \multirow{2}{*}{ Pumps } & Isentropic efficiency & $85 \%$ \\
\hline & Motor/gearbox losses & 0 \\
\hline \multirow{5}{*}{$\begin{array}{c}\text { Feed Water } \\
\text { Heaters }\end{array}$} & Terminal temperature difference ${ }^{a}$ & $5^{\circ} \mathrm{F}\left(2.8^{\circ} \mathrm{C}\right)$ \\
\hline & Drain cooler approach ${ }^{\text {a }}$ & $10^{\circ} \mathrm{F}\left(5.6^{\circ} \mathrm{C}\right)$ \\
\hline & Pressure drop & 0 (both sides) \\
\hline & Energy loss & $1 \%$ \\
\hline & Fouling factor & 0 \\
\hline \multirow{3}{*}{ Condenser } & Condenser pressure & $1.5 \mathrm{psia}(0.1 \mathrm{bar})$ \\
\hline & Cooling water temperature rise & $20^{\circ} \mathrm{F}\left(11.1^{\circ} \mathrm{C}\right)$ \\
\hline & Pressure drop & 0 (both sides) \\
\hline \multirow{3}{*}{$\begin{array}{c}\text { Steam } \\
\text { Generator }\end{array}$} & Desired duty (to calculate steam flow rate) & $300 \mathrm{MW}$ \\
\hline & Steam exit temperature & $850{ }^{\circ} \mathrm{F}\left(454^{\circ} \mathrm{C}\right)$ \\
\hline & Steam side pressure drop & 174 psi (12 bar) \\
\hline Pipes & Pressure drop in pipes & 0 \\
\hline
\end{tabular}

a [The following definitions are from GateCycle Help] Terminal Temperature Difference (TTD) is defined as the difference between cold outlet temperature and hot-side saturation temperature (see figure below). In the TTD design method, the hot inlet stream flow will be demanded from upstream based on the calculated feedwater heater performance. This is the usual design-point method for the feedwater heater performance. Drain Cooler Approach Temperature (DCA) is defined in the figure below. The drain cooler represents a heat exchanger section between the exiting hot stream flow and the incoming cold stream flow. The input DCA is therefore the desired temperature difference between these two streams. A typical value for this is $10^{\circ} \mathrm{F}$.

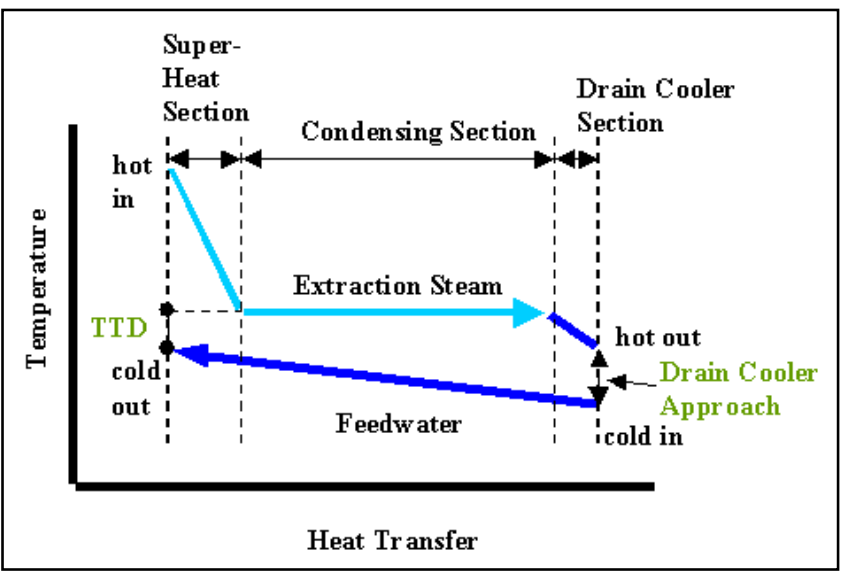


FASTER Test Reactor Preconceptual Design Report

March 31, 2016

Table 4-2: Stream Conditions from GateCycle Model

\begin{tabular}{|c|c|c|c|c|c|c|c|}
\hline Stream & From & To & $\begin{array}{c}\text { Flow } \\
\mathrm{kg} / \mathrm{sec}\end{array}$ & $\begin{array}{c}\text { Pressure } \\
\mathrm{MPa}\end{array}$ & $\begin{array}{c}\text { Temperature } \\
\text { C } \\
\end{array}$ & $\begin{array}{c}\text { Enthalpy } \\
\mathrm{kJ} / \mathrm{kg}\end{array}$ & Quality \\
\hline S1 & PUMP2 & GLD1 & 103.4113 & 2.1029 & 46.65 & 197.079 & 0 \\
\hline S10 & FWH2 & FWH3 & 103.411 & 2.1029 & 97.80 & 411.2929 & 0 \\
\hline S11 & ST3 & M2 & 3.2425 & 0.0483 & 80.47 & 2465.539 & 0.9224 \\
\hline S12 & SSR1 & M2 & 1.5709 & 0.1379 & 239.02 & 2951.358 & 1 \\
\hline S13 & FWH1 & M1 & 20.0093 & 0.0483 & 52.21 & 218.5222 & 0 \\
\hline S14 & M3 & V1 & 1.7514 & 1.0342 & 288.94 & 3027.404 & 1 \\
\hline S15 & FWH2 & FWH1 & 15.1957 & 0.1034 & 83.25 & 348.5841 & 0 \\
\hline S16 & SP1 & SEAL2 & 130.0203 & 3.9093 & 268.68 & 2869.771 & 1 \\
\hline S17 & FWH3 & FWH2 & 11.6724 & 0.2551 & 103.35 & 433.32 & 0 \\
\hline S18 & PUMP3 & FWH5 & 143.1892 & 16.712 & 222.55 & 959.6943 & 0 \\
\hline S19 & FWH5 & FWH4 & 8.3318 & 3.9093 & 228.11 & 981.6572 & 0 \\
\hline $\mathrm{S} 2$ & CND1 & PUMP2 & 103.4113 & 0.0103 & 46.49 & 194.5912 & 0 \\
\hline S20 & FWH3 & DA1 & 103.4104 & 2.1029 & 125.32 & 527.6408 & 0 \\
\hline S21 & ST3 & CND1 & 82.595 & 0.0103 & 46.49 & 2275.106 & 0.87 \\
\hline $\mathrm{S} 22$ & ST2 & SP2 & 110.862 & 0.9446 & 177.42 & 2626.777 & 0.9272 \\
\hline S23 & FWH4 & DA1 & 28.1986 & 2.4132 & 183.37 & 778.6751 & 0 \\
\hline S24 & RH2 & ST3 & 93.6771 & 0.9446 & 243.98 & 2931.737 & 1 \\
\hline S25 & SP1 & RH2 & 3.2374 & 3.9093 & 268.68 & 2869.771 & 1 \\
\hline S26 & M6 & FWH4 & 8.2209 & 2.4132 & 222.07 & 1003.499 & 0.0272 \\
\hline S27 & SSR1 & CND1 & 0.4788 & 0.1379 & 239.02 & 2951.358 & 1 \\
\hline S28 & ST2 & SP3 & 16.6296 & 2.4132 & 222.07 & 2785.476 & 0.9919 \\
\hline S29 & GLD1 & FWH1 & 103.4113 & 2.1029 & 46.65 & 197.079 & 0 \\
\hline S3 & FWH1 & FWH2 & 103.411 & 2.1029 & 77.69 & 326.8663 & 0 \\
\hline S30 & GLD1 & M1 & 0.3276 & 0.1 & 238.34 & 2951.358 & 1 \\
\hline S31 & M1 & CND1 & 20.3369 & 0.0483 & 62.73 & 262.5437 & 0 \\
\hline S32 & SSR1 & GLD1 & 0.3276 & 0.1379 & 239.02 & 2951.358 & 1 \\
\hline S33 & FWH4 & PUMP3 & 143.1892 & 3.0682 & 219.29 & 940.6294 & 0 \\
\hline S34 & M2 & FWH1 & 4.8134 & 0.0483 & 80.47 & 2624.093 & 0.9911 \\
\hline S35 & SRC2 & SSR1 & 0 & 0.0965 & 148.89 & 2774.395 & 1 \\
\hline S36 & SP1 & FWH5 & 8.3318 & 3.9093 & 268.68 & 2869.771 & 1 \\
\hline S37 & SEAL2 & ST2 & 127.4913 & 3.9093 & 268.68 & 2869.771 & 1 \\
\hline S38 & V1 & DA1 & 1.7514 & 1.0342 & 288.94 & 3027.404 & 1 \\
\hline S39 & SEAL2 & M3 & 0.8118 & 1.0342 & 218.67 & 2869.771 & 1 \\
\hline S4 & DA1 & PUMP1 & 143.1892 & 0.9446 & 177.42 & 751.7422 & 0 \\
\hline S40 & SEAL1 & M3 & 0.9396 & 1.0342 & 352.70 & 3163.602 & 1 \\
\hline S41 & SEAL1 & M4 & 0.6601 & 0.1379 & 344.44 & 3163.602 & 1 \\
\hline S42 & SEAL2 & M4 & 1.7172 & 0.8274 & 214.19 & 2869.771 & 1 \\
\hline S43 & M4 & SSR1 & 2.3773 & 0.1379 & 239.02 & 2951.358 & 1 \\
\hline S44 & FWH5 & SG & 143.1892 & 16.712 & 246.20 & 1068.471 & 0 \\
\hline S45 & SP3 & RH1 & 4.9835 & 2.4132 & 222.07 & 2785.476 & 0.9919 \\
\hline S46 & RH1 & RH2 & 93.6771 & 0.9446 & 217.07 & 2870.524 & 1 \\
\hline S47 & MSEP1 & RH1 & 93.6771 & 0.9446 & 177.42 & 2774.018 & 1 \\
\hline S48 & ST1 & SP1 & 141.5895 & 3.9093 & 268.68 & 2869.771 & 1 \\
\hline S49 & SP3 & FWH4 & 11.6461 & 2.4132 & 222.07 & 2785.476 & 0.9919 \\
\hline S5 & SG & SEAL1 & 143.1892 & 15.512 & 454.00 & 3163.602 & 1 \\
\hline S50 & M5 & FWH3 & 11.6726 & 0.2551 & 128.10 & 1474.399 & 0.4296 \\
\hline S51 & MSEP1 & M5 & 7.3562 & 0.9446 & 177.42 & 751.7422 & 0 \\
\hline S52 & RH1 & M6 & 4.9835 & 2.4132 & 222.07 & 953.271 & 0 \\
\hline S53 & RH2 & M6 & 3.2374 & 3.9093 & 248.98 & 1080.818 & 0 \\
\hline S54 & SP2 & MSEP1 & 101.0332 & 0.9446 & 177.42 & 2626.777 & 0.9272 \\
\hline S55 & SP2 & DA1 & 9.8288 & 0.9446 & 177.42 & 2626.777 & 0.9272 \\
\hline S6 & PUMP1 & FWH4 & 143.1892 & 3.0682 & 177.81 & 754.5505 & 0 \\
\hline S7 & ST3 & M5 & 4.3164 & 0.2551 & 128.10 & 2705.985 & 0.9948 \\
\hline S8 & SEAL1 & ST1 & 141.5895 & 15.512 & 454.00 & 3163.602 & 1 \\
\hline S9 & ST3 & FWH2 & 3.5233 & 0.1034 & 100.57 & 2570.618 & 0.9529 \\
\hline Cooling Water Inlet & CND1 & CND1 & 3756.721 & 0.1034 & 15.56 & 65.3944 & 0 \\
\hline Cooling Water Exit & CND1 & CND1 & 3756.721 & 0.1034 & 26.67 & 111.8556 & 0 \\
\hline
\end{tabular}




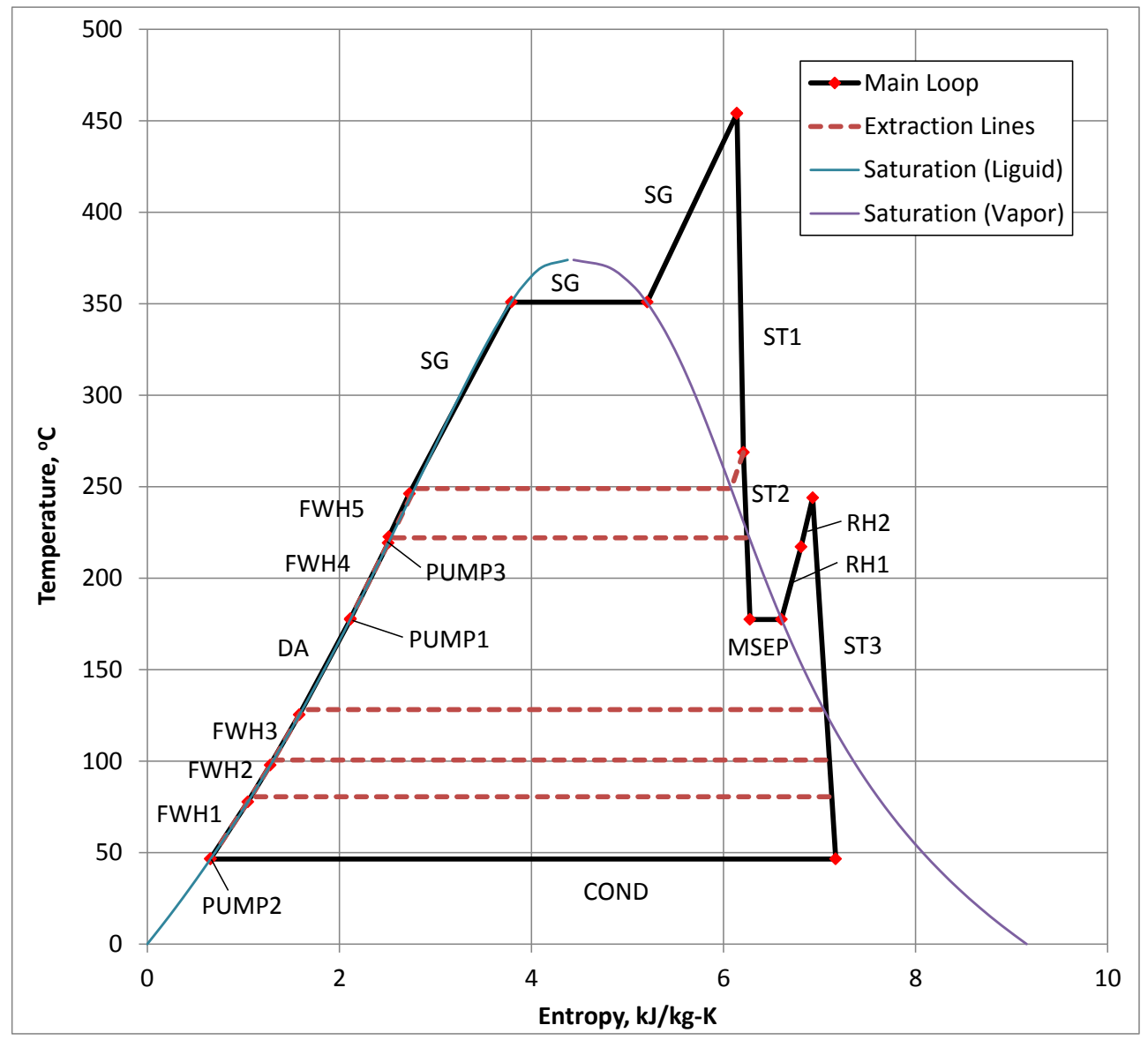

Figure 4-2: Temperature-Entropy Diagram of FASTER Steam Cycle

Table 4-3: Steam Cycle Power Balance

\begin{tabular}{lcc}
\hline \multicolumn{1}{c}{ Equipment } & GateCycle Icon & Power, MW \\
\hline High Pressure Turbine & ST1 & 41.605 \\
Intermediate Pressure Turbine & ST2 & 28.342 \\
Low Pressure Turbine & ST3 & 57.995 \\
\hline Total Shaft Power & - & 127.942 \\
Generator Output & - & 125.383 \\
\hline Condensate Pump & PUMP2 & -0.257 \\
Feedwater Low Pressure Pump & PUMP1 & -0.402 \\
Feedwater High Pressure Pump & PUMP3 & -2.730 \\
\hline Net Steam Cycle Power & & $\mathbf{1 2 1 . 9 9 3}$ \\
\hline
\end{tabular}

The FASTER steam cycle has not yet been optimized. In fact, the entire steam plant layout in Figure 4-1 may not be optimal. This cycle layout, with three turbine stages and moisture separation and reheat between the stages, was developed for commercial applications, such as the ABR-1000, to maximize the cycle efficiency. The maximum cycle efficiency and, therefore, maximum plant output are not the primary missions of the test FASTER reactor and, therefore, may not be required for this plant. The capital cost of the cycle may be a more important factor in selecting the steam plant design and operating conditions. Thus, it is possible that the steam plant layout in Figure 4-1 may be changed later as a result of the FASTER plant cost analysis. 
One particular area of the tradeoff between the steam cycle cost and performance is the moisture separation with reheat between the turbine stages. Table 4-4 shows the required heat transfer areas (tube surface) as calculated by GateCycle for the steam plant heat exchangers. By far, the two largest heat exchangers are the two stages of the steam reheater. Therefore, these two components are expected to be the most expensive heat exchangers in the steam plant (with the exception of the steam generator, the design of which is not included into the GateCycle model). So, if the capital cost limitations become more important for the FASTER testing facility than the amount of power delivered to the grid, these two heat exchangers will be the primary candidates for size reduction or even elimination. In either case, both the cycle layout and conditions (such as main steam pressure) may be changed from those presented in Figure 4-1.

For similar reasons, and also due to site-specific environmental conditions, the design of the condenser in Table 4-4 and the condenser pressure in Figure 4-1 should only be considered preliminary in this report and could change in the future.

The U.S. DOE is currently supporting the development of the supercritical $\mathrm{CO}_{2}\left(\mathrm{~S}_{-}-\mathrm{CO}_{2}\right)$ Brayton cycle with the goal of demonstration through pre-commercial scale. If significant reductions in cost can be demonstrated by switching from a superheated steam cycle to a $\mathrm{S}-\mathrm{CO}_{2}$ Brayton cycle and the $\mathrm{S}-\mathrm{CO}_{2}$ Brayton cycle will be ready in time for deployment with FASTER, then the S$\mathrm{CO}_{2}$ Brayton cycle may be considered as a less costly power conversion alternative for FASTER.

Table 4-4: Heat Transfer Surface Area

\begin{tabular}{lcc}
\hline \multicolumn{1}{c}{ Equipment } & GateCycle Icon & Area, $\mathbf{~ m}^{\mathbf{2}}$ \\
\hline Condenser & CND1 & 2,454 \\
\hline Feedwater Heater, Stage 1 & FWH1 & 379 \\
Feedwater Heater, Stage 2 & FWH2 & 301 \\
Feedwater Heater, Stage 3 & FWH3 & 340 \\
Feedwater Heater, Stage 4 & FWH4 & 636 \\
Feedwater Heater, Stage 5 & FWH5 & 460 \\
\hline Reheater, Stage 1 & RH1 & 10,360 \\
Reheater, Stage 2 & RH2 & 7,947 \\
\hline
\end{tabular}




\section{Shutdown Heat Removal System}

The shutdown heat removal system is completely independent from the normal decay heat removal through the intermediate heat transport system, and is activated only when the normal heat removal system is disabled. The system consists of three independent, redundant, and diverse heat removal loops. Each loop consists of a small in-vessel direct reactor auxiliary cooling system (DRACS), a secondary natural draft heat exchanger (NDHX), an expansion tank, and an exterior stack that forms the natural draft pathway for dissipating the decay heat to the atmosphere. A schematic diagram showing key elements of the system is shown in Figure 5-1.

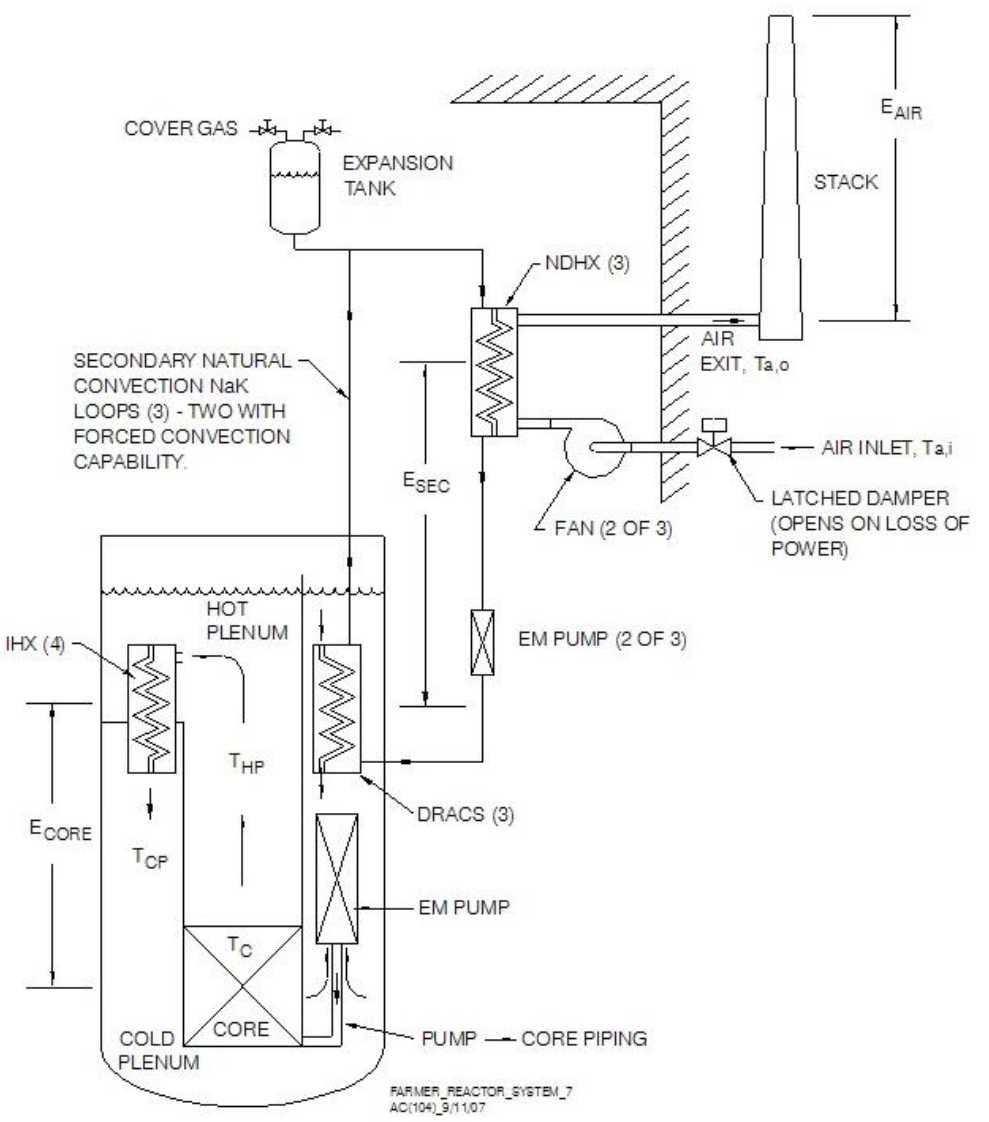

Figure 5-1: Schematic Diagram of Shutdown Heat Removal System

The DRACS heat exchangers are positioned directly in the sodium cold pool. Moreover, there are no valves or other mechanical devices that isolate the primary sodium from the DRACS. Thus, during full power operation, primary cold pool sodium circulates at a modest flow rate through the shell side of the DRACS. However, when activated, buoyancy-driven natural convection flow of the primary sodium through the DRACS is initiated.

The core decay heat is transferred by natural convection flow of primary sodium from the reactor hot pool through the IHX flow path to the cold pool. Heat from the primary sodium cold pool is then transferred through the DRACS to the secondary sodium-potassium (NaK) eutectic passing through the heat exchanger tubes. All three loops are capable of operating in a natural convection mode, in which buoyancy driven convection causes the secondary $\mathrm{NaK}$ to circulate through the natural draft heat exchangers where the airflow transfers the heat from the $\mathrm{NaK}$ to the 
atmosphere. The secondary $\mathrm{NaK}$ flow circuits (one for each of the three independent systems) are completely passive without any valves or constrictions to limit the flow during normal operation or shutdown conditions.

On the tertiary (air) side of the systems, the natural convection circuits are passive except for magnetically latched dampers that prevent air flow on the air inlet side of the three NDHXs. Upon loss of electrical power to the electro-magnetic latch, the dampers fail by gravity in the open position. The DRACS are brought into full operation by opening of these dampers. The dampers are designed to provide an air leak rate that corresponds to nominally $1 \%$ of the full design flow rate in the closed position, which results in a parasitic heat loss of $\sim 22.5 \mathrm{~kW}$ during full power operation. This minor heat loss is included in the design to maintain the correct natural convection flow patterns in the primary, secondary, and tertiary sides of the system so that proper natural convection flow patterns are established immediately upon system activation. Moreover, continuous heat addition to the system is desirable in regions where the ambient temperature can fall below the $\mathrm{NaK}$ freezing temperature of nominally $-13^{\circ} \mathrm{C}$.

Alternatively, two of the three DRACS loops are capable of operating in a forced convection mode to control (i.e., limit) the heat removal rate from the reactor vessel during planned shutdowns (e.g., fuel shuffling operations). As shown in Figure 5-1, the secondary NaK sides of these two loops are equipped with EM pumps, so that the loop flowrates can be modulated by adjusting the applied voltage to the pumps. The tertiary air loops on these two units are also equipped with fans so that the heat removal rate through the NDHXs can be adjusted as needed. The EM pumps and fans are selected since these devices have large open flow areas that do not significantly impede natural convection when the loops are operated in that manner.

The three DRACS are designed to remove $750 \mathrm{~kW}$ each at normal operating conditions. The thermal rating for each DRACS thus corresponds to $0.25 \%$ of the core full power rating of 300 $\mathrm{MW}_{\mathrm{t}}$. The three DRACS are thus capable of removing $2.25 \mathrm{MW}$ of decay heat at design conditions. Since the DRACS are located inside the reactor vessel, any leakage from the DRACS or ancillary piping will not lead to coolant drain down. The DRACS are annular in shape, and are mounted inside of the well of cold pool in the redan.

Key design parameters for the DRACS are summarized in Table 5-1, while a drawing that illustrates key features is provided in Figure 5-2. The DRACS is a shell- and-tube, countercurrent flow-type heat exchanger with primary flow on the shell-side, and NaK flow on the tube side. Primary sodium from the cold pool enters the shell side of the DRACS through an annular ring opening in the shroud located just below the upper tube sheet. The sodium flows by natural convection down through the tube bundle while dissipating heat. The sodium then returns to the cold pool through a second annular ring opening located just above the lower tube sheet. Cold secondary $\mathrm{NaK}$ enters the DRACS through a $6.03 \mathrm{~cm}$ diameter downcomer. The downcomer delivers the cold $\mathrm{NaK}$ through the lower tube sheet into a header manifold, where it then turns $180^{\circ}$ and rises through the tube bank in counter current flow to the shell side primary sodium. The hot secondary NaK exits the tubes into an upper header manifold, and then flows through an annular riser which is concentric to the downcomer. The downcomer is double walled with an annular gap for thermal insulation between the hot and cold streams. 
Table 5-1: DRACS Design Parameters

\begin{tabular}{|c|c|}
\hline Characteristic & \\
\hline Heat transfer capacity, $k W$ & 750 \\
\hline Heat transfer area, $m^{2}$ & 7.64 \\
\hline Primary sodium temperature, inlet, $C^{\circ} \%$ tlet, $C^{\circ}$ & $510 / 355$ \\
\hline Primary sodium mass flowrate, $\mathrm{kg} / \mathrm{s}$ & 3.793 \\
\hline Secondary NaK temperature, inlet, $C^{\circ} \%$ outlet, $C^{\circ}$ & $328 / 484$ \\
\hline Secondary NaK mass flowrate, $\mathrm{kg} / \mathrm{s}$ & 5.47 \\
\hline Tube outer diameter, $\mathrm{cm}$ & 2.22 \\
\hline Tube wall thickness, mm & 0.9 \\
\hline Tube pitch, $\mathrm{cm}$ & 3.79 \\
\hline Effective tube length, $m$ & 2.489 \\
\hline Number of tubes & 44 \\
\hline Upper tubes sheet area, $m^{2}$ & 0.053 \\
\hline Upper tube sheet thickness, $\mathrm{mm}$ & 25 \\
\hline Lower tube sheet area, $m^{2}$ & 0.053 \\
\hline Lower tube sheet thickness, $\mathrm{mm}$ & 25 \\
\hline Riser piping-OD, $\mathrm{cm}$ & 8.89 \\
\hline Riser piping thickness, $\mathrm{mm}$ & 5.49 \\
\hline Down comer piping $O D, \mathrm{~cm}$ & 6.03 \\
\hline Down comer piping thickness, $\mathrm{mm}$ & 3.912 \\
\hline Shell OD, cm & 32.26 \\
\hline Shell wall thickness, mm & 9.525 \\
\hline Material & $9 \mathrm{Cr}-1 \mathrm{Mo}$ \\
\hline
\end{tabular}




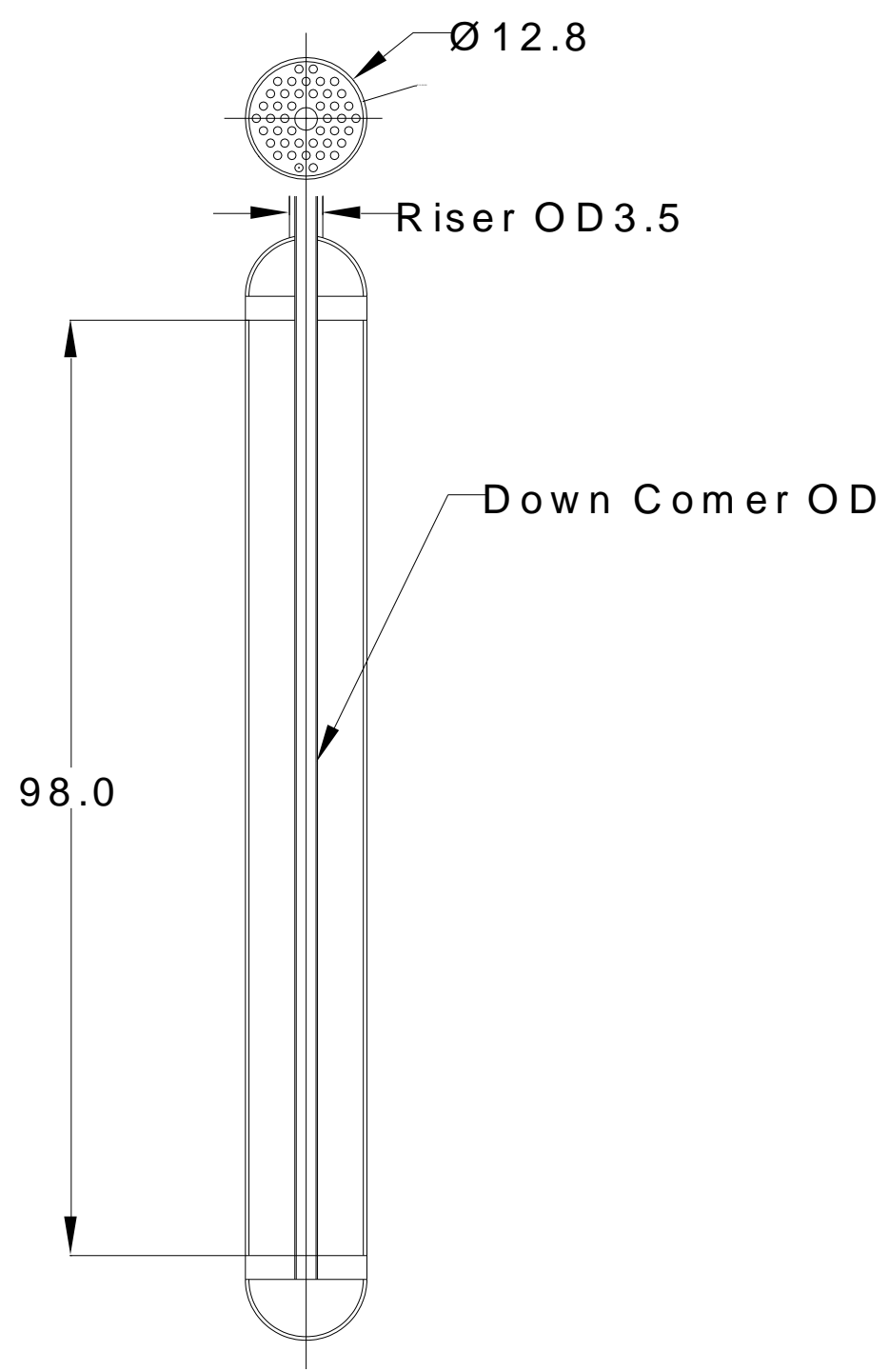

Figure 5-2: Details of DRACS Design

Both the downcomer and the annular riser pipes are equipped with bellows just above the shroud to accommodate any differences in thermal expansion between the piping and the body of the DRACS itself. The upper tube sheet is welded to the shroud, while the lower tube sheet floats. Thus, the design accommodates differential thermal expansion within the tube bank.

Consistent with the thermal rating of the DRACS, each NaK-to-air NDHX is designed to remove $750 \mathrm{~kW}$ decay heat. The unit is a horizontal tube, cross-flow design. Key design parameters are summarized in Table 5-2. The unit is equipped with a fire suppression plate and catch basin to mitigate the effects of a NaK tube bundle leak. The damper to the unit is magnetically latched to fail open under gravity upon loss of electric power. The unit will also have a manual hand-wheel operation capability. 
Table 5-2: NDHX Design Parameters

\begin{tabular}{lc}
\hline Characteristic & \\
\hline Heat transfer capacity & $750 \mathrm{~kW}$ \\
Design & $\begin{array}{c}\text { Transverse-finned tube } \\
\text { cross-flow, four pass }\end{array}$ \\
Active tube length & $7.8 \mathrm{~m}$ \\
Number of tubes & 34 \\
HX tube OD & $4.22 \mathrm{~cm}$ \\
Tube wall thickness & $3.55 \mathrm{~mm}$ \\
Fin height & $3.2 \mathrm{~mm}$ \\
Tube horizontal center-to-center spacing & $7.62 \mathrm{~cm}$ \\
Tube vertical center-to-center spacing & $10.2 \mathrm{~cm}$ \\
Stack riser cross-sectional area & $4.34 \mathrm{~m}$ \\
Stack height & $5.0 \mathrm{~m}$ \\
Material & Type 304 \\
& stainless steel \\
\hline
\end{tabular}

Air flow through each NDHX is induced through a dedicated exhaust stack, one for each unit. Each stack is $5 \mathrm{~m}$ high and $4.34 \mathrm{~m}^{2}$ in cross section. The stacks are of lightweight steel construction and are insulated. Each secondary $\mathrm{NaK}$ loop contains an expansion tank to accommodate changes in system volume due to variations in temperature. The tank has one NaK nozzle on the bottom and one gas nozzle on the top, which supplies argon cover gas to the tank and permits pressure control. The tank is located at the high point in the loop. The resultant NaK static head is sufficient to operate the loop with expansion tank cover gas pressures at, or slightly below, atmospheric pressure. In the event of a leak in the DRACS, loss of radioactive primary sodium into the secondary $\mathrm{NaK}$ loop will not occur. In the event of a leak in the NDHX, the resultant spill is minimized because of the low expansion tank operating pressure. 


\section{Fuel Handling System}

A conceptual design for a pantograph type Fuel Handling Machine (FHM) has been developed for FASTER. The FHM is a mechanical system which is operated using several computer controlled direct current servo motors located above the reactor head. The FHM is designed as a removable mechanism which can be exchanged during reactor shutdown to perform scheduled maintenance on the system's mechanical components. The FHM is supported by the primary reactor vessel cover.

The cover gas space above the liquid sodium inside the reactor vessel determines the overall height of the FHM main structural support tube to assure that all of the moving mechanical components (other than bare rotating shafts) are submerged in the liquid sodium at all times. Exposed surfaces inside the cover gas space may be subjected to condensation and freezing of sodium vapor (sodium frost) and possible deposition of sodium oxides.

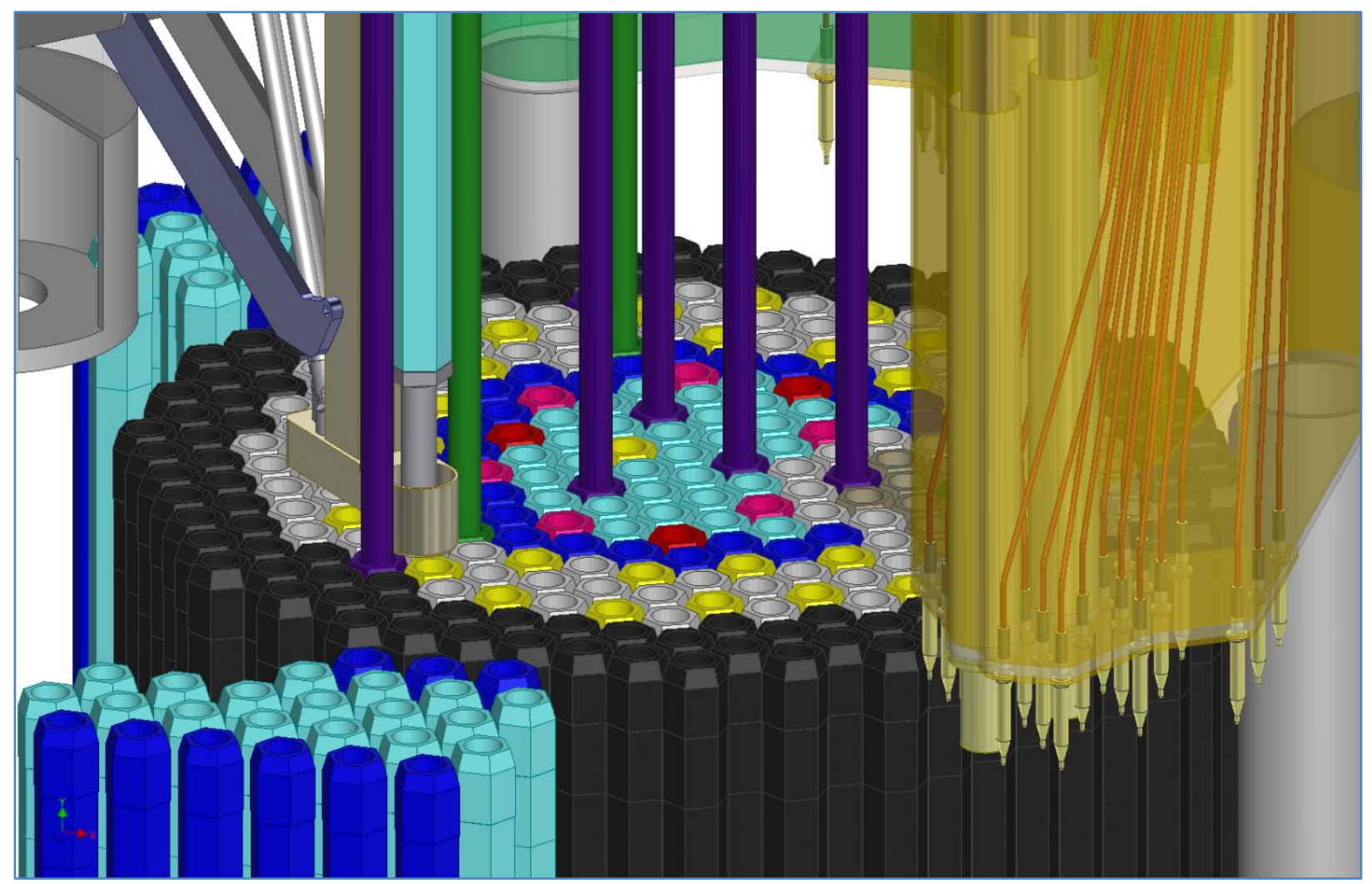

Figure 6-1: FHM Located Above the Core Assembly (1 - Instrument Tree and 1 - FHM Removed for Clarity)

\subsection{Pantograph FHM}

The FHM design was developed to reduce the height of the mechanism to suit a smaller sized primary vessel due to the planned compact nature of FASTER. Figure 6-2 shows the overall assembly of the pantograph mechanism concept in the fully extended and retracted positions. Although preliminary, enough detail has been incorporated to simulate and evaluate its overall operational characteristics. 
The FHM design concept presented here does not attach to the grid plenum near the lower end of the main structural support tube, although a configuration which does attach may be developed in the future if detailed structural analyses indicate that it is required. A tapered feature on the core hold down assembly engages features in the top of the core assemblies and may help to reduce the deflections at the bottom of the main structural support tube while under refueling loads (this has to be investigated further with more detailed analyses performed).

The FHM remains in the reactor vessel during reactor operation. The design intention is to remove the fuel handling system for scheduled maintenance periods (and replace with a removable plug) for cleaning and inspection of the primary structures and mechanical drive system components.

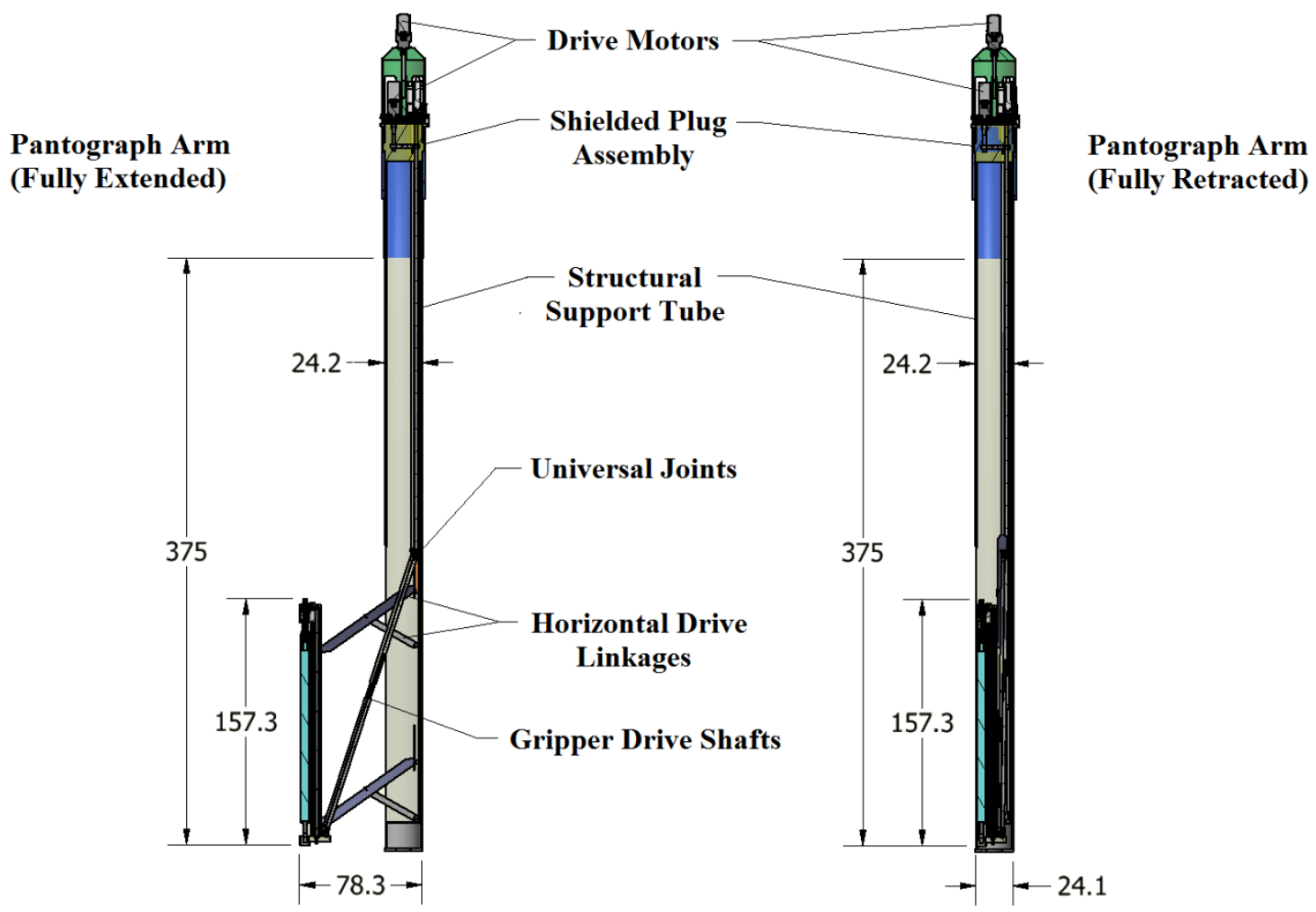

Figure 6-2: FHM in Fully Extended and Retracted Positions

Figure 6-3 shows an exploded assembly view of the pantograph FHM, which identifies the major components of this conceptual design.

The pantograph is controlled by a computerized drive system which provides several distinct and isolated motions to manipulate the fuel, control rod, reflector, and shielded assemblies inside of the reactor vessel. The drive motors utilize planetary reduction gear sets to achieve the required torque to move the simulated core assembly while under the maximum design loads. Calculations for the maximum forces required to operate the mechanism have been used to estimate the size of various components based on expected frictional resisting forces. 


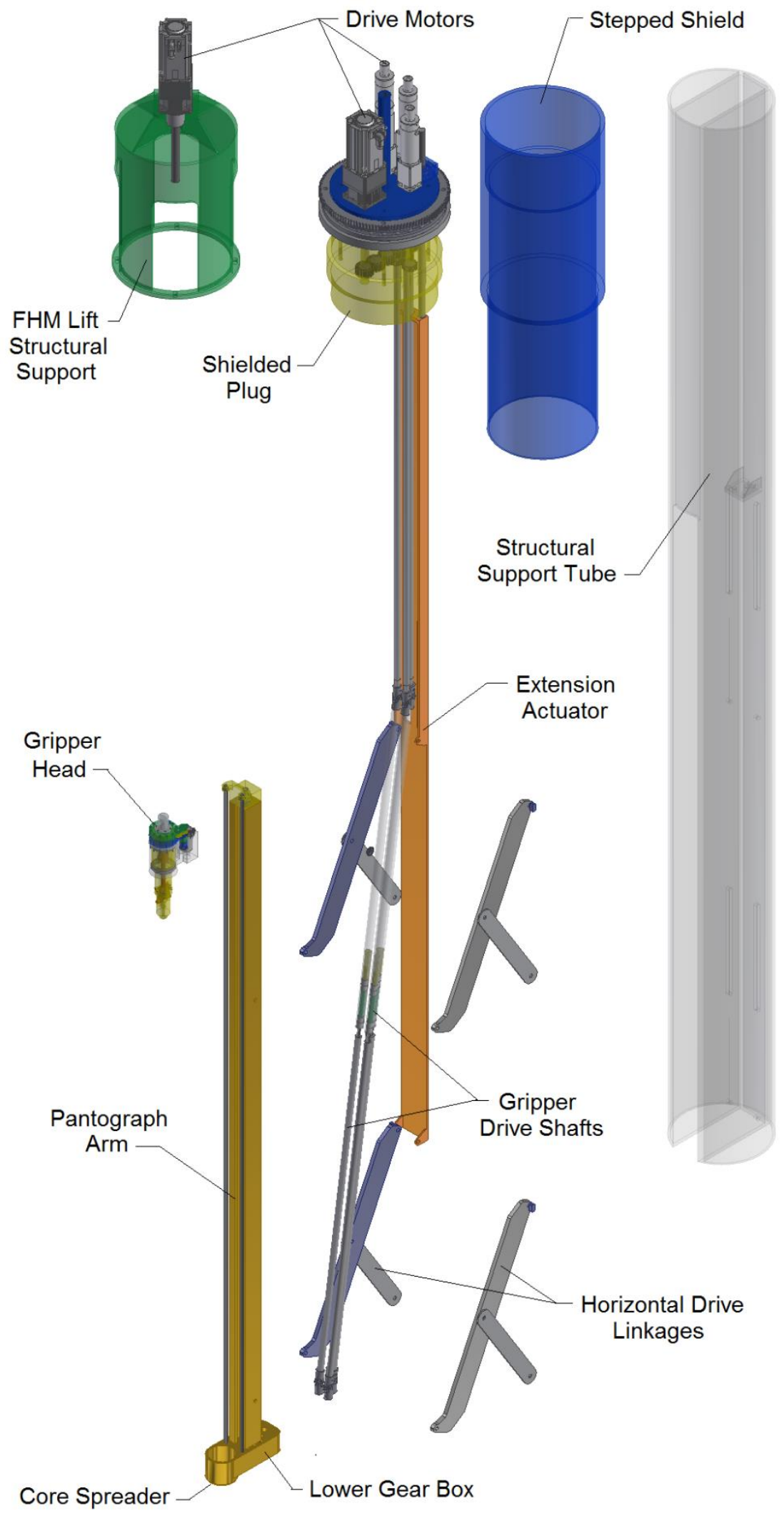

Figure 6-3: Overall Exploded Assembly View of Pantograph FHM 
The design of the FASTER FHM requires attention to several parameters in its operation; a preliminary list of the design requirements is provided here (additional requirements may be identified or requirements may be removed as the design matures):

- 3 Removable FHMs mounted in the fixed reactor head enclosure.

- Ability to transfer straight or bowed core assemblies in liquid sodium between core, storage and transfer positions inside FASTER.

- Minimize the height of FHM to fit small compact reactor vessels.

- Required (Isolated) Control Motions of Core Assembly using FHM.

- Rotate FHM with respect to the vessel cover.

- Apply "hold down and spreading forces" to surrounding core assemblies by raising or lowering the FHM from above the vessel cover.

- Extend or retract the pantograph arm horizontally to reach all required positions inside the reactor vessel.

- Raise and lower the core assembly into pantograph arm (6,000 lbs. (6,690 N) max load).

- Rotate core assembly while it is fully removed from reactor core.

- Open and close gripper jaws while lowered to engage/disengage core assembly.

- Utilize simple (standard) mechanisms wherever possible to reduce number of components.

- Design to allow provisions for manual operation and visual position feedback above vessel cover.

- Utilize multiple redundant positional feedback encoders.

- Minimize the number and types of penetrations and seals required for operation.

- Be mindful of the design requirements for the UIS and other internal reactor components to eliminate interferences during operation.

- Handle bowed core assemblies of up to $38 \mathrm{~mm}$ (1.5") free bow.

- Positional accuracy of +/- $2.5 \mathrm{~mm}$ Horizontal and Vertical at Hold Down.

- Each gripper jaw is designed to individually support entire design load.

- Design control system and structural components for refueling motion times (including dynamic response).

- Incorporate shielding and eliminate steaming paths using stepped components.

- Design seals to minimize the leakage rates of the cover gas.

- Design in accordance with the material temperature dependent allowable stress values from Table 1 of the ASME Boiler and Pressure Vessel Code.

- Material selections and heat treatments based upon performance in liquid sodium cooled fast reactor environment (including radiation damage).

- Provide the ability to manually recover from malfunctions during fuel handling operations from above the reactor cover. 
- Allow for easy inspection and maintenance of drive system components above the reactor cover.

- Control load rates, directions and notify operator of out-of-limit conditions.

- Monitor seal leakage rates on operator panel.

The complexity of the compact FHM and its driving mechanism is increased over the original PFR and PRISM type refueling machines due to the relocation of drive shaft connections from the top of the pantograph arm, to a gearbox at the bottom of the pantograph arm in the current concept. The re-location of these connections reduced the overall height of the pantograph FHM by approximately 1.75 meters ( $\sim 6$ feet $)$.

A stepped shielded circular plug rotates on a set of bearings which support the entire weight of the mechanism from the vessel cover. Bi-directional servo gear motors which drive the mechanism motions are placed above this shielded plug for ease of inspection, maintenance, manual control access, and increased reliability. Manual connections for operating the pantograph (in case of computer or electrical failure) are located on the top of the stepped circular plug. Mechanical and electronic visual indicators show the positions and orientations of all mechanism components during fuel handling operations.

The pantograph FHM is controlled by a computerized drive system which provides several distinct and separate motions to move the fuel, control rod, reflector, and shielded assemblies inside of the reactor vessel. Accelerations provided by the drive motors are ramped up (or slowed down) at a controlled rate to their maximum velocities to reduce the effects of shock loading on the mechanical components and maximize their useful lifetimes. The FHM must be designed such that actuation of any of the single isolated motions does not affect (change) the others.

The controlled motions provided are:

- Raising or lowering of the entire mechanism to apply a required hold down and spreading forces to the core assemblies surrounding the core assembly being inserted or removed from the core (this action is performed only when the pantograph arm is located above the position of interest).

- Horizontal positioning of the pantograph arm above the core assembly of interest via extension or retraction of the pantograph arm linkages (this action is performed only while the entire mechanism is lifted above the core).

- Rotation of the pantograph inside the vessel to reach various positions above the core by rotation of the mechanism on the bearings between the vessel cover and stepped plug (performed only while the entire mechanism is lifted above the core and the arm is retracted into the main structural support tube).

- Raising or lowering the core assembly by rotation of a screw mechanism in the gripper head which uses a series of shafts and gears inside the pantograph arm (performed when the FHM assembly is in the lowered or "hold down" position).

- Rotation of the core assembly inside the pantograph arm by rotating the gripper using a series of shafts and gears (this is performed only while the core assembly is fully lifted). 
- Opening or closing of the gripper to engage or release the core assembly being serviced through a series of shafts and gears (this is performed only with the core assembly fully lowered).

Forces applied by the motors are transmitted through stepped shafts which penetrate the shielded plug to operate the pantograph mechanism (Figure 6-4). The plug and shafts have several types and sets of seals to assure that the argon cover gas atmosphere inside the reactor vessel is not contaminated by the air atmosphere inside the reactor building. The main structural support for the pantograph arm is a hollow tube with a U-shaped welded insert which the pantograph arm retracts into. This tube is attached to the underside of the stepped shield plug.

Several concepts were evaluated for the external drive system component arrangements, a final optimized design has yet to be selected and generated for the FASTER FHM drive systems.

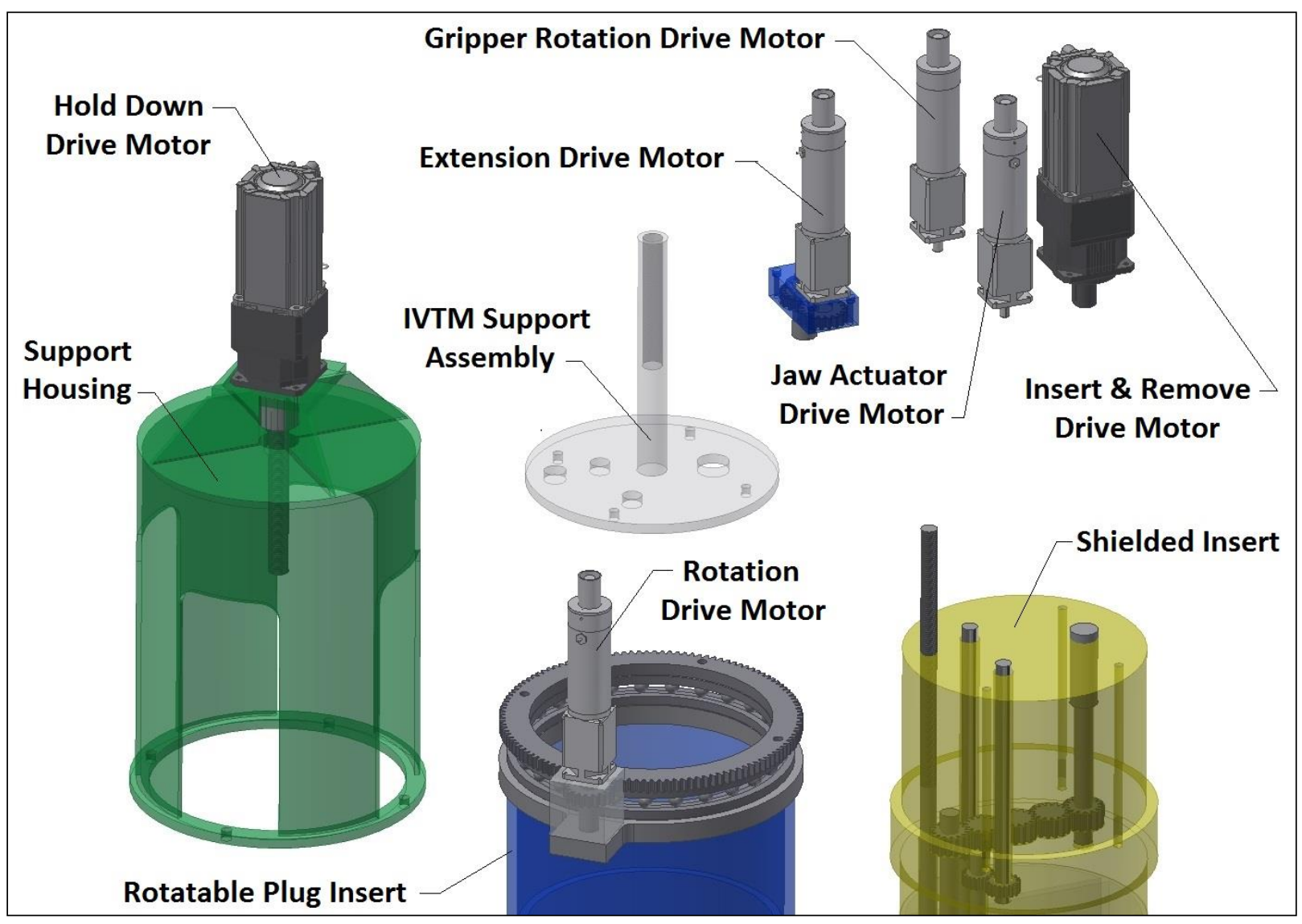

Figure 6-4: Pantograph FHM Drive System Component Arrangement

The theory of mechanism design defines all of the kinematic and kinetic properties of mechanical systems. Kinematics is concerned with the analysis of the relative motion of components in mechanical systems. The kinematics of the FHM and its components will be analyzed to evaluate the coordination of input and output positions, velocities and accelerations, the associated generated motions, transmission angles, and mechanical advantage throughout its entire range of motion. 
Kinetics is concerned with the analysis of motions and responses of mechanisms by externally applied forces and masses of the mechanism components. The FHM and its components will be analyzed to include the evaluation of effects on the mechanism due to inertial forces (acceleration of masses and vibrations), motion time response, elastic body dynamics (stresses, deformations and buckling), the effects of unbalance and impact due to design (component tolerances) and wear driven clearances.

The extension/retraction motion is actuated by raising or lowering a shaft using a drive screw outside of the sodium vessel. The shaft is connected to the top of an extension actuator located inside the U-shaped support tube. The extension actuator is designed for a clearance fit inside the U-shaped insert and connects using sliding joints. The mechanical advantage of the mechanism changes based upon the angle between the primary drive linkage connections and the drive shaft when the pantograph arm is fully retracted to the angle between the primary linkage connections and the drive shaft when the pantograph is fully extended.

The mass of the pantograph arm and linkages are accelerated based upon the force which is transmitted by the extension actuator drive shaft. The acceleration of the mass is not constant if the force applied remains unchanged and therefore must be analyzed and controlled using the computerized control system. Appropriate proportional, integral, and differential gains must be calculated and input into the control system algorithms to assure accuracy of position, limit component velocities, and minimize shock loading. This preliminary layout of the pantograph will be optimized in the future to take full advantage of the finalized geometric constraints.

Primary horizontal drive linkages (which are designed to provide the horizontal motion of the pantograph arm) connect to the pantograph arm using revolute joints and to the U-shaped structural tube using revolute and sliding bearing joints (Figure 6-5). The secondary drive linkages connect to the primary linkages (at the midpoint between the primary linkage end connections) and the U-shaped support tube using simple revolute joints.

Extension drive shafts which operate the gripper jaw open/close, gripper rotation, and gripper insert/remove motions are located in the space between the horizontal drive linkages of the pantograph FHM assembly (Figure 6-6). 


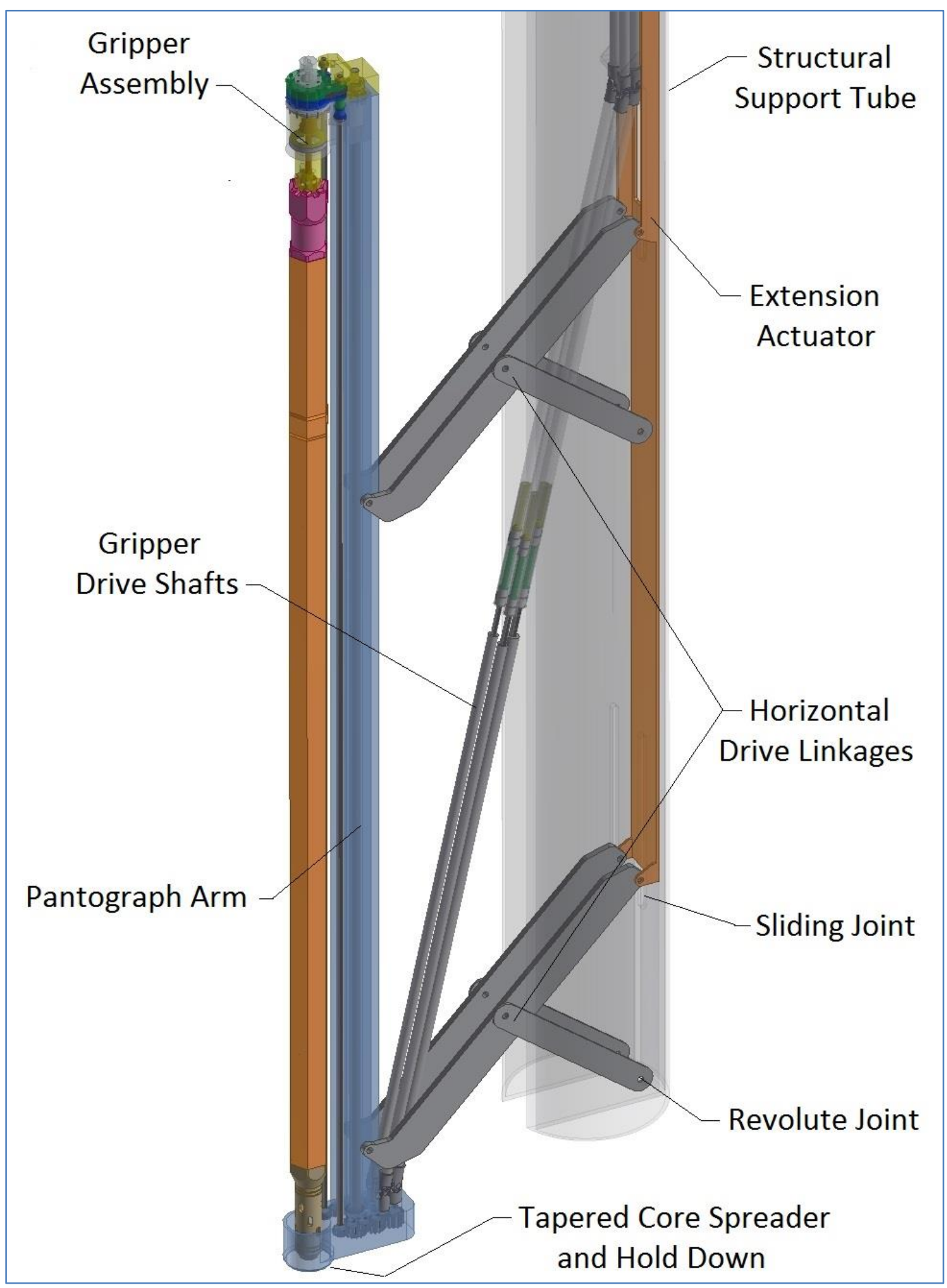

Figure 6-5: Assembly view of the pantograph FHM showing its major components. 
As the pantograph arm extends, the extension shafts which control the gripper vertical motion, rotation, and open/close actuation are allowed to rotate at the ends via the universal joints and extend in the middle using a spline shaft and recirculating spline nut arrangement. The maximum angle of rotation of the universal joints when the pantograph arm is fully extended is less than 17.5 degrees.

The gripper is operated using a set of circular extension drive shafts which transmit the forces from the stepped drive shafts in the shielded plug assembly. The circular extension drive shafts are connected at the top (to the stepped drive shafts) using universal joints (Figure 6-6). The shafts and upper universal joints are connected to a welded foundation which is located inside the U-shaped structural support tube.

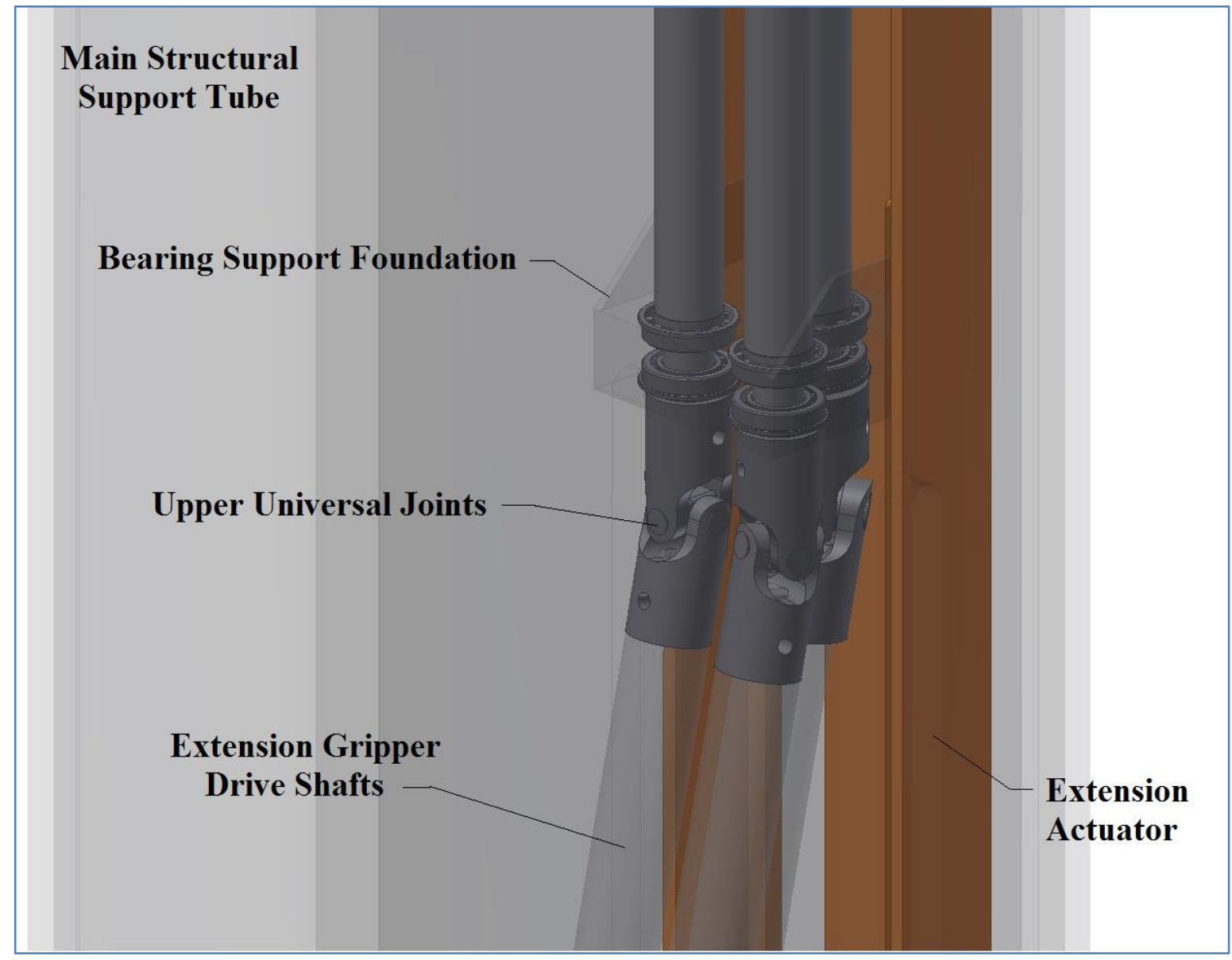

Figure 6-6: Upper Universal Joints for FHM Drive System

The rotation of a single universal joint causes non-uniformity in the transmitted motion through the joint due to a cyclically varying angular velocity ratio (Figure 6-7) between the input and output shaft. As a remedy, the lower universal joint is appropriately phased to eliminate the transmission of the cyclically varying angular velocity going into the gear box on the lower end of the pantograph arm. The extension shafts, however, are subjected to the cyclically varying angular velocity and this should be taken into account in their design. 


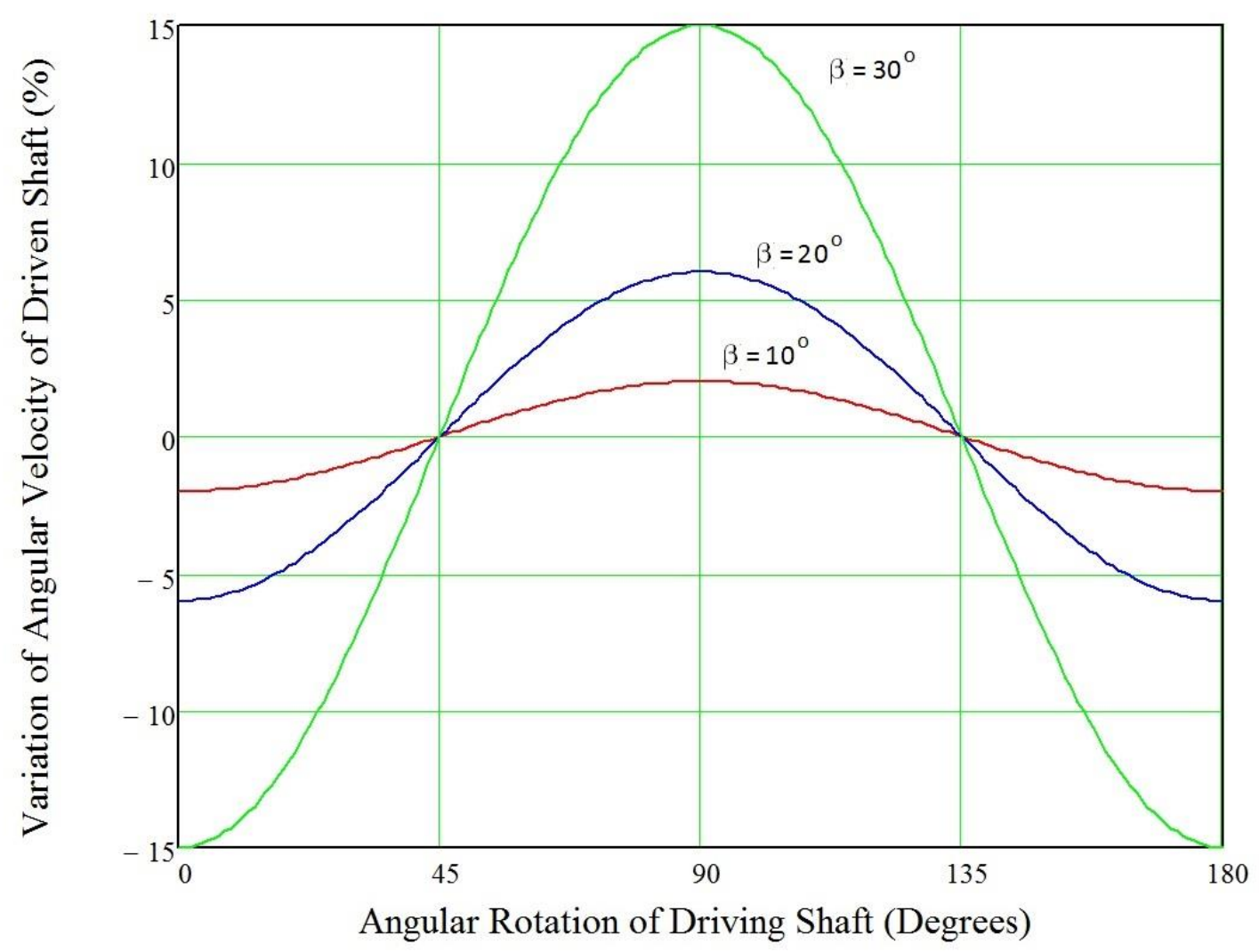

$\beta$ is the angle of bend in the universal joint

Figure 6-7: The Velocity Ratio Variation through a Universal Joint with Angle of Bend

Universal joints also experience secondary couples or "rocking torques" in the plane of the yokes which tend to bend the shafts and rock them about their support bearings. The loads calculated by evaluating the rocking torques while the components are under their maximum design loads will be used to size the support bearings located at the ends of the universal joints in the welded foundation and top of the gearbox in the pantograph arm.

The extension shafts use sets of spline shafts and spline nuts located near the middle of the drive shafts which allow the length of the drive shafts to change as the pantograph arm is extended or retracted (Figure 6-8). The spline nuts are held inside the upper shaft using spacer tubes to control their axial location and standard shaft keys are used to control the angular orientation inside the outer shaft. A welded cap secures the components inside the shaft.

The lower shaft has a spline shaft which engages the spline nuts in the upper (outer) shaft assembly torque and power is transmitted to the lower shaft through the spline shaft and spline nut assemblies. The lower shaft is connected (at the bottom) to the gear box on the pantograph arm using a second set of universal joints which are phased to the universal joints at the top of the upper shafts to eliminate transmitted angular velocity variations to the drive gears in the gear box at the bottom of the pantograph arm. 


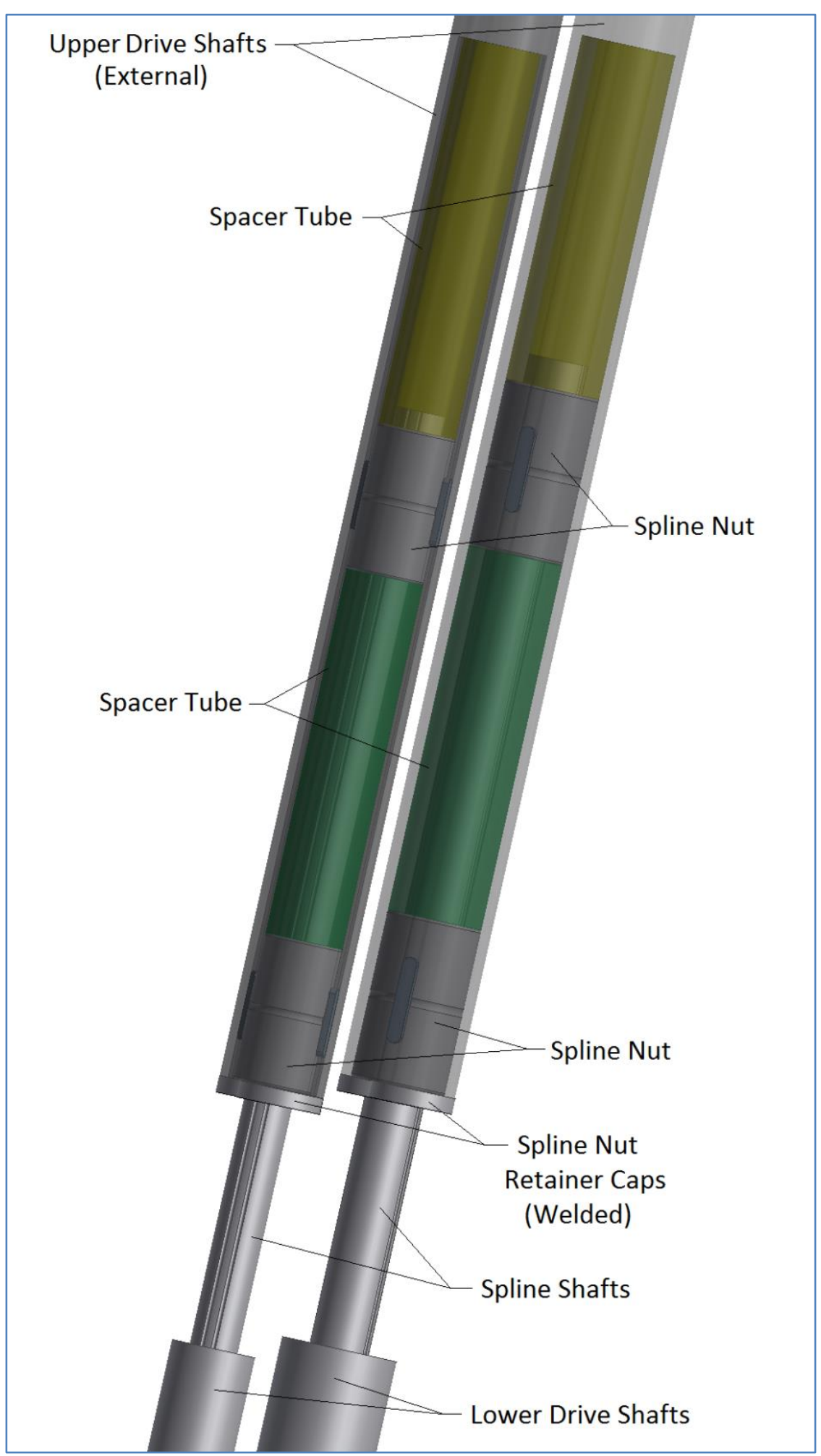

Figure 6-8: Details of Extension Shaft Arrangement

The lower universal joints then attach to another set of shafts which penetrate the gear box on the bottom of the pantograph arm (Figure 6-9) and transmit the rotational forces to the gear sets using standard shaft keys. The main (larger) gears drive the gripper head up and down inside the 
machined pantograph arm assembly using a screw type drive. The remaining two gear sets provide the gripper jaw open/close actuation and gripper rotation using spline shafts which are located inside the pantograph arm assembly. The gear box is designed using several machined components for easy manufacturing and assembly. Drain holes will be designed into the gearbox to prevent trapping of liquid sodium when the FHM is removed for inspection and maintenance.

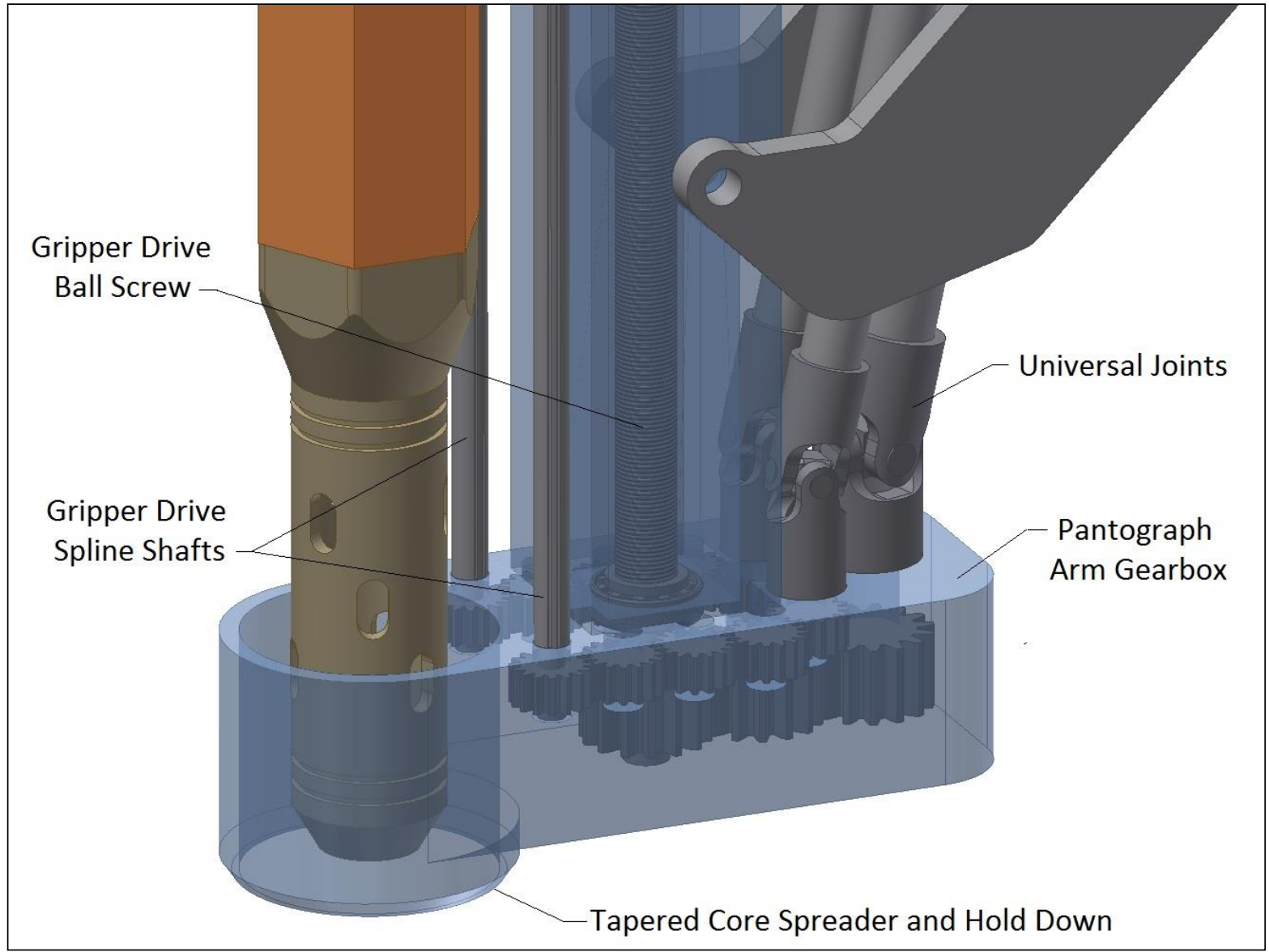

Figure 6-9: Lower Universal Joint Connections to Pantograph Arm Gearbox

The bottom of the pantograph arm has a tapered feature machined into it at the interface where it contacts the surrounding core assemblies when the hold down is engaged (Figure 6-10). The top of the core assemblies are designed with a mating tapered feature (Figure 6-11), as the hold down is lowered onto the core assemblies, the machined tapered features mate. Continued lowering of the pantograph causes a slight spreading of the surrounding core assemblies. This slight spreading of the surrounding core assemblies helps reduce the loads required to insert or remove a core assembly from the reactor core. The tapered feature also assures accurate alignment of the gripper to the handling socket of the core assembly being handled when the hold down is engaged. Depending on the angles of the mating tapers of the core spreader of the FHM and the machined tapers in the top of the reactor core assemblies, the horizontal positioning accuracy of the FHM can easily be increased to +/- 5 millimeters (or more) and still accurately engage the assemblies in the reactor core as the hold down is lowered. This unique design feature also acts as a radial support at the bottom of the Fuel Handling Machine greatly 
reducing deflections and stresses as the feature is engaged and fuel handling loads are applied by the machine.

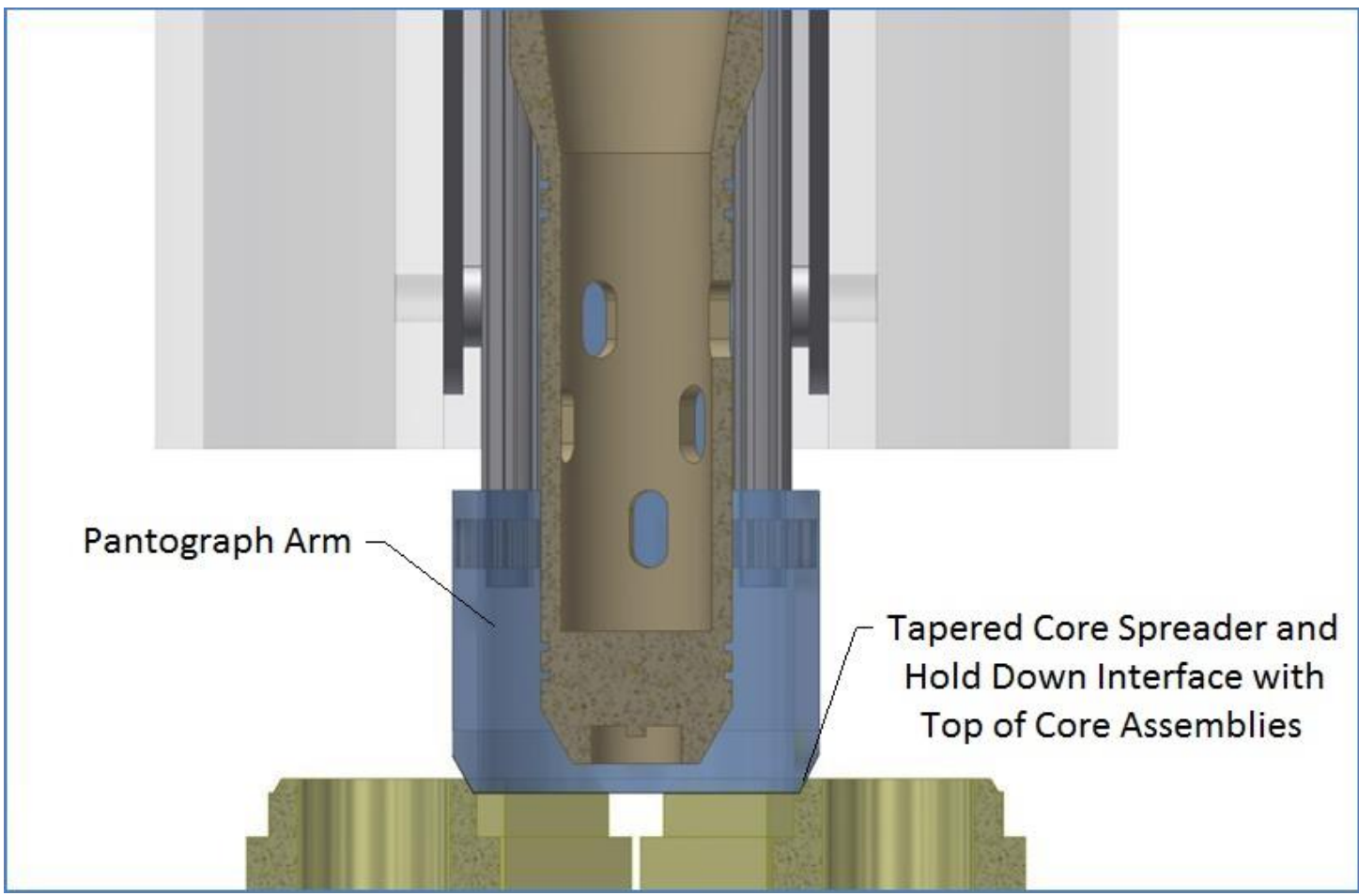

Figure 6-10: Core Assembly Spreader and Hold Down Interface at the Surrounding Core Assemblies 


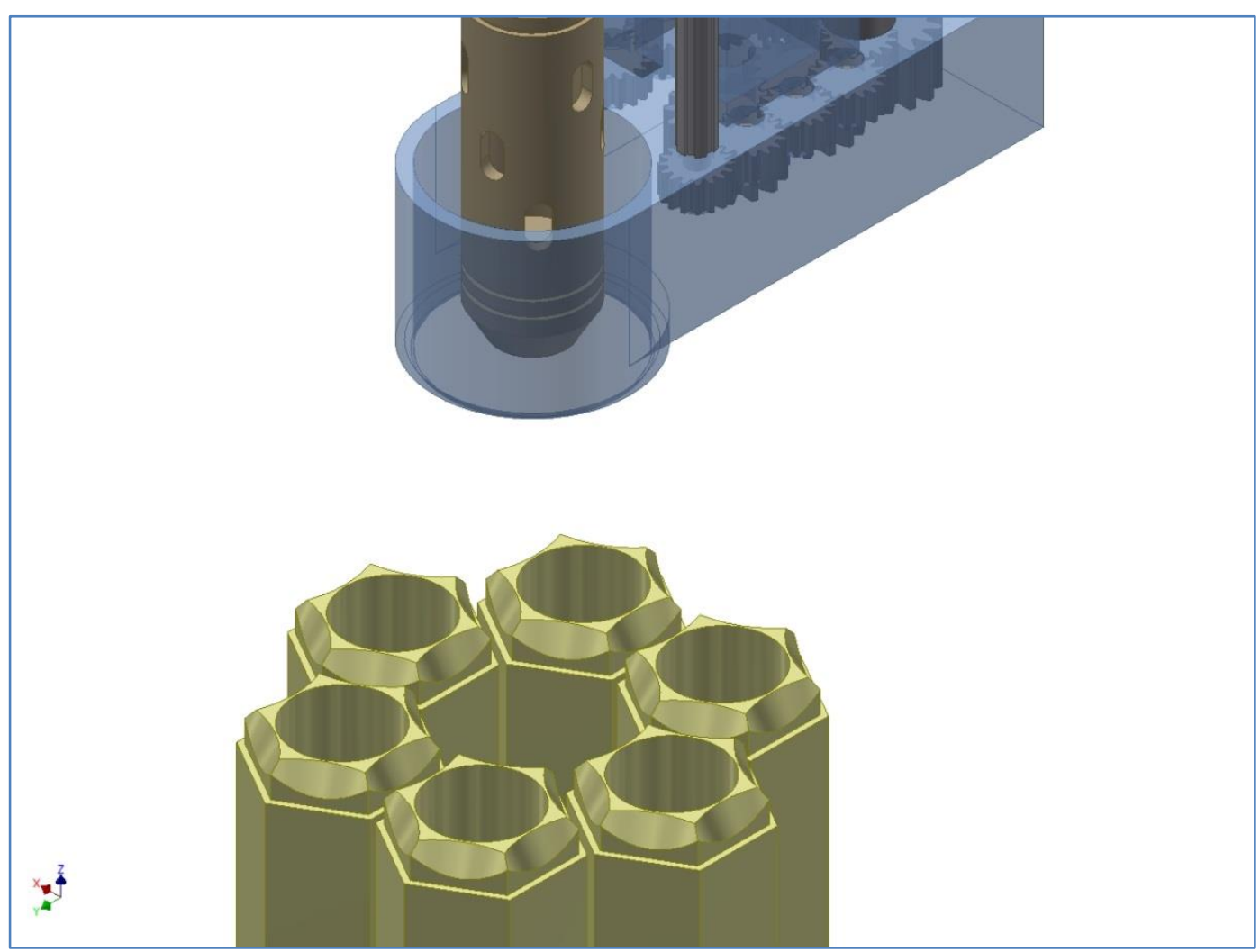

Figure 6-11: Matching Tapered Features on Top of Core Handling Socket Required for Spreader Feature Operation

Spline shafts which are used to operate the gripper jaws and gripper rotation are supported at the bottom by the lower gear box assembly and at the top by the upper bearing support block (Figure 6-9 and Figure 6-14). The spline shafts penetrate through clearance holes in the gripper drive head assembly which allow the head to move vertically while inserting or removing a core assembly from the reactor core. Appropriately sized radial and thrust bearings support the spline shafts based on the maximum calculated loads expected during operation.

Operation of all gripper motions can be actuated manually through a set of socket type connections in the top of the drive shafts in the upper bearing support block. These connections can be accessed using tools which extend through the vessel cover as a secondary manual backup.

Figure 6-14 shows an isometric view of the upper pantograph arm assembly with a socket type core assembly fully raised inside. When a core assembly is fully raised into the pantograph arm, the top of the pantograph arm assembly is approximately $530 \mathrm{~mm}$ (21 inches) from the top surface of the raised core assembly (this may be reduced with further optimization). The overall height of the pantograph arm is $530 \mathrm{~mm}$ longer than the core assembly itself (as the bottom of the core assembly is raised above the hold down contact surface). The gripper jaws are shown engaging the cylindrical slot inside the top of the socket type core assembly. 
The current concept utilizes tapered roller and thrust bearings at the shaft support points. These bearings have been sized based on calculated loads for the combined weights and loads applied to the structure during operation (Figure 6-12).

Basic Static Radial Load Rating

$$
\mathrm{C}_{\text {or }}:=6430 \cdot\left(\frac{\mathrm{lbf}}{\text { in }^{2}}\right) \cdot\left(1-\frac{\mathrm{D}_{\mathrm{we}} \cdot \cos (\alpha)}{\mathrm{D}_{\mathrm{pw}}}\right) \cdot \mathrm{i} \cdot \mathrm{Z} \cdot \mathrm{L}_{\mathrm{we}} \cdot \mathrm{D}_{\mathrm{we}} \cdot \cos (\alpha)
$$

Basic Dynamic Radial Load Rating

$$
\mathrm{C}_{\mathrm{r}}:=\mathrm{f}_{\mathrm{cm}} \cdot\left[\mathrm{i} \cdot \mathrm{L}_{\mathrm{we}} \cdot\left(\frac{1}{\text { in }}\right) \cdot \cos (\alpha)\right]^{\frac{7}{9}} \cdot \mathrm{Z}^{\frac{3}{4}} \cdot\left[\mathrm{D}_{\mathrm{we}} \cdot\left(\frac{1}{\text { in }}\right)\right]^{\frac{29}{27}}
$$

Basic Dynamic Axial Load Rating $\quad \mathrm{C}_{\mathrm{a}}:=\mathrm{f}_{\mathrm{cm}} \cdot\left[\mathrm{L}_{\mathrm{we}} \cdot\left(\frac{1}{\text { in }}\right) \cdot \cos (\alpha)\right]^{\frac{7}{9}} \cdot \mathrm{z}^{\frac{3}{4}} \cdot\left[\mathrm{D}_{\mathrm{we}} \cdot\left(\frac{1}{\text { in }}\right)\right]^{\frac{29}{27}} \cdot \tan (\alpha)$

Basic Static Axial Load Rating

$$
\mathrm{C}_{\mathrm{oa}}:=32150 \cdot\left(\frac{\mathrm{lbf}}{\text { in }^{2}}\right) \cdot\left(1-\frac{\mathrm{D}_{\mathrm{we}} \cdot \cos (\alpha)}{\mathrm{D}_{\mathrm{pw}}}\right) \cdot \mathrm{Z} \cdot \mathrm{L}_{\mathrm{we}} \cdot \mathrm{D}_{\mathrm{we}} \cdot \sin (\alpha)
$$

Figure 6-12: AFBMA Load Ratings for Tapered Roller Bearings

Solid sleeve type radial and thrust bearings are an option which will easily fit into the space reserved for the roller bearings being utilized and are being considered as an alternative (Figure 6-13) should the testing of roller bearings in the Mechanisms Engineering Test Laboratory (METL) facility indicate excessive wear or inadequate bearing life in the liquid sodium environment.

The hydrodynamic bearings would use the liquid sodium coolant as the lubricant. Preliminary calculations for these types of bearings have been performed using the properties of liquid sodium at the anticipated refueling temperatures. The gap between radial bearings is calculated based upon the Sommerfield number for the bearing dimensions (diameter and length) and is chosen to minimize journal friction based upon the calculated maximum bearing load, fluid viscosity and shaft rotation speed (as possible considering manufacturing tolerances and operating conditions). 


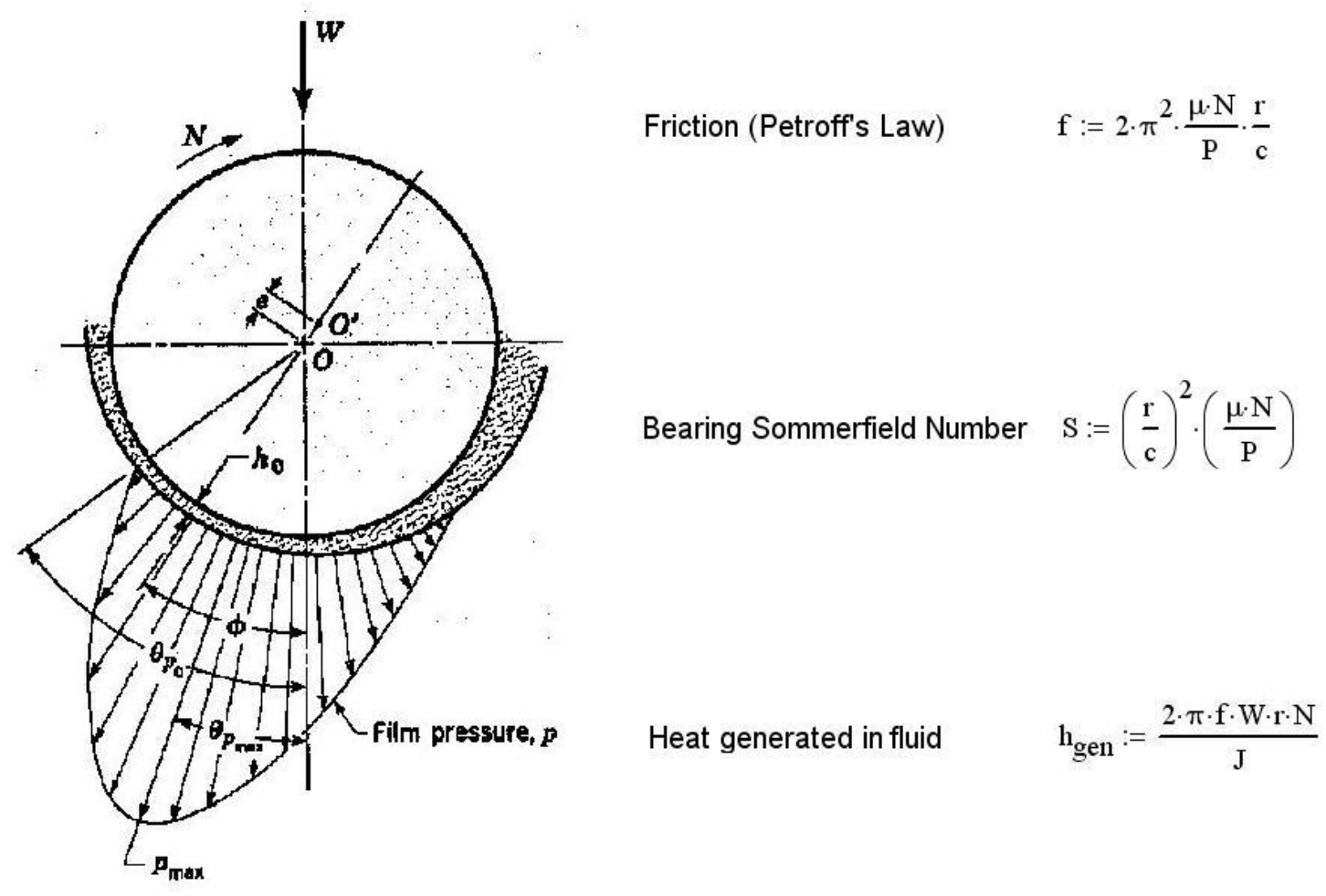

Temperature rise including bearing side flow loss

$$
\Delta \mathrm{T}_{\mathrm{f} 2}:=\frac{0.103 \cdot \mathrm{P}_{\mathrm{t}}}{1-\frac{1}{2} \cdot\left(\frac{\mathrm{Q}_{\mathrm{s}}}{\mathrm{Q}}\right)} \cdot \frac{\left(\frac{\mathrm{r}}{\mathrm{c}}\right) \cdot \mathrm{f}}{\frac{\mathrm{Q}}{(\mathrm{r} \cdot \mathrm{c} \cdot \mathrm{N} \cdot \mathrm{l})}}
$$

\section{Figure 6-13: Typical Analysis for Hydrodynamic Bearing Design Based on Sommerfield Number}

Gears which transmit forces to the open/close and rotation stages from the spline shafts have been attached to the top of the spline nut retainer assemblies. The spline nuts are held inside the retainer assemblies using standard shaft keys. The spline nut retainer assemblies are supported using radial bearings captured in the gripper head assembly (Figure 6-14). These spline nuts ride on the spline shafts as the gripper drive head moves vertically in the machined pantograph arm assembly. Forces are transmitted through these gear sets to rotate and open or close the gripper assembly. Holding forces between the spline nuts and the spline shaft contacting surfaces should be minimal as the actuation of the gripper jaw open/close motion occurs only while the core assembly is fully lowered and gripper rotation motion is applied only while the core assembly is in the fully raised position. 


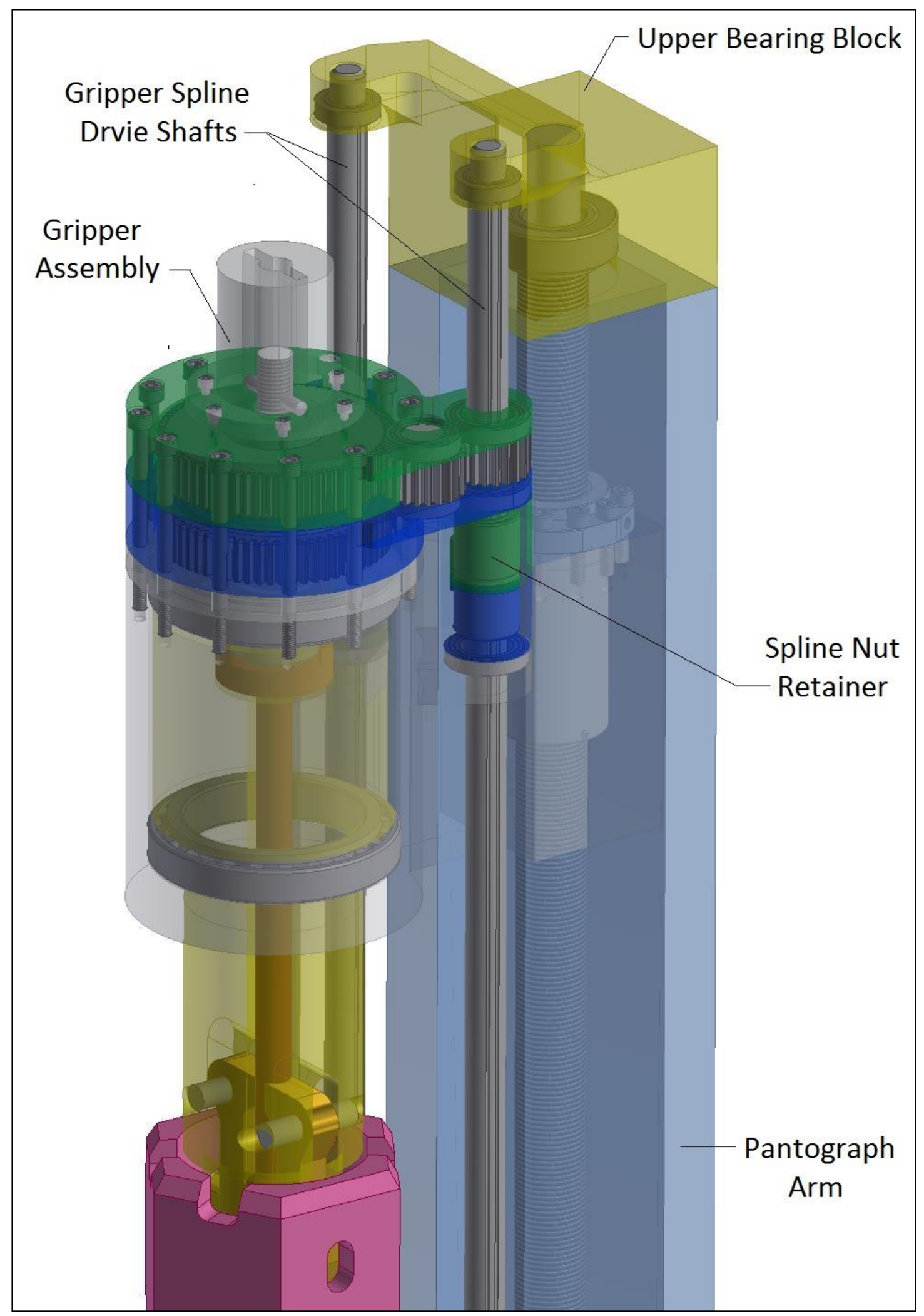

Figure 6-14: Gripper Drive Mechanism at Top of Pantograph Arm 
The spline shaft which controls the opening and closing of the gripper jaws operates a set of gears which engage a gripper jaw actuator shaft. The gripper jaw actuator shaft is keyed into the gripper actuator shaft guide (Figure 6-15). The gripper jaw actuator shaft and gear through which it passes are threaded, so as the gear turns, the gripper actuator shaft is raised. The gripper actuator shaft is attached to the jaw actuator (Figure 6-15) using a revolute joint which allows the gripper rotation stage to be isolated from the open/close operation.

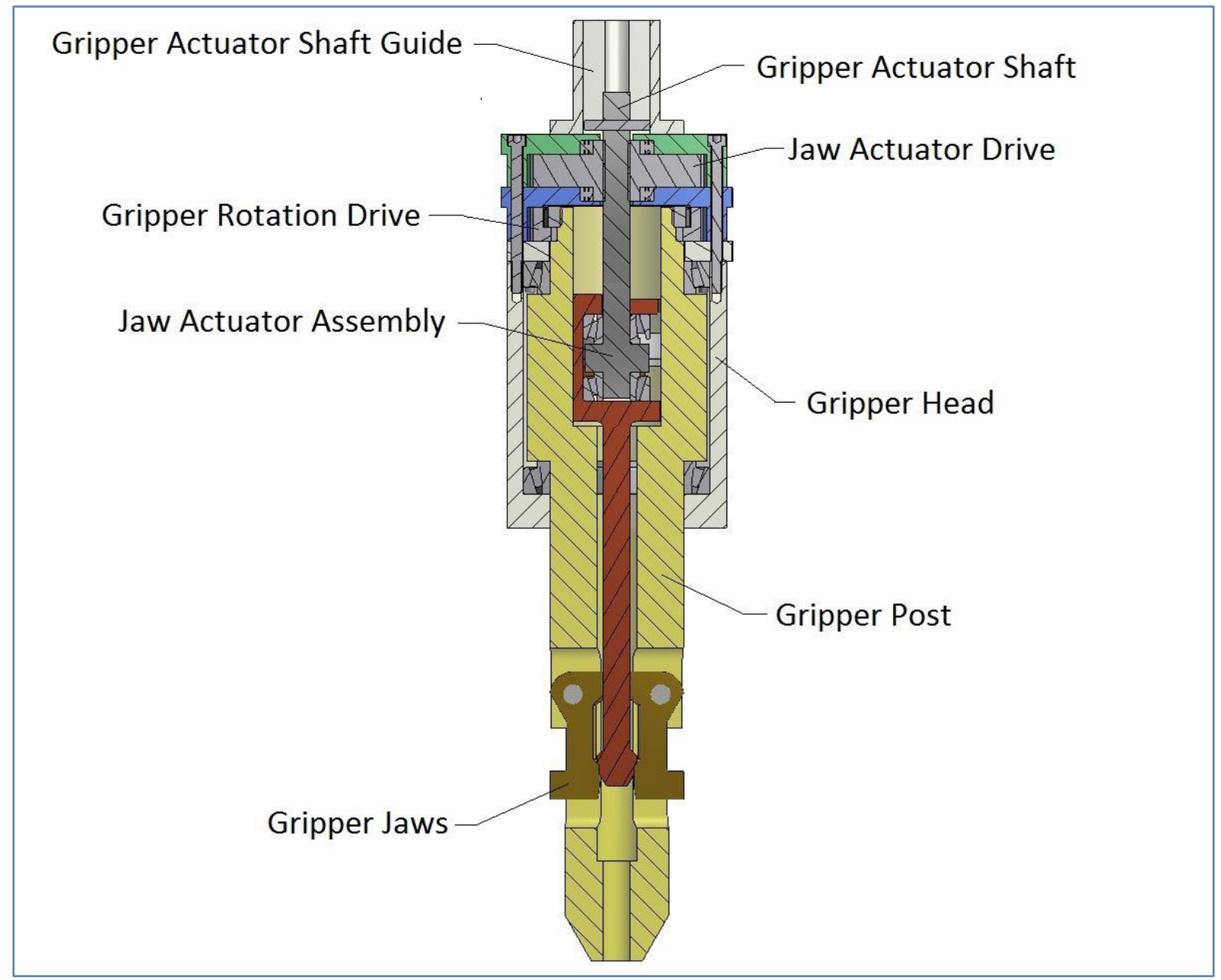

Figure 6-15: Section View through Gripper Head Assembly

The spline shaft which controls the rotational orientation of the core assembly inside the pantograph arm operates a set of gears, the last of which is keyed to the top of the gripper post (Figure 6-15). The gripper assembly is supported inside the gripper head on a tapered roller bearing which allows ease of rotation during operation (Figure 6-15 and Figure 6-17).

The gripper assembly is designed to fit and operate inside the confines of the pantograph arm assembly. Figure 6-16 shows the gripper assembly in the closed and open positions (jaws extended and retracted). The gripper assembly is designed for easy assembly and maintenance access inside the pantograph arm assembly. As the jaw actuator is raised or lowered it changes the angle of the jaws to the open (retracted) or closed (extended) positions through a sliding contact motion. A unique gripper jaw support feature engages the base of the jaws behind the 
location where the jaws contact the fuel assembly. The support of the gripper jaws at the bottom by the jaw actuator has been show to significantly reduce bending stresses in the gripper jaw.

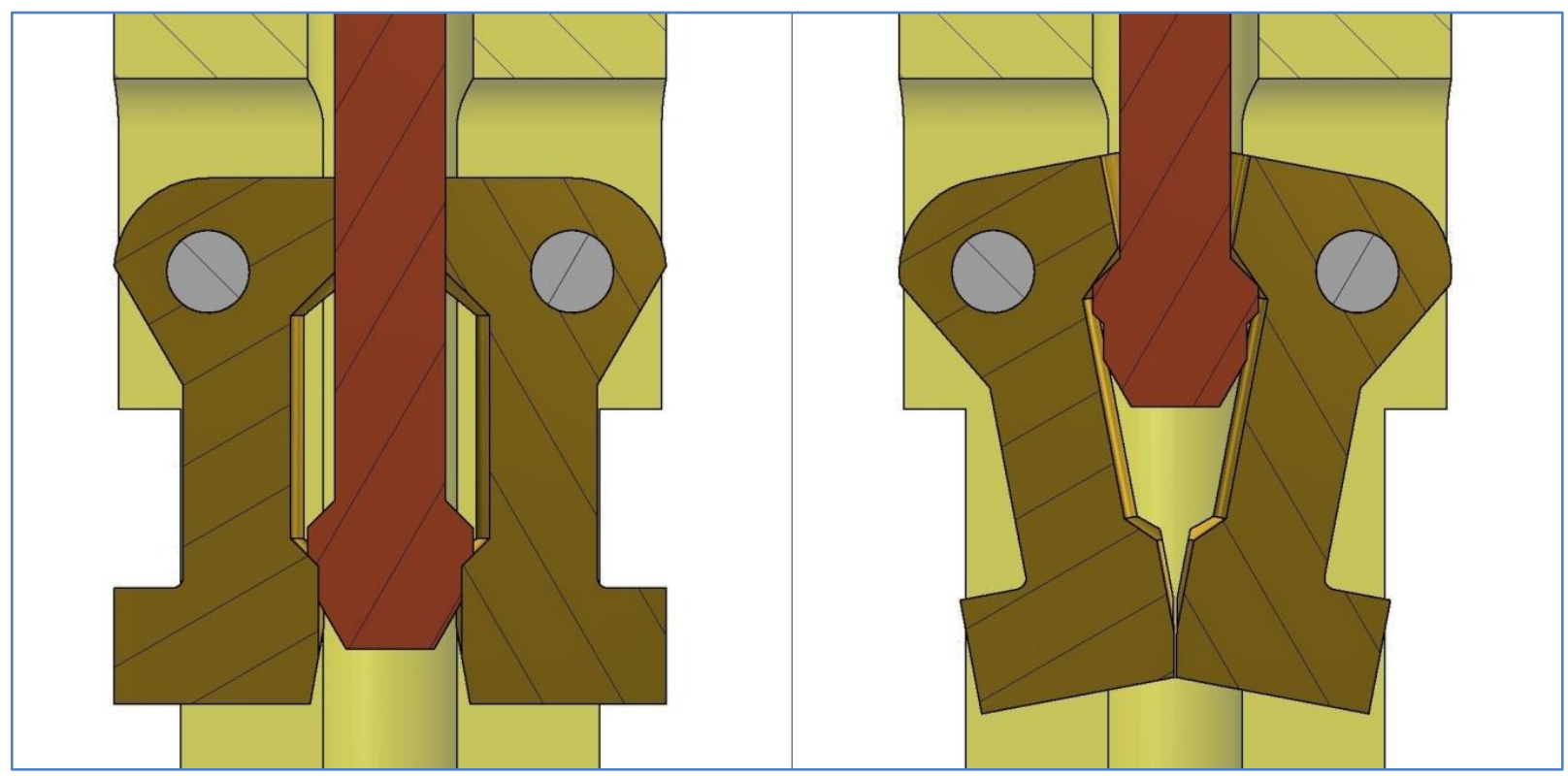

Figure 6-16: Gripper Jaws in the Extended and Retracted Positions using Jaw Actuator

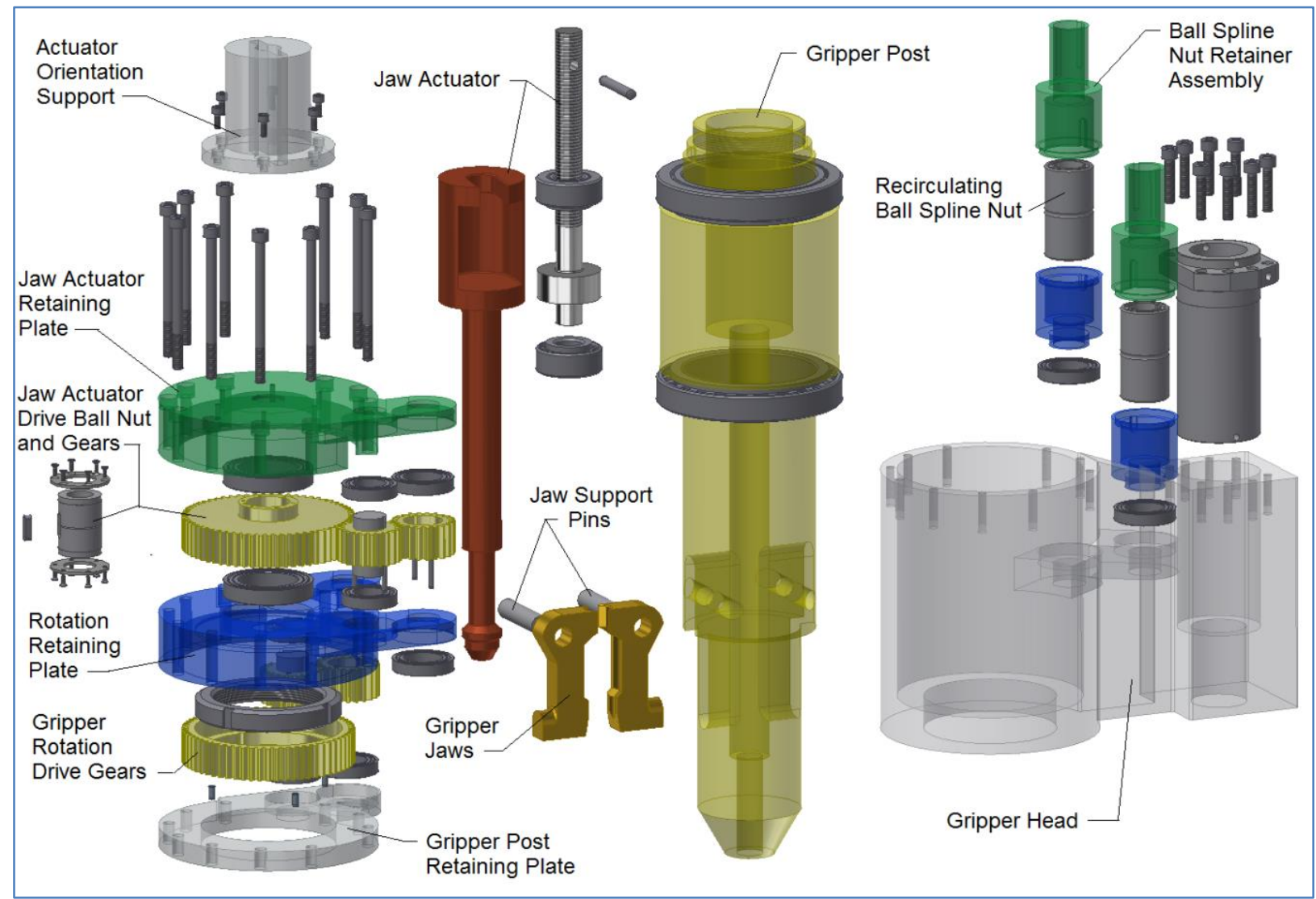

Figure 6-17: Exploded Assembly View of FASTER Gripper Assembly 
The pantograph arm was designed with sufficient clearances to operate in the region between an instrumented assembly and closed loop assembly at the maximum angle of attack. The operation was verified in the model of the reactor vessel and internal components. Removal of the pantograph assembly is easily achieved by retracting the pantograph arm and rotating it to the park position. Control cables, wiring and other external connections are removed, then a cask is placed over the port in the reactor vessel cover. The assembly is then lifted into the cask and a temporary plug is installed in the reactor vessel cover. The cask is then moved to a maintenance facility in a separate building for cleaning and maintenance operations. A spare back-up pantograph may then be installed into the vessel cover port for continued operation if required.

The material choices for the pantograph components are based on data from operational experience of EBR-II. For the major structural components, 304 or 316 stainless steel has been shown to perform well in the liquid sodium environment. For components which slide past each other (bearing surfaces) investigations show that Inconel 718, various stellite alloys and hastelloy performed well in tests of self-welding.

Design loads of $6000 \mathrm{lbs}$ for insertion or removal of a fuel assembly were used to analyze a simplified structural assembly by applying a vertical load to the hold down surface on the bottom of the fully extended pantograph arm (Figure 6-18). Stresses and deflections were calculated for the linkages and support tube structural members.

The calculated maximum stresses were below ASME Table 1A maximum allowable stresses for the chosen structural materials operating at elevated temperatures of 250 and $650^{\circ} \mathrm{C}$ (further optimization of the structural components should help reduce the weight of the fuel handling machine). The maximum calculated deflection of the structure due to the applied loads was less than $2.8 \mathrm{~mm}$. 


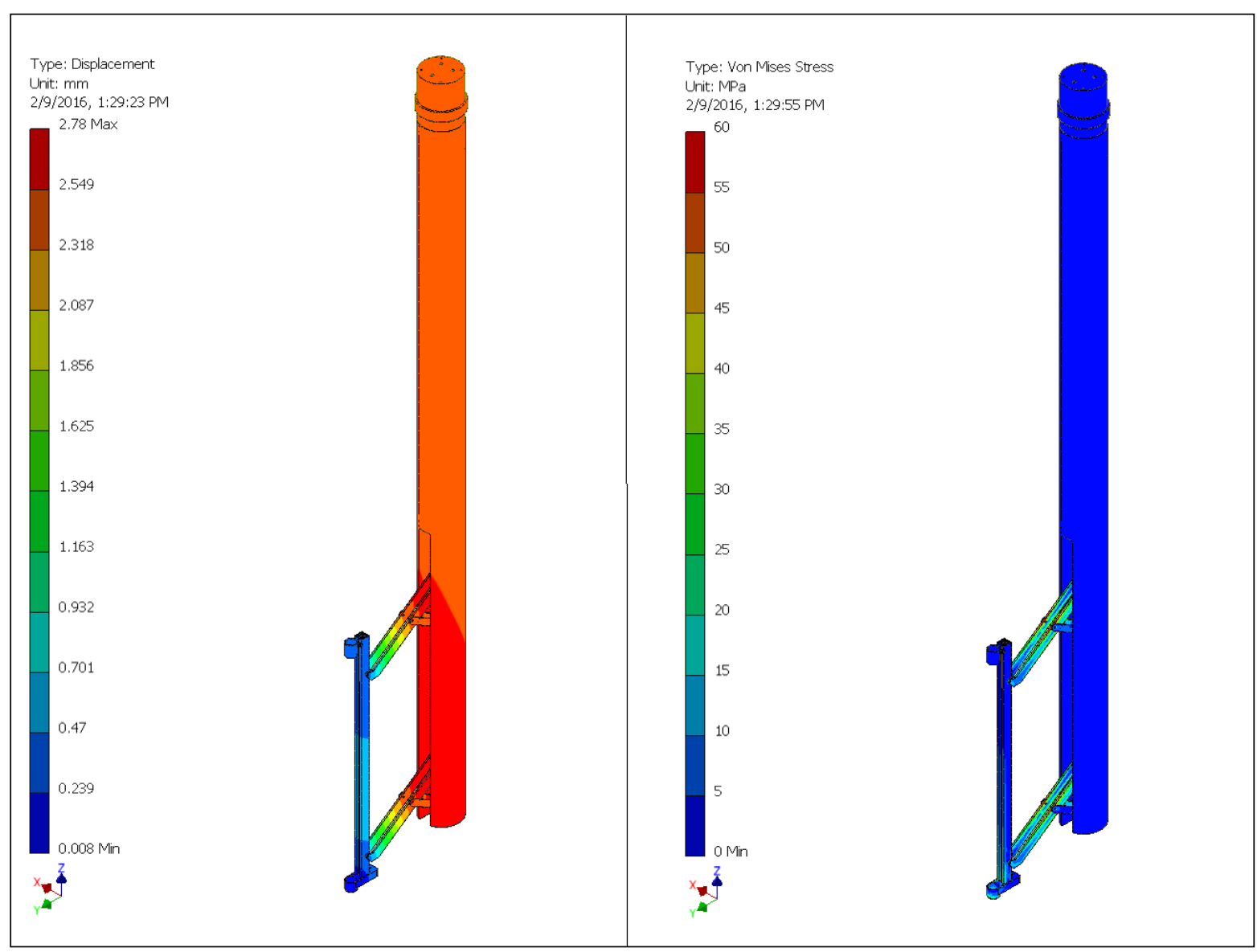

Figure 6-18: Static Deflection and Stress Results for 6000 lb Force on Hold Down Surface

A modal analysis was performed on the structural assembly of the FHM to preliminarily evaluate its natural frequencies (assuming no damping factor applied from the sodium liquid). The results of the preliminary analyses (Figure 6-19) show the first natural frequency of the structure (3.39 hertz as the lowest calculated natural structural frequency). With the damping forces from motion in the sodium applied, as well as slight design modifications to the support structure, the minimum natural frequency should be increased (these damping forces are to be calculated and added to a future analysis). 


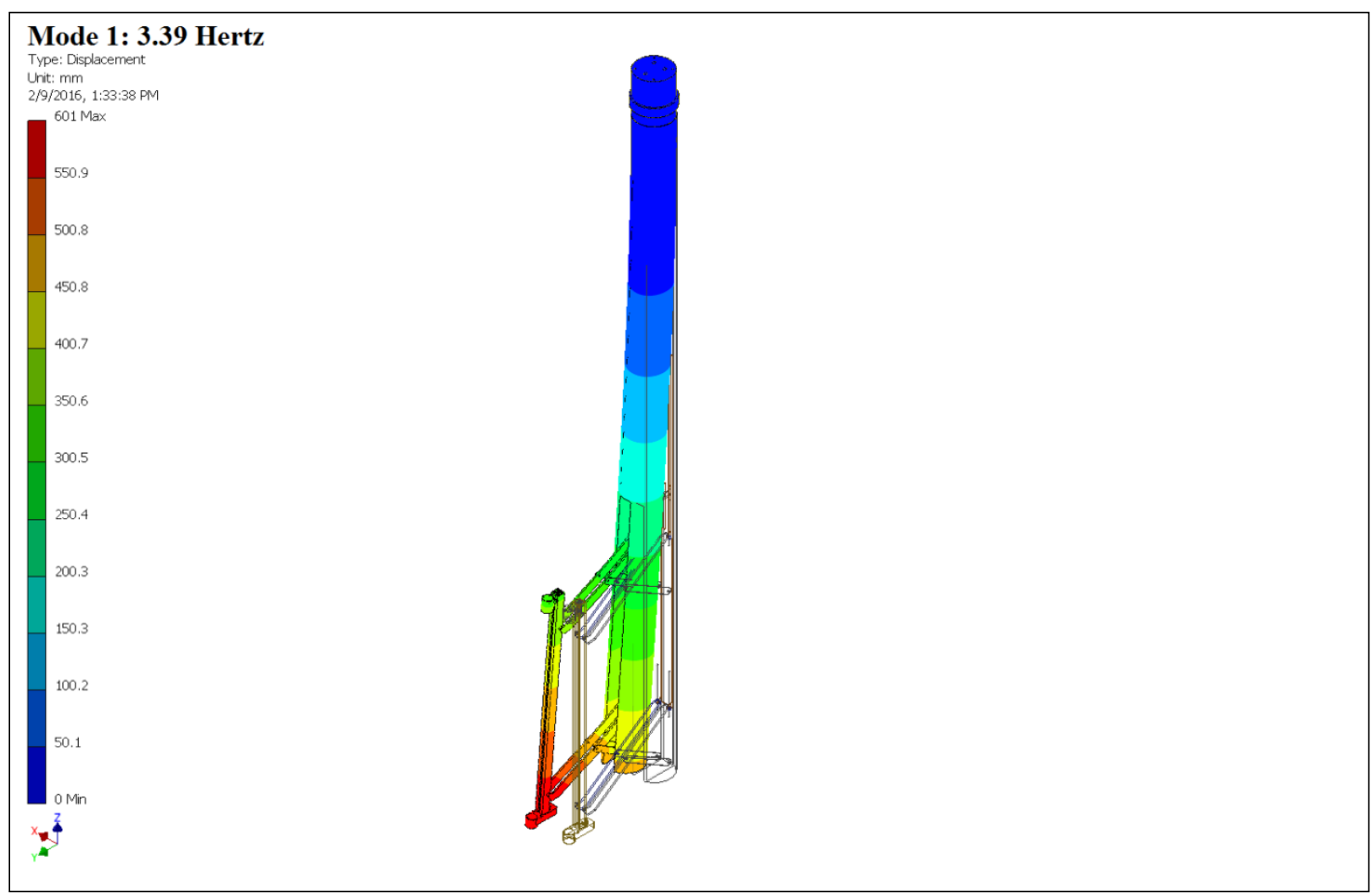

Figure 6-19: Modal Analysis Results for the FASTER FHM (First Modal Frequency 3.39 Hertz)

Critical buckling loads were calculated for a preliminary FHM assembly based on the load case of 6,000 lbs force applied vertically to the hold down face. The critical buckling load from the results of the linear elastic analysis performed in ANSYS was calculated as 37.8 times the applied load (Figure 6-20). The finalized design of the structure will be analyzed to evaluate both linear elastic and non-linear (plastic) buckling loads to assure adequate factors of safety. 


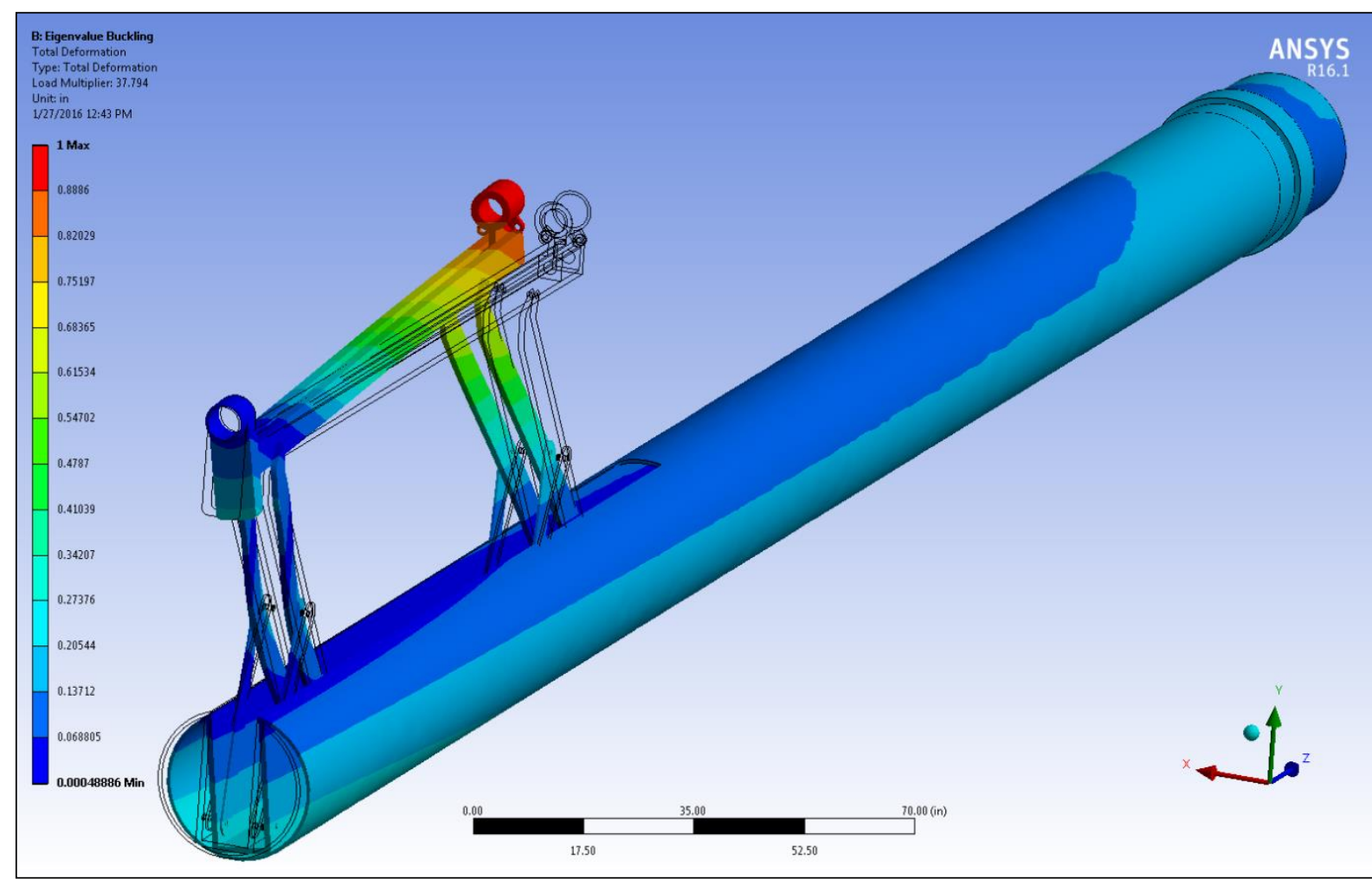

Figure 6-20: Finite Element Analysis Results of Linear Buckling Analysis for FASTER FHM

Seismic analysis is yet to be performed for the pantograph while immersed in the sodium fluid. The sloshing forces of the sodium fluid in the reactor vessel will be included in the seismic analysis of the fuel handling system.

Transient dynamic analysis of the overall structure in sodium will be performed based on the transient fluid forces caused by the sodium flow past the structure. A 2-way fluid structure interaction analysis will be performed on the finalized structure inside the reactor vessel to verify the vibrational response of the FHM structure to the flowing sodium.

The gripper assembly was analyzed by engaging a fuel element with the gripper jaws and applying the 6000 pound vertical load to the fuel element. Frictionless contact constraints were defined between all components in the assembly. The applied load causes a higher stress in the corners of the jaws nearest the contact point of the fuel assembly (Figure 6-21) due to stress concentration effects. An alternative jaw design (using a flat jaw top surface in lieu of a curved surface) was evaluated in an attempt to reduce the stress concentration effects at the top surface of the jaw. Results of the preliminary analyses are presented for comparison, but further design optimization needs to be performed before a final design configuration is chosen.

Performing these analyses with the jaw support feature installed at the bottom of the jaw actuator reduced the maximum bending stress in the jaw by more than a factor of two versus an unsupported jaw design concept which had been evaluated for comparison. 


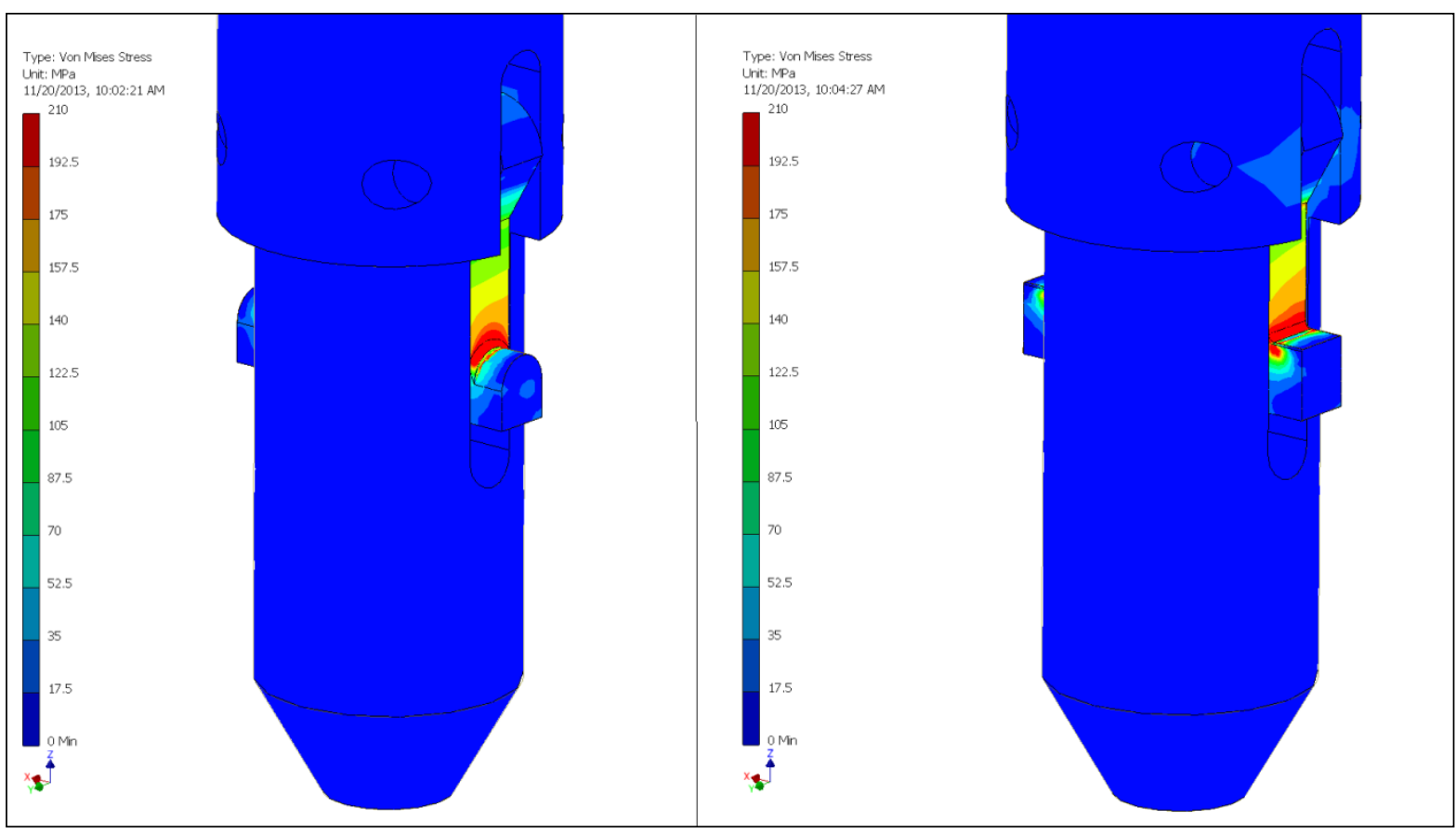

Figure 6-21: Stress Analysis Results for the Gripper Assembly using Different Jaw Designs

\subsubsection{FHM Driving Mechanism}

Hand calculations were performed to determine the torques required to rotate a core assembly inside the pantograph arm using the spline shaft drive assemblies. The calculations provided an estimate on the maximum angular displacement difference between the core assembly held in the gripper jaws and the bottom of the spline shaft housed inside the pantograph arm. Based on the mass moment of inertia of the core assembly, gripper core, gears, and spline shafts (Figure 6-22), the angular deviation through the spline shaft was calculated based on a constant acceleration from zero to 6 revolutions per minute in 1 second. Assuming a 0.1 coefficient of friction between the support bearings and recirculating ball spline nut and 0.2 between the gear contact faces during rotation, the torque required to rotate the raised core assembly was determined. The calculated torsional load was applied to the gear sets, spline shafts, universal joints and drive shafts for preliminary sizing purposes. Maximum stresses and deflections were calculated for all of the components to assure strength and verify (minimize) angular deviations through the drive system due to the applied loads. The calculated angular deformations were summed to determine the maximum deviation between the drive motor shafts and the core assembly connection which was less than 2 degrees. 
The purpose of this calculation is to determine the angular deflection and stress in the ball spline shaft which is used to rotate a core assembly inside the pantograph arm assembly. The frictional load is based upon the maximum weight of a core assembly supported by tapered roller bearings, including gear contact friction and gear support bearings inside the gripper head.
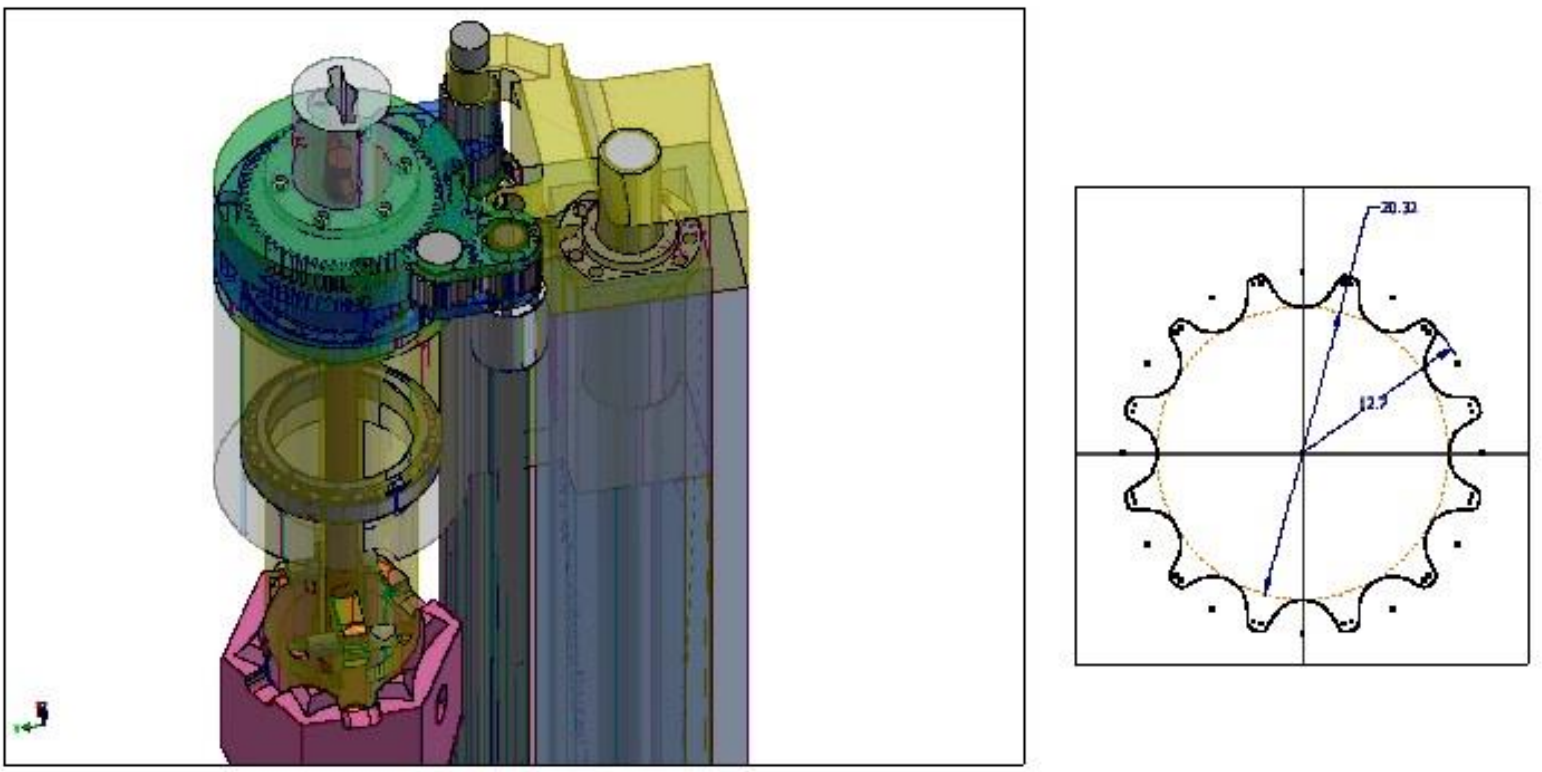

$$
\begin{array}{ll}
\text { Mass Rotating in Gripper Head: } & \mathrm{M}_{\mathrm{a}}:=550 \cdot \mathrm{kg} \\
\text { Tapered Bearing Friction: } & \mu_{\mathrm{t}}:=0.1 \\
\text { Roller Bearing Friction: } & \mu_{\mathrm{b}}:=0.1 \\
\text { Gear Contact Friction: } & \mu_{\mathrm{g}}:=0.2 \\
\text { Gear Teeth on Large Gear: } & \mathrm{N}_{\mathrm{L}}:=63 \\
\text { Gear Teeth on Small Gear: } & \mathrm{N}_{\mathrm{S}}:=22 \\
\begin{array}{l}
\text { Angular Velocity of Mass: } \\
\text { (Maximum) }
\end{array} & \omega_{\mathrm{m}}:=6 \frac{\mathrm{rev}}{\mathrm{min}} \\
\begin{array}{l}
\text { Maximum Angular Acceleration of Mass: } \\
\text { (acceleration from } \omega=0 \text { to max in } 1 \mathrm{sec} \text { ) }
\end{array} & \alpha_{\mathrm{m}}:=\frac{2 \cdot \pi}{10} \cdot \frac{\mathrm{rad}}{\mathrm{sec}^{2}}
\end{array}
$$

Figure 6-22: Dynamic Analysis basis of the Spline Shaft Based on Acceleration of the Mass

\subsubsection{Gear and Motor Sizing}

Gears were analyzed and sized in accordance with ANSI/AGMA 2001-D04:2005 standards for the calculated loading conditions assuming a continuous service life exceeding 20,000 hours of 
continuous operation. Deflections of the gears under the expected loading conditions were calculated based on the properties of the materials under consideration at the expected operating temperatures.

Finite element analyses using adaptive re-meshing were performed on a pair of gears subjected to the maximum torques in the pantograph assembly (Figure 6-23). Although the convergence parameter was set to a very low value, the maximum stresses calculated using the finite element method were far below those calculated using the American Gear Manufacturers Association standard calculation methodology.

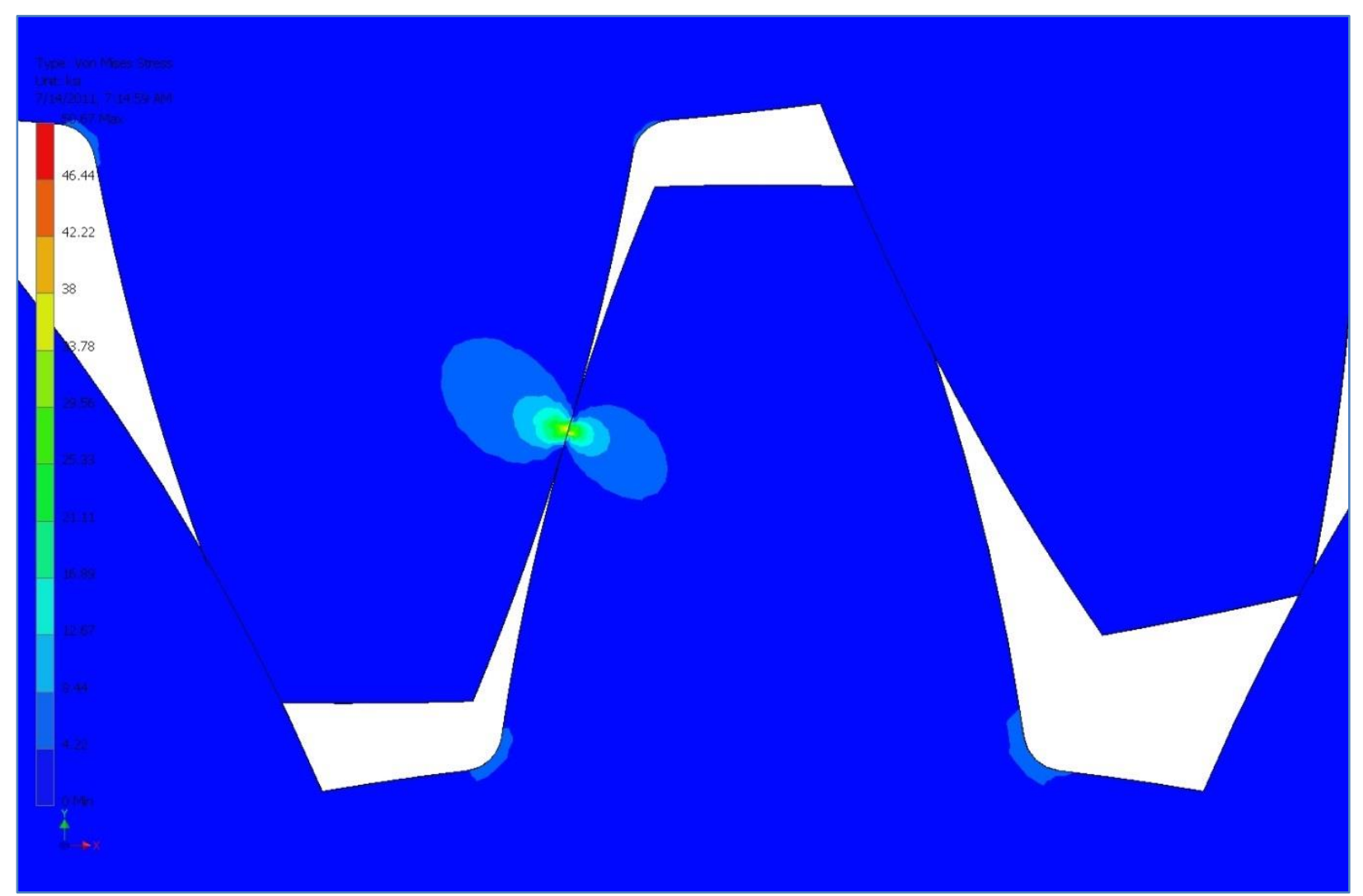

Figure 6-23: Finite Element Analysis Severely Underestimates Gear Contact and Bending Stresses

Hertz contact stresses were calculated for a pair of cylinders (matching the radius of the gear contact faces) contacting under compressive loading. The principal contact stresses and the equivalent contact stresses were calculated and plotted through the depth of the gear tooth (Figure 6-24). The results of the analysis indicate peak equivalent stresses below the contact surface. These results help explain gear tooth pitting as cracks initiate sub-surface and propagate outward causing small pieces of material to "flake" from the gear contact surface. 


$$
\sigma_{e}(z):=\frac{1}{\sqrt{2}} \cdot \sqrt{\left.\left.\left(\sigma_{x}(z)-\sigma_{y}(z)\right)^{2}+\left(\sigma_{y}(z)-\sigma_{z}(z)\right)^{2}+\left(\sigma_{z}(z)-\sigma_{x}(z)\right)^{2}+6 \cdot\left(\tau_{x y}(z)\right)^{2}+\tau_{y z}(z)\right)^{2}+\tau_{z x}(z)^{2}\right)}
$$

At a depth of 0.0023 inches, the effective stress is at a maximum

$$
\left.\sigma_{e^{(}(0.0023} \text { in }\right)=1.948 \times 10^{4} \mathrm{psi}
$$

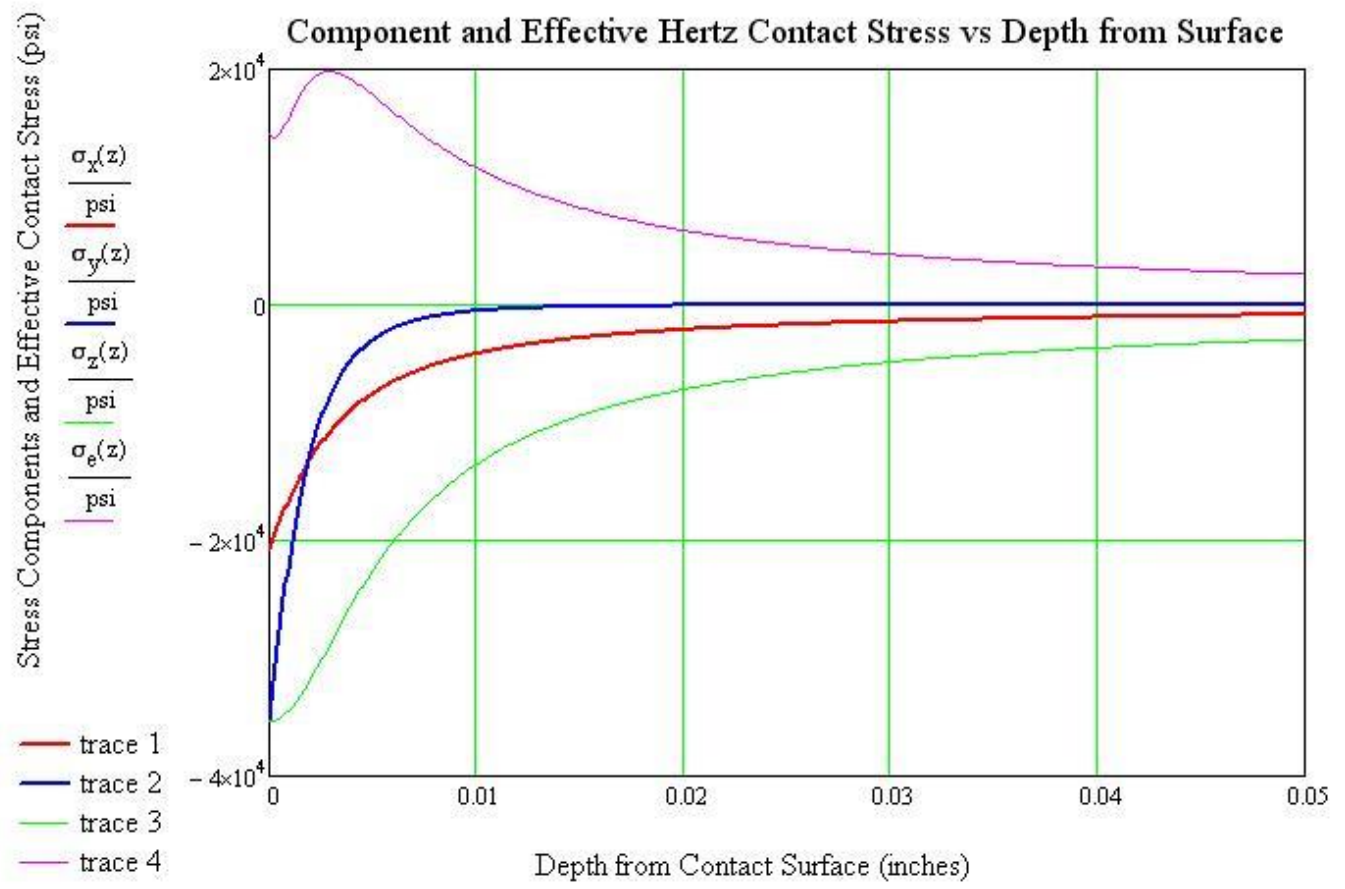

Figure 6-24: Hertz Contact Stress Distribution Indicates Peak Stress below Contact Surface

The equations for the safety factors for contact fatigue and bending fatigue are show in Figure 6-25. The primary gears in the FHM were preliminarily analyzed in accordance with the requirements of the ANSI/AGMA 2001-D04:2005 standards as a reference. The material properties chosen for the gear materials in the calculations were conservatively estimated based upon the properties of Inconel 718.

Sizing and estimates of gear lifetimes for continuous operation based upon expected operation cycles of the FHM can be generated once the finalized refueling schedule is generated.

Gear clearances due to manufacturing tolerances and wear may cause varying contact vibration over time. By controlling manufacturing tolerances, gear material, the type of gears used in the assembly and the control system parameters, the effects of these vibrations can be anticipated and minimized. 


$$
\begin{aligned}
& \text { Safety Factor of Contact Fatigue: } \\
& \mathrm{S}_{\mathrm{H} 12}:=\frac{\mathrm{s}_{\mathrm{ac}} \cdot \mathrm{Z}_{\mathrm{n} 12} \cdot \mathrm{C}_{\mathrm{H} 12}}{\mathrm{C}_{\mathrm{p}} \cdot \mathrm{K}_{\mathrm{T}} \cdot \mathrm{K}_{\mathrm{R}} \cdot \sqrt{\mathrm{F}_{\mathrm{t}} \cdot \mathrm{K}_{\mathrm{o}} \cdot \mathrm{K}_{\mathrm{v}} \cdot \mathrm{K}_{\mathrm{s} 12} \cdot \frac{\mathrm{K}_{\mathrm{m} 12}}{\mathrm{~d}_{\mathrm{wl}} \cdot \mathrm{b}_{\mathrm{w}}} \cdot \frac{\mathrm{C}_{\mathrm{f} 12}}{\mathrm{I}}}} \\
& \text { Safety Factor of Bending Fatigue: } \\
& \mathrm{S}_{\mathrm{F} 12}:=\frac{\mathrm{s}_{\mathrm{at12}} \cdot \mathrm{Y}_{\mathrm{N} 12} \cdot \mathrm{Y}_{\mathrm{A} 12}}{\mathrm{~K}_{\mathrm{T}} \cdot \mathrm{K}_{\mathrm{R}} \cdot \mathrm{F}_{\mathrm{t}} \cdot \mathrm{K}_{\mathrm{o}} \cdot \mathrm{K}_{\mathrm{v}} \cdot \mathrm{K}_{\mathrm{s} 12} \cdot \frac{\mathrm{P}}{\mathrm{b}_{\mathrm{wF} 12}} \cdot \frac{\mathrm{K}_{\mathrm{m} 12} \cdot \mathrm{K}_{\mathrm{B} 12}}{\mathrm{~J}_{12}}}
\end{aligned}
$$

Figure 6-25: AGMA Defined Safety Factors for Contact and Bending Fatigue

The lifetime reduction factors used in the AGMA safety factor equations include:

- I- Geometry factors for pitting resistance

- $\mathrm{Z}_{\mathrm{n} 12}$ - Stress cycle factor for pitting resistance

- $\mathrm{C}_{\mathrm{H} 12}$ - Hardness ratio factor

- $\mathrm{K}_{\mathrm{O}}$ - Overload factor

- $\mathrm{K}_{\mathrm{V}}$ - Dynamic Factor

- $\mathrm{K}_{\mathrm{S} 12}-$ Size factor

- $\mathrm{K}_{\mathrm{m} 12}-$ Load distribution factor

- $\mathrm{J}_{12}-$ Geometry factor for bending strength

- $\mathrm{Y}_{\mathrm{N} 12}-$ Stress cycle factor for bending strength

- $\mathrm{Y}_{\mathrm{A} 12}-$ Reverse loading factor

- $\mathrm{C}_{\mathrm{f} 12}$ - Surface condition factor

- $\mathrm{K}_{\mathrm{B} 12}-$ Rim thickness factor

- $\mathrm{K}_{\mathrm{R}}$ - Reliability factor

- $\mathrm{K}_{\mathrm{T}}$ - Temperature factor

- $\mathrm{C}_{\mathrm{P}}-$ Material factor

Where:

$s_{a c}$ - Allowable contact stress number $s_{a t 12}-$ Allowable bending stress number

$F_{t}-$ Nominal tangential force acting on teeth

$d_{w 1}$ - Operating pitch diameter of gear

$b_{w}$ - Operating tooth width

$P$ - Normal pitch 
$b_{w F 12}-$ Operating tooth width

Lifetime reduction factors for gear materials which operate in a liquid sodium environment have not yet been developed and therefore tests must be performed to select appropriate materials and sizing requirements before the next advanced fast reactor fuel handling system design is finalized.

The motor which drives the gripper head vertically in the pantograph arm has been preliminarily sized based on an expected raising or lowering time of the core assembly of approximately 1 minute. Calculations were performed to preliminarily size the motor which provides the torque required to raise or lower a "stuck" core assembly based upon the use of an ACME type screw drive mechanism using a conservative friction coefficient in the lead screw (Figure 6-26).

The calculation was used to select a DC servo reduction gear motor which would apply the required torque at a shaft output speed which would fully raise a "stuck" core assembly in approximately one minute. Although the current design utilizes ball screws in the design (which would require much lower torque to operate), a worst case approach was used to size the motor. Typical friction coefficients for ball screw assemblies $(\sim 0.08)$ are a fraction of that used in this motor sizing calculation as an example. In the final design analysis, all of the frictional loads and energy losses of bearings, ball screws, spline nuts, gears and other rolling/sliding and mechanical components should be included for the final motor sizing calculations.

The effects of shock loading on the motor and reduction gear unit due to dynamic elastic structural responses of the FHM should also be included in the sizing. 
The purpose of this calculation is to determine the motor size required to raise a "stuck" core assembly 175 inches within a minute. Using the torque calculated to raise or lower a core assembly, and using the gear ratios from the gripper to the drive motor, the horsepower required at the drive shaft on top of the vessel cover is calculated. The single start leadscrew is 175 inches long with 2 threads per inch and must raise the core assembly within 1 minute.

$$
\begin{aligned}
& \mathrm{T}_{\mathrm{R}}:=3090 \cdot \mathrm{in} \cdot \mathrm{lbf} \\
& \mathrm{n}:=350 \cdot \frac{\mathrm{rev}}{\min } \\
& \mathrm{HP}:=\frac{\mathrm{T}_{\mathrm{R}} \cdot \mathrm{n}}{63000} \\
& \mathrm{~T}_{\mathrm{R}} \cdot \mathrm{n}=17.16 \cdot \mathrm{hp}
\end{aligned}
$$

With a gear ratio of 23 to 32 , the horsepower required at the input shaft is:

$$
\begin{aligned}
& \mathrm{HP}_{\text {req }}:=\frac{32}{23} \cdot \mathrm{T}_{\mathrm{R}} \cdot \mathrm{n} \\
& \mathrm{HP}_{\text {req }}=23.874 \cdot \mathrm{hp}
\end{aligned}
$$

With a gear reducing motor that operates at $1200 \mathrm{rpm}$, the required continuous torque from the motor is:

$$
\begin{aligned}
& \mathrm{HP}_{\text {motor }}:=\mathrm{HP}_{\text {req }} \cdot \frac{350}{1200} \\
& \mathrm{HP}_{\text {motor }}=6.963 \cdot \mathrm{hp} \\
& \mathrm{T}_{\text {motor }}=\frac{\mathrm{HP}_{\text {motor }}}{1200 \cdot \frac{\text { rev }}{\min }} \\
& \mathrm{T}_{\text {motor }}=365.725 \cdot \mathrm{in} \cdot \mathrm{lbf}
\end{aligned}
$$

Figure 6-26: Typical Motor Sizing Calculation Based on Required Torque

The FHM must have manual back-up drive ability in case any of the components fail during fuel handling operations. The manual back-up drive system will be located in the maintenance area above the reactor vessel cover. The manual drive system will be capable of the following operations:

- Raise or lower the FHM (hold down) 
- Raise or lower core assembly inside the FHM arm

- Retract or extend the FHM arm into the structural tube

- Engage or disengage the gripper jaws

- Rotate the gripper

The FHM must be able to be operated manually from above the reactor vessel cover (maintenance area) in case of power failure, this can be accomplished by adding 90 degree drive components for operation by hand crank or using a portable drive motor (Figure 6-27). Geared down indicators display visual position information (Figure 6-28) to the manual drive system operator

Braking systems may be incorporated to secure the FHM components during operation to assure mechanical components not being operated will not drift due to mechanical vibrations imparted from the environment.

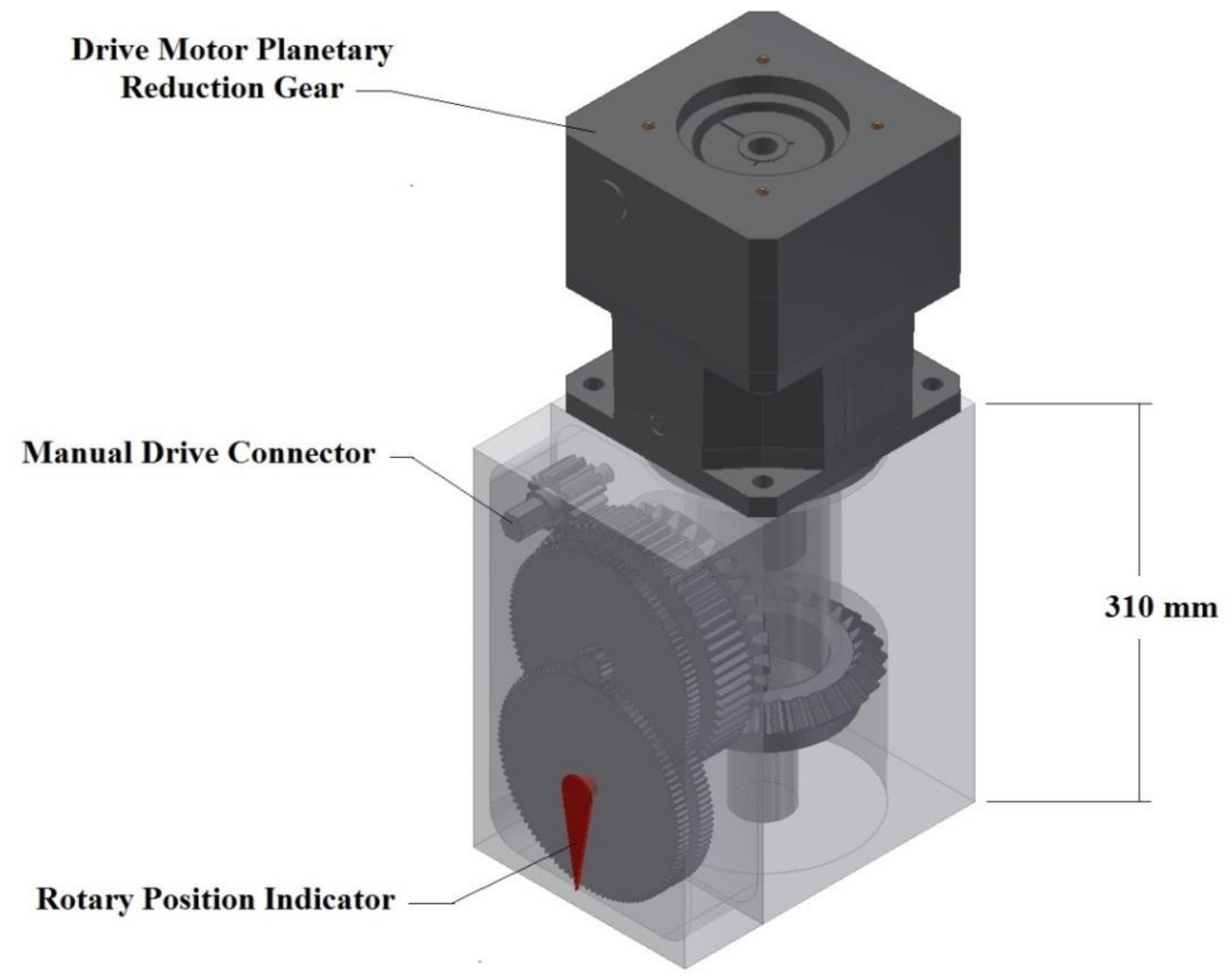

Figure 6-27: Conceptual Design of the Manual Drive Back-up and Visual Position Indicator 


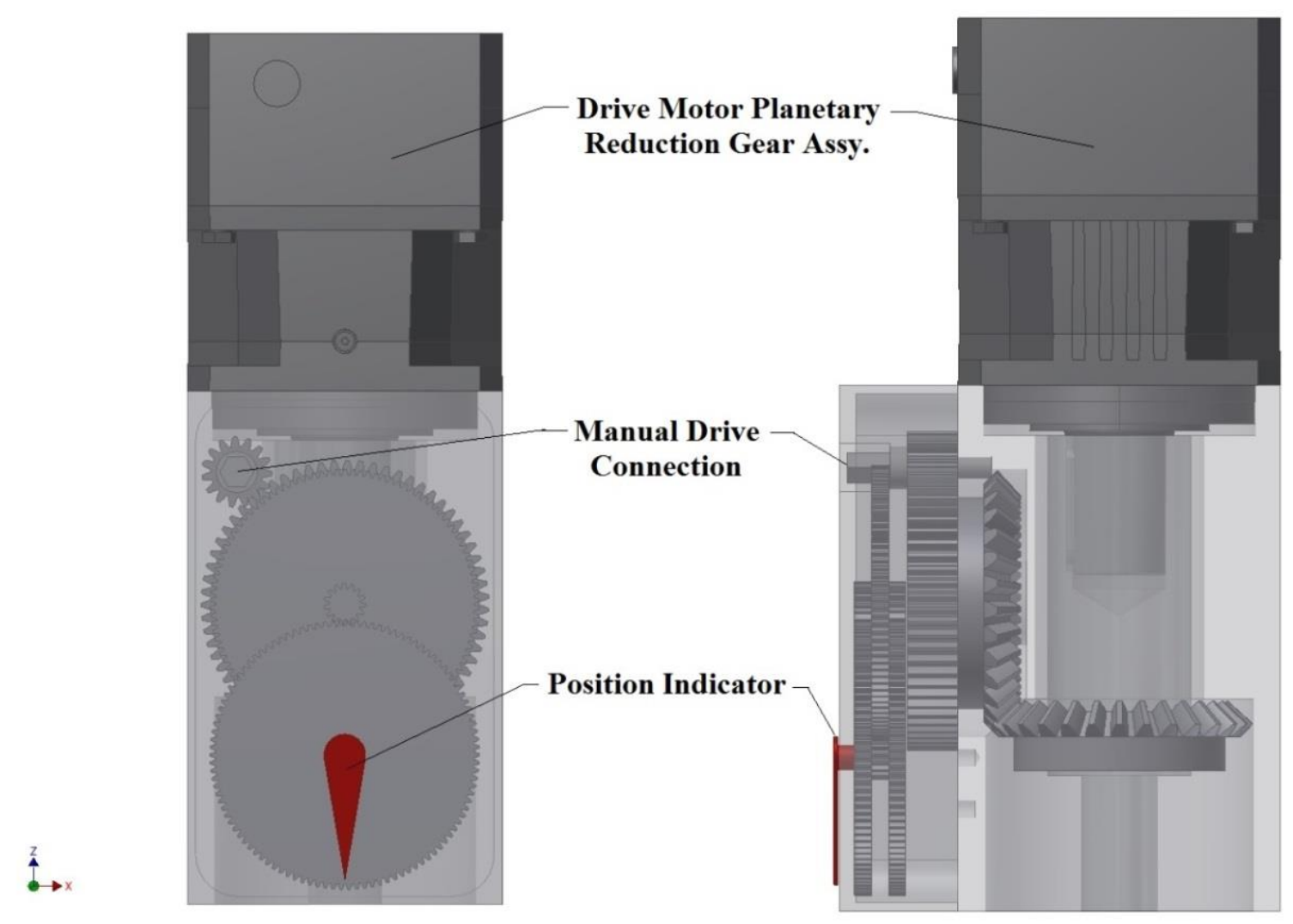

Figure 6-28: Elevation Views of the Manual Drive Back-up and Rotary Position Indicator

\subsection{Time required for fuel handling operations}

The time required for fuel handling operations for FASTER is based upon a specific sequence of events (or operations) which are performed after the shutdown of the reactor. The following estimates are based upon refueling times for EBR-II and calculations performed for the latest FHM design.

- After shutdown, the reactor is prepared for fuel handling operations.

- The fuel handling procedure includes transfer of core assemblies between the reactor vessel core positions, the fuel transfer position, into the fuel unloading machine through the fuel transfer port and to the transport cask for transfer to the fuel cleaning and examination facility.

- Several transport casks will be required for efficient handling operations.

- The fuel unloading machine and transport casks must be shielded, leak tight, and have argon gas purge systems with shielded filters for particulate removal.

- The fuel unloading machine and transport casks must have cooling capabilities to remove heat from a spent core assembly of a maximum $2.0 \mathrm{~kW}$.

- The fuel unloading machine must also have the ability to preheat a new core assembly (from the top down) to $200^{\circ} \mathrm{C}$ before insertion into the reactor vessel. 
- The fuel unloading machine and transport casks must have battery back-up for the argon gas heat removal systems.

- The fuel unloading machine must precisely align with the fuel transfer port and transport cask located in the pit.

- Estimated times provided are based upon EBR-II fuel handling times.

- Reactor has been shut down and reactor temperature has been reduced to $200^{\circ} \mathrm{C}$.

Table 6-1: Estimated Times for General Fuel Handling Operations

\begin{tabular}{lcc}
\hline Task & Duration & Source \\
\hline Preparatory Procedures & 2.5 hours & EBRII \\
Prepare Core Operation & 1.5 hours & EBRII \\
*Prepare and Preheat EVTM & 90 minutes (initial) & EBRII \\
*Load New CA into Transfer Cask and move to pit & 30 minutes & EBRII \\
$\begin{array}{l}\text { Move/Connect EVTM to Transfer Cask } \\
\text { Load New Core Assembly into EVTM and Disconnect }\end{array}$ & 20 minutes & EBRII \\
$\begin{array}{l}\text { Preheat Core Assembly in EVTM using heated argon } \\
\text { Move EVTM, Align \& Connect to FTP }\end{array}$ & 3.5 hours & EBRII \\
$\begin{array}{l}\text { Insert New core assembly (CA) into reactor Transfer } \\
\text { Position }\end{array}$ & 23 minutes & EBRII \\
$\begin{array}{l}\text { Move New CA to ISV or core using FHM } \\
\text { *Load New CA into Transfer Cask \& move to pit }\end{array}$ & EBRII \\
$\begin{array}{l}\text { Disconnect EVTM from FTP and move to Transfer } \\
\text { Cask (TC) }\end{array}$ & 30 minutes & Calculated \\
\hline
\end{tabular}

*indicates operation which may be performed simultaneously with others

\subsection{Typical FHM Cycle Operations inside the Reactor Vessel}

Fuel handling operations consist of the following sequence of tasks (which occur in the sequence listed) to reposition a core assembly inside the reactor vessel:

1. Rotate the FHM plug to the appropriate angular location.

2. Extend the FHM arm above the appropriate core assembly.

3. Lower the FHM to engage the hold down to surrounding core assemblies.

4. Rotate the gripper to the appropriate angular orientation.

5. Lower the gripper to engage the core assembly handling socket.

6. Extend the gripper jaws into the handling socket jaw keyways.

7. Raise the gripper to lift the core assembly inside the FHM arm. 
8. Raise the FHM to disengage the hold down from reactor core.

9. Retract the FHM arm fully inside the structural support tube.

10. Rotate the FHM plug to align FHM arm with appropriate storage location.

11. Rotate the gripper to the appropriate storage angular orientation.

12. Extend the FHM arm above the appropriate storage location.

13. Lower the FHM to engage the hold down to the storage position.

14. Lower the gripper to insert the core assembly into the storage position.

15. Retract the gripper jaws to disengage from the core handling socket keyways.

16. Raise the gripper to disengage the gripper from the core handling socket.

17. Raise the FHM to disengage the hold down from the storage position.

18. Retract the FHM arm fully into the FHM structural support tube.

Table 6-2: Estimated Time Required for Individual FHM Motions

\begin{tabular}{lc}
\hline Task & Time Required \\
\hline Preparation for Fuel Handling & 2 hours, 30 minutes \\
\hline Connect/Disconnect CRDL Gripper & 5 minutes* \\
\hline Remove/Insert CRDL & 5 minutes* \\
\hline Connect/Disconnect CRDL at top of Instrument Tree & 10 minutes \\
\hline Rotate Instrument Trees for refueling & 15 minutes \\
\hline Rotate FHM Plug & 4 min/rev (fast), \\
& 8 min/rev (slow) \\
\hline Extend/Retract Arm (1650 mm - maximum) & 4 minutes (calculated) \\
\hline Raise/Lower Hold Down & 5 minutes \\
\hline Rotate Gripper & mm @ 1mm/sec) \\
\hline Raise/Lower Gripper ( 5,000 mm) & 6 RPM (1 revolution in 10 seconds) \\
\hline Extend/Retract Jaws & 2 minutes \\
\hline *Indicates time based on EBR-II fuel handling records
\end{tabular}

The following preliminary schedules for fuel handling operations have been developed based upon the individual operation times listed above. Preliminary schedules have been developed for fuel handling operations assuming a standard 8 hour work shift. Figure 6-29 shows the schedule of events during the first shift of fuel handling operations, Figure 6-30 shows the schedule of events which occur during each subsequent shift. 


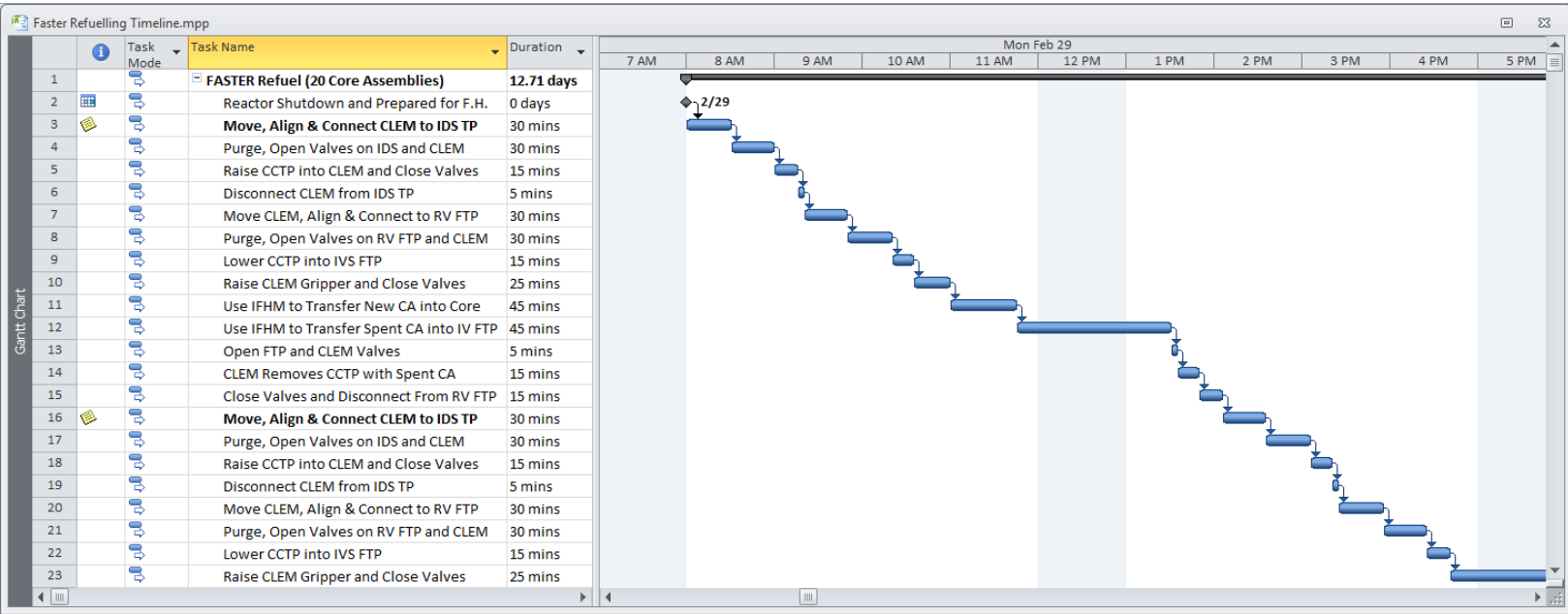

Figure 6-29: Preliminary Time Estimate for Initial Shift Fuel Handling Operations

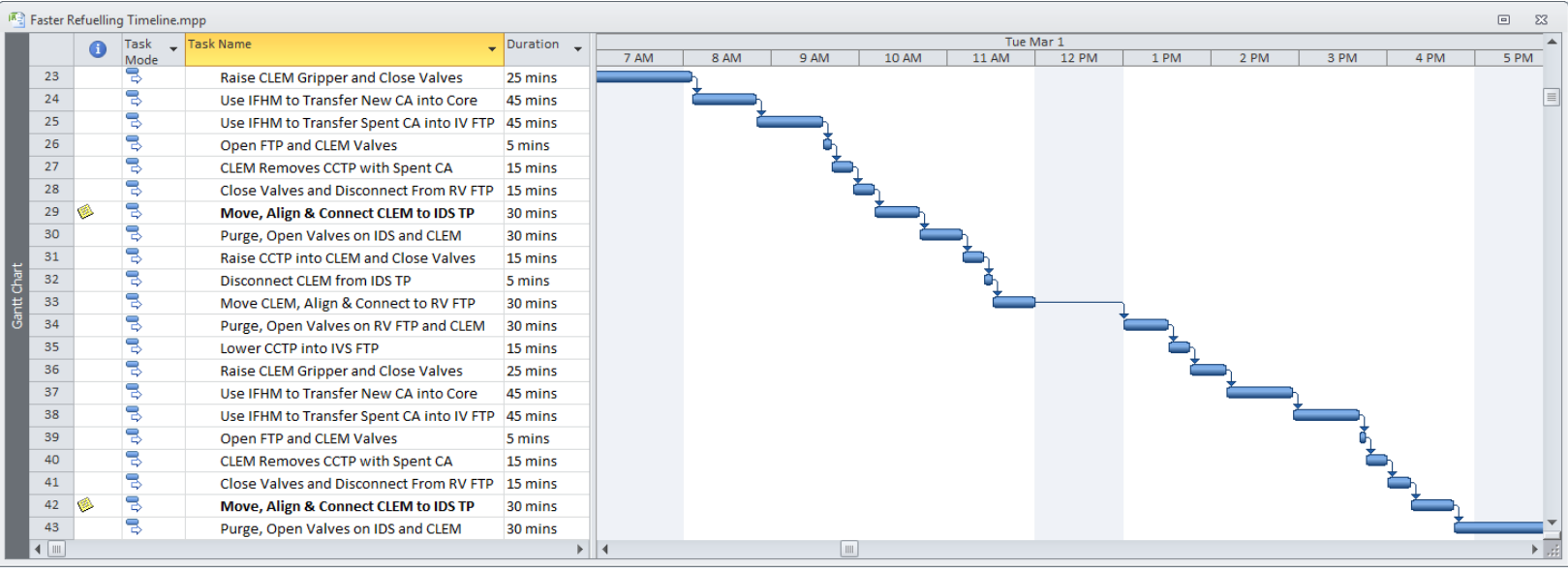

Figure 6-30: Preliminary Time Estimate for Subsequent Shift Fuel Handling Operations

During a nominal re-fueling cycle for FASTER, 20 driver (fuel) assemblies will be removed and replaced. The number of core assemblies to be replaced during the re-fueling cycle is based upon the current planned layout which consists of:

- 55 fuel core assemblies

- 39 test assemblies

- 22 moderator assemblies

- 77 reflector assemblies

- 111 shield assemblies

- 9 control rod assemblies

The total number of assemblies inside the reactor core is 313 . 
Fuel Loading Operations

For fuel loading operations with 1.6 core assemblies loaded for the first shift and 1.6 loaded each additional shift, the overall time (in work shifts) for loading 20 new core assemblies is approximately 13 normal work shifts (assuming the required manpower is available).

- 17 days for single shift per day operation (including weekends)

- 9 days for two work shifts per day operation (including weekends)

- 5 days for three shift per day operation

\section{Fuel Unloading Operations}

For fuel unloading operations with 1.6 core assemblies loaded per shift (assuming that all of the preparation and core procedures have been performed prior to the fuel loading operations), the overall time (in work shifts) for unloading 20 spent core assemblies is approximately 13 normal work shifts (assuming the required manpower is available).

- 17 days for single shift per day operation (including weekends)

- 9 days for two work shifts per day operation (including weekends)

- 5 days for three shift per day operation

Heating time for a new core assembly (at loading) using heated argon in EBR-II EVTM listed as 90 minutes. The actual time to preheat a core assembly is estimated to be 3.5 hours, but the core assemblies may be preheated before loading into the EVTM.

\subsection{Control System Design Recommendations}

The computer controlled system will utilize feedback sensors to measure forces during core assembly handling procedures. Feedback sensors available vary widely, but they should be chosen while considering their operation in an elevated temperature and radiation environment while subject to mechanical vibrations and shock. Accelerometers can be placed on the FHM structure to monitor vibrations experienced during use. Load cells may be used to monitor the forces applied to the FHM from the drive motor system. Monitoring the current drawn by the motors during FHM operation gives another indication of loads encountered by the system.

Mechanical contact sensing rods may also be incorporated into the FHM design to indicate that the gripper is fully engaged into the top of the core assembly before engaging the gripper jaws.

Intelligent programming will allow the system to orient the core assembly correctly by estimating the angular variance between the drive motor and core assembly due to elastic deformations of the drive mechanism components under load.

The computer control system must have programmed "no-go" zones to prevent contact with reactor internal components during refueling operations. The refueling system should be disabled during reactor operation and only enabled after all of the reactor shut down interlocks have been established and refueling system operational parameters are met.

The control system must sense and display the following information on the operator's panel: 
- FHM angular position with respect to the vessel cover.

- Hold down location (height above core assemblies and weight (force) applied to core).

- FHM arm position (extended location) and dynamic forces.

- Gripper vertical position and rotation angle with respect to the reactor core and dynamic forces.

- Gripper jaw engagement status (jaws extended or retracted with force monitoring).

Forces applied by the FHM drive system are monitored and alarms (with automatic stop motion signals) are used to notify the operator out of limit conditions and prevent damage to FHM components. A conceptual layout for the operators display panel is shown in Figure 6-31. The active FHM should be highlighted on the operators screen to indicate it is the FHM being controlled and the instrument tree orientation should also be displayed.

The control system for the FHM should be designed for fully automatic operation from a predefined database with minimal input from the operator, but, must also have the ability to be operated in a stepwise fashion by the operator.

From the operator's panel, the user should be able to manually select any core assembly (using the mouse), the core assembly should highlight and a small window should open which lists all of the pertinent data for that core assembly.

The data for the core assembly may include (but not be limited to):

- Core position,

- Core assembly Serial Number,

- Core assembly angular orientation,

- Core assembly age and history (where and how long in core), and

- Failed fuel pin status.

The user should then be able to select a storage position using the mouse and the fuel handling system (if the position is available to accept a core assembly) should automatically perform all actions required to move the core assembly to the new position and orientation. 


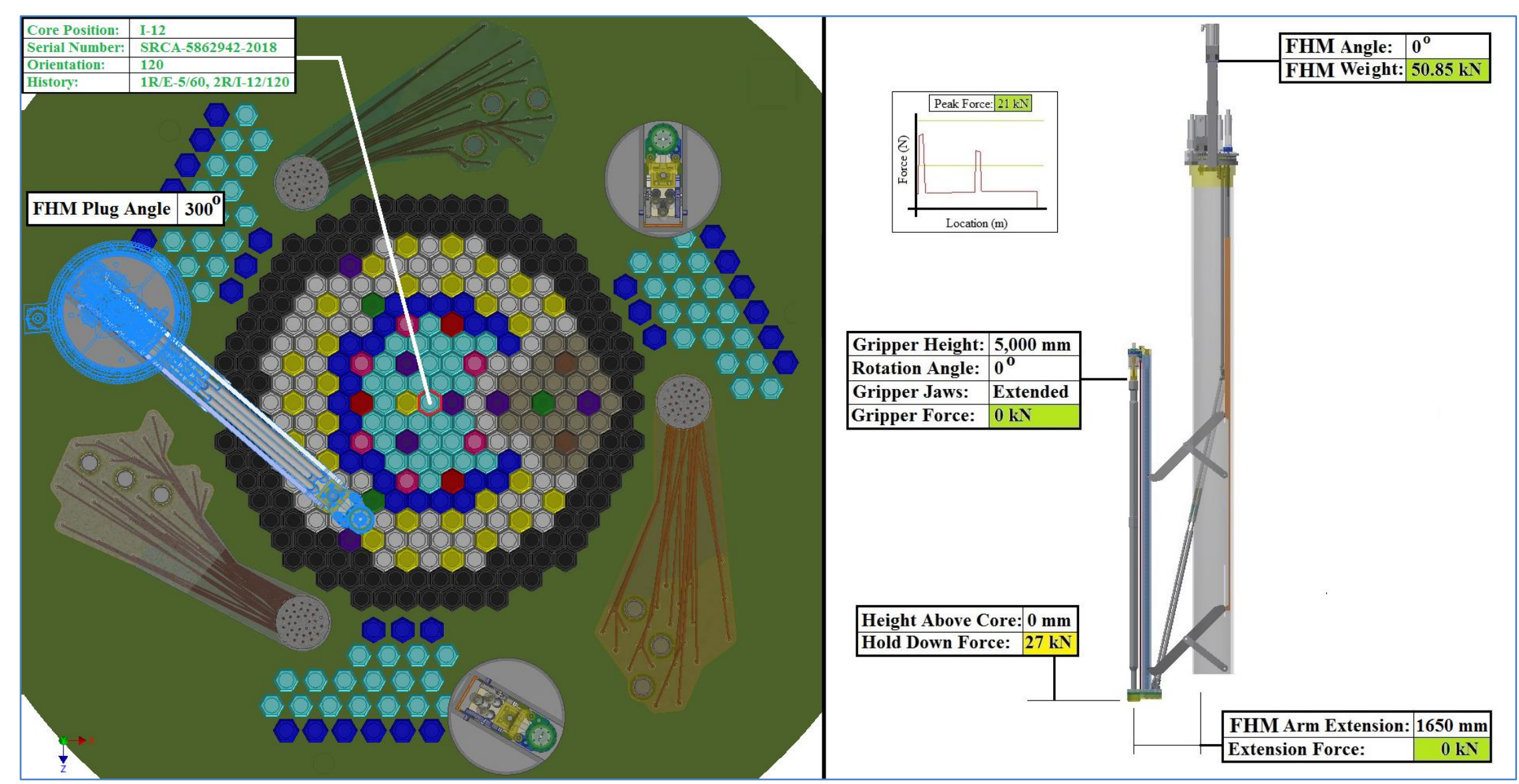

Figure 6-31: Conceptual FASTER - FHM Operators Display Pane 


\subsubsection{Positional Tolerances for the FHM}

The control system for the fuel handling system should receive information from the reactor system which identifies that it is ready for fuel handling. The program which operates the fuel handling control system should read this data and verify the reactor status before it allows fuel handling operations to commence.

The software should also read the status of the fuel handling system by performing diagnostic checks and system tests to identify problems in the system before fuel handling operations are allowed, these tests may check the status of communications, load cell and other sensor status, perform preliminary motion operational checks (in the park position) to assure that potential build-up of sodium oxides does not impair the FHM performance and other system checks.

A simplified programming flowchart is shown in Figure 6-32. This flowchart forms a basis for the program which is needed to perform refueling operations during reactor shutdown (maintenance) periods. The flowchart shows all of the steps required by the fuel handling system to move core assemblies to the in-vessel storage positions, shuffle fuel positions in the reactor core and move fresh core assemblies from the in-vessel storage positions to positions inside the reactor core. The flowchart may also be used to transfer core assemblies from the in-vessel storage to the fuel transfer position (and vice versa) for removal of spent fuel or installation of new fuel assemblies using the ex-vessel fuel handling machine.

Each "block" in the program flowchart which represents a single controlled motion of the fuel handling system (highlighted in yellow in Figure 6-32) is actually a separate program subroutine which incorporates force monitoring and position feedback parameters (for the specific movement function) which assure that prescribed load limits during fuel handling operations are not exceeded and provide for accurate positioning of the FHM inside the reactor vessel.

The following individual motions are to be controlled in the FHM fuel handling system:

- Rotation of the FHM plug (angular control accuracy of 0.14 degrees),

- Extension/Retraction of the FHM arm (linear accuracy of $+/-2.5 \mathrm{~mm}$ ),

- Raise or lower FHM plug (hold down load accuracy of $27 \mathrm{kN}+/-3 \%$ ),

- Gripper rotation (angular accuracy of 0.5 degrees),

- Raising/Lower the gripper head (positon accuracy $+/-2.5 \mathrm{~mm}$ ), and

- Engage/Disengage the gripper jaws (2 position control).

Each of these drive systems will require force and position feedback monitoring while velocities and accelerations will be limited through the system design and proper definition of control parameters.

The control parameters for a single FHM motion (in this case the hold down motion by raising or lowering the FHM plug) is discussed here as an example. The FHM is located in the reactor vessel cover and has a series of inflatable seals which isolate the cover gas atmosphere inside the 
reactor vessel. The mass of the FHM is supported by a load limiter assembly. The load limiter assembly is an arrangement of compression springs which compress approximately $10.6 \mathrm{~mm}$ while supporting the entire estimated $78 \mathrm{kN}$ weight of the FHM. A load cell which is connected to the top of the load limiter assembly provides multiple redundant feedback signals to the control system which measures the total amount of load applied by the FHM to the surrounding core assemblies in the reactor core. The load cell is connected to a ball screw which is sized to support the load of the FHM for an appropriate lifetime. The ball screw is supported through a recirculating ball nut assembly which is connected through a planetary reduction gear assembly to a DC servo motor which applies the torque required to raise or lower the FHM and apply the specified hold down force to the surrounding core assemblies in the reactor.

At some point as the FHM is lowered to a vertical position (depending on the relative thermal expansions of components in the reactor vessel), the hold down contacts surrounding core assemblies and begins to transfer load as the springs in the load limiter decompress. The estimated load applied to the surrounding core assemblies should be at least equal to the maximum fuel handling load for insertion of a stuck core assembly to assure the FHM hold down does not lift off of the surrounding core assemblies. The rate at which the FHM moves vertically should be limited to approximately $1 \mathrm{~mm}$ per second to allow the control system time to measure the rate at which the load is changing as the load is transferred and adjust the speed of the motor so the system halts at the set hold down load (within a specified tolerance range). It is assumed that the control system measures the load cell data at least 10 times per second so it can make appropriate adjustments and slow the motor speed gradually to minimize shock loading to the drive system components.

The damping in this system will be small due to losses and friction in the inflatable seals and linear slide rails which support and guide the FHM plug to prevent metal to metal contact between the FHM plug and the reactor head, therefore the type of control scheme chosen must be evaluated through careful analysis of the response of each drive system.

Sensors such as accelerometers are located on the FHM structure to monitor vibrations in the mechanical system and may be used to help predict failures of mechanical components in the FHM. Thermocouples are mounted at various locations on the FHM structure to measure the temperature of the components. The temperature feedback information will be used in the position control systems as required to increase the accuracy of the positioned component. 
FASTER Test Reactor Preconceptual Design Report

March 31, 2016

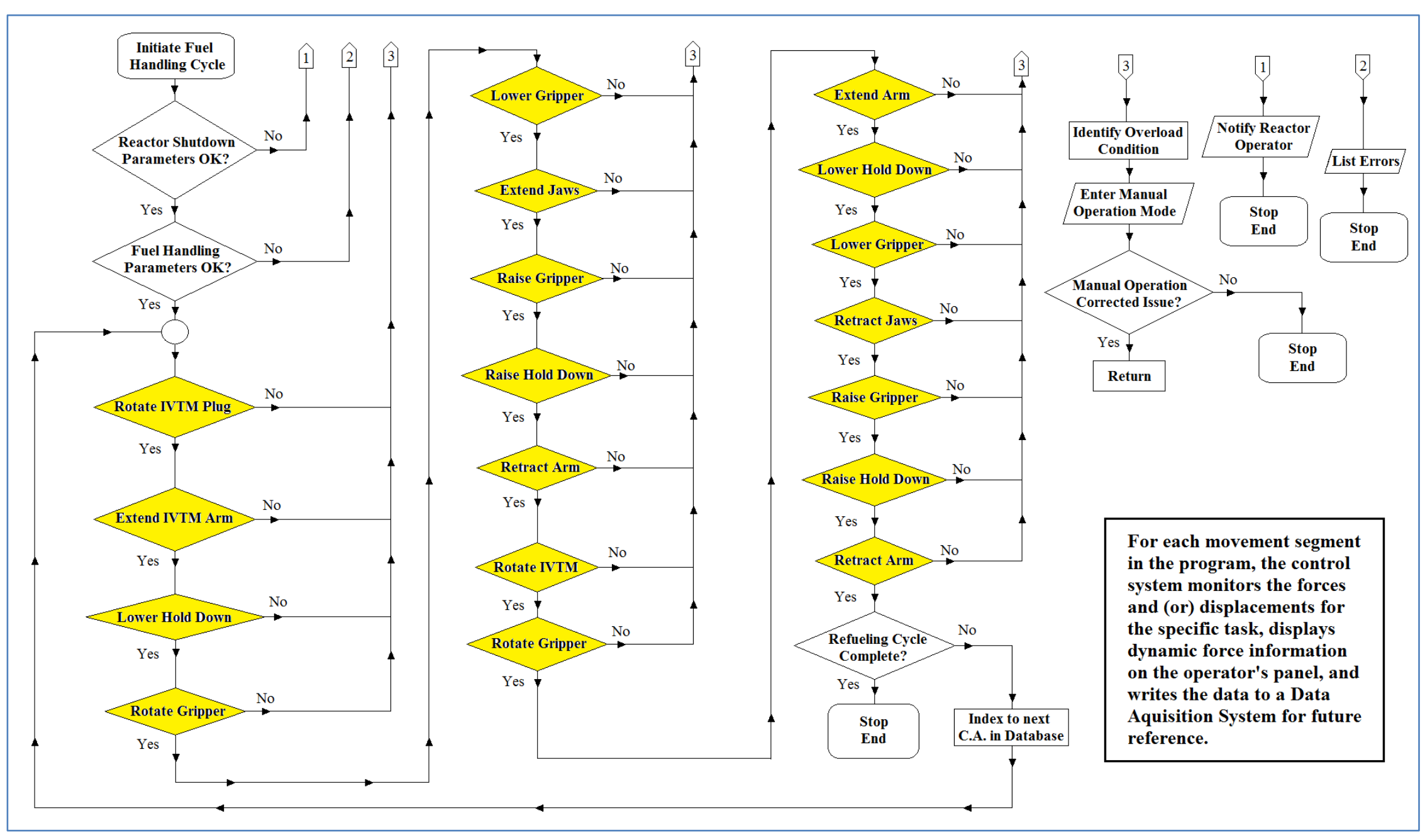

Figure 6-32: FHM Control System Programming Flowchart 


\subsubsection{Core Hold-Down Control System using Force Control}

The computer controlled system will utilize feedback sensors to measure forces during core assembly handling procedures. Feedback sensors available vary widely, but they should be chosen while considering their operation in an elevated temperature and radiation environment while subject to mechanical vibrations and shock. Accelerometers can be placed on the FHM structure to monitor vibrations experienced during operation. Load cells may be used to monitor the forces applied to the FHM from the drive motor system. Monitoring the current drawn by the motors during FHM operation gives another indication of loads encountered by the system. The proper calculation and definition of the proportional, differential, and integral gains (as required) used in the various individual driven motions of the computer control system coupled with the signals from the feedback sensors will assure accurate location of the FHM inside the reactor vessel and reduce shock loading experienced by the mechanical components which make up the FHM. Intelligent programming will allow the system to automatically orient the core assembly correctly by estimating the angular variance between the drive motor and core assembly due to elastic deformations of the drive mechanism components under load, while feedback sensors will verify positions of the components in the fuel handling system.

The loads applied to the top of the surrounding core assemblies by the FHM hold down feature can be controlled using a compression die spring assembly to slowly transfer weight of the FHM after initial contact (Figure 6-33). Without a load limiter, the weight of the FHM is transferred to the surrounding core assemblies almost instantaneously at the point of contact. The use of a load limiter prevents overload and shock loading of the mechanical components in the FHM drive system.

The load limiter supports the entire weight (80,000 Newton) of the FHM from above the reactor vessel cover. Multiple redundant sensors in the load limiter can be used to measure the force transferred to the core assemblies as a reduction in weight supported by the load cell.

Loads applied to the surrounding core assemblies are controlled using the variable speed of the motor which raises and lowers the FHM.

A load limiter should also be included in the gripper jaw actuator; the Scott Russell straight line mechanism extension actuator and the raise/lower gripper drive systems to limit the load applied to the mechanical components at the end of travel positions and minimize shock loading. The rotation stage of the gripper has no "hard" stops and therefore does not require a load limiter, the rate at which the gripper rotation stage accelerates the mass will be controlled through the proportional, differential and integral gains which are defined in the computer control system.

Mechanical contact sensing rods may also be incorporated into the FHM design to indicate that the gripper is fully engaged into the top of the core assembly before engaging the gripper jaws although load limiting devices and force feedback sensors will indicate if the jaws make contact with the core handling socket inner surface before the jaws are fully extended into the jaw sockets in the core assembly handling socket (this indicates that the gripper is in the incorrect angular position with respect to the jaw sockets in the core assembly being handled). 


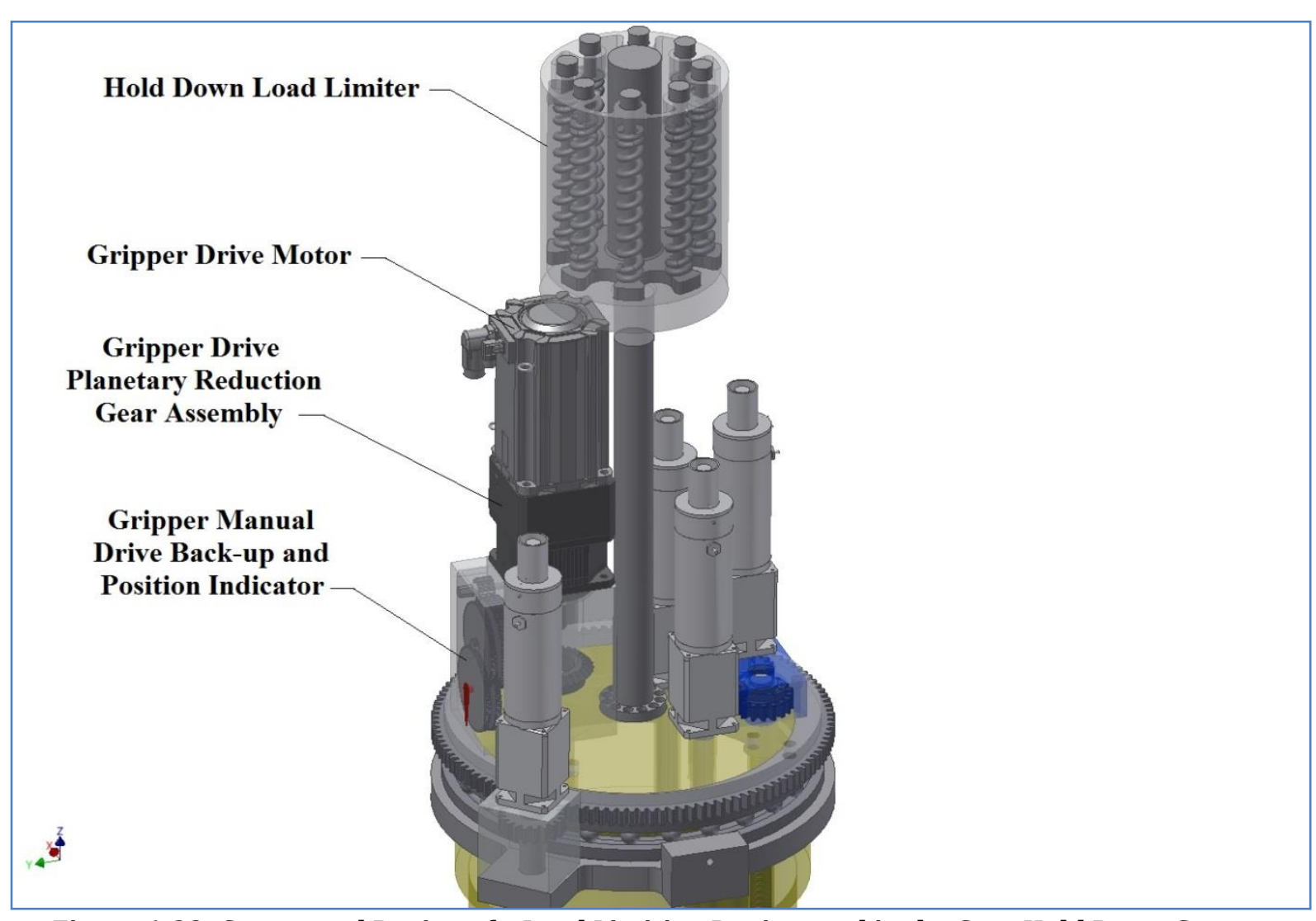

Figure 6-33: Conceptual Design of a Load Limiting Device used in the Core Hold Down System

Preliminary analyses have been performed on the load limiter concept to size an array of supporting springs which are compressed by approximately $10 \mathrm{~mm}$ while supporting the weight of the FHM (Figure 6-34). As the FHM is slowly lowered using the drive motors above the FHM plug, load is gradually transferred from the load limiter to the surrounding core assemblies through the hold down feature on the bottom of the FHM arm.

The load limiter concept uses a circular array of eight compression die springs held inside a pair of welded and machined assemblies to support the weight of the FHM. The springs are compressed $10.6 \mathrm{~mm}$ while supporting the entire weight of the FHM, as load is transferred to the surrounding core assemblies, the springs decompress by $3.8 \mathrm{~mm}$ when $27 \mathrm{kN}$ of the FHM weight is supported by the core.

The die springs are located using an array of slide pins installed through holes in the outer support. The slide pins are threaded into an array of holes in the inner support to secure the die springs in their required positions. Preliminary analyses have been performed to verify the lifetime of the spring design used in the load limiter.

The type of control system parameters (proportional, integral, and derivative controller gains) calculated for each individual drive systems will vary based upon its physical makeup, positional or load accuracy requirements. An example of a basic positioning system with feedback for the core hold down system is shown in Figure 6-35. 


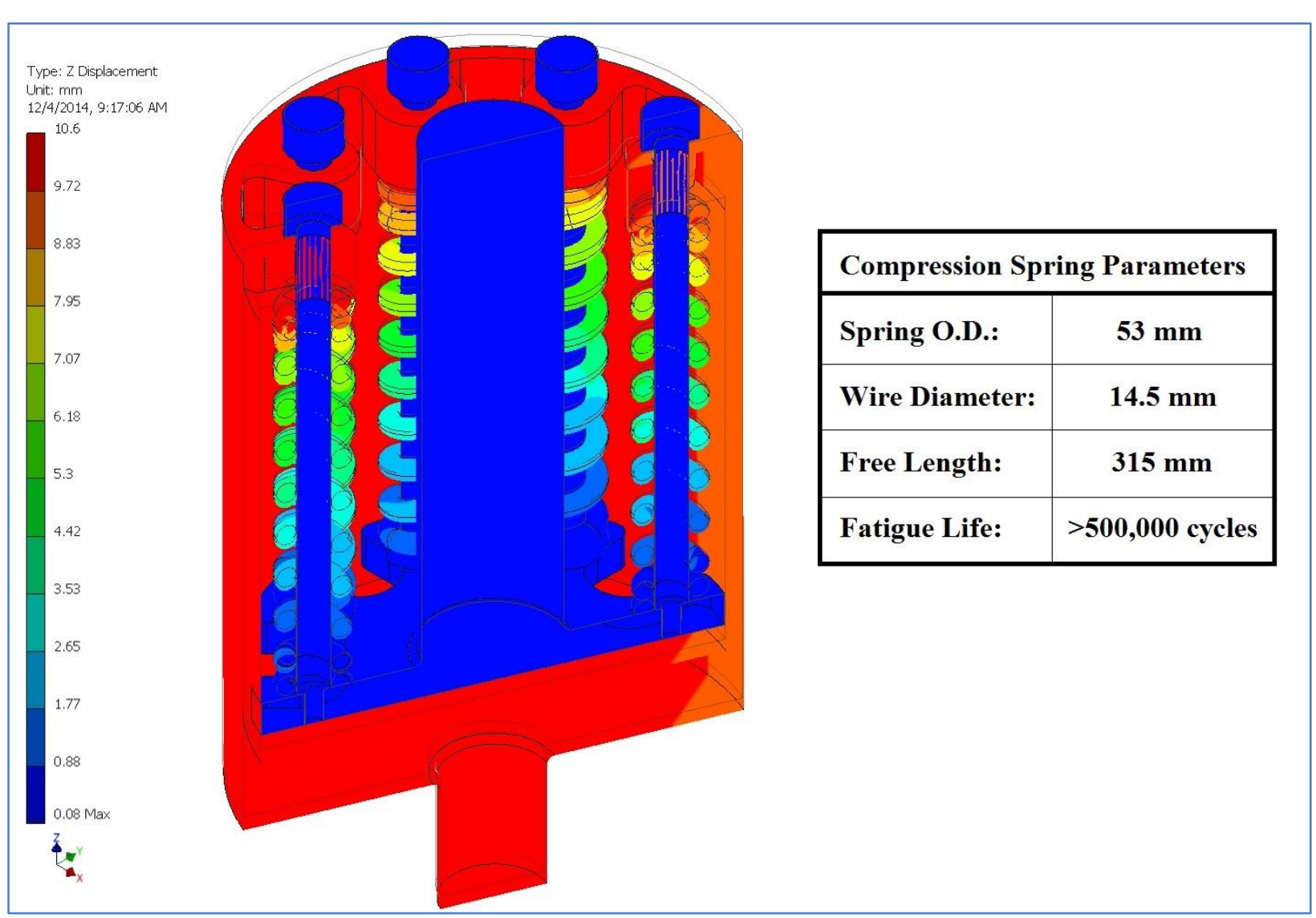

Figure 6-34: Analysis of Conceptual Load Limiting Device for Core Hold Down

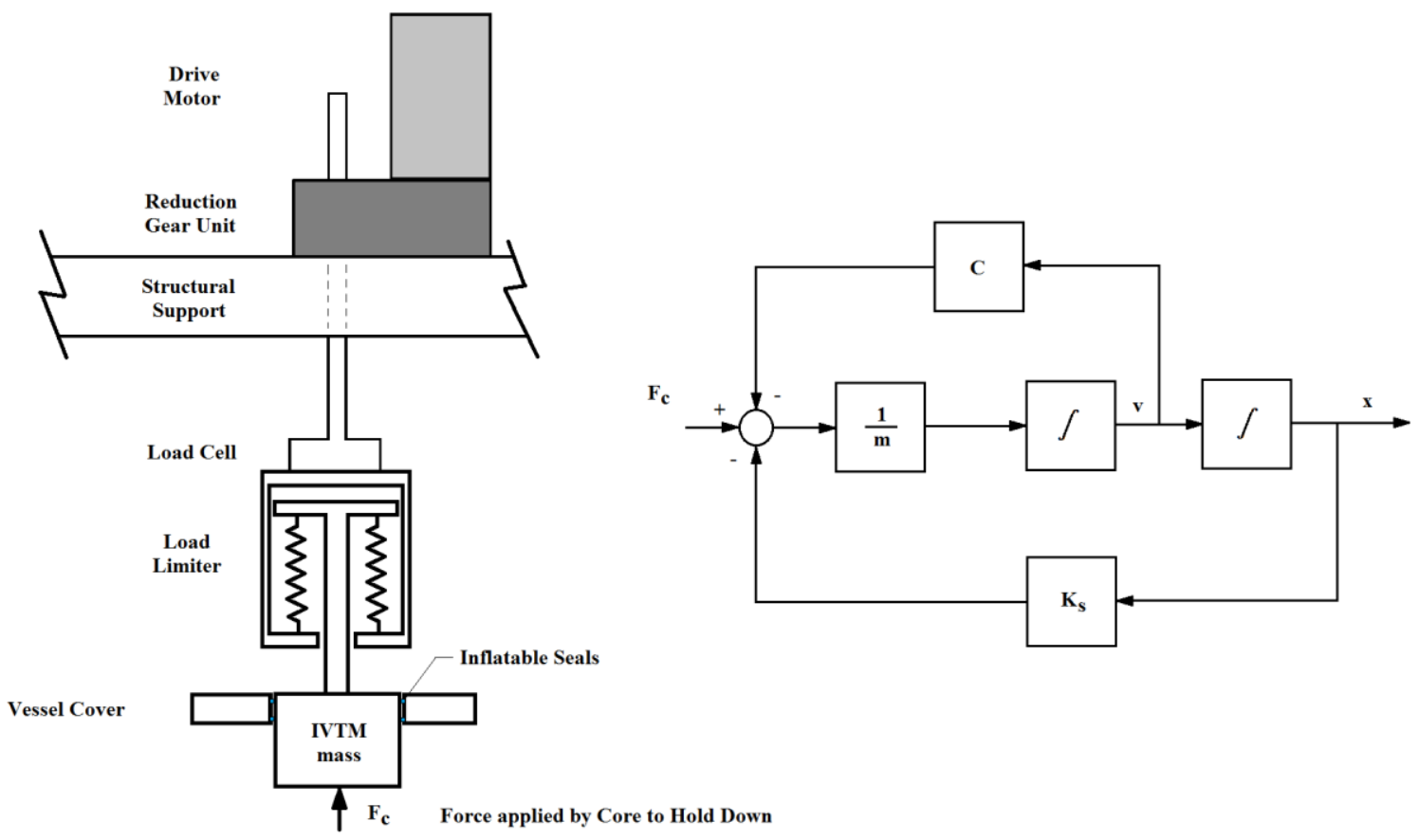

Figure 6-35: General Positioning System with Feedback 
Proportional control schemes use a feedback signal to adjust the controlled parameter in proportion to the error that exists between the measured versus input value. Using a proportional control scheme may allow a constant error to exist between the command input and controlled output variable unless feedforward compensation is used.

PI (Proportional Integral) control schemes uses feedback signals to adjust the controlled parameter by increasing the control signal as long as the error is non-zero to "accelerate the error back to zero" and eliminates the offset error experienced when using only proportional control schemes.

PID (Proportional Integral Derivative) control schemes use feedback signals to additionally adjust the controlled parameter based on the rate at which the controlled parameter error is changing to reduce the error back to zero. PID controllers offer the most robust control strategy and most commercially available motion control computers are designed to operate in this mode. The three gain factors $\left(\mathrm{K}_{\mathrm{P}}, \mathrm{K}_{\mathrm{I}}\right.$ and $\mathrm{K}_{\mathrm{D})}$ for each controlled FHM motion are calculated based upon the physical system design parameters to optimize the system response time, eliminate overshoot and oscillations around the input set point and increase system accuracy. A standard single motion feedback control system block diagram is shown in Figure 6-36, the associated primary, disturbance and error signal transfer functions for the block diagram are shown in Figure 6-37.

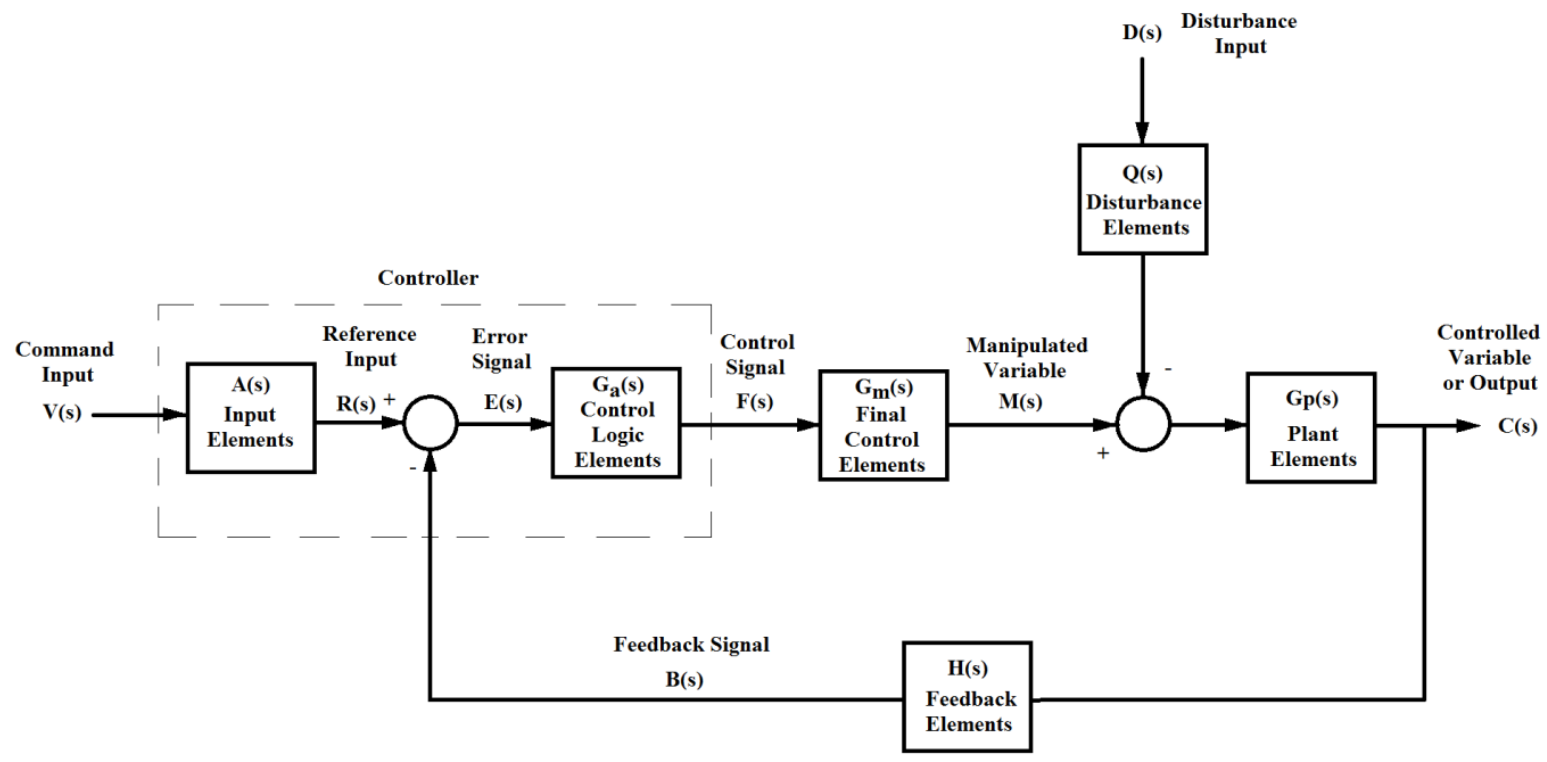

Figure 6-36: General Block Diagram for a Positioning System with Feedback 


$$
\begin{aligned}
\text { Primary Transfer Function: } & \frac{C(s)}{V(s)}=A(s) \frac{G a(s) G m(s) G p(s)}{1+G a(s) G m(s) G p(s) H(s)} \\
\text { Disturbance Transfer Function: } & \frac{C(s)}{D(s)}=-Q(s) \frac{G p(s)}{1+G a(s) G m(s) G p(s) H(s)} \\
\text { Error Signal: } & \text { E(s) }=\frac{A(s) V(s)+G p(s) H(s) Q(s) D(s)}{1+G a(s) G m(s) G p(s) H(s)}
\end{aligned}
$$

Figure 6-37: Transfer Functions for the General Positioning System with Feedback

\subsubsection{Uncertainty and Error in Position}

Errors and uncertainty in the controlled parameters must be considered in the control system design to help determine the actual position tolerance for the components being controlled.

Tolerances in measured positions and forces using various transducers will add to the uncertainty of the controlled parameter. Variations in the reactor environmental temperatures during fuel handling operations will affect the position of the controlled parameter with respect to the drive system input.

As an example, the drive system which raises or lowers the gripper contains gears, circular drive shafts, recirculating ball splines and shafts, ball screws and recirculating ball nuts and roller bearings.

Loads through the drive system will cause elastic deformations in the mechanical components which will cause a relative position error seen from the drive motors. Friction in drive components will cause the retention of a small amount of positional inaccuracy due to retained elastic strains at the controlled component after the driving load is removed.

All of the mechanical components in the drive system have small clearances in their design to allow relative motion. Gears are designed with "backlash" (a radial clearance at the pitch diameter) which provides clearance allowances for thermal expansion etc. during operation. The tolerances of these components at manufacture must be evaluated to determine the total uncertainty in position of the controlled parameter with respect to the position of the drive motor.

Once all of the uncertainties are combined as each physical system dictates, the overall system control parameters and appropriate controller gains may be determined. 


$$
e_{o}=-\left\{K_{P} \times e_{i}+K_{I} \int_{0}^{t} e_{i} d t+K_{D} \frac{d e_{i}}{d t}\right\}-C \frac{d e_{o}}{d t}
$$

The individual motion system response time constant, damping ratio, and natural frequency are the primary measures of transient performance of the dynamic system. By adjusting the gains in the computer controller which operates the particular motion system being driven, the transient response of the particular motion system can be optimized based upon command control inputs.

The control system is able to respond to a user input command from the control panel based upon the calculated controller gains and keep the controlled variable near the set value in spite of externally applied disturbances. Mechanical vibrations are one example of externally applied disturbances which could affect the position of the driven components inside the reactor vessel.

The mechanical components will experience wear during use which will increase the uncertainty in position of the controlled parameters over time. The rates at which the various mechanical components (gears, bearings, recirculating ball screws, recirculating ball splines and universal joints) wear in the liquid sodium environment must be evaluated and understood to allow for proper material selection and system design for fuel handling systems used in liquid metal cooled reactors.

\subsection{Sealing and Insulation}

The proposed seal design used to isolate the cover gas inside the reactor vessel from the environment in the reactor maintenance area uses a pressurized inert gas chamber attached to the top of the vessel cover (in the maintenance area). The welded pressurized gas seal vessel uses a standard blind flange as the base component; it is sealed to the vessel cover using a standard metallic gasket ring to seal against the vessel cover top surface. The blind flange which makes up the base of the vessel has a clearance hole drilled through it to allow the drive shaft to penetrate (without contact). The blind flange, when secured to the top of the vessel cover (using standard bolt pattern) compresses a stack of alternating heat treated inconel 718 Belleville washers and graphite seals (Figure 6-38) which are used in areas which exceed 200 degrees C. The Belleville washers (Figure 6-39) apply a compressive load to the graphite seals which assures a consistent seal between the drive shaft and vessel cover as the seals wear under use. The drive shafts should be highly polished in the region where the seals contact the shaft to reduce wear and shedding of seal material. The top of the inert gas pressurized seal chambers utilizes multiple elastomeric seals between the highly polished shaft surface and the seal chamber. The temperature of the seal chamber and drive shaft in the area of the elastomeric seals can be controlled by changing the length of the seal chamber (and shaft) above the reactor plug.

To reduce the possibility of seal material particles from entering the high temperature liquid coolant, a formed metal ring which has a formed inner edge shaped like a "cup" is attached to the shaft at assembly. The purpose of the formed ring is to catch any seal material particles that separate during operation and fall into the pressure vessel. During normal maintenance periods 
between reactor operation runs, the components may be cleaned and polished, worn components may be replaced and then components are re-assembled to promote trouble free operation.

The pressurized inert gas chamber is a welded assembly consisting of the stainless steel base flange, a piece of standard stainless steel tube (or pipe) and a welded top flange which houses several elastomeric seals. The top flange is machined with features for multiple seals and a pattern of blind holes which are used to secure the retainer for upper seals.

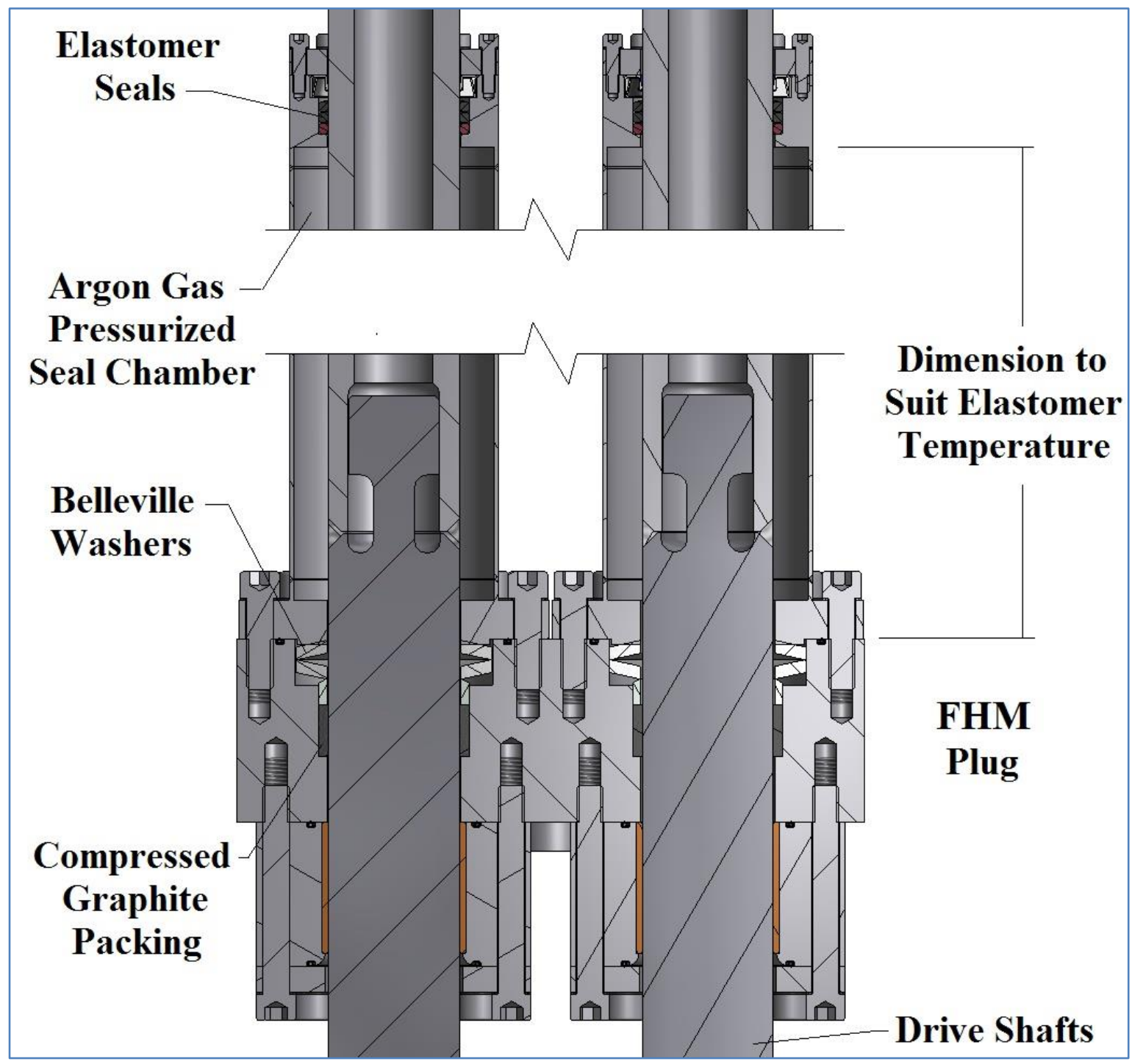

Figure 6-38: Sealing Arrangement for Shaft Penetrations in Reactor Vessel Head 

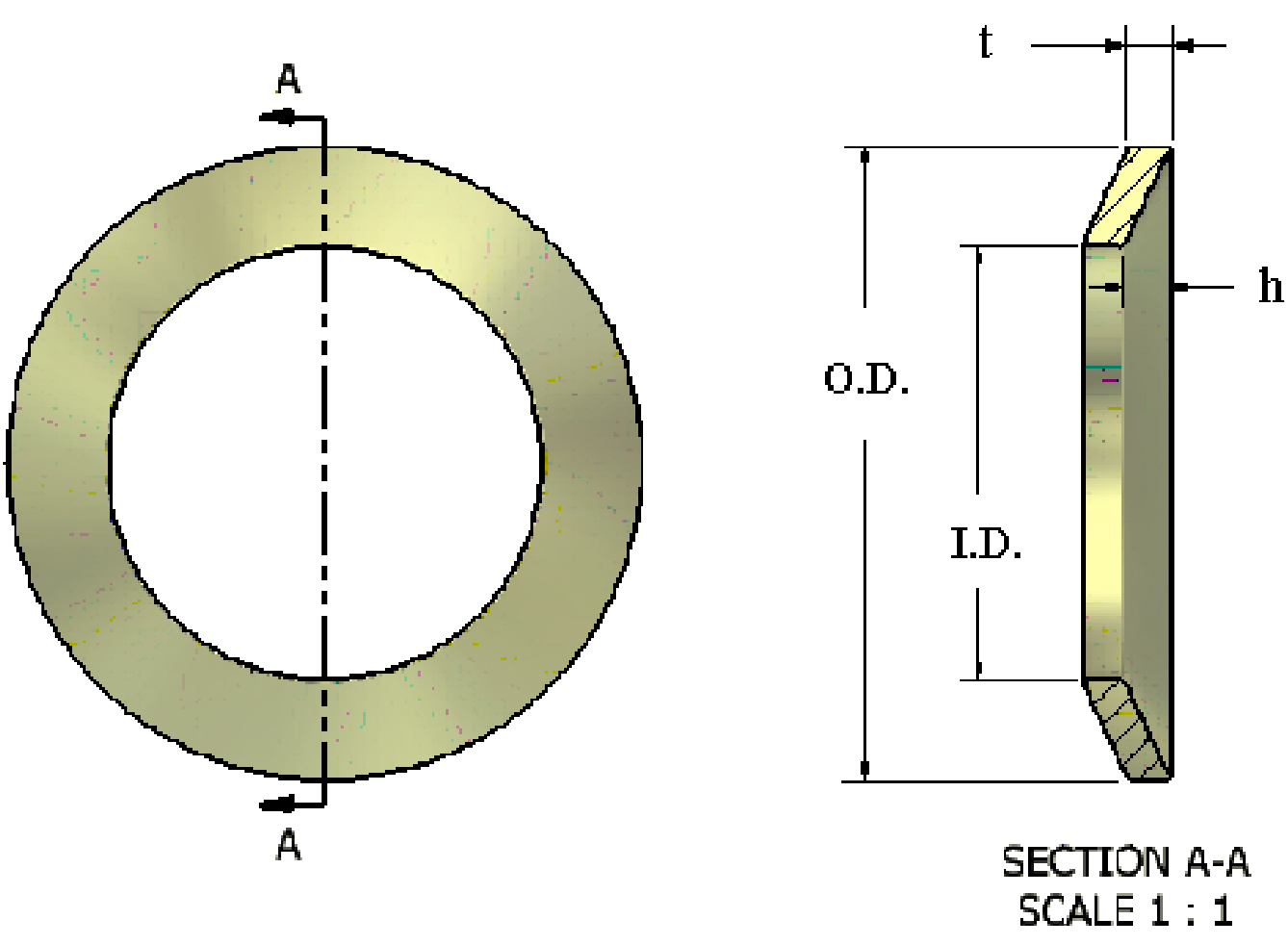

Figure 6-39: Typical Belleville Washer Design Parameters

Insulation of the FHM assembly on top of the vessel cover to limit heat loss into maintenance areas can be accomplished using various appropriate insulating materials and will be specified at a future date.

\subsection{FHM Mockup Test}

There is insufficient test data available which verifies the operation of many of these mechanical components in a high temperature flowing liquid sodium environment. Most of the tests performed to date have been tests of rubbing a pin on a plate under load in a high temperature flowing liquid sodium environment to evaluate self-welding of various material combinations.

A testing program at Argonne National Laboratory (METL - Mechanisms Engineering Testing Laboratory) has been initiated to test various types of mechanical components (bearings, gears, universal joints, etc.) manufactured from various materials under design loading conditions in an elevated temperature flowing liquid sodium environment. These components, tested under actual loading conditions will provide sufficient data for the development of future advanced reactor fuel handling mechanisms. The facility will be available for testing mechanical components for FASTER in the near future.

Experiments performed will be designed to measure:

- Increases in wear rates for mechanical components, 
- Increases in friction between mechanical components,

- Changes to mechanical component alloy (surface and core),

- Changes to component material micro crystal structures,

- Self-welding (galling) evaluation through measurement of component separation force

- Changes to material hardness,

- Corrosion rates of component materials,

- Decreases in fatigue life for materials,

- Increases in creep rates for materials, and

- Additional tests to be defined. 


\section{Ex-Vessel Refueling Operations}

Core assembly handling operations outside of a sodium-cooled fast reactor primary vessel are performed using heavily shielded gas-tight casks which transport the new and spent core assemblies through maintenance areas inside the reactor containment building. The core assemblies must be moved from transfer positions located high inside the reactor vessel, through sealed Fuel Transfer Ports (FTP) - (valves which are located above the reactor head) and into a mobile Ex-Vessel Transfer Machine (EVTM). The EVTM is used to move the core assemblies between the fuel transfer ports (and interim decay storage vessel or core conditioning station - if applicable) and a transfer tunnel which houses an Inter Building Cask (IBC) used to transfer the core assemblies out of the reactor containment building.

Spent fuel assemblies which have been stored inside the reactor vessel for up to a year (to provide a reduction in decay heat generated to a maximum of approximately 2 kilowatts per assembly) are capable of being handled by the EVTM. The spent fuel assemblies will also be coated with a thin film of liquid sodium which would react if exposed to air, so an inert gas (argon) must be used to isolate the core assemblies during transfer operations and prevent ingress of air into the reactor vessel. Personnel working in maintenance areas inside the reactor containment building must be protected from excessive radiation exposure levels (to ensure doses are as low as reasonably achievable) using shielding throughout all fuel handling operations.

The Ex Vessel Transfer Machine for FASTER is used to insert new (or remove spent) core assemblies (between one of the three fuel transfer positions inside the reactor vessel), instrumented assemblies, and closed loop assemblies (from their fixed positions in the reactor vessel head) (Figure 7-1) into the interim storage vessel or a core component conditioning station (if applicable). The largest component to be handled is the closed loop assembly. The closed loop assembly is disconnected above the reactor vessel cover when it is to be replaced. The height of the section of the closed loop assembly to be removed using the EVTM is equal to the height of the section above the vessel cover plus the distance from the top of the vessel cover to the bottom of the closed loop assembly inside the reactor vessel inlet plenum. 


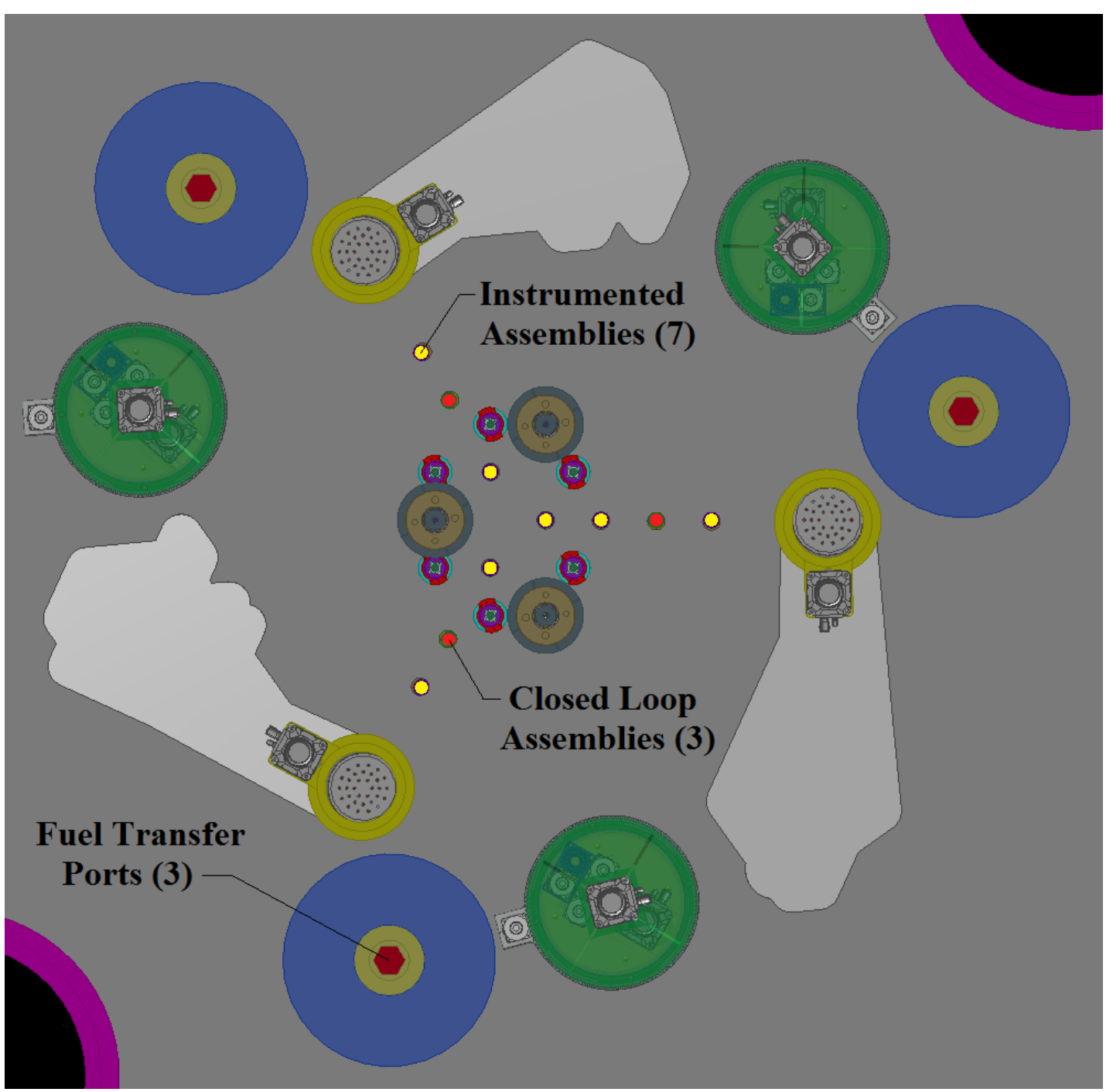

Figure 7-1: Instrumented, Closed Loop Assemblies, and Fuel Transfer Positions in Reactor Head

\subsection{Functions}

The ex-vessel transfer machine for the FASTER shall provide the capability to handle routinely removable core components by:

- Preheating non-irradiated core component that are destined for insertion into the reactor vessel.

- Transfer non-irradiated core components between the inter-building cask loading station and the fuel transfer port (and Interim Decay Storage Tank (IDS) or Conditioning Station).

- Transfer bare, irradiated and decayed fuel assemblies between fuel transfer port and the inter-building cask (and IDS or Conditioning Station).

- Transfer bare, irradiated non-fueled core components between fuel transfer port and the inter-building cask (and IDS or Conditioning Station). 


\subsection{Overall Requirements for the FASTER EVTM}

\subsubsection{Process Requirements}

The EVTM shall perform the functions of the above section while participating in the FASTER reactor refueling task. Each year about 55-60 core components will be handled by the EVTM. The EVTM shall provide the following features:

- Self-propelled electro-mechanical carriage

- Shielded cask to minimize personnel radiation exposure

- Provide argon gas blanket in a leak tight vessel

- Thermally monitored and controlled environment inside vessel

- Preheat new core assemblies with flowing argon gas before insertion into reactor

- Active cooling of spent core assemblies

- Ability to handle bowed core assemblies

- Moves on linear guide rails between FTP and IBC

- Accurately aligns to FTP and IBC using alignment pins

- Rotating plug port at bottom of the shielded vessel

- Seals to FTP and IBC

- Battery back-up provides temporary power to cooling and drive systems

- Molecular sieve and vapor filter removes contaminants from argon gas

- Scrapers clean ports during operation

- Provides argon gas purge to remove liquid sodium from spent core assemblies

- Safety interlocks prevent unintended system component operation

- Control panel which indicates status of all system components

\subsubsection{Mechanical Requirements}

The EVTM shall meet the following mechanical design requirements:

1. Protect and preserve the integrity of core components and experimental data (if necessary) during handling and transfer operations.

2. The EVTM gripper shall:

- Provide normal gripper operating capacities of $680 \mathrm{~kg}$ [TBD - 1,500lbs] pull and about [TBD] $\mathrm{kg}$ push .

- Provide an emergency pull capability of [TBD] $\mathrm{kg}$.

3. The EVTM cask interior cavity pressure shall be controlled in a manner that is compatible with the interfacing argon systems while mated to the transfer port. 
4. The EVTM cask shall have the capability of catching, storing, and discharging dripping sodium as a routine operation.

5. Guide pins or similar devices shall be provided to facilitate precise alignment between fuel transfer port and IVTM and IBC and IVTM.

6. The materials of construction in the EVTM shall not react chemically or galvanically with each other, or with components handled by the EVTM.

\subsubsection{Structural Requirements}

The EVTM cask shall have the structural integrity to:

- Be removed from the carriage by use of the facility crane.

- Withstand a free drop of [TBD] meters onto a surface which shall be designed to protect against the loss of shielding and containment integrity.

- Withstand a free drop of [TBD] $\mathrm{cm}$ onto the containment floor without the loss of shielding or containment integrity.

- Withstand and transmit tornado loads (if applicable) into the carriage.

- Withstand and transmit seismic loads from the EVTM cask to the carriage and/or transfer port.

The carriage assembly shall have the structural capability to:

- Support the EVTM cask and control system during core component operations

- Withstand and transmit tornado loads into the facility floor through the outriggers and wheels.

- Withstand and transmit seismic loads in the facility floor through outriggers and wheels.

\subsubsection{Thermal Requirements}

The EVTM shall provide temperature control of the contained core components to the following limits:

- Remove $2 \mathrm{~kW}$ [TBD] of decay heat from [TBD] day decay cycle during normal handling operations while keeping the fuel pin cladding temperature below $[\mathrm{TBD}]^{\circ} \mathrm{C}$.

- Keep the cladding temperature of heat producing core components below [TBD] ${ }^{\circ} \mathrm{C}$ during emergency conditions.

- Maintain the preheat temperature on non-irradiated core components while transferring them to the in-vessel storage location.

- Limit the peak fuel pin temperature of bare fuel assemblies being transferred into the IBC to a $[\mathrm{TBD}]{ }^{\circ} \mathrm{C}$ thermal shock differential. 


\subsubsection{Tornado Requirements (reserved)}

\subsubsection{Seismic Requirements}

The EVTM shall be designed in accordance with seismic criteria as defined in [TBD] and FASTER structural response curves for seismic design of FASTER equipment, as follows:

- The EVTM shall be classified as a Seismic Category I item.

- The EVTM shall not damage other FASTER equipment which must meet Category I seismic requirements during:

i. In-transit operations with the cask closure valve shut.

ii. Non-transit fuel transfer operations between the EVTM and floor stations with cask closure valve open.

\subsubsection{Radiation Requirements}

- The EVTM pressure retaining boundary shall be designed to prevent the release of radioactivity in excess of the limits specified in [TBD].

- The EVTM shielding shall be design to reduce radiation levels to $2 \mathrm{mr} /$ hour at the cask surface, and $20 \mathrm{mr} /$ hour at the bottom of the cask closure valve and $200 \mathrm{mr} /$ hour streaming during transfer through the mating fuel transfer port.

- The EVTM pressure retaining boundary and shielding design shall be based on holding the following core components:

- As a minimum, a $2 \mathrm{~kW}$ (or TBD) decay-heat driver fuel assembly with the following gamma ray and neutron source strength:

- As a minimum, an irradiated reflector assembly with [TBD] day cobalt activity levels as shown in \#.

\subsubsection{Safety Requirements}

The EVTM shall meet the following safety requirements:

- The EVTM shall be designed to be returned to a safe state should any system or component failure occur.

- Redundant or backup systems shall be provided such that accident sensing devices shall remain functional under accident conditions.

- Manually initiated EVTM functions shall be interlocked to prevent simultaneous actions which would result in major operational interferences, except during override operations.

- Redundant internal gas circulation systems shall be provided to meet the operating temperature limits when handling $2 \mathrm{~kW}$ core components. These systems shall be limited to compressed argon gas bottles and a redundant argon pump/motor with associated piping and controls. 
- The integrity of the cask pressure retaining boundary shall be maintained by pressurizing between the seals as each separable surface with clean argon as the buffer gas.

- The EVTM braking system design shall assure that the physical integrity of the cask contents is maintained during stops.

- The status of each EVTM subsystem shall be monitored and an alarm shall sound if any critical parameter exceeds the safe operations level.

- An alarm shall indicate off-normal condition upon initiation of improper operating sequence by unlocking override panel.

- Emergency power shall be supplied to the EVTM through its power cable and facility floor outlet from the facility diesel electrical bus. The required emergency power level shall be that required to reestablish and maintain safe EVTM conditions. Battery backup power may also be provided as necessary.

- Noncombustible and fire resistant material shall be used where practical. Sodium contact with nonmetallic items (insulation, electrical equipment) shall be prevented by proper design. Firefighting equipment shall be supplied.

- EVTM braking system and rail stops shall ensure physical protection of plant personnel and equipment.

- Visual and audible annunciators and key lockouts shall be provided on access to all control system override control panels.

- Manual override features shall be incorporated in the EVTM to permit electrical or mechanical override if malfunctions occur. Selection of the override mode shall be based on providing the capability of continuing normal operations or to return to stabilized safe conditions.

- Single component failure that will result in subsequent damage to core components shall be minimized by design to maximum extent possible.

\subsubsection{Design Life - reserved}

\subsubsection{Maintenance - reserved}

\subsubsection{Instrumentation and Controls - reserved}

\subsubsection{Interface Requirements}

Facility Interfaces:

- The EVTM shall be designed to be disassembled into components sized for transfer through the equipment airlock.

- During normal operations, the EVTM shall interface with the following system and components:

- The Inter-Building Cask Station,

- The EVTM cask interface seal to the fuel transfer port,

- The carriage wheels to the fuel transfer port/EVTM rail clearances, 
- The EVTM cask cavity alignment with the fuel transfer port,

- The EVTM control system with the fuel transfer port power and control, communications, and operational interlocks,

- The EVTM control system with the building floor receptacles for EVTM electrical power, and

- The EVTM argon gas hoses with the fuel transfer port for radioactive argon exhaust and clean argon supply.

- The EVTM carriage shall position the cask vertically by means of the cask elevator for the following conditions:

- To clear the fuel transfer port upon approaching the transfer port station,

- To align/seal the cask to the fuel transfer port at the transfer station, and

- To facilitate drip pan and gripper change out at the drip pan/gripper change station.

- The cask shall interface with the internal atmospheres of the fuel transfer port and the inter-building cask.

- The EVTM cask shall interface with the overhead crane in the Reactor Containment Building.

- The EVTM shall be designed to operate on a standard rail system. The line, grade, and parallelism of the rails shall be within the following tolerances: TBD

The following FASTER systems interface with the EVTM:

- Building electrical power,

- Communications,

- Reactor Containment Building,

- Service piping,

- Heating and Ventilation,

- Plant Fire Protection,

- Reactor Vessel,

- Reactor Refueling System,

- Maintenance System, and

- Argon gas supply and processing system.

\subsubsection{Equipment Interfaces}

The following equipment interfaces have been identified:

- The EVTM gripper shall interface with the:

- Fueled core assembly,

- Reflector assembly,

- Shield assembly, 
○ Control rod assembly, and

- Instrumented core assembly.

- The EVTM gripper shall be capable of removing a core component (with up to a $\sim 2.54 \mathrm{~cm}$ (or TBD) bow) from the in-vessel transfer station through the fuel transfer port.

- The EVTM shall be capable of depositing and removing core components from the following locations:

- In-vessel fuel transfer station and

- Inter-building cask transfer station.

- The EVTM gripper shall be designed to no bind with the inner surfaces of the core component while gripping or releasing a core component.

\subsubsection{Handling Interfaces}

The following handling interface requirements have been identified:

- The core components shall have a handling interface compatible with the EVTM gripper.

- The EVTM cask shall include lifting devices to facilitate handling by the overhead crane.

- The design features of handling equipment such as lifting fixtures, bails, alignment devices, and connects to facilitate radioactive maintenance shall be coordinated with the design of similar features and other reactor refueling system items.

- EVTM components shall be provided with features to facilitate lifting and positioning with a minimum of personnel contact. Pick-up points shall be located so as to distribute the supporting force uniformly to hold the module in the desired attitude for assembly. Preference shall be given to permanently installed lifting bails over the use of removable bails and fixed eye or trunnion type pick-up points.

The FASTER EVTM consists of a shielded cask with a core assembly gripper and associated drive system, inert gas cooling system designed for 2,000 watts of heat removal, an inert gas purification system, and battery back-up system which are mounted on an electromechanically propelled carriage. The EVTM operates on an " $x-y$ " frame and track structure (Figure 7-2) which can accurately and repeatedly position the shielded cask centerline over any of the fuel transfer port centerlines (3), the closed loop positions (3), the fixed instrumented assembly positions (7), the inter-building transfer cask port, the interim decay storage vessel transfer port centerline, or the core conditioning station transfer port centerline (if applicable). The EVTM cask positioning system will be computer controlled using servo motors with feedback sensors and appropriate safety interlocks. The EVTM will have a battery back-up system in case of the loss of offsite power. The " $x-y$ " carriage may also be manually operated using hand cranks attached to the drive motors in case of an extended loss of off-site power. 


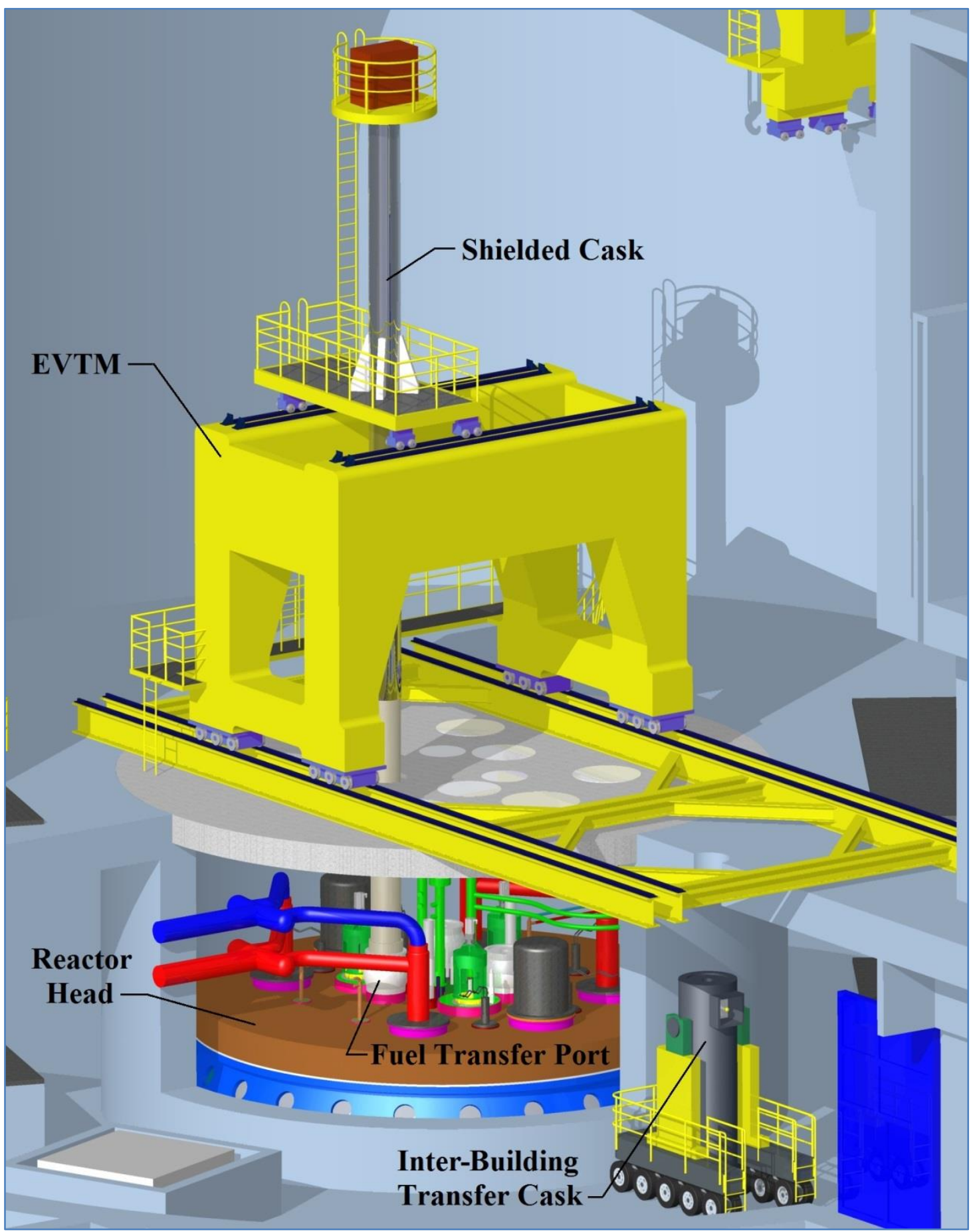

Figure 7-2: Preliminary layout of the EVTM in position over a Fuel Transfer Port

The FASTER EVTM shielded cask is adequately shielded to safely handle core assemblies with radiation levels up to $10^{6} \mathrm{R}$ measured at a distance of 12 inches from the sub-assembly. Purified (and thermally controlled) argon is passed through the inside of the shielded cask from the top to control the temperature of the component being transported. The argon gas is vented through the bottom of the cask and returned to the purification system. The EVTM uses a molecular sieve and vapor filter which utilizes a two stage filtration process which accepts contaminated gas from the 
shielded cask and passes it through a 304 stainless steel knitted wire mesh to remove sodium vapor and droplets by a cold trapping process. The still contaminated gas is then passed through a second filter stage which consists of a packed bed of $1 / 8$ " diameter sodium alumino-silicate pellets which removes the sodium and fission product gasses which are entrained in the argon gas.

The EVTM raises or lowers the shielded cask to seal and engages mechanical interlocks to any of the transfer ports listed above. The EVTM purges any trapped volume of air with inert gas before the EVTM cask or transfer port valves are opened. Core assemblies are transferred using a "sodium pot (as appropriate)" which is transferred to or from the EVTM cask using various mechanisms inside the reactor vessel and EVTM cask. Transfer port valves and EVTM cask valves are then closed and any trapped volume of cover gas in the space between the EVTM and transfer port valves is collected, filtered and stored in a shielded decay storage tank. The EVTM cask is raised and the cask is repositioned over the target port using the " $x-y$ " frame and track structure and the process is repeated until fuel handling operations are completed.

As the reactor has three fuel handling machines, the EVTM can utilize the three fuel transfer ports successively while the fuel handling machines inside the reactor vessel are transferring new core assemblies from the sodium pots and replacing them with spent core assemblies before removal by the EVTM. This design allows continuous operation of the fuel handling system while minimizing wait time.

\subsection{Fuel Transfer Ports}

The fuel transfer ports for FASTER will be designed to align and provide a gas tight seal to the bottom surface of the EVTM shielded cask. An auxiliary shield ring on the EVTM cask will be used to shield around the connection to the fuel transfer port to prevent radiation streaming as an activated core assembly is passed through the connection region.

The fuel transfer port valve is attached to the top of the primary vessel cover and incorporates a hole which is sized to allow any core assembly and the EVTM gripper to pass through. The fuel transfer ports for FASTER will be computer controlled using servo motors with feedback sensors and appropriate safety interlocks. Battery back-up drive systems will be incorporated in the event of power disruption. The valve is operated by rotating 90 degrees to either open or close. The valve consists of a shielded cylindrical weldment which fits inside a split lead shielded support assembly and uses roller bearings between its stub shafts and the fixed supports in the bearing housing. The valve is located above the biological shield on top of the vessel cover and incorporates argon gas purge lines which are used to permit the flow of purified argon purge gas during the subassembly heating cycles. Exhaust of argon gas is sent through the cover gas cleanup system nozzle of the primary vessel.

A manual back-up drive system is incorporated in the design in case of an extended loss of offsite power. When not in use, a protective shielded plug is inserted onto the top of the valve body to protect the fuel unloading machine sealing surface.

The FASTER fuel transfer port will utilize a solenoid operated mechanical interlock system which uses index pins to ensure the valve is in the proper orientation (open or closed positions). 
The valve operation is coordinated using the fuel handling control system: a signal from the control system energizes a solenoid (which withdraws the indexing pin) and allows actuation of the fuel transfer port valve. A manual release for the indexing pin is incorporated in the interlock system design. A pair of limit switches is used to indicate whether the valve is in the open or closed positions. A second pair of limit switches is used on the valve housing for redundancy. Another interlock prevents lifting of the EVTM cask until both of the valves are closed and locked conditions are met through the control system.

A six bladed (spaced at 60 degrees) scraper tool will be incorporated into the EVTM gripper to clean the hex shaped opening in the gripper guide tube. The purpose of the tool is to remove the build-up of any sodium frost on the guide tube inner surface before components are removed.

When replacement of silicone rubber O-ring seals in the fuel transfer port is required, a Lucite glovebox (which seals to the vessel cover) is placed over the top of the fuel transfer port housing and purged with argon. The valve is then opened and a shield plug is installed in the transfer tube. The upper valve seat is then removed for replacement of the seals.

\subsection{Inter-Building Transfer Cask Design Requirements}

The following requirements have been identified for the inter-building transfer cask:

- Use of shielded coffin to minimize personnel radiation exposure,

- Mate and precisely align with EVTM,

- Provide leak tight sealing to maintain argon gas blanket,

- Monitor temperatures and provide active cooling of spent core assemblies (2 kilowatts decay heat per core assembly) using the cooling system,

- A battery backup for temporary cooling system operation shall be included,

- Argon shall be filtered and purified using the gas cooling system, and

- Ability to connect to the wash station for excess sodium coating removal. 


\section{Sodium Purification Systems}

This section provides a description of the sodium purification systems that will be utilized in FASTER. Section 8.1 describes the primary sodium purification system (PSPS). The secondary purification system is described in Section 8.2.

\subsection{Primary Sodium Purification System}

The primary sodium purification system (PSPS) provides continuous purification of the primary sodium and consists of the following loops: 1) primary sodium recirculating loop - cold trapping loop, 2) sodium-potassium alloy (NaK) loop, and 3) silicone loop.

The purification system provides control of impurity concentrations of sodium hydride, sodium monoxide, cesium, and possible other fission products at temperatures just above the melting point of sodium. The control of impurities in sodium is required to lessen the corrosion rate of reactor vessel, piping, and materials since sodium impurities could cause metal surface removal (which could affect the load-carrying capability of reactor materials), fouling of heat- transfer surfaces through surface deposits, and reduced mechanical properties of materials caused by changes in base alloy composition.

Major components of the sodium purification system are the primary sodium purification plug containing the sodium suction and return lines, sodium surge tank, electromagnetic pump, nuclide trap, cold trap (an economizer and crystallizer tank), a NaK loop, and a silicone loop.

The nuclide trap is designed to trap Cs-137 and possibly other fission products from the incoming sodium, upstream of the cold trap. The nuclide trap consists of a type 304 stainless steel cylinder that contains reticulated vitreous carbon, a very porous, low-density carbon filter material, to adsorb fission products. Depending upon shielding design, the trap can contain a significant curie count of Cs-137. A second filter mounted inside the cylinder contains a sintered stainless steel filter to prevent any of the carbon material from being carried out of the nuclide trap and into the main sodium coolant.

The cold trap consists of a regenerative heat exchanger to minimize overall heat losses and a crystallizer tank to cold trap the sodium impurities. The heat exchanger is on the wall near the crystallizer within the shielded cell. The regenerative heat exchanger is intended to reduce the heat losses resulting from cooling the primary sodium from $355^{\circ} \mathrm{C}$ down to cold-trapping temperatures. It is also intended to heat up the purified sodium from the cold trap to approximately bulk sodium temperature for return to the primary tank. The sodium crystallizer tank removes the sodium oxide and other impurities from the primary sodium through precipitation on wire-mesh cylinders and in stilling baffles. It is cooled by the $\mathrm{NaK}$ loop.

\subsubsection{PSPS Performance Requirements}

The above background was provided as a basis for developing preliminary performance specifications for the FASTER PSPS. As noted, under steady state operating conditions the PSPS should be functionally capable of maintaining the sodium plugging temperature (as measured with a plugging meter) at $\leq 150^{\circ} \mathrm{C}$. Under these conditions, there will be no material compatibility issues with austenitic stainless steels comprising the primary heat transport system. Consistent 
with this specification, the practical limits on oxygen and hydrogen levels in the primary sodium loop are set at $2.5 \mathrm{ppm}$ and $0.2 \mathrm{ppm}$, respectively.

Regarding the overall capacity of the PSPS cold trapping system to remove impurities, the estimated cumulative amount of oxygen and hydrogen (in the form of $\mathrm{Na}_{2} \mathrm{O}$ and $\mathrm{NaH}$ ) introduced into the primary system over the design plant lifetime of 30 years is summarized in Table 8-1. The same information is shown graphically in Figure 8-1. The technical bases for these estimates are also summarized in Table 8-2. As indicated, the design basis total oxide mass to remove from the primary sodium over the plant lifetime amounts to $1050 \mathrm{~kg} \mathrm{Na}_{2} \mathrm{O}$ (equivalent to $271.1 \mathrm{~kg}$ of oxygen), whereas the total hydride mass is $520.2 \mathrm{~kg} \mathrm{NaH}$ (equivalent to $21.7 \mathrm{~kg}$ hydrogen). Note that these estimates cover removal of the initial impurities present in the sodium received on site, as well as that expected to accumulate as a result of annual refueling operations assuming 55 assembly replacements per year [19]. The estimates do not include any impurities that may be introduced by off-normal operating conditions such as pump lubricant leakage or accident air ingress into the system as well as any test activity involved in the operation.

Table 8-1: Cold Trap Oxygen-0xide Removal Requirements from Primary Sodium Integrated Over the Plant Lifetime

\begin{tabular}{|c|c|c|c|c|}
\hline $\begin{array}{c}\text { Time from } \\
\text { Reactor } \\
\text { Startup } \\
\text { (years) }\end{array}$ & $\begin{array}{c}\mathrm{Na}_{2} \mathrm{O} \\
\text { Mass (kg) }\end{array}$ & $\begin{array}{c}\mathrm{NaH} \\
\text { Mass }(\mathbf{k g})\end{array}$ & $\begin{array}{c}\text { Total }\left(\mathrm{Na}_{2} \mathrm{O}-\right. \\
\mathrm{NaH}) \text { Mass }(\mathrm{kg})\end{array}$ & Technical Basis/Rationale \\
\hline 0 & 167.8 & 129.9 & 297.7 & $\begin{array}{l}\text { Equivalent to the oxygen mass in } 534 \mathrm{MT} \\
\text { of sodium inventory at a initial level of } 50 \\
\text { ppm, plus conservatively estimated initial } \\
\text { hydrogen content from the surface of the } \\
\text { system (assuming the oxygen arises from } \\
\mathrm{H}_{2} \mathrm{O} \text { on the surface). }\end{array}$ \\
\hline 10 & 462.0 & 260.0 & 722 & $\begin{array}{l}\text { Assumes } 55 \text { fuel assembly replacements } \\
\text { per year [5], each leading to } 138 \mathrm{~g} \text { of }\end{array}$ \\
\hline 30 & 1,050 & 520 & 1,570 & $\begin{array}{l}\text { oxygen and } 9.9 \mathrm{~g} \text { of hydrogen ingress; see } \\
\text { Table } 8-2 \text {. }\end{array}$ \\
\hline
\end{tabular}

Table 8-2: EBR-II Primary Sodium Steady-State Impurity Levels at Full Power (62.5 MW $\mathrm{MW}_{\text {th }}$ [20]

\begin{tabular}{lc}
\hline Impurity & Level \\
\hline Oxygen & $1.2 \mathrm{ppm}$ \\
Hydrogen & $80 \mathrm{ppb}$ \\
Tritium & $3.0 \mathrm{kBq} / \mathrm{g}$ \\
\hline
\end{tabular}

The above discussion provides the principle specifications for the PSPS. However, it is also necessary to quantify the impurity levels and reduction rates for a few key operational periods. The first deals with initial plant startup. As noted in Table 8-1, an initial oxygen concentration of $50 \mathrm{ppm}$ in the primary sodium inventory is assumed plus estimated initial hydrogen content from the surface of the system as a preliminary design basis for the FASTER PSPS. On this basis, the design maximum sodium flowrate through the FASTER PSPS is set at $492 \mathrm{lpm}$, Given the primary sodium volume of $655 \mathrm{~m}^{3}$, analysis indicates that with a cold trapping efficiency of 50\%, 
then it would take approximately $<240$ hours (or 10 days) of PSPS operations to reduce the oxygen concentration in the primary sodium to the $2.5 \mathrm{ppm}$.

CT Operating Time vs. Trap Impurity Mass

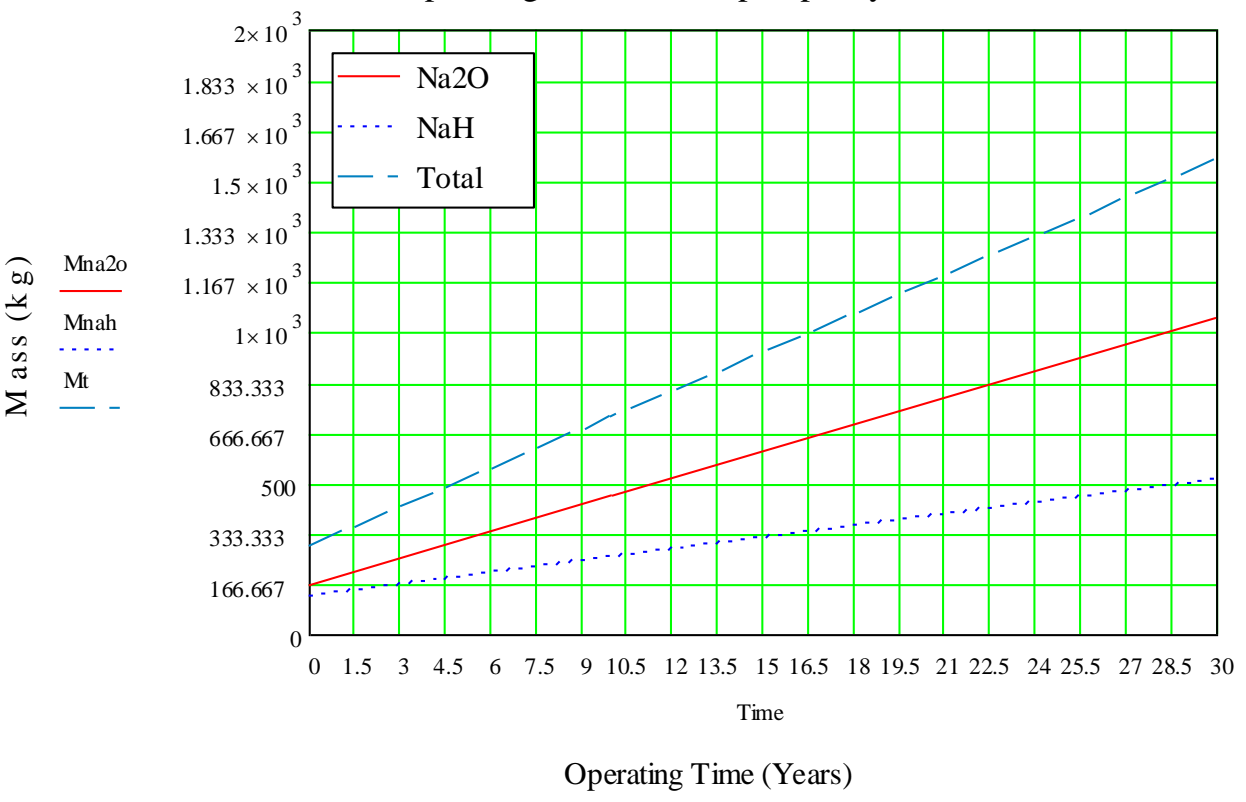

Figure 8-1: Estimate Oxide-Hydride Deposition in the Primary Sodium to be Removed by the PSPS Over the Plant Lifetime

The other operational period in which oxygen concentration is expected to increase is during fuel handling. Assuming an upper bound of 55 fuel handling operations per year [19], then from Table 8-1 the conservative estimate of oxygen ingress is $7.59 \mathrm{~kg}$ during this stage. Under the same assumption regarding cold trap efficiency and using system flowrate of $227 \mathrm{lpm}$, then it also would take less than total of 10 days to reduce the oxygen concentration in the primary system back below $2.5 \mathrm{ppm}$. This time scale is not expected to impact or limit reactor restart following refueling operations.

The final preliminary specification on the PSPS required to carry out a pre-conceptual design is the capacity of the fission product nuclide trap. The expected average cesium deposition in the primary sodium is provided in Table 8-3.

Table 8-3: Cesium-134 and -137 Deposition in Primary Sodium per Fuel Pin Failure [21] [22]

\begin{tabular}{lcc}
\hline Isotope & Activity, $\mathbf{C i}$ & $\mathbf{t}_{\mathbf{1 / 2}}, \mathbf{\text { years }}$ \\
\hline Cs -134 & 32.5 & 2.06 \\
Cs -137 & 60.4 & 30.17 \\
Total & 92.6 & $\mathrm{n} / \mathrm{a}$ \\
\hline
\end{tabular}

As noted, up to $92.6 \mathrm{Ci}$ of $\mathrm{Cs}-134$ and $\mathrm{Cs}-137$ could be deposited as a result of a fuel pin failure. However, the operational experience from EBR-II indicates that for metallic fuel, unintended pin failures are extremely rare. In lieu of a specification on the expected fuel pin failure rate, it is assumed that up to 48 pins could fail over the plant lifetime (This assumption is based on the 
world-wide fast reactor operating experience that indicates a nominal pin failure rate of 1 pin/year. Therefore, there are 30 pin failures per thirty (30) years of plant life time. Also by considering the design margin of 18 pin failures for plant life due to testing, this will give 48 pin failures). This would require a total nuclide trapping capacity of $\sim 4,445 \mathrm{Ci}$ for cesium). As background, the EBR-II fission product trap was designed for up to 10 pin failures (i.e., $500 \mathrm{Ci}$ capacity). Also note that fuel pins were deliberately failed in EBR-II as part of the RBCB program. The choice of 2,230 $\mathrm{Ci}$ as the design basis for the FASTER nuclide trap assumes a scaling up of the EBR-II nuclide trap design by a factor of 4.5, which is less than the approximate scaling up factor of 6 based on power level between the two plants. The nuclide trap is designed to be replaceable. With this provision, the 2,230 $\mathrm{Ci}$ nuclide trap has a 15 year design lifetime. The trap thus provides extensive fission product retention capability, as well as the flexibility to cover unforeseen events that may lead to additional pin failures over the course of the plant lifetime (i.e. the trap can be replaced).

The operational data for EBR-II indicates that with a well-designed nuclide trap [23], the cesium level in the primary sodium will be reduced back down to equilibrium levels after approximately four passes through the trap, which given the preliminary PSPS design flowrate of $0.49 \mathrm{~m}^{3} / \mathrm{min}$, would be less than 4 days.

Based on the above discussion, a summary of high level performance requirements for the FASTER PSPS are provided in Table 8-4. 
Table 8-4: Summary of High Level FASTER PSPS Performance Requirements

\begin{tabular}{|c|c|c|c|}
\hline No. & Specification & Functional Requirement & Basis/Approach \\
\hline 1 & $\begin{array}{l}\text { Purify sodium after installation in } \\
\text { the reactor vessel in a timely } \\
\text { manner so as not to impede plant } \\
\text { operations or degrade SSCs. }\end{array}$ & $\begin{array}{l}\text { Reduce sodium plugging } \\
\text { temperature in as-received } \\
\text { sodium to } \leq 150^{\circ} \mathrm{C} \text { within } \\
10 \text { days. }\end{array}$ & $\begin{array}{l}\text { Equivalent to the oxygen mass in } 534 \mathrm{MT} \\
\text { of sodium inventory at an initial level of } 50 \\
\text { ppm, plus conservatively estimated initial } \\
\text { hydrogen content from the surface of the } \\
\text { system (assuming the oxygen arises from } \\
\mathrm{H}_{2} \mathrm{O} \text { on the surface). } \\
\text { Plugging meter required for verification }\end{array}$ \\
\hline 2 & $\begin{array}{l}\text { Maintain sodium purity during } \\
\text { normal steady state plant } \\
\text { operation }\end{array}$ & $\begin{array}{l}\text { Maintain sodium plugging } \\
\text { temperature } \leq 150^{\circ} \mathrm{C}\end{array}$ & $\begin{array}{l}\text { Plugging meter required for verification } \\
\text { System design to meet Req. \# } 1 \text { will } \\
\text { envelope this case. }\end{array}$ \\
\hline 3 & $\begin{array}{l}\text { At completion of refueling } \\
\text { operations, reestablish sodium } \\
\text { purity in a timely manner }\end{array}$ & $\begin{array}{l}\text { Reduce sodium plugging } \\
\text { temperature to } \leq 150^{\circ} \mathrm{C} \\
\text { within } 2 \text { days. }\end{array}$ & $\begin{array}{l}55 \text { assembly replacements; see Table } 2 \text { for } \\
\text { O/H ingress. } \\
\text { Plugging meter required for verification } \\
\text { System design to meet Req. \# } 1 \text { will } \\
\text { envelope this case. }\end{array}$ \\
\hline 4 & $\begin{array}{l}\text { Provide capability to remove } \\
\text { oxide and hydride from the } \\
\text { primary sodium over the } 30 \text { year } \\
\text { plant design lifetime without } \\
\text { impeding plant operations }\end{array}$ & $\begin{array}{l}\text { Cold trap design for the } \\
\text { plant life of } 30 \text { years to } \\
\text { manage up to } 1570 \mathrm{~kg} \text { of } \\
\text { oxide/hydride. }\end{array}$ & $\begin{array}{l}\text { Impurity basis is provided under Req. \#'s } 1 \\
\& 3 . \\
\text { Incorporate sufficient cold trap capability } \\
\text { initially (i.e., provide a startup trap plus at } \\
\text { least one backup), or } \\
\text { Plan for change-out of the cold trap once it } \\
\text { becomes plugged over a timescale of one } \\
\text { refueling outage }\end{array}$ \\
\hline 5 & $\begin{array}{l}\text { Provide capability to trap out } \\
\text { cesium from failed fuel pins from } \\
\text { primary sodium in a timely } \\
\text { manner to maintain plant dose } \\
\text { rates at acceptable levels \& } \\
\text { reduce potential source term }\end{array}$ & $\begin{array}{l}\text { Provide trapping capability } \\
\text { for up to } 48 \text { pin failures } \\
\text { over the plant lifetime }\end{array}$ & $\begin{array}{l}92.6 \text { Ci Cs- } 134 \text { \& Cs- } 137 \text { release per pin } \\
\text { failure. } \\
\text { Design nuclide traps to accommodate } 48 \\
\text { pin failures, viz. equivalent to } 4,445 \text { Ci of } \\
\text { Cs- } 134 \text { \& Cs- } 137 \text {. } \\
\text { Trap is replaceable. } \\
\text { Nuclide trap trapping capacity scaled up } \\
\text { from the EBR-II nuclide trap design by a } \\
\text { factor of } 4.5 \text {, which is less than the } \\
\text { approximate scaling up factor of } 6 \text { based } \\
\text { on power level between the two plants. }\end{array}$ \\
\hline
\end{tabular}

\subsubsection{Overall System Description}

Major components of the PSPS system are shown in Figure 8-2; the layout adopts most of the major features of the EBR-II primary sodium purification system.

The major components are the nozzle plug penetration through the reactor vessel head, the sodium surge tank, an economizer, a cold trap, and a nuclide trap. There are three subsystems that are also part of the main purification loop: i) a sodium sampling loop, ii) the surge tank syphon break system, and iii) a plugging loop. The nozzle penetration and sodium surge tank are located above the reactor vessel, while the balance of the equipment is positioned in a sodium purification 
and sampling cell located below the sodium level in the reactor building. The equipment is positioned in this manner so that sodium will drain by gravity from the piping connecting the reactor vessel to the primary sodium purification system under either normal or off-normal conditions when they syphon break system is activated.

During normal operation, sodium flows from the nozzle through piping to the surge tank inlet. Thereafter the flow continues out of the bottom of the surge tank to the EM pump in the purification cell. The surge tank and piping are heavily shielded, and all piping is insulated and trace heated. Within the purification cell, sodium flows through the pump to the cold trap and back to the reactor vessel through the nozzle.

The system also includes a nuclide trap designed to retain Cs-134, Cs-137, and other fission products. The cold trap system features a regenerative heat exchanger (economizer) to minimize unrecoverable heat losses associated with cooling the sodium to a temperature at which impurities will precipitate out. In this concept, additional heat sink for the trap is provided by a nitrogen gas cooling system. 


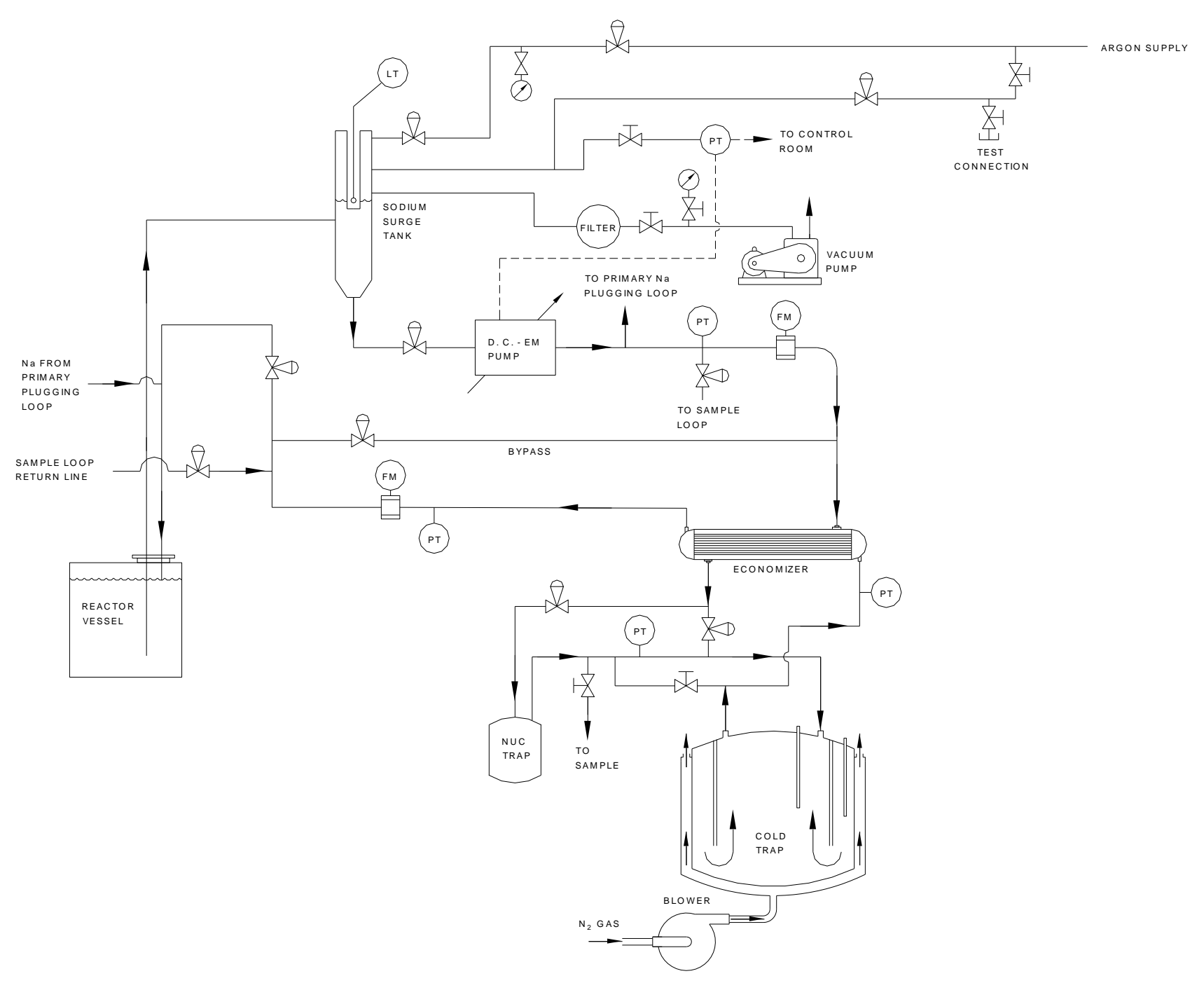

Figure 8-2: Preliminary Piping Diagram of FASTER Primary Sodium Purification System 
Finally, the EBR-II primary sodium purification system only used one cold trap, and one cold trap is shown in this pre-specific design concept. As described in previous section, based on the estimated impurity generations rates expected over the 30 year plant design lifetime, two or more cold traps will most likely be required to meet the plant purification system requirements for a cold trap mesh volume of $2.8 \mathrm{~m}^{3}$. Thus, as for EBR-II, change-out of the cold trap would be required after several years of plant operations if the single cold-trap design is adopted. A further design option would be to add a second redundant cold trap as is being adopted for the secondary loop in FASTER.

In addition to purifying sodium, another function of the primary purification system is to measure the impurity level (e.g. plugging temperature) of the primary sodium (Figure 8-2 and Figure 8-3). The plugging loop draws sodium from downstream of the surge tank outlet, and returns sodium to the primary loop return line to the reactor vessel. Pressure head driving flow through the plugging loop is provided by the main line EM pump. The sodium plugging temperature is measured by a plugging temperature indicator in the loop.

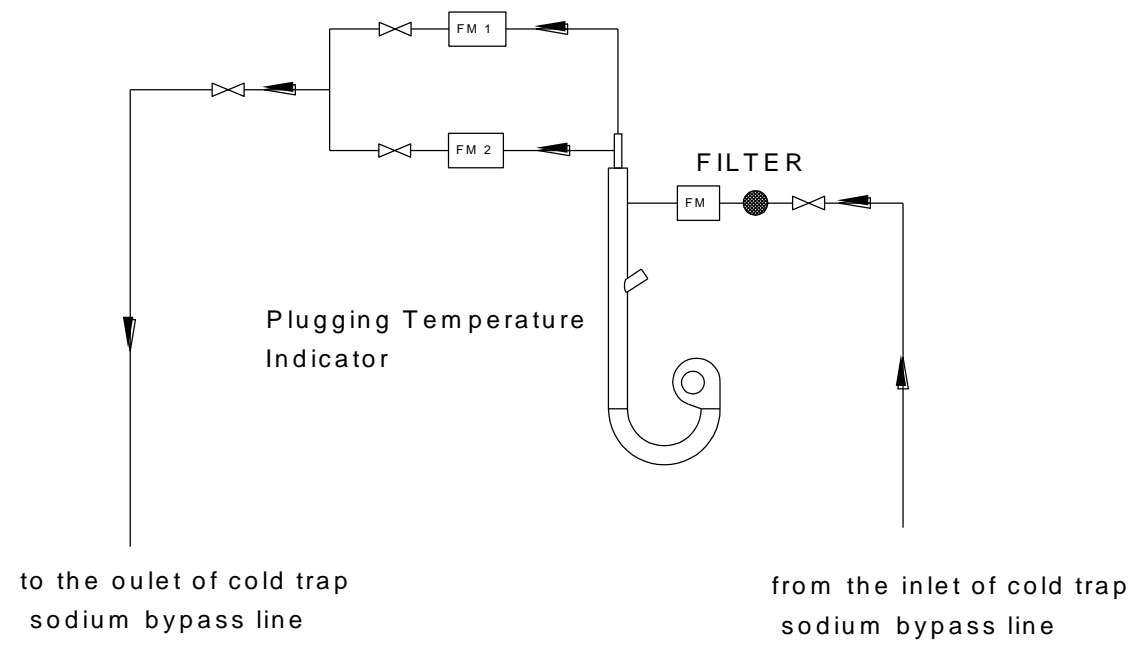

Figure 8-3: FASTER Primary Sodium Plugging Loop

In order to provide the capability to analyze the chemical content of the primary sodium, a sampling loop is also provided (see Figure 8-2 and Figure 8-4). Similar to the plugging loop, the sampling station loop draws sodium from downstream of the sodium surge tank outlet, and returns sodium to the primary loop return line to the reactor vessel. Pressure head driving sodium through the plugging loop is provided by the main line EM pump. The impurity contents of the sodium in the primary loop can either be analyzed off-line from the sodium samples collected in the sodium sampling station, or online by an oxygen-hydrogen meter module /equilibration module. 
FASTER Test Reactor Preconceptual Design Report

March 31, 2016

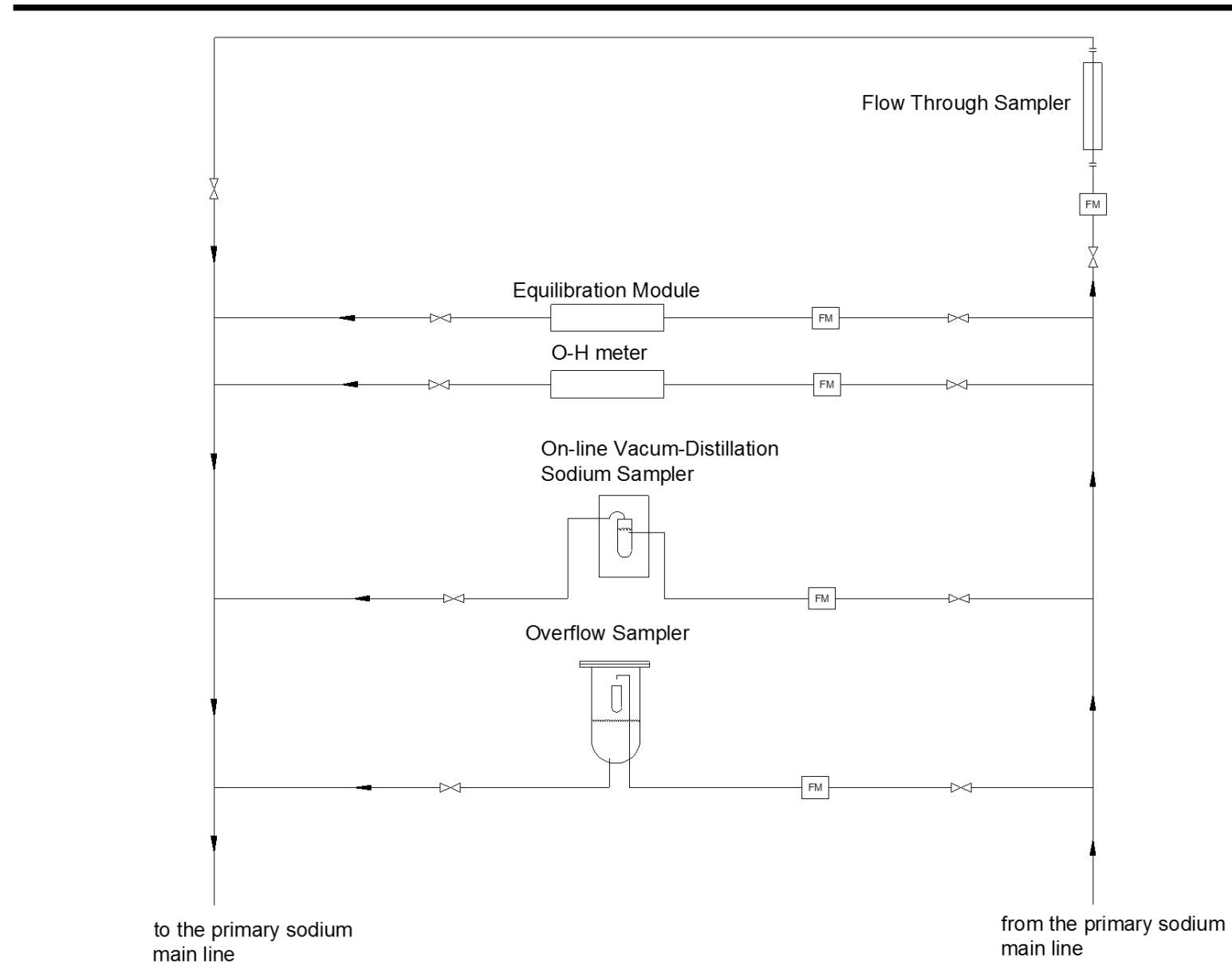

Figure 8-4: Primary Sodium Sampling Station 


\subsection{Intermediate Sodium Purification System}

This subsection provides details on the intermediate sodium purification system (ISPS), or secondary purification system. Similar to the PSPS, the ISPS must provide continuous purification of the intermediate sodium by controlling impurity levels.

\subsubsection{ISPS Performance Requirements and Design Considerations}

In order to have a solid design basis for sizing the cold trap, estimates of sodium impurity source rates are essential for the different reactor operating modes.

There are various operation modes for FASTER, and sodium impurity source rates are different for these various modes. The oxygen and hydrogen concentrations in the IHTS loop can be estimated during normal power operation, initial startup operation, and refueling operations based on past operating experience for sodium fast reactors. On the other hand, the impurity concentrations in the IHTS loop have to be estimated based on postulated conditions for abnormal events during the life of the reactor.

\subsubsection{Impurity Source Rates for Normal Power Operation}

The main source of impurity during power operation in the IHTS loop is hydrogen permeated through tube walls from the steam side of the steam generator (SG). The steel tube used in the steam generator(s) oxidizes slowly in the steam environment, releasing nascent hydrogen, which defuses through the steel into the sodium. Most of this hydrogen defuses through the tubes into the sodium coolant and must be continuously removed [24]. Since the hydrogen permeation through the tube walls is the dominant source of contamination for the secondary sodium during normal operation, a fair estimate of the hydrogen source rate from the SG is essential for sizing the secondary cold trap of FASTER.

Two data references from previously designed reactors are available for use as a technical basis for estimating the sodium impurity source rate for FASTER (see Table 8-5).

The first data source is from the EBR-II program design at Argonne National Laboratory. This reactor had a power level of $62.5 \mathrm{MW}_{\mathrm{t}}$ and had one IHTS loop with a steam generator. The steam generator consisted of eight parallel natural circulation evaporators, a conventional steam drum, and two parallel once-through super heaters. The tubes used in the EBR-II steam generators were double wall tubes constructed with $21 / 4 \mathrm{Cr}-1 \mathrm{Mo}$ material. The hydrogen source rate during normal operation was $1.1 \times 10^{-12} \mathrm{~g} / \mathrm{cm}^{2}-\mathrm{sec}[20]$. 
Table 8-5: Steam Generator Tube Designs from Different Reactor Designs

\begin{tabular}{|c|c|c|c|c|c|c|}
\hline $\begin{array}{l}\text { Reactor } \\
\text { Plant }\end{array}$ & $\begin{array}{c}\text { Hydrogen } \\
\text { Source Rate } \\
\left(\mathrm{g}(\mathbf{H}) / \mathrm{cm}^{2}-\right. \\
\mathrm{sec})\end{array}$ & $\begin{array}{c}\text { Oxygen } \\
\text { Source } \\
\text { Rate } \\
\text { (g }(\mathbf{O}) / \text { day })\end{array}$ & $\begin{array}{c}\text { Plant } \\
\text { Thermal } \\
\text { power } \\
\text { (MW) per } \\
\text { loop }\end{array}$ & $\begin{array}{c}\text { Total SG } \\
\text { Tube Wall } \\
\text { Thickness } \\
(\mathbf{m m})\end{array}$ & $\begin{array}{l}\text { SG Tube } \\
\text { Material }\end{array}$ & Note \\
\hline$E B R-I I$ & $1.1 \times 10^{-12}$ & 0.3 & 62.5 & 4.57 & $\begin{array}{c}2.25 \mathrm{Cr}-1 \\
\mathrm{Mo}\end{array}$ & See $[20,25]$ \\
\hline$C R B R P$ & $9.765 \times 10^{-12}$ & & 325 & 2.77 & $\begin{array}{c}2.25 \mathrm{Cr}-1 \\
\mathrm{Mo}\end{array}$ & See [25] \\
\hline FASTER & $7.8 \times 10^{-12}$ & 0.72 & 300 & 5.9 & $\begin{array}{c}\text { Mod } 9 \\
\text { Cr-1 Mo }\end{array}$ & $\begin{array}{c}\text { Scale up } \\
\text { based on } \\
\text { the ABTR } \\
\text { steam } \\
\text { generator } \\
\text { design See } \\
\text { [26] }\end{array}$ \\
\hline
\end{tabular}

The second data source is the CRBR program in the US. This reactor was designed with a power level of $975 \mathrm{MW}_{\mathrm{t}}$ with three (3) IHTS loops. The steam generators for each loop were integral units containing the evaporators and super heaters. The steam generators for CRBR were constructed with single wall tubes and the tube material was also $21 / 4 \mathrm{Cr}-1 \mathrm{Mo}$. The nominal hydrogen source rate for the IHTS loops was estimated as $2 \times 10^{-11} \mathrm{lb} / \mathrm{ft}^{2}-\mathrm{sec}\left(9.765 \times 10^{-12} \mathrm{~g} / \mathrm{cm}^{2}\right.$ sec) [27]. This rate is almost an order of magnitude higher than that of EBR-II. There are various factors that contribute to the hydrogen diffusive transport rate, including the tube wall thickness, hydrogen concentration in the coolant, the solution constant of hydrogen in the sodium, the temperature in the steam generator and the permeability of hydrogen in the tube wall material. In other words, the design of a steam generator largely dictates the hydrogen source rate for the IHTS loop. It appears in this case that the double wall tubes used in EBR-II steam generator (with a tube wall thickness twice as thick as that for CRBR) is one of the reason why the secondary hydrogen source rate for EBR-II is less than that for CRBR.

The overall thermal power of the FASTER is $300 \mathrm{MW}_{\mathrm{t}}$. The steam generator of the FASTER is constructed with single wall tubes made with 9Cr-1Mo. The FASTER tube wall thickness is comparable to the CRBR tube wall thickness. Even though the design of the SG in FASTER is an integrated type, the overall surface area for hydrogen permeation through the SG tubes should be proportional to the thermal power for either CRBR or EBR-II given the respective steam generator thermal ratings. From this perspective, the SG design of the FASTER is more similar to the SG design in CRBR than in EBR-II. Therefore, the IHTS hydrogen source rate for CRBR is chosen as the reference point for the FASTER design.

Another consideration is the material used for the SG tubes. The assumption that the hydrogen permeation rate through the $21 / 4 \mathrm{Cr}$-1Mo steel is higher than $9 \mathrm{Cr}-1 \mathrm{Mo}$ steel is based on two reports. Jurgen and Riecke [28] reported that the chromium content in steel has a positive impact on reducing the hydrogen diffusion through the steel. In addition, Beaver and Leitten [29] 
indicated that the corrosion rates of low-alloy steels appear to be an order of magnitude higher than those of the martensitic, ferritic steels, which means more hydrogen is generated in $21 / 4 \mathrm{Cr}-$ 1 Mo steel than in 9Cr-1Mo steel.

Based on the hydrogen source rate of $2 \times 10^{-11} \mathrm{lb} / \mathrm{ft}^{2}-\mathrm{sec}\left(9.765 \times 10^{-12} \mathrm{~g} / \mathrm{cm}^{2}-\mathrm{sec}\right)$ for the IHTS loop of CRBR, the IHTS hydrogen source rate from the SG is therefore estimated as $\sim 7.8 \times 10^{-12}$ $\mathrm{g}(\mathrm{H}) / \mathrm{cm}^{2}$-sec by considering all factors mentioned above that impact hydrogen permeation through steels. Tritium is also produced during reactor operation in the primary loop through ternary fission in the fuel and subsequent diffusion of the tritium through the cladding into the sodium. Tritium may also form by activation of boron in the control rods present in the reactor core. A certain portion of the tritium from this fission/activation process will permeate through tube walls in the IHX (intermediate heat exchanger) tubes into the secondary side of FASTER. It is noted that although production of tritium by ternary fission is significant from a dose perspective, the corresponding amount of hydrogen (eventually forming $\mathrm{NaH}$ ) produced by this process is small compared to that introduced by permeation through the tube wall of the SGs and is therefore neglected in this study for cold trap sizing.

Finally, the small but measurable oxygen source rate introduced into the IHTS loop is most likely due to oxygen contamination in the cover gas. An average oxygen ingress rate of $0.3 \mathrm{~g} / \mathrm{day}$ was estimated for the EBR-II IHTS loop [20]. Therefore, the source rate of oxygen for the IHTS loop of FASTER can be approximately scaled up to $7.3 \mathrm{~g} /$ day by considering the power levels of 300 $\mathrm{MW}_{\mathrm{t}}$ and 62.5.MW $\mathrm{t}$ for FASTER and EBR-II respectively.

\subsubsection{Impurity Source Rates During Initial Startup Operation}

The impurity sources for the IHTS loop during initial startup mainly come from the residual moisture on the sodium wet surface of components and piping of the IHTS loop. The surface area for the FASTER IHTS loop has been estimated. The impurity of oxygen per unit area is adopted as $2 \mathrm{~g} / \mathrm{m}^{2}$ [30]. The assumption was made that all hydrogen in the sodium is produced from moisture $\left(\mathrm{H}_{2} \mathrm{O}\right)$ reacting with sodium that can continue to react with sodium completely since unlimited sodium supply for the reaction, therefore the impurity of hydrogen per unit area can also be estimated as $0.25 \mathrm{~g} / \mathrm{m}^{2}$ based on the stoichiometric relationship between the mass of hydrogen in water released in the $\mathrm{Na}-\mathrm{H}_{2} \mathrm{O}$ reaction. Another source of impurities during this operation is due to impurities present in the sodium inventory from the vendor as mentioned in PSPS. To provide an indication of the level of impurities that may be present during this stage, the EBR-II procurement specifications for reactor grade sodium are shown in Table 8-6, along with the actual levels in the material in the as-received condition. Oxygen was not included in the initial specifications, most likely due to the fact that oxygen level can be influenced by handling procedures once the material leaves the factory, as well as the fact that the operators intended to reduce the oxygen content to an acceptable level using the ISPS once the secondary system was filled. As an indication of the potential levels, other reactor programs have placed specifications on the maximum oxygen content in procured reactor grade sodium in the range of 50 to $100 \mathrm{ppm}$. Furthermore, suppliers have published specifications on oxygen levels in reactor grade sodium to be $<50 \mathrm{ppm}$. On these various bases, an oxygen concentration of $50 \mathrm{ppm}$ in the initial secondary sodium inventory is assumed as mentioned in Section 8.1. 
Table 8-6: Initial Impurity Levels in EBR-II Reactor Grade Sodium

\begin{tabular}{lcc}
\hline Impurity & $\begin{array}{c}\text { Procurement } \\
\text { Specification } \\
\text { (ppm) }\end{array}$ & $\begin{array}{c}\text { As-Received } \\
\text { (ppm) }\end{array}$ \\
\hline Boron & 5 & $<1$ to 2 \\
Cadmium & 20 & $<1$ \\
Calcium & 10 & $<2$ to 8 \\
Carbon & 50 & 5 to 29 \\
Indium & 30 & 7 to 12 \\
Lithium & 20 & $<1$ \\
Oxygen & & $<50$ ppm [31] \\
Hydrogen & & Not available \\
\hline
\end{tabular}

\subsubsection{Impurity Sources from Other Operations}

For the IHTS loop, hydrogen permeation from the primary side of the FASTER reactor is very small during fuel handling compared with the hydrogen permeation from the steam generator during normal power operation. Therefore, using the normal operation hydrogen source rate for the IHTS loop during fuel handling operations provides a conservative basis for sizing the secondary cold trap.

The impurity source rates after accidents will be refined after SG tube rupture analyses are completed.

Based on the above discussion Table 8-7 summarizes the impurity source rates of oxygen, hydrogen, and tritium for various operational phases as well as the technical basis for these estimates. 
Table 8-7: Estimated FASTER IHTS Loop Oxygen, Hydrogen, and Tritium Source Rates

\begin{tabular}{|c|c|c|c|}
\hline Impurity & Stage & Source & Technical Basis \\
\hline Oxygen & \multirow{3}{*}{$\begin{array}{l}\text { Initial } \\
\text { IHTS loop } \\
\text { Sodium Fill }\end{array}$} & $50 \mathrm{ppm}$ & $\begin{array}{l}\text { Maximum oxygen concentration in " } \mathrm{R} \text { " grade sodium inventory } \\
\text { [31]. }\end{array}$ \\
\hline Oxygen & & $2 \mathrm{~g} / \mathrm{m}^{2}$ & Initial oxygen concentration on the surface of component [30] \\
\hline Hydrogen & & $0.25 \mathrm{~g} / \mathrm{m}^{2}$ & $\begin{array}{l}\text { Based on stoichiometric relation of the water and hydrogen in the } \\
\text { reaction of sodium and moisture }\left(\mathrm{H}_{2} \mathrm{O}\right)\end{array}$ \\
\hline Oxygen & \multirow{3}{*}{$\begin{array}{l}\text { Normal } \\
\text { Power } \\
\text { Operation }\end{array}$} & $0.72 \mathrm{~g} / \mathrm{day}$ & $\begin{array}{l}\text { Scaled up from EBR-II [20] oxygen source rate of secondary } \\
\text { sodium loop from the power level of } 62.5 \mathrm{MW}_{\mathrm{t}} \text { to } 150 \mathrm{MW}_{\mathrm{t}}\end{array}$ \\
\hline Hydrogen & & $7.3 \mathrm{~g} / \mathrm{day}$ & $\begin{array}{l}\text { Estimated based on CRBRP nominal hydrogen source flux rate } \\
\text { [27] of } 9.8 \times 10^{-12} \mathrm{~g} / \mathrm{cm}^{2}-\mathrm{sec} \text { with SG heat transfer surface area of } \\
1,084 \mathrm{~m}^{2} .\end{array}$ \\
\hline Tritium & & $2.2 \mathrm{GBq} / \mathrm{day}^{\mathrm{a})}$ & $\begin{array}{l}\text { EBR-II operations [20], linearly scaled up from power of the } \\
\text { reactors. }\end{array}$ \\
\hline Oxygen & \multirow{3}{*}{ Refueling } & $\sim 0$ & \multirow{3}{*}{$\begin{array}{l}\text { The impurity sources due to refueling operation are insignificant, } \\
\text { and the operation period itself has much shorter duration } \\
\text { comparing with the period of normal operation. Therefore, } \\
\text { impurity sources of refueling can be ignored for this operation. }\end{array}$} \\
\hline Hydrogen & & $\sim 0$ & \\
\hline Tritium & & insignificant & \\
\hline
\end{tabular}

${ }^{\text {a) }}$ Equivalent to $0.006 \mathrm{mg} / \mathrm{day}$, or $2.2 \mathrm{mg} /$ year based on $290 \mathrm{EFPD}$, given the tritium specific activity of 9,600 Ci/g.

\subsubsection{Impurity Mass Accumulations for IHTS loop Through the Lifetime of the Plant}

Based on the estimated impurity source rates of oxygen, hydrogen, and tritium for the FASTER secondary sodium system (see Table 8-7) during routine operations, the total mass of each impurity can be calculated for the 30 year design lifetime of FASTER (see Table 8-8).

Table 8-8: Total Accumulated Impurity Mass for IHTS Sodium Loop*

\section{Time from \\ (years)}

Reactor $\quad \mathrm{Na}_{2} \mathrm{O}$

Startup Mass

(kg)

\section{$\mathrm{NaH}$}

Mass (kg)

Total $\left(\mathrm{Na}_{2} \mathrm{O}\right.$ -

NaH) Mass (kg)

Technical Basis/Rationale

Impurities present in initial sodium inventory: equivalent to the oxygen mass

\begin{tabular}{ccccl}
0 & 16.9 & 38.1 & 55.0 & $\begin{array}{l}\text { in } \\
\text { ppm. Initial hydrogen content } \\
\text { conservatively estimated assuming the } \\
\text { oxygen arises from } \mathrm{H}_{2} \mathrm{O} .\end{array}$ \\
\hline 0 & 13.0 & 29.5 & 42.5 & $\begin{array}{l}\text { From initial moisture on the IHTS } \\
\text { surface. }\end{array}$ \\
\hline 0 & 29.9 & 67.6 & 97.5 & $\begin{array}{l}\text { Total from initial sodium inventory and } \\
\text { surface moisture. }\end{array}$ \\
\hline 10 & 65.1 & 683.6 & 748.7 & $\begin{array}{l}\text { The source rate of hydrogen } \mathrm{during} \\
\text { normal operation is } 7.8 \times 10^{-12} \mathrm{~g} / \mathrm{cm}^{2}-\mathrm{sec}, \\
\text { and for oxygen the rate is } 0.72 \mathrm{~g} / \mathrm{day} .\end{array}$ \\
\hline 30 & 85.5 & 1,966 & 2,051 &
\end{tabular}

\footnotetext{
Also see Table 8-7.
} 


\subsubsection{Overall System Description}

Two main features have been adopted from the EBR-II secondary purification system for the design of the FASTER purification system. The first feature is the inclusion of a recirculating loop to keep the sodium level in the expansion tank constant. This feature provides a stable hydraulic environment for the main intermediate heat transport EM pump in the secondary loop. The cold trap (CT) and plugging temperature indicator (PTI) units are also incorporated into the system to purify the sodium by piping the sodium from the expansion tank. The second feature is the use of a passive syphon break to terminate the hydraulic connection in the expansion tank in case of a sodium leak in the purification system. This feature prevents emptying the contents of the expansion tank and the IHTS loop in the event of sodium leakage from the purification system. The advantage of passive syphon break system is that the system is passive. It is mechanically designed into the expansion tank, which only allows sodium from the recirculating loop to flow into the expansion tank in one direction by pumping force from the inlet tube. Whenever a leakage happens in the sodium recirculating loop, the sodium level in the expansion tank will become lower. This will break the syphon mechanism at the top of the inlet tube to prevent the sodium from being sucked back into the recirculating system. A level indicator should be installed in the expansion tank to detect minimum sodium level in the tank. An alarm should go off if the sodium in the expansion tank drops below a set point to check the possibility of leakage in the recirculating and purification systems.

The main function of the secondary purification system is to purify the IHTS sodium in which contamination from the steam generator (SG) is continuously introduced, along with other sources. The FASTER secondary purification system is designed to achieve the objectives of robustness and reliability.

To support a robust and redundant operating environment, each of the two (2) IHTS loops is served by one purification loop with the goal of having one cold trap in operation during normal operations, with one cold trap in reserve. Therefore, two (2) cold traps are included in each of the secondary sodium purification loops.

For each sodium purification loop, one cold trap is used for cleaning of the system during initial fill and commissioning, or post-accident cleaning in the case of the sodium-water reaction in the IHTS. The other cold trap is for the normal operations.

There are two basic operational modes for this design; namely, normal operation with CT1 on line, and normal operation with CT2 on line.

For the operation with CT1 on line(See Figure 8-5 ), sodium flows from the weir in the storage tank through an EM-pump to the cold trap with flow to the PTI and the sampling station in parallel. The purified sodium then continues to flow into the expansion tank (ET) and through an overflow line in the tank before returning back to the sodium storage tank. This completes the sodium recirculation in the loop. 


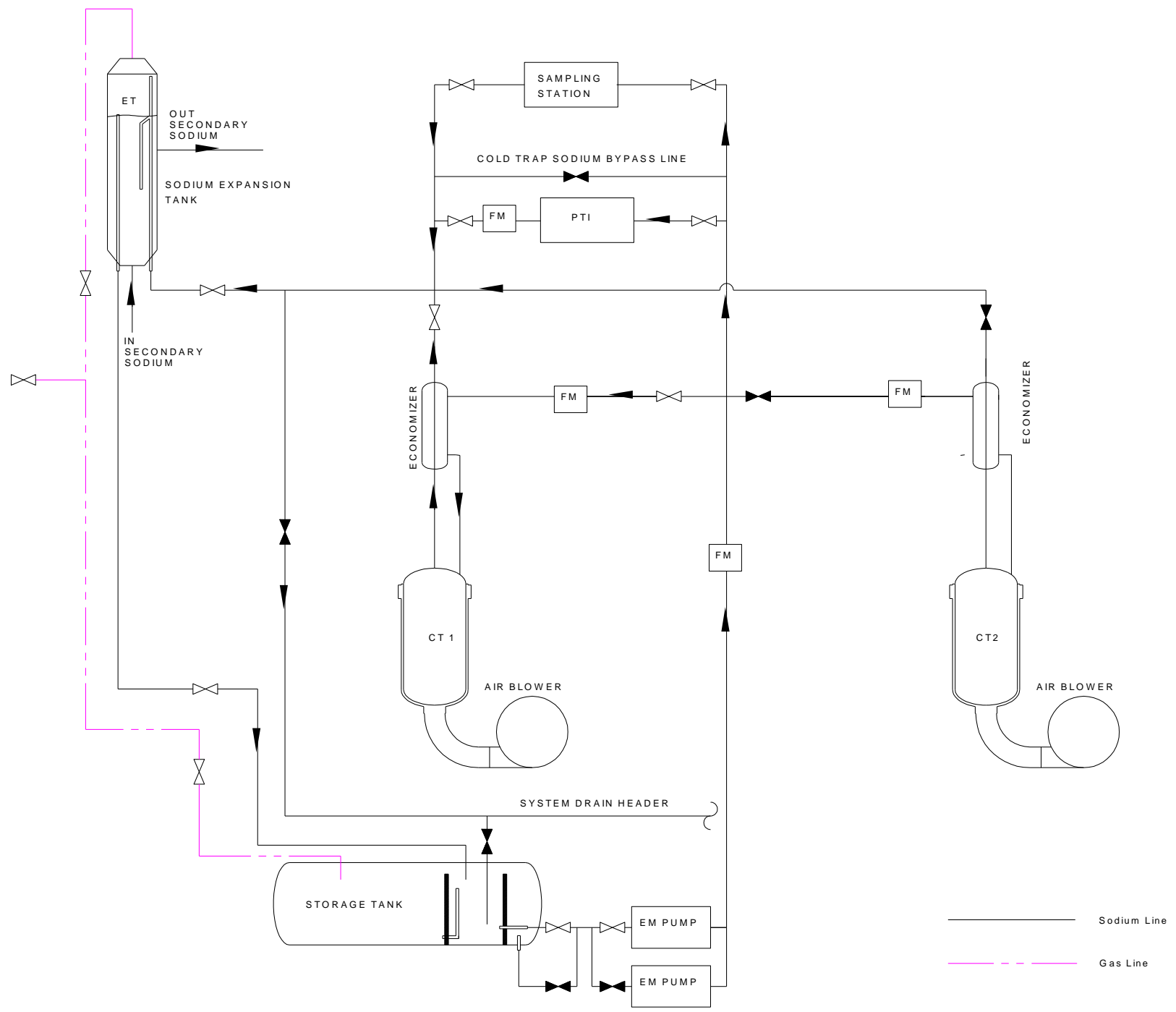

Figure 8-5: Preliminary Piping Diagram of PGSFR ISPS- Normal Operation with CT1 on Line 


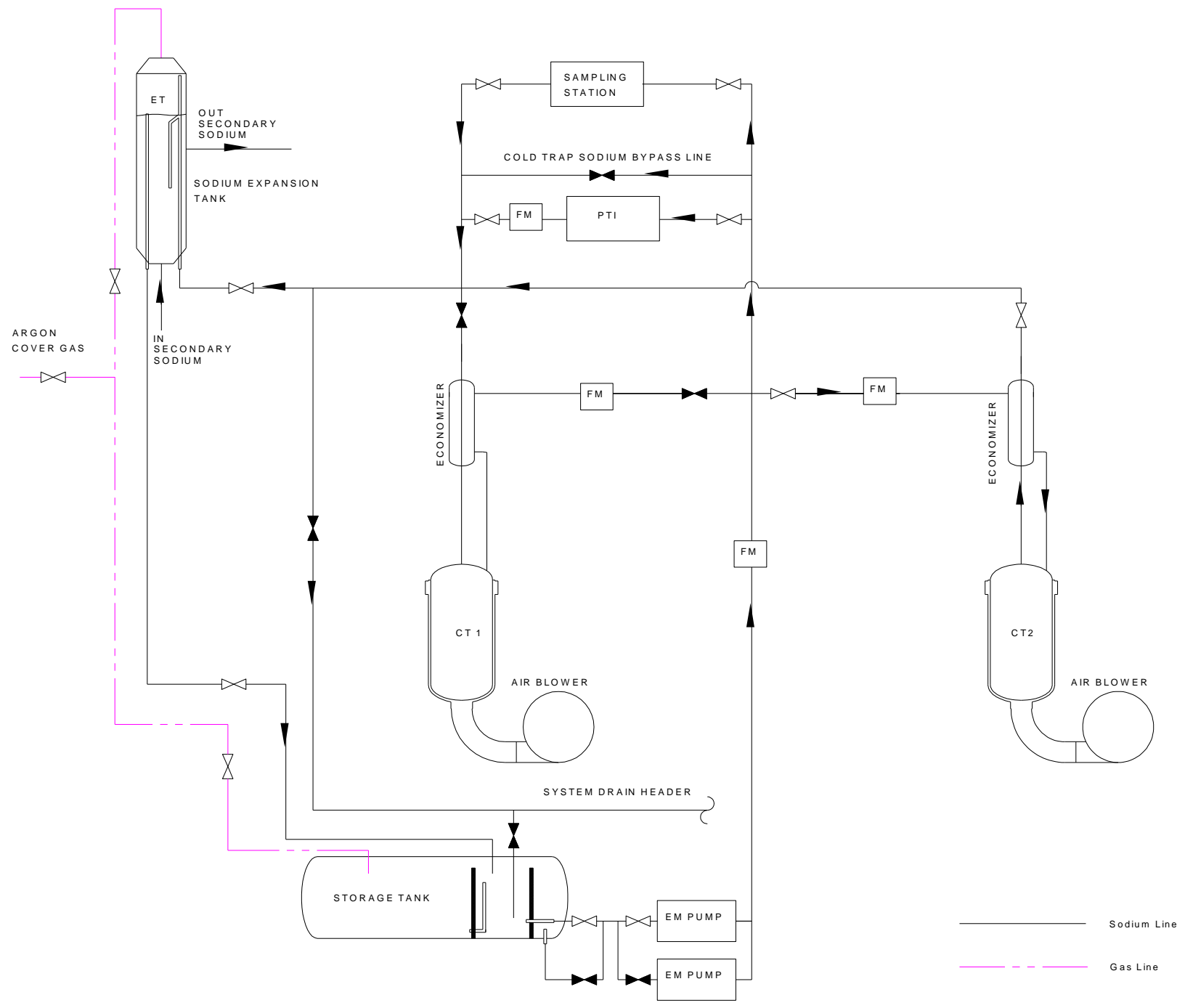

Figure 8-6: Preliminary Piping Diagram of PGSFR ISPS- Normal Operation with CT 2 on Line 
The operation with CT2 on line (see Figure 8-6) is initiated by setting valves in the system to change the sodium flow path. In this case, sodium follows the same flow path as the first choice except that cold trap CT1 is removed from the circulation path in the purification system, and cold trap CT2 is switched (by valve actuation) into operation thus allowing sodium to flow through CT2 . Either of these two cold traps can be used as a backup if another one is out of service for maintenance, regeneration, or replacement.

In addition to purifying sodium, another function of the secondary purification system is to measure the plugging temperature of the IHTS loops. There is one (1) sodium plugging loop for each secondary purification loop (see Figure 8-5). The plugging loop is piped in parallel with the cold trap loop and sampling station. The EM pump pushes a portion of the sodium from the recirculating loop through the plugging loop. The sodium plugging temperature is measured by a plugging temperature indicator in the loop. See Figure 8-2 for additional details.

To provide capability to analyze the actual chemical contents in the sodium, each secondary purification loop includes one (1) sampling station loop (see Figure 8-4). The sampling station loop that is parallel with the cold trap and plugging loops can be put on- or off-line by using various valves in the loop. The pressure difference on the bypass line of the cold trap forces the sodium from the recirculation loop into the sampling station. The impurity contents of the sodium in the IHTS loop can be either analyzed off-line from the sodium samples collected in the sodium sampling station, or online by the Oxygen-Hydrogen meter module /equilibration module.

Finally, other than the above mentioned functions, there are some additional features in the FASTER design that will make the system more reliable and robust.

A bypass line between the inlet and outlet of the cold trap allows sodium to bypass the cold trap, the PTI and the sampling station. This feature ensures that the sodium in the expansion tank can always be kept at a constant level even if the cold trap, plugging temperature indicator, or sampling station has been taken off-line from the loop.

At some point it may be necessary to drain the IHTS sodium contents into the storage tank. If this occurs, the sodium in the storage tank could be purified by circulating sodium between the cold trap and storage tank without passing though the expansion tank. This is achieved by opening the valve on the by-pass line between the inlet of the expansion tank and the storage tank.

\subsubsection{Functions and Specifications of Major Components}

Each IHTS sodium purification loop consists of two (2) cold traps, two (2) economizers, a plugging loop, a sampling station, and a portion of the sodium recirculation loop. Only the functions and specifications of the cold trap, economizer, plugging meter are presented in this report. Also, the characteristics of the EM pump and flow meter in the recirculating loop are briefly described. The IHTS purification system is preliminarily specified according to ASME pressure vessel code. 


\subsubsection{Cold Trap}

\section{Functions}

The cold trap is a major component in the sodium purification system. For the FASTER IHTS loop, the cold trap removes sodium impurities (mostly sodium hydride) from the main intermediate loop by precipitation. The main impurity to cold trap out of the IHTS sodium loop is sodium hydride. The source rate of this impurity is almost constant, and arises due to hydrogen diffusion through the tubes on the water-side of the steam generator. Also, there is a small oxygen source rate into the IHTS sodium loop that forms sodium oxide. The possible predominant source of this impurity is cover gas contamination. Finally, tritium diffuses from the primary side of the sodium loop through the tubes of the IHXs; the tritium is produced by ternary fission in the fuel, and formed by neutron activation of boron carbide control rods. All these impurities can be effectively taken out from the sodium in the secondary loop by means of cold trapping. The effectiveness of the purification process is determined by the sodium flow rate to the cold trap, the source rate of the impurities, and finally the efficiency of the cold trap. The capacity of the cold trap is predominately determined by the size of the cold trap. Due to the nature of the impurity sources in the FASTER secondary loop, the cold traps in the IHTS system are operated continuously during normal operations. The limit for the hydrogen in the secondary sodium loop is set at $0.2 \mathrm{ppm}$ and $5 \mathrm{ppm}$ for oxygen.

\section{Design Dimensions}

A typical cold trap design is shown in Table 8-9 and Figure 8-7, which is in the ISPS system of FASTER. The cold trap is a cylindrical shaped ASME compliant pressure vessel. The outer diameter is $1.372 \mathrm{~m}$ (54 inch), overall length is $3.27 \mathrm{~m}$ (128.8 inch), and 190 longitudinal cooling fins are welded on the cylinder outer surface. The interior of the cold trap is divided vertically by a cylindrical wall into two concentric sections. The top of the cylindrical wall is welded to the inside surface of the cold trap top head. The bottom of the wall is open to both the central and annular regions. The sodium inlet and outlet are positioned on the top head and radially centered in the annular and central regions, respectively. Both the annular and central regions are filled with the stainless steel wire mesh. The wire mesh in these two regions affectively increases the surface area for impurity precipitation. The length of the meshed section is about $2.03 \mathrm{~m}(80$ inch), which leaves the top and bottom of the cold trap regions free of packing material. The flange near the top head of the cold trap allows the finned portion of the cold trap to sit in an air jacket enclosure. The opening on the bottom of the air jacket is connected to an air blower through an air duct. The $0.66 \mathrm{~m}$ (26in) diameter of the air jacket inlet is sized to minimize the noise and pressure drop of the system. The openings on the flange are for air outlets. To reduce the channeling behavior of the sodium in the cold trap due to the low sodium flow rate, a set of baffles is implemented in the annular region. Four (4) thermocouples are implemented in the annulus and two (2) are implemented in the central region through the top head to provide multiple measuring points. 
Table 8-9: FASTER IHTS Cold Trap Design Dimensions

\begin{tabular}{|c|c|}
\hline - Design parameters & - Design values \\
\hline - $\quad$ Shell OD, m (inch) & - $1.37(54)$ \\
\hline - Shell Thickness, mm (inch) & - $9.53(0.375)$ \\
\hline - Shell ID, m (inch) & - $1.346(53)$ \\
\hline - Shell Overall Length, m (inch) & - $\quad 3.27(128.8)$ \\
\hline - Vertical Cylinder wall OD, m (inch) & - $0.533(21)$ \\
\hline $\begin{array}{l}\text { - Vertical Cylinder Wall Thickness, mm } \\
\text { (inch) }\end{array}$ & • $\quad 12.7(0.5)$ \\
\hline - Vertical Cylinder ID, m (inch) & - $0.508(20)$ \\
\hline $\begin{array}{l}\text { Overall Length of the Vertical Cylinder, } \\
\mathrm{m} \text { (inch) }\end{array}$ & - $2.78(109.4)$ \\
\hline - Number of Baffles, Inner (outer) & - $3(2)$ \\
\hline - Baffle Thickness, mm (inch) & - $12.7(0.5)$ \\
\hline - OD of the Inner Baffle, m (inch) & - $1.12(44)$ \\
\hline - ID of the Outer Baffle, m (inch) & - $\quad 0.89(35)$ \\
\hline - Baffle Pitch, cm (inch) & - $51(20)$ \\
\hline - Fin Height, cm (inch) & - $6.35(2.5)$ \\
\hline - Fin Thickness, mm (inch) & - $3.429(0.135)$ \\
\hline - Fin Length, m (inch) & - $2.286(90)$ \\
\hline - Number of Fins & - 190 \\
\hline - $\quad$ Material for Cold Trap & - $9 \mathrm{Cr}-1 \mathrm{Mo}-\mathrm{V}$ \\
\hline - Mesh volume, $\mathrm{m}^{3}\left(\mathrm{inch}^{3}\right)$ & - 2.8 \\
\hline - Mesh wire diameter, mm (inch) & - $0.28(0.011)$ \\
\hline - Mesh Density, $\mathrm{kg} / \mathrm{m}^{3}\left(\mathrm{lbm} / \mathrm{ft}^{3}\right)$ & - $400(24.97)$ \\
\hline - Material for Mesh & $\begin{array}{l}\text { - } 304 \text { Stainless Steel, soft } \\
\text { temper }\end{array}$ \\
\hline - Air jacket ID, m (inch) & • $1.5386(60.575)$ \\
\hline - $\quad$ Air Jacket Inlet ID, m (inch) & - $0.66(26)$ \\
\hline - $\quad$ Air Jacket outlet ID, m (inch) & - $0.32(12.5)$ \\
\hline - Number of Air Jacket Outlets & - 4 \\
\hline - Material for Air Jacket & $\begin{array}{l}\text { - } 304 \text { stainless steel or } \\
\text { carbon steel }\end{array}$ \\
\hline
\end{tabular}




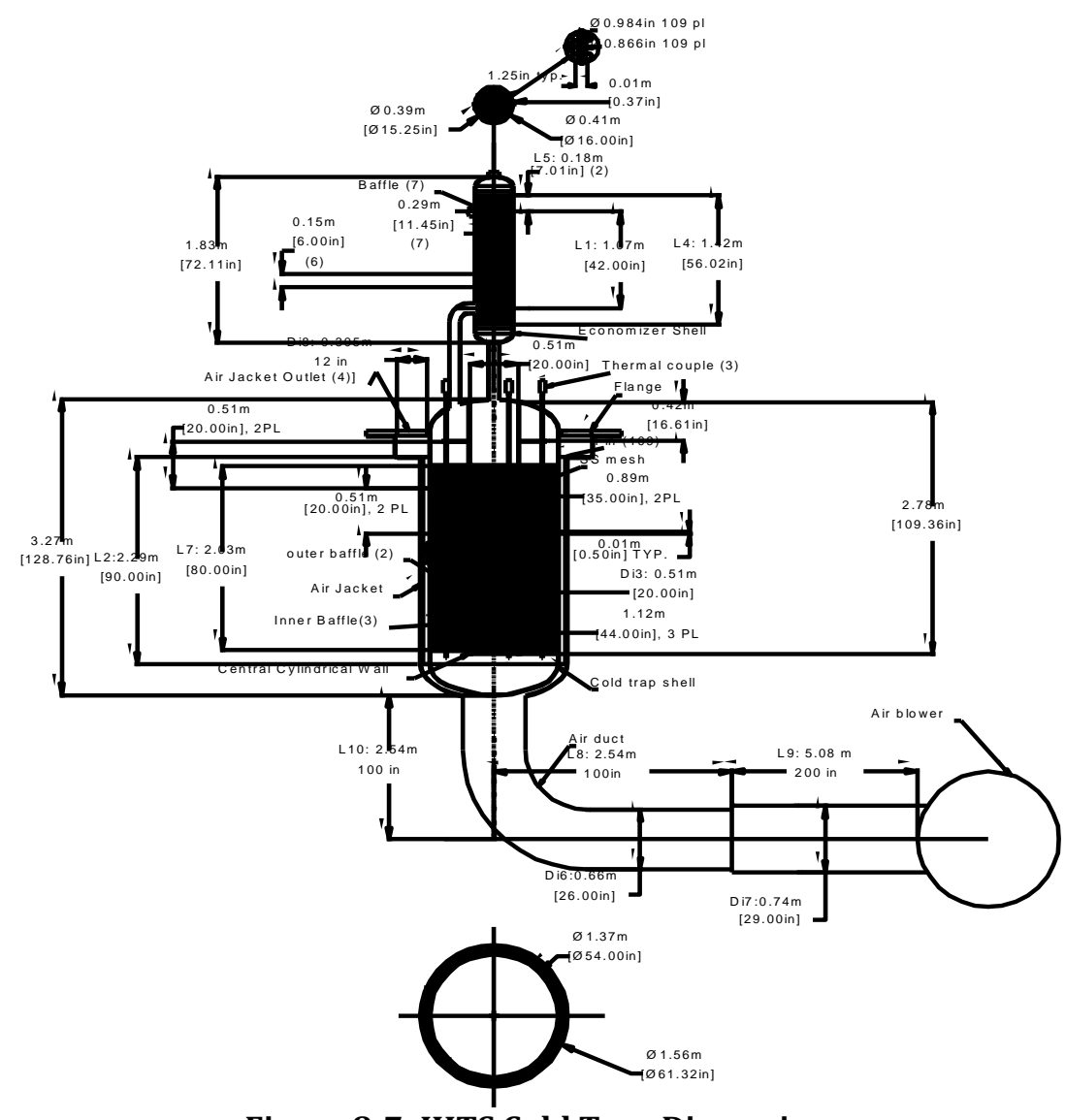

Figure 8-7: IHTS Cold Trap Dimensions

\subsubsection{Economizer}

\section{Functions}

The function of the economizer is to recuperate the heat during the process of cold trapping. The economizer is a regenerative heat exchanger used as part of the forced-air cooled cold trap assembly to minimize system heat losses, reduce thermal shock, and reduce total heat removal requirements of the trap.

\section{Design Dimensions}

Table 8-10 and Figure 8-7 show a typical design of an economizer for FASTER. The economizer is a tube in shell heat exchanger. The outer diameter of the shell is $0.41 \mathrm{~m}$ (16 inch) and the overall shell length is $1.83 \mathrm{~m}$ (72.1 inch). There are 109 tubes with an effective tube length of $1.07 \mathrm{~m}$ (42 inch) and outer diameter of $25 \mathrm{~mm}$ (0.984 inch). Seven (7) 25\% cut baffles are implemented in the economizer to augment mixing and heat transfer of the unit. 
Table 8-10: FASTER IHTS Economizer Design Dimensions

\begin{tabular}{|c|c|}
\hline - Design Parameters & - Design Values \\
\hline - Shell OD, m (inch) & $\begin{array}{ll} & 0.406(16)\end{array}$ \\
\hline - Shell Thickness, mm (inch) & - $9.53(0.375)$ \\
\hline - Shell ID, m (inch) & - $0.387(15.25)$ \\
\hline $\begin{array}{l}\text { - Shell Overall Length, m } \\
\text { (inch) }\end{array}$ & - $1.83(72)$ \\
\hline - Tube OD, mm (inch) & - $25(0.984)$ \\
\hline $\begin{array}{l}\text { - Tube Wall Thickness, mm } \\
\text { (inch) }\end{array}$ & - $1.5(0.059)$ \\
\hline - Tube ID, mm (inch) & - $22(0.866)$ \\
\hline - Tube Pitch, mm (inch) & - $31.75(1.25)$ \\
\hline $\begin{array}{l}\text { Effective Tube Length, } \mathrm{m} \\
\text { (inch) }\end{array}$ & - $1.067(42)$ \\
\hline - Tube Length, m (inch) & - $1.423(56)$ \\
\hline - Number of Tubes & - 109 \\
\hline - Type of Baffle & - $25 \%$ cut \\
\hline - Baffle Thickness, mm (inch) & - $9.53(0.375)$ \\
\hline - Baffle Pitch, cm (inch) & - $15.24(6)$ \\
\hline - Number of Baffles & - 7 \\
\hline
\end{tabular}

\subsubsection{Plugging Meter}

\section{Functions}

The major requirement of plugging meter for FASTER sodium system is to be able to measure sodium plugging temperature which reflects the required limit of impurities of oxygen and/or hydrogen in the sodium. Many variations of plugging meter design existed today, but there are two basic forms of design. The first form is a fluted valve or orifice plate type, and the second form is a Frit type (EBR-II). From the experiences of EBR-II, the Frit-type PTI has proved to be very sensitive device for measuring plugging temperatures in the EBR-II primary and secondary sodium systems [32]. By employing the continuous method or/and oscillating method of measuring, the Frit-type plugging meter is able to measure $121^{\circ} \mathrm{C}\left(250^{\circ} \mathrm{F}\right)$ or lower plugging temperature in the sodium system. By contrast, the plugging temperature can be measured by a fluted valve plugging meter is higher due to impact of sodium flow changes to the temperature readout during the measuring.

The function of the plugging meter in the secondary loop is to determine the plugging temperature of the sodium. It is basically a sodium-to-sodium (economizer) and sodium-to-air regenerative heat exchanger. Sodium entering the plugging loop from the recirculating system flows through an inlet filter and a permanent magnet flow meter. The sodium then enters the side 
of the regenerative heat exchanger near the top. The sodium flows downward through the outer annulus where an air blower induces flow on the outside of the heat exchanger that cools the sodium in the outer annulus. The sodium reverses at the bottom and flows upward into two flow paths; one through the plugging filter, the other bypassing the plugging filter. The plugging and bypassing flows pass through individual flowmeters and throttling valves. They combine downstream of the throttle valves to flow back to the recirculating system.

\section{Design Dimensions}

Table 8-11 and Figure 8-8 show a typical plugging meter design for PGSFR. The plugging meter is a tube in tube type of heat exchanger. The outer diameter of the outer pipe is $4.22 \mathrm{~cm}(1.66$ inch), the outer diameter of the intermediate tube is $2.54 \mathrm{~cm}(1 \mathrm{inch})$, and the outer diameter of the inner tube is $1.27 \mathrm{~cm}(0.5 \mathrm{inch})$. The overall length of plugging meter is $87 \mathrm{~cm}(34.3 \mathrm{inch})$. The plugging filter is located at the bottom of the annulus between the intermediate tube and inner tube, where a thermocouple in a thermo well is located. All the sodium inlet and outlet ports are $1.71 \mathrm{~cm}(0.68 \mathrm{inch})$. There are 18 longitudinal cooling fins in the cooling section of the plugging meter. The purpose of cooling fins is to increase surface area of cooling on the air coolant side due to low thermal heat transfer coefficient of air. The fins are $0.95 \mathrm{~cm}(0.38 \mathrm{inch})$ high, $25.4 \mathrm{~cm}$ (10 inch) long, and have a thickness of $0.26 \mathrm{~cm}$ ( $0.1 \mathrm{inch})$. The inner diameter of the air jacket is $6.88 \mathrm{~cm}(2.71 \mathrm{inch})$, which guides the flow around the finned section of the plugging meter. An air blower is connected at the bottom of the air jacket through a $6.4 \mathrm{~cm}(2-1 / 2$ inch) duct. The outlet diameter of the air jacket is a $4.5 \mathrm{~cm}$ (1.77 inch) pipe. 
Table 8-11: FASTER IHTS Plugging Meter Design Dimensions

\begin{tabular}{|c|c|}
\hline - Design parameters & - Design values \\
\hline - Inner tube OD, cm (inch) & • $1.27(0.5)$ \\
\hline - Inner tube ID, cm (inch) & - $1.09(0.43)$ \\
\hline - Inner tube wall thickness, mm (inch) & - $0.889(0.035)$ \\
\hline - Intermediate tube OD, cm (inch) & - $2.54(1.00)$ \\
\hline - Intermediate tube ID, cm (inch) & - $2.36(0.93)$ \\
\hline $\begin{array}{l}\text { Intermediate tube wall thickness, } \\
\text { mm (inch) }\end{array}$ & $\bullet \quad 0.889(0.035)$ \\
\hline - Outer tube OD, cm (inch) & - $4.22(1.66)$ \\
\hline - Outer tube ID, cm (inch) & - $3.66(1.44)$ \\
\hline $\begin{array}{l}\text { - Outer tube wall thickness, mm } \\
\text { (inch) }\end{array}$ & - $\quad 2.77(0.109)$ \\
\hline - Fin type & - Longitudinal rectangular \\
\hline - Fin surface area $\mathrm{m} 2 / \mathrm{m}(\mathrm{ft} 2 / \mathrm{ft})$ & - $\quad 0.347(1.14)$ \\
\hline - Fin Height, cm (inch) & - $0.95(0.38)$ \\
\hline - Fin Thickness, mm (inch) & - $\quad 2.54(0.1)$ \\
\hline - Fin Length, cm (inch) & - $\quad 25.4(10)$ \\
\hline - Number of Fins & - 18 \\
\hline - Material for plugging meter & - $9 \mathrm{Cr}-1 \mathrm{Mo}-\mathrm{V}$ \\
\hline $\begin{array}{l}\text { - Plugging filter wire diameter, } \mathrm{mm} \\
\text { (inch) }\end{array}$ & - TBD \\
\hline $\begin{array}{l}\text { Plugging filter density, } \mathrm{kg} / \mathrm{m}^{3} \\
\left(\mathrm{lbm} / \mathrm{ft}^{3}\right)\end{array}$ & - $\mathrm{TBD}$ \\
\hline - Plugging filter material & - $\mathrm{TBD}$ \\
\hline - Air Jacket OD, cm (inch) & - $7.30(2.88)$ \\
\hline - Air Jacket ID, cm (inch) & - $\quad 6.88(2.71)$ \\
\hline - Air Jacket wall thickness, mm (inch) & - $\quad 0.21(0.08)$ \\
\hline - $\quad$ Air Jacket Inlet ID, cm (inch) & - $4.5(1.77)$ \\
\hline - Number of Air Jacket Outlets & - 1 \\
\hline - Material for Air Jacket & $\begin{array}{l}\text { - } 304 \text { stainless steel or carbon } \\
\text { steel }\end{array}$ \\
\hline
\end{tabular}




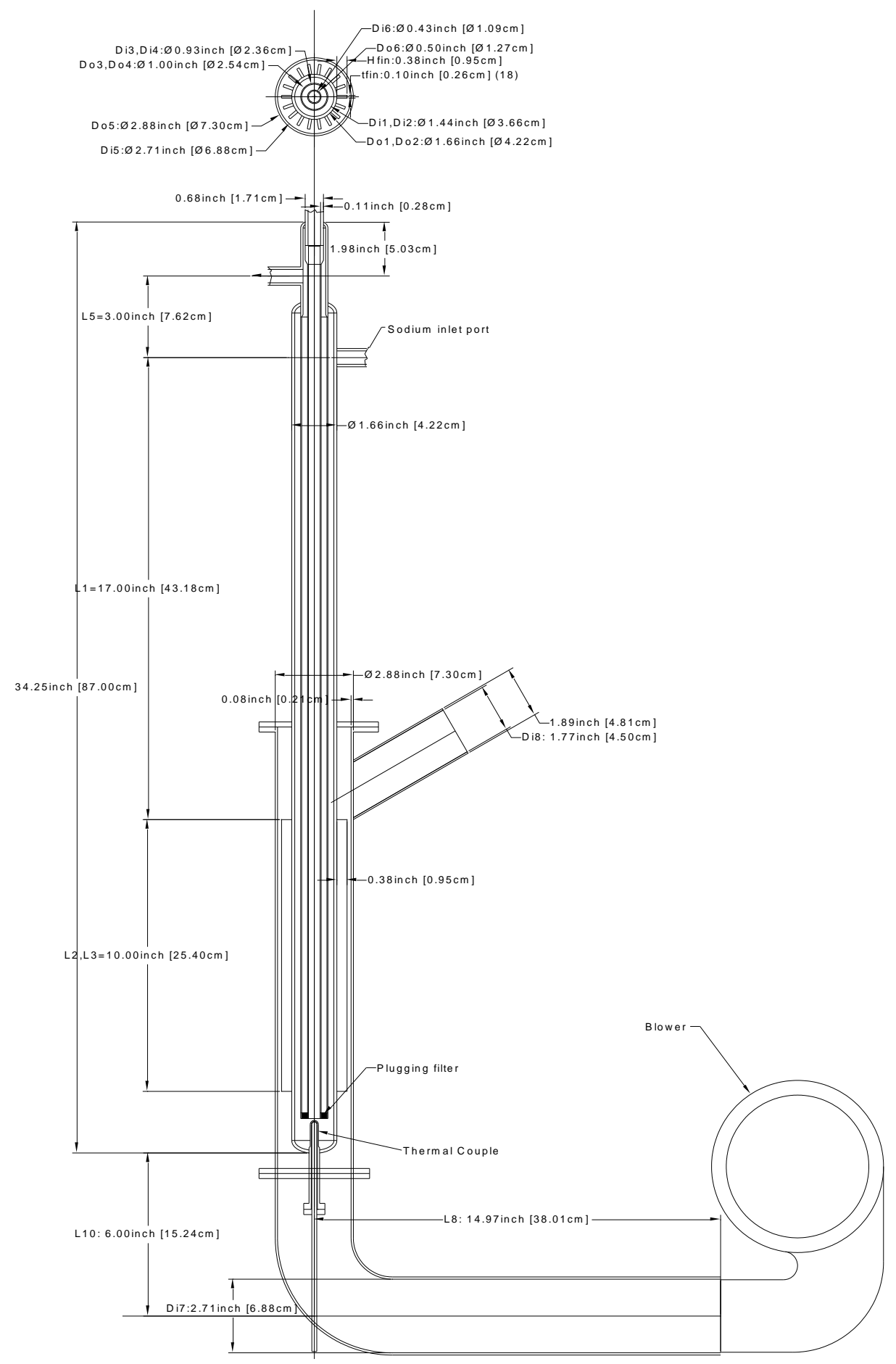

Figure 8-8: IHTS Plugging Meter Dimensions

\subsubsection{EM Pumps for the Recirculating Loops}

An EM pump in the recirculating loop provides a stable sodium pressure head for the IHTS loop through the expansion tank. The pump also provides the driving head to transport sodium from 
the main IHTS loop to the cold trap, plugging meter and sampling station. Lastly, the EM pump can provide the pressure head to refill the IHTS system after a sodium dump. The major pressure head loss the pump has to overcome are the pressure drop from the cold trap, the hydraulic head between the storage tank and the expansion tank, and the frictional losses from the pipes and components in the recirculating system. During normal sodium purification in the IHTS, the pump can provide a flow rate of up to $75 \mathrm{gpm}(284 \mathrm{~L} / \mathrm{min})$. The required pressure head for the pump is estimated to be about $70 \mathrm{psig}(483 \mathrm{kPa})$ at that flow rate. During sodium filling for the IHTS loop, two such pumps, connected in parallel, can be used for one loop to speed up the sodium filling process, or during emergency purification after an event such as a sodium-water reaction in the SG. Therefore, there are two design options for recirculating the sodium in the loop. The first option is to use two EM-pumps with flow rate of $75 \mathrm{gpm}(284 \mathrm{~L} / \mathrm{min})$ each and the head pressure of $70 \mathrm{psig}(483 \mathrm{kPa})$. The second option is to use one EM-pump with flow rate of $150 \mathrm{gpm}(568 \mathrm{~L} / \mathrm{min})$ and the head pressure of $70 \mathrm{psig}(483 \mathrm{kPa})$. The first option has the feature of redundancy and the second option may be more cost effective. In any case, the pump should be able to work in a range of near 0 to nominal full flow rate at a maximum temperature of $370^{\circ} \mathrm{C}$ $\left(700^{\circ} \mathrm{F}\right)$.

\subsubsection{Flow Meter for the Recirculating Loop}

\section{Flow Meters for Plugging Loops}

There are three (3) flowmeters in the plugging loop. The two flowmeters installed in the plugging line and bypass line are highly sensitive because the accuracy of the plugging temperature critically depends on sensing flow changes in these two loops. See FM1 and FM2 in Figure 8-9. The flow meter should be able to work in flow rate range of $0 \sim 68 \mathrm{~L} / \mathrm{hr}(0 \sim 0.3 \mathrm{gpm})$. The flow meter which measures the total flow through the plugging loop does not have to be as sensitive as FM1 and FM2. See FM in Figure 8-3. The flow rate range of this meter should also be of 0 68 $\mathrm{L} / \mathrm{hr}$. (0 0.3 gpm). All three flow meters should be able to work at maximum temperature of $370^{\circ} \mathrm{C}\left(700^{\circ} \mathrm{F}\right)$.

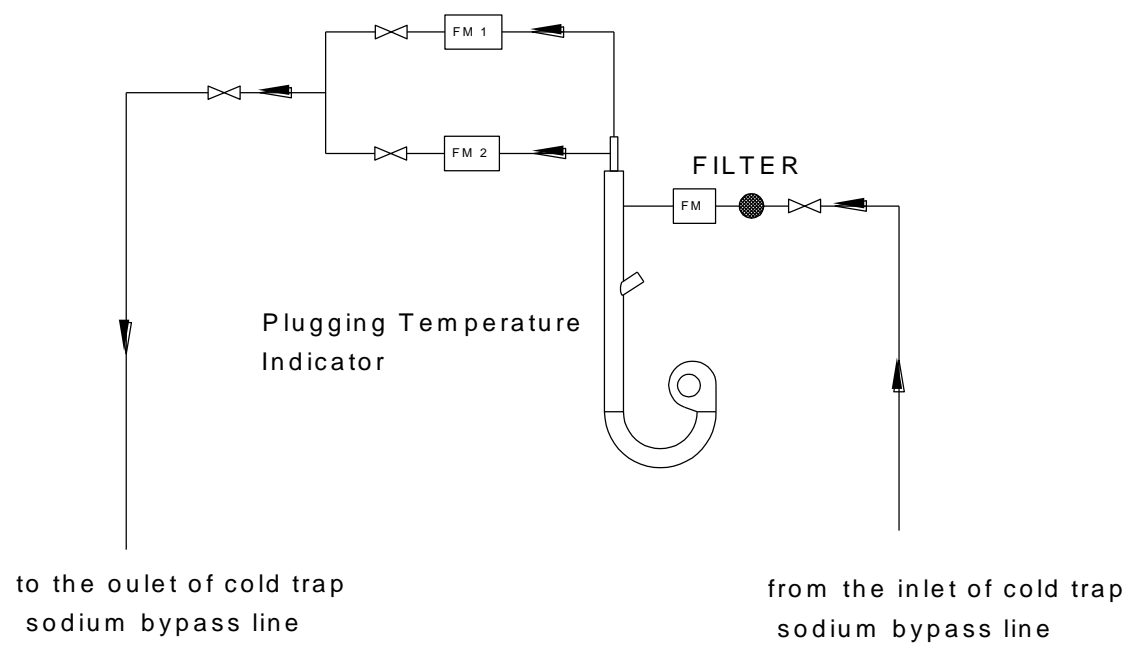

Figure 8-9: FASTER Secondary Sodium Plugging Loop 
Flow Meters for the Recirculating Loop

The flow meters in the recirculating loop monitor the sodium flow rate at up to $150 \mathrm{gpm}$. The temperature control of the cold trap is achieved by changing the sodium flow rate through the cold trap and changing the air flow rate in the air jacket. Sodium temperature can be adjusted by controlling sodium flow through the cold trap. The maximum temperature for the meters should be $370^{\circ} \mathrm{C}\left(700^{\circ} \mathrm{F}\right)$. 


\section{Instrumentation and Control}

\subsection{Plant Monitoring System}

The Plant Monitoring System (PMS) displays and logs plant process variables for use in determining plant state with respect to operation and safety. The process variables measured in the following four major systems are identified and described: the primary heat transport system, the intermediate heat transport system, the decay heat removal system, and the sodium-water pressure relief system. A description of the Balance of Plant (BOP) instrumentation is omitted as it is considered conventional technology.

\subsubsection{Primary Heat Transport System}

The Primary Heat Transport System (PHTS) removes heat from the reactor core and transfers it to the Intermediate Heat Transport System during normal operation. The primary system components are arranged in a pool-type layout with all the components residing within the reactor vessel. Sodium coolant is delivered to the core inlet plenum by mechanical pumps that take their suction from the cold pool. The sodium is heated as it passes through the core fuel subassemblies and then exits into the hot pool. From the hot pool the sodium flows into the primary side of the intermediate heat exchanger. The sodium exits the heat exchanger where it mixes with the coolant in the cold pool completing the coolant flow circuit. A capability to remove decay heat from the primary system is provided by the Direct Reactor Auxiliary Cooling System.

Monitoring systems are provided to enable the operator to determine that the PHTS is maintaining plant process variables in the design range for each mode of operation including regular operation, maintenance, shutdown, and refueling. A measured value is output to different locations according to its use. These locations can include the control room, the remote shutdown location, and panels local to the equipment where the value is measured. All sensors have an accompanying performance specification. This specification is derived from the intended use of the measured value. The specification for a sensor is determined by considering measurement requirements. Consideration is given to the following:

- Environment - The conditions (temperature, radiation, etc.) the sensor will need to operate in.

- Accuracy - An upper bound for the allowable uncertainty in the measured value.

- Range - The process variable range over which the sensor will need to operate while meeting accuracy and reliability requirements.

- Service Life - The value chosen should reflect how accessible the sensor is for maintenance and replacement tasks.

- Reliability - The probability that the sensor remains within specifications for its service life given the local environment.

Measurements are made of the following process variables that are important from an operation and safety standpoint. 


\section{Neutron Flux}

The neutron flux monitoring system has several functions: to provide measurements that aid in reactor startup and enable efficient plant control, to monitor reactivity changes during core operation, and to detect abnormal power conditions that could threaten the integrity of the fuel. As part of a test reactor, this system also provides neutron flux measurement to characterize irradiation conditions for test locations and assemblies. Thus, the flux monitoring system provides control signals for normal plant operation, signals to the plant protection system to initiate reactor protective trips, and measurements for the testing program. The system is capable of measuring the neutron flux level at all times and power levels from subcritical operations to above $150 \%$ of rated power.

Typically, fission chamber detectors will monitor neutron source flux level on a linear scale during startup and also on a wide-range log scale that covers a range of operation of approximately ten decades. A compensated ion chamber detector will monitor the neutron flux levels on a linear scale that covers power operation from approximately $1 \%$ up to $150 \%$. The power range detectors are used for reactor power control and for detecting the over-power condition for protection. Detectors are housed in air-cooled thimbles located on the outside periphery of the core shield.

\section{Temperature}

A temperature measurement system is used to sense process temperatures for indication of all important components and for forwarding signals for control functions, safety functions, and for continuous trend monitoring and plant heat balance and sodium inventory calculations.

Specific sensors include those to measure the sodium coolant temperatures exiting the fuel assemblies for control of reactor outlet temperature and for protection to detect coolant overtemperature; those for measuring reactor cold-leg and hot-leg temperatures for heat balance calculations; and those for measuring core inlet temperature for control and to detect high core inlet temperature for protection. The hot-leg temperatures for heat balance calculations are taken at the inlet of each intermediate heat exchanger. Additional sensors are provided for indication only. These are located at the IHX shell side outlet, at the decay heat exchanger shell-side inlet and decay heat exchanger shell-side outlet, in the upper internal structure region, on the reactor vessel surface, on the reactor head surface, in the PHTS cover gas, at the PHTS pump inlet, on the pump motor, on the reactor shield surface, and axially in the cold-pool sodium.

Resistance temperature detectors (RTDs) are used as the sensing elements to provide the accuracy required for heat balance calculations. They are installed in pairs to provide redundant measurements in the event of RTD failure. This is necessary due to inaccessibility of element locations during normal plant operation. For assemblies where the fuel handling machine prevents placement of thermocouples at their outlet, an indication of temperature conditions is obtained from neighboring subassemblies.

\section{Pressure}

A pressure measurement system is used to sense process pressures for indication of all important components and for forwarding signals for control functions and for safety functions. 
In additions, sensors will be provided to measure PHTS pump pressures for indication only. These sensors are provided for monitoring the hydraulic performance of the pump. The measurements will be taken at the outlet of the pump and the inlet of the pump. Additional indication measurements will be taken above the PHTS sodium in the cover gas, between the reactor and guard vessel, and in the fully-mixed region of the hot pool for use in calculating core pressure drop. IHX primary-side inlet pressure signal is also provided for comparison with the IHX intermediate-side outlet pressure signal. An alarm circuit monitors the differential pressure and alarms if the indicated IHTS to PHTS differential pressure drops below the alarm set point. This is to alert the operator that a minimum differential pressure has been violated.

Typically, sodium pressure is measured by transferring fluid pressure from the high temperature sodium process to a remotely mounted pressure sensor transmitter via an intermediate fluid $(\mathrm{NaK})$. Redundancy is provided where sensors are inaccessible during normal operation.

\section{Mass Flow Rate}

A coolant flow rate measurement system is used to sense process flow rate for indication and for forwarding signals for control functions and for safety functions. Sensors are provided to measure the sodium flow rate in each primary pump outlet pipe for use in indication, as a flow feedback signal to the PHTS controller (which is part of the plant control system), and for utilization in the protection system. The coolant flow rate is measured by a permanent magnet (PM) flow meter. Each flow magnet is provided with a thermocouple to detect over temperature. A flux measurement coil is also provided in each flow meter assembly. This device terminates at a local panel for utilization by a portable test instrument. For mechanical pumps, the flow rate can be inferred from measurements of pump motor speed and the pump performance curve. Additional flow rate sensors of ultrasonic or Venturi-type may be provided for diversity and redundancy in event of failure of the magnetic flow meter.

\section{Level}

A sodium level measurement system is used to sense the sodium level in the primary vessel hot pool and cold pool. The system is provided with both wide-range type and narrow-range sensors for indication and alarming. The wide-range probe is used to indicate during fill and drain and to provide maximum and minimum level alarm functions. The narrow-range probe is used for more accurate measurement of sodium level during normal power range operation for sodium inventory monitoring. The narrow-range probe signal is monitored by high and low level alarm units which alert the operator when normal operational limits have been exceeded. Some sensors are reserved for the plant protection system to measure hot-to-cold pool level differences. For level measurements, probes of the inductive type and acoustic type are typically used.

\section{Primary Pump}

The primary pump is of the centrifugal type and is driven by a coupled motor-generator set. A primary pump monitoring system is required to sense pump variables for indication, for forwarding signals to the plant control system for control functions, and to the plant protection system. Sensors to measure shaft speed for indication, control, and protection are provided. In particular, pump speed is an input signal to the primary coolant flow rate controller. The signal also serves as a diverse measurement of coolant flow rate for input to the high reactor flux/flow trip. Additional sensors are also needed to measure the following variables for indication and 
annunciation: motor voltage, motor current, motor vibration, stator temperature, and bearing temperature. These variables provide a measure of pump motor-generator health. The pump will be automatically tripped when an anomalous speed indication or operating condition is sensed. These conditions can be inferred by comparing the actual measurements against known relationships that exist during normal operation of the pump. The intent is to avoid conditions that lead to a pump shaft seizure.

\section{Sodium Leaks}

The primary system employs a double wall to ensure containment of the radioactive primary sodium. The reactor vessel (inner wall) contains the sodium and the guard vessel (outer wall) acts as a double containment in the event of a leak in the primary vessel. The annulus between the reactor and guard vessel walls is filled with an inert gas. This gas prevents fire in the annulus in the event of a leak in the reactor vessel. Sensors will be provided to detect any leakage of primary sodium from the reactor vessel into the annulus. The detector system consists of a contact probe and an associated electrical circuit. The probe is extended to the bottom of the annulus.

\section{$\underline{\text { Activity }}$}

Sensors will be provided to detect abnormal activity in the sodium cover gas. The detector system consists of gamma radiation detectors and an associated electrical circuit.

\section{Delayed Neutrons}

A Failed Fuel Detection and Location System (FFDLS) is provided to detect and locate a breach of the cladding of a fuel pin. The operation of the FFDLS relies on detecting phenomena associated with a breach. Any type of breach (other than from a fabrication defect) results from stress caused either by fission-gas pressure or by fuel-cladding mechanical interaction due to fuel swelling at high burn-up. A mechanistic sequence of fission-product release occurs to the primary system upon breach of cladding. Bond sodium above the breach site will be expelled by the pressure of stored gas in the plenum, bringing with it any surviving short-lived $(<55 \mathrm{~s})$ delayedneutron (DN) pre-cursors of $\mathrm{Cs}$, I, and $\mathrm{Br}$ that were released from the fuel by recoil and local diffusion and were dissolved in the bond. Subsequently, stable and long-lived fission gas will escape to the primary sodium and be entrained therein, both $\mathrm{Xe}$ and $\mathrm{Kr}$ being insoluble in sodium. The sodium containing the dissolved delayed-neutron precursors and the entrained fission gases ultimately enters the intermediate heat exchangers. On exiting the IHXs, radioactive $\mathrm{Xe}$ and $\mathrm{Kr}$ released from the breach will escape to the argon cover gas space and be detected, while the DN activity will rapidly dissipate.

The system consists of sensors for the detection and localization of a breach of the cladding of a fuel element for indication. The implementation of the failed-fuel localization capability requires that during fuel element fabrication the plenum region of each fuel element be charged with 1-2 $\mathrm{mL}$ of a mixture of stable $\mathrm{Xe}$ and $\mathrm{Kr}$ isotopes, each mixture unique to one core fuel assembly, or possibly to a group of fuel assemblies. An online mass spectrometer capable of accurately measuring the isotopic content of these noble gases will sample gas from an ancillary Cover Gas Cleanup System (CGCS) in order to identify which in-reactor assembly (or group of assemblies) contains the breached element. The CGCS will be required to control activity of the primary system at times of fuel failure. 
The FFDLS might potentially employ two different sensors to detect a breach: a Ge-Li $\gamma$ detector and its associated electronics to detect (and identify) a release of radioactive fission-gas isotopes; and a set of fission-chamber detectors along each of the four IHXs to monitor release of delayedneutron precursors. However, for the latter system the transport time of delayed-neutron precursors from the breach site through the hot pool to the IHX is significant compared to the half-lives of the precursors. Consequently the signal-to-noise ratio for detecting precursor emissions among the neutron background will be diminished. Additionally, the breach signal is limited to the initial blowdown of the sodium bond from a breach by pressurized stored fission gas in the plenum. The bond sodium that is ejected contains precursors present through diffusion and recoil which are in comparatively small concentrations compared to the fuel which stays behind. It is therefore judged impractical to attempt to sense a breach through delayed neutron detection. The FFDLS will additionally employ a mass spectrometer to provide a failed-fuel localization capability. The FFDLS system will be designed to interrogate a supply of cover gas that has been aged for $\geq 5 \mathrm{~min}$ in order to suppress the activity of short-lived $(37 \mathrm{sec}){ }^{23} \mathrm{Ne}$ (an activation product of primary sodium).

\section{$\underline{\text { Seismic }}$}

Sensors will be provided to detect seismic motion for input to the plant protection system for reactor shutdown function. Detectors for both horizontal and vertical motion will be provided for sensing seismic activity.

\section{Control Rod Position}

Sensors will be provided to detect control rod position for indication and for input to PHTS power control system. Diverse detectors to measure control rod position will be adopted.

\subsubsection{Intermediate Heat Transport System}

The Intermediate Heat Transport System (IHTS) transfers heat from the primary system to the balance of plant during normal operation. The IHTS serves to isolate the radioactive primary system sodium from the water coolant in the balance of plant. The IHTS is equipped with a pressure relief system to prevent pressurization of the primary system in the event of a steam generator tube leak. High pressure water would flow into the IHTS and react chemically with the sodium to produce hydrogen gas and produce an increase in pressure. Measurements are made of the following process variables that are important from an operational and safety standpoint.

\section{Temperature}

A temperature measurement system is used to sense process temperatures for indication of all important components and for forwarding signals for control functions, for safety functions, and for continuous trend monitoring and plant heat balance and sodium inventory calculations. More specifically, sensors will be provided to measure sodium temperatures at the steam generator shell-side outlet for display and for input to the reactor shutdown logic to detect the loss of heat sink event. Additional sensors measure for display of sodium temperatures at the steam generator shell-side inlet. The intermediate system flow rate measurement will be calibrated by means of an IHTS heat balance by measuring sodium temperatures at the IHX tube-side inlet and outlet. Additional sensors are provided to measure sodium temperatures in the Sodium Storage Tank, Sodium Expansion Tank, Sodium Expansion Tank cover gas, and Sodium Storage Tank cover gas. 
Sodium temperatures are measured at the inlet and outlet pipes of each steam generator. Dual element RTDs are used at each location as the sensing device to provide the accuracy required for heat balance and sodium inventory calculations. RTDs provide relatively slow response and high accuracy and are installed in thermowells. The dual element feature provides an operational spare in the event of an RTD failure.

\section{Pressure}

A pressure measurement system is required to sense process pressures for indication of all important components and for forwarding signals to the plant control system for control functions and to the plant protection system for safety functions. Sensors are provided for measuring the sodium pressure at the sodium pump inlet and outlet in each loop and for monitoring pump hydraulic performance. Additional sensors measure the expansion tank (ET) cover gas pressure and sodium storage tank cover gas pressure as well as sodium pressure at the IHX tube-side outlet for alarming on low intermediate-to-primary system pressure differential and for monitoring differential pressures between intermediate loops.

For each location, pressure is measured by transferring fluid pressure from the high temperature sodium process to a remote mounted pressure sensor transmitter via an alternative fluid (NaK).

\section{Mass Flow Rate}

A coolant mass flow rate measurement system is used to sense process flow rate for indication of the intermediate system and for forwarding signals for control functions and for safety functions. Sensors are provided to measure IHTS sodium flow rate for display, for input to the IHTS flow control system, and for input to the PCS for PHTS/IHTS flow ratio trip/alarm signal. The sodium flow rate is measured with a PM flow meter. The flow meter is installed around piping. A flux measurement coil is also provided in each flow meter assembly. This device terminates at a local panel for utilization by a portable test instrument.

\section{Level}

Sensors are provided to measure sodium level in the IHTS expansion tank and sodium storage tank for each IHTS loop. These measurements are used to determine the fill and normal operating levels for: information to the plant operator of the sodium level in each loop for normal plant control, evaluation of the IHTS leakage, sodium inventory calculations, and detection/alarm of off-normal high/low levels. For the expansion tank an alarm signal indicating achievement of the IHTS fill level from the narrow range level probe or an excessive level drop from the wide range level probe is sent to the PCS. The PCS alerts the operator to terminate the IHTS fill via the pump control system and the alignment of the valves. Each expansion tank has a separate high level alarm which is used for indication of high sodium level due to an intermediate size sodium/water reaction event. Sodium inductive level probes are used to measure level.

\section{Sodium Leak}

Several probe type leak detectors are installed in intermediate system components to detect the leakage of sodium due to failure of components and pipes. Failure of a component may result in the leakage of sodium into the bottom of the component casing. If sufficient sodium accumulates, 
it will cause an electrical circuit shortage between the leak detector electrode and the component casing. The electrical shortage will actuate an alarm in the control room.

Sensors are provided for monitoring hot-leg leakage, cold-leg leakage, expansion tank piping leakage, expansion tank leakage, and sodium storage tank leakage. Additional sensor monitor leakage on bellows sealed valves to detect bellows failure. All leak detectors consist of electrode type probes located near the bottom of a component and connected to an electrical circuit.

\section{Hydrogen Concentration}

The presence of hydrogen in significant concentrations in the IHTS is an indicator of a sodiumwater reaction resulting from a steam generator tube leak. Sensors are provided to measure for display and annunciation of the hydrogen gas concentration in the intermediate sodium in the pipe exiting the steam generator and in the shell near the exit of the steam generator and in the cover gas of the expansion tank.

\section{Intermediate Pumps}

The IHTS pump is an electromagnetic pump. An intermediate system pump monitoring system is required to sense pump variables for display and for forwarding signals to the plant control system for control functions.

\section{$\underline{\text { Seismic }}$}

Sensors are provided to detect seismic motion for input to plant protection system for reactor shutdown function. Sensors are to monitor both in-containment and out-of-containment piping. Detectors for both horizontal and vertical motion will be provided for sensing seismic activity.

\subsubsection{Decay Heat Removal System}

The Direct Reactor Auxiliary Cooling System (DRACS) provides a means for removing heat from the primary system after reactor shutdown. The DRACS heat exchanger (3) (a tube-andshell HX) is submerged in the FASTER reactor vessel cold pool. It is connected via piping to an air dump heat exchanger (AHX) located outside of containment. Dampers on the AHX minimize the parasitic losses from the emergency decay heat removal system during normal operation and will open fully upon a protective signal or loss of power. Measurements are made of the following process variables that are important from a safety standpoint.

\section{Temperature}

Sensors are provided to measure the temperatures of the three in-vessel decay heat exchangers. These sensors are mounted immediately above where the DRACS piping penetrates the vessel deck. These sensors are not subjected to high radiation fields since the DRACS coolant does not become significantly radioactive while inside the primary vessel. However, these sensors are exposed to relatively high-temperatures associated with the primary vessel sodium. Additional sensors measure the temperature of the three air heat exchangers at the air inlet to the shell-side of the air natural convection heat exchanger and at the outlet. Sensors are also needed to measure the sodium temperature in the DRACS sodium expansion tank and the cover gas temperature in the DRACS sodium expansion tank. 
Finally, additional sensors measure the air temperature at the outlet of the DRACS stacks. All temperatures are measured with thermocouples.

\section{Pressure}

Sensors are provided to measure the expansion tank cover gas pressure and to measure the differential pressure across the DRACS. Pressure is measured by transferring fluid pressure from the high temperature sodium process to a remote mounted pressure sensor transmitter via $\mathrm{NaK}$ fluid.

\section{Mass Flow Rate}

Sensors are provided to measure the sodium flow rate in the DRACS coolant circuit as well as the air flow rate in the stack of each of the four DRACS air heat exchangers. The sodium flow rate is measured with a permanent magnet flow meter. The flow meter is installed around piping. A flux measurement coil is also provided in each flow meter assembly.

\section{Level}

A level measuring system on the expansion tank of each DRACS coolant circuit is able to detect a leak in the DRACS coolant circuit to be inferred through a change in level. Sodium inductive level probes are used to measure level.

\section{Sodium Leak}

Several probe type leak detectors are installed in DRACS components to detect for the leakage of sodium due to failure of components and pipes. Failure of a component may result in the leakage of sodium into the bottom of the component casing. If sufficient sodium accumulates, it will cause an electrical circuit shortage between the leak detector electrode and the component casing. The electrical shortage will actuate an alarm in the control room. All leak detectors consist of electrode type probes located near the bottom of a component and connected to an electrical circuit.

\section{Louver Position}

A dedicated sensor measures mechanical position of the louvers on each air dump heat exchanger. This measurement is provided as an input signal to the louver position controller.

\subsubsection{Sodium-Water Pressure Relief System}

The sodium-water pressure relief system is designed to accommodate a pressure surge in the IHTS in the event of a sodium-water reaction in a steam generator. The pressure relief capability is enabled by rupture-disc assemblies. Each assembly contains two rupture discs in series. In the event of a small water-sodium reaction, the IHTS expansion tank is provided with a rupture-disc assembly for IHTS pressure relief. A line connects the cover gas region of the IHTS expansion tank with the cover gas region of the IHTS Sodium Storage Tank (SST). The rupture-disc assembly in this line normally prevents the two regions from communicating hydraulically through this line. However, upon a water-sodium reaction event, the pressure in the expansion tank would increase along with the pressure in rest of the IHTS. The rupture disc bursts (the SST was up to this point isolated from the IHTS through rupture disc assemblies) and opens a path to the SST for IHTS pressure relief. In the event of a large water-to-sodium reaction, a Sodium Dump Tank (SDT) (also known as a Reaction Product Separator Tank) is provided in each IHTS 
loop for discharge of sodium from the IHTS after the sodium has been contaminated by sodiumwater reaction products. A rupture-disc assembly is installed in a pipe line (Reaction Products Vent Line) that tees off of the main IHTS loop piping. IHTS sodium is present on that side of the assembly that connects to the loop piping. The rupture discs are designed to rupture upon overpressure of IHTS sodium providing a path for the sodium to flow through the assembly. Multiple assemblies are strategically located in the main IHTS loop piping to provide a path for sodium to flow to the SDT to relieve the pressure. The reaction products that accumulate in the SDT are propelled into a cyclone separator upon rupture of a downstream rupture-disc assembly. Solids that separate out are returned to the SDT while gases pass on through this ruptured rupture-disk assembly, through a hydrogen igniter, and out a stack to the atmosphere. Several instrumentation and control systems are dedicated to the quantities of greater relevance and interest such as:

\section{Temperature}

A series of temperature measurements for display is to be provided along a path that traces the egress of water-sodium reaction products out of the IHTS piping. The path begins upstream of one of the rupture-disc assemblies that tees off of the main IHTS piping circuit. The path continues through the assembly, on to the sodium dump tank, through an exit pipe to a liquidvapor cyclone separator, through a rupture-disk assembly, through a hydrogen igniter, and out a flare stack. All temperatures are measured with thermocouples.

\section{Pressure}

Sensors are provided for pressure measurement immediately downstream from the rupture-disk assembly in the Reaction Products Vent Line and in the Sodium Dump Tank. The signals are transmitted to the plant protection system for shutdown. The pressure is sensed by a pressure indicating switch which provides a signal for annunciation.

\section{Level}

Sodium inductive level probes are provided for level measurement in the Sodium Dump Tank.

\section{Sodium Leak}

Sensors are provided in the gas space between each rupture disk pair to detect leakage past the first rupture disk and downstream of the rupture disc in the pipes leading to the Sodium Dump Tank. The leak detectors will be of the spark-plug type.

\subsection{Plant Control System}

The purpose of the Plant Control System (PCS) is to maintain the neutron flux, coolant flow rates, and other plant processes at levels that meet requirements imposed to ensure safety, efficiency and protection of plant equipment. The PCS is responsible for plant control during start-up, power generation, shutdown, and standby. It monitors and regulates the neutron flux and compensates reactivity changes resulting from fuel burnup, temperature effects, and other factors. The PCS is responsible for coordinating the operation of the nuclear island systems with those of the power conversion system and the auxiliary systems. The PCS shall provide a Supervisory Control System (SCS) to manage the actions of low-level control systems so as to achieve overall plant operating objectives. The SCS shall have the capability to coordinate, as a function of plant state and target state, the setpoints of the individual lower-level controllers. It also has the capability to enable/disable through interlocks the plant control systems whose operation is operating-mode 
(i.e., startup, at-power operation, shutdown maintenance, and refueling) dependent. It is required that when the plant is at-power and generating electricity, the SCS is controlling the plant operation. However, the operator shall have the capability to take manual control of the plant. This will satisfy the regulatory requirement that the operator be ultimately responsible for control of the plant.

\subsubsection{Principles of Operation}

The function of the plant control system is to regulate the plant variables consistent with irradiation needs and electricity production while maintaining a balance between power production and heat removal so that plant temperatures remain within safe limits. This is achieved by sensing plant process variables and appropriately commanding actuators. Reactor heat production is managed by motor driven neutron absorbers while heat removal is managed by variable flow rate pumps. By combining rod reactivity and flow rate changes it is possible to keep the reactor coolant inlet and outlet temperatures essentially constant over the assigned load range. All licensed reactors exhibit a degree of self-regulation when it comes to maintaining core power in balance with heat removal rate. In the case of FASTER this inherent property is particularly pronounced. The feedback control systems that are developed in this report take advantage of this to improve safety and operability. On a very basic level these improvements stem from the need for less control rod motion compared to other reactor types. This is largely a result of a small fuel temperature rise compared to the coolant temperature rise, a characteristic of metal fuel. The quasi-static reactivity model provides a clear and easily understood representation for how core power and temperature are linked and the role of control rods for controlling reactor power. The time constants of the temperature feedback processes are such that the temperatures that are responsible for feedbacks are essentially in equilibrium with the instantaneous power, flow rate, and inlet temperature. A quasi-static reactivity balance on the reactor gives, relative to some equilibrium zero-reactivity reference state

$$
\rho_{n e t}=A(P-1)+B\left(\frac{P}{W}-1\right)+C \delta T_{i}+\rho_{e x t}
$$

where

$$
\begin{aligned}
& P=p / p_{0}, \quad W=w_{p} / w_{p_{0}}, \quad \delta T_{i}=T_{i}-T_{i_{0}}, \\
& A=\alpha_{d} \Delta T_{f 0}, \\
& B=\left(\frac{\alpha_{r}}{2}+\alpha_{c r}+\frac{\alpha_{N a}}{2}+\frac{\alpha_{d}}{2}+\frac{\alpha_{e}}{2}+\alpha_{b}\right) \Delta T_{c 0}, \\
& C=\alpha_{r}+\alpha_{c r}+\alpha_{v}+\alpha_{N a}+\alpha_{d}+\alpha_{e}
\end{aligned}
$$

where $p$ is power, $w_{p}$ is primary flow rate, $T_{i}$ is reactor inlet temperature, and a reference state is identified by the subscript 0 . The subscript ext denotes external reactivity; $\alpha$ is a temperature reactivity feedback coefficient with $d, r, c r, v, N a, e$, and $b$ denoting Doppler feedback, core radial expansion, control rod expansion, vessel expansion, coolant density, fuel axial expansion, and bowing, respectively. $\Delta T$ is core temperature rise, and subscripts $f$ and $c$ denote fuel and coolant respectively. 
An ideal scenario for control of reactor power in an SFR is for normalized power to very nearly equal normalized coolant mass flow rate over the operating power range without the need for control rod reactivity. Then reactor temperature rise is near constant with power, and temperature variation with load is avoided so that thermal fatigue of structures is minimized. Further, the need for rod motion is minimized, which has safety advantages. The condition under which this scenario is approached is deduced by inspection of Eq. 9-2. It occurs for a large value of $B$ compared to $A$ which implies that the power-to-flow ratio $(P / W)$ will remain near unity over the mass flow rate range, and hence power range, without the need for significant control rod reactivity. The power-to-flow ratio with no control rod motion over the load range then is a convenient figure of merit for assessing the degree to which power inherently follows flow. A value of unity gives the ideal scenario described above. An expression for the normalized powerto-flow ratio is obtained from Eq. (7.1),

$$
\frac{P}{W}=\frac{A+B}{A W+B}
$$

where it is assumed inlet temperature and rod reactivity remain constant. This figure of merit as calculated for the FASTER core, which uses metal fuel, is compared with that of a representative oxide-fueled core. The comparison, presented in Table 9-1, indicates that the metal core has a much greater natural tendency for its power to follow coolant mass flow rate. That is, the core power can be maneuvered over the load range using flow rate alone while maintaining nearconstant core temperature rise i.e., without the need for control rod reactivity addition.

Table 9-1: Comparison for Metal and Oxide Cores of Tendency of Core Power to Inherently Follow Flow

\begin{tabular}{clcc}
\multicolumn{4}{c}{ Rate } \\
\hline & & Metal & Oxide \\
\hline & $A, \$$ & -0.339 & -1.24 \\
& $B, \$$ & -1.414 & -0.50 \\
$\frac{P}{W}$ & $W=100 \%$ & 1 & 1 \\
& $W=30 \%$ & 1.15 & 2.00 \\
\hline
\end{tabular}

\subsubsection{Operating Strategy}

The design strategy for the control system decomposes the plant response to a change in electric generator load into two components. Different physical phenomena control each. There is the equilibrium state the plant will reach asymptotically in time (i.e., steady-state) in response to the perturbed condition, and there is the dynamic component of the response (i.e., transient) which can be regarded as superimposed on the asymptotic state. In turn, the plant temperature response is regarded as being controlled by two different controllers. The steady-state control algorithm, or load schedule as it is known, manages steady state temperatures. The dynamic controller manages the dynamic response component.

\section{Steady-State}

The load schedule specifies over the load range how the control variables, e.g., steam, primary and intermediate system flow rate, and control rod position - are coordinated as functions of 
steady-state electric load. The load schedule also identifies the resulting plant temperatures and pressures including the values of the controlled variables, i.e., those variables called out as requiring that their values be explicitly set over the load range. The number of controlled variables is equal to the number of actuators that can be independently varied. If there are four actuators, then the values of four process variables can be set arbitrarily and independently of one another, to the extent that the plant physics permit. Plant power is normally included as a controlled variable.

The selection of controlled variables is as follows:

- Steam temperature is to be maintained constant to minimize thermal stress in the turbine.

- Primary cold pool temperature is to be maintained constant since it has a large thermal mass and is not readily maneuvered.

- Reactor outlet temperature is to be maintained constant to avoid thermal stresses in the upper internal structures and the hot side temperatures of the nuclear steam supply system (NSSS). Or equivalently, the core power-to-flow ratio is to be maintained constant.

The values of these three variables (and plant power) are controlled through primary, intermediate, and steam flow rates, and control rod reactivity. The feedwater pressure is a boundary condition and is held constant over the load range. The feed water temperature is also a boundary condition. Its effect on the load schedule is, however, examined parametrically. The controlled and control variables are summarized in Figure 9-1.

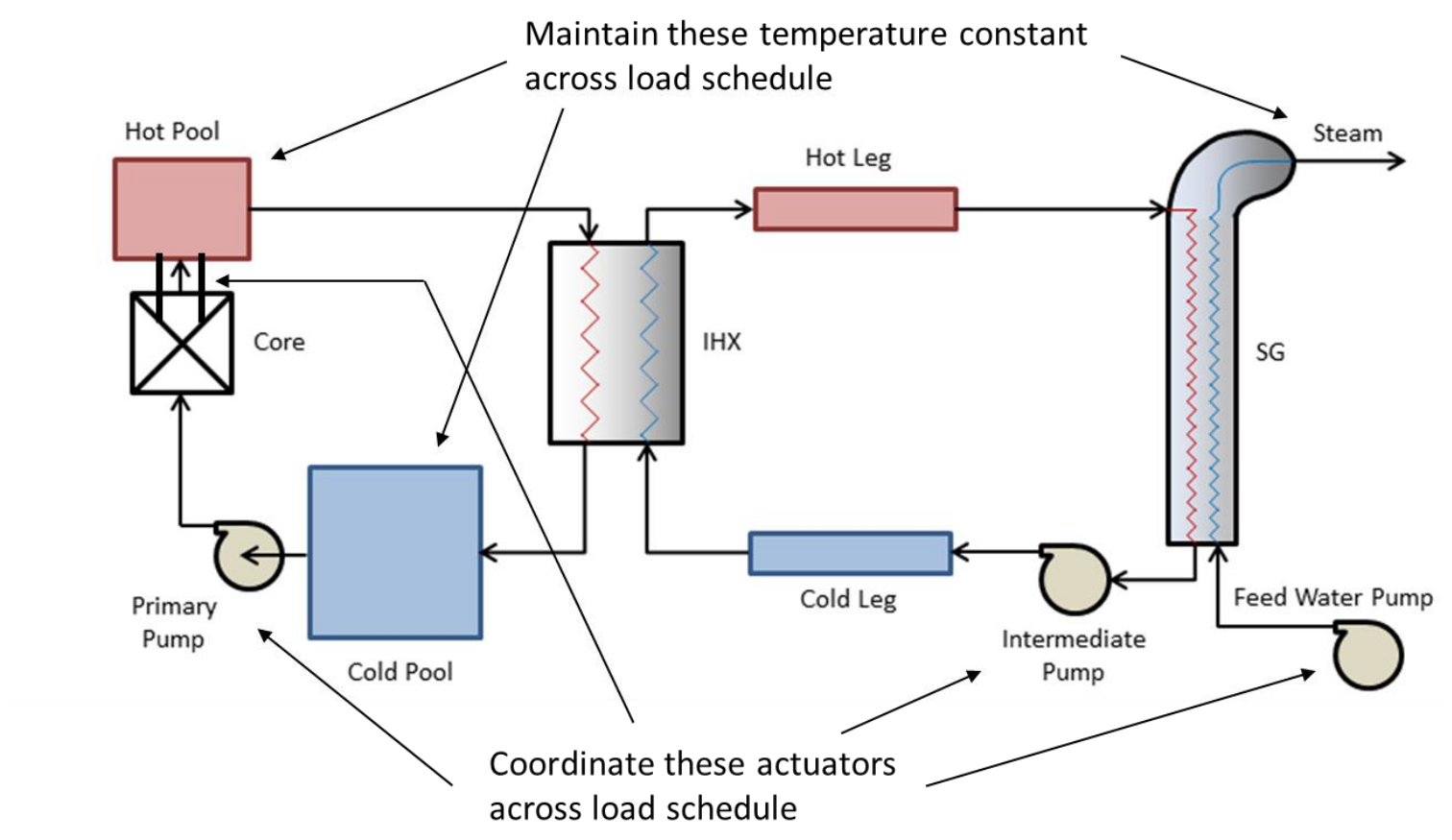

Figure 9-1: Schematic of Plant Showing Control and Controlled Variables

\section{$\underline{\text { Transient }}$}

The transient component of the plant response is shaped by the dynamic sub-system controllers. These controllers use feedback control loops to reshape the inherent dynamic response of the 
plant which is a function of plant component time constants and natural feedback mechanisms. The objective of the dynamic controllers is to limit rapid changes in temperature that would otherwise occur during transients as a result of imbalances between power production and heat removal rate. The approach is to try to keep the controlled process variables near their load schedule value given the instantaneous electric power. As steam power changes in time, the instantaneous value is used to index into the load schedule to return the values of controlled variables. The feedback controllers are designed to force the value of the controlled variable back to the instantaneous load-schedule value.

\subsubsection{Architecture}

The supervisory control system uses a hierarchical structure for coordinating actuators so that the steady state and transient objectives described above are met. The supervisory control system design as it presently exists for FASTER is shown in Figure 9-2. The design has four levels of functionality, hence the term "hierarchical". The levels are: supervisory controller, subsystem controllers, actuator-local controllers, and actuators. The design specific details of each level are described in this section.

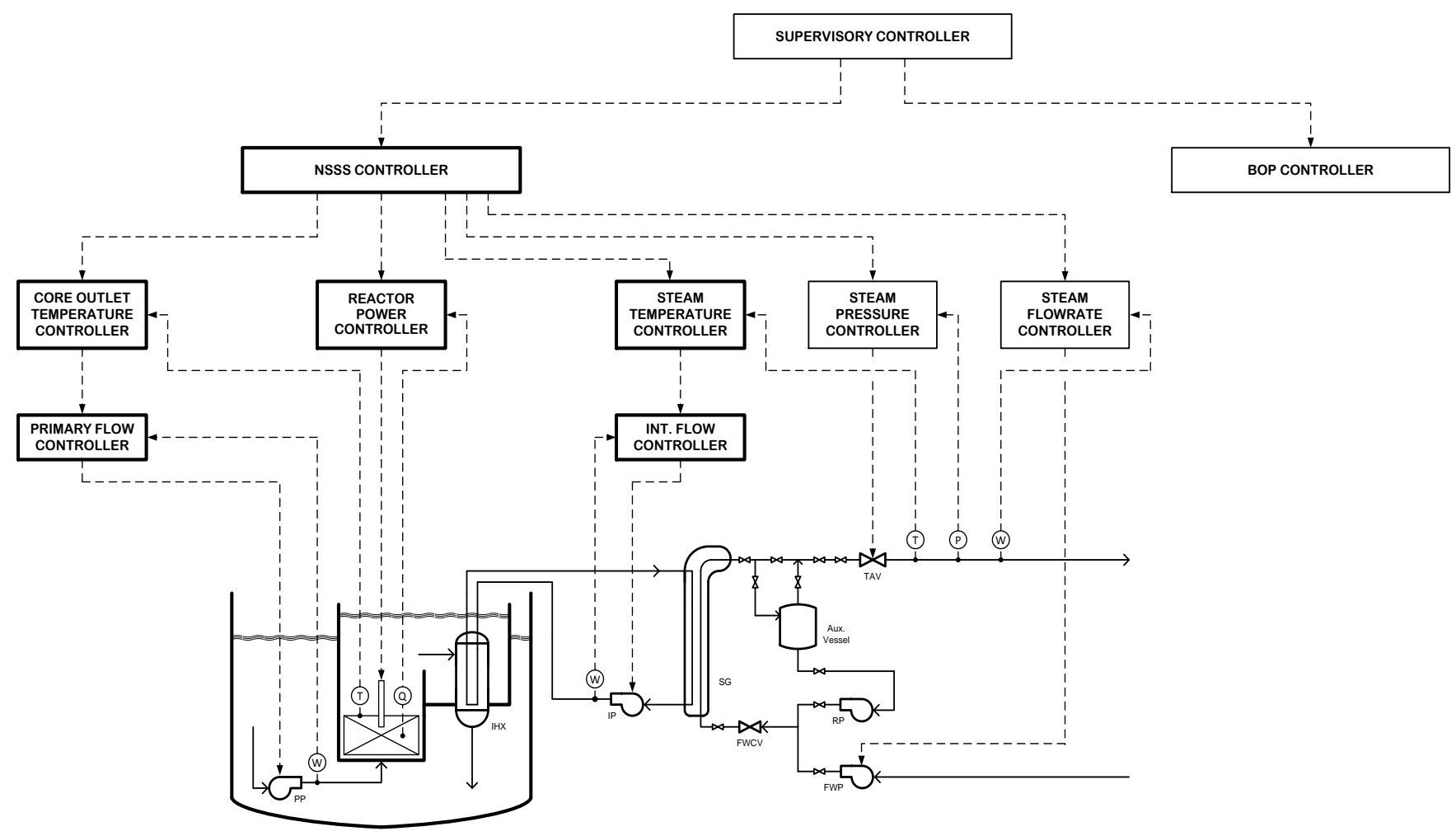

Figure 9-2: Schematic of Supervisory Control System

The general concept of operation of the supervisory control system, based on a level-by-level description, is as follows. A demand signal for steam is received. The demand value is input to the supervisory controller which in turn provides an appropriate setpoint value for each of the subsystem controllers at the level below. The subsystem controllers in turn command actuators such that the actuators deliver on the setpoint value. The setpoint has units of a controlled process variable, for example mass flow rate or reactivity. The actuators themselves are driven by inputs 
that typically have units different from the setpoint signal coming from the subsystem controller. Typical units are voltage or current if the commanding signal is electrical in nature. Or for an actuator whose mechanical behavior is known but perhaps its electromotive characteristics are not yet known (early design stage), or are not modeled, then the commanding signal might be mechanical torque or power. The job of the actuator-local controller is to make this unit conversion and deliver the controlled process variable value by accepting the subsystem process variable setpoint and appropriately commanding the actuator at the lowest level.

\section{Supervisory Controller}

The supervisory controller accepts the current demand for steam flow demand and uses this to index into the load schedule to retrieve values for the controlled variables. These values act as setpoints for lower level subsystem controllers. This is illustrated schematically in Figure 9-3where the setpoints into the subsystem controllers are labeled.

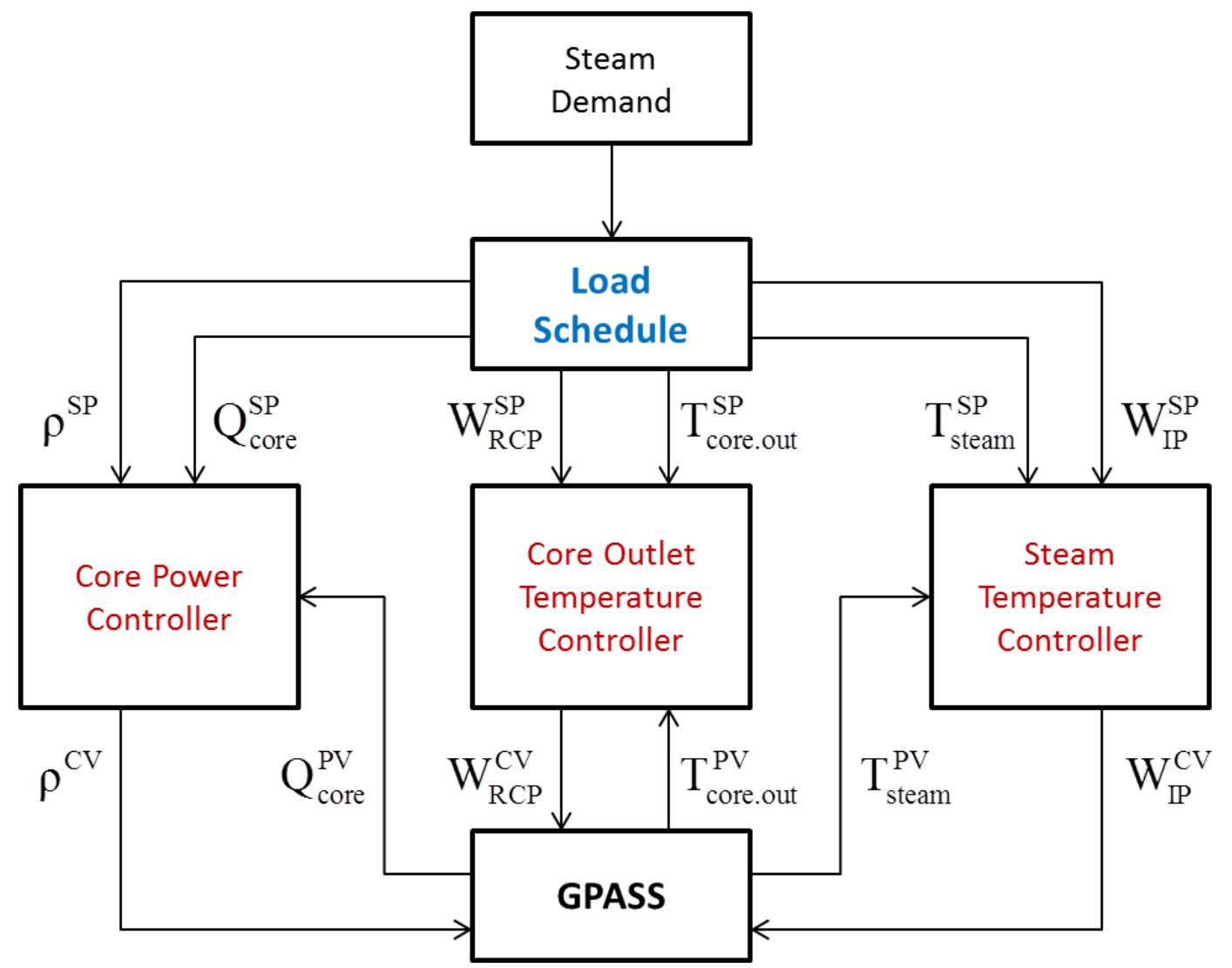

Figure 9-3: Supervisory Control System. $\mathrm{SP}=$ Setpoint, $\mathrm{PV}=$ Process variable, $\mathrm{CV}=$ Controlled Variable

The load schedule specifies the values of the control variables needed to achieve the desired values for the controlled variables at each steady-state power in the $30-100 \%$ normal operating range. The load schedule is prepared by providing values for the controlled variables (knowns) and solving the plant thermal-hydraulic equations for the values of the controlled variables (unknowns). A series of such calculations over the load range yields the load schedule. 


\section{Subsystem Controllers}

The subsystem controllers each individually regulate one controlled variable to maintain its value close to the load schedule during a transient. The controller compares the setpoint with the measured process variable to generate an error signal. The error signal is input to a proportionalintegral (PI) controller that generates an output signal for the associated controlled variable that acts to drive the error to zero over time. Then operating simultaneously but independently of each other, as shown in Figure 9-3, the entire plant is maintained at approximately the load schedule. Each of the three subsystem controllers is described below. The core power controller is shown in Figure 9-4. Core power is directly controlled by control rod action. By comparing current core power and set point core power from the load schedule, core power error is estimated forwarded to a PI controller which calculates control rod reactivity to drive the error to zero.

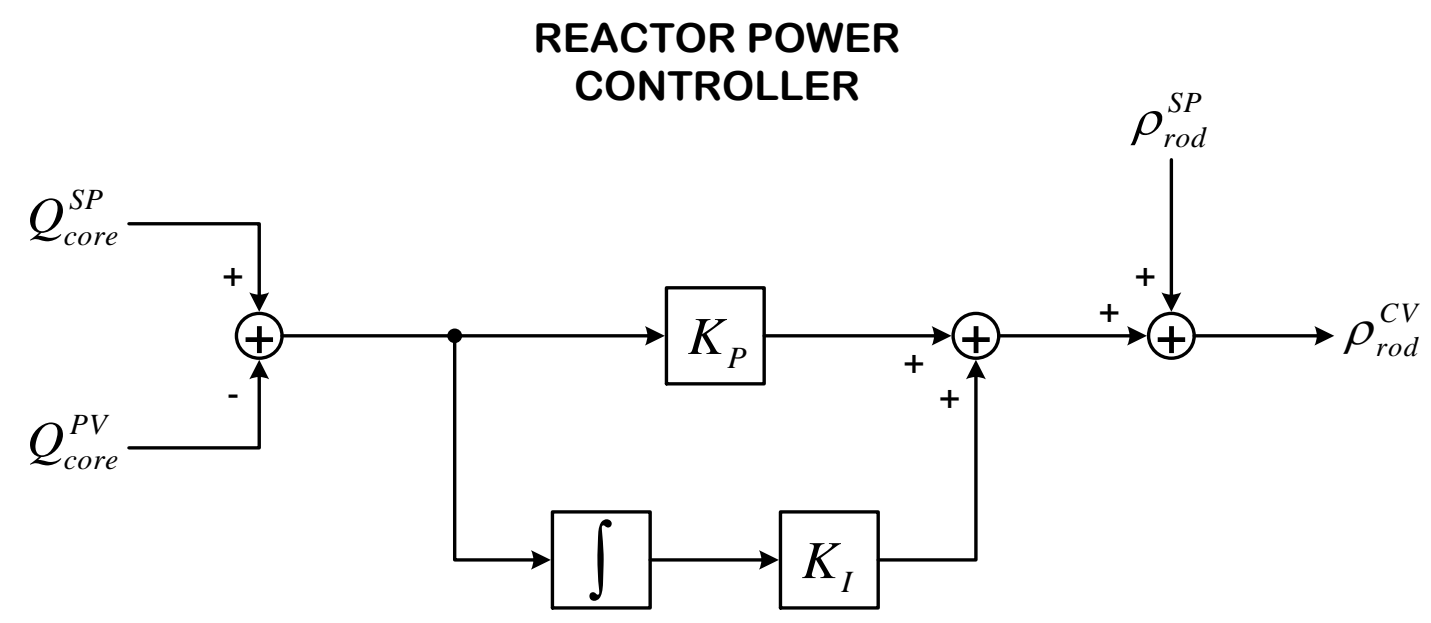

Figure 9-4: Core Power Subsystem Controller

The core outlet temperature controller is shown in Figure 9-5. Core outlet temperature is controlled by varying the primary sodium pump flow rate. By comparing current core outlet temperature with its set point value from the load schedule, core outlet temperature error is calculated and is forwarded to a PI controller to control the pump primary.

CORE OUTLET TEMPERATURE CONTROLLER

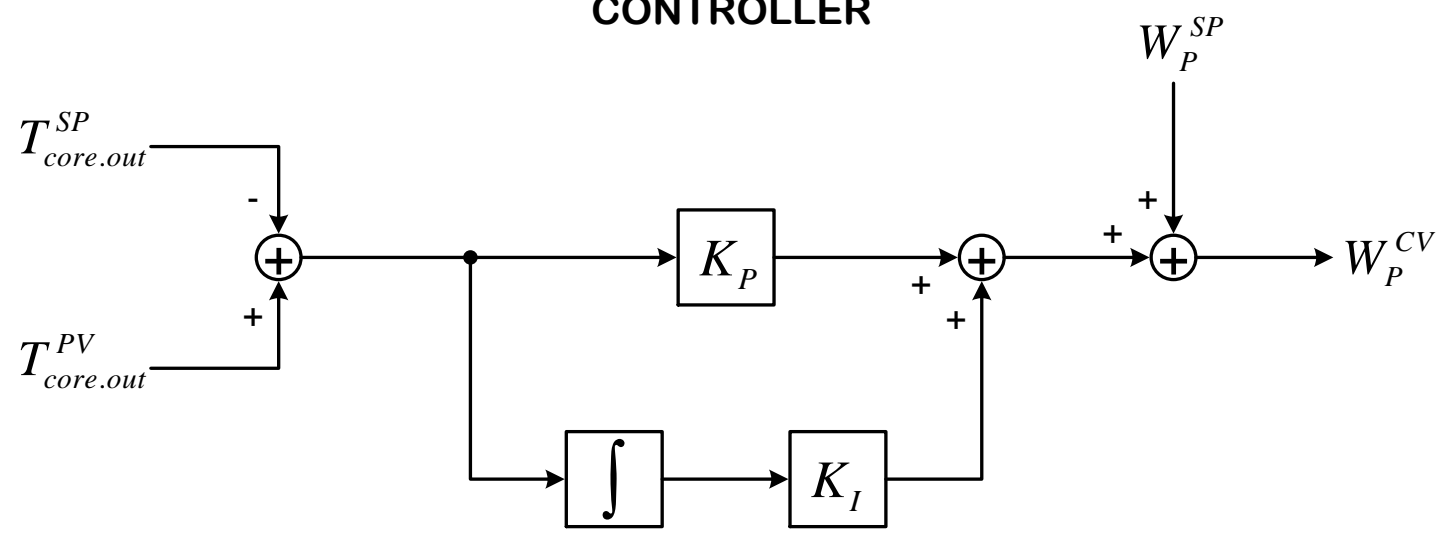

Figure 9-5: Core Outlet Temperature Controller 
The steam temperature controller is shown in Figure 9-6. To control the steam temperature, intermediate sodium flow rate is varied. By comparing current steam temperature with its set point value from load schedule, steam temperature error is calculated and is forwarded to a PI controller to vary the intermediate system mass flow rate to regulate the steam temperature.

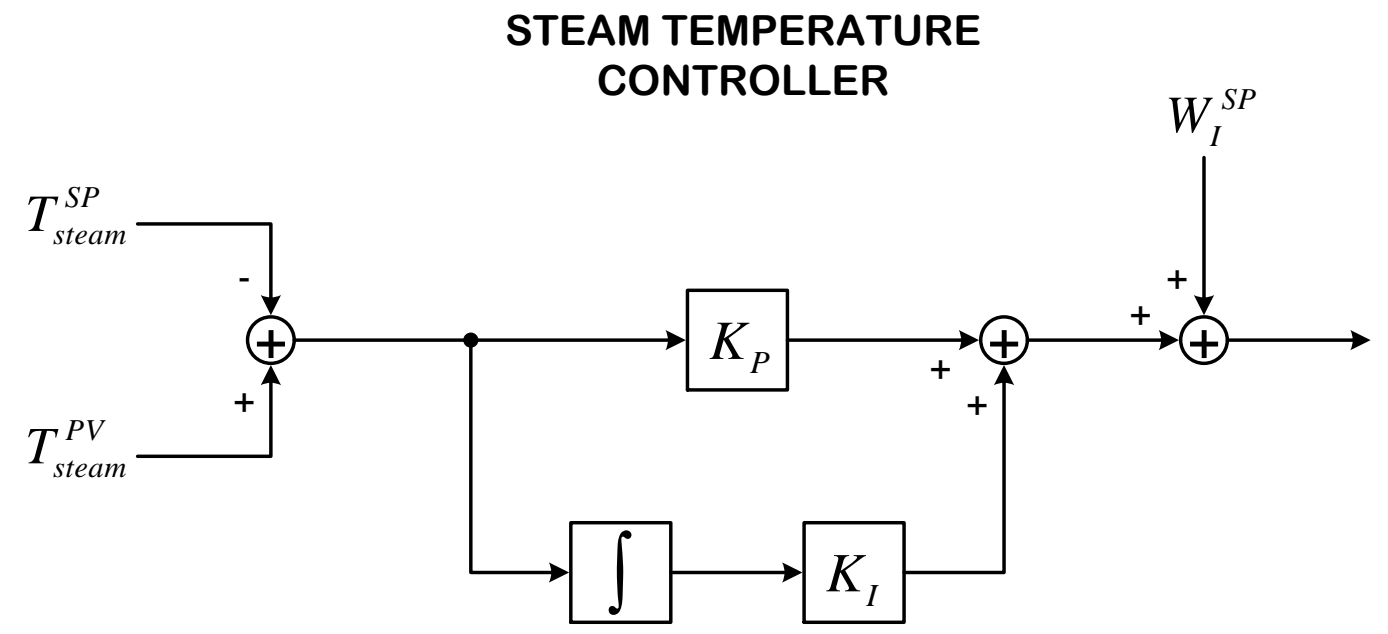

Figure 9-6: Steam Temperature Controller

\section{Actuator-Local Controllers}

An actuator that is required to control a process variable does not normally come equipped with a setpoint-driven feedback controller to accomplish this. Such a controller tends to be application specific as it requires (1) a sensor to measure the variable to be controlled (such a sensor is application specific), and (2) the units of the signal commanding the actuator are in general different from the controlled process variable. A case in point is the primary and intermediate system pumps. Typically these pumps are driven by voltage while flowrate is the controlled variable. An application-specific feedback controller therefore is needed that accepts a mass flow rate setpoint while driving the voltage in a manner that forces the mass flowrate error signal to go to zero. The introduction of the actuator-local controller for the core outlet temperature controller and the steam temperature controller are shown in Figure 9-7 and Figure 9-8, respectively. 


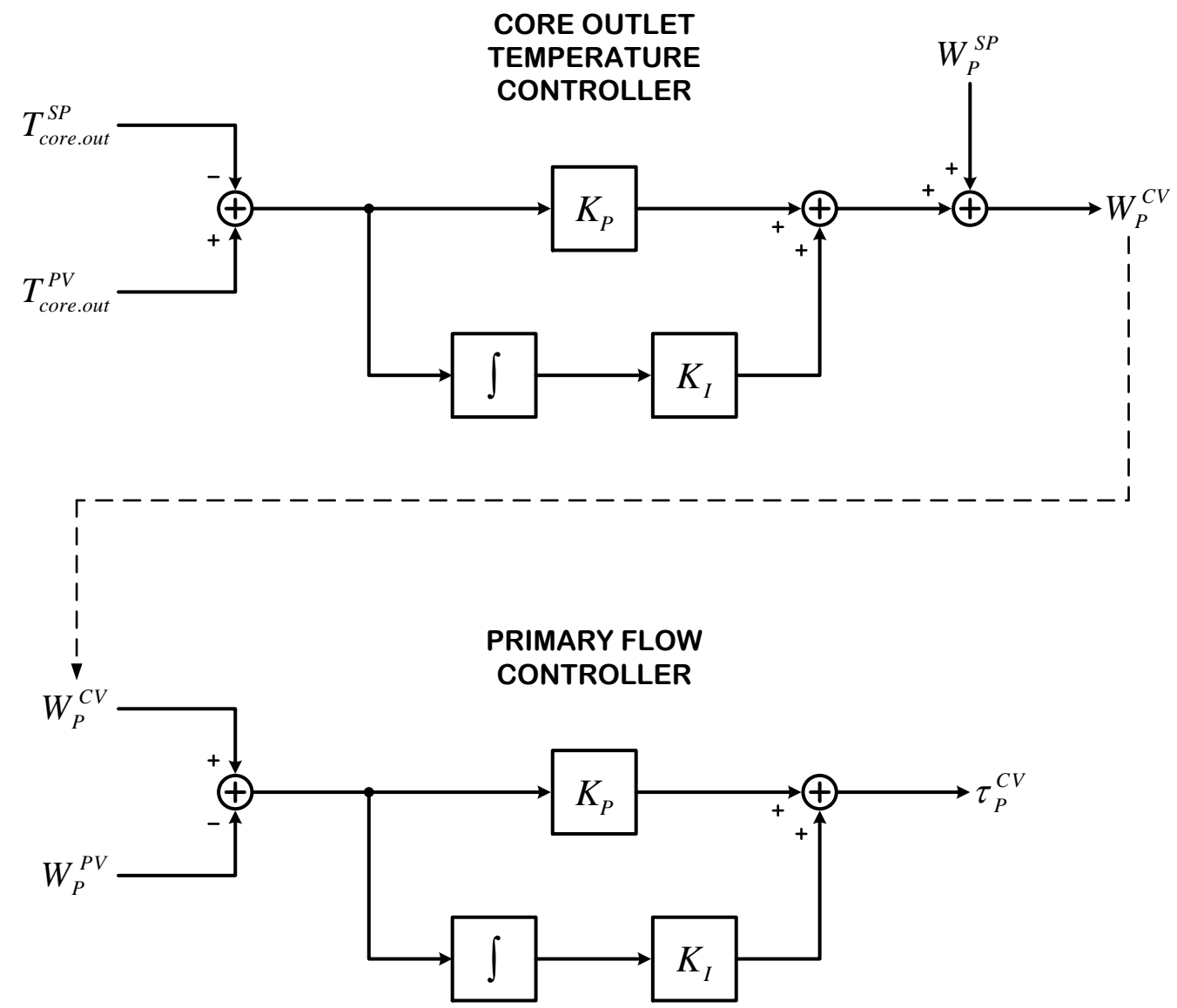

Figure 9-7: Core Outlet Temperature Controller with Actuator-Local Controller 


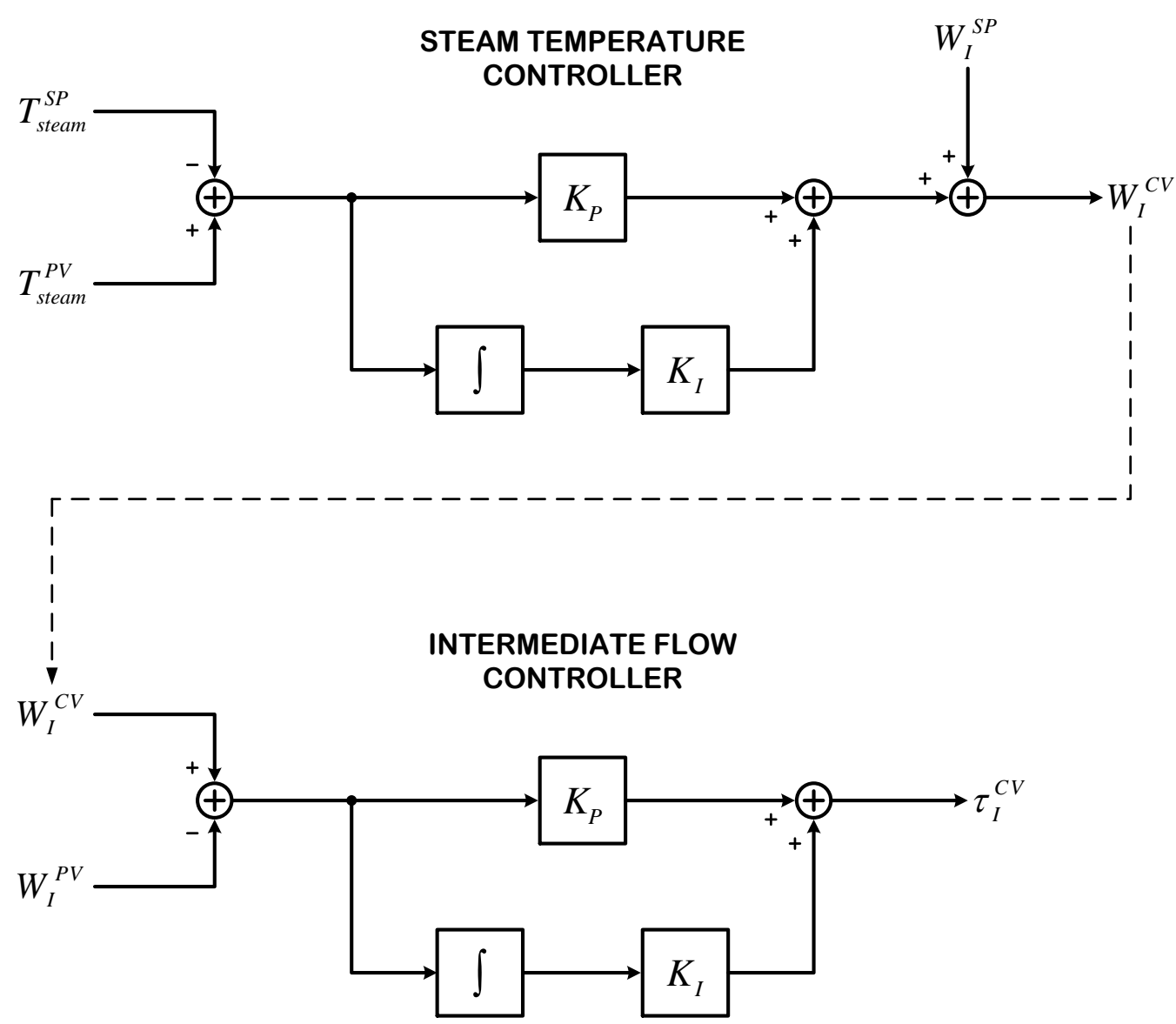

Figure 9-8: Steam Temperature Controller with Actuator-Local Controller

\subsubsection{Operating Mode Logic}

Three different plant operating conditions are normally associated with the startup of an SFR; these conditions are described below.

\section{Ambient Condition}

The Ambient Condition is an isothermal plant state at the standard temperature and pressure (STP) condition. Primary and intermediate systems are not filled with sodium while the steam generator system is filled with water. Fuel is not loaded yet.

\section{Refueling Condition}

The Refueling Condition is an isothermal plant state with the sodium temperature sufficiently above the solidus temperature to prevent the sodium from freezing. To maintain sodium in the liquid state in the steam generator shell, the water in the tubes is maintained at $200^{\circ} \mathrm{C}$ saturated liquid conditions. In-service inspection of the steam generator is performed at ambient conditions and coincides with a refueling outage. To prevent freezing of sodium in the steam generator the intermediate heat transport system must be drained. The steam generator water must also be drained to provide for probe access during in-service inspection. 
Hot Standby Condition

The Hot Standby Condition is the plant condition at which the reactor is sub-critical with the NSSS isothermal at the temperature of saturated water at the operating pressure. The reactor is ready to be critical.

The Startup mode takes the plant from the ambient to the hot standby condition by using pump work and heater power to raise the temperature of the NSSS. Upon exiting the Startup mode the Reactor-Leading mode is entered. During this mode the grid is charged with accepting the electric power output of the plant. This mode extends from nominally zero electric power to the low end of the normal electric power range, $30 \%$. The operator is free of having to meet grid demands. This provides the flexibility needed to raise power to the low end of the normal power range, $30 \%$, at which this point is exited. In Load-Following mode the plant is designed to meet changes in grid demand over the normal electric power range, 30 to $100 \%$.

Table 9-2 lists controllers and process variables controlled as a function of the operating mode while Figure 9-9 shows the control logic for the supervisory control system.

Table 9-2: Controllers and Process Variables Controlled as a Function of Operating Mode

\begin{tabular}{|c|c|c|c|}
\hline \multirow[b]{2}{*}{ Controller } & \multicolumn{3}{|c|}{ Operating Mode } \\
\hline & Startup & Reactor-Leading & Load-Following \\
\hline Control Rod Position & Reactor Criticality & Reactor Power & Reactor Power \\
\hline Primary Pump & Primary Flowrate & Primary Flowrate & Primary Flowrate \\
\hline Intermediate Pump & Intermediate Flowrate & Intermediate Flowrate & Intermediate Flowrate \\
\hline Recirculation Pump & $\begin{array}{l}\text { Recirculation } \\
\text { Flowrate }\end{array}$ & $\begin{array}{l}\text { Recirculation } \\
\text { Flowrate }\end{array}$ & - \\
\hline Primary Pool Heater & Heater Power & - & - \\
\hline Aux. Vessel Outlet Valve & Steam Pressure & Steam Pressure & - \\
\hline Feedwater Pump & - & SG Flowrate & Steam Flowrate \\
\hline $\begin{array}{l}\text { Feedwater Control } \\
\text { Valve }\end{array}$ & - & - & $\begin{array}{c}\text { Steam Pressure (SG } \\
\text { outlet) }\end{array}$ \\
\hline $\begin{array}{l}\text { Turbine Admission } \\
\text { Valve }\end{array}$ & - & - & Steam Pressure (Turbine) \\
\hline Steam Generator Level & SG Level & SG Level & SG Level \\
\hline Aux. Vessel Level & Aux. Vessel Level & Aux. Vessel Level & - \\
\hline
\end{tabular}




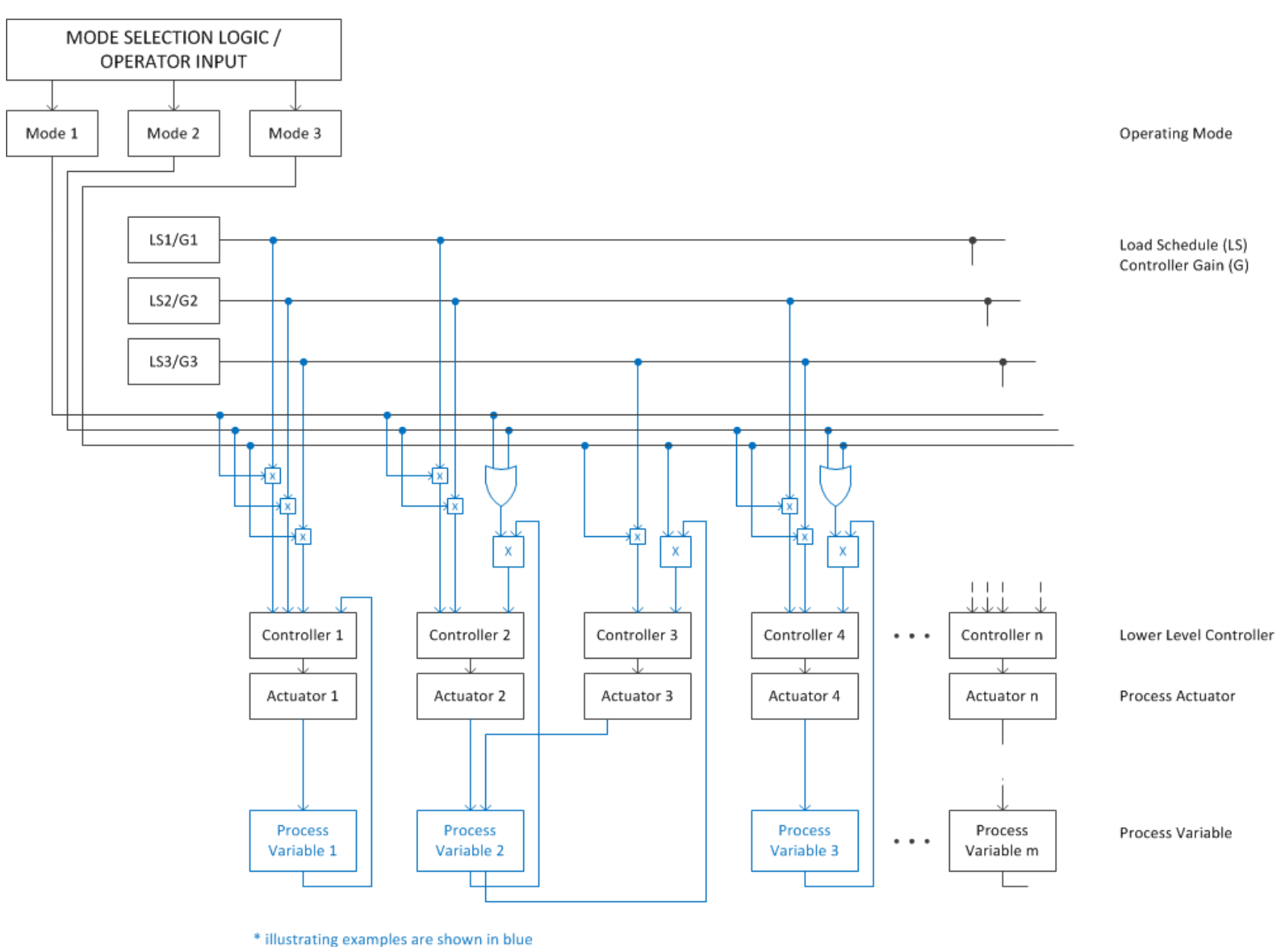

Figure 9-9: Representative Control Logic for the Supervisory Control System

\subsubsection{Load Schedule}

Starting from the ambient condition, the plant passes through the refueling condition and the hot standby condition before finally reaching the condition at the bottom of the load-following range of operation. Table 9-3 summarizes the transition phases and associated mode of plant operation.

The following sub-sections describe the startup sequences from the ambient condition to the power operation at the rated power. The description does not include the details regarding operation of the auxiliary systems such as sodium purification system, decay heat removal system, etc., but focuses on the quasi-equilibrium states of primary, intermediate, and steam generator systems. Simplified parameter profiles (temperature and flowrate) during the plant startup are provided in Figure 9-10 and Figure 9-11. 
FASTER Test Reactor Preconceptual Design Report

March 31, 2016

Table 9-3: Plant Transition Phases

\begin{tabular}{|c|c|c|c|}
\hline Transition Phase & Reactor Power & SG Flow & SG Outlet Condition \\
\hline Refueling to Hot & & & Saturated Water \\
\hline Standby (Startup & $0 \%$ & Recirculation & 200 to $351^{\circ} \mathrm{C}$ \\
\hline Mode) & & & 1.55 to $16.7 \mathrm{MPa}$ \\
\hline $\begin{array}{l}\text { Hot Standby to } 30 \% \\
\text { Power (Reactor } \\
\text { Leading Mode) }\end{array}$ & 0 to $30 \%$ & Recirculation to Once-Through & $\begin{array}{c}\text { Saturated Water } \\
\text { to Superheated Steam } \\
351 \text { to } 503^{\circ} \mathrm{C} \\
16.7 \mathrm{MPa}\end{array}$ \\
\hline $\begin{array}{l}\text { Power Ascension } \\
\text { (Load Following } \\
\text { Mode) }\end{array}$ & 30 to $100 \%$ & Once-Through & $\begin{array}{l}\text { Superheated Steam } \\
503^{\circ} \mathrm{C}, 16.7 \mathrm{MPa}\end{array}$ \\
\hline
\end{tabular}

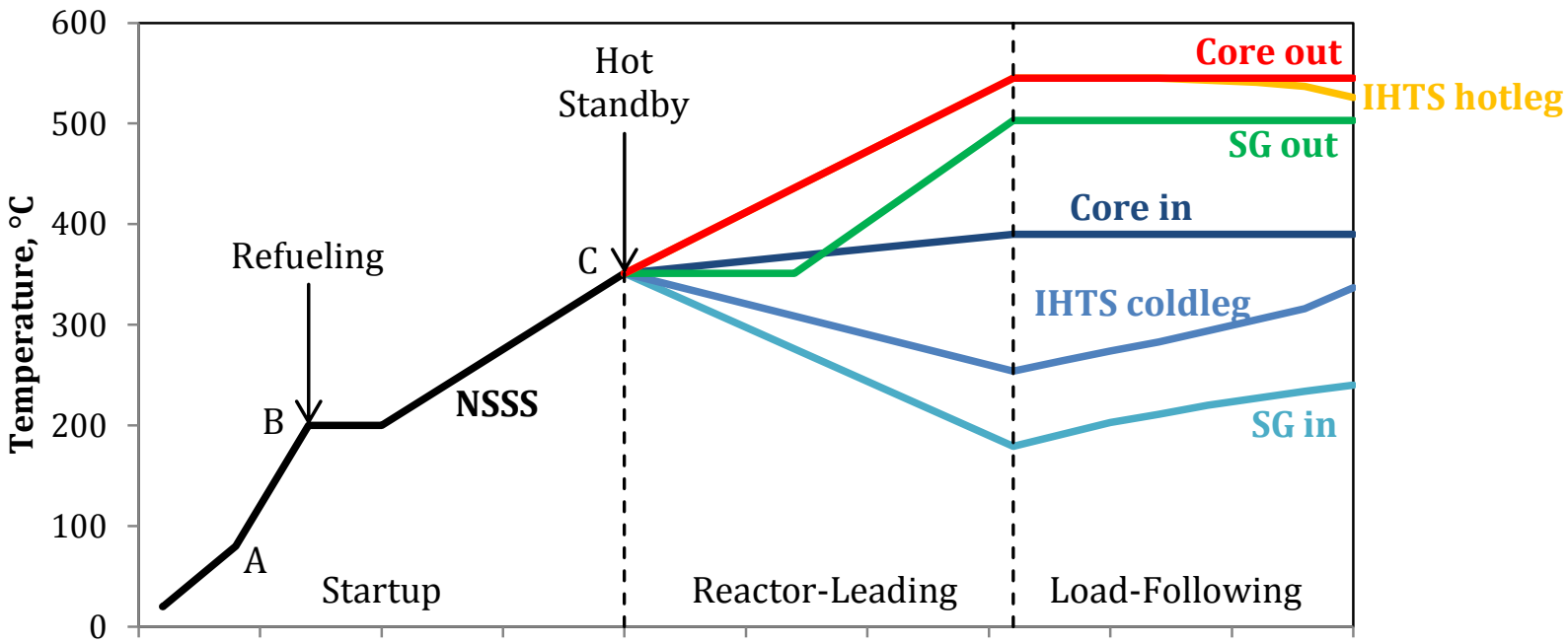

Figure 9-10: Temperature Profiles During Plant Startup

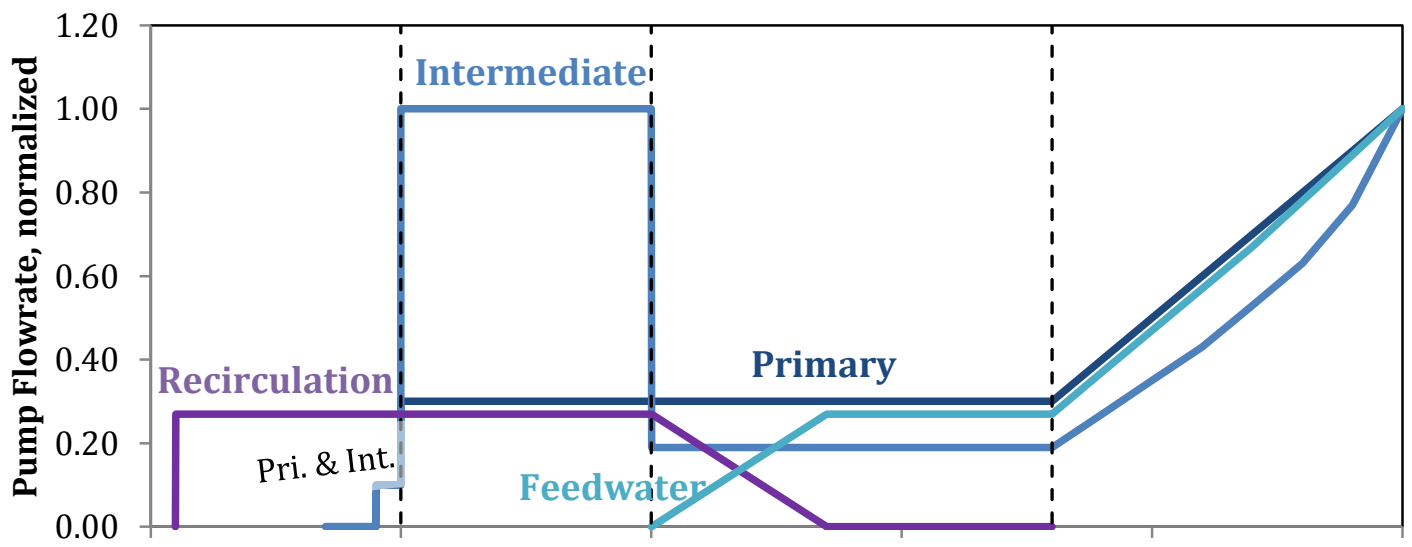

Figure 9-11: Flowrate Profiles during Plant Startup 


\subsection{Plant Protection System}

The Plant Protection System (PPS) provides an automated capability for energizing safety equipment to maintain the plant state within safe limits. The PPS functions independent of the PCS and provides alarm signals to alert the operator to adverse conditions and provide trip signals to actuate safety systems. The PCS provides logic to enable/disable alarms and trip signals as a function of the selected operating mode of the plant. The plant protection system is designed to shut down the reactor when one or more process variables move beyond predetermined thresholds. The system, therefore, limits damage to the reactor, including the fuel, and prevents the release of radioactive materials to the environment by retaining them within either the reactor vessel or primary containment. The plant protection system operates independently of the plant control system.

The sensors used for the plant protection system are separate from those used for plant control and are similar to those used in the FFTF design. Among the reactor head major penetrations, one will be dedicated to a 'proximity test plug' consisting of a flange, plug, seals, drywells, thermocouples, fittings and attaching hardware. Such assembly houses the instrumentation supplies to measure coolant outlet temperature for the Plant Protection System and also monitors the temperature of the reactor head.

The following parameters are monitored by the plant protection system and are used to trip the reactor when an abnormal condition is detected:

- Neutron flux and coolant temperature at core outlet: protect against overpower transients and prevent high fuel temperatures.

- Sodium level: scram the reactor upon low pool level indicating coolant leakage from reactor vessel into guard vessel. Scram the reactor on low level in the intermediate heat transport loop expansion tank indicating loss of coolant from the loop.

- Pump status and rate of change of flow rate: protect against loss of flow and uncontrolled flow changes.

- Intermediate loop pressure and SG hydrogen levels: loss of steam generator (SG) integrity would be indicated by an abnormal pressure increase on the shell side of the SG and/or detection of hydrogen produced by sodium/water reactions.

- Delayed neutron emission levels in the primary coolant and fission gas concentration in the cover gas: these parameters are indicators of fuel integrity.

- Acoustic signals: ultrasonic sensors detect the presence of subcooled boiling, which can indicate flow blockages within subassemblies.

The plant protection system also allows the reactor to be scrammed manually. Switches in the control room can be used by the operator to shut down the reactor at any time. 


\subsubsection{Engineered Safety System Actuation}

The two major engineered safety system actuation signals (ESSAS) are:

\section{Decay Heat Removal Actuation Signal (DHRAS)}

The DHRAS shall be provided to actuate the components of DRACS necessary to remove decay heat and sensible heat from the PHTS right after reactor shutdown when the cooling of PHTS using the steam/feedwater system is unavailable. The DHRAS actuates the dampers of sodium-air heat exchangers in DRACS to be opened. This provides continuous adequate core cooling which limits core damage and assures the integrity of reactor coolant boundary. The DHRAS shall be initiated by any of the following setpoints: high subassembly outlet temperature signal, high power to PHTS flow ratio signal, high core inlet temperature signal, high SG shell outlet temperature signal, low hot pool sodium level signal, reactor vessel sodium leak signal, high neutron flux signal, or high neutron flux change rate signal. Provisions for manual initiation from the control room and remote shutdown panel are required.

\section{Containment Isolation Actuation Signal (CIAS)}

The CIAS shall be provided to mitigate the consequences of a release of radioactive material. The CIAS isolates the containment structure by closing the valves of process lines penetrating the containment. The CIAS shall be initiated by any of the following: high neutron flux signal, high neutron flux change rate signal, or a high radiation inside containment signal. Provisions for manual initiation from the control room and remote shutdown panel are required.

The Engineered Safety Features Actuation Signals shall be generated as specified below:

- High subassembly outlet temperature: the high subassembly outlet temperature signal is generated to initiate the operation of DRACS which cool the reactor core in the event of a loss of PHTS flow rate.

- High power to PHTS flow ratio: the high power to PHTS flow ratio signal is generated to initiate the operation of DRACS which cool the reactor core in the event of a loss of PHTS flow rate.

- High core inlet temperature: the high core inlet temperature signal is generated to initiate the operation of DRACS which cool the reactor core in the event of a loss of heat sink in IHTS) or steam/feedwater system.

- High SG shell outlet temperature: the high SG shell outlet temperature signal is generated to initiate the operation of DRACS which cool the reactor core in the event of a loss of heat sink in IHTS or steam/feedwater system.

- Low hot pool sodium level: the low hot pool sodium level signal is generated to initiate the operation of DRACS which cool the reactor core in the event of primary sodium leak.

- Reactor vessel sodium leak: the reactor vessel sodium leak signal is generated to initiate the operation of DRACS which cool the reactor core in the event of primary sodium leak.

- High neutron flux: the high neutron flux signal is generated to initiate the operation of DRACS which cool the reactor core in the event of transient overpower. CIAS is also generated to close containment isolation valves to mitigate the release of radioactive materials to the environment. 
- High neutron flux change rate: the high neutron flux change rate signal is generated to initiate the operation of DRACS which cool the reactor core in the event of transient overpower. CIAS is also generated to close containment isolation valves to mitigate the release of radioactive materials to the environment.

\subsubsection{Reactor Trip Signals}

The Reactor Trip Signals shall be generated as specified below:

- High subassembly outlet temperature trip: high subassembly outlet temperature trip shall be provided in conjunction with the ESSAS to protect against the loss of PHTS flow rate (e.g., PHTS pump stuck or trip, pump discharge pipe break).

- High power to PHTS flow ratio trip: high power to PHTS flow ratio trip shall be provided in conjunction with the ESSAS as a diverse trip parameter for loss of PHTS flow rate. It shall also be provided by the Diverse Protection System (DPS) to protect against Anticipated Transient without Scram (ATWS) and Common Cause Failure (CCF).

- High core inlet temperature trip: high core inlet temperature trip shall be provided in conjunction with the ESSAS to protect reactor from the loss of heat sink in IHTS or steam/feedwater system (ex. IHTS pump trip, loss of feedwater).

- High SG shell outlet temperature trip: high SG shell outlet temperature trip shall be provided in conjunction with the ESSAS as a diverse trip parameter for loss of heat sink in IHTS or steam/feedwater system.

- Low hot pool sodium level trip: low hot pool sodium level trip shall be provided in conjunction with the ESSAS to protect against the loss of primary coolant and ensure the core cooling capability.

- Reactor vessel sodium leak trip: reactor vessel sodium leak trip shall be provided in conjunction with the ESSAS as a diverse trip parameter for the reactor vessel leak. The sodium leak of reactor vessel into guard vessel is detected in the gap between reactor vessel and guard vessel.

- Overpower trip: overpower trip shall be provided in conjunction with the ESSAS to limit the maximum power and to ensure the integrity of fuel and reactor coolant boundary from unplanned overpower transient.

- Variable overpower trip: variable overpower trip shall be provided in conjunction with the ESSAS to limit the power change rate and help mitigate the consequences of control assembly withdrawal.

- Diverse Protection System (DPS): the DPS shall be designed for reduction of risk from ATWS. 
Table 9-4: Trip Parameters for Representative Design Basis Events

\begin{tabular}{|c|c|c|c|c|}
\hline \multirow[b]{2}{*}{ Trip Parameters } & \multicolumn{4}{|c|}{ Design Basis Events } \\
\hline & $\begin{array}{c}\text { Loss of } \\
\text { PHTS } \\
\text { Flow Rate } \\
\end{array}$ & $\begin{array}{c}\text { Loss of Heat Sink in } \\
\text { IHTS or } \\
\text { Steam/Feedwater } \\
\text { system or SG leak }\end{array}$ & $\begin{array}{c}\text { Primary } \\
\text { Sodium } \\
\text { Leak }\end{array}$ & $\begin{array}{c}\text { Transient } \\
\text { Overpower }\end{array}$ \\
\hline Power to PHTS flow ratio $\left(1^{\text {st }}\right)$ & $\mathrm{O}$ & & & \\
\hline Subassembly outlet temp. $\left(2^{\text {nd }}\right)$ & $\mathrm{O}$ & & & \\
\hline Core inlet temp. $\left(1^{s t}\right)$ & & $\mathrm{O}$ & & \\
\hline SG shell outlet temp. $\left(2^{\text {nd }}\right)$ & & $\mathrm{O}$ & & \\
\hline Reactor vessel sodium leak $\left(1^{\text {st }}\right)$ & & & $\mathrm{O}$ & \\
\hline Hot pool sodium level $\left(2^{\text {nd }}\right)$ & & & $\mathrm{O}$ & \\
\hline Power (Neutron flux) $\left(1^{\text {st }}\right)$ & & & & $\mathrm{O}$ \\
\hline $\begin{array}{l}\text { Variable power (Neutron flux } \\
\text { change rate) }\left(2^{\text {nd }}\right)\end{array}$ & & & & $\mathrm{O}$ \\
\hline
\end{tabular}

\subsection{Test Assembly and Loop Instrumentation}

The instrumented assemblies (also called open test assemblies) provide for the irradiation and testing of fuels, materials, and specimens under prototypical reactor conditions with continuous monitoring of quantities of interest (such as temperature, pressure, etc.). These parameters are measure via dedicated instrument lines which reach each assembly through dedicated experimenters' leads from the center island of the reactor head. Seven locations for independently instrumented open test assemblies are envisioned for the FASTER design. Instrumented assemblies use a standard fuel duct with an attached stalk to guide the instrumented lines. Flow is controlled with an inlet orifice. Open test assemblies were also part of the FFTF design which represents a good starting point for the design and engineering of instrumented assemblies for FASTER. In FFTF three types of specimens were compatible with the open test assembly design:

1. Un-encapsulated Fuel Element Experiments: this category includes fissile and control materials encased in cladding, but not encapsulated within another boundary. Experimental procedure stated that 31 experimental fuel elements had to be extensively tested in the encapsulated configuration before being accepted for testing in the unencapsulated configuration.

2. Encapsulated Fuel Element Experiments: this category includes capsules that: a) contain fissile materials; b) were intentionally pressurized during assembly; c) contain absorber materials; d) contain non-fissile materials that may generate significant quantities of gas during irradiation; and e) contain non-fissile materials whose compatibility with the primary coolant is unknown.

3. Encapsulated Structural Materials Experiments: this category includes capsules not intentionally pressurized prior to irradiation and which contain materials that: a) were known to be compatible with the primary coolant; and b) did not generate significant quantities of gas under irradiation. These experiments also included "weeper" capsules which allowed intentional ingress of primary coolant sodium into the capsule. 
Similar to the FFTF design, instrumented assemblies loaded with fuel elements allow for monitoring of parameters such as sodium temperature within the fuel bundle, cladding temperature, duct temperature, fuel centerline temperature, and fission gas pressure within the pin. Transducers can also be used to measure differential pressure within the fuel bundle. In FFTF, up to fifty-one leads for pressure, temperature, and electrical connections were used; this number is assumed to be a lower bound for FASTER instrumented assemblies. In FFTF, in addition, open test assemblies could be removed from the core by severing the instrumentation leads, and then reinserted in the core for a post-irradiation open test. Instrumented assemblies loaded with encapsulated structural experiments allow for evaluating the irradiation behavior of structural materials. Similarly to the FFTF design, those assemblies provide detailed temperature control and measurements during irradiation as well as density and dimensional measurements on test specimens during reactor shutdown. In FFTF the open test assemblies, loaded with material specimens, could contain up to forty-eight canisters, thirty of which with independent temperature control and a total of $2500 \mathrm{~cm}^{3}$ of in-core irradiation volume per assembly. In addition, up to eighty-two leads for pressure, temperature, and electrical connections were available. Again, this is considered a lower bound for FASTER instrumented assemblies. Instrumented assemblies loaded with structural material specimens are also designed to be removed from the core at the end of an operating cycle, the test specimens can be examined and the experiment can be reinserted into the core for the start of the next cycle.

In terms of operability of instrumented assemblies, it should be noted that the exit coolant temperature from an open test position experimental subassembly should not differ more than $40^{\circ} \mathrm{C}$ from the average exit coolant temperature for driver fuel or blanket subassemblies assumed to be in the core positions surrounding the experimental subassembly. This requirement is based on maximum allowable alternating stresses in the upper structure of the reactor resulting from sodium mixing effects.

The testing capability offered by instrumented assemblies is not limited simply to fuels and materials irradiation testing. The opportunity for online monitoring of quantities of interest not just at channel inlet or outlet but along the core axis offers the potential for advanced instrumentation test capability. In particular, open test assemblies can be used for online and direct measurements of parameters of interest (such as temperature and pressure); such assemblies could then be engineered to host traditional instrumentation and advanced instrumentation for a head-to-head comparison of performance under irradiation and harsh environmental conditions. Proper protocols for experimental procedure, verification and validation of instrumentation probes can be developed and applied to specific conditions, test assemblies, and core locations. The types of probes that could be tested include ones adopting innovative physical principles for either the measurement itself (e.g., acoustic sensors) or for the data acquisition and transmission (wireless sensors). In addition in-core tests could also be focused on self-powered instrumentation (through either heat or radiation) to be used under accident conditions such as station blackout. Such sensors could be of vital importance in the performance of long term plant diagnosis during beyond design basis accidents when power supply to traditional instrumentation lines may not be available for extended periods of time. Finally, extensive data processing will be required for all the above mentioned testing capabilities 
to characterize performance curves of advanced instrumentation under different experimental conditions and radiation fields.

The closed test loops will provide the same instrumentation capabilities envisioned for the instrumented test assemblies. In addition, dedicated instrumentation and controllers will also be needed out of core for the operation of the loop itself, depending on the specific design and operating parameters of each fluid to be tested within the loop (see also Section 3.1.7 for more details on preliminary design for different coolant options). Control of temperature, pressure, and flow rates will be crucial to allow for monitoring of the test conditions under which irradiation in the experimental loops is to be performed. Closed test loops may also allow for simulation of postulated accident conditions, and ad-hoc instrumentation for such experimental capability is envisioned.

\subsection{Advanced Instrumentation Test Capability}

The instrumentation and control (I\&C) hardware, software, and configuration in FASTER will reflect the state of the art to ensure the test reactor achieves the primary mission of being an irradiation facility. I\&C shall be designed to maximize the system availability while facilitating extended operation and monitoring of the facility, reactor, and test conditions. However, the test reactor will also offer several capabilities for testing advanced instrumentation which, while not necessary for the mission of the facility itself, do provide significant technological value and the potential for technological breakthrough demonstration in fields very important for the future of nuclear technologies such as sensors, instrumentation, and control systems.

There are two major areas of advanced instrumentation test capability: in-core and ex-core. Incore refers to all testing of instrumentation purposely placed under irradiation to characterize the behavior and test the performance under severe environmental conditions. Ex-core, on the other hand, refers to all conditions that while potentially still characterized by the presence of ionizing radiation, are focused on sensors and instrumentations meant for application outside the nuclear reactor core and more in general to any other region, system, or component of the facility including the control system architecture itself. This separation is important not only under the functional point of view, but also to illustrate how the facility can be used for demonstration of instrumentation technologies for a wide variety of plant needs not limited just to the nuclear island and the primary circuit but extended also to the balance of plant and auxiliary systems. The full set of advanced instrumentation testing capabilities will serve therefore both as testing and technological demonstration, significantly extending the scientific and technological benefits provided by the test reactor as irradiation facility.

The instrumented assembly and experimental loops will provide a one-of-a-kind capability for validation of advanced simulation tools. Fuel pin wire wraps induce complex three-dimensional mixing that has historically has not been accurately represented in design calculations. Designers understood the limitations of their models and correspondingly introduced uncertainty factors to account for lack of fidelity. In turn this leads to a derating of the core. Ongoing research and development of multi-physics simulations for improving fast reactor economics is specifically targeting improved prediction of subassembly temperatures by better modeling the effect of wire wrapped induced mixing. The usefulness of these models for future design work and recovery of 
thermal margin is critically dependent on validating these models against prototypic experiment data.

The instrumented assembly and experimental loops offer then a unique opportunity to generate prototypic experiment data for validation of these advanced computational design tools. With the multi-lead capability provided by the instrumented subassembly, it is possible to provide a spatially rich set of temperature measurements within the fueled assembly. The needed measurements can be acquired using two different measurement capabilities. The first uses thermocouples embedded in wire wraps to sense local coolant temperature. The second approach replaces the wire wrap with a stainless steel capillary of the same outside diameter through which is threaded an optical fiber. This so-called Bragg fiber is capable of generating temperature data to the sub-centimeter level along its length yielding here-to-fore unrealized spatial resolution of coolant temperature within a fueled assembly. The development of these fibers for higher temperature applications is ongoing. It is not unexpected that soon there will be a fiber capable of operating at SFR temperatures for the short time needed at full power to acquire the needed steady-state temperature data.

\subsubsection{In-Core}

To test advanced instrumentation in-core, the test locations provided by the facility can be used. In particular, open test assemblies can be used for online and direct measurements of parameters of interest (such as temperature and pressure); such assemblies could then be engineered to host traditional instrumentation and advanced instrumentation for a head-to-head comparison of performances under irradiation and harsh environmental conditions.

The types of sensors that could be tested include ones adopting innovative physical principles for either the measurement itself (e.g., acoustic sensors) or for the data acquisition and transmission (wireless sensors). In addition in-core tests could also be focused on self-powered instrumentation (through either heat or radiation) to be used under accident conditions such as station blackout. Such sensors could be of vital importance to be able to perform long term plant diagnosis during beyond design basis accidents when power supply to traditional instrumentation lines may not be available for extended periods of time.

\subsubsection{Out-of-Core}

To test advanced instrumentation ex-core, the test reactor will present several out-of-core locations and components that could be engineered to accommodate advanced instrumentation. Similar to the in-core testing capability, new sensors that could be tested include ones adopting innovative physical principles for either the measurement itself (e.g., acoustic sensors) or for the data acquisition and transmission (wireless sensors).

The following list summarizes the in-core and out-of-core advanced instrumentation needs that could be addressed by experimental campaigns in FASTER:

- Instrumentation able to measure the subassembly outlet temperature providing fast response and no instrumentation leads.

- Instrumentation for liquid sodium flow rate able to improve the accessibility and reliability issues. 
- Testing advanced instrumentation in instrumented assemblies and experimental loops.

- Instrumentation for sodium level indicator less bulky than the actual one, based on old inductive technology.

- Instrumentation based on new technologies such as acoustic or microwave.

- Use of laser spectroscopy for hydrogen leak detection and possibly any type of leak using Laser Induced Breakdown Spectroscopy.

- Acoustic surveillance coupled with virtual reality for In Service Inspection and early identification of loose parts.

- Development of instrumentation for monitoring and diagnostic of inherent safety capabilities with the potential of altering the qualification needs of instrumentation possibly reducing the number of instruments required and/or reducing the cost.

\subsection{Data Handling and Signal Transmission System}

The data handling and transmission system is a distributed computing system linking the plant control system with all remaining aspects of plant monitoring, trending, and data analysis. It also provides remote access to plant data and operational status.

\section{7 Communications System}

A diverse set of equipment will be available for communication among plant personnel and between the plant and outside agencies. Diversification ensures the ability to communicate during both normal plant operations and in the event of severe plant disruptions. The communication system consists of:

- Public address system for intra-plant communications. The system delivers site-wide or localized messages along with alarms such as fire, high radiation, and evacuation alarms.

- Microwave communications system to provide a wireless link between the plant and neighboring DOE facilities.

- Portable radio systems for two-way communications at any plant location. These systems are used for maintenance operations, traffic control, and fire protection. A separate system is used by plant security personnel.

- Security intercom system for closed communications between security personnel at the main security station and remote security stations.

- Offsite law enforcement radio system for communication with outside law enforcement agencies.

- Conventional telephone network for routine intra-plant and inter-office communications.

\subsection{On-Line Fault Detection and Diagnosis}

In addition to testing advanced instrumentation there is the opportunity for testing advanced operator aids. With the advances made in computer hardware, software, and automated reasoning algorithms it is now possible to consider an operator advisory system as a means to manage the enormous amount of information an operator must process. The operator advisory system will have sensor validation and component fault diagnosis capabilities. 
The objective of the sensor validation capability is to:

- Detect sensor output drift or failure due to sensor degradation.

- Correct the sensor output until such time as the sensor can be either re-calibrated or replaced, such as during a planned shutdown, recognizing that sensors are not readily accessible for maintenance during operation.

The objective of the fault diagnosis capability is to:

- Reason from sensor data the origin of a fault.

- Be sufficiently general in approach that the heart of the algorithm does not need to be reworked with each new application.

\subsection{Industrial Security and Safeguards System}

The industrial security and safeguards system is designed to protect plant equipment and personnel, and to prevent the theft of special nuclear materials. The system is designed to defend against the design basis threats specified in regulations. The key requirements for the security and safeguards systems are:

- Allow plant access only to authorized personnel and material

- Prevent the theft of special nuclear materials

- Prevent the sabotage of critical plant equipment

- Deter, detect, and delay unauthorized activities and assaults on the plant

To minimize the required size of the security force, the plant is divided into nuclear and nonnuclear areas, each operated with appropriate levels of security. All safety grade components and systems are located within the nuclear island to minimize the area requiring the highest level of protection. 


\section{Auxiliary Sodium Systems}

In order to ensure long term, safe operations of the sodium systems, the chemistry of the system must be controlled and monitored by a set of auxiliary systems that are common to all liquid metal reactors. Although the chemistry does not affect the nuclear operation directly, it is important for the hydrodynamics of the system as well as for the corrosion and contamination control. One goal is to ensure stable hydrodynamics on the long term to promote an efficient and constant heat transfer, which can be affected by oxide formation or mass transfer within the nonisothermal circuit. Another goal is to ensure the maintenance and component handling easiness by reducing the activated corrosion products.

The following auxiliary sodium systems are included:

- Sodium purification system for purification and monitoring of sodium circuits, such as crystallization and plugging indicators

- Cover gas purification system for purification and monitoring of the argon cover gas

- Sodium sampling and analysis system for contamination monitoring primary and secondary sodium storage system.

- Sodium reaction system for component handling, cleaning, and decontamination (located in the Maintenance Building)

The sodium purification system deals not only with the hydrogen and oxygen impurities introduced during the initial startup or maintenance operations, but also with other potential source of impurities such as the sodium/water interaction products. 


\section{Reactor Containment Building and Site}

Figures II.9-1 shows the overall site plan for the FASTER site. Table II.9-1 lists all the site buildings and provides their dimensions and footprint. This site plan is independent of the ultimate FASTER site and does not take into account (or credit) for any existing facilities at a particular DOE site.

Table II.9-1 Site Buildings with Dimensions

\begin{tabular}{|l|c|c|c|c|}
\hline Building Name & Footprint $\left(\mathrm{ft}^{2}\right)$ & Length (ft) & Width (ft) & Height (ft) \\
\hline Security Gate House & 1,350 & 41 & 33 & 16 \\
\hline Administrative Building & 6,230 & 89 & 70 & 37 \\
\hline Reactor Building & 9,217 & 108 dia & & 190 \\
\hline $\begin{array}{l}\text { Reactor Auxiliary Building - } \\
\text { South }\end{array}$ & 3,666 & 78 & 47 & 100 \\
\hline $\begin{array}{l}\text { Reactor Auxiliary Building - } \\
\text { North }\end{array}$ & 3,666 & 78 & 47 & 100 \\
\hline $\begin{array}{l}\text { Reactor Auxiliary Building - } \\
\text { West }\end{array}$ & 6,390 & 83 & 77 & 100 \\
\hline Turbine Building & 2,850 & 219 & 129 & 93 \\
\hline Reactor Service Building & 10,560 & 110 & 96 & 91 \\
\hline Emergency Generator Building & 375 & 25 & 15 & 12 \\
\hline Cooling Towers (each) & 140 & 16.5 & 8.5 & 18.5 \\
\hline Pump House (each) & 1,550 & 50 & 31 & 32 \\
\hline Wastewater Treatment Plant & 1,200 & 40 & 30 & 16 \\
\hline Interior Security Fence \#1 & 31,460 & 286 & 110 & - \\
\hline Interior Security Fence \#2 & 39,676 & 218 & 182 & \\
\hline Exterior Security Perimeter Fence & 750,360 & 1,110 & 676 & - \\
\hline
\end{tabular}




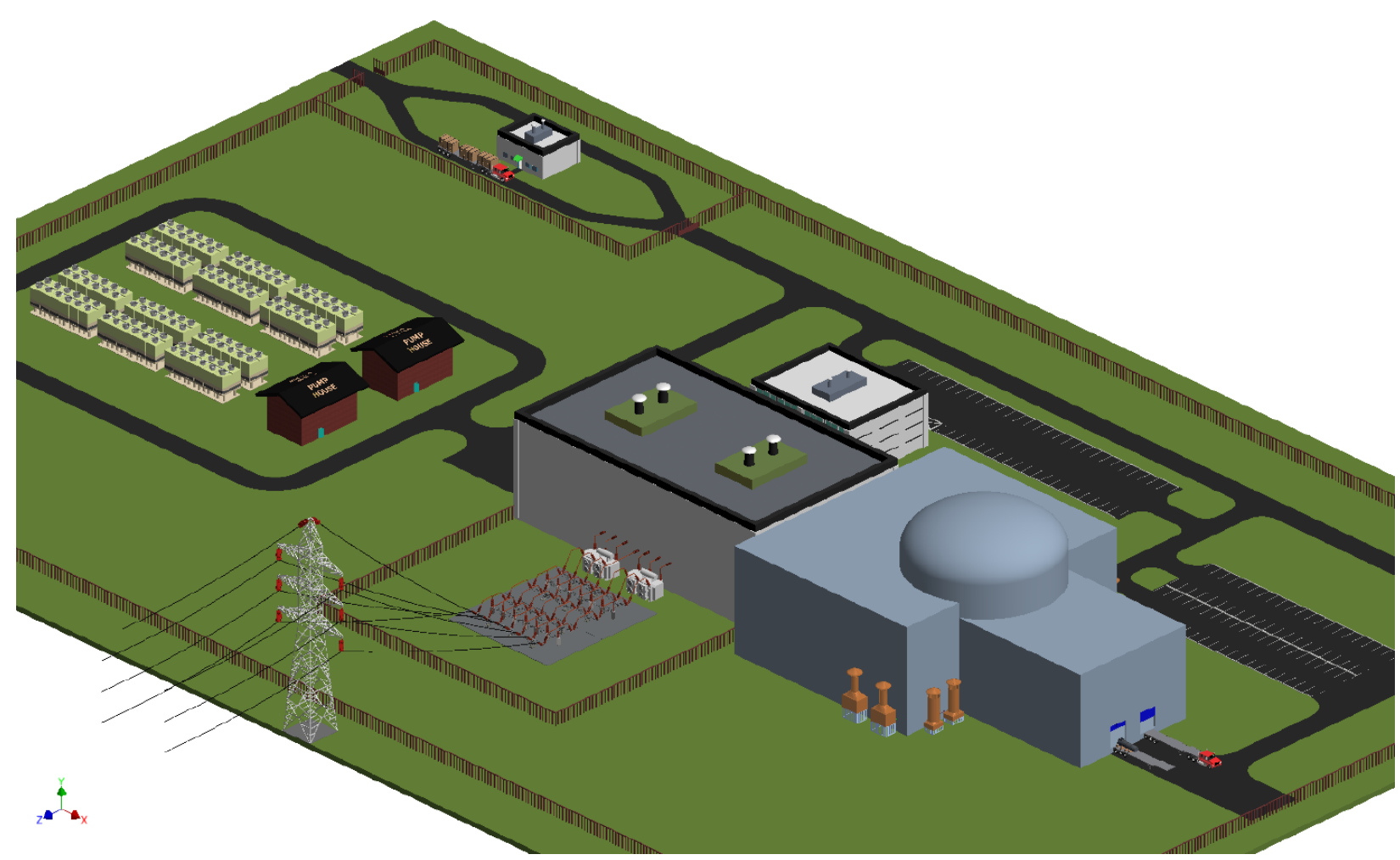

Figure 12 - FASTER Reactor Site

The reactor building, as schematically indicated in Figure II.9-2, encloses the entire primary reactor system and is constructed on a seismically stable basemat. The building is a reinforcedconcrete containment structure that contains an inner reactor containment dome, and is designed for a maximum leak rate of $0.1 \% /$ day at an internal pressure of $10 \mathrm{psig}$. The reactor building is a conventional reactor containment structure with the reactor vessel assembly located mostly below grade. All of the primary radioactive systems are located mostly below grade within the reactor building.

The major functions of the reactor building are as follows:

- Contain radioactive material following the unlikely event of an accidental radioactivity release from the primary reactor system.

- House and structurally support the reactor vessel, guard vessel, the shield/air baffle cooling system, support structure of the primary system and temporary fuel handling equipment, biological shielding, and associated equipment and structures.

- Provide adequate space for the operation, maintenance, and removal of equipment housed within the containment structure during periodic maintenance.

- Facilitate sodium and non-sodium fire protection for all safety equipment; this includes separation of redundant systems required for safe shutdown and for maintaining the reactor in safe shutdown condition.

- Provide protection for all safety equipment from the environment and natural phenomena such as floods, winds, tornadoes, and earthquakes. 
- Maintain pressure within the containment boundary at less than 0.5 psig negative with respect to the exterior, except during pressurization accidents.

- Limit leakage from the containment boundary to no more than $0.1 \%$ of its contained volume per day at an internal pressure of 10 psig.

- Maintain the integrity of the containment boundary during all design loadings, including a maximum long term containment atmosphere temperature of 50EC under normal operating and design basis accident containment atmosphere conditions.

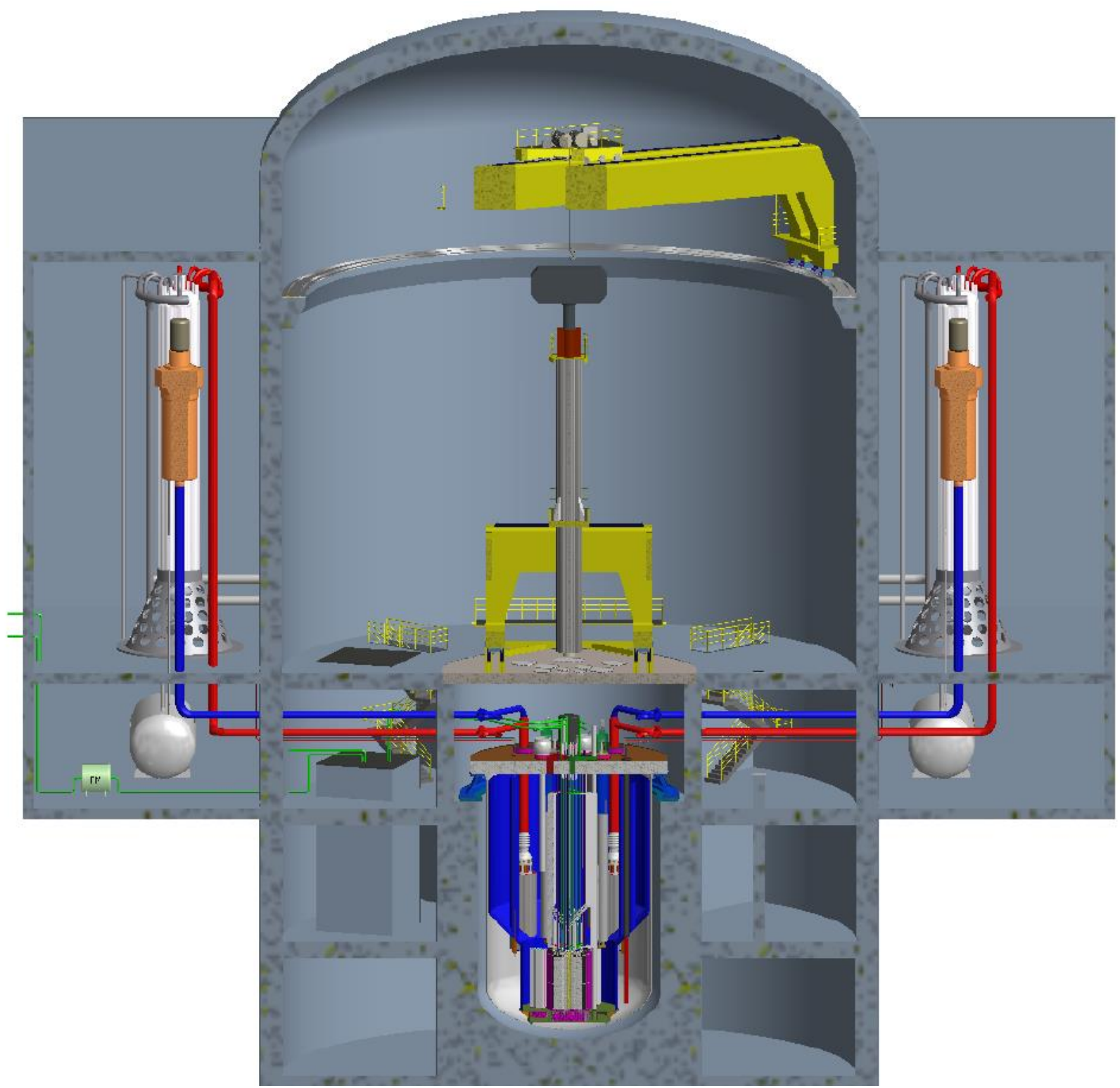

Containment Design Requirements

Figure 13 - Reactor Building

The reactor building will be designed to the rules of the current ASME Boiler and Pressure Vessel Code, Section III, Division 2, "Code for Concrete Reactor Vessels and Containments," Subsection CC for concrete containment. These rules provide for: material, design, fabrication, 
construction, examination, testing, marking, stamping, and preparation of reports for prestressed and reinforced concrete containment. The containment components covered by the ASME B\&PV Code include: (1) structural concrete pressure resisting shells and shell components; (2) shell metallic liners; (3) and penetration liners extending the containment liner through the surrounding shell concrete.

Additionally, the reactor building must be designed for natural hazards, such as an earthquake, wind and flood. The design must also conform to the NRC regulatory guides (Federal Regulations 10 CFR 50 and 10 CFR 100) for seismic and other natural hazards.

\section{Penetrations and Transfer Openings}

A large number of penetrations through the reactor building shell are required for access of personnel, equipment, freight, electrical conductors, and service fluids. These penetrations are grouped into three broad classifications: large mechanical penetrations, small mechanical penetrations, and electrical penetrations. These penetrations use pressure-tight seals consisting of appropriate materials. These seals are protected from the building atmosphere since this atmosphere could become hot enough to destroy the seals should a major sodium/air reaction occur. All seals are designed to withstand the same maximum pressure of $10 \mathrm{psig}$ for the building. To provide adequate assurance that the total leak rate of the reactor containment boundary remains less than the design value of $0.1 \%$ of the free volume per day, selected penetrations are leak tested annually.

The large penetrations are comprised of three airlocks (personnel, emergency personnel, and equipment airlocks). The airlocks allow equipment and personnel access to the reactor plant while maintaining building containment integrity at all times. All airlocks are cylindrical steel-welded shells that have a sealed door at each end. The doors are electrically or mechanically interlocked to allow only one door at a time to be opened. The equipment airlock is the largest of the three; it connects the reactor building to an equipment transfer location outside the facility. The personnel airlock is smaller than the equipment airlock; it connects the operating floor area of the reactor plant to the control/personnel service building and serves as the normal personnel entrance and exit. The emergency airlock is the smallest of the three. It provides an emergency exit from the reactor building should the personnel airlock become blocked. All airlock doors are periodically pressure tested.

\section{Cooling Requirements}

The shutdown heat removal system transfers the decay heat from the bulk sodium in the reactor vessel directly to the atmosphere through heat exchangers located on the outside of the reactor building. Therefore, there are no unusual cooling requirements for the reactor building internal atmosphere. A standard heating, ventilation and air conditioning (HVAC) system maintains the internal atmosphere around 22EC at all times. 


\section{FASTER Test Reactor Safety}

This section provides an overview of the safety basis and analyses adopted and completed for the FASTER design. Section 12.1 provides an overview of the FASTER safety basis, accident sequences relevant to FASTER are identified in Section 12.2, an overview of a mechanistic FASTER source term is provided in Section 12.3, and results of safety analyses are provided in Section 12.4.

\subsection{Safety Basis}

The safety goals in nuclear power reactor design and operation are to ensure the health and safety of the public, to protect the plant operating staff from harm, and to prevent plant damage. Traditionally, these goals have been fulfilled by an approach that 1) minimizes risk by maximizing safety margins in design and operation, 2) reduces the likelihood of potentially harmful events by providing safety systems to deal with anticipated events, and 3) provides additional design features to mitigate the harmful consequences of low probability events. This approach is usually identified as "defense in depth."

The basic principle of "defense in depth" is to provide multiple levels of protection against release of radioactive material. One part of defense-in-depth is physical barriers, like the multiple barriers to release of radioactivity provided by the fuel cladding, the primary coolant system boundary, and the reactor containment building. Generally, active or passive safety systems are provided to protect the physical barriers. These include the reactor shutdown systems and the reactor cooling systems. Inherent characteristics of the design, such as negative reactivity feedback and long flow coast-down, may provide an additional level of protection. Emergency planning provides an additional layer of defense-in-depth, should the other barriers be threatened. However, in all instances, the "defense in depth" strategy depends on the independence of the protective measures, so that no single event can breach more than one protective level.

The FASTER safety design approach implements the "defense in depth" strategy by adopting the traditional three levels of safety. In addition, the FASTER design features have been selected to provide significant safety margin enhancements by inherent passive safety responses to upset conditions and equipment failures.

At the first level, FASTER is designed to operate with a high level of reliability, so that accident initiators are prevented from occurring. The first level of safety is ensured in part by selection of fuel, cladding, coolant, and structural materials that are stable and compatible, and provide large margins between normal operating conditions and limiting failure conditions. An arrangement of components was adopted that allows monitoring, inspection, and testing for performance changes or degradation. Finally, the FASTER design provides for repair and replacement of components as necessary to ensure that safety margins are not degraded.

The selection of liquid sodium coolant and metallic fuel with a pool-type primary system arrangement provides a highly reliable reactor system with large operational safety margins. The coolant thermophysical properties provide superior heat removal and transport characteristics at low operating pressure with a large temperature margin to boiling. The metallic fuel operates at a relatively low temperature, below the coolant boiling point, due to its high thermal conductivity. The pool-type primary system confines all significantly radioactive materials within a single 
vessel, allows for easy removal and replacement of components, and shutdown heat removal by natural circulation.

At the second level of safety, FASTER is designed to provide protection in the event of equipment failure or operating error. This level of protection is provided by engineered safety systems for reactor shutdown, reactor heat removal, and emergency power. Each of these safetygrade backup systems functions in the event of failure in the corresponding operating system, and are subjected to continuous monitoring and periodic testing and inspection.

The FASTER design provides an independently powered and instrumented secondary reactor shutdown system that operates automatically to reduce reactor power rapidly in the event that the primary shutdown system fails. For shutdown cooling, the FASTER design includes a safetygrade emergency heat removal system, independent from the normal heat removal system and capable of removing residual decay heat by natural circulation. In addition to the normal offsite power supply, FASTER is equipped with a second independent offsite power connection. The two offsite power connections are supplemented by a safety-grade onsite emergency power supply.

The third level of safety provides additional protection of the public health and safety in an extremely unlikely event that is not expected to occur in the life of the plant, or which was not foreseen at the time the plant was designed and constructed. In the FASTER design, the Level 3 protections for cooling assurance and containment of radioactivity are provided by the reactor guard vessel and the reactor containment building. The reactor guard vessel is designed to hold primary coolant in the event of a leak in the primary coolant system. The reactor guard vessel ensures that the reactor core and the primary and emergency heat removal paths remain covered with primary sodium and cooled by the emergency heat removal system, even if the primary reactor vessel fails. If primary coolant leaks and oxidizes in the reactor building air atmosphere, or if failures of the cladding and the primary system barriers lead to release of gaseous fission products, the reactor containment building provides a final low-leakage barrier to release of radioactivity to the environment.

The three levels of safety together are the safety design basis for FASTER. For the purposes of subsequent safety design development, qualification, and documentation, it is customary during the conceptual design phase to identify general design criteria (GDC) that collectively serve as the basis for safety assessment of the design. GDCs for advanced reactors, and SFRs in particular, are currently being developed in a joint DOE and NRC initiative. The FASTER design satisfies all of those currently existing draft SFR advanced GDCs.

The proposed FASTER design is capable of accommodating various beyond-design-basis accident initiators without producing high temperatures and conditions that might lead to a severe accident, such as coolant boiling, cladding failures, or fuel melting. The inherent neutronic, hydraulic, and thermal performance characteristics of the FASTER design provide self-protection in beyond-design-basis sequences to limit accident consequences without activation of engineered systems or operator actions. This characteristic has been termed 'inherent passive safety.' 
The efficacy of such passive safety was demonstrated through two landmark tests conducted on the Experimental Breeder Reactor-II (EBR-II), namely SHRT-45R, a loss-of-flow without scram test, and BOP-302R, a loss-of-heat-sink without scram test. With the automated safety systems disabled, the two most demanding accident initiating events were deliberately induced with the reactor at full power, first one then the other. Each time the reactor simply coasted to a safe low power state without any damage at all to the fuel or any reactor component. These tests proved conclusively that passive safety design is achievable for metallic-fueled fast reactors with sodium cooling.

Within the overall safety framework for FASTER, passive safety serves to provide additional margins for public protection in the event of very low probability events whose frequency of occurrence is lower than the normal threshold for deterministic assessment. The FASTER passive safety performance characteristic ensures that no abnormal radioactivity releases will occur in the event of beyond-design-basis accidents, and that all of the multiple defense-in-depth barriers (fuel cladding, reactor vessel, containment building) for public protection will remain intact, just as for design basis accidents. The passive safety performance of FASTER eliminates the potential for severe accident consequences in very low frequency, beyond-design-basis sequences. Consequently, for FASTER, beyond-design-basis accidents need to be considered only in the context of probabilistic risk assessments.

Security must now be considered as an integral part of the design. The inherent and passive safety features of FASTER offer a high level of protection against malevolent events, as well as against accidents. Since the inherent and passive features do not rely on operator action, external power or functioning of active components, they remove these potential vulnerabilities. In addition, the location of the reactor vessel, the core, and the primary heat transport system mostly below grade within a strong containment structure provides protection against external threats. 


\subsection{Identification of Accident Sequences}

It is necessary to calculate a set of Anticipated Operating Occurrences (AOOs), Design Basis Accidents (DBAs), Design Extension Conditions (DECs), and Severe Accidents (SAs) for the Preliminary Safety Information Document (PSID), the Probabilistic Risk Assessment (PRA), the Preliminary Safety Analysis Report (PSAR), and the Final Safety Analysis Report (FSAR). The SAS4A/SASSYS-1 systems analysis code [33] will be the main analysis tool utilized in carrying out analyses of plant transients and postulated accidents.

A preliminary list of AOOs (Table 12-1), DBAs (Table 12-2), DECs (Table 12-3), and SAs (Table 12-4) has been formulated for FASTER. The AOOs, DBAs, DECs, and SAs for FASTER include those that have been previously identified for metallic-fueled SFRs together with those particular to the closed loop systems. A category for Severe Accidents is included in part to indicate the proper categorization of an unprotected station blackout accident.

Table 12-1: Preliminary List of A00s for FASTER

- Reactor trip from full power

- Reactor trip from full power with minimum decay heat

- Reactor trip from partial power

- Uncontrolled rod insertion

- Uncontrolled rod withdrawal from full power

- Uncontrolled rod withdrawal from 30 percent power

- Uncontrolled rod withdrawal from startup with automatic trip

- Change in flowrate of one primary coolant pump

- Loss-of-power to one primary coolant pump

- Change in flowrate of one intermediate coolant pump

- Loss-of-power to one intermediate coolant pump

- Loss of a feedwater pump

- Loss of all feedwater to a steam generator

- Increase in feedwater flow to a steam generator

- Water-side isolation and blowdown of a steam generator

- Inadvertent opening of turbine bypass valve

- Turbine trip without reactor trip

- Turbine trip with reactor trip

- Loss of all offsite power

- Inadvertent actuation of decay heat removal system loop

- Operating basis earthquake reactivity insertion 
- Primary coolant pump mechanical failure (sudden pump seizure)

- Intermediate coolant pump electrical failure

- Main feedwater line rupture

- Main steam line rupture

- Reactor trip without pump trip

- Rupture disc failure in Sodium Water Reaction Pressure Relief System

- Water-side isolation and blowdown of a steam generator with failure of inlet isolation valve to close

- Water-side isolation of a steam generator with failure of water dump valve to open

- Water-side isolation of a steam generator with failure of one steam relief valve to open

- Inadvertent draining of an intermediate sodium loop

- Intermediate-to-primary sodium leak in one Intermediate Heat Exchanger

- Decay heat removal system-to-primary sodium leak in one Direct Heat Exchanger

- Primary sodium leak from sodium purification circuit

- Small sodium leak from an Intermediate Heat Transport System loop

- Air ingression leakage into the primary sodium cover gas circuit

- Leakage through reactor vessel upper head closure penetration seals

- Air ingression leakage into the Intermediate Heat Transport System sodium cover gas circuit

- Fuel element loading error in fuel assembly

- Fuel assembly loading error in core

- Loss of all offsite power and failure of emergency diesel generators

- Station blackout

- Design basis fuel handling accident

- Closed Loop System loss-of-power to one primary loop pump

- Closed Loop System loss-of-power to all primary loop pumps

- Closed Loop System loss-of-power to one secondary loop pump

- Closed Loop System loss-of-power to all secondary loop pumps

- Closed Loop System primary circuit pipe rupture

- Closed Loop System secondary circuit pipe rupture 
Table 12-3: Preliminary List of DECs for FASTER

- Safe shutdown earthquake

- Intermediate heat transport system sodium line rupture

- Design basis steam generator sodium-water reaction

- Reactor vessel leak

- Rupture of primary coolant circuit between primary coolant pump and core inlet

- Unprotected uncontrolled single rod withdrawal from full power

- Unprotected loss of power to all Primary Heat Transport System pumps

- Unprotected loss of power to all Intermediate Heat Transport System pumps

- Unprotected loss of feedwater to all steam generators

- Unprotected spurious trip of one Primary Heat Transport System pump

- Unprotected spurious trip of one Intermediate Heat Transport System pump

Table 12-4: Preliminary List of SAs for FASTER

- Unprotected station blackout

- Large partial inlet blockage 


\subsection{Source Term}

Development of a source term and assessment of the offsite consequences that can result from a radionuclide release are typically the final components of an integrated safety analysis for a reactor. Historically, source term analyses for LWRs have utilized bounding, deterministic assumptions, where the inventories and release fractions are based on LWR fuel forms and accident scenarios. A series of LWR-derived source terms has been developed by the NRC beginning in the 1960s.

Currently, existing guidance from the NRC on acceptable source term methodologies and release fractions can be found in TID-14844, "Calculation of Distance Factors for Power and Test Reactor Sites" [34], NUREG-1465, "Accident Source Terms for Light-Water Nuclear Power Plants" [35], and Regulatory Guide 1.183, "Alternative Radiological Source Terms for Evaluating Design Basis Accidents at Nuclear Power Reactors" [36]. TID-14844, released in 1962, provides a bounding source term for oxide fuel that reflected the state of knowledge at the time of the document's release. To address the shortcomings of TID-14844, NUREG-1465 and RG 1.183 were released in 1995 and 2000, respectively. The modern source terms were developed for a range of LWR accident scenarios, and reflected improvements in the knowledge state such that actual LWR fuel inventories and consideration of core melt progression and radionuclide retention phenomena were included in the best-estimate source terms.

Despite improvements in the NRC-supported source term methodologies, TID-14844, NUREG1465, and RG 1.183 are considered to be inappropriate for use in development of an SFR source term. Each of these source terms is based on LWR-specific accident scenarios which are not directly translatable to SFRs, as the dominant accident sequences and severe accident progression phenomena vary significantly between designs. Also, many of the assumptions utilized in these source terms are deterministic, if not bounding. Improvements in the knowledge state and computational capabilities have led to renewed interest in development of a mechanistic source term (MST) that includes more realistic treatment of release and retention phenomena and consideration of important uncertainties.

To that end, ongoing work at Argonne on development of an MST for a pool-type, metal-fuel SFR has resulted in identification of the significant sources and important transport and retention mechanisms for releases from core damage and fuel handling accidents [37]. To facilitate the development of an SFR MST, the effort in [37] defined an MST as follows:

An SFR MST is the result of an analysis of radionuclide release, in terms of quantities, timing, and other characteristics, resulting from the specific event sequences being evaluated. It is developed using best-estimate phenomenological models of the transport of radionuclides from the source through all holdup volumes and barriers, taking into account mitigation features, and finally, into the environs.

The preliminary MST effort found that the majority of transport and retention mechanisms are well understood, however, uncertainty remains in the understanding of radionuclide formation, transport, and release in-pin as a function of burnup, particularly high burnup. The next stages of the Argonne MST effort include quantification of releases from fuel as a function of temperature and burnup, and a demonstration calculation of an MST which will predict the release to the 
environment beginning from the onset of a characteristic SFR accident. The following subsections provide a brief description of the source term phenomena for in-core and ex-core releases. Additional details on these processes can be found in [37].

\subsubsection{In-Core Transport and Retention Phenomena}

Key transport and retention phenomena for an in-core release in an SFR are briefly discussed in this subsection. Fuel melting, relocation, freezing, and retention within the core are not discussed, however a detailed review of these phenomena can be found in [38]. For a pool-type SFR, the key barriers to release include:

1. Fuel Matrix,

2. Cladding,

3. Primary Sodium,

4. Primary Circuit Boundary, and

5. Containment.

Transport and retention phenomena expected to be encountered within each boundary are described below. Discussion of the unique phenomena affecting both particulates and vapors is included. A diagram of the release and transport processes that will occur following an in-core release can be found in Figure 12-1.

The processes described below indicate that there is significant radionuclide retention in the primary sodium for all radionuclide groups other than the noble gases. Subsequent vaporization to the cover gas region is very small, and requires an extended period of time to occur. These phenomena, along with radionuclide retention within the fuel matrix, are important as they can significantly reduce the radionuclide inventory that is available for release from subsequent barriers in the defense-in-depth philosophy.

\section{Retention within the Fuel Pin}

The creation of fission gases during normal operation causes the fuel to swell, reducing and removing the fuel-clad gap and displacing bond sodium. Subsequently, fission gas pockets will interconnect to form pathways to the fission gas plenum. Some fission products will migrate to the bond sodium, which will be displaced to the fission gas plenum as the result of fuel swelling. Any fission gas release from the fuel matrix will travel through the displaced bond sodium. In the case of FASTER, fission gas generation is expected to occur in lower quantities due to the relative decrease in maximum burnup.

Pin failure can occur as the result of eutectic formation or excessive hoop stress. If fuel temperatures remain near the eutectic formation temperature, only localized fuel melting can be expected; significantly higher temperatures are required for fuel melting to occur beyond the eutectic regions. At extreme accident temperatures, rapid rates of eutectic penetration can be expected.

Upon cladding breach, gases and vapors contained within the fission gas plenum will be released to the primary sodium, along with the bond sodium and any fission products that have dissolved 
in the bond sodium. If fuel pin failure is the result of eutectic penetration of cladding, only the outermost eutectic region will be molten. If pin failure is the result of excessive hoop stress, and the failure precludes fuel melting at the periphery of the pin, fuel ejection cannot occur. Without significant additional fuel melting, the release from fuel is expected to be minimal due to the compatibility between metal fuel and sodium. Many radionuclides will be retained in the fuel matrix, as uranium is an excellent solvent.

\section{Retention within the Primary Sodium}

Prediction of the behavior of radionuclides within primary sodium requires the consideration of numerous chemical thermodynamic processes which are dependent on the phase of the element or compound. Additionally, radionuclides in the solid (particulate) phase will experience varying phenomena depending on their chemical composition (e.g. element versus compound) and solubility in sodium.

Gases and vapors with high vapor pressure and low sodium solubility (e.g. noble gases) will travel directly to the cover gas and not condense or dissolve in sodium. The remaining vapors may condense to the liquid phase and dissolve upon contact with cooler sodium, or they may nucleate within a bubble and be transported as aerosols. Vapors that have high solubility in sodium will dissolve directly in sodium. Dissolved vapors may then adsorb onto primary system structure, depending on the properties of the dissolved element/compound and material of the structure.

Particulates that are released from the pin may become entrapped within a vapor or gas bubble. Interaction of these particulates with sodium can occur if the particulates migrate to the surface of the bubble or the bubble collapses and the vapor condenses. Particulates can also dissolve in sodium and be transported with the flowing sodium; entrainment of particulates in the moving sodium stream can also occur. Adsorption onto structure may occur, particularly in regions of the primary system with relatively cooler temperatures. Mechanical deposition can also occur, where entrained particulates would be the primary candidates for this transport mechanism. For particulates that have adsorbed onto structure, redissolution is possible if there is a change in primary system temperature, as solubility is highly dependent on temperature. Resuspension of mechanically deposited particulates can occur if flow conditions adjacent to the structure change.

\section{Behavior in Cover Gas}

Vapors and gases that were transported directly through primary sodium in bubbles will be released to the cover gas region upon reaching the primary sodium and cover gas interface. Any particles entrapped within the bubbles may also be released to the cover gas region when the bubble bursts at the surface. Vapors, gases, and particulates dissolved in sodium must vaporize to escape the sodium; in the absence of sodium boiling, evaporation is the only mechanism by which this can occur, where the vapor pressure of a substance is the dominant characteristic affecting evaporation rates.

Radionuclides that do vaporize and enter the cover gas are likely to condense onto the surfaces of structures or particulates due to the relatively cooler environment in the cover gas. However, it should be noted that highly volatile vapors and gases will not condense. Airborne particulates can be removed from the cover gas by mechanical deposition onto structure, or by gravitational 
settling. Since volatility typically increases with temperature, resuspension and revaporization of particulates is possible if the temperature in the cover gas region increases. Resuspension of mechanically deposited particles can occur as the result of mechanical shock or vapor flow increase.

\section{Behavior in Containment}

Airborne radionuclides may transport to the upper containment area through leakage pathways in the reactor head. Typically, a reactor head has a design basis leak rate on the order of $0.1 \%$ volume per day, however, accident conditions that result in increased cover gas temperatures may lead to an increased reactor head leak rate. The phenomena anticipated to occur in the cover gas is expected to also occur in containment, although the presence of oxygen and water vapor can lead to the creation of additional compounds and aerosol particles, where agglomeration of particles can lead to the removal of vapors or particulates.

Similar to the reactor head, the containment is expected to have a small design basis leak rate, which can allow for the leakage of airborne radionuclides. However, thermal conditions in containment are not expected deviate significantly from ambient atmospheric conditions assuming a sodium fire or similar associated accident does not occur, meaning the design basis leak rate is assumed to be the limiting leak rate. Leak plugging of release pathways can limit the release from containment, where the aerosols formed in containment due to condensation and reactions with oxygen and water vapor can mechanically deposit near and in the leakage pathways, therefore reducing the flow area. 


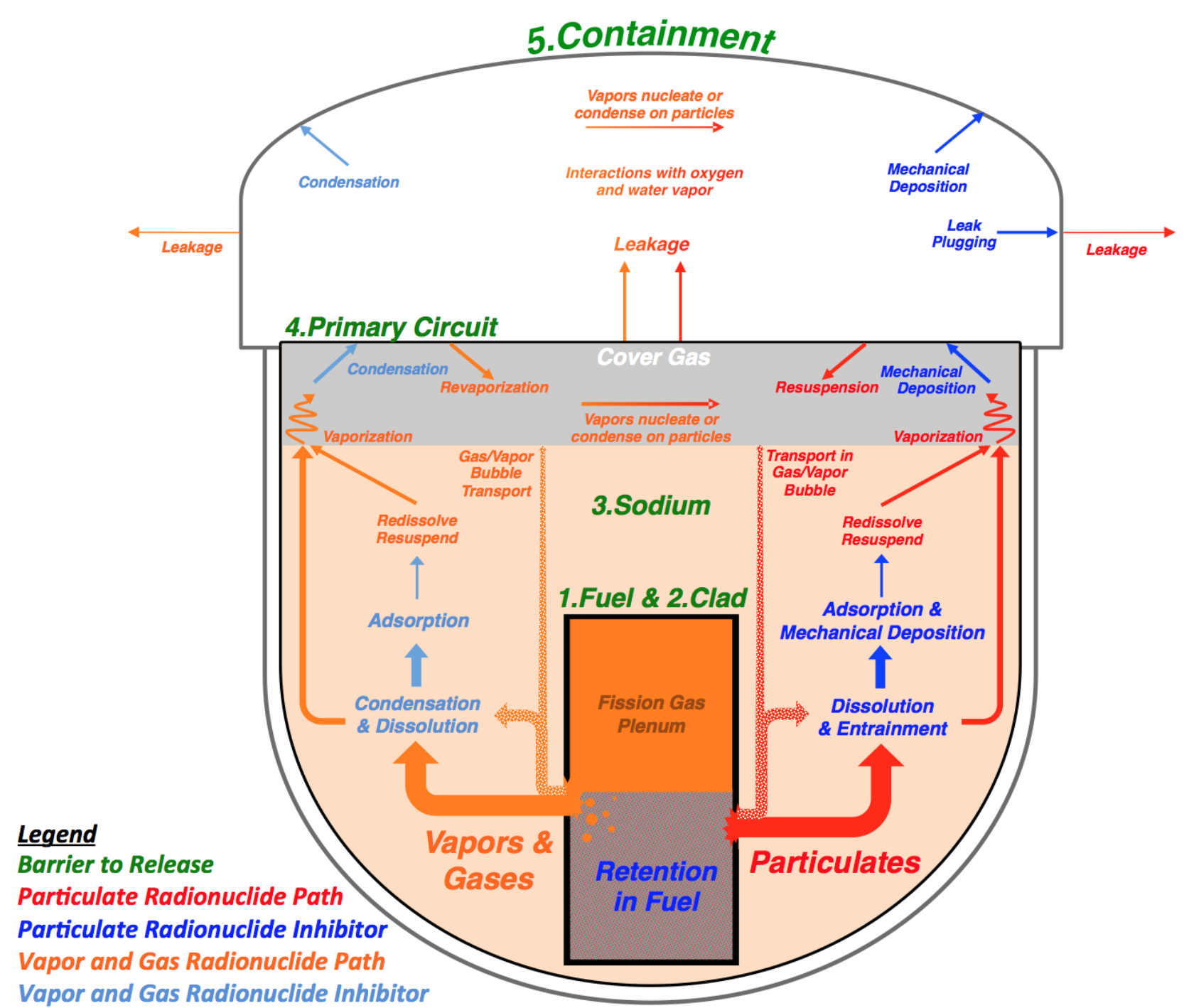

Figure 12-1: Transport and Retention Phenomena for In-Core Releases

\subsubsection{Ex-Core Transport and Release Phenomena}

This section briefly describes the transport and retention phenomena associated with radionuclide releases originating from locations outside the core. In the case of an SFR, it is likely that the largest releases will result from accidents that occur beyond the primary system boundary, as two key retention barriers, the primary sodium and cover gas, are already bypassed. Accidents considered here include a primary sodium fire, a spent fuel handling accident, and releases from cleanup systems.

In an SFR, a primary sodium fire is most likely to occur as the result of maintenance error during shutdown that allows air to ingress into the cover gas region, penetrate the argon (which is denser than air), and interact with the primary coolant. The transport and deposition mechanisms that would normally occur in the cover gas and containment are expected to take place. However, increased vaporization rates of sodium and dissolved radionuclides can occur as the result of increased temperatures at the surface of the sodium pool. Also, additional radionuclides are 
expected to be transported from the sodium directly by the sodium oxides that are formed during burning. Condensation in the cover gas is not expected as local temperatures will likely be higher due to the energy released by the sodium fire. A sodium oxide layer will form near the surface of the pool as the result of the fire, but the combustion of sodium near the core is not likely due to the depth of the sodium pool. Radionuclide release rates will be highly dependent on atmospheric conditions and the quantity of sodium burned.

In the event a spent fuel handling accident, breach of the sodium-filled cask can allow air ingress, which presents the opportunity for a sodium fire. Self-ignition of sodium at low temperatures (< $200^{\circ} \mathrm{C}$ ) is not expected [39]. In the event of ignition, the transport mechanisms expected to occur during a primary sodium fire would also apply. In addition, fuel pins could experience increased temperatures due to their proximity to the fire. Radionuclides that escape the pins are likely to vaporize due to increased temperatures. In the absence of a sodium fire, the vaporization, deposition, and condensation phenomena that occur in the cover gas region are expected to occur.

In the case of FASTER, release from the primary sodium purification system can originate from either the cesium trap or cold trap. The most challenging scenario would involve a sodium fire in which vaporization of sodium and the contents of the traps occurs; in this scenario, phenomena similar to that of a primary sodium fire would occur. However, a limited source of oxygen for the combustion process is expected as the traps will be located within a sealed, robust vault that is constructed to withstand sodium leaks and fires. In the absence of a sodium fire within the vault, and without vault breach, limited releases are expected. A steel-lined vault prevents the interaction of sodium and concrete. Also, it should be noted that the vault is housed within containment, providing an additional barrier to release.

Contents of the distillation column of the cover gas cleanup system are expected to primarily be krypton, xenon, and any activated argon that has been removed from the cover gas. Krypton and xenon will only be present if pin failure occurs, as a noble gas tagging system is utilized to track pin breach. Neon-23 may also be present in the column as it is the decay product of activated sodium. The distillation column, and the cold box in which it is housed, is likely to be located outside containment. Because the contents of the column are primarily noble gases with relatively short half-lives, any holdup before release to the environment will reduce the source term. The magnitude of the source term will be strongly dependent on the operating history and duration, including the number of pin failures and the time-in-cycle for the driver fuel. 


\subsection{Safety Performance}

The normal process of performing safety assessments considers a spectrum of design basis accidents (DBAs) as tests of the various safety systems. These DBAs generally assume single failures. Accidents within the design basis must be accommodated by the design and shown to present risks to the public that are within regulatory limits. Beyond the design basis, there exists a class of accidents of such low probability that they have been termed "hypothetical." These events involve multiple failures of safety grade systems, and usually are considered to have a frequency of less than $10^{-6}$ per reactor-year. Because of the potentially severe consequences of accidents in this class, they have received significant regulatory scrutiny in prior sodium-cooled fast reactor licensing reviews for the purpose of characterizing thermal and structural safety margins beyond the design basis. These accidents are referred to as design extension conditions (DECs).

Three accident scenarios, each involving failure of both reactor scram systems, have received attention in past licensing safety assessments. In the unprotected transient overpower (UTOP) sequence, it is assumed that one control rod is withdrawn and the reactor scram systems fail to operate. In the unprotected loss-of-heat-sink (ULOHS) accident, it is assumed that heat removal through the power conversion system is lost and the reactor scram systems do not activate. The UTOP and ULOHS transients are classified as design extension conditions. In the unprotected station blackout (USBO) sequence, it is assumed that power is lost to all primary and secondary coolant pumps and the reactor scram systems fail to activate. The USBO transient has an even lower frequency of occurrence than the other two and is classified as a severe accident (SA). As the USBO transient is the maximum hypothetical accident, it was included in these analyses to be a bounding case. Taken collectively, these three accident initiators encompass the three primary ways that an operating reactor can be perturbed, i.e., by a change in coolant flow, by a change in reactivity, or by a change in coolant inlet temperature.

A preliminary safety analysis was performed of the FASTER design using the systems analysis code SAS4A/SASSYS-1 [33] to assess the reactor's safety performance during DEC transients. A series of USBO, UTOP, and ULOHS transients were simulated at both beginning-of-equilibrium cycle (BOEC) and end-of-equilibrium cycle (EOEC) conditions, except for the UTOP, which was only simulated at BOEC because the control rods are already withdrawn at end-of-equilibrium cycle. The model used to analyze these transient scenarios is described in Section 12.4.1. Section 12.4.2 presents the safety limits and the results of the transient scenarios.

The transient scenarios were simulated with a nominal direct reactor auxiliary cooling system (DRACS) heat rejection rate of $0.25 \%$ per DRACS unit. The transients were also simulated with DRACS heat rejection rates as high as $0.5 \%$ per unit to quantify the benefits of higher heat rejection rates and whether or not the cost of a larger direct reactor auxiliary cooling system would be justified by an improved safety performance.

\subsubsection{SAS4A/SASSYS-1 Model}

Because the FASTER concept is still in the preconceptual design phase, the design itself is constantly evolving. The core and PHTS models were created based on the current design. Existing models of the IHTS and DRACS for a similar SFR design were modified for the 
preliminary FASTER safety analyses. The SAS4A/SASSYS-1 model used for the FASTER safety analysis is described in the sections below.

\section{$\underline{\text { Core }}$}

In SAS4A/SASSYS-1, the thermal-hydraulic performance of a reactor core is analyzed with a model consisting of a number of single-pin channels. The channel model provides input to specify a single fuel pin and its associated coolant and structure. A single-pin model represents the average pin in an assembly, and assemblies with similar reactor physics and thermal-hydraulic characteristics are grouped together. A number of channels are selected to represent all assemblies in the reactor core.

Figure 12-2 illustrates the geometry used in the SAS4A/SASSYS-1 channel thermal-hydraulic model. Heat generated in the fuel is assumed to travel radially through the cylindrically symmetric pin into the coolant. SAS4A/SASSYS-1 models include axial zones to represent the fueled and gas plenum regions as well as up to six upper and lower reflector zones. Each axial zone is also connected to a structure region, which can be used to model components such as the wire-wrap or duct walls. Two-node slab geometry is used to represent both the reflector and structure regions.

At each axial location, temperatures are calculated at multiple radial nodes in the fuel, cladding, reflectors, and structure. A single bulk coolant temperature is assumed at each axial location. One-dimensional, radial heat transport calculations are performed at each axial segment from the fuel, through the cladding, and into the coolant. Heat transfer is also calculated from the coolant to the gas plenum, reflector, and structure regions. The momentum equation is solved to determine the axial coolant flow. Convective heat transfer is assumed to dominate so axial heat conduction is neglected. 


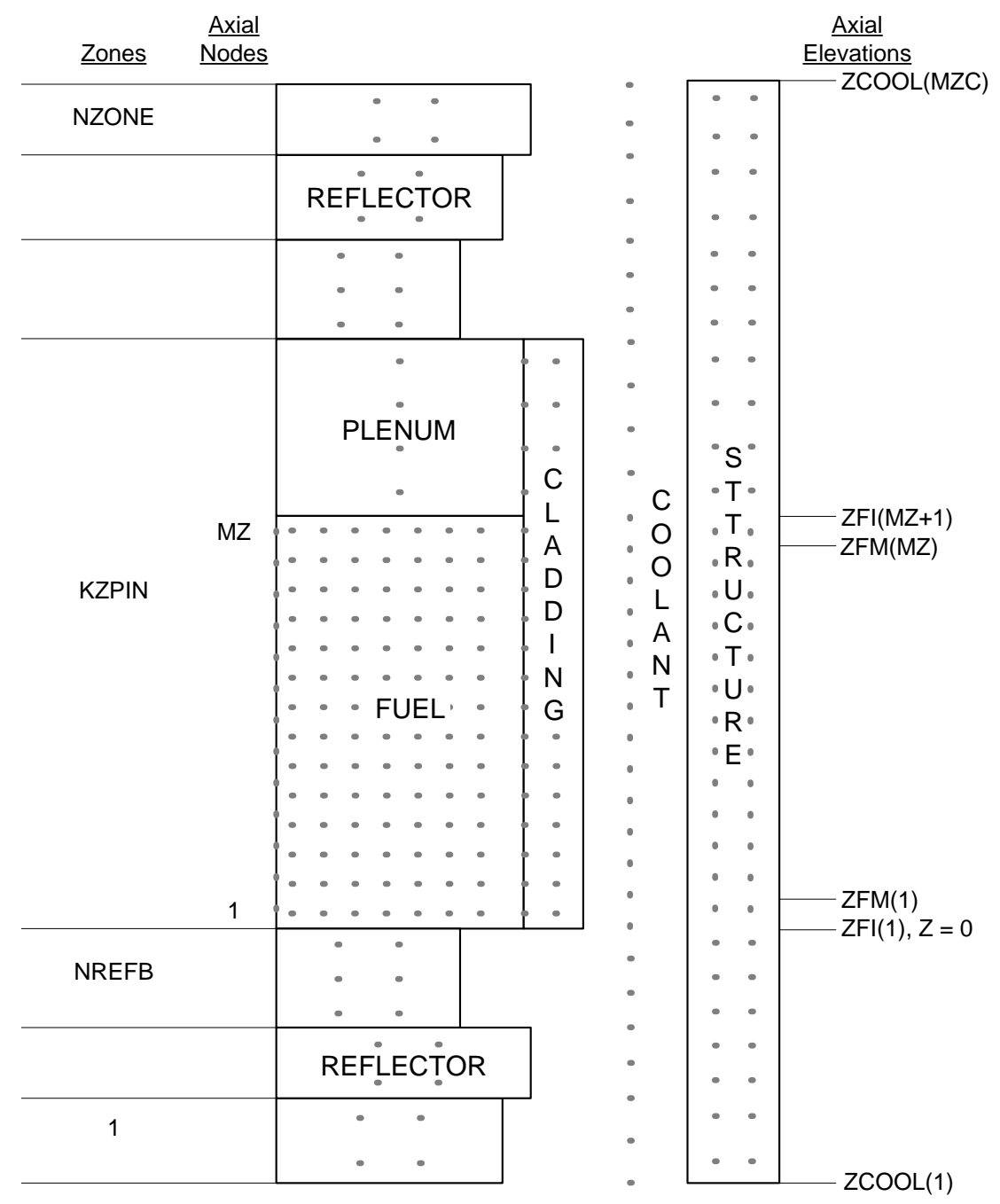

Figure 12-2: PRIMAR-4 Model of the Primary Sodium Heat Transport System

\section{Number of Core Channels}

For the preliminary FASTER safety analysis, a simple representation of all core assemblies was used where each SAS4A/SASSYS-1 channel represents all assemblies of one type (fuel, reflector, test, shield, control, and graphite). The one exception is for the fuel assemblies, where the inner core and outer core assemblies were represented by two channels. In addition to these "regular" channels, a peak channel was added to calculate peak temperatures during the transients.

Table 12-5 lists the 7 regular channels and 1 peak channel and also provides the power and flow per assembly for each channel. The steady-state assembly power and flow values were calculated with PERSENT [8] and SuperEnergy-2 [14], respectively. Channel powers and flow rates were calculated as an average over all assemblies in the channel. The assembly-outlet temperatures, given for both BOEC and EOEC conditions, represent assembly power-to-flow ratios as well as heat transfer between adjacent assemblies. The flow orifice zones are fixed, so the steady-state assembly flow distribution is the same for BOEC and EOEC conditions for the regular channels. 
Table 12-5: Core Channels

\begin{tabular}{rlccccc}
\hline & \multicolumn{1}{c}{ Type } & $\begin{array}{c}\text { Pins Per } \\
\text { Assembly }\end{array}$ & Assemblies & $\begin{array}{c}\text { Power per Assembly } \\
\text { BOEC/EOEC (MW) }\end{array}$ & $\begin{array}{c}\text { Flow per } \\
\text { Assembly } \\
(\mathbf{k g} / \mathbf{s})\end{array}$ & $\begin{array}{c}\text { Outlet Temp. } \\
\text { BOEC/EOEC } \\
\left({ }^{\circ} \mathbf{C}\right)^{\mathbf{a}}\end{array}$ \\
\hline 1 & Inner Core & 271 & 30 & $6.30 / 6.25$ & 31.6 & $512.4 / 511.3$ \\
2 & Outer Core & 271 & 25 & $4.15 / 4.19$ & 21.4 & $507.3 / 509.0$ \\
3 & Control & 91 & 9 & $0.078 / 0.080$ & 0.359 & $504.1 / 505.3$ \\
4 & Test & 91 & 39 & $0.065 / 0.068$ & 0.327 & $506.8 / 510.5$ \\
5 & Reflector & 91 & 77 & $0.047 / 0.048$ & 0.231 & $502.9 / 507.4$ \\
6 & Graphite & 91 & 22 & $0.0006 / 0.0007$ & 0.004 & $472.5 / 476.2$ \\
7 & Shield & 61 & 111 & $0.005 / 0.005$ & 0.031 & $480.8 / 485.1$ \\
\hline 8 & Peak Core & 1 & 1 & $7.61 / 3.70^{\mathrm{b}}$ & $30.9 / 14.9^{\text {a,b }}$ & $548.9 / 550.0$ \\
\hline
\end{tabular}

The inner and outer core fuel assemblies have identical geometries. Differences in the SAS4A/SASSYS-1 input for the inner and outer core fuel channels is limited to the plutonium content of the fuel, which affects fuel properties such as thermal conductivity, the assembly-wise power production and flow rate, and the reactivity feedback coefficients. The core channel map is shown in Figure 12-3.

\section{Peak Channels}

The peak channel in the FASTER SAS4A/SASSYS-1 model was introduced to calculate maximum temperatures in the core. The peak channel is represented by a single pin. Because the geometric channel input is entered on a per-pin basis, the peak channel geometric input is identical to the input for the regular core channels.

The power production and flow rate in the peak channel were selected to match the peak coolant temperature calculated by the SuperEnergy-2 sub-channel code. The peak coolant temperature is shown in the final column for the peak channel in Table 12-5. The power used to represent the peak channel is the average per-pin power of the assembly where this peak coolant temperature was calculated. The flow rate in the peak channel was reduced from the average assembly flow rate so that the coolant outlet temperature for the peak pin matches the maximum coolant outlet temperature calculated in the SuperEnergy-2 calculations. This was done to account for subchannel flow variations within the assemblies.

The peak coolant temperature locations (assemblies) are calculated to be different for the BOEC and EOEC conditions. Therefore, both the power and flow rate for the peak pin are different for BOEC and EOEC core models. 


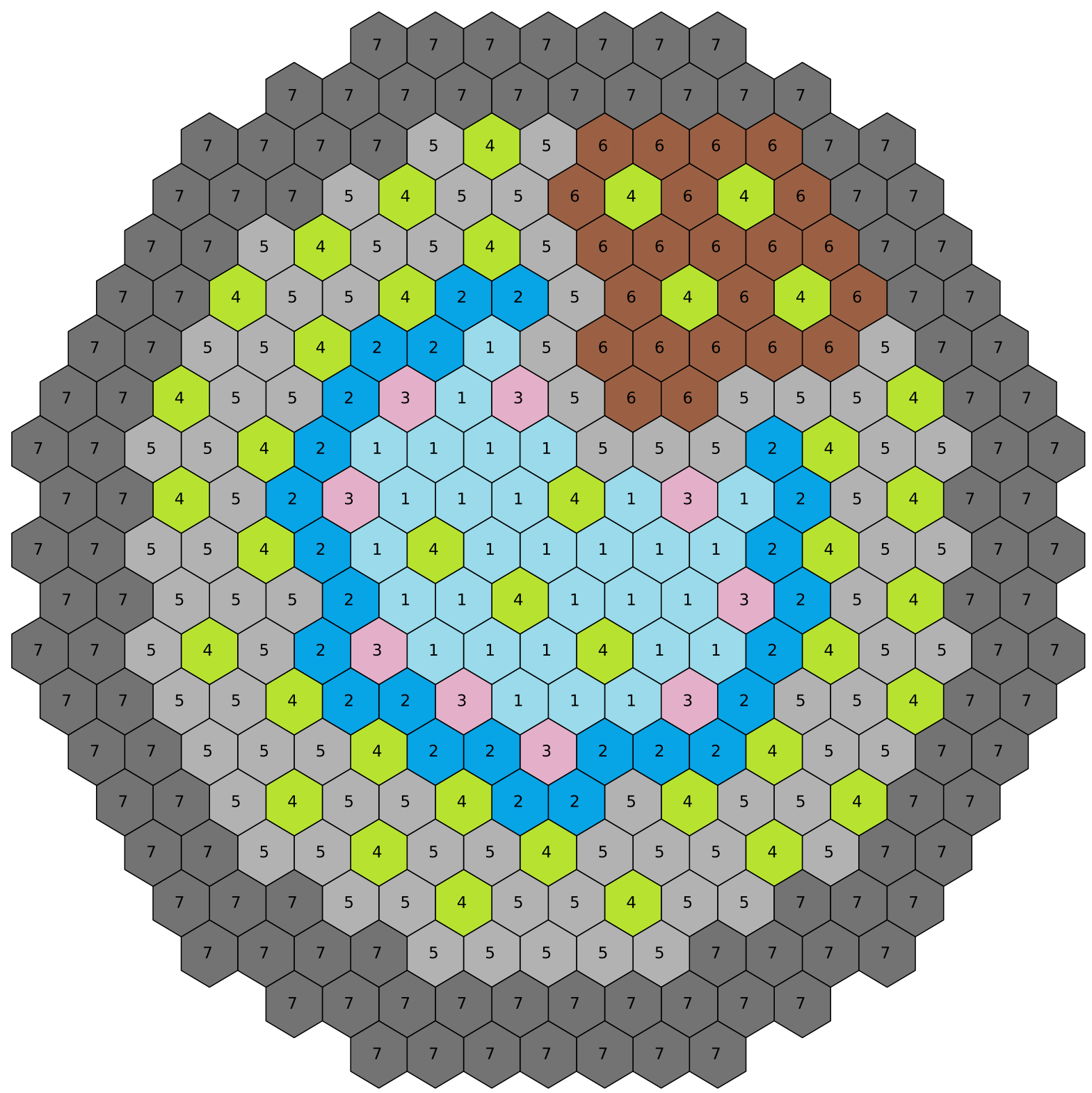

Figure 12-3: SAS4A/SASSYS-1 Core Channels and Heat Transfer Areas

Because SAS4A/SASSYS-1 requires an integer number of pins per assembly in a channel, a single pin cannot easily be separated from the rest of the pins in a regular channel. Therefore, as shown in Table 12-5 the total number of pins in the regular channels is preserved, and the peak channel adds an extra pin to the core, along with the corresponding power and flow for each of these pins. To preserve the total core power and flow, the power and flow rates in the regular channels were adjusted for the "removed" power and flow fractions from the peak pin. However, since the peak channel only represents one pin out of 30 assemblies, each with 271 pins, those adjustments are very small, around $0.01 \%$, and do not significantly affect temperatures or reactivity feedbacks in the regular channels.

Since the total number of pins in the main channels is preserved, the coolant, cladding, fuel, and structure masses in the regular channels are not affected by the addition of the peak channel. 
Therefore, the reactivity feedbacks calculated for the regular channels will represent the feedback from those assemblies. Any feedback from the peak channel would be an addition to that. In order to avoid calculating that "extra" feedback, all the reactivity input for the peak channel is ignored in the calculations (i.e., zeros are entered in the input).

The peak pin channel is also excluded from the channel-to-channel heat transfer calculations, which are discussed below. For the reasons discussed above, the peak channel is only introduced to calculate and track peak coolant, cladding, and fuel temperatures in the core. The peak channel has a negligible effect on the power and flow results in the core and has no effect on the core reactivity feedbacks.

\section{Core Geometry}

Figure 12-4 illustrates the axial geometry of the different channel types in the core model. Most of the core model dimensions were provided by the neutronics analysis (Section 3.1). Several dimensions had to be assumed or inferred. An example is the transition region from the blocktype reflector to the fuel pin region, which is not explicitly modeled in the current neutronics analysis. The SAS4A/SASSYS-1 model simulates this region, but with assumed dimensions and the understanding that these dimensions are likely to change when more detailed assembly design is developed. In Figure 12-4, Zones 1 and 2 represent the lower reflector in the fuel channels. Zone 1 is a $0.85 \mathrm{~m}$ long block-type reflector with three semi-circular coolant channels. The channel diameters are calculated to be $58.5 \mathrm{~mm}$ to preserve the $33 \%$ coolant volume fraction used in the neutronics analysis. Zone 2 is a $10 \mathrm{~cm}$ long transition zone from the block-type reflector to the fuel pins. It is modeled as solid structure with a central coolant channel. The channel diameter is calculated as $71.6 \mathrm{~mm}$ to preserve the same $33 \%$ coolant volume fraction in this region.

Zone 3 includes the fuel and fission gas plenum, which are $0.8 \mathrm{~m}$ and $0.52 \mathrm{~m}$ tall, respectively. These heights reflect the hot (i.e., at operating temperature) dimensions for irradiated fuel. There are 20 axial segments in the fuel zone and 5 axial segments in the fission gas plenum. Because a multiple-zone fission gas plenum is not currently supported by SAS4A/SASSYS-1, the model neglects the effects of the bond sodium pushed up into the bottom of the fission gas plenum. In future model updates the portion of the gas plenum that is filled with sodium could be modeled as a blanket, which would allow for sodium expansion into that region to be accounted for. For the current model, the reactivity feedback of sodium in the gas plenum region is neglected because even as the temperature changes, the total mass of the sodium remains the same.

Zones 4-6 represent the upper reflector. The first two zones are similar to the lower reflector zones, but inverted. Zone 4 is the transition from fuel pins to the block-type upper reflector. Zone 5 has the same geometry as the lower block-type reflector zone, Zone 1 . The last upper reflector zone, Zone 6, is the fuel handling socket region. It was modeled as a solid structure with a single $105 \mathrm{~mm}$ diameter circular coolant channel to conserve the $71 \%$ coolant volume fraction used in the neutronics analysis. The lengths of Zones $4-6$ are $0.1,0.4$, and $0.3 \mathrm{~m}$, respectively. 


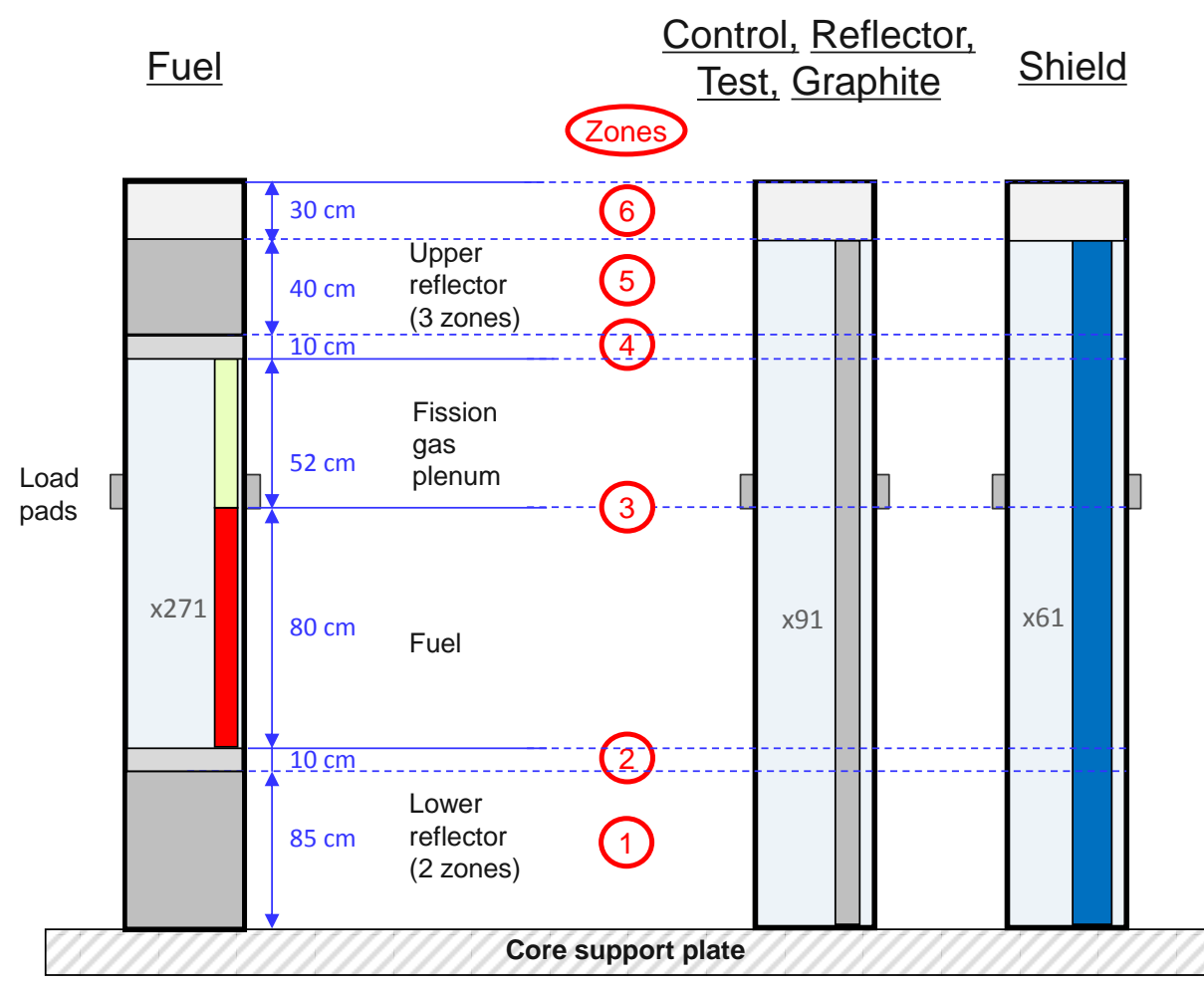

Figure 12-4: SAS4A/SASSYS-1 Core Channels Axial Geometry

The following form loss coefficients are currently assumed in the fuel channels:

- 1.0 at the assembly inlet,

- 0.6 at the transition from the block-type reflector,

- 0.8 at the pin zone inlet, and

- 1.0 at the assembly outlet.

These coefficients will need to be updated when the detailed assembly design is available. With the current values, the highest pressure drop is calculated for Channel 1 at $0.51 \mathrm{MPa}$. The assembly-inlet orifice coefficients are adjusted by SAS4A/SASSYS-1 for the other channels to obtain the same pressure drop across all channels.

The assembly load pads are assumed to be located immediately above the fuel pins at the border of fuel and fission gas plenum regions. Although the height of the load pads is neglected, the load pads elevation is important for the radial expansion feedback calculation. The sodium in the interassembly gap is assumed to be stagnant and is modeled as a part of the structure region smeared with the assembly duct wall.

The fuel channel geometry is identical for BOEC and EOEC conditions. In both cases, the fuel is conservatively assumed to have expanded into contact with the cladding inner surface, which increases the fuel centerline temperature by reducing the fuel thermal conductivity and displacing the very high thermal conductivity sodium from the gap. For BOEC conditions, assuming fuel- 
cladding contact corresponds to a minimum fuel burnup of $1 \%$, rather than fresh fuel. Only a fraction of the fuel will be fresh at the very beginning of the BOEC cycle.

The axial geometry of the reflector, test, graphite, and shield channels are illustrated in Figure 12-4. As shown in Table 12-5, the test and graphite assemblies have very small contributions to the total core power and flow. Therefore, uncertainties in the geometry of these assemblies, which are still being developed for FASTER, will not significantly affect the results of the safety analysis. An exception to this could be the use of fuel in the test assemblies; these cases should be analyzed in the future on a case-by-case basis. Because they produce very little power and have very little flow, both the graphite and test assemblies are assumed to have exactly the same geometry as the reflector assemblies, i.e., 91 HT9 rods spanning the entire assembly height, except for the assembly handling socket, as shown in Figure 12-4. Modeling the test assemblies with steel rods, rather than just sodium volume, will also lead to conservative safety analysis results. A negative coolant void worth was calculated for these assemblies, such that replacing a portion of the coolant with structure in these assemblies will result in less negative coolant density reactivity feedback for transients where the coolant temperature increases.

The control assemblies are currently modeled as being at the fully insertion position, as illustrated in Figure 12-4. This approach preserves the geometry of the control assemblies, but does not account for the fact there will be more sodium in the core region when the control rods are withdrawn. To account for this difference, the coolant void reactivity input for the control channel was corrected by a multiplication factor to preserve the total coolant void worth in the SAS4A/SASSYS-1 steady-state calculations, compared to that obtained in the neutronics analysis which was done at the actual control rod position. Further refinements to the control channel model to reflect the actual positions in the core will be implemented later, when the control rod design is finalized for FASTER.

For all non-fueled assemblies, Zone 6 represents the assembly-handling region, which is assumed to be identical to the assembly handling region for the fuel assemblies. Zones 1-5 represent the solid pin bundle regions in these assemblies. The number of pins and pin diameters are different for the control, shield, and reflector (and test and graphite) assemblies. For assembly-to-assembly heat transfer calculations, the axial mesh is identical to the fuel assemblies. For example, Zones 1 and 2 in the non-fueled channels have the same heights and axial segments as Zones 1 and 2 for the fuel channel. Because SAS4A/SASSYS-1 requires a fuel pin region for all channels, even channels representing assemblies without fuel, the "fuel" pins are assumed to be solid HT9 for all non-fueled assemblies.

\section{Channel-to-Channel Heat Transfer}

The core model includes heat transfer between neighboring assemblies. Heat transfer areas were calculated based on the corresponding number of assembly sides in contact for different channels. The complete number of assembly sides participating in the heat transfer between channels is listed in Table 12-6 for all channel pairs. As discussed above, Channel 8 is not included in the heat transfer calculations. The number of assembly sides was used to calculate the total heat transfer perimeter (or area per unit height) based on the assembly dimensions. 
The heat transfer coefficient was calculated to account for the thermal resistance of the nominal 3 $\mathrm{mm}$ inter-assembly sodium gap, which is assumed to be filled with stagnant sodium, and two halves of the outer duct wall node thickness, one on each side of the gap. The resulting heat transfer coefficient per unit area for the channel-to-channel heat transfer was calculated to be 6.85 $\mathrm{kW} / \mathrm{m}^{2}-\mathrm{K}$. With this heat transfer coefficient, it was found that the SAS4A/SASSYS-1 model predicts more heat transfer than the SuperEnergy-2 simulation does. This overprediction is mainly due to temperature variations between the six assembly sides for each channel (or assembly), which are not accounted for in a single-structure-temperature approach in SAS4A/SASSYS-1. To better match the outlet temperatures in non-fueled assemblies calculated by SuperEnergy-2, which are shown in Table 12-5, the heat transfer coefficient was multiplied by a factor of 0.1 for all channels. It should be noted that channel-to-channel heat transfer mostly affects the temperatures in the non-fueled assemblies, which do not represent any limiting conditions in the unprotected transients. For the fuel assemblies, the assembly-to-assembly heat transfer rate is small compared to the power generation with the channel-to-channel heat transfer model only affecting steady-state temperatures by $1^{\circ} \mathrm{C}$. Additionally, the fuel assemblies do not show as large of a temperature variation between the assembly sides as the SuperEnergy-2 results. Still, in future model updates, methods to improve heat transfer to non-fueled assemblies need to be considered.

Table 12-6: Number of Assembly Sides Participating in the Channel-to-Channel Heat Transfer

\begin{tabular}{ccccccc}
\hline Channels & 2 & 3 & 4 & 5 & 6 & 7 \\
\hline 1 & 20 & 27 & 23 & 6 & 0 & 0 \\
2 & & 23 & 32 & 27 & 0 & 0 \\
3 & & & 0 & 4 & 0 & 0 \\
4 & & & & 137 & 24 & 18 \\
5 & & & & & 23 & 69 \\
6 & & & & & & 15 \\
\hline
\end{tabular}

Reactivity Feedbacks

The SAS4A/SASSYS-1 model calculates the following reactivity feedbacks:

- Fuel Doppler,

- Fuel density (and axial expansion),

- Cladding (structure) density,

- Coolant density,

- Control rod movement, including control rod driveline, reactor vessel, and below-the-core structures expansion, and

- Core radial expansion.

The Doppler, axial expansion, cladding density, and coolant density reactivity feedback coefficients that are used in the SAS4A/SASSYS-1 model were generated using first order perturbation theory by the PRESENT code (version 11.0) utilizing $\mathrm{P}_{5}$ transport calculations from DIF3D-VARIANT [40]. The radial expansion and control rod expansion feedbacks were 
calculated based on the differences in $\mathrm{k}_{\text {eff }}$ values. The first three feedbacks are applicable to the fueled assemblies only (Channels 1 and 2).

The fuel Doppler feedback was calculated from the average fuel temperature change at each axial segment. A 1/T dependence is assumed for the change in reactivity. Input parameters are entered for two Doppler coefficients, one with coolant present and the other with coolant voided.

SAS4A/SASSYS-1 linearly interpolates between these two values during the transient based on the sodium density to calculate the Doppler feedback.

The calculations for the reactivity feedbacks due to fuel, cladding, and coolant density changes are similar to each other. The coolant feedback is calculated in each zone for all channels but the fuel and cladding feedbacks are calculated in the fuel zone for only the fuel channels. The cladding temperature was used for the feedback due to both cladding and structure density changes under the assumption that the temperature changes in the cladding and structure are similar during a transient.

Core axial expansion was calculated based on fuel and cladding density changes. As densities decrease, the fuel and cladding expand and push the mass higher up. The displaced mass in each pin is relocated above the fuel to conserve mass. The change in mass at each segment is then converted to a reactivity change based on user-input fuel and cladding axial worth distributions. Since fuel has a higher worth in the center of the core, axial expansion will move the fuel from a region of high worth (center of the core) to a region of low worth (top of the core) introducing a negative reactivity feedback.

During each transient, an assumption of "soft" fuel in contact with cladding is used. This assumption is implemented by using the force balance model for the coupled fuel and cladding expansion, but by providing zero for the fuel's Young's modulus. With this input, the amount of axial expansion for both the fuel and the cladding will be defined by the cladding thermal expansion. Additionally, the control rod positions are fixed during the calculation of fuel and cladding feedback coefficients so the fuel density feedback also accounts for the axial expansion of fuel relative to the control rods.

The total calculated worths for the coolant (shown as void), cladding (and structure), and fuel are shown in Table 12-7 for each channel at BOEC and EOEC conditions. Note that these results are the total worths for each channel, not per assembly. The cladding and fuel worths are calculated for the fueled channels, Channels 1 and 2. Channel 3 has the largest coolant worth due to the large coolant volume fraction, especially at EOEC conditions when the control rods are withdrawn. It can also be observed that the individual and reactor total reactivity coefficients are similar for BOEC and EOEC conditions. The only noticeable exception is the coolant worth in the control channels, where some portion of the coolant is displaced from the core zone by partially inserted control rods at BOEC conditions.

The channel-dependent reactivity input described above was partially verified by comparing the total coolant, cladding (and structure), and fuel worths calculated by SAS4A/SASSYS- 1 for each channel with the neutronics results that would be obtained with $100 \%$ mass change assuming linear feedback. For all coefficients and all channels, the difference is limited by $+/-5 \%$, which 
can be explained by differences in assumed density. For the fuel, the difference is small, less than $1 \%$ for all channels, confirming consistent fuel mass assumptions. For the coolant,

SAS4A/SASSYS-1 uses the steady-state temperatures and densities, so assuming an average density for all nodes, which is the assumption for the neutronics calculations, will result in less mass in the lower segments and more mass in the higher segments. For the cladding (structure) worth, the SAS4A/SASSYS-1 results include the inter-assembly sodium gap.

Table 12-7: Reactivity Coefficients by Channel

\begin{tabular}{ccccccc}
\hline \multicolumn{7}{c}{ BOEC Conditions } \\
\hline Channel & Type & $\begin{array}{c}\text { Void } \\
\mathbf{( \$ )}\end{array}$ & $\begin{array}{c}\text { Clad. } \\
\mathbf{( \$ )}\end{array}$ & $\begin{array}{c}\text { Fuel } \\
\mathbf{( \$ )}\end{array}$ & $\begin{array}{c}\text { Unvoided } \\
\text { Doppler } \\
(\mathbf{T} \square \mathbf{K} / \square \mathbf{T})\end{array}$ & $\begin{array}{c}\text { Voided } \\
\text { Doppler } \\
(\mathbf{T} \square \mathbf{K} / \square \mathbf{T})\end{array}$ \\
\hline 1 & Inner Core & -0.67 & -3.51 & 116.2 & -0.0020 & -0.0016 \\
2 & Outer Core & -1.17 & 1.27 & 40.6 & -0.0010 & -0.0009 \\
3 & Control & -2.17 & 0 & 0 & 0 & 0 \\
4 & Test & -0.41 & 0 & 0 & 0 & 0 \\
5 & Reflector & -0.59 & 0 & 0 & 0 & 0 \\
6 & Graphite & $-8 \mathrm{E}-07$ & 0 & 0 & 0 & 0 \\
7 & Shield & -0.02 & 0 & 0 & 0 & 0 \\
\hline \multicolumn{2}{r}{ Reactor Total } & $\mathbf{- 5 . 0 3}$ & $\mathbf{- 2 . 2 4}$ & $\mathbf{1 5 6 . 8}$ & $\mathbf{- 0 . 0 0 3 1}$ & $\mathbf{- 0 . 0 0 2 5}$ \\
\hline
\end{tabular}

EOEC Conditions

\begin{tabular}{ccccccc}
\hline Channel & Type & $\begin{array}{c}\text { Void } \\
\mathbf{( \$ )}\end{array}$ & $\begin{array}{c}\text { Clad. } \\
\mathbf{( \$ )}\end{array}$ & $\begin{array}{c}\text { Fuel } \\
\mathbf{( \$ )}\end{array}$ & $\begin{array}{c}\text { Unvoided } \\
\text { Doppler } \\
(\mathbf{T} \square \mathbf{K} / \square \mathbf{T})\end{array}$ & $\begin{array}{c}\text { Voided } \\
\text { Doppler } \\
(\mathbf{T} \square \mathbf{K} / \square \mathbf{T})\end{array}$ \\
\hline 1 & Inner Core & -0.51 & -4.04 & 110.2 & -0.0022 & -0.0017 \\
2 & Outer Core & -1.35 & 1.38 & 42.8 & -0.0012 & -0.0010 \\
3 & Control & -2.66 & 0 & 0 & 0 & 0 \\
4 & Test & -0.43 & 0 & 0 & 0 & 0 \\
5 & Reflector & -0.66 & 0 & 0 & 0 & 0 \\
6 & Graphite & $-7 \mathrm{E}-07$ & 0 & 0 & 0 & 0 \\
7 & Shield & -0.02 & 0 & 0 & 0 & 0 \\
\hline \multicolumn{2}{l}{ Reactor Total } & $\mathbf{- 5 . 6 2}$ & $\mathbf{- 2 . 6 6}$ & $\mathbf{1 5 3 . 0}$ & $\mathbf{- 0 . 0 0 3 4}$ & $\mathbf{- 0 . 0 0 2 7}$ \\
\hline
\end{tabular}

The core radial expansion feedback in the transient simulations was calculated using the simple radial expansion model. This model neglects assembly bowing and assumes straight-line expansion between the core support plate and above-core load pads, as illustrated in Figure 12-5. 


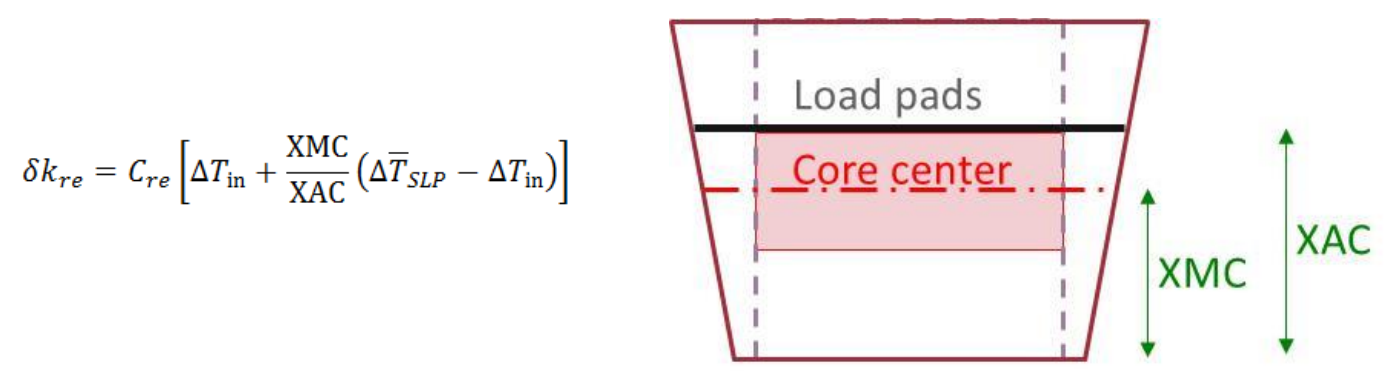

Figure 12-5: SAS4A/SASSYS-1 Simple Radial Expansion Model

The coefficient $C_{r e}$ was calculated based on the core reactivity change for an assumed $1 \%$ increase in the assembly pitch with a corresponding decrease in atom density of the structures and fuel to preserve mass. The $1 \%$ change in pitch is then converted to a change in temperature based on the thermal expansion coefficient for the selected structural material.

Because the simple radial expansion model supports only a single input for $C_{r e}$, the value of $C_{r e}$ that was input for each transient depends on the expected dominant component. For station blackout and transient overpower accidents, core radial expansion is dominated by the temperature rise in the core and, therefore, the expansion of the load pads. The thermal expansion coefficient for the load pad material, HT9, evaluated at the steady-state core-outlet temperature $\left(1.379 \cdot 10^{-5} 1 / \mathrm{K}\right)$ was selected for the $C_{r e}$ input for these transients. For loss of heat sink transients, the core-inlet temperature changes faster than the core-outlet temperature so the core radial expansion feedback is dominated by the expansion of the core support plate. Therefore, the material properties of the Type 316 stainless steel support plate, evaluated at the steady-state core-inlet temperature, were used for the thermal expansion coefficient $\left(1.919 \cdot 10^{-5} 1 / \mathrm{K}\right)$ and the $C_{r e}$ input. Additionally, for the ULOHS transient it was conservatively assumed that the abovecore load pads remain in contact even when the core support plate expands. The values of the $C_{r e}$ coefficient for each transient are presented in Table 12-8.

Table 12-8: Core Radial Expansion Reactivity Feedback Coefficient

\begin{tabular}{lcc}
\hline $\boldsymbol{C}_{\boldsymbol{r e}}[\mathbf{\$} / \mathbf{K}]$ & BOEC & EOEC \\
\hline$U S B O$ and UTOP & -0.003150 & -0.003193 \\
ULOHS & -0.004383 & -0.004441 \\
\hline
\end{tabular}

The distances XAC and XMC in Figure 12-5 were calculated based on the hot dimensions. It was assumed that the load pads are located immediately above the fuel region, so XAC is equal to the sum of the lower reflector zone heights and the fuel column height. XMC is equal to the sum of the lower reflector zone heights plus one-half of the fuel column height. The XMC/XAC ratio was calculated to be 0.771 .

The option to use the inlet plenum wall temperature rather than the coolant temperature was used to calculate the core radial expansion feedback. The load pad temperature was assumed to be the structure temperature in the first fission gas plenum segment. To calculate the radial expansion of the active core, only the fuel channels, Channels 1 and 2, were included into the calculation of the average load pads temperatures. 
The control rod driveline (CRDL) expansion feedback is calculated in SAS4A/SASSYS- 1 based on a second-order approximation of the control rod position relative to the core:

$$
\delta k_{C R}=A_{C R D E X} \Delta z+B_{C R D E X} \Delta z^{2}
$$

where $\Delta z$ in is the relative change in the control rod position in the core as a function of time. Vessel expansion, which causes the bottom-supported core to be pulled away from the control rods, was calculated using the control system module.

The coefficients $A_{C R D E X}$ and $B_{C R D E X}$ were obtained using a quadratic fit of the control rod worth curve (S-curve). Figure 12-6 shows how the primary and secondary control rod curves were fit around their corresponding critical positions to obtain the coefficients for CRDL feedback for BOEC and EOEC conditions.

For the UTOP transient, the single most reactive control rod is assumed to have withdrawn from the core, so the $A_{C R D E X}$ and $B_{C R D E X}$ coefficients for primary control rods are calculated based on the "All-minus-one" control rod worth curve, which accounts for movement of all control rods except for the rod already withdrawing from the core. No calculations were done for the UTOP transient at EOEC conditions because the control rods are already withdrawn from the core.

Because the control rods are partially inserted at BOEC conditions, the CRDL feedback is much stronger at this point in the fuel cycle. This effect represents the most significant difference between the BOEC and EOEC results for the unprotected transient simulation presented below, since the rest of the reactivity feedbacks are similar for BOEC and EOEC conditions.

The CRDL expansion in SAS4A/SASSYS-1 is calculated based on the coolant and CRDL structure temperature changes in the upper internal structure (UIS) volume, which is treated separately from the hot pool volume. Until a more detailed analysis of the coolant flow from the core into the UIS is performed, only the flow from Inner Core assemblies (Channel 1) will be included into the calculations of coolant temperatures in the UIS. 

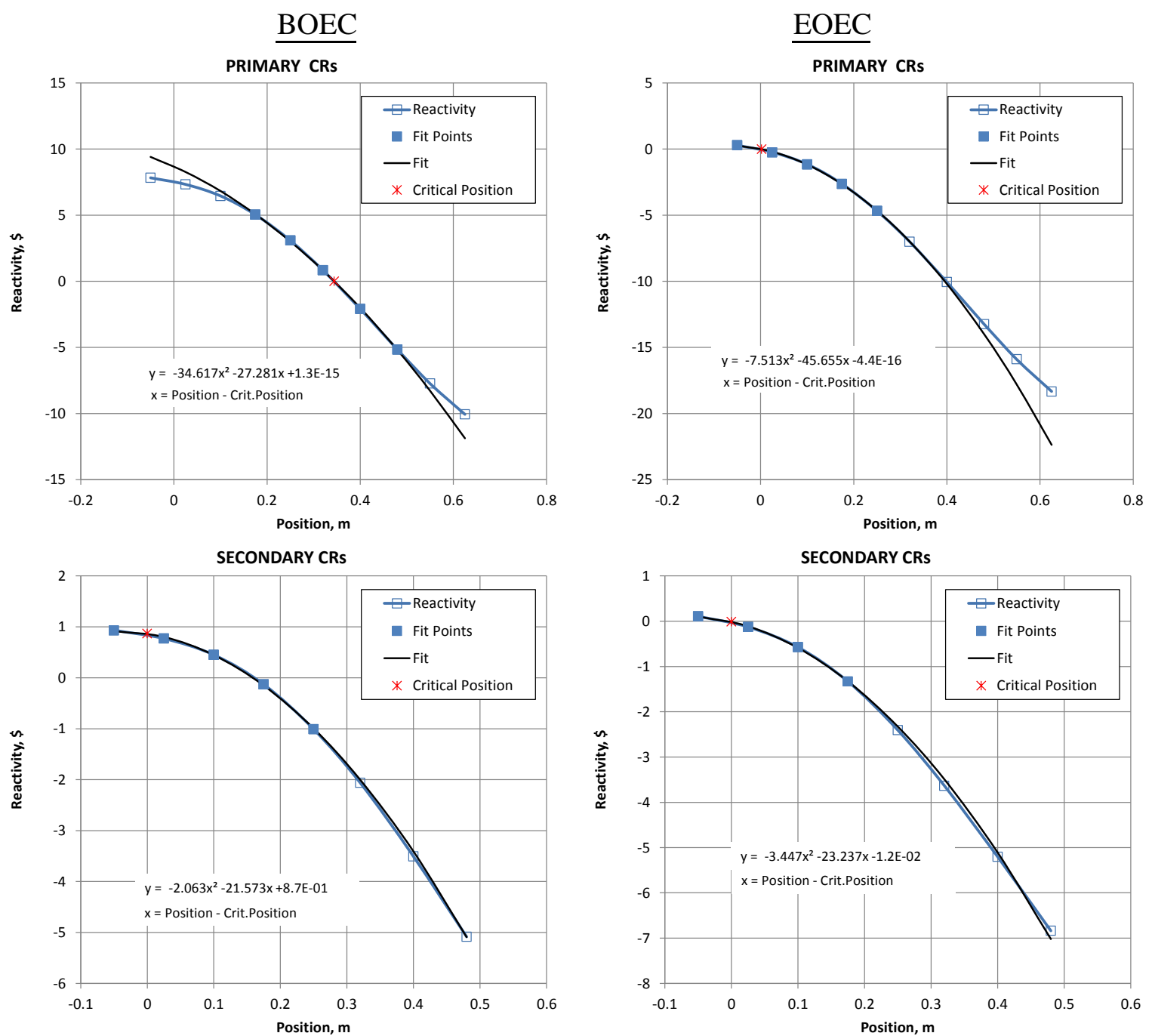

Figure 12-6: Obtaining Coefficients for CRDL Feedback, All Transients Except UTOP

Table 12-9: CRDL Reactivity Feedback Coefficients

\begin{tabular}{cccc}
\hline & & BOEC & EOEC \\
\hline \multirow{2}{*}{ USBO and ULOHS } & $A_{C R D E X}(\$ / m)$ & -36.67939 & -10.96056 \\
& $B_{C R D E X}\left(\$ / m^{2}\right)$ & -48.85333 & -68.89136 \\
\hline \multirow{2}{*}{ UTOP } & $A_{C R D E X}(\$ / m)$ & -30.47011 & \multirow{2}{*}{ N/A } \\
& $B_{C R D E X}\left(\$ / m^{2}\right)$ & -42.65949 & \\
\hline
\end{tabular}

\section{PRIMAR-4 Heat Removal Systems Model}

The PRIMAR-4 module simulates the thermal hydraulics of the primary, intermediate, and direct reactor auxiliary cooling systems in SAS4A/SASSYS-1. A simplified example of PRIMAR-4 geometry is illustrated in Figure 12-7. Compressible volumes, or CVs, are zero-dimensional volumes that are used to represent larger volumes of coolant, typically inlet and outlet plena 
pools, as well as pipe tees. CVs are characterized by their pressure, temperature, elevation, and volume.

Compressible volumes are connected by liquid segments, which are composed of one or more elements. Elements are modeled by one-dimensional, incompressible, single-phase flow and can be used to model pipes, valves, pumps, heat exchangers, steam generators, and more. Elements are characterized by their pressure, temperature, elevation, and mass flow rate.

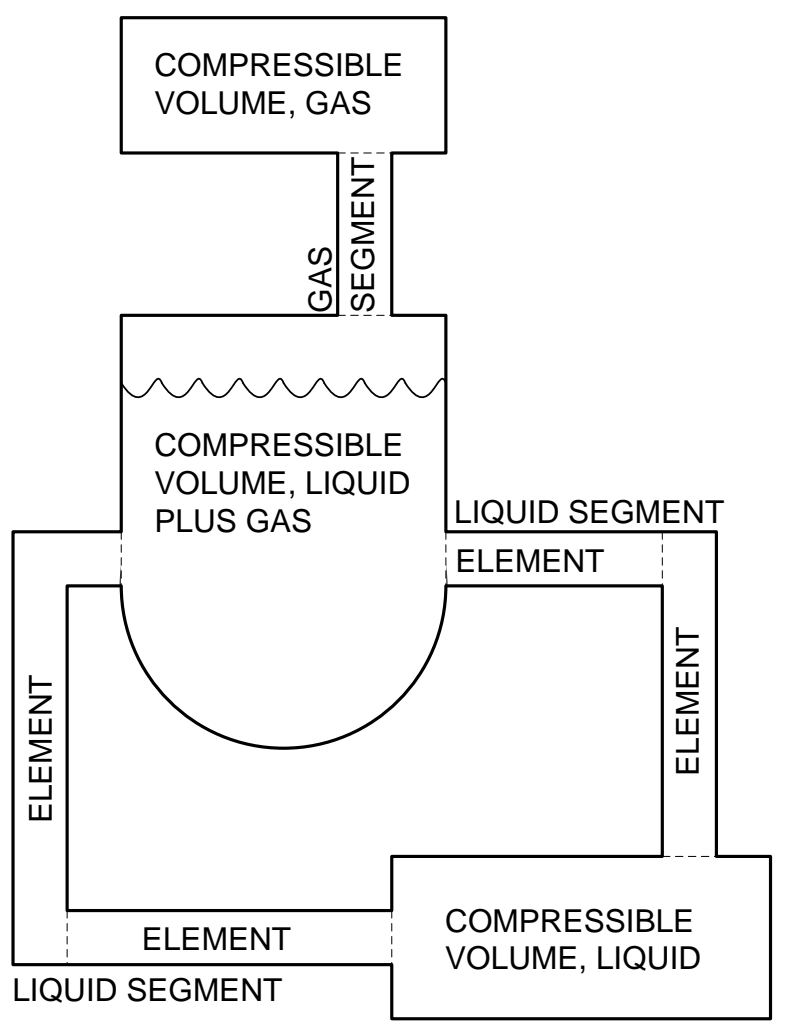

Figure 12-7: SAS4A/SASSYS-1 PRIMAR-4 Modeling

\section{PRIMAR-4 Geometry}

Figure 12-8, Figure 12-9, and Figure 12-10 illustrate the PRIMAR-4 models of the primary heat transport system (PHTS), intermediate heat transport system (IHTS), and direct reactor auxiliary cooling system (DRACS), respectively. Selected input parameters for the elements and compressible volumes in these systems are listed in Table 12-10, Table 12-11, and Table 12-12.

Element 1 represents the eight core channels. At steady-state, sodium enters the core from the inlet plenum (CV1) at a temperature of $355^{\circ} \mathrm{C}$ and discharges into the hot pool (CV2) at an average of $510^{\circ} \mathrm{C}$. Element 2 represents the primary-side, i.e., shell-side, of IHXs 1 and 2 and Element 4 represents the primary side of IHXs 3 and 4 . Because the heat exchangers are identical, multiplicity is used to represent the first two heat exchangers with one element and the other two heat exchangers with another element. SAS4A/SASSYS-1 has a limit of 4 heat exchangers so in order to model the decay heat exchangers, the number of IHXs modeled was reduced. Elements 3 
and 5 represent the IHX outlets with sodium discharged into CV4, the bulk portion of the cold pool.

CV3 represents the upper portion of the cold pool and feeds the decay heat exchangers. In pool type SFRs, thermal stratification and heat transfer between the hot and cold pools through the redan produce higher temperatures in the upper portion of the cold pool. The component-tocomponent heat transfer model was used to specify heat transfer between the upper cold pool and the hot pool, which produces higher temperatures in CV3 than in CV4. Additional analysis beyond the scope of this work is necessary to determine the proper heat transfer rate to capture the higher temperatures at the top of the cold pool.

CV5 represents a very small portion of sodium at the bottom of the cold pool. This volume does not play a significant role in the transients analyzed but was reserved for modeling the stagnant sodium at the bottom of the cold pool. Additional analysis is required to determine exactly how sodium stagnates after the primary sodium pumps trip.

In the intermediate heat transport systems, Segments 9-12 represent IHTS 1 and Segments 13-16 represent IHTS 2. A simple steam generator model provides the boundary for both loops. In most transients, the steam generator is represented by a normalized sodium temperature drop that either remains at $100 \%$ or drops to $0 \%$.

Element 15 represents the shell side of the decay heat exchangers for the direct reactor auxiliary cooling system. As with the IHXs, multiplicity is used to model two heat exchangers with one element. The third decay heat exchanger is not modeled as one of the DRACS units is assumed to be unavailable.

Segment 17 and CV14 represent the intermediate side of the decay reactor auxiliary cooling system. Since sodium in the DRACS operates under natural circulation conditions, there is no pump. Element 40 is the air dump heat exchanger (AHX) and the air mass flow rate is governed by natural circulation. The user provides an air loss coefficient and SAS4A/SASSYS-1 calculates the air flow rate along the outside of the tubes, providing the boundary for the passive DRACS. When fully operational at nominal reactor side temperatures, a single AHX rejects $0.25 \%$ power $(0.75 \mathrm{MW})$ for a total of $0.5 \%$. 


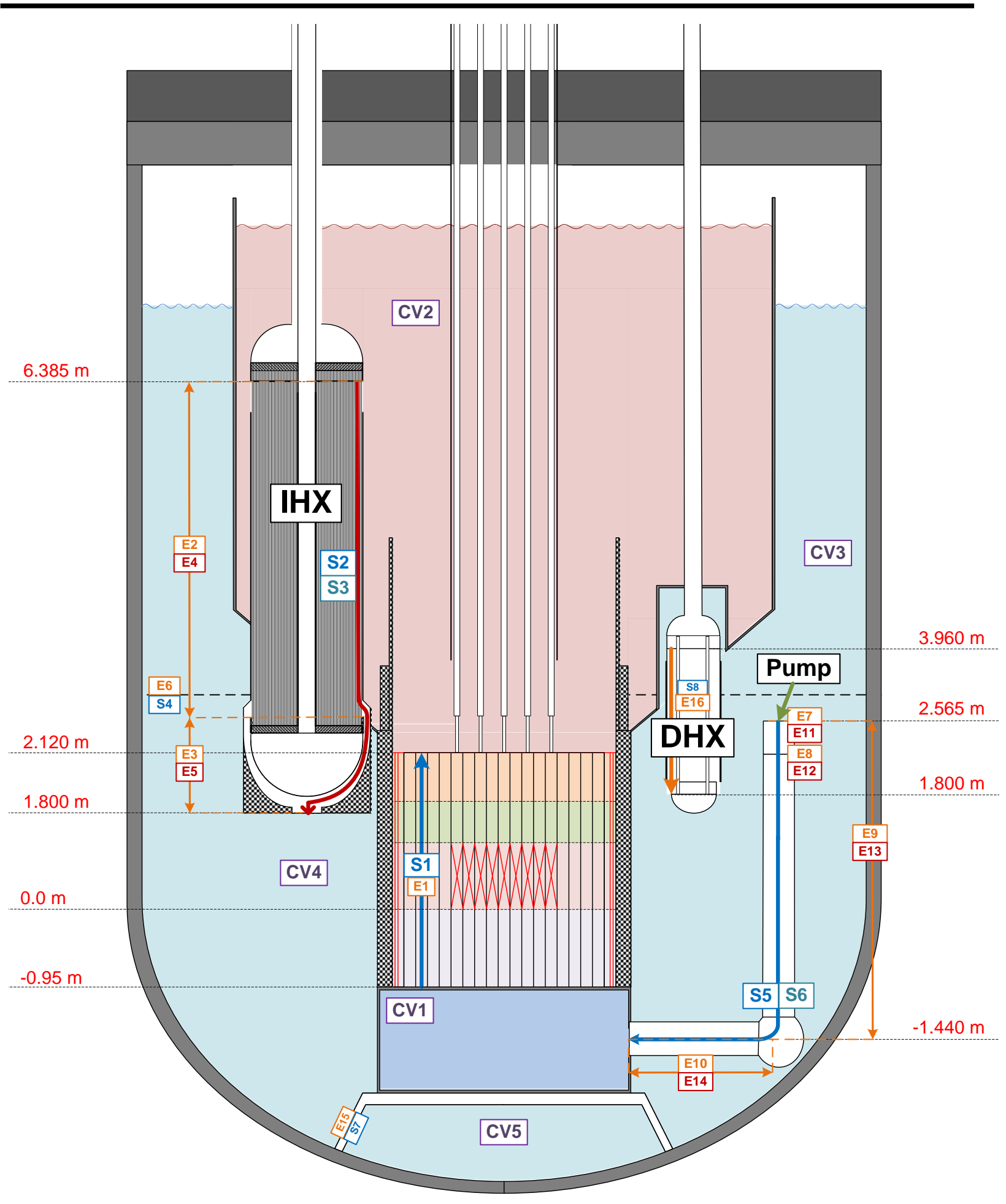

Figure 12-8: PRIMAR-4 Model of the Primary Sodium Heat Transport System 


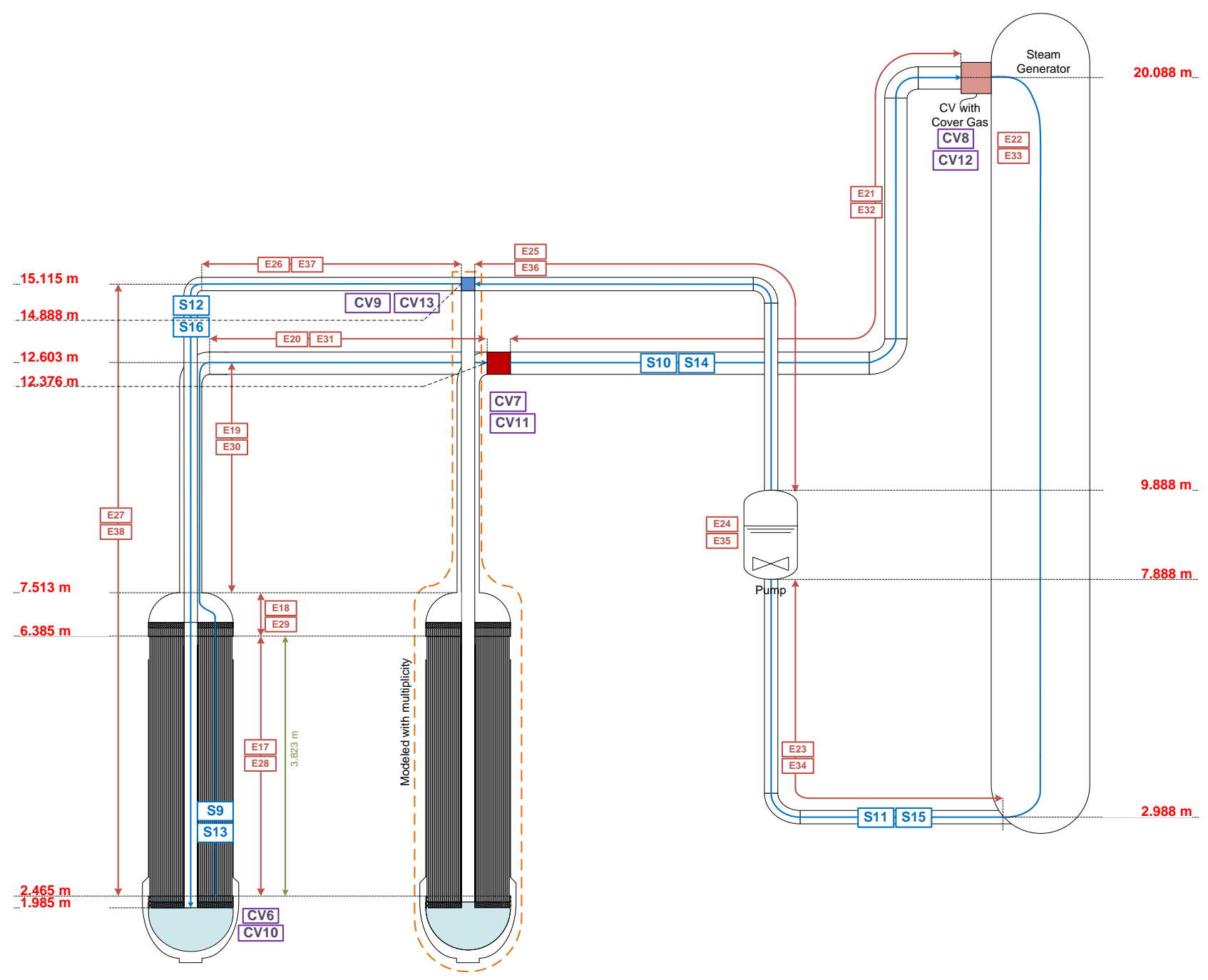

Figure 12-9: PRIMAR-4 Model of the Intermediate Sodium Heat Transport System 


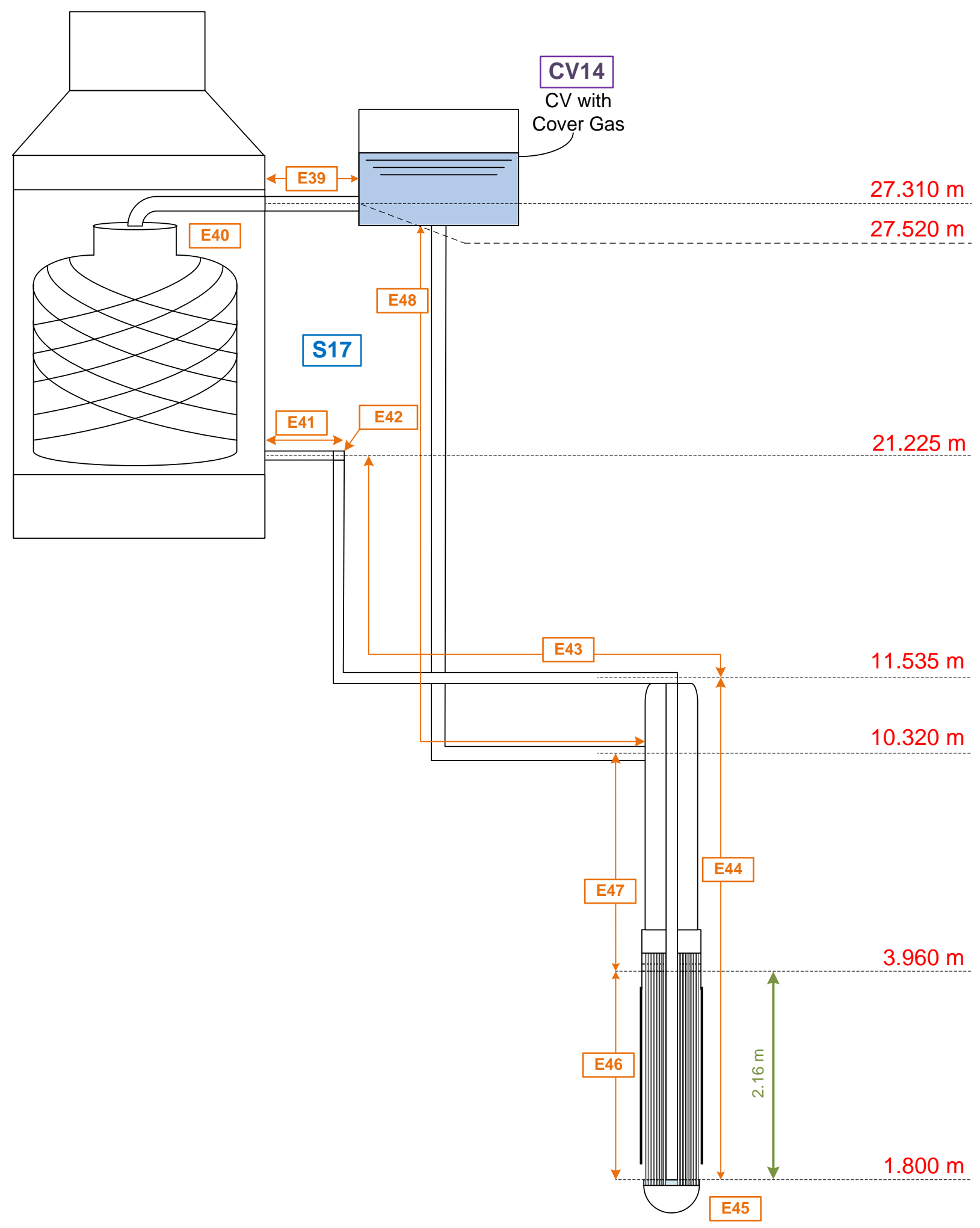

Figure 12-10: PRIMAR-4 Model of the Direct Reactor Auxiliary Cooling System 
Table 12-10: Primary System Element and Compressible Volume Input Parameters

Hydraulic Flow

Diameter Area Length

\begin{tabular}{|c|c|c|c|c|c|c|}
\hline \multirow[b]{2}{*}{ Element \# } & \multirow[b]{2}{*}{ Description } & & Diameter & \multirow{2}{*}{$\left(\mathbf{m}^{2}\right)$} & \multirow{2}{*}{$(\mathbf{m})$} \\
\hline & & Inlet & Outlet & $(\mathbf{m})$ & & \\
\hline 1 & Core & -0.95 & 2.120 & - & - & 3.070 \\
\hline 2 & IHX 1 and 2, Primary-Side & 6.385 & 2.562 & 0.029 & 0.409 & 3.920 \\
\hline 3 & IHX 1 and IHX 2 Discharge & 2.562 & 1.800 & 0.165 & 0.184 & 0.815 \\
\hline 4 & IHX 3 and 4, Primary-Side & 6.385 & 2.562 & 0.029 & 0.409 & 3.920 \\
\hline 5 & IHX 4 and IHX 4 Discharge & 2.562 & 1.800 & 0.165 & 0.184 & 0.815 \\
\hline 6 & $\begin{array}{l}\text { Flow from Upper to Bulk } \\
\text { Cold Pool }\end{array}$ & 2.880 & 2.880 & 0.798 & 2.0 & 0.100 \\
\hline 7 & Pump 1 Inlet & 2.565 & 2.565 & 0.623 & 1.357 & 1.205 \\
\hline 8 & Pump 1 & 2.565 & 2.565 & - & - & 0.001 \\
\hline 9 & Pump 1 Discharge & 2.565 & -1.440 & 0.314 & 0.101 & 4.005 \\
\hline 10 & Core Inlet Pipe & -1.440 & -1.440 & 0.248 & 0.126 & 1.668 \\
\hline 11 & Pump 2 Inlet & 2.565 & 2.565 & 0.623 & 1.357 & 1.205 \\
\hline 12 & Pump 2 & 2.565 & 2.565 & - & - & 0.001 \\
\hline 13 & Pump 2 Discharge & 2.565 & -1.440 & 0.314 & 0.101 & 4.005 \\
\hline 14 & Core Inlet Pipe & -1.440 & -1.440 & 0.248 & 0.126 & 1.668 \\
\hline 15 & $\begin{array}{l}\text { Flow from Bulk to Lower } \\
\text { (Stagnant) Cold Pool }\end{array}$ & -2.700 & -2.700 & 1.000 & 17.929 & 0.001 \\
\hline 16 & DHX Primary-Side & 3.960 & 1.800 & 0.044 & 0.053 & 2.880 \\
\hline CV \# & Description & Sodium Volume $\left(\mathrm{m}^{3}\right.$ & & $\begin{array}{l}\text { Volume } \\
\left(\mathbf{m}^{3}\right)\end{array}$ & $\begin{array}{r}\text { Total } \\
(\mathrm{n}\end{array}$ & $\begin{array}{l}\text { olume } \\
3 \text { ) } \\
\end{array}$ \\
\hline 1 & Inlet Plenum & 8.20 & & - & & \\
\hline 2 & Hot Pool & 343.20 & & 27.62 & 370 & \\
\hline 3 & Upper Cold Pool & 44.80 & & 61.45 & 106 & \\
\hline 4 & Bulk Cold Pool & 173.00 & & - & 173 & \\
\hline 5 & Lower (Stagnant) Cold Pool & 1.0 & & - & & \\
\hline
\end{tabular}


Table 12-11: Intermediate Heat Transport System Element and Compressible Volume Input Parameters

\begin{tabular}{|c|c|c|c|c|c|c|}
\hline \multirow[b]{2}{*}{ Element \# } & \multirow[b]{2}{*}{ Description } & \multicolumn{2}{|c|}{ Elevations (m) } & \multirow{2}{*}{$\begin{array}{c}\text { Hydraulic } \\
\text { Diameter } \\
\text { (m) }\end{array}$} & \multirow{2}{*}{$\begin{array}{c}\text { Flow } \\
\text { Area } \\
\left(\mathbf{m}^{2}\right) \\
\end{array}$} & \multirow{2}{*}{$\begin{array}{c}\text { Length } \\
\text { (m) }\end{array}$} \\
\hline & & Inlet & Outlet & & & \\
\hline 17,28 & IHX, Intermediate-Side & 2.465 & 6.385 & 0.014 & 0.252 & 3.920 \\
\hline 18,29 & IHX Discharge & 6.385 & 7.513 & 0.422 & 0.560 & 1.148 \\
\hline 19,30 & Hot Leg & 7.513 & 12.603 & 0.457 & 0.164 & 5.090 \\
\hline 20,31 & Hot Leg & 12.603 & 12.376 & 0.457 & 0.164 & 5.068 \\
\hline 21,32 & Hot Leg & 12.376 & 20.088 & 0.457 & 0.164 & 25.320 \\
\hline 22,33 & Steam Generator & 20.088 & 2.988 & 0.051 & 0.051 & 25.100 \\
\hline 23,34 & Cold Leg & 2.988 & 7.888 & 0.457 & 0.164 & 9.163 \\
\hline 24,35 & Pump & 7.888 & 9.888 & - & - & 2.000 \\
\hline 25,36 & Cold Leg & 9.888 & 14.888 & 0.457 & 0.164 & 17.094 \\
\hline 26,37 & Cold Leg & 14.888 & 15.115 & 0.457 & 0.164 & 5.068 \\
\hline 27,38 & IHX Downcomer & 15.115 & 1.985 & 0.457 & 0.164 & 13.130 \\
\hline CV \# & Description & $\begin{array}{r}\text { Sodiu } \\
\text { Volume }\end{array}$ & & $\begin{array}{l}\text { Volume } \\
\left(\mathbf{m}^{\mathbf{3}}\right)\end{array}$ & Total & $\begin{array}{l}\text { olume } \\
3 \text {, }\end{array}$ \\
\hline 6,10 & IHX Inlet Plenum & 0.36 & & - & & 60 \\
\hline 7,11 & Hot Leg Manifold & 0.54 & & - & & 40 \\
\hline 8,12 & Expansion Volume & 2.35 & & 2.523 & & 82 \\
\hline 9,13 & Cold Leg Manifold & 0.54 & & - & & 40 \\
\hline
\end{tabular}

Table 12-12: Decay Heat Removal System Element and Compressible Volume Input Parameters

\begin{tabular}{|c|c|c|c|c|c|c|}
\hline \multirow[b]{2}{*}{ Element \# } & \multirow[b]{2}{*}{ Description } & \multicolumn{2}{|c|}{ Elevations (m) } & \multirow{2}{*}{$\begin{array}{c}\text { Hydraulic } \\
\text { Diameter } \\
\text { (m) }\end{array}$} & \multirow{2}{*}{$\begin{array}{c}\text { Flow } \\
\text { Area } \\
\left(\mathbf{m}^{2}\right) \\
\end{array}$} & \multirow{2}{*}{$\begin{array}{c}\text { Length } \\
\text { (m) }\end{array}$} \\
\hline & & Inlet & Outlet & & & \\
\hline 39 & Cold Leg & 27.520 & 27.310 & 0.090 & 0.006 & 5.503 \\
\hline 40 & AHX, Sodium-Side & 27.310 & 21.330 & 0.031 & 0.048 & 8.978 \\
\hline 41 & Cold Leg & 21.330 & 21.225 & 0.090 & 0.006 & 2.000 \\
\hline 42 & Pump & 21.225 & 21.225 & 0.090 & 0.006 & 0.001 \\
\hline 43 & Cold Leg & 21.225 & 11.535 & 0.090 & 0.006 & 33.039 \\
\hline 44 & Cold Leg and DHX Downcomer & 11.535 & 1.800 & 0.085 & 0.006 & 9.674 \\
\hline 45 & DHX Inlet Plenum & 1.800 & 1.800 & 1.000 & 0.076 & 0.218 \\
\hline 46 & DHX, Intermediate-Side & 1.800 & 3.960 & 0.009 & 0.007 & 2.880 \\
\hline 47 & Hot Leg & 3.960 & 10.320 & 0.174 & 0.089 & 6.360 \\
\hline 48 & Hot Leg & 10.320 & 27.310 & 0.090 & 0.006 & 35.799 \\
\hline CV \# & Description & \multicolumn{2}{|c|}{$\begin{array}{c}\text { Sodium } \\
\text { Volume }\left(\mathbf{m}^{3}\right)\end{array}$} & $\begin{array}{l}\text { Volume } \\
\left(\mathrm{m}^{3}\right)\end{array}$ & \multicolumn{2}{|c|}{$\begin{array}{c}\text { Total Volume } \\
\left(\mathbf{m}^{3}\right)\end{array}$} \\
\hline 14 & Expansion Volume & \multicolumn{2}{|c|}{0.468} & 4.627 & \multicolumn{2}{|c|}{5.095} \\
\hline
\end{tabular}


Control Rod Driveline and Reactor Vessel Expansion

The control rod insertion depth in the core is affected by expansions of the control rod drivelines, reactor vessel, and core support structures. For transients where the cold pool temperature rises, reactor vessel expansion lowers the core away from the control rods, which effectively withdraws the control rods. For the ULOHS and USBO transients, this effect provides the most significant positive reactivity feedback. As the drivelines expand, the control rods are inserted further into the core. To properly track the control rod insertion depth during a transient, a model was created utilizing both the traditional CRDL model and the SAS4A/SASSYS-1 control system module. It was assumed that below the bottom of the active fuel, reactor vessel expansion and core support structure expansion occur at the same rate and magnitude and they therefore cancel each other out.

The traditional CRDL model, which is described above in the core model section, was used to calculate expansion of the control rod drivelines based on heat transfer with sodium discharged from specified core channels flowing through a representative UIS. For this analysis, the control rod and control rod drivelines were expanded together as one component with a nominal length of $9.92 \mathrm{~m}$.

The control system was used to model reactor vessel expansion. Although the traditional CRDL model allows users to model reactor vessel expansion, the control system was used for reactor vessel expansion so both components of the control rod insertion depth feedback could be examined individually.

The total length of the reactor vessel that was considered to expand was $8.08 \mathrm{~m}$, which is the length from the cold pool sodium level to the bottom of the active fuel. Because the cold pool was represented by multiple CVs, the reactor vessel expansion calculation was based on multiple compressible volume wall temperatures. The wall temperature of $\mathrm{CV} 3$, which represents the upper portion of the cold pool, was used to calculate the expansion of the 5.2 meters of reactor vessel above the midplane of the decay heat exchanger up to the cold pool level. The wall temperature of $\mathrm{CV} 4$, which represents the bulk portion of the cold pool, was used to calculate the expansion of the 2.88 meters of reactor vessel between the bottom of the active fuel and the decay heat exchanger midplane. Figure 12-11 illustrates the components in the CRDL and vessel expansion model.

The upper reactor vessel and lower reactor vessel expansions were calculated using the same expression:

$$
\Delta z=\alpha H \Delta T(t)
$$

where

$\alpha=$ thermal expansion coefficient $(1 / \mathrm{K})$,

$H=$ nominal height $(\mathrm{m})$, and

$\Delta T=$ temperature change from steady-state conditions $(\mathrm{K})$. 
A thermal expansion coefficient of $2.0 \times 10^{-5} 1 / \mathrm{K}$ was assumed. For the portion of the reactor vessel expansion corresponding to the bulk cold pool, the change in temperature of the wall for CV4 was used.

$\Delta T$ is represented slightly differently for $\mathrm{CV} 3$ to account for the elevated temperatures at the top of the cold pool that have been predicted by CFD analysis of other pool-type SFRs. Accounting for higher temperature at the top of the cold pool is important because it changes the amount of reactor vessel expansion that occurs in transients where the difference between the hot pool temperature and cold pool temperature changes. Consider a loss of heat sink transient where the entire primary system equilibrates at the hot pool temperature. Because the vessel wall at the top of the cold pool starts at a higher temperature than the rest of the vessel, the temperature rise there will not be as large, and the reactor vessel expansion will be smaller. For the control system model, the CV3 wall temperature was approximated as:

$$
T_{\text {Wall,CV3 }}(t)=a T_{\text {cold pool }}(t)+(1-a) T_{\text {hot pool }}(t)
$$

where

$$
\alpha=0.437 .
$$

This coefficient was calculated for a pool-type SFR of a similar design. Further analysis is required to determine the appropriate value for FASTER. Future updates to the model would be necessary to better capture heat transfer from the hot pool using the component-to-component heat transfer model as well as heat transfer between CV3 and the reactor vessel wall. Expansion of the fuel also moves the top of the fuel past the control rods. As discussed in the core model section above, this expansion is accounted for in the axial fuel expansion calculation. 


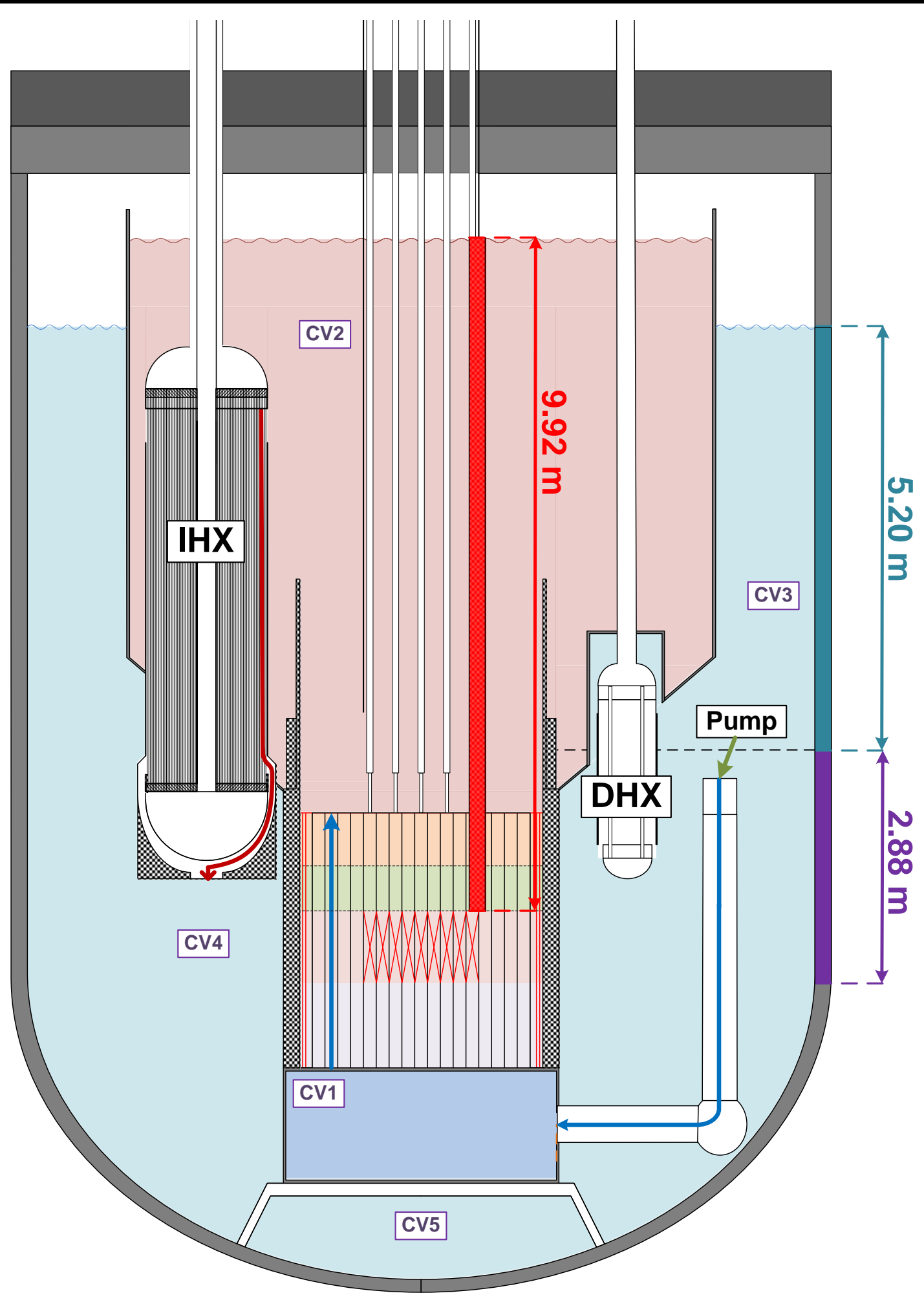

Figure 12-11: Components in Control Rod Driveline and Reactor Vessel Expansion Model 
12.4.2 Results

Three types of transients were simulated on a Mac Pro running OS X Version 10.9.5 with the SAS4A/SASSYS-1 fast reactor safety analysis code, Developmental Version 5.1, Revision 1915:

- Unprotected transient overpower (UTOP),

- Unprotected loss of heat sink (ULOHS), and

- Unprotected station blackout (USBO).

In each scenario, it was assumed that the Reactor Protection System (RPS) fails to scram the control rods. Best estimate simulations were performed to determine the maximum temperatures that occur during each transient and ensure that acceptable margins to various safety limits are maintained. The transient initiators are summarized in Table 12-13 and each transient is fully defined in the sections below. Safety margins are defined below.

Table 12-13: Transient Initiators

\begin{tabular}{lccc}
\hline Initiator & UTOP & ULOHS & USBO \\
\hline PHTS Pumps Trip & & & $\mathrm{X}$ \\
IHTS Pumps Trip & & $\mathrm{X}$ & $\mathrm{X}$ \\
Feedwater Pumps Trip & & $\mathrm{X}$ & $\mathrm{X}$ \\
Single Control Rod Withdrawal & $\mathrm{X}$ & & \\
\hline
\end{tabular}

A primary pump trip is initiated by quickly decreasing the pump torque to zero. The sodium flow rate coasts down according to the inertia of the pumps and, following the flow coast down, natural circulation flow is established. An intermediate pump trip is simulated in the same way as a primary pump trip.

Because the steam generators represent the boundary conditions in the SAS4A/SASSYS-1 model, the feedwater pumps are not modeled. To model the loss of heat rejection through the steam generators, which accompanies a feedwater pump trip, the temperature drop across the steam generators is quickly reduced to zero at the beginning of the ULOHS and USBO transients. For the UTOP scenario, the steam generator was conservatively assumed to maintain the steady-state heat rejection rate throughout the transient. In reality, increased sodium temperatures in the IHTS would produce higher steam generator heat rejection rates so this assumption leads to higher temperatures.

Each transient scenario was simulated at BOEC conditions. The ULOHS and USBO transients were also simulated at EOEC conditions. Because the primary and secondary control rods are already withdrawn at EOEC conditions, the UTOP transient initiator does not apply at EOEC.

FASTER has three DRACS units, each providing a nominal heat rejection rate of $0.25 \%$ of the initial total reactor power level when fully activated. During the transient simulations, the DRACS air dampers are assumed to activate five seconds after the transient begins, representing a short delay between flow rate, temperature or power measurements exceeding allowable limits, and the reactor protection system providing the signal to activate the DRACS units. DRACS activation is assumed to occur over a five-second period. Before the DRACS units are activated 
and the air dampers open, the steady-state DRACS heat rejection rate predicted by

SAS4A/SASSYS-1 is $0.09 \%$ per DRACS unit. The steady-state heat rejection rate depends on the position of the air dampers when the DRACS are in standby mode, which has not yet been determined. Because the DRACS units are assumed to activate promptly after the start of each transient, the steady-state DRACS heat rejection rate does not significantly affect the transient results. All heat rejection rates correspond to a decay heat exchanger primary-side sodium inlet temperature of $355^{\circ} \mathrm{C}$.

For each transient, it was assumed that the air dampers in one of the DRACS units fail to open. To be conservative, it was assumed that zero heat rejection was available through that DRACS unit. In reality, a DRACS unit would provide a small amount of heat rejection, even if the air damper were completely closed. With only two DRACS units available, the nominal heat rejection rate is $0.5 \%$ for each transient. The heat rejection rate increases during the transient scenarios as the cold pool temperature increases.

\section{Safety Margins}

For each transient scenario, the following safety margins were considered:

- Coolant boiling,

- Fuel melting,

- Cladding integrity, and

- Reactor vessel integrity.

Because severe accidents have a lower frequency of occurrence, they can be analyzed with higher allowable temperatures. However, for these analyses, the USBO transient was scrutinized under the same limits as the two design extension conditions.

SAS4A/SASSYS-1 automatically calculates the peak in-core fuel, cladding, and coolant temperatures, and these temperatures are reported for each transient below along with the saturation temperature at the location of the peak coolant temperature. SAS4A/SASSYS-1 also reports the minimum margin to sodium boiling, which, because the sodium saturation temperature depends on pressure, may occur at a different location than the peak sodium temperature.

The FASTER model uses fuel property models built into SAS4A/SASSYS-1 for the fuel thermal conductivity, specific heat, and density. For the transient analysis, a fuel melting temperature of $1071^{\circ} \mathrm{C}$, which is provided in [41], was assumed for FASTER's U-Pu-6Zr fuel.

For the cladding integrity limit, the peak cladding temperature can be used to estimate cladding wastage due to fuel-cladding eutectic formation. Cladding degradation due to eutectic penetration is a threshold reaction. The threshold for FASTER's U-Pu-6Zr fuel was not available; however, for $\mathrm{U}-\mathrm{Zr}$ fuel the eutectic formation has a threshold of $715^{\circ} \mathrm{C}$. At temperatures near $715^{\circ} \mathrm{C}$, the reaction is slow and it may take several hours for the cladding to fully degrade. At higher temperatures, around $1075^{\circ} \mathrm{C}$, fuel-cladding eutectic penetration occurs much more rapidly. However, for the transients that were analyzed, cladding temperatures exceeded the long-term 
$715^{\circ} \mathrm{C}$ threshold for less than 30 seconds. Therefore, only a negligible amount of eutectic penetration will occur.

Structural analysis will be needed to calculate damage to the reactor structures, such as the reactor vessel, redan, or upper internal structures, due to elevated temperatures during each transient. Of all the structures, the integrity of the reactor vessel is of the most concern since it provides the boundary for the primary circuit coolant. $1350^{\circ} \mathrm{F}\left(732^{\circ} \mathrm{C}\right)$ was used in the SAFR Preliminary Safety Information Document [6]. In the absence of a detailed structural analysis, this value was assumed for the structure and pool temperature limit.

\section{UTOP}

The unprotected transient overpower accident is initiated by an unintended withdrawal of the most reactive control rod over 15 seconds until it reaches a rod stop, which limits the reactivity insertion to 50ф. For the most reactive control rod, the rod stop would have to limit the control rod withdrawal to $8.6 \mathrm{~cm}$. A $50 \varnothing$ rod stop limit is larger than is typically assumed for SFR analyses. The $50 \phi$ limit was initially selected because the worth per unit length of the control rods early in the FASTER design process was larger than for more traditional SFR designs. The control rod worth per unit length was decreased later in the design process but the $50 \phi$ rod stop limit was maintained as a conservative assumption. For this UTOP analysis, the feedback coefficients due to control rod driveline and reactor vessel expansion were reduced to account for the control rod that has withdrawn and, therefore, does not contribute to those feedback effects.

\section{Beginning of Equilibrium Cycle}

At the start of the BOEC UTOP transient, fission power increases due to the sudden reactivity insertion. After 15 seconds, a total of $50 \notin$ has been inserted and the external reactivity insertion stops. As power increases, temperatures in the core increase quickly, introducing negative feedbacks that act to reduce the reactivity. When the external reactivity insertion stops at 15 seconds, total power has peaked at $155 \%$ and the net reactivity is at $12 \phi$. Net reactivity then begins to decrease as the reactivity feedbacks become more negative.

Fuel and cladding temperatures increase the fastest, producing $-9 \phi$ of reactivity from Doppler feedback and $-8 \notin$ from axial core expansion. As sodium temperatures increase, the coolant density reactivity feedback introduces another $-3 \notin$ within the first minute. Twenty-five seconds into the transient, the increased structure temperatures at the above core load pads cause the core to expand radially, which inserts another $-21 \phi$ of reactivity. After 30 seconds, sodium temperatures in the upper internal structure increase and the drivelines begin to expand. The drivelines continue to expand, producing a reactivity feedback of $-27 \phi$. Within the first 60 seconds of the transient, net reactivity becomes negative and total power starts to decrease back towards $100 \%$.

After 5 minutes, the hot pool temperature is leveling off while temperatures in the cold pool are still increasing. The reactor vessel expands as the cold pool heats up, which pulls the bottomsupported core away from the control rods and produces a positive reactivity feedback. The temperature rise in the hot pool is a few degrees larger than the cold pool temperature rise so the control rod driveline expansion feedback produces more negative reactivity than the positive reactivity vessel expansion. The remainder of the transient is uneventful as net reactivity remains 
at zero and total power returns to $100 \%$. Figure 12-12 and Figure 12-13 illustrate power production and the reactivity feedbacks during this transient.

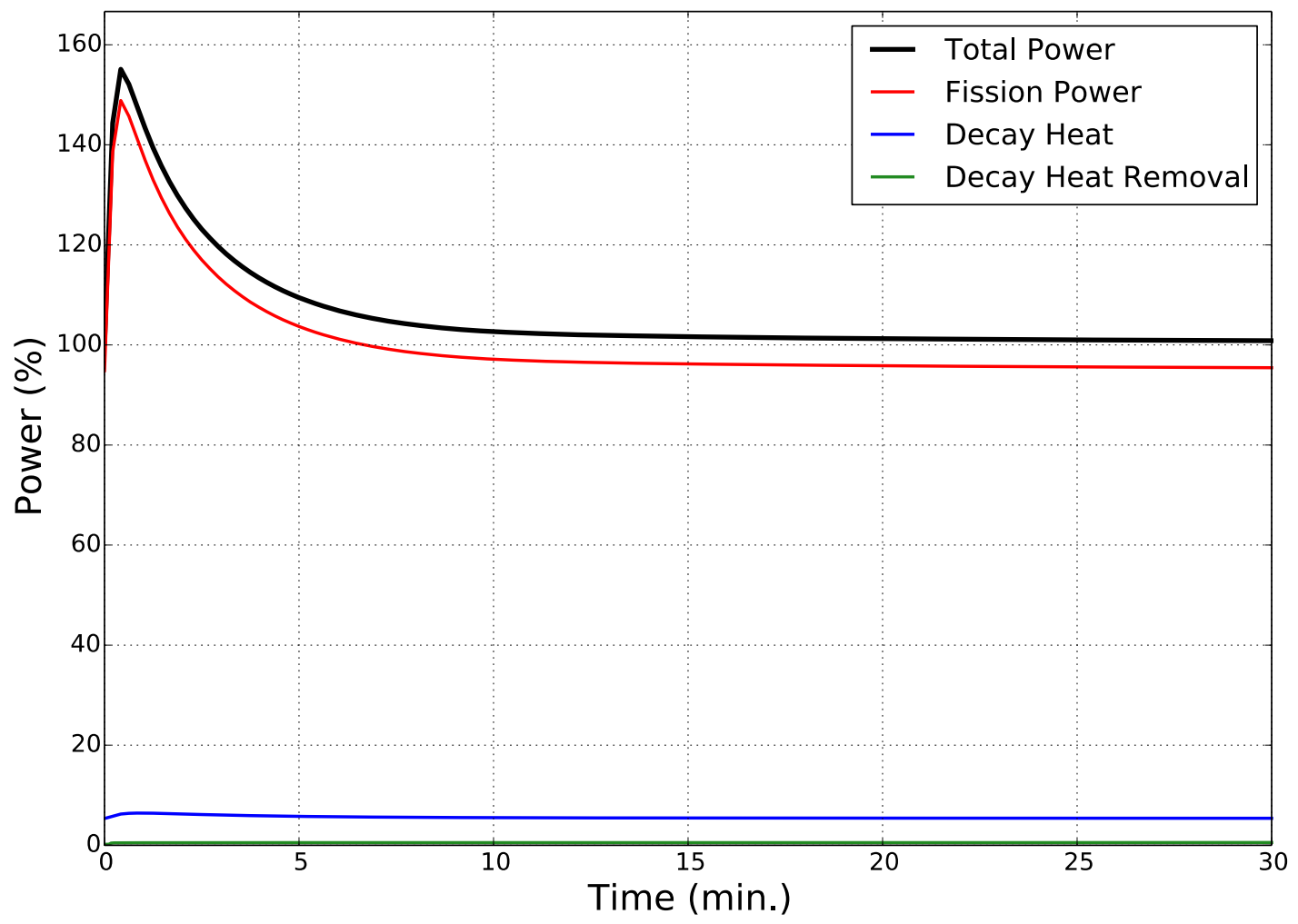

Figure 12-12: BOEC UTOP with 2 DRACS Units: Total, Fission, and Decay Heat Power Production 


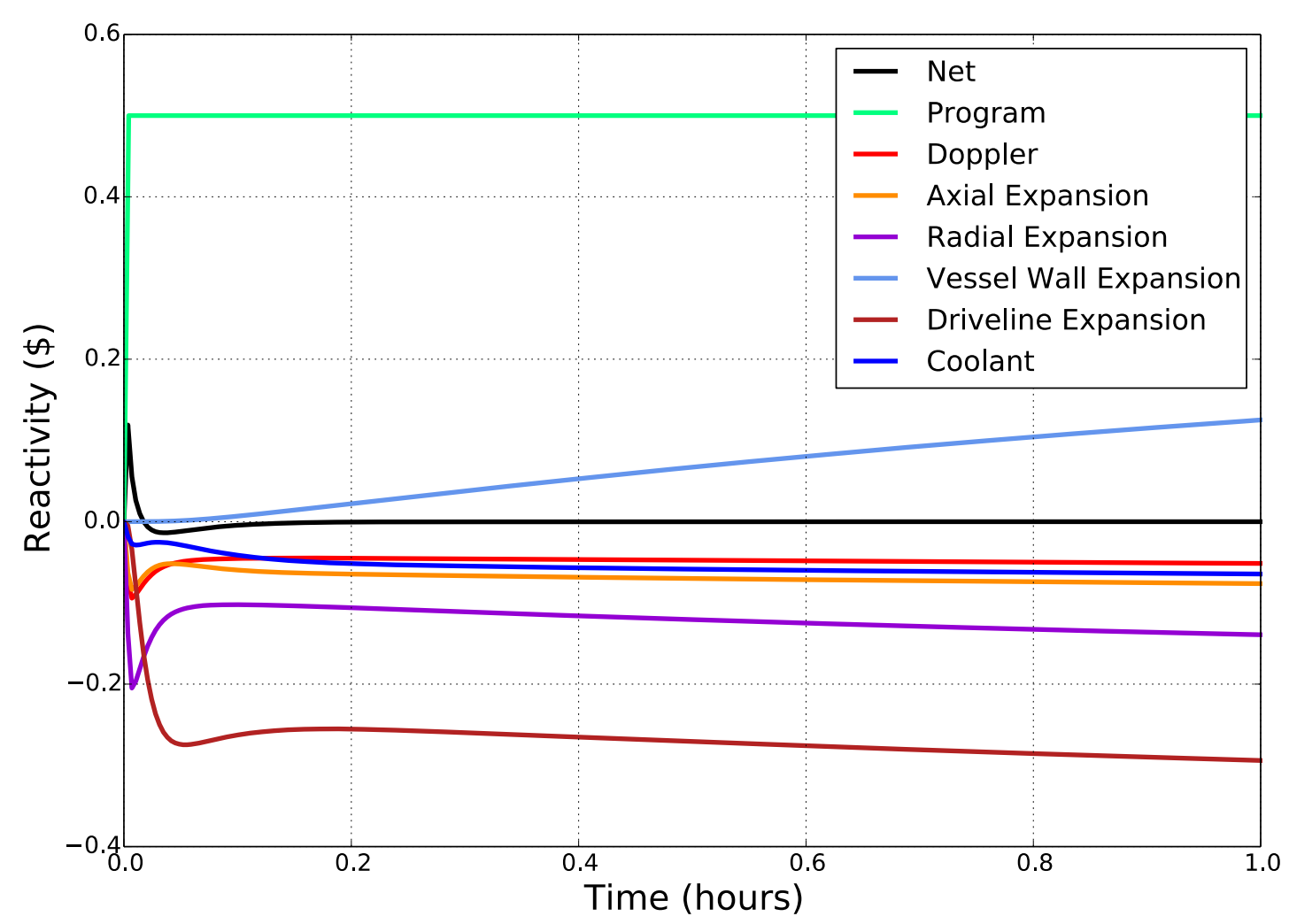

Figure 12-13: BOEC UTOP with 2 DRACS Units: Reactivity Feedbacks

Fuel, cladding, and cooling temperatures, which are illustrated in Figure 12-14, were highest in Channel 8. The peak fuel temperature was $889^{\circ} \mathrm{C} 23$ seconds into the transient, and the minimum fuel melting margin decreased from $359^{\circ} \mathrm{C}$ to $182^{\circ} \mathrm{C}$. At the same time, cladding temperatures peaked at $688^{\circ} \mathrm{C}$, remaining below the $715^{\circ} \mathrm{C}$ threshold for slow eutectic formation. Coolant temperatures also peaked 23 seconds into the transient, reaching a maximum temperature of $657^{\circ} \mathrm{C}$. Figure $12-14$ shows the saturation temperature at the location of the peak sodium temperature. During the UTOP transient, the peak sodium temperature occurred near the top of the fuel region. The minimum margin to boiling was $292^{\circ} \mathrm{C}$ during the UTOP, occurring near the top of the assembly where the saturation temperature was lower due to the lower pressure. 


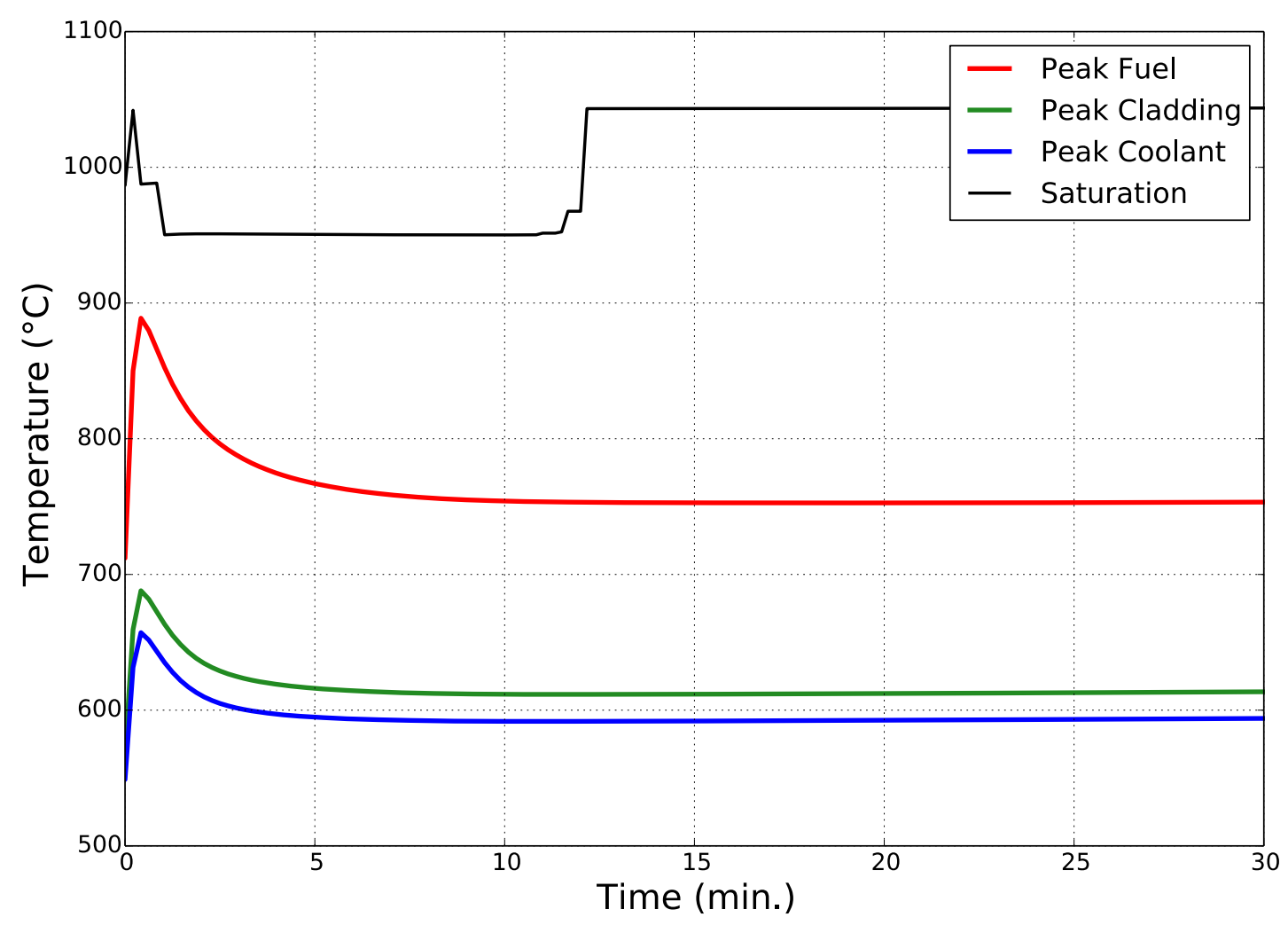

Figure 12-14: BOEC UTOP with 2 DRACS Units: Peak In-Core Temperatures

This UTOP scenario progresses very quickly with temperatures peaking during the first halfminute and power nearly decreasing back to $100 \%$ after five minutes. For the rest of the transient, the peak temperatures in the core remain approximately $60^{\circ} \mathrm{C}$ higher than the initial steady-state temperatures.

Because the core is producing more than $100 \%$ of the steady-state power and the steam generators are rejecting most of that, the DRACS heat rejection rate does not significantly affect the results. The transient progression with a total of $1.0 \%$ DRACS heat rejection instead of $0.5 \%$ produced nearly identical results.

\section{End of Equilibrium Cycle}

The control rods are withdrawn at end of equilibrium cycle conditions so the transient initiator for this case does not apply.

\section{ULOHS}

The unprotected loss of heat sink accident is initiated by the intermediate sodium and feedwater pumps tripping. Because the steam generators are the boundary of the SAS4A/SASSYS-1 model, the resulting loss of heat rejection through the steam generators was modeled by quickly reducing the temperature drop across the steam generators to zero at the start of the transient. This assumption is conservative as there would still be a small amount of heat rejection even after the feedwater pumps trip. 
Beginning of Equilibrium Cycle

After the intermediate pumps trip, heat rejection through the intermediate heat exchangers decreases rapidly. The IHX primary-side outlet temperature begins to increase, causing the cold pool to heat up. The cold pool sodium mass is very large so the temperature increases slowly. The core inlet temperature increases at the same rate, introducing small but prompt negative feedbacks. The axial core expansion and sodium density feedbacks are the strongest effects during the first two minutes, reaching $-6 \phi$ and $-5 \phi$, respectively. Together, these two feedbacks provide sufficient negative reactivity to drive the fission power down. At the same time, the reactor vessel begins to heat up and expand, which slowly pulls the core away from the control rods. Because the reactor vessel mass is so large, its temperature lags behind the increasing cold pool temperature so the reactor vessel expansion feedback is introduced slower than the in-core feedbacks. Before the reactor vessel expansion feedback exceeds $5 \phi$, the net reactivity has been less than $-13 \notin$ for more than four minutes.

Even as the core inlet temperature increases, the temperature rise across the core is decreasing, and the control rod drivelines are exposed to the colder sodium discharged from the core. This introduces a positive reactivity feedback as the drivelines contract, partially withdrawing the control rods from the core. The control rod driveline temperature increases and decreases out of phase with the core inlet temperature, which introduces power oscillations during the beginning of the transient. Fifteen minutes into the transient, when fission power is around $1 \%$, the net reactivity becomes positive, and fission power increases to $3.6 \%$. The core outlet temperature begins to increase again, causing the drivelines to heat up, which expands the control rods back into the core. Net reactivity returns to zero 40 minutes into the transient after the control rod driveline and core inlet temperatures come into phase with one another.

During the rest of the first hour, temperatures throughout the primary system converge and they gradually increase as total power production is slightly larger than the DRACS heat rejection rate. The cold pool experiences the largest temperature increase, so the largest reactivity feedback effect is due to reactor vessel expansion. Approximately 8 hours into the transient, the cold pool temperature has leveled off and the reactor vessel expansion reactivity feedback stabilizes at approximately $1.2 \$$. The radial core expansion and control rod driveline expansion feedbacks, and to a lesser degree the axial core expansion and sodium density feedbacks, are sufficiently large to balance out the very positive vessel expansion feedback and maintain a critical core. Within 10 hours, the cold pool is hot enough that the DRACS heat rejection rate matches the total power production. As the transient continues, fission power is small enough that decay heat production gradually decreases. Fission power increases to compensate for the decreasing decay heat and the system remains in equilibrium with a power level of 0.9\%. Figure 12-15 and Figure 12-16 illustrate power production and the reactivity feedbacks during this transient. 
FASTER Test Reactor Preconceptual Design Report March 31, 2016

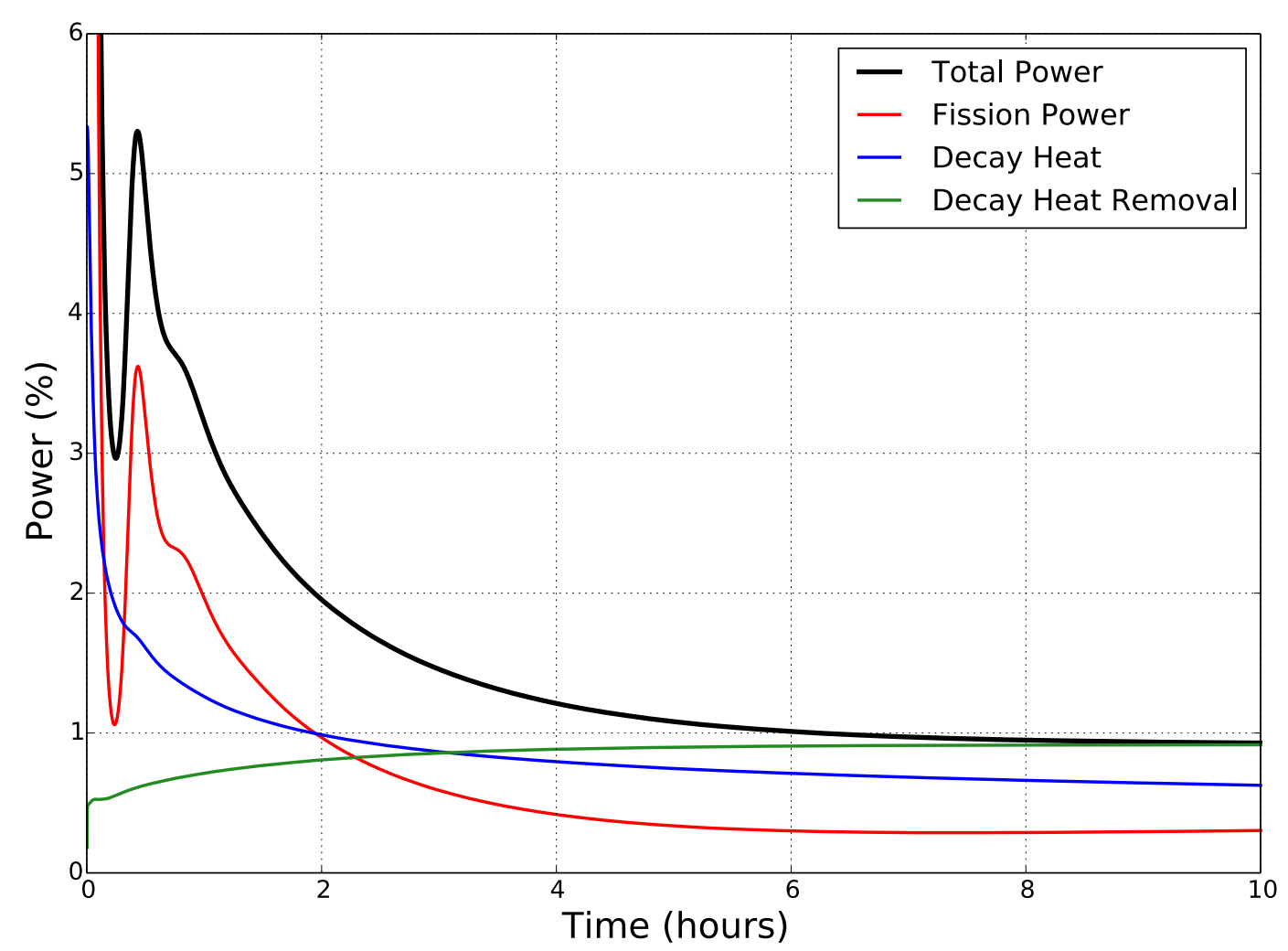

Figure 12-15: BOEC ULOHS: Total, Fission, and Decay Heat Power Production

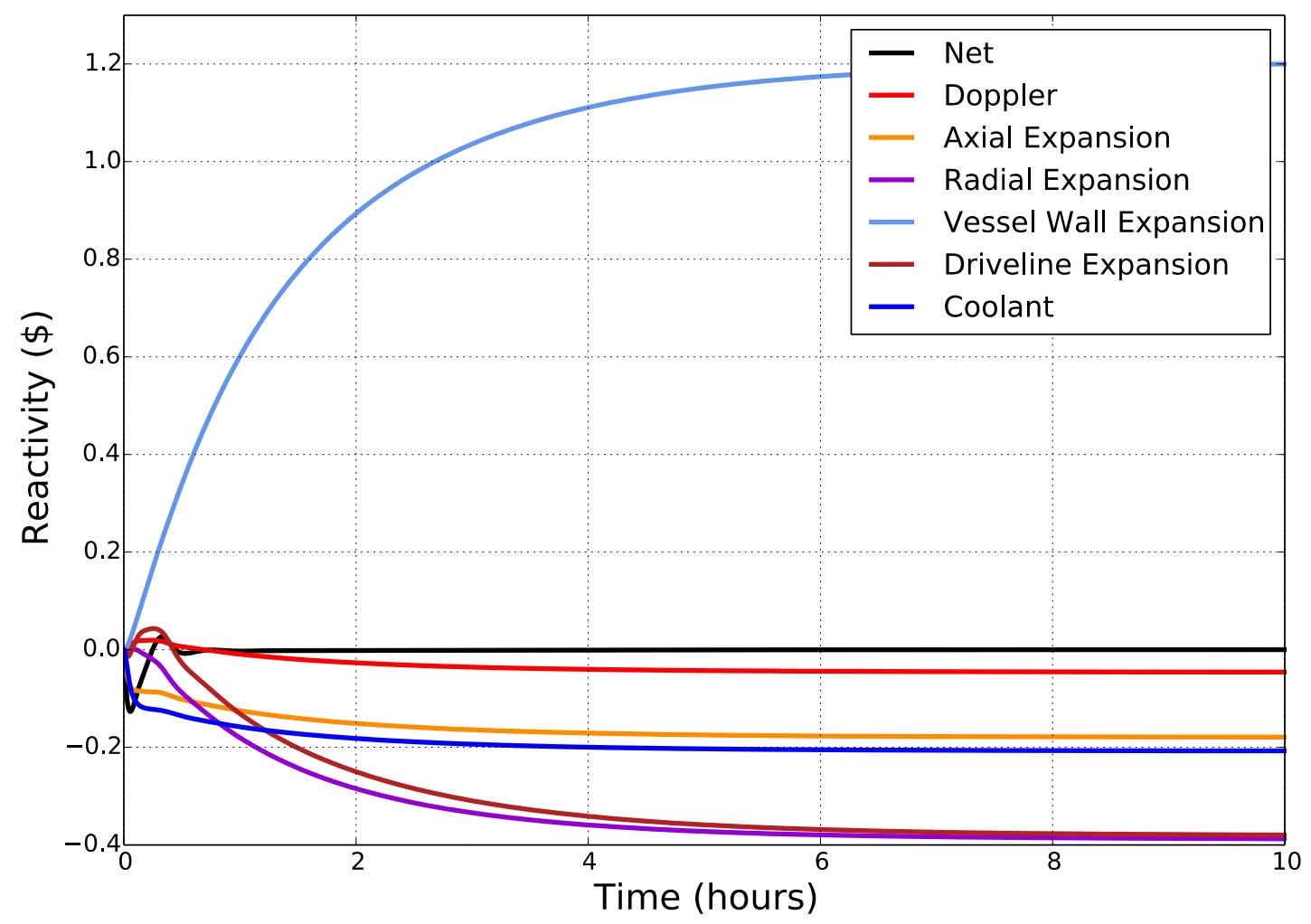

Figure 12-16: BOEC ULOHS: Reactivity Feedbacks 
Peak temperatures within the core are illustrated in Figure 12-17 and sodium outlet temperatures and temperatures throughout the primary system are illustrated in Figure 12-18. The black line in Figure 12-17 represents the saturation temperature at the location of the peak sodium temperature. The location of the peak sodium temperature changes during the transient, and the saturation temperature is lower as the peak temperature moves higher in the core to areas with a lower pressure. Because net reactivity remains negative for the 13 minutes of the transient and the primary pumps are still running, the peak fuel temperature never increases during the transient. The peak cladding and coolant temperatures only rise $1^{\circ} \mathrm{C}$ and $15^{\circ} \mathrm{C}$, respectively. There is no significant decrease in the fuel melting or sodium boiling margins. Clad temperatures have not increased enough for eutectic formation to be a concern and the maximum cold pool temperature is $562^{\circ} \mathrm{C}$, well below the $732^{\circ} \mathrm{C}$ limit.

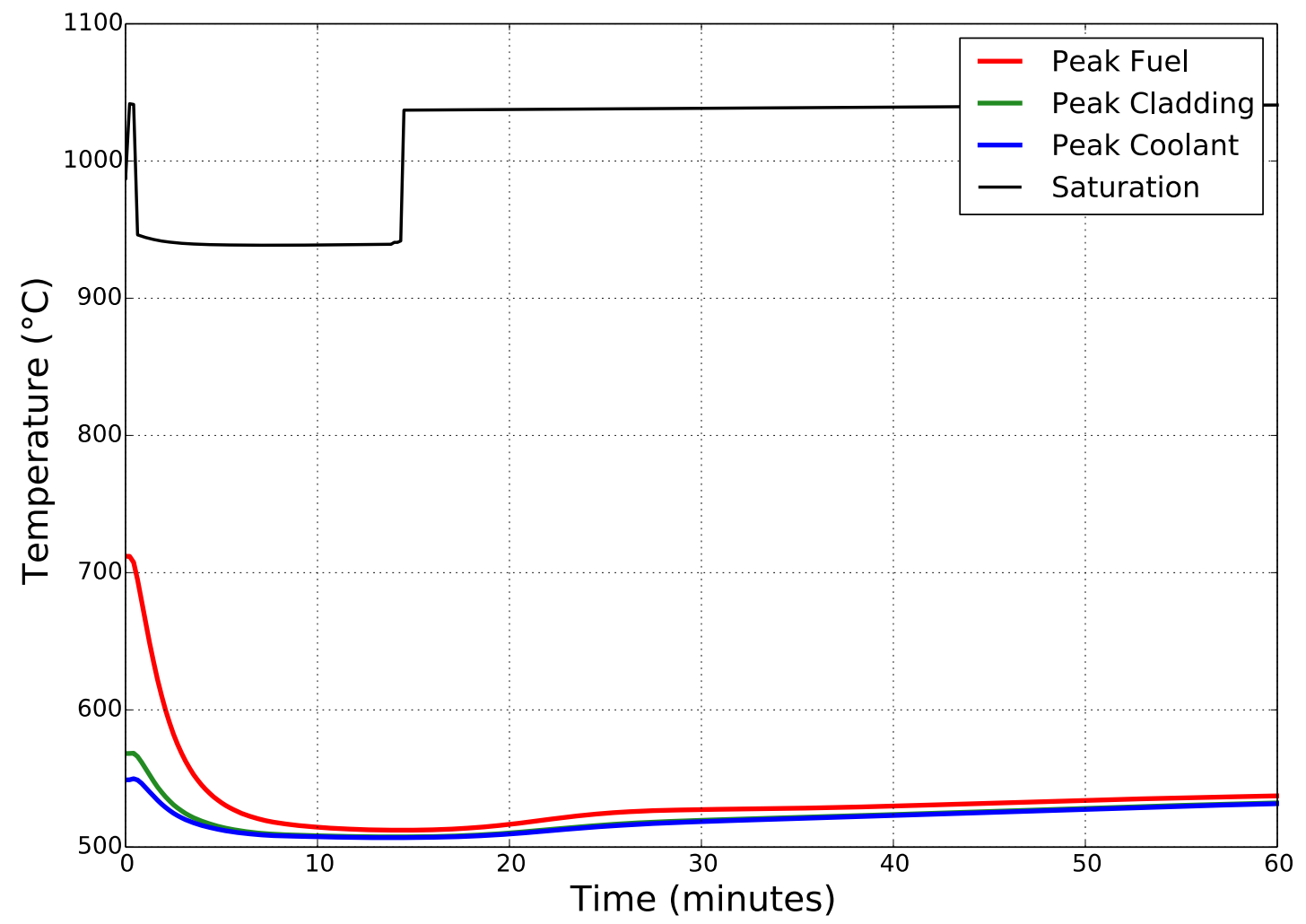

Figure 12-17: BOEC ULOHS: Peak In-Core Temperatures 


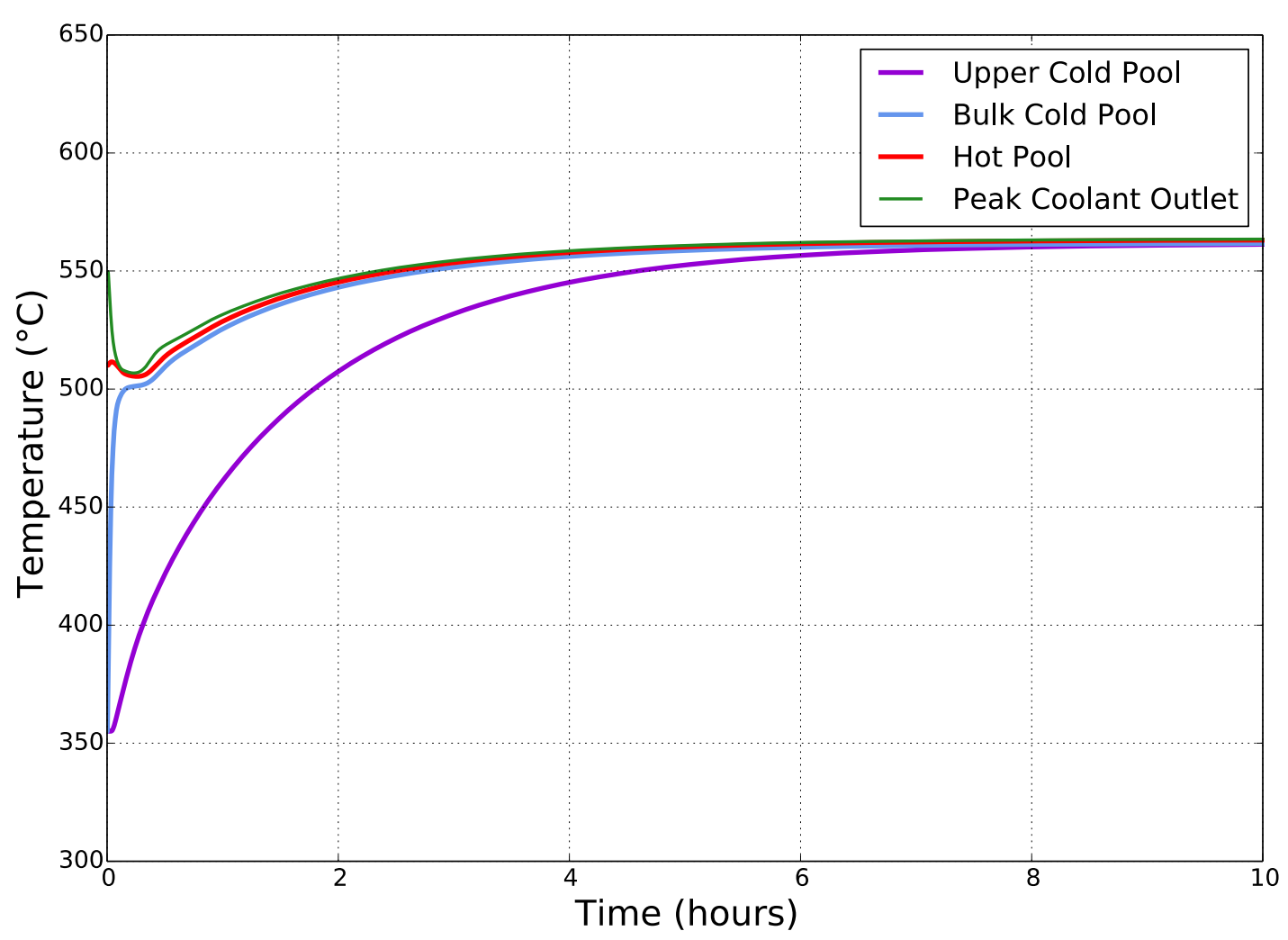

Figure 12-18: BOEC ULOHS: Primary System Temperatures

Analysis of the ULOHS transient at BOEC conditions was repeated with a nominal 1.0\% DRACS heat rejection rate. Results with the increased heat rejection were not significantly different. The DRACS heat rejection rate reached the total power production around 6 hours instead of 10 hours, and the system equilibrated at approximately $560^{\circ} \mathrm{C}$ instead of $562^{\circ} \mathrm{C}$. Temperatures in the core decreased at the same rate at the beginning of the transient so the peak temperatures were nearly identical with the higher rejection rate. These results demonstrated that a $0.5 \%$ total DRACS heat rejection rate is sufficient and there is limited benefit of increasing to $1.0 \%$.

\section{End of Equilibrium Cycle}

Because the control rods are withdrawn at EOEC, the EOEC ULOHS transient is much more benign than at BOEC conditions. Vessel expansion drives the ULOHS during BOEC conditions. But with the control rods are already withdrawn at EOEC, the magnitudes of the vessel expansion and control rod driveline expansion feedbacks are significantly reduced. Temperatures throughout the primary system still converge around the steady-state hot pool temperature, but instead of having to work against a large positive vessel expansion reactivity insertion, the negative feedback effects, particularly the coolant density and axial expansion feedbacks, drive net reactivity as low as $-13 \phi$ very quickly. Net reactivity remains negative until after the DRACS heat rejection rate exceeds the total core power production.

With the net reactivity remaining negative for several hours, instead of returning to zero as it does at BOEC conditions, fission power drops to zero within 20 minutes, leaving only the heat generated by decay heat. The DRACS heat rejection rate is sufficiently large that decay heat 
decreases below the heat rejection rate in less than 4 hours, and temperatures throughout the system begin to decrease. Power production and rejection are illustrated in Figure 12-19.

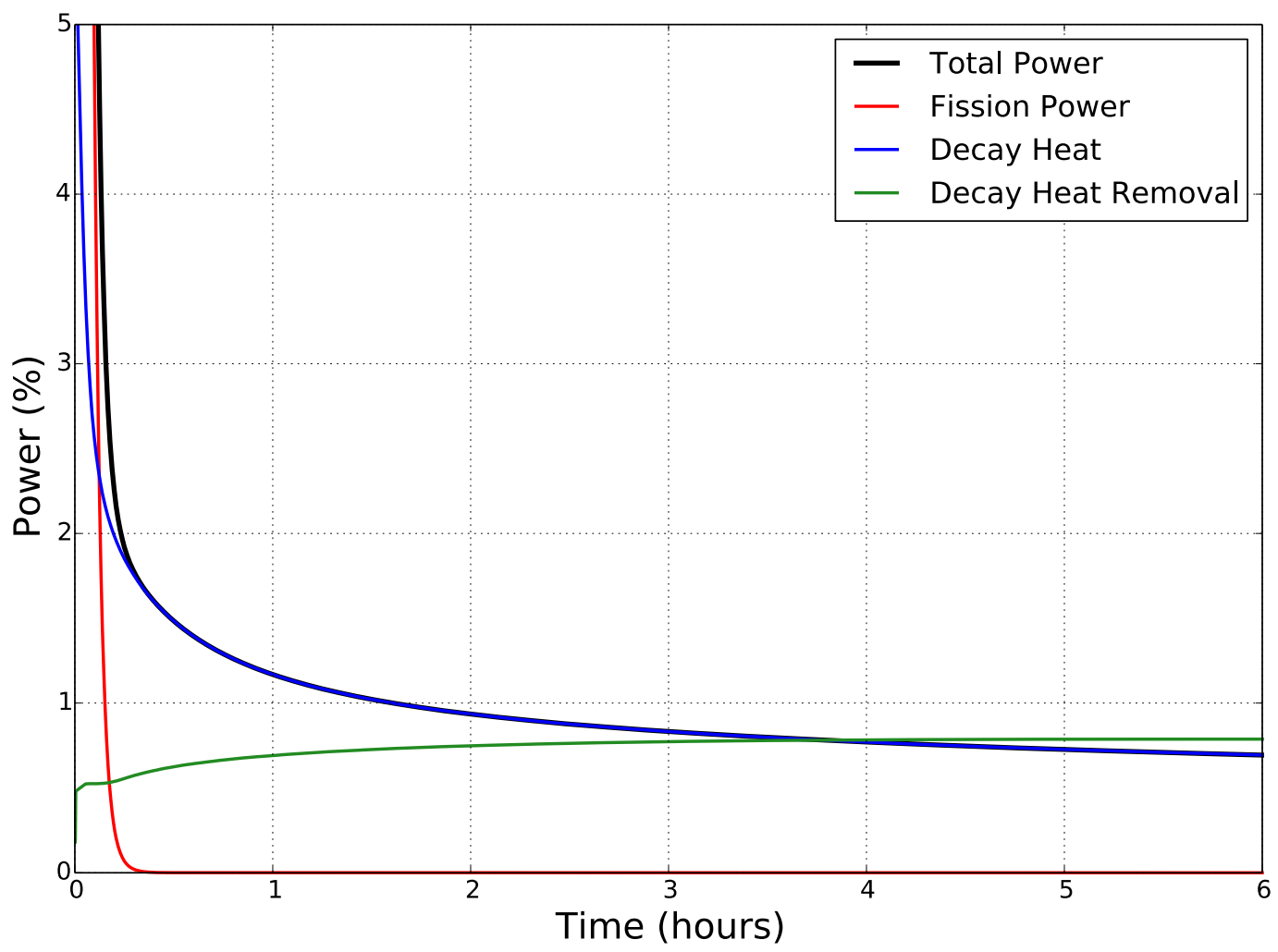

Figure 12-19: EOEC ULOHS: Total, Fission, and Decay Heat Power Production

In-core temperatures barely increase at the beginning of the transient. A boiling margin of $396^{\circ} \mathrm{C}$ is maintained. As with the BOEC cases, there is no significant decrease in the fuel melting margin and primary system pool temperatures remain well below the $732^{\circ} \mathrm{C}$ limit with the cold pool temperature peaking at $500^{\circ} \mathrm{C}$. Cladding temperatures have also not increased enough for any eutectic formation. Peak in-core temperatures are illustrated in Figure 12-20 and the hot and cold pool temperatures are illustrated in Figure 12-21. 
FASTER Test Reactor Preconceptual Design Report March 31, 2016

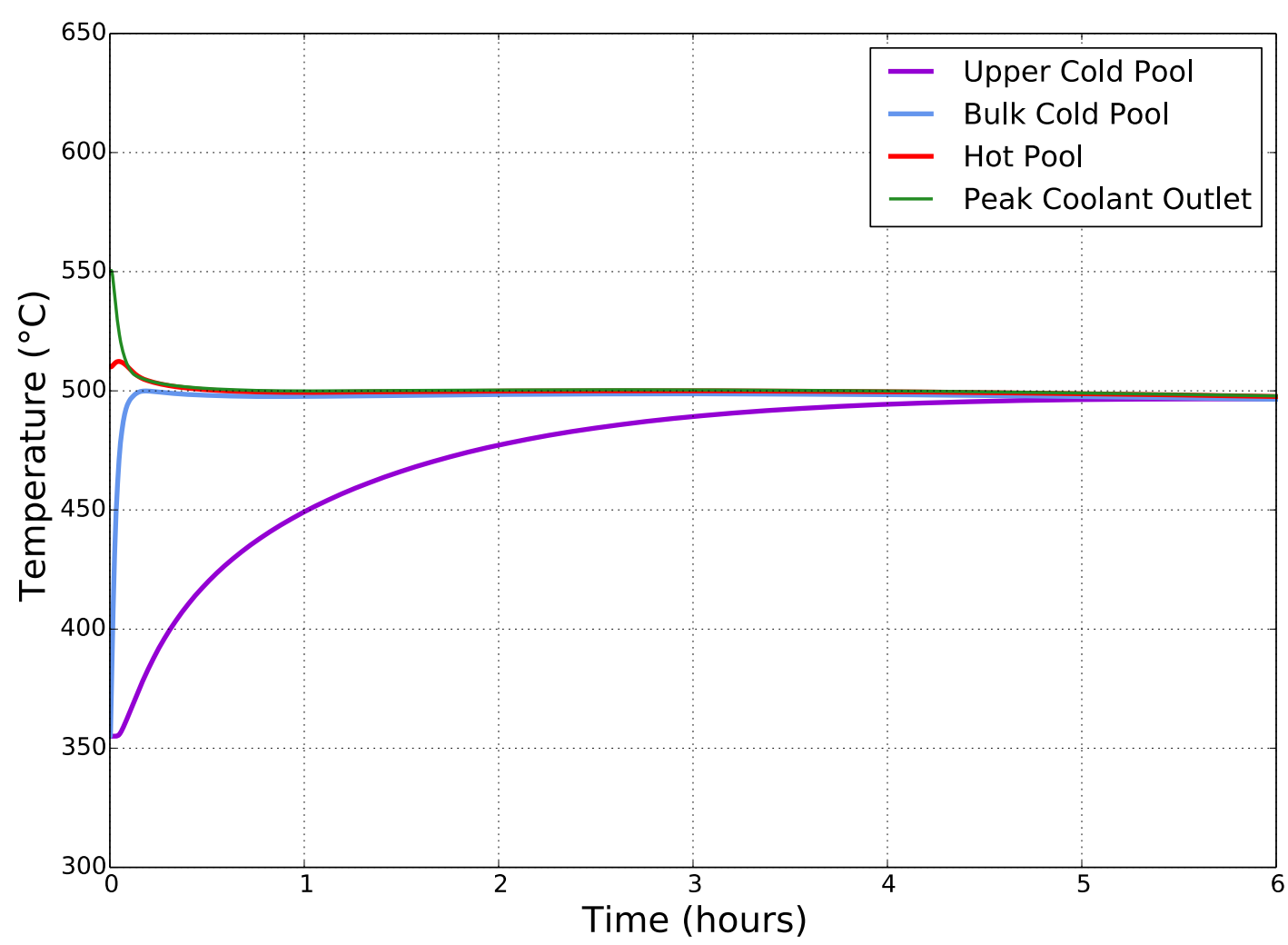

Figure 12-20: EOEC ULOHS: Primary System Temperatures

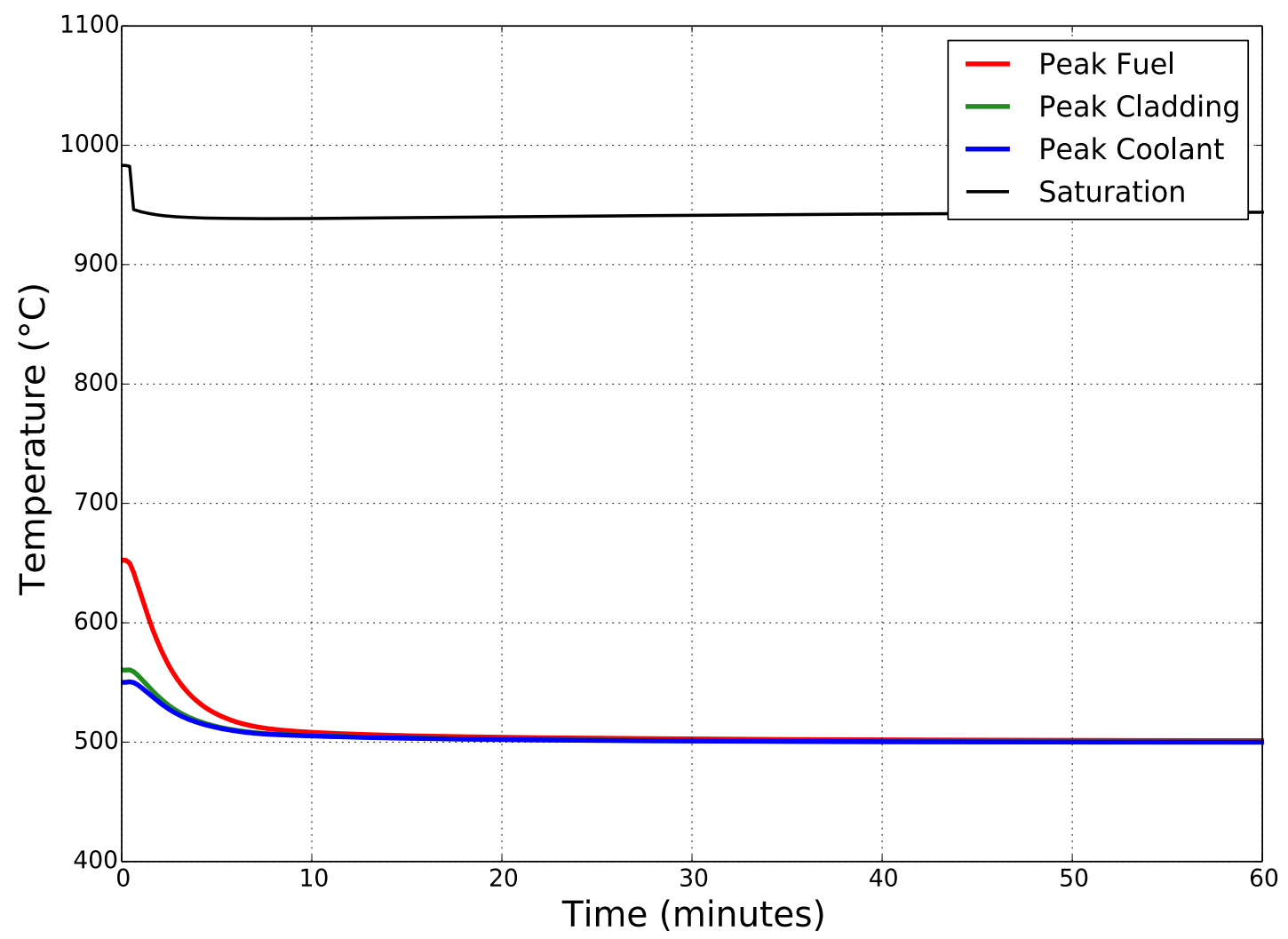

Figure 12-21: EOEC ULOHS: Peak In-Core Temperatures 


\section{USBO}

The unprotected station blackout transient is initiated by the primary, intermediate, and feedwater pumps tripping. As the primary sodium pump has not yet been designed, the USBO was simulated with an approximate primary flow halving time of 10 seconds. As with the ULOHS transient, the loss of heat rejection through the steam generators was modeled by reducing the temperature drop across the steam generators to zero at the start of the transient.

\section{Beginning of Equilibrium Cycle}

The beginning of this transient is driven by an increasing power-to-flow ratio as the primary sodium flow rate decreases. Elevated core temperatures induce axial fuel and cladding expansion, producing a reactivity feedback of $-8 \phi$. Radial core expansion, which is driven by elevated structure temperatures at the above core load pads, reaches $-31 \phi$. As the fission power decreases, temperatures in the core begin to decrease and the net reactivity starts to become less negative. While the core is cooling down, hot sodium has been washing over the control rod drivelines, causing them to expand and push the control rods further into the core. Five minutes into the transient, the CRDL feedback reaches $-54 \phi$.

As with the ULOHS, the core begins to cool down. The control rod driveline temperature decreases and the CRDL feedback becomes less negative. The out-of-phase temperature changes in the core and for the drivelines cause the net reactivity to become positive at 11 minutes. Doppler, radial core expansion, axial expansion, and the coolant density feedbacks are all positive. Net reactivity peaks at $10 \notin$ before the hotter temperatures in the core induce a negative response from the in-core reactivity feedbacks, particularly radial expansion. The 8-minute period of positive net reactivity causes fission power to increase from approximately zero to $3 \mathrm{MW}$ before the net reactivity becomes negative again and the fission power begins to decrease.

Because the feedwater pumps have tripped, the only heat rejection is through the DRACS units. For the remainder of the transient, net reactivity remains very slightly negative and fission power decreases gradually. Decay heat also continues to decrease until total power matches the heat rejection capacity of the decay heat removal system around 17 hours. The amount of time before heat rejection matches total power production is longer than for the ULOHS transient because lower cold pool temperatures are maintained during the USBO transient, and so the DRACS heat rejection rate is lower. More time is required for the cold pool temperatures to gradually increase and decay heat production to decay away.

The highest in-core temperatures occur during the first minute of the transient. The peak fuel temperature only increases from $712^{\circ} \mathrm{C}$ to $741^{\circ} \mathrm{C}$, so a very large fuel melting margin is maintained. Cladding temperatures increase close to the fuel temperatures, reaching a peak of $720^{\circ} \mathrm{C}$. This is slightly above the threshold for slow eutectic formation; however, cladding temperatures only remain above the threshold for less than 30 seconds so there is no significant cladding reduction due to fuel-cladding eutectic penetration. Sodium temperatures in the core peak at $719^{\circ} \mathrm{C}$ and a sodium boiling margin of $234^{\circ} \mathrm{C}$ is maintained. With a maximum cold pool temperature of $462^{\circ} \mathrm{C}$, long-term structural stability is not a concern for the reactor vessel. Figure 12-22 illustrates power production and rejection, Figure 12-23 and Figure 12-24 illustrates the reactivity feedbacks, and Figure 12-25 illustrates the peak in-core temperatures at the beginning of the transient. 


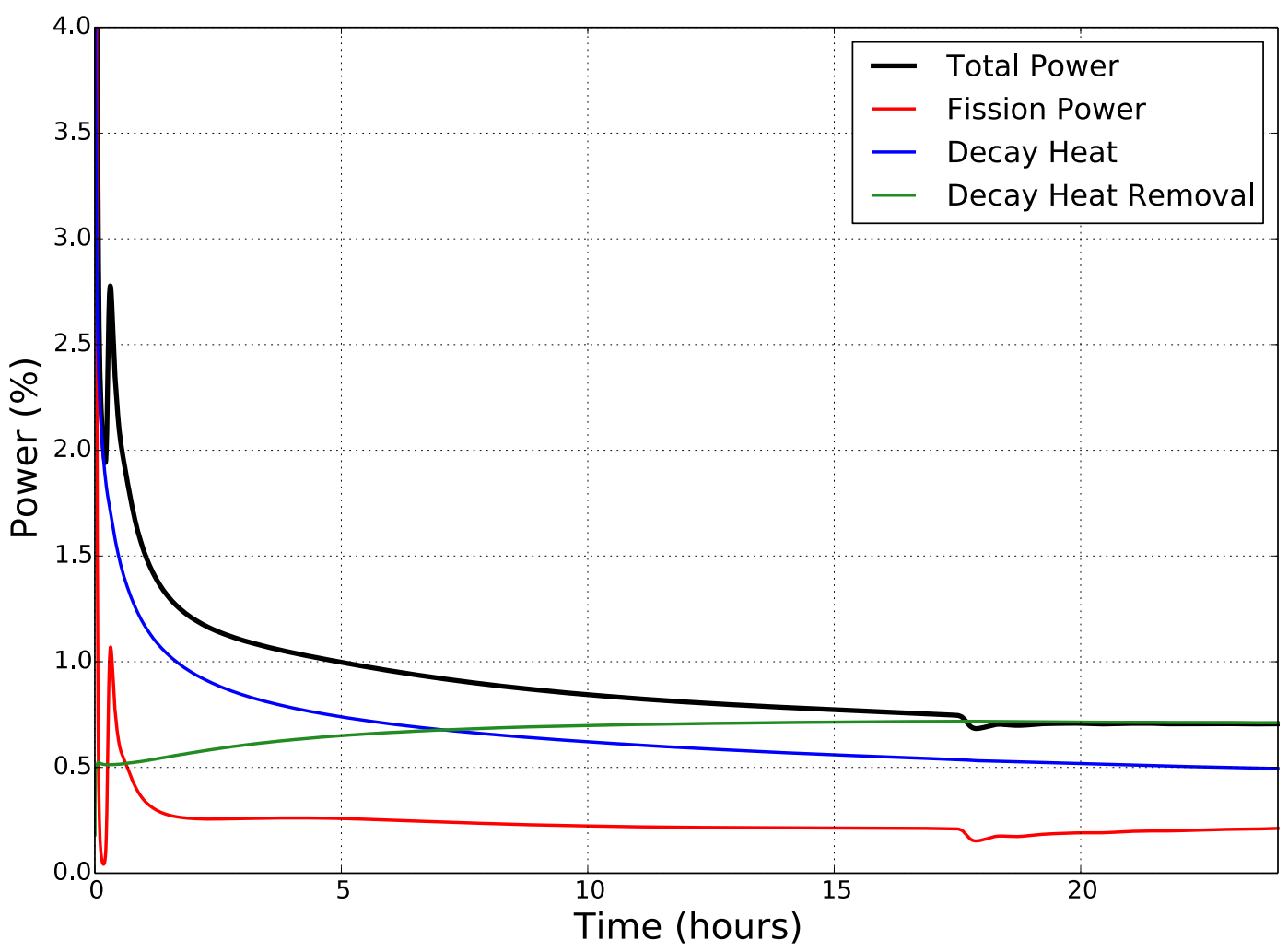

Figure 12-22: BOEC USBO: Total, Fission, and Decay Heat Power Production

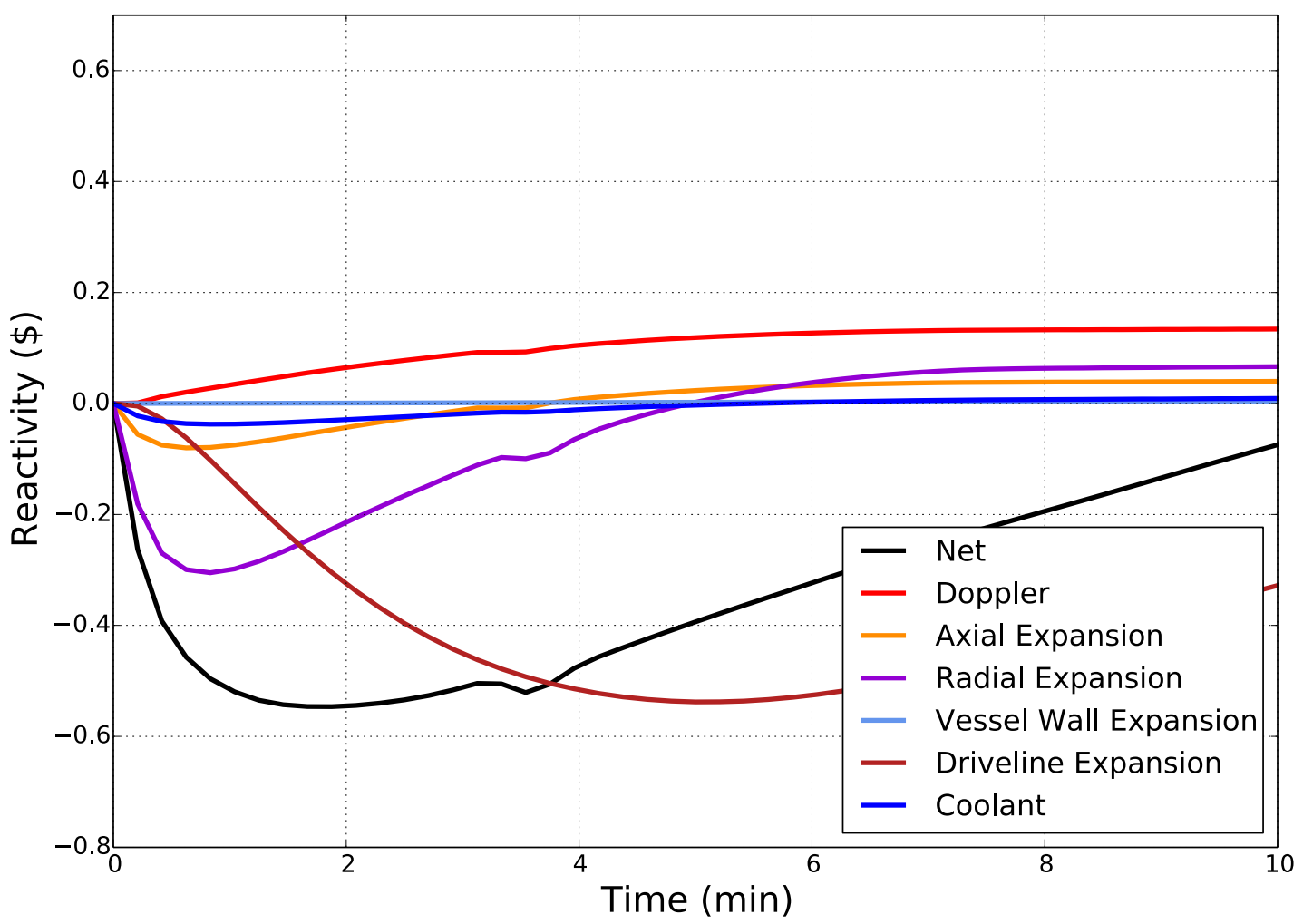

Figure 12-23: BOEC USBO: Reactivity Feedbacks, Short-Term 


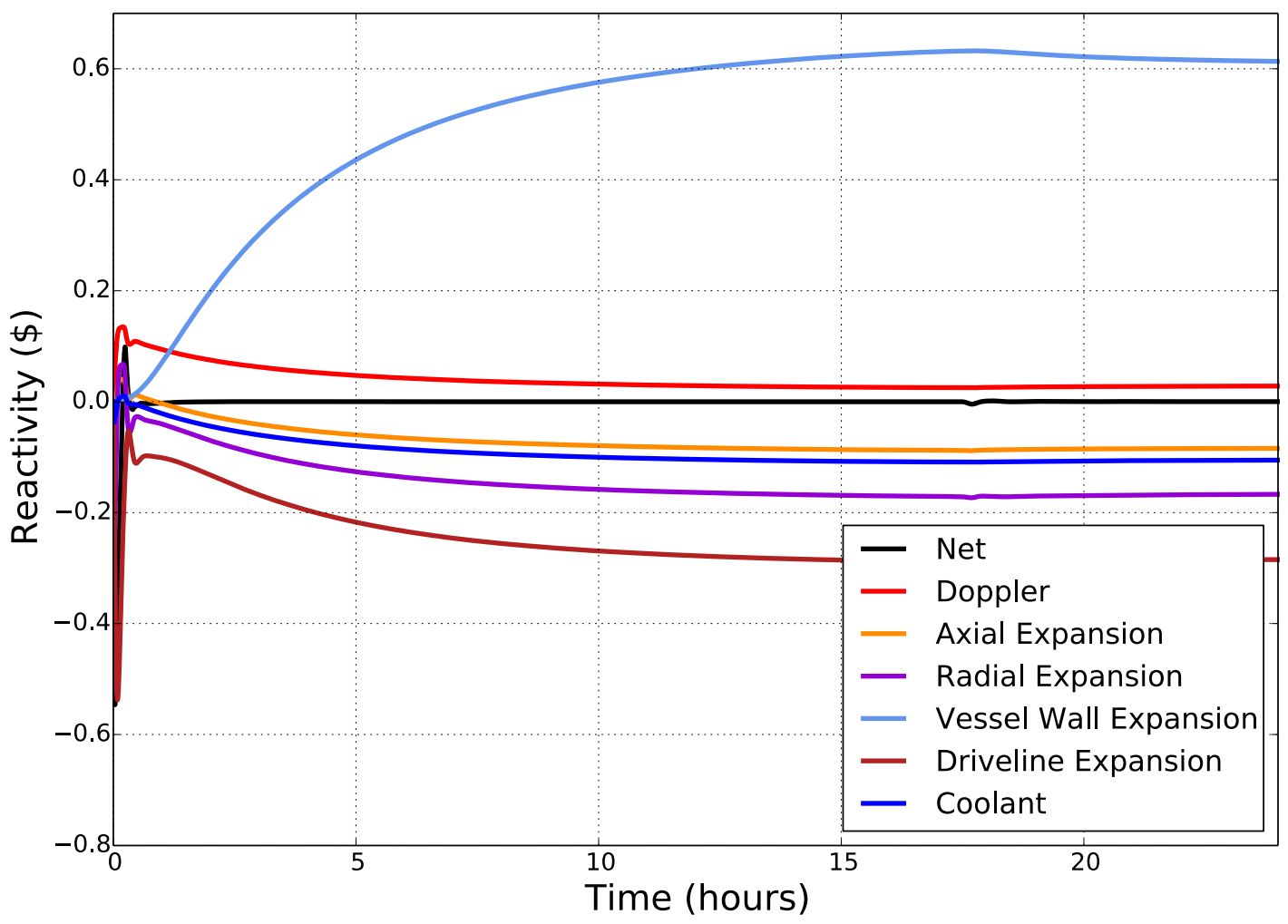

Figure 12-24: BOEC USBO: Reactivity Feedbacks, Long-Term

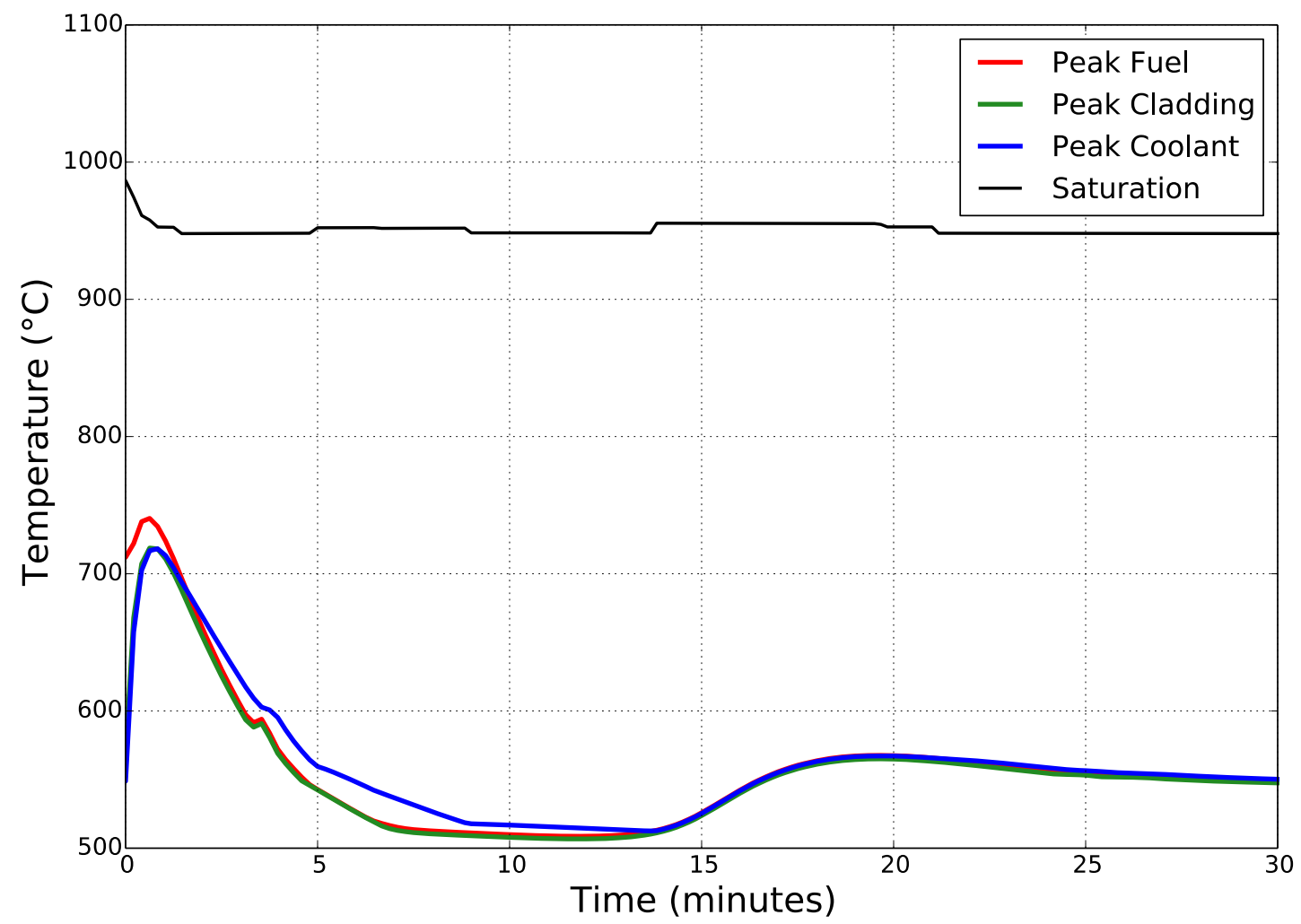

Figure 12-25: BOEC USBO: Peak In-Core Temperatures 
The BOEC USBO transient was also simulated with a nominal heat DRACS heat rejection rate of $1.0 \%$. With a heat rejection rate $0.5 \%$, fission power remained at approximately $0.2 \%$ in order to maintain equilibrium between heat rejection and total power. With 1.0\% DRACS heat rejection, decay heat coasts down at a similar rate so fission power needs to be higher to maintain the power balance. After one day, fission power is more than 3 times larger than for the $0.5 \%$ DRACS case.

Even with the fission power level at the end of the transient, however, the peak fuel, cladding, and coolant temperatures are unchanged. Temperatures peak during the USBO during the first minute of the transient, before the heat rejection rate affects the core. The smaller $0.5 \%$ heat rejection rate was sufficient because it produced very large safety margins, with the reactor equilibrating at a lower power level than for a $1.0 \%$ heat rejection rate.

\section{End of Equilibrium Cycle}

The USBO was simulated at EOEC, and the results are very similar to the BOEC results. The cold pool temperature increases more than the hot pool temperature so reactor vessel expansion is larger than the control rod driveline expansion. However, because the control rods are already withdrawn, the reactivity feedback due to the change in the control rod insertion depth is very small. Net reactivity decreases to $-48 \varnothing$ within the first minute, and because the driveline expansion feedback is less, the out-of-phase driveline and core inlet temperatures do not produce as large fission power swings. Where net reactivity rebounded to $10 \phi$ for the BOEC case, net reactivity rebounds only to $1.5 \phi$ at EOEC. Within 4 hours, fission power is essentially zero and decay heat slowly decreases until total power drops below the DRACS heat rejection capacity at 8 hours.

As with the BOEC case, the peak temperatures occur within the first minute. The safety margins are all larger at EOEC with fuel, cladding, and coolant temperatures all remaining below $700^{\circ} \mathrm{C}$ for the EOEC USBO. Figure 12-26 illustrates power production and DRACS heat rejection. Figure 12-27 and Figure 12-28 illustrate the reactivity feedbacks. Figure 12-29 illustrates the peak in-core temperatures. 
FASTER Test Reactor Preconceptual Design Report March 31, 2016

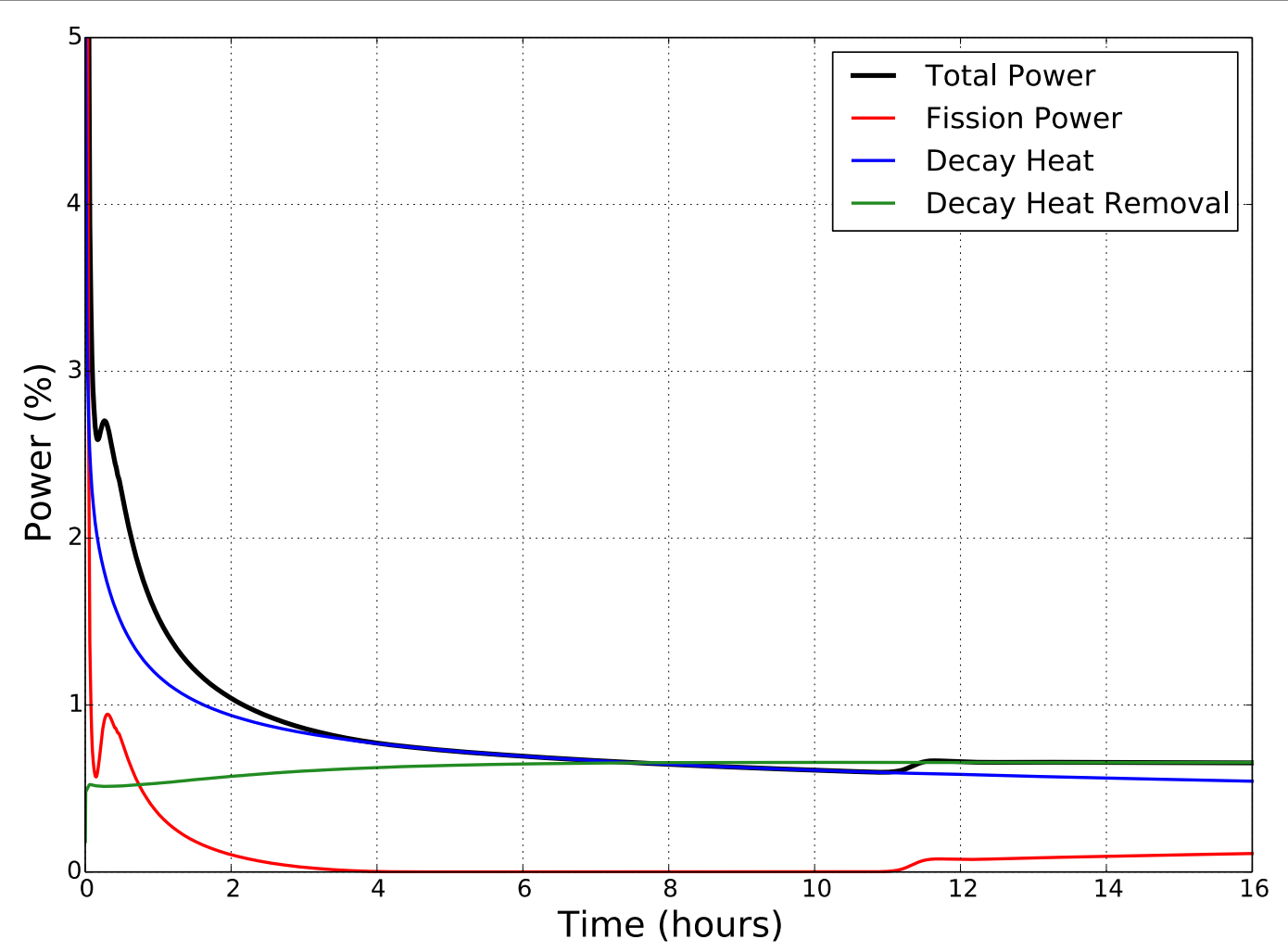

Figure 12-26: EOEC USBO: Total, Fission, and Decay Heat Power Production

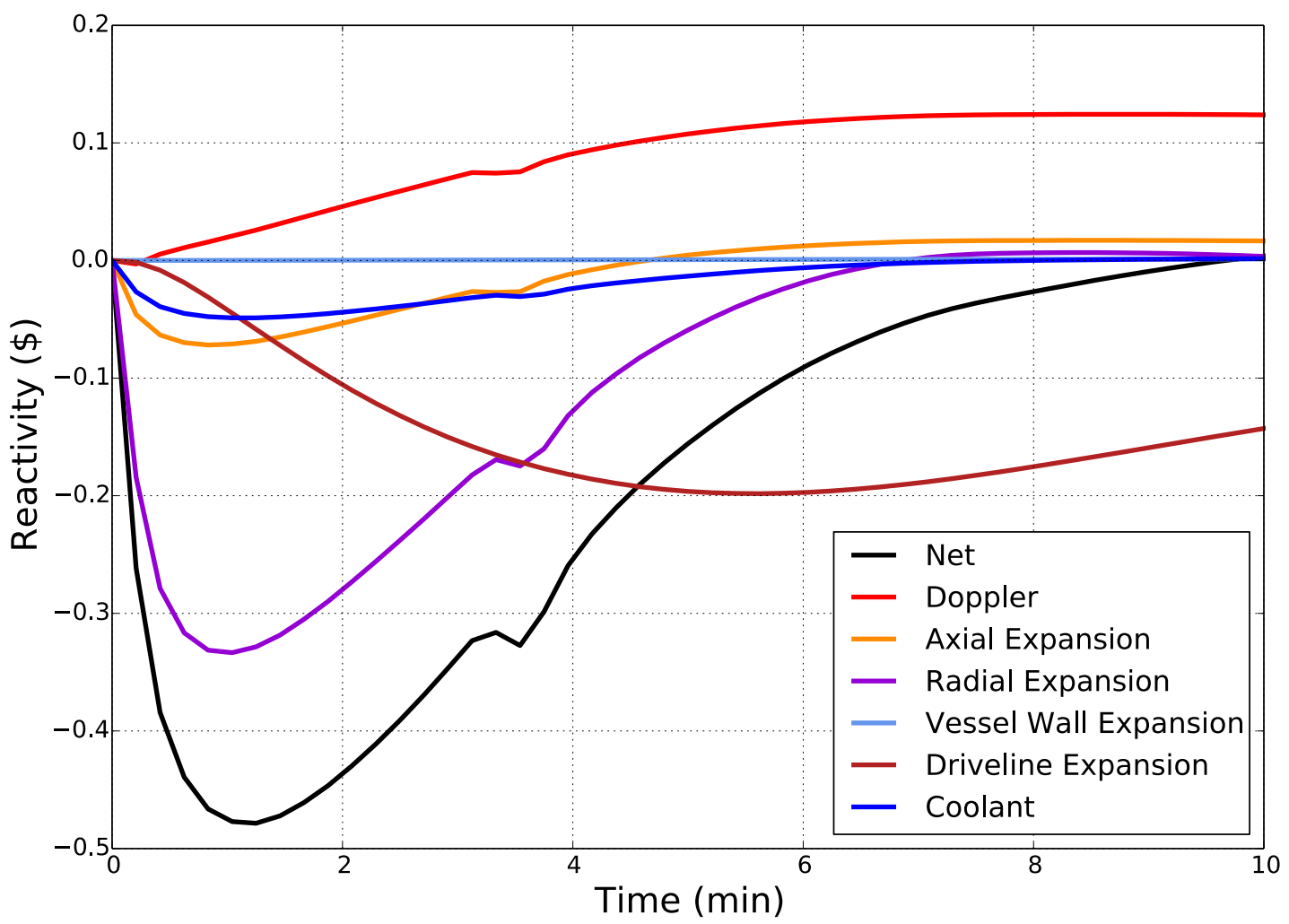

Figure 12-27: EOEC USBO: Reactivity Feedbacks, Short-Term 
FASTER Test Reactor Preconceptual Design Report March 31, 2016

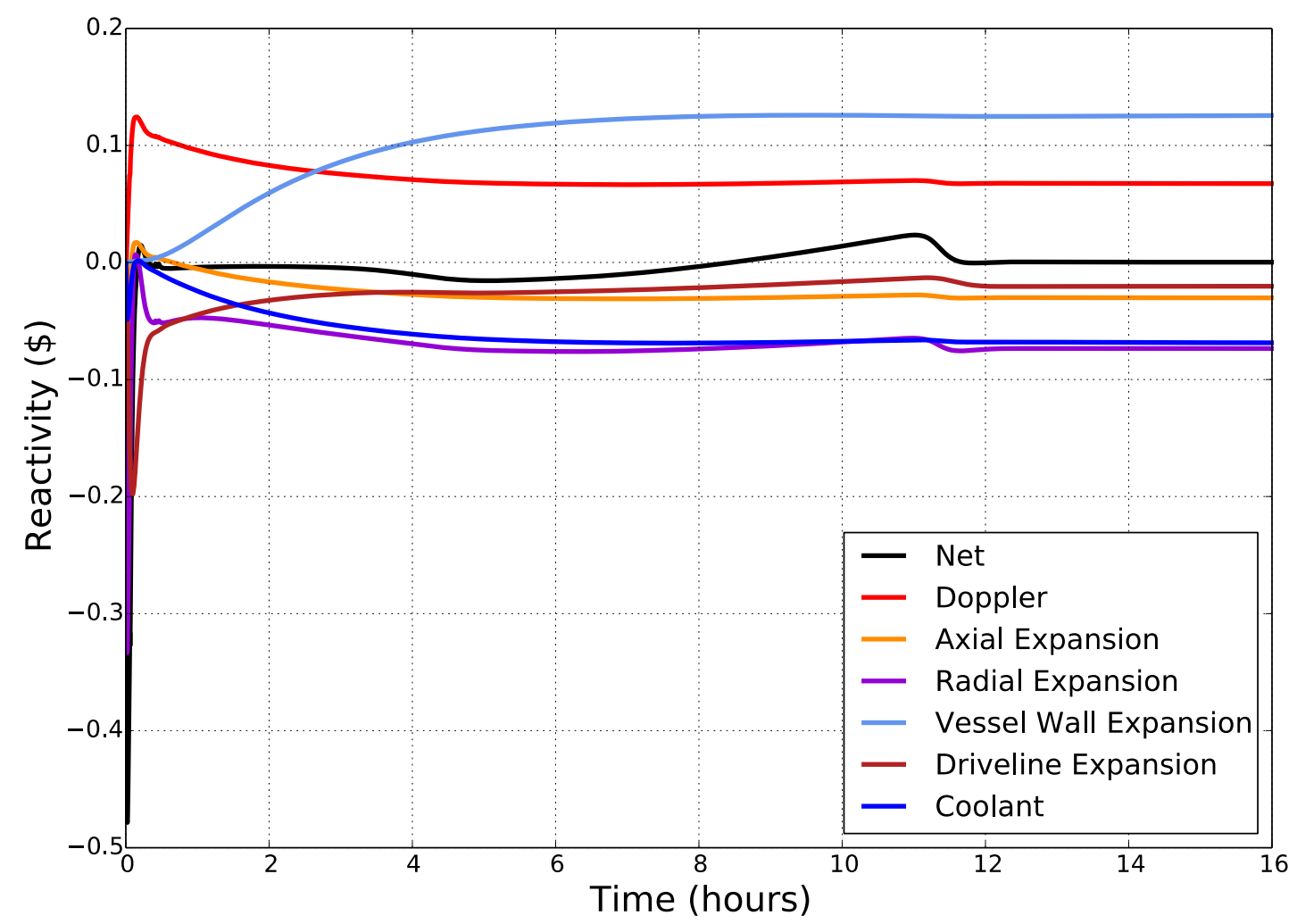

Figure 12-28: EOEC USBO: Reactivity Feedbacks, Long-Term

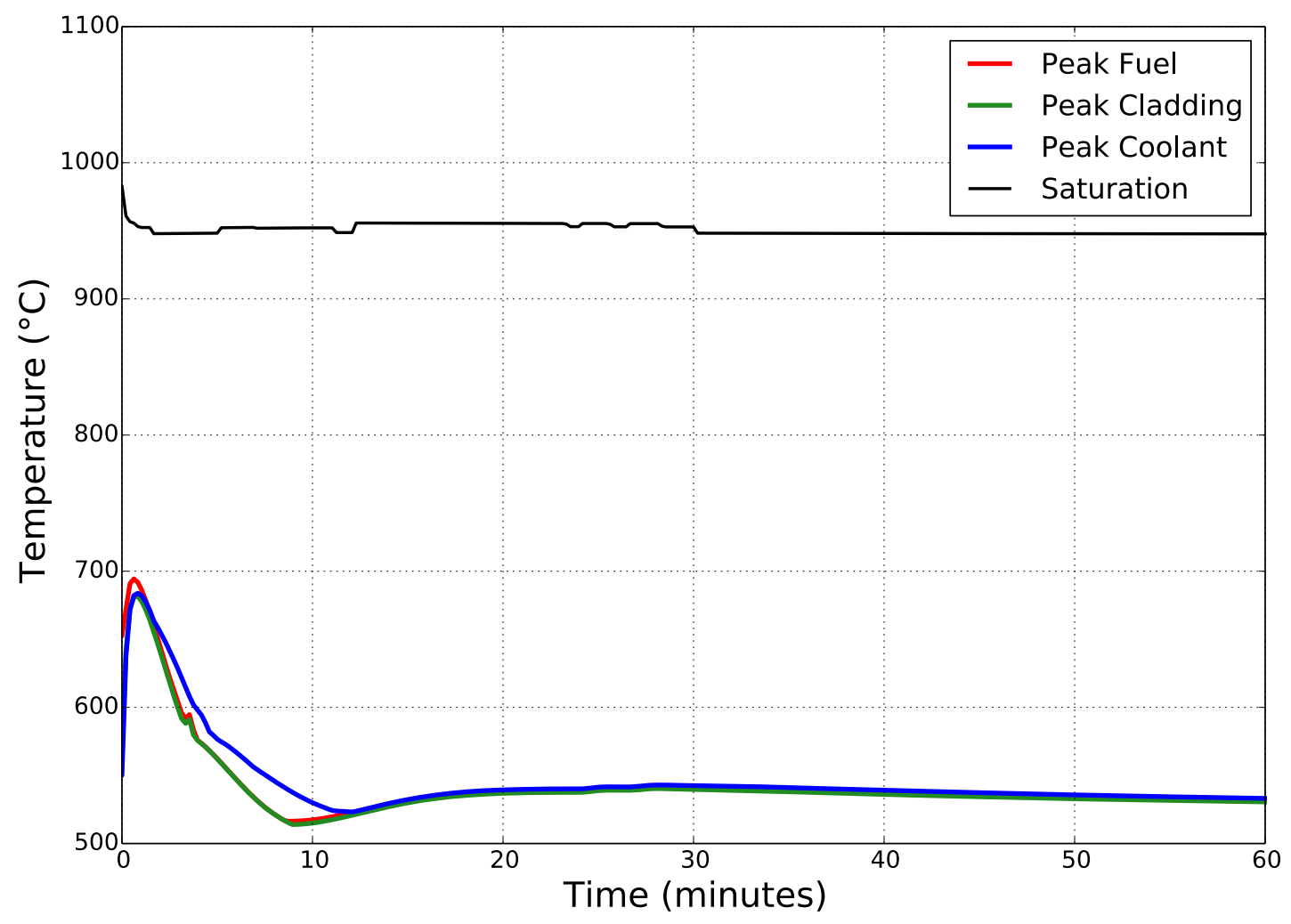

Figure 12-29: EOEC USBO: Peak In-Core Temperatures 


\subsubsection{Summary of Unprotected Transient Analyses}

Three types of transient scenarios were analyzed for the FASTER design: unprotected transient overpower, unprotected loss of heat sink, and unprotected station blackout. These transients were simulated using SAS4A/SASSYS-1 at both beginning of equilibrium cycle and end of equilibrium cycle conditions, except for the UTOP scenario, which was only simulated at BOEC conditions. For each transient, failures of both the primary and secondary reactor scram systems were assumed. Because of the favorable reactivity feedbacks, relatively low peak fuel, cladding, and coolant temperatures were obtained during the transients and the reactor vessel temperature remained well below the limit for ensuring structural stability. Table 12-14 and Table 12-15 list the predicted peak temperatures and safety margins, respectively, for the BOEC transients and EOEC transients.

Table 12-14: Peak Temperatures for BOEC and EOEC Transients

\begin{tabular}{lcccc}
\hline \multicolumn{5}{c}{ Beginning of Equilibrium Cycle } \\
\hline & Coolant & Cladding & Fuel & $\begin{array}{c}\text { Reactor } \\
\text { Vessel }\end{array}$ \\
\hline Nominal & $549^{\circ} \mathrm{C}$ & $568^{\circ} \mathrm{C}$ & $712^{\circ} \mathrm{C}$ & $355^{\circ} \mathrm{C}$ \\
UTOP & $657^{\circ} \mathrm{C}$ & $688^{\circ} \mathrm{C}$ & $889^{\circ} \mathrm{C}$ & $415^{\circ} \mathrm{C}$ \\
ULOHS & $564^{\circ} \mathrm{C}$ & $569^{\circ} \mathrm{C}$ & $712^{\circ} \mathrm{C}$ & $562^{\circ} \mathrm{C}$ \\
USBO & $719^{\circ} \mathrm{C}$ & $720^{\circ} \mathrm{C}$ & $741^{\circ} \mathrm{C}$ & $462^{\circ} \mathrm{C}$ \\
\hline \multicolumn{5}{c}{} \\
\hline \multicolumn{5}{c}{} \\
\hline Eominal & $550^{\circ} \mathrm{C}$ & $560^{\circ} \mathrm{C}$ & $652^{\circ} \mathrm{C}$ & $355^{\circ} \mathrm{C}$ \\
ELOHS & $551^{\circ} \mathrm{C}$ & $561^{\circ} \mathrm{C}$ & $653^{\circ} \mathrm{C}$ & $500^{\circ} \mathrm{C}$ \\
USBO & $684^{\circ} \mathrm{C}$ & $684^{\circ} \mathrm{C}$ & $694^{\circ} \mathrm{C}$ & $431^{\circ} \mathrm{C}$ \\
\hline
\end{tabular}

Table 12-15: Safety Margins for BOEC and EOEC Transients

\begin{tabular}{lcccc}
\hline \multicolumn{5}{c}{ Beginning of Equilibrium Cycle } \\
\hline & $\begin{array}{c}\text { Sodium } \\
\text { Boiling }\end{array}$ & $\begin{array}{c}\text { Rapid Clad } \\
\text { Eutectic }\end{array}$ & $\begin{array}{c}\text { Fuel } \\
\text { Melting }\end{array}$ & $\begin{array}{c}\text { Reactor Vessel } \\
\text { Service Level D }\end{array}$ \\
\hline Nominal & $399^{\circ} \mathrm{C}$ & $507^{\circ} \mathrm{C}$ & $359^{\circ} \mathrm{C}$ & $377^{\circ} \mathrm{C}$ \\
$U T O P$ & $292^{\circ} \mathrm{C}$ & $387^{\circ} \mathrm{C}$ & $182^{\circ} \mathrm{C}$ & $317^{\circ} \mathrm{C}$ \\
$U L O H S$ & $391^{\circ} \mathrm{C}$ & $506^{\circ} \mathrm{C}$ & $359^{\circ} \mathrm{C}$ & $170^{\circ} \mathrm{C}$ \\
$U S B O$ & $234^{\circ} \mathrm{C}$ & $355^{\circ} \mathrm{C}$ & $330^{\circ} \mathrm{C}$ & $270^{\circ} \mathrm{C}$ \\
\hline
\end{tabular}

End of Equilibrium Cycle

\begin{tabular}{lcccc}
\hline & $\begin{array}{c}\text { Sodium } \\
\text { Boiling }\end{array}$ & $\begin{array}{c}\text { Rapid Clad } \\
\text { Eutectic }\end{array}$ & $\begin{array}{c}\text { Fuel } \\
\text { Melting }\end{array}$ & $\begin{array}{c}\text { Reactor Vessel } \\
\text { Service Level D }\end{array}$ \\
\hline Nominal & $398^{\circ} \mathrm{C}$ & $515^{\circ} \mathrm{C}$ & $419^{\circ} \mathrm{C}$ & $377^{\circ} \mathrm{C}$ \\
ULOHS & $396^{\circ} \mathrm{C}$ & $514^{\circ} \mathrm{C}$ & $418^{\circ} \mathrm{C}$ & $232^{\circ} \mathrm{C}$ \\
USBO & $268^{\circ} \mathrm{C}$ & $391^{\circ} \mathrm{C}$ & $377^{\circ} \mathrm{C}$ & $301{ }^{\circ} \mathrm{C}$ \\
\hline
\end{tabular}




\section{Balance of Plant Systems (Various)}

\subsection{Compressed Gas System}

The compressed gas system distributes compressed gases throughout the reactor plant from the point of storage or compression to the point of use. Four subsystems comprise this compressed gas system. They are 1) Service Air System, 2) Instrument Air System, 3) Hydrogen System, and 4) Carbon Dioxide System.

\section{System Requirements}

The service air system shall provide the following:

- Air for various plant fuel handling systems.

- Air for maintenance systems, unloading devices, tools, miscellaneous cleaning, and inspection services.

- Breathable air for required stations.

The instrument air system shall supply the following:

- Clean dry air to instrumentation, controls, pneumatic piston and diaphragm valve operators, and air locks located in all areas of the plant.

- The service air system.

The hydrogen system shall provide hydrogen gas to the main generator for cooling the stator core and rotating field. The carbon dioxide system shall provide carbon dioxide gas for generator purging.

\section{System Description}

The service air system provides compressed air for use by various plant systems such as the fuel handling system, maintenance systems, unloading devices, tools, miscellaneous cleaning, and inspection services. The system also delivers breathable air to required stations. The service air system receives compressed air from the instrument air system. The service air system is a distribution system of piping and valves that takes compressed air from the instrument air header and distributes it to the users.

The service air system operates at all times providing compressed air during normal plant operation or when the plant is shut down. The service air system is not safety related. The instrument air system provides clean, oil-free dry air for operation of instruments and controls, pneumatic piston and diaphragm valve operators and air locks in all areas of the plant. The instrument air system operates at all times to provide compressed air during normal plant operation or when the plant is shutdown, since compressed air is required during plant shutdown as well as during normal plant operation.

The instrument air system also supplies the service air system, as needed. The instrument air system is not safety related. Safety-related items requiring instrument air are supplied from local safety-class accumulators. The hydrogen system stores and supplies hydrogen gas to the main 
generator for cooling of the generator stator core and rotor during operation. The hydrogen system is not safety related.

The carbon dioxide system stores carbon dioxide in liquid form, processes the carbon dioxide liquid to carbon dioxide gas, and supplies the gas to the main generator for purging. The carbon dioxide system is not safety related.

\subsection{Chilled Water System}

The chilled water system provides chilled water during normal plant operation for air conditioning and removal of heat from the following areas or systems:

- Nuclear island (NI) HVAC and balance of plant (BOP) HVAC system.

- Process cooling in the NI maintenance building.

- Recirculating gas system.

The system includes chillers, pumps, expansion tanks, piping, valves, and related components. A refrigerant pumpout and storage system is also provided for maintenance. The system does not include air cooling coils in air conditioning units nor heat transfer equipment in process cooling systems. Cooling water for the chiller condensers is provided by the plant service water system.

\subsection{Radioactive Waste System}

The radioactive waste system (RWS) provides the equipment and facilities for collecting, processing, monitoring, storing, and disposing of liquid and solid radioactive wastes. The RWS processes both liquid radioactive wastes and solid radioactive wastes.

\section{System Requirements}

The following functions shall be provided by the RWS:

- Liquid Radioactive Waste Subsystem (LRWS)

- Collect radioactive liquid waste for processing, recycle, or disposal.

- Provide sample points and equipment to monitor the chemical and radioactive content of liquid wastes.

- Process and concentrate radioactive liquid waste.

- Store processed or reclaimed liquid for reuse or disposal.

- Control discharges to assure compliance with applicable regulatory standards.

- Solid Radioactive Waste Subsystem (SRWS)

- Radwaste Solidification System - 1) Receive and measure the radiation levels of small low activity level components from other systems and determine temporary storage, processing or disposal requirements. 2) Compact, package, and prepare compactible radioactive solid wastes for disposal. 
- Radwaste Disposal Management System - 1) Establish the necessary interfaces with other systems for packaging and disposal of large non-compactible radioactive solids. 2) Develop an inventory control system that provides for accountability of radioactive materials.

The following general design requirements shall apply:

- The general system design shall provide as-low-as-reasonably achievable (ALARA) radiation protection for maintenance and plant operating personnel.

- The system shall have the capability to monitor and record discharges to the environment.

- The equipment and its associated supports are to be classified as nonseismic.

- The quality of the discharged water shall comply with the governing water quality standards.

Prior to discharge to the environment, a laboratory analysis of all liquids to be discharged to the environs shall be performed to assure that the activity requirements for such discharges are met. An acid and caustic solution supply, neutralization and $\mathrm{pH}$ control system shall be provided, with the capability to adjust the $\mathrm{pH}$ of all liquid wastes which are collected, prior to further processing.

Receive radioactive sodium generated by the fuel handling and fuel receiving, storage and shipping systems. Provide control functions for the LRWS and SRWS to maintain the design, operating and performance parameters during all operating modes.

\section{System Description}

The RWS provides the equipment and facilities for collecting, processing, monitoring, storing and disposing of liquid and solid radioactive waste. The RWS consists of two subsystems: (1) the LRWS and (2) the SRWS. The LRWS collects and processes radioactive liquid wastes in order to reduce the volume of radioactive wastes which must ultimately be disposed of. This volume reduction is performed by extracting the solid contaminants from the collected liquids and then concentrating the extracted contaminants. The liquids, less solid content, are processed to produce a purified, decontaminated effluent in accordance with the regulatory requirements for discharge off-site. The SRWS collects and processes both concentrated liquid and solid wastes which are radioactive and prepares these waste substances for storage and disposal.

The RWS facilities are located adjacent within the radwaste/maintenance building. Equipment within the buildings has been located and arranged in a manner which isolates the operating and maintenance galleries from the equipment to achieve as low a level of personnel radiation exposure as is reasonably achievable.

\subsection{Nuclear Island Heating, Ventilation, and Air Conditioning System}

The nuclear island (NI) heating, ventilating, and air conditioning (HVAC) system maintains environmental conditions within design limits throughout the noninert areas of the NI buildings, and in conjunction with the radiation monitoring system and plant protection system (PPS) limits the release of radioactive materials from the NI buildings.

\section{System Requirements}


The NI HVAC system shall serve the following buildings:

- Reactor Building

- Control Building (CB)

- Steam Generator/Aux Building

and shall perform the following functions:

- Maintain the temperature, humidity, pressure, and cleanliness of the air atmospheres in the various building spaces during normal plant operation.

- Maintain, as necessary, the temperature, humidity, pressure, and cleanliness of the air atmospheres in the areas containing safety-related equipment during normal plant operation and during off-normal conditions.

- In conjunction with the radiation monitoring system and PPS, maintain the release of airborne radioactive materials to the outside environment below the acceptable limits during normal operation and off-normal conditions.

- Limit the intake of hazardous airborne materials into certain safety-related and occupied areas, such as the control room.

All safety-related ventilation trains shall consist of two redundant 100\% capacity equipment trains, and designed to Seismic Category I requirements. No single failure of any active component of the safety-related subsystems will result in loss of that subsystem's safety-related functions.

\section{System Description}

The nuclear island HVAC system serves the Reactor Building, Control Building, and Steam Generator Building. The NI HVAC system provides heating, ventilating, and air conditioning for the various non-inerted atmospheric areas of the Nuclear Island buildings during normal and abnormal conditions. The system maintains the temperature, humidity, pressure, and air cleanliness as required. The NI HVAC system, in conjunction with the radiation monitoring system and PPS, limits the release of radioactive materials from the buildings by filtration of exhausted air and/or by isolation of the buildings.

\subsection{Balance of Plant Heating, Ventilation, and Air Conditioning System}

The BOP HVAC systems provide heat, ventilation, cooling, humidity control, and control of airborne contamination as required for the equipment and activities in the BOP buildings.

\section{System Requirements}

The BOP HVAC systems shall provide heat, ventilation, cooling, humidity control, pressure, and control of airborne contamination or any combination of these functions to the BOP buildings or portions of buildings as required for proper operation of equipment and for personnel comfort. 
System Description

The BOP HVAC system consists of several subsystems serving various areas of the BOP buildings, each performing specialized functions as required for the area served. Each subsystem consists of combinations of various basic components as required to satisfy the performance requirements for that sub-system. These basic components include air handling units, fans or blowers, cooling and heating coils, filters of various efficiencies, duct work, dampers, isolation valves, carbon absorbers, instrumentation and controls, and other accessories as required.

Facilities served by the BOP HVAC System include:

- Turbine Generator Building

- Balance of Plant Services Building

- Radwaste/Maintenance Building

- Cooling Tower Pumphouse

- Fire Protection Pumphouse

- Switchyard Relay House

- Circulating Water Pumphouse

- Gate House

- Emergency Generator Buildings

- Auxiliary Boiler House

- Water Treatment Plant

- Sewage Treatment Plant

- Well Water Pumphouse

\subsection{Fire Protection System}

System Requirements

The FPS provides the means to detect, and in some cases, anticipate, fires throughout the reactor plant, and to minimize the fire hazard to personnel and equipment. The FPS shall provide the means to prevent, control, and mitigate the consequences of plant fires through the following general functions:

- Detect fires, or incipient fires, activate alarms, suppress fires, extinguish fires, isolate and confine fires, protect personnel from smoke and heat and protect safety-related systems and components to assure continued readiness and operation.

The FPS shall be comprised of two subsystems: the sodium fire protection system (SFPS), which addresses sodium or sodium-potassium fires; and the non-sodium fire protection system (NSFPS), which addresses fires of non-alkali metal origin or involvement.

\section{System Description}

The SFPS provides the means for detecting, locating, confining, suppressing, and extinguishing sodium and $\mathrm{NaK}$ fires. Special requirements imposed by the presence of sodium and $\mathrm{NaK}$ in the plant result in employing special fire protection methods in the SFPS. These methods include passive catch pans and fire-suppression decks, and manually operated, portable fire extinguishers. 
Fire detectors and associated instrumentation are used to inform the plant operator of the existence and location of a fire. The effectiveness of these fire protection methods for limiting fire losses and the spread of airborne contaminants is augmented by fire barriers, fire doors, fire dampers, low-leakage penetrations, and similar isolation devices provided by the building design, and by the heating and ventilation system.

The fire protection water supply system provides water at the design pressure and quantity to the sprinkler, deluge, and water spray systems, and the yard hydrants. The water storage tanks, fire pumps, and hydrants are all nonseismic Category I components. One (1) seismically qualified (Seismic Category I) pump, taking its suction from two (2) seismically qualified (Seismic Category I) storage tanks, provides water at the design pressure and quantity to special service wet standpipes located in buildings and areas of the plant containing systems, equipment and components essential for reactor safe shutdown.

\subsection{Re-circulating Gas Cooling System}

Reserved.

\subsection{Fuel Receiving, Storage, and Shipping System}

The fuel receiving, storage, and shipping system (FRSSS) provides for the receiving and unloading of new core assemblies, inspection, temporary storage, provision for inventory control of all core assemblies, examination of irradiated core assemblies, and preparation and loading of irradiated core assemblies for shipment off-site. Also provided is the instrumentation and control system that is used to operate the FRSSS and the fuel handling system. This system interfaces closely with the fuel handling system, the fuel handling facility, and the liquid metal auxiliary system.

\section{System Requirements}

The primary requirements of the fuel receiving, storage, and shipping system (FRSSS) are as follows:

- Receive, inspect, store, and prepare new core assemblies for insertion into the reactor. Core assemblies are defined as fuel, reflector, control, and radial shield assemblies.

- Make selected measurements on irradiated core assemblies and prepare irradiated core assemblies for shipment to an off-site location.

- Provide inventory control for all core assemblies at all times within the plant.

- During transfer operations, the FRSSS shall be capable of cooling fuel assemblies for an indefinite period.

- Total storage capacity in air cell shall be about 1200 positions.

- A fuel handling cell (FHC) shall provide for preparation of irradiated core assemblies for shipment. 


\section{System Description}

The fuel receiving, storage, and shipping system (FRSSS) provides the means of receiving, storing, inspecting, and shipping reactor core assemblies, including fuel, blanket, control, and radial shield assemblies, within the reactor facility. The FRSSS also assists in the refueling of the reactor. The FRSSS is located in the Fuel Handling Facility. New core assemblies enter the fuel handling facility, are unloaded from their shipping containers and inspected, and are temporarily stored in the FHC. See fuel handing section for more details on refueling operations.

\subsection{Circulating Water System}

The circulating water system provides cooling water flow to the main condenser and the turbine plant component cooling water heat exchangers to remove waste heat rejected by the turbinegenerator cycle. The circulating water rejects this waste heat to the atmosphere by means of mechanical draft cooling towers.

\section{$\underline{\text { System Requirements }}$}

- The circulating water system shall be capable of removing the design heat load placed on the turbine condenser. The system shall also remove the heat load rejected through the turbine plant component cooling water heat exchangers.

- The circulating water system shall be capable of removing the heat load from a 50 percent steam dump occurring at summer design condition.

The safety classification of the circulating water system piping, equipment, and components shall be nonsafety. Provisions shall be made to isolate portions of the system for major maintenance without removing the generating unit from operation.

\section{System Design}

The circulating water system provides cooling water for the main condenser and the turbine plant component cooling water heat exchangers. Circulating water pumps in separate bays in a pump house take suction from a flume connecting the cold water basins of the mechanical draft cooling towers. Cooled water is pumped through a pipeline to the main condenser and back to the cooling towers. Turbine plant component cooling water pumps, in a separate bay, pump water through a pipeline to the turbine plant heat exchangers and discharge into the circulating water pipe downstream of the main condenser.

\subsection{Service Water System}

The service water system consists of three subsystems, namely: the turbine plant water, the nuclear island service water, and the turbine plant component cooling water. All three of these subsystems are closed loop cooling systems and in total their function is to provide cooling for all plant systems and components except the main turbine condenser. With the exception of the nuclear island service water subsystem, the heat load is rejected to the recirculating water system. The nuclear island service water subsystem rejects heat to two separate cooling towers. 


\section{$\underline{\text { System Requirements }}$}

- The turbine plant water and turbine plant component cooling water subsystems are nonsafety grade.

- The NI service water subsystem is safety grade.

- It shall be possible to isolate portions of the system for major maintenance without removing the generating unit from operation.

- The NI service water subsystem shall be designed to meet the single failure criteria.

\section{System Design}

It is expected, based upon prior concepts, that the service water flowrate of approximately 1,600 gpm will suffice for a $300 \mathrm{MW}$ th pool-concept plant $(5,000 \mathrm{gpm}$ service water flowrate can accommodate the needs of a 1000MWth plant).

\subsection{Treated Water System}

The treated water system receives raw water from the well water system and supplies various levels of treated water for the entire plant needs. The principle plant water needs are: (1) makeup water for the main cooling towers, (2) demineralized water, and (3) potable water.

\section{System Requirements}

To provide water at the appropriate specifications to the following systems and components:

- Potable water

- Fire Protection Water Demineralized Water Condensate

- Makeup

- Auxiliary Boiler Makeup

- Turbine Component Cooling Makeup

- Sodium Cleanup System Decontamination Facility

The treated water system is not safety grade.

\section{System Design}

This system consists of piping, tanks, valves, instrumentation, and controls necessary to supply the quantity and quality of water to operate, maintain, and protect the plant.

\subsection{Industrial Waste Water Treatment System}

The waste water treatment system collects, treats, and disposes of all nonradioactive liquid plant wastes originating from the plant floor drain system, lube oil storage area drains, auxiliary boiler, chemical storage area drains, the makeup water treatment system, the condensate polishing system, and sanitary waste system. 
System Requirements

- This system is not safety grade.

- The system shall receive, handle, and treat the following liquid wastes:

- All demineralizer regeneration waste water

- M/U gravity mixed media filter backwash

- M/U activated carbon filter backwash

- All plant floor drains

- Cooling coil drainage

- M/U clarifier blowdown

- Auxiliary boiler blowdown

- All plant sewage during plant construction and operating lifetime.

System Design

The system consists of a system of piping, valves, storage tanks, polishers, and components for treating the industrial wastewater generated on the FASTER site.

\subsection{Liquid Metal Auxiliaries System}

The liquid metal auxiliaries system (LMAS) consists of the following:

- Sodium and NaK Receiving System - Provides for receipt, transfer to storage, and unloading of plant liquid metals.

- Primary Auxiliary Liquid Metal System - Provides reactor sodium purification and facilities for EVST sodium storage and draining.

- EVST Auxiliary Liquid Metal System - Provides EVST sodium purification and cooling for fuel stored in the EVST.

- Intermediate Auxiliary Liquid Metal System - Provides purification of intermediate sodium.

System Requirements

The liquid metal auxiliaries system shall be designed to meet the following general requirements:

- Receives, melts, and transfers to storage all sodium delivered to the site.

- Receives, stores, purifies, and distributes all $\mathrm{NaK}$.

- Provides the pumps and piping to transfer sodium and $\mathrm{NaK}$.

- Provides the pumps and piping to fill and drain all sodium and NaK systems.

- Separate, independent, purification capability shall be provided, as necessary, for the primary sodium and for the sodium in each of the four intermediate heat transport system loops. There shall be no permanent connection between primary sodium components and intermediate sodium components. 
System Description

The various subsystems of the liquid metal auxiliaries system are described in the following sections:

- Sodium and $\mathrm{NaK}$ Receiving System - The sodium and $\mathrm{NaK}$ receiving system receives all sodium and $\mathrm{NaK}$ needed by the plant. The sodium receiving system provides the capability to melt the contents of a sodium tank car, or sodium drum, and transfer it to the system to be filled. The capability to transfer $\mathrm{NaK}$ from drums to storage vessels and to circulate and purify $\mathrm{NaK}$ during system loading and cleanup is also provided by the system.

\subsection{Inert Gas Receiving and Processing System}

The inert gas receiving and processing system (IGRPS) provides inert gases and vacuum, as required by other systems of FASTER, including: (1) cover gas, (2) cell-inerting atmospheres, (3) valve actuation gas in inerted cells, (4) cooling gas, (5) gas for certain seals, for component cleaning, and other services, and (6) vacuum for liquid metal transfer and gas analysis purposes.

The system consists of five subsystems, as follows:

- Helium Gas Distribution Subsystem

- Argon Gas Distribution Subsystem

- Nitrogen Gas Distribution Subsystem

- Radioactive Helium Processing Subsystem (RHPS)

\section{System Requirements}

The IGRPS shall meet the following general requirements:

- Receive, store, transfer, and distribute inert gas used on the site.

- Provide cover gas for the intermediate heat transport system (IHTS).

- Provide inert gas to the fuel transfer machine (FTM) and fuel transfer tubes

- Provide cover gas for the reactor shutdown heat removal systems.

- Provide a nitrogen atmosphere for the space between the reactor vessel its guard vessel.

- Provide nitrogen for the cooling of the primary and intermediate cold traps

- Process all vented gas prior to reuse in the plant or release to the environment.

Those portions of the IGRPS classified safety grade are the piping, vapor traps, and the first two valves which form a part of the reactor vessel boundary or the fuel storage tank boundary.

\section{System Description}

The IGRPS is composed of the following subsystems:

- The radioactive argon gas distribution subsystem, which distributes fresh and recycled argon principally to the reactor vessel cover gas space and portions of the fuel handling system.

- The intermediate argon gas distribution subsystem, which distributes fresh argon mainly to the cover gas spaces of the IHTS.

- The nitrogen gas distribution subsystem, which primarily distributes nitrogen to the inerted spaces between the reactor vessel and its guard vessel. 
Radioactive Argon Gas Distribution Subsystem - The radioactive argon gas distribution subsystem is composed of high pressure storage vessels (tube banks), pressure regulating valves, stop valves, piping, emergency gas bottles, vapor traps, filters, and relief systems. All the cover gas cell and equipment spaces that require argon use recycled argon to minimize consumption. The level of radioactivity in the recycled argon gas is reduced by the RHPS to a level such that it will not cause a radiation hazard.

Intermediate Argon Gas Distribution Subsystem - The intermediate argon gas distribution subsystem is composed of liquid argon storage tanks, pressure control valves, stop valves, piping, vapor traps, filters, and relief systems. Argon is distributed to the Steam Generator building for use as a cover gas in the intermediate heat transport system (IHTS), IHTS cold traps, and SWRPS rupture disc areas. Argon is distributed to the auxiliary buildings for use as the cover gas for DRACS NaK expansion and drain vessels. The fuel handling facility is supplied with argon gas for various fuel handling system uses.

Nitrogen Gas Distribution Subsystem - The nitrogen gas distribution subsystem is composed of liquid nitrogen storage tanks, vaporizers, pressure control valves, stop valves, piping, filters, and relief systems. Nitrogen gas is used for inerting the annulus between the Reactor Vessel and its guard vessel. It is also used for steam generator water-side purging.

Radioactive Argon Processing Subsystem - The radioactive argon processing subsystem is composed of a vacuum vessel, vacuum compressors, a surge vessel, charcoal absorber vessels, piping, pressure control valves, stop valves and particulate filters. It is located in shielded cells in the lower level of the reactor building. The RHPS cleans up the argon gas that is normally vented from the reactor cover gas space and the FTM and FHC such that the gas can be safely recycled with an acceptable radiation hazard to personnel external to the recycled helium piping.

\subsection{Other Auxiliary Systems}

\subsubsection{Reactor Vessel Heating System}

Four electrical reactor vessel immersion heaters provide supplementary heating of the bulk primary sodium to maintain a minimum sodium temperature of $120^{\circ} \mathrm{C}$ whenever the reactor is not operating at sufficient power to make up for the total heat losses from the primary system. Heaters are also required during the initial sodium fill and startup.

Each heater is installed through a heater nozzle in the reactor vessel cover. Power to the heaters is supplied from 480V 3-phase AC power or, if necessary, by an emergency diesel generator.

\subsection{Emergency and Backup Systems}

There are emergency and backup systems required to ensure that plant monitoring capability is available and for personnel safety under a loss of electrical power situations. Backup power is 
also provided for investment protection in certain parts of the plant to reduce the possibility of damage due to high temperatures resulting from off-normal conditions.

The emergency and backup systems are integrated with the subsystems that they service, and are usually specific to that system. The majority of emergency backup systems are electrical. These include standby gas or diesel generators, battery backup banks, and standby operating components such as pumps, fans, and blowers. The subsystems that incorporate these emergency and backup components include: primary sodium circulation, shutdown cooling, thimble cooling, and shield cooling.

Flywheels are incorporated into the motor for the primary sodium pumps. The flywheels provide for an appropriate and specific primary flow coast down that matches the reduction in power during plant shutdown following a scram and assists in the transition from forced flow to convection flow through the reactor.

With failure of the main pumps (loss of flow), the reactor will scram, the motor flywheel will ensure an appropriate pump coastdown to remove the fission product decay heat produced in the reactor. Transition to natural convection will still occur assisted by the motor flywheels. The flywheels are located on the pump motors to maintain appropriate sodium circulation and flow coastdown during loss of normal and backup power.

The emergency power is supplied by the standby generator. If this power source also fails, a storage battery which is connected in parallel with the rectifier output will operate the pump effectively for approximately 30 minutes. As the batteries discharge, the resulting gradual flow reduction will provide a transition from forced flow to natural convection cooling. 


\section{Licensing Strategy}

For the PRISM and SAFR designs, which were also SFRs utilizing metallic fuel with strong inherent reactivity feedbacks and passive safety, PSIDs were prepared by each vendor and submitted to the U.S. NRC, and preapplication interactions between each vendor and NRC staff were conducted. For PRISM, the NRC issued a Preapplication Safety Evaluation Report (PSER), NUREG-1368 [42], concluding that "no obvious impediments to licensing the PRISM design had been identified." Work on SAFR was discontinued by DOE before the NRC evaluation was completed but DOE requested that NRC document what they had done. The resulting SAFR PSER, NUREG-1369 [43], concluded that the SAFR design had the potential for a level of safety at least equivalent to then current LWR plants. In 2010, General Electric Hitachi provided the NRC with a draft licensing strategy for the PRISM design for informal NRC consideration.

FASTER will be licensed under 10 CFR Part 50 as a testing facility that also produces electricity onto an electrical grid. The PSAR must include the principal design criteria for the facility. 10 CFR Part 50 Appendix A, "General Design Criteria for Nuclear Power Plants," establishes minimum requirements for the principal design criteria for water-cooled nuclear power plants similar in design and location to plants for which construction permits have previously been issued by the NRC and provides guidance to applicants for construction permits in establishing principal design criteria for other types of nuclear power units. Historically, specific SFR principal design criteria were developed for CRBR, PRISM, and SAFR, instead of directly utilizing the General Design Criteria (GDC) from 10 CFR Part 50 Appendix A. A set of draft SFR design criteria has been developed under a joint initiative between DOE and the NRC. The criteria include five new criteria specific to SFRs. A report containing the SFR criteria was prepared by DOE and transmitted to the NRC. The NRC internally reviewed the criteria and is expected to soon issue a report for public comment. It is expected that this will be followed by NRC guidance including SFR principal design criteria. The FASTER design satisfies the current draft SFR principal design criteria and will satisfy the final criteria included in the NRC guidance.

Under the DOE-funded Regulatory Technology Development Plan, work has been launched to develop the SFR safety analysis codes and methods required for use in a licensing framework, and to identify the Quality Assurance (QA) requirements for licensing applications. A report [44] was recently prepared that identifies the types of safety analysis computer codes that may be required for licensing of metallic-fueled SFRs and assesses the current status of existing relevant safety analysis codes including existing QA practices.

Pre-conceptual, conceptual, and final design will be carried out consistent with the DOE CD-0, CD-1, etc. process. A licensing strategy and schedule will be developed for FASTER.

Preapplication meetings will be held with the NRC. As required, a PSID will be prepared. A PRA will be performed. Interactions will be conducted with the NRC to pursue applications for a construction permit and operating license. A PSAR will be prepared as part of an application for a construction permit. A FSAR will be prepared as part of an application for an operating license.

Testing of the particular metallic fuel type used in FASTER will be carried out to obtain the data needed to enable the use of this fuel. The FASTER design utilizes structural materials that are currently qualified for use by the appropriate ASME codes, with the exception of the Hastelloy-N alloy envisioned for use in closed loop systems for liquid salt. If a need for closed loop testing 
with liquid salt continues, then effort will be devoted to developing and submitting a code case for Hastelloy-N. Development of required safety analysis computer codes meeting QA requirements for licensing use shall be completed, and the codes will be used in preparation of the PSAR and FSAR. The FASTER design shall incorporate instrumentation to detect postulated sodium leakages from sodium and NaK piping and components consistent with ASME Boiler and Pressure Vessel Code requirements for Nuclear Power Plant components.

The licensing strategy will include a strategy for testing of components for FASTER including fuel assemblies, control rods and control rod drive systems, fuel handling systems, steam generators, intermediate heat exchangers, sodium pumps, as well as instrumentation for use in FASTER. Testing will be carried out, where feasible, in existing testing facilities including the Mechanisms Engineering Test Laboratory (METL) sodium facility at Argonne, as well as new testing facilities that will be identified and assembled. Appropriate QA requirements for test data will be identified and followed.

Following the granting of an operating license, fabrication of the first core and loading of the first core, then criticality, low power testing, and ascent to full power shall be carried out. During the ascent to full power, transient testing shall be carried out to determine the actual FASTER reactivity feedback behavior and to verify that it meets the requirements for inherent passive safety and inherent passive shutdown. 


\section{Cost and Schedule}

\subsection{Schedule}

It is expected that the following notional schedule will be used for the design and construction of FASTER.

- 1 year for conceptual design

- 2 years for preliminary design

- 3-5 years for detailed design, licensing, and long-lead item fabrication

- $\quad<5$ years for construction and final licensing

Total of 11 to 13 years for the FASTER reactor project from CD-0 with the assumption that there are no constraints on cash flow for the project and that licensing will not be the limiting factor. The schedule that includes the remaining research and development to get the FASTER power plant up and running will extend the schedule to 15 years or less with a concurrent R\&D program. This schedule is consistent with a small modular advanced demo plant such as PRISM Mod A which has a power level slightly greater than FASTER. The sodium closed loop technology development will run in parallel with the schedule to construct and startup FASTER and use as its starting base, the sodium closed loop technology developed for FFTF. The non-sodium closed loop technology development will be independent of the main FASTER power plant construction, licensing, and operations and will not impact the schedule to startup FASTER.

\subsection{Design, Licensing, and Construction Costs}

It is estimated that the FASTER test reactor with the steam plant will cost approximately $\$ 2.8 \mathrm{~B}$ (with a 30\% contingency) to design $(\sim \$ 1.1 \mathrm{~B})$ and construct (with each closed loop contributing $\sim 100 \mathrm{M}$ (includes contingency) to overall estimated TPC). If it was decided to remove the steam plant and just dump the 300MWth of heat to the atmosphere, then the TPC cost (design and construction) would be significantly less than $\$ 2.5 \mathrm{~B}$ because the project would save both the cost for design, equipment, and construction for the steam plant (everything from the steam generators through the steam plant and electrical yard). In addition, the FASTER design team did not take any explicit credit during the cost estimate for prior design work and technology development work that may have been performed that would relate to the FASTER reactor plant. So, as the FASTER test reactor moves forward, more detailed cost estimates will better refine these cost figures.

The annual FASTER reactor plant operating costs in power generation mode are estimated to be less than $\$ 100 \mathrm{M}$. The FASTER reactor plant annual operating costs including irradiation operations are expected to be less than $\$ 150 \mathrm{M}$ (using FFTF as the high end basis) [7]. All estimates are in 2016 dollars. The replacement fuel is estimated to cost about \$20M/year. The FASTER reactor will provide $120 \mathrm{MW}_{\mathrm{e}}$ to the electrical grid at the location of installation. The FASTER reactor is expected to achieve a capacity factor of $80 \%$ or greater while putting power on the grid. The sales from this power are expected to be around $\$ 89 \mathrm{M}$ to $\$ 100 \mathrm{M}$ per year depending upon overall electrical generation capacity and power purchasing agreements, offsetting the operational and fuels costs. 
The cost and schedule estimates are based upon the best available information from the ALMR program, the FFTF project, and current consumer price index and construction cost index escalation factors averaged to 2016.

\subsubsection{Initial Core Load}

There are two components to the initial core load. The first is the investment required to put the infrastructure in place to fabricate fuel that satisfies NRC requirements. Licensed and qualified fuel fabrication capacity is a significant part of the investment necessary to allow the FASTER plant to begin normal operation. This is an integral part of the development of the FASTER plant. At this stage of the design concept, there are large uncertainties associated with the cost of establishing this manufacturing capacity. The assumption is that given the relatively small quantity of fuel that the manufacture will be done by a DOE facility that is upgraded to satisfy NRC requirements.

The initial core load will consist of 55 fuel assemblies each containing about $50 \mathrm{~kg}$ of U-Pu-6Zr fuel which is about 3 liters of fuel per assembly. The total for the initial core load is about $0.1 \%$ of the annual fuel fabrication required to supply the entire commercial nuclear industry. The point being that it is far below commercial scale and should be accommodated by a small scale operation not unlike what had been previously done for past fast test reactors, but in this case they must meet NRC requirements which is thought to be significantly more stringent than for past fast test reactors.

The cost of licensing the fuel fabrication is included in the overall licensing process with the licensing of the fuel and reactor being an integral process. The cost of refurbishing the fuel fabrication technology to meet the NRC requirements with sufficient capacity to fabricate the initial core load in a reasonable time period will be significant. The FASTER plant during normal operation will be replacing on average about 60 fuel assemblies per year which defines the minimum capacity once normal operation begins. No cost estimate is available for this part of the FASTER plant. It is very heavily dependent on how much of the previous experience is accepted by the NRC and the assumption that past capacity can be refurbished or replicated in largely existing facilities, the incremental investment should be encompassed in the overall contingency of FASTER plant.

Detailed cost estimates for alternative approaches will need to be developed in the future. If new facilities without the benefit of past experience are required, the cost will grow to be a significant part of the other all project cost.

This or another facility will also need to be capable of fabricating all other assembly types that will be loaded into the reactor. Since these do not involve fuel materials, this will require no shielding or remote operations and be a relatively small fraction relative to the fuel cost.

Given the large uncertainties, at this point the cost is included in the overall capital investment. Early on in the process, the facilities to fabricate these materials need to be identified and cost estimates and schedules need to be developed. 


\subsection{Operation, Maintenance and Fuel Cost}

This section covers all costs associated with FASTER reactor plant operations from the start of normal operations through the end of the decommissioning and decontamination (D\&D). All costs associated with advancing the technology, licensing the technology, construction, and commissioning the FASTER reactor plant including the initial core load are included in Section 15.2 .

The basis for the estimate of the total annual costs for the FASTER reactor plant is described below. There is a large uncertainty in these costs. The annual FASTER reactor plant operating costs are estimated to be less than $\$ 100 \mathrm{M}$ including replacement fuel costs as high as $\$ 20 \mathrm{M} /$ year.

Including the operation of irradiation experiments, test loop operation, and other experimental functions will increase costs significantly. It is not clear whether these costs should be included or attributed to the cost of the experiments. Including these costs in the FASTER reactor plant annual operating costs will raise the costs significantly. Based on the operation costs of FFTF which seems to have included these costs, the high end of the costs is expected to be less than \$150M [7]. All estimates are in 2016 dollars.

\subsubsection{Operation and Maintenance Cost}

The cost of operating and maintaining FASTER is very difficult to estimate. The first reason is that being a test reactor, if the cost of running the experiments and related equipment is included in this estimate, then one has to assume the most complex set of experiments, operation of all the closed loops, etc. The staff to support all of these experiments can be very large. It will add a lot to the overall operation and maintenance $(\mathrm{O} \& \mathrm{M})$ costs. Even estimating just the bare minimum staff required for routine operation of the reactor over its assumed 30 year lifetime is very challenging. There are no directly comparable estimates and all require large extrapolations from much larger reactors. The larger reactors operating under U.S. NRC regulations are all water reactors. The larger sodium reactors where information is available are for design concepts that have yet to be built. As a result, this leads to significant uncertainties for the O\&M cost for the FASTER plant. Given that the goal is a very rough first order estimate, a few data points were examined, combined with some knowledge on the behavior of water reactors as a function of size, and engineering judgment were applied to provide a rough estimate for operating the FASTER reactor plant in just power production mode without experimental staff or other related costs. To provide a rough estimate with the experimental costs included, the information available from FFTF was evaluated.

There was a report on the cost of FFTF conducted by GAO in April 1992. This report estimated the annual operating costs at nearly $\$ 90$ million, which when escalated to 2016 are $\$ 150$ to $\$ 160$ million. What is included in this cost estimate is not completely clear. It did estimate the cost of nonoperating standby at an annual cost of $\$ 50$ to $\$ 60$ million which corresponds to around $\$ 100$ million per year. This suggests a staff on the order of 1,000 full time equivalent employees while the reactor is in standby.

The current state of commercial nuclear power plant operation in the U.S. would be the AP1000 units under construction today. A single unit is estimated to have annual operating costs of around $\$ 100$ million while producing around $1100 \mathrm{MW}_{\mathrm{e}}$ from a $3300 \mathrm{MW}_{\text {th }}$ reactor. For context, the 
FASTER reactor plant is $120 \mathrm{MW}_{\mathrm{e}}$ and $300 \mathrm{MW}_{\text {th. }}$. Existing commercial reactors are expected with the average non-fuel O\&M costs was reported as 1.51 cents $/ \mathrm{kWh}(2013 \$)$, which would be $\$ 120$ million for a typical $1000 \mathrm{MW}_{\mathrm{e}}$ reactor.

The cost of a commercial-scale sodium-cooled fast reactor was estimated [45]. This estimate was done in 1994 and the design was a twin $840 \mathrm{MW}_{\text {th }}$ reactor cores supplying heat to a $622 \mathrm{MW}_{\mathrm{e}}$ turbine/generator system. Escalating the O\&M cost estimate to 2016 yields an annual O\&M of approximately $\$ 100$ million.

All costs estimates for commercial scale nuclear power plants are in the roughly $\$ 100$ million nonfuel annual operating costs, which includes D\&D costs estimated in Section 15.3.3. It is anticipated that there would be significant cost savings for a reactor that $1 / 10^{\text {th }}$ scale, the costs will likely be far above $10 \%$ since large economy of scales are anticipated.

\subsubsection{Fuel Cost}

The initial investment in development of the fuel fabrication capacity is part of the overall cost required to start operation of FASTER. The fuel costs for ongoing operations are the average annual costs of refueling, which essentially are the O\&M and feedstock costs for the fuel fabrication facility. One key assumption is the plutonium used as feedstock will be provided at no cost. The uranium and zirconium will also be very small contributors. The only feedstock cost that may be significant is the structural material for the fuel assemblies. The availability and cost of the necessary structure materials is currently uncertain. Relative small quantities of these materials may result in high unit costs. If so, this will raise the cost of fabrication of other nonfuel assemblies making their costs more important.

Given the lack of directly applicable information to estimate the costs for operating the fuel fabrication capacity, assuming the upper bound of unit cost for fabrication of Pu-bearing fuels of approximately $\$ 7000$ per $\mathrm{kg}$ which is for a commercial scale facility, but also includes the capital costs amortized along with the O\&M. This should be a conservative estimate of the annual O\&M for this facility. Using this value that is likely very conservative (it implies a staff of well over 100 to fabricate just over one fuel assembly per week), is $\$ 20 \mathrm{M}$ per year. The cost is likely significantly less, but at this point there is not a better estimate.

\subsubsection{Decommissioning and Decontamination Cost}

While the D\&D costs will be quite significant when the facility ultimately goes through $D \& D$, as long as the FASTER reactor plant operates for a significant period of time, the annual cost associated with funding that eventual D\&D is relatively small. Since this is assumed to be a government owned facility, actual payments to a sinking fund, the traditional method for evaluating the annual cost, are not likely [47]. However, the equivalent sinking fund payments were used to quantify this value. There is a significant uncertainty in what the actual cost of D\&D will eventually be. Typically utilities pay between 0.1 and 0.2 cents/kW-hr [48], which would correspond to less than $\$ 2 \mathrm{M}$ per year. This would result in a fund with on the order of $\$ 100 \mathrm{M}$ (2016 \$), which is consistent with the D\&D of Fermi 1 which was estimated at about \$60M [49] (2016 \$). The costs associated with the eventual D\&D of the FASTER reactor plant are currently insignificant compare to the uncertainty in the other non-fuel O\&M costs. 
FASTER Test Reactor Preconceptual Design Report

March 31, 2016 
FASTER Test Reactor Preconceptual Design Report

March 31, 2016 


\section{Works Cited}

[1] GateCycle. (2016) GE Power \& Water GateCycle Software. [Online]. https://getotalplant.com/GateCycle/docs/GateCycle/index.html

[2] Hanford Engineering Development Laboratory, "A Summary Description of the Fast Flux Test Facility," HEDL-400, 1980.

[3] D.J. Oakley, "Closed Loop In-Reactor Assembly (CLIRA) A Fast Flux Test Facility Vehicle, HEDL-SA-1605FP," in American Society of Mechanical Engineers Winter Annual Meeting, San Francisco, 1978.

[4] Idaho National Laboratory, "FY 2009 Advanced Test Reactor National Scientific User Facility Users' Guide," INL/EXT-08-14709, 2009.

[5] Editor: Fanning, T.H., "The SAS4A/SASSYS-1 Safety Analysis Code System: User's Guide," ANL/NE-12/4, Argonne National Laboratory, 2012.

[6] Personal communication with C. Grandy

[7] U.S. General Accounting Office, "Fast Flux Test Facility on Standby, Awaiting DOE Decision on Fugure Missions," GAO/RCED-92-121FS, 1992.

[8] M. A. Smith, C. Adams, W. S. Yang, and E. E. Lewis, "VARI3D \& PERSENT: Perturbation and Sensitivity Analysis," Argonne National Laboratory, ANL/NE-13/8, 2013.

[9] M. A. Smith, E. E. Lewis, and E. R. Shemon, "DIF3D-VARIANT 11.0, A Decade of Updates," Argonne National Laboratory, ANL/NE-14/1, 2014.

[10] D. C. Wade and E. K. Fujita, "Trends Versus Reactor Size of Passive Reactivity Shutdown and Control Performance," Nuclear Science and Engineering, vol. 103, pp. 182-195, 1989.

[11] C. P. Cabell, "A Summary Description of the Fast Flux Test Facility," Hanford Engineering Development Laboratory, HEDL-400, 1980.

[12] Idaho National Laboratory, "FY 2009 Advanced Test Reactor National Scientific User Facility Users' Guide," INL/EXT-08-14709, 2009.

[13] D. J. Oakley, "Closed Loop In-Reactor Assembly (CLIRA) A Fast Flux Test Facility Vehicle," American Society of Mechanical Engineers Winter Annual Meeting, San Francisco, HEDL-SA-1605FP, 1978.

[14] K. L. Basehore and N. E. Todreas, "SUPERENERGY-2: A Multiassembly Steady-State Computer Code for LMFBR Core Thermal-Hydraulic Analysis," Pacific Northwest National Laboratory, PNL-3379, 1980.

[15] Fink, J. and Leibowitz, L., "Thermophysical Properties of Sodium," ANL-CEN-RSD-79-1, 1979.

[16] C. Grandy, et al., Personal communication with C. Grandy, 2007.

[17] A. Moisseytsev, E. Hoffman, and C. Grandy, "Selection of Core Outlet Temperature and Impacts on Fast Reactor Economics," Nuclear Technology, vol. 173, pp. 251-269, 2011.

[18] GE Power \& Water. GateCycle Software. [Online]. https://getotalplant.com/GateCycle/docs/GateCycle/index.html

[19] C. Grandy et al., "FASTER Test Reactor Preconceptual Design Report Summary," Argonne National Laboratory, ANL-ART-40, 2016.

[20] M. M. Osterhout, "Control of Oxygen, Hydrogen, and Tritium in Sodium Systems and 
Experimental Breeder Reactor II," UAC-41069, Argonne National Laboratory, 1978.

[21] Personal communication with M. Farmer, 2016.

[22] E. Jin, Personal communication with T. Kim, Feb. 24, 2016.

[23] W. H. Olson and W. E. Ruther, "Controlling Cesium in the Coolant of the Experimental Breeder Reactor II," Nuclear Technology, vol. 46, December 1979.

[24] S. R. Adams, "Theory, Design, and Operation of Liquid Metal Fast Breeder Reactors, Including Operational Health Physics," Idaho National Engineering Laboratory, NUREG/CR-4375, 1985.

[25] International Atomic Energy Agency, "Fast Reactor Database - 2006 Update," Vienna, 2006.

[26] Y. I. Chang, P. J. Finch, and C. Grandy, "Advanced Burner Test Reactor Preconceptual Design Report," Argonne National Laboraotry, ANL-ABR-1 (ANL-AFCI-173), 2006.

[27] H. L. Sletten, "Cold Trap Requirements for PHTS and IHTS Sodium Purification," Atomics Internationl North American Rockwell, DOE/TIC-11040, 1974.

[28] H. J. Grabke and E. Riecke, "Absorption and Diffusion of Hydrogen in Steels," Materials and Technology, vol. 34, no. 6, pp. 331-342, 2000.

[29] B. J. Beaver and C. F. Leitten, Jr., "A Survey of the Corrosion of Martensitic and Ferritic Stainless Steels in Pressurized Water," Oak Ridge National Laboratory, ORNL-TM-539, 1963.

[30] R. Abramson, X. Elie, J. M. Saur, M. Thevenin, and F. Velin, "Evolution of Sodium Purification: RAPSODIE, PHENIX, SUPER-PHENIX," in Proceedings of the Internationl Conference on Liquid Metal Technology in Energy Production, Champion, PA, 1976, pp. 51-59.

[31] C. Grandy, Personal communication with Marc Matusewithch (Columbia Sales International, Inc), July 7, 2013.

[32] W. H. Olson and R. A. Washburn, "EBR-II Experience with Frit-Type Plugging Temperature Indicators," in International Conference on Liquid Metal Technology in Energy Production Proceedings, Richland, WA, 1980.

[33] T. H. Fanning, ed., "The SAS4A/SASSYS-1 Safety Analysis Code System," Nuclear Engineering Division, Argonne National Laboratory, Argonne, IL, ANL/NE-12/4, 2012.

[34] U.S. Atomic Energy Commission, "Calculation of Distance Factors for Power and Test Reactor Sites," TID-14844, 1962.

[35] U.S. Nuclear Regulatory Commission, "Accident Source Terms for Light-Water Nuclear Power Plants," NUREG-1465, 1995.

[36] U.S. Nuclear Regulatory Commission, "Alternative Radiological Source Terms for Evaluating Design Basis Accidents at Nuclear Power Reactors," RG 1.183, 2000.

[37] Grabaskas, D., Brunett, A., Bucknor, M., Sienicki, J., and Sofu, T., "Regulatory Technology Development Plan: Sodium Fast Reactor - Mechanistic Source Term Development," Argonne National Laboratory, ANL-ART-3, 2015.

[38] Tentner, A., "Severe Accident Approach - Final Report, Evaluaton of Design Measures for Severe Accident Prevention and Consequence Mitigation," ANL-GENIV-128, 2010.

[39] Newman, R., "The Ignition and Burning Behavior of Sodium Metal in Air," Progress in 
Nuclear Energy, vol. 12, no. 2, pp. 119-147, 1983.

[40] G. Palmiotti, E. E. Lewis, and C. B. Carrico, "VARIANT: VARIational Anisotropic Nodal Transport for Multidimensional Cartesian and Hexagonal Geometry Calculation," Argonne National Laboratory, ANL-95/40, 1995.

[41] L. Leibowitz, E. Veleckis, and R. A. Blomquist, "Solidus and Liquidus Temperatures in the Uranium-Plutonium-Zirconium System," Journal of Nuclear Materials, vol. 154, pp. 145153, 1988.

[42] U.S. Nuclear Regulatory Commission, "Preapplication Safety Evaluation Report for the Power Reactor Innovative Small Module (PRISM) Liquid-Metal Reactor," NUREG-1368, 1994.

[43] Reserved

[44] A. J. Brunett and L. L. Briggs, Argonne National Laboratory, Unpublished Information, 2015.

[45] Reserved

[46] H. I. Bowers, L. C. Fuller, and M. L. Myers, "Cost Estimating Relationships for Nuclear Power Plant Operation and Maintenance," Oak Ridge National Laboratory, ORNL/TM$10563,1987$.

[47] U.S. Nuclear Regulatory Commission. (2015, April) Financial Assurance for Decommissioning. [Online]. http://www.nrc.gov/waste/decommissioning/finan-assur.html

[48] World Nuclear Association. (2016, January) Decommissioning Nuclear Facilities. [Online]. http://www.world-nuclear.org/info/Nuclear-Fuel-Cycle/Nuclear-Wastes/DecommissioningNuclear-Facilities/

[49] International Atomic Energy Agency, "Decommissioning of Fast Reactors after Sodium Draining," IAEA-TECDOC-1633, 2009.

[50] Gordon and Breach, "Sodium Pumps, Valves, Piping, and Auxiliary Equipment, Chap. 1," in Sodium-NaK Engineering Handbook. New York, NY: Science Publishers, Inc, 1978, vol. IV.

[51] International Atomic Energy Agency, Status of Liquid Metal Cooled Fast Reactor Technology, Chap. 8. Vienna, Austria: IAEA, 1999.

[52] J. R. Davis, G. E. Deegan, J. D. Leman, and W. H. Perry, "Operating Experience with Sodium Pumps at EBR-II," Argonne National Laboratory, ANL/EBR-027, 1970.

[53] H. O. Monson, et al., "Components for Sodium Reactors," in Proceedings of the Third International Conference on the Peaceful Uses of Atomic Energy, vol. 8, Geneva, 1964, pp. 588-599.

[54] A. S. Korolkov, "Operating Experience with BOR-60: Basic Results and Prospects," International Atomic Energy Agency, TM-27172 and TM-26984, TWG-FR/123, Working Material, 2005.

[55] H. O. Charnock and H. B. Holz, "Sodium Systems Components," Atomic International, North American Rockwell, Sodium Technology, Session IV 1970.

[56] M. P. Nikulin, et al., "Experience Gained During BR-10 Reactor Operation," International Atomic Energy Agency, TM-27172 and TM-26984, TWG-FR/123, Working Material, 2005.

[57] W. Babcock, "State of Technology Study - Pumps Experience with High Temperature Sodium Pumps in Nuclear Reactor Service and Their Application to FFTF," Battelle 
FASTER Test Reactor Preconceptual Design Report

March 31, 2016

Memorical Institute Pacific Northwest Laboratories, Richland, WA, BNWL-1049, UC-80, Reactor Technology, 1969. 
FASTER Test Reactor Preconceptual Design Report

March 31, 2016 


\section{Argonne}

Nuclear Engineering Division

Argonne National Laboratory

9700 South Cass Avenue, Bldg. 208

Argonne, IL 60439-4842

www.anl.gov 